\title{
ROUTLEDGE
HANDBOOKS
总
}
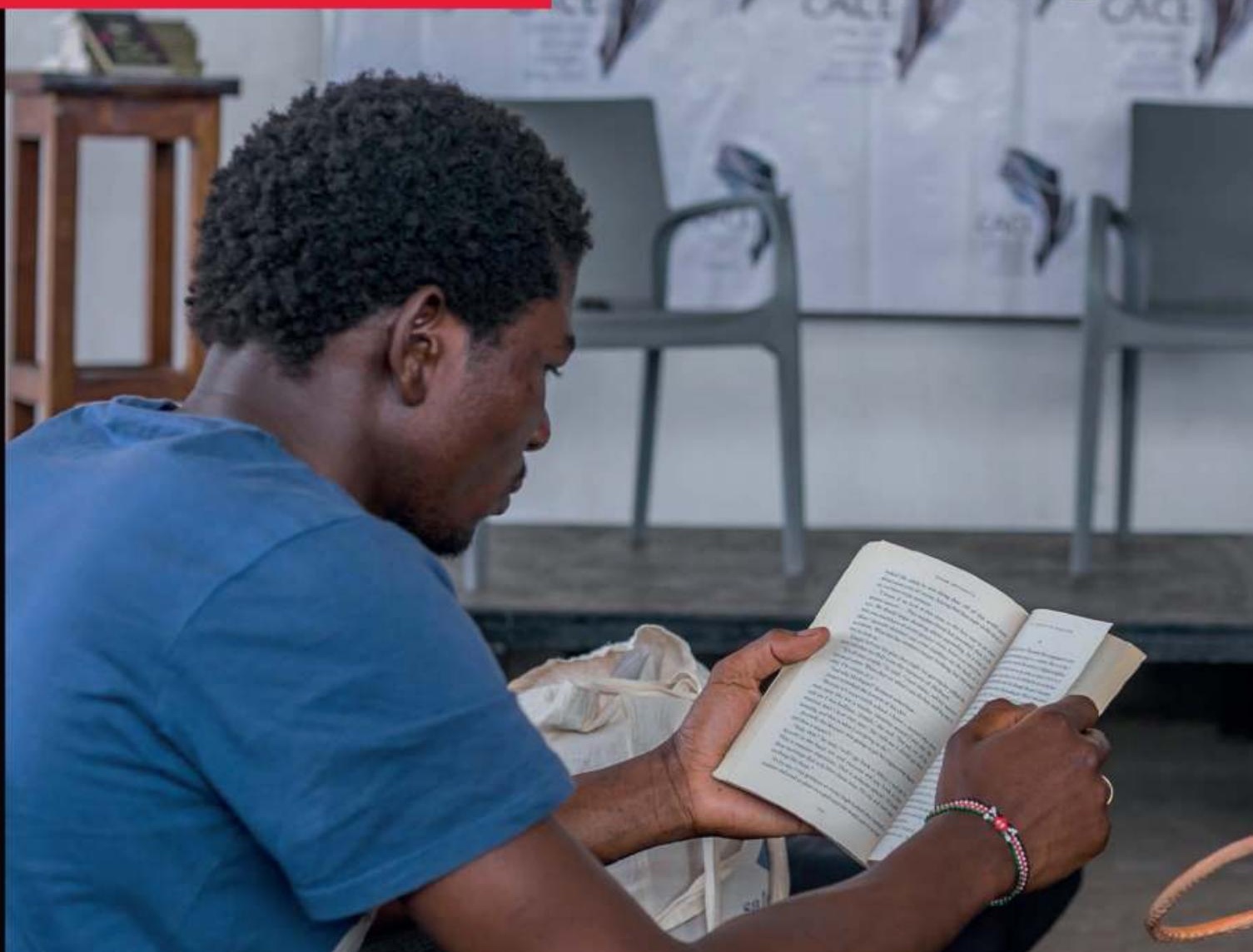

Routledge Handbook of African Literature

Edited by Moradewun Adejunmobi and Carli Coetzee 


\section{Routledge Handbook of African Literature}

The turn of the twenty-first century has witnessed an expansion of critical approaches to African literature. The Routledge Handbook of African Literature is a one-stop publication bringing together studies of African literary texts that embody an array of newer approaches applied to a wide range of works. This includes frameworks derived from food studies, utopian studies, network theory, eco-criticism, and examinations of the human/animal interface alongside more familiar discussions of postcolonial politics.

The handbook is divided into seven parts: i) Mapping political agencies, ii) Journeys, geographies, identities, iii) Working through genre, iv) The world of and beyond humans, v) Everyday sociality, vi) Bodies, subjectivities, affect, vii) Literary networks. In each, contributors address the themes of the section from a variety of perspectives in conjunction with analysis of different literary texts. All chapters are original research essays written by a broad spectrum of scholars with expertise in the subject, providing an application of the most recent insights into analysis of particular topics or application of particular critical frameworks to one or more African literary works.

The handbook will be a valuable interdisciplinary resource for scholars and students of African literature, African culture, postcolonial literature and literary analysis.

Moradewun Adejunmobi is Professor of African Studies in the African American and African Studies Department at the University of California, Davis, USA. She has published widely on Francophone African literature, multilingualism and translation in African literature and cinema, as well as on Nollywood and the Nigerian film industry.

Carli Coetzee is Research Associate at SOAS, University of London Honorary Research Fellow at the School of Literature, Language and Media at the University of the Witwatersrand, Johannesburg, and the Editor of the Journal of African Cultural Studies. 


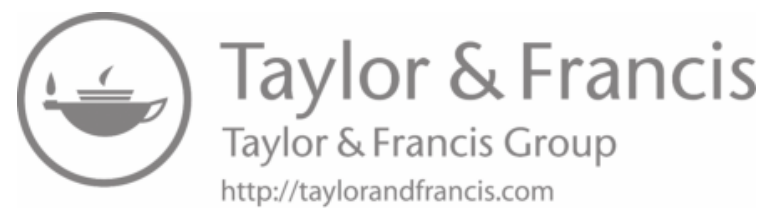




\section{Routledge Handbook of African Literature}

Edited by Moradewun Adejunmobi and Carli Coetzee 
First published 2019

by Routledge

2 Park Square, Milton Park, Abingdon, Oxon OX14 4RN

and by Routledge

52 Vanderbilt Avenue, New York, NY 10017

Routledge is an imprint of the Taylor \& Francis Group, an informa business

(C) 2019 selection and editorial matter, Moradewun Adejunmobi and Carli Coetzee; individual chapters, the contributors

The right of Moradewun Adejunmobi and Carli Coetzee to be identified as the authors of the editorial material, and of the authors for their individual chapters, has been asserted in accordance with sections 77 and 78 of the Copyright, Designs and Patents Act 1988.

With the exception of Chapter 4 , no part of this book may be reprinted or reproduced or utilised in any form or by any electronic, mechanical, or other means, now known or hereafter invented, including photocopying and recording, or in any information storage or retrieval system, without permission in writing from the publishers.

Chapter 4 of this book is available for free in PDF format as Open Access from the individual product page at www.routledge.com. It has been made available under a Creative Commons Attribution-Non Commercial-No Derivatives 4.0 license.

Trademark notice: Product or corporate names may be trademarks or registered trademarks, and are used only for identification and explanation without intent to infringe.

British Library Cataloguing in Publication Data

A catalogue record for this book is available from the British Library

Library of Congress Cataloging-in-Publication Data

Names: Adejunmobi, Moradewun, editor. | Coetzee, Carli, editor.

Title: Routledge handbook of African literature / edited by Moradewun Adejunmobi and Carli Coetzee.

Description: New York : Routledge, 2019. | Includes index.

Identifiers: LCCN 2018049132 (print) | LCCN 2018050654 (ebook) | ISBN 9781315229546 (Ebook) | ISBN 9781351859387 (Adobe Reader) | ISBN 9781351859370 (Epub) | ISBN 9781351859363 (Mobipocket) | ISBN 9781138713864 (hardback)

Subjects: LCSH: African literature-21st century-History and criticism. |

African literature-20th century-History and criticism.

Classification: LCC PR9340 (ebook) | LCC PR9340 .R68 2019 (print) | DDC $820.996-\mathrm{dc} 23$

LC record available at https://lccn.loc.gov/2018049132

ISBN: 978-1-138-71386-4 (hbk)

ISBN: 978-1-315-22954-6 (ebk)

Typeset in Bembo

by Taylor \& Francis Books 


\section{Contents}

List of contributors

1 Introduction 1

Moradewun Adejunmobi and Carli Coetzee

\section{PART I}

Mapping Political Agencies

2 'Children of the Cold War': Rethinking African literary generations through the global conflict

Monica Popescu

3 Ethics and the politics of the ordinary in African literature

Chielozona Eze

4 Globalisation, mobility and labour in African diasporic fiction Anna-Leena Toivanen

5 Towards an ethics of the humanitarian imagination Allison Mackey

\section{PART II}

Journeys, Geographies, Identities

6 Decolonising the Afropolitan: Intra-African migrations in post-2000 literature

Rebecca Fasselt

7 History, imperial eyes and the 'mutual gaze': Narratives of African-Chinese encounters in recent literary works Ying Cheng 
Contents

8 Ethnicity in post-2000 African writing Aghogho Akpome

9 Mythopoesis of the self: Nation, textuality and the writer as political hero Rotimi Fasan

\section{PART III}

\section{Working through Genres}

10 How to be a writer in your 30s in Lagos: Self-help literature and the creation of authority in Africa

Rebecca Jones

11 Gothic supernaturalism in the 'African imagination': Locating an emerging form

Rebecca Duncan

12 Contested filial voice in African female-authored autobiographies Marciana Nafula Were

13 'I can't go forward; I must go back': Ben Okri's (p)anachronistic utopias Ian P. MacDonald

\section{PART IV}

The World of and beyond Humans

14 African literature, audience and the search for the (non)human

Cajetan Iheka

15 Dirty ecology: African women and the ethics of cultivation

Sarah L. Lincoln

16 African fictions, animal figures and anthropocentric frameworks

Jesse Arseneault

17 Depictions of Kenyan lands and landscapes by four women writers Ng'ang'a Muchiri 


\section{PART V}

Everyday Sociality

18 Geopolitical and global topologies in fiction: Islam at the fault lines in Africa and the world

Shirin Edwin

19 Appetite and everyday life in African literature

Delores B. Phillips

20 'Foundational fictions': Variations of the marriage plot in Flora Nwapa's early Anglophone-Igbo novels

F. Fiona Moolla

21 Drinking scenes: Alcohol in the Francophone African novel

Pim Higginson

\section{PART VI}

\section{Bodies, Subjectivities, Affect}

22 Desire and freedom in Yvonne Vera's fiction

Grace A. Musila

23 The forms of shame and African literature

Naminata Diabate

24 Scattered testimony: Locating the Rwandan genocide in transnational witnessing

Martina Kopf

25 Contestations through same-sex desire in Jennifer Nansubuga

Makumbi's Kintu

Edgar F. Nabutanyi

\section{PART VII}

Literary Networks

26 The Story Club: African literary networks offline

Stephanie Bosch Santana

27 Language and prizes: Exploring literary and cultural boundaries

Doseline Kiguru 
Contents

28 Publishers' networks and the making of African literature: Locating communities of readers and writers

Kate Wallis

29 Literary networks in the Horn of Africa: Oromo and Amharic intellectual histories

Sara Marzagora and Ayele Kebede

Index

443 


\section{Contributors}

Moradewun Adejunmobi is Professor of African Studies in the African American and African Studies Department at the University of California, Davis. She has published widely on Francophone African literature, multilingualism and translation in African literature and cinema, as well as on Nollywood and the Nigerian film industry. She is the author of J. J. Rabearivelo, Literature, and Lingua Franca in Colonial Madagascar (1996) and Vernacular Palaver: Imaginations of the Local in Non-Native Languages in West Africa (2004).

Aghogho Akpome currently lectures in the Department of English, University of Zululand. His research interests include literary (re)historicisation, culture criticism, narratives of identity/ difference and nation (especially within postcolonial literatures), literary representations of migration as well as African studies more broadly.

Jesse Arseneault is Assistant Professor of English at Concordia University in Montreal, Canada, where he teaches in the field of global Anglophone literatures. His primary research interests consider the place of animality in African literary, cultural and scholarly production, highlighting both the place of animals in these fields and the effects of colonialism's campaigns of animalisation on the African human. Typically revolving around South African post-apartheid literary and cultural texts, his research also explores themes from postcolonial studies, cultural studies, queer theory, posthumanism and globalisation studies.

Ayele Kebede is a PhD candidate in the Centre for Cultural, Literary and Postcolonial Studies at SOAS University of London. His PhD is the first full-length study comparing Oromo and Amharic literary traditions. His research stresses the importance of multilingual methodologies in the study of world literature and contributes to the ERC-funded project Multilingual Locals and Significant Geographies (MULOSIGE). Before he moved to London, Ayele was a lecturer in the Department of English Language and Literature at Bule Hora University, Ethiopia.

Stephanie Bosch Santana is Assistant Professor of Comparative Literature at the University of California, Los Angeles. Her work, which has been supported by the Mellon Foundation and the American Council of Learned Societies, focuses on Anglophone and African language fiction from Malawi, South Africa, Zambia and Zimbabwe. Her current book project examines an alternative history of literary forms in periodical print and digital media from the 1950s to the present. Bosch Santana's work has been published in Research in African Literatures, the Journal of African Cultural Studies, Wasifiri and the Johannesburg Salon. She is also an editor of the blog Africa in Words. 
Ying Cheng is Assistant Professor in the Department of Asian and African Languages and Cultures, Peking University, China. Her research interests include popular culture in Africa, African visual and performance arts, and cultural interactions between China and Africa. Her $\mathrm{PhD}$, awarded by SOAS, University of London in 2016, focused on the transformation of popular theatre culture in urban Nigeria. Her thesis, 'Is Theatre Dying in Nigeria? Recycling Popular Theatre in Metropolitan Lagos', won the Lagos Studies Association's Best Doctoral Thesis award in 2018. In recent years, she has published articles in journals including the Journal of African Cultural Studies, African Theatre, African Arts and the Annual Review of African Studies in China.

Carli Coetzee is Research Associate at SOAS, University of London, Honorary Research Fellow at the School of Literature, Language and Media at the University of the Witwatersrand, Johannesburg, and the Editor of the Journal of African Cultural Studies. She has published widely on African literature and on the ethics of knowledge production from and about Africa and Africans. She is the author of Accented Futures: Language Activism and the Ending of Apartheid (2013) and Written under the Skin: Blood and Intergenerational Memory in South Africa (2019).

Naminata Diabate is Assistant Professor of Comparative Literature at Cornell University. A scholar of sexuality, biopolitics and postcoloniality, Diabate's research primarily explores African, African American, Caribbean and Afro-Hispanic literatures, film and new media. These explorations take the trans-African context as their points of departure to make broader contributions to transnational reflections on questions of agency and resistance. Her book, Naked Agency: Genital Cursing and Biopolitics in Africa is forthcoming in Autumn 2019 (Duke University Press). Currently Diabate is working on her second book: African Sexual Pleasures under Neoliberalism.

Rebecca Duncan gained her DAAD-funded PhD in 2015 from Justus-Liebig University, Gießen, and currently teaches in the Division of Literature and Languages at the University of Stirling, where she is affiliated to the International Centre for Gothic Studies. She has research interests in postcolonial literary and visual cultures, with emphases on Southern Africa, speculative genres, and materialist and ecocritical perspectives. Her monograph South African Gothic: Anxiety and Creative Dissent in the Post-Apartheid Imagination and Beyond was released in June 2018.

Shirin Edwin is Associate Professor of Comparative Literature at New York University, Shanghai. Her research focuses on Islam and feminism in African literatures. She studies questions of gender, transnational Islam and the relationship between African and world literatures. She is the author of Privately Empowered: Expressing Islamic Feminism in Northern Nigerian Fiction (2016, Northwestern UP). She has published in Gender, Place and Culture: A Journal of Feminist Geography, the Journal of African Cultural Studies, Gender and Education and the Journal of Middle Eastern Women's Studies, among others.

Chielozona Eze studied philosophy and literature at Purdue University. He is Professor of African literature at Northeastern Illinois University and Extraordinary Professor of English at Stellenbosch University, South Africa. He is the author of Ethics and Human Rights in Contemporary African Women's Literature (Palgrave Macmillan, 2016), and Race, Decolonization, and Global Citizenship in South Africa (University of Rochester Press, 2018). 
Rotimi Fasan is Professor of African Literature, Postcolonial and World Literatures in the Department of English and International Studies, Osun State University (Nigeria), where he is also Head of Department. He has spent postdoctoral fellowship terms in universities in Europe and Africa. His research has been published in some of the leading journals of African literature and cultural studies, including in Africa and in the Journal of African Cultural Studies, while his weekly column in Vanguard Media is widely read in Nigeria and abroad.

Rebecca Fasselt is Lecturer in the Department of English at the University of Pretoria, where she teaches African and postcolonial literature. She is particularly interested in literary and cultural connections between South Africa and other parts of Africa. She has published on Afropolitanism, African chick lit, the short story in South Africa post-2000 and first-person plural narration. Her articles can be found in English Studies in Africa, Research in African Literatures, Ariel, the Journal of Southern African Studies, the Journal of Commonwealth Literature and Poetics Today.

Pim Higginson is Professor of Global French Studies, University of New Mexico, Albuquerque. He works on literatures and cultures from France, the United States and Francophone Africa. His The Noir Atlantic: Chester Himes and the Birth of the Francophone African Crime Novel (Liverpool University Press, 2011) explored the influence of African American author Chester Himes (1909-1984) on Francophone African crime fiction. Continuing his engagement with comparative Black Atlantic studies, his 2017 Scoring Race: Jazz, Fiction, and Francophone Africa (Boydell and Brewer) studies jazz's reception in France and Francophone Africa and how French discourses on jazz shaped subsequent Francophone African aesthetic deployments of this potentially emancipatory American music.

Cajetan Iheka is Assistant Professor of English at the University of Alabama. His research focuses on African literature and film, postcolonial studies, ecocriticism and world literature. $\mathrm{He}$ is the author of Naturalizing Africa: Ecological Violence, Agency, and Postcolonial Resistance in African Literature (Cambridge University Press, 2018), and co-editor of African Migration Narratives (University of Rochester Press, 2018).

Rebecca Jones is Lecturer at the Department of African Studies and Anthropology, University of Birmingham. She is currently completing a monograph on Nigerian travel writing in Yoruba and English. Her research interests include travel writing; Nigerian literary, print and popular cultures, including Yoruba literature; and inter-religious encounters in southwest Nigeria. She is also an editor of the blog Africa in Words (www.africainwords.com), which focuses on African cultural production.

Doseline Kiguru has a PhD in English from the University of Stellenbosch. She works at the British Institute in Eastern Africa and is a Research Associate at the University of the Free State. Her research engages with issues of cultural and literary production in Africa with a major focus on the publishing and prize industries, and the effects that they have on local literary production. In her research on the contemporary literary scene on the continent, she engages with questions of language use in literature, significance of writers' organisations, influence and availability of training for creative writing, history of publishing and promotion of literature on the continent, among others. 
Martina Kopf is Senior Lecturer in African Literatures at the Department of African Studies, University of Vienna. Her areas of interest include development discourses in fiction and narrative; intercultural feminism; postcolonial cultural criticism; Africa in colonial writing of the first half of the twentieth century; memories of violence; and ethics of representation. She is the author of Trauma und Literatur: Das Nicht-Erzählbare erzählen (Brandes \& Apsel, 2005), and coedited Political Storytelling: From Fact to Fiction (Käte Hamburger Kolleg/Centre for Global Cooperation Research, 2016) and Developing Africa: Concepts and Practices in 20th Century Colonialism (Manchester University Press, 2014).

Sarah L. Lincoln is Associate Professor of English and Director of literary studies at Portland State University, where she teaches postcolonial literature and theory, ecocriticism and world cinema. She is the author of essays on Nigerian literature and culture, Southern African writers and Caribbean studies, and is currently at work on a book entitled The Idea of Gardening: Postcolonial Literature and the Ethics of Cultivation, which studies the politics and poetics of gardening in the wake of colonial violence.

Ian P. MacDonald is Assistant Professor of English at Florida Atlantic University. He has previously published work in Research in African Literatures and the Cambridge Journal of Postcolonial Literary Inquiry. His work probes the intersection of speculative fiction and literature from Africa and the diaspora, and he is completing a book called Alter-Africas: Speculative Topographies in African and Diasporic Science Fiction, which assesses the ways in which SF's colonial legacy in the travelogue and discovery narrative serves as a combative frame for thinking African futures.

Allison Mackey is Professor of English Literature at the University of the Republic, Uruguay. She is also Research Associate at the University of the Free State, South Africa, where she held a postdoctoral fellowship in 2015 and 2016. Her work has been published in journals such as College Literature, English Studies in Canada, Research in African Literatures, TOPIA: Canadian Journal of Cultural Studies, Safundi: Journal of South African and American Studies and Science Fiction Studies.

Sara Marzagora is an intellectual historian of Ethiopia and the Horn of Africa, currently working as Postdoctoral Research Fellow at SOAS, University of London. She has published on Ethiopian historiography, Ethiopian political thought and Amharic print culture. She is the leader of the Horn of Africa strand of the Multilingual Locals and Significant Geographies (MULOSIGE) research project, which investigates the multilingual literary cultures of North India, the Maghreb and the Horn of Africa. She is currently completing a book manuscript on Ethiopian conceptualisations of the 'global' in the first half of the twentieth century.

F. Fiona Moolla is Associate Professor in the English Department and Chair of the Arts Higher Degrees Committee at the University of the Western Cape. She is the author of Reading Nuruddin Farah: The Individual, the Novel \& the Idea of Home (James Currey, 2014), and the editor of Natures of Africa: Ecocriticism and Animal Studies in Contemporary Cultural Forms (Wits UP, 2016), among other academic and non-academic publications. She currently heads a project on romantic love in African literature and culture.

Ng'ang'a Muchiri is Assistant Professor in English at the University of Nebraska, Lincoln. His research interests lie in African and African Diaspora literature written in Swahili, English and French. He is currently working on a scholarly monograph titled Writing Land, Righting Land: 
Literary Depictions of Contemporary African Landscapes. At the University of Nebraska, Lincoln he designs and teaches courses in African literature, eco-criticism, and Caribbean writers.

Grace A. Musila is Associate Professor in the Department of African Literature, University of the Witwatersrand, Johannesburg. She is the author of $A$ Death Retold in Truth and Rumour: Kenya, Britain and the Julie Ward Murder (James Currey/Boydell \& Brewer, 2015), which explores Kenyan and British interpretations of the 1988 murder of British tourist Julie Ann Ward in Maasai Mara Game Reserve, Kenya. She also co-edited Rethinking Eastern African Intellectual Landscapes (Africa World Press, 2012) with James Ogude and Dina Ligaga. She writes on Eastern and Southern African literatures and popular culture, and is the Editor at large, Africa, for the Journal of African Cultural Studies.

Edgar F. Nabutanyi holds a PhD from the English Department, Stellenbosch University. $\mathrm{He}$ is currently a lecturer in the Department of Literature, Makerere University. His research interests converge around the representations of vulnerable subjects in public discourses. His recent publications include 'The Paradox of Same-sex Representations: The Presence/Absence of Gays in Ugandan Short Stories', Imbizo: International Journal of Literary and Comparative Studies 8.1 (2017), 'Dominance, Silence, and Homoerotic Pleasures in Nakisanze's The Triangle', in College Literature 45.4 (2018) and 'The City as a Metaphor of Safe Queer Experimentation in Ugandan Short Stories' forthcoming in African Literature Today.

Delores B. Phillips is Associate Professor in the Department of English at Old Dominion University, where she teaches and conducts research in postcolonial theory and literature. Her research explores the politics of consumption in Anglophone literature and culinary writing. She is the author of many articles and has published in a range of journals including Postcolonial Studies, Cultural Critique and The Projector.

Monica Popescu is Associate Professor and William Dawson Scholar of African Literatures at McGill University. She is the author of South African Literature Beyond the Cold War (which won the 2012 Gustave O. Arlt Award in the Humanities) and The Politics of Violence in PostCommunist Films, and co-editor of a special issue of the Journal of Postcolonial Writing on 'Alternative Solidarities: Black Diasporas and Cultural Alliances during the Cold War'. She is also the co-editor of the Routledge Series in Cultures of the Global Cold War.

Anna-Leena Toivanen holds a Marie Skłodowska-Curie Individual Fellowship at CEREP (Centre d'Enseignement et de Recherche en Etudes Postcoloniales), University of Liège, Belgium. Her current research project focuses on Afro-European mobilities and cosmopolitanisms in contemporary Franco- and Anglophone diasporic African literatures. Her recent work has been published in Studies in Travel Writing, English Studies in Africa, Research in African Literatures, Matatu, the Journal of Commonwealth Literature and the Journal of African Cultural Studies.

Kate Wallis is Lecturer in World Literatures in the Department of English at the University of Exeter. She is currently working on a monograph exploring pan-African literary networks post2000, building on her doctoral research on Kwani Trust, Farafina and Cassava Republic Press. Her work has been published in Wasafiri and Research in African Literatures, and she is co-editor of a forthcoming special issue of Eastern African Literary and Cultural Studies on 'New Approaches to Literary Activism in 21st Century Africa'. She is a director for Kigali-based publishing company Huza Press and an editor (and co-founder) of www.africainwords.com. 
Marciana Nafula Were is Associate Researcher in the English Department, Stellenbosch University, South Africa and a lecturer at the Tom Mboya University College, Kenya. Her research interests are in life narratives, oral literature, gender studies and postcolonial studies. Her PhD research was on political autobiographies of African women politicians. Were wrote the biography of Julia Auma Ojiambo, a Kenyan female politician, as her MA research project. Currently Were lives in Homa Bay, Kenya. 


\section{Introduction}

\section{Moradewun Adejunmobi and Carli Coetzee}

This Handbook is a volume of critical approaches applied to literature, and its subject is African literary studies. Its contents are intended to materialize a project of expanding and complexifying scholarship in African literary studies as a research area in its own right. Our goal as editors has been to make a range of critical engagements with African literature more visible to scholars working in this area, but also to provide additional impetus for pushing beyond the boundaries of familiar critical engagements with African literature. The result in this edited work is an emphasis on more recent rather than more established critical approaches. Specifically, The Handbook of African Literature aims to serve as an aggregation of studies of African literary texts embodying some of the newer critical approaches from the end of the twentieth to the early decades of the twenty-first century. Deliberately, chapters in this Handbook are not grouped under such customary headings as 'Postcolonial Theory' or 'Globalism' or 'Afropessimism' though these terms and related propositions are surely implicated in the kinds of interpretations advanced by several of our contributors. Because the adopted headings do not correspond to any specific and already-determined body of principles, they better enable the Handbook to fulfill its mission as a template for extending the scope of African literary studies. In short, these are headings whose subjects of inquiry are far from being settled and sedimented. For this reason, they remain open to revision and for the accretion of additional analytical proposals as opportunity presents itself.

We seek then, in this volume, to further encourage the development of a robust practice of critical engagement with African literature where the most sophisticated forms of literary criticism expressly focused on African literature are at the center rather than the periphery of expanding scholarship in world literary studies. This does not mean neglecting other relevant streams of literary theorizing, but using our readings of African literature as occasions to propose new questions for world literary studies. It also means using our application of critical frameworks developed on the basis of reading non-African literatures as an opportunity to review the questions already being debated in African literary criticism, rather than undertaking these tasks as ends in themselves. However, and in order to proffer additional directions for theorizing starting with African literary studies, we will need to move away from a default position that consists of invoking African literature merely as an illustration for existing theories, but not as a basis for crafting alternative modes of investigation and theoretical insight. 
In many respects, the Handbook of African Literature responds to the concern expressed in Tejumola Olaniyan and Ato Quayson's compendium, African Literature: An Anthology of Criticism and Theory regarding the relative invisibility of African literary criticism $(2007,1)$. However, and unlike Olaniyan and Quayson's volume, this Handbook is not an anthology of African literary theorizing. Instead it offers a collection of critical readings of diverse works of African literature, organized around critical points of entry, rather than around the more commonplace classifications of genre and periodization, such as, for example, the novel, poetry, twentieth century drama, orature and so on. ${ }^{1}$ In its organization, the Handbook is conceptualized as a fountainhead for additional research rather than as an encyclopedic reference work. The entry points for critical engagement in this Handbook are grouped under seven headings, each comprising four chapters, and covering subjects that have attracted attention among critics of African literature in recent time. There can be little doubt that the seven sections of the Handbook do not represent a totality of possible approaches to African literature for the current time. They are merely staging posts intended to signal a format for broadening critical conversation around African literature by developing additional aggregations of related subjects for discussion.

Many contributors to the Handbook focus on literary texts written after 2000, not because they are more significant than earlier works, but because we are of the opinion that developing new models for engaging these texts is called for. With the exception of the chapters in the section of the Handbook titled 'Literary Networks,' each chapter provides an original interpretation of one or more works of African literature. Like Olaniyan and Quayson (2007, 1), we, too, believe that 'African literary and critical production are not discrete entities, but in a relationship of both supportive and critical, mutually affective intimacy.' African literature here is always read in context: in the context of other interpretations of similar works (theme, author, regional provenance), in the context of significant and relevant debates in humanities and social science research, in the context of other literary studies, but principally in dialogue with African literary studies. Accordingly, we endorse a methodology that might be described as one of highly contextualized interpretation, referencing as many relevant critical and theoretical frameworks as are applicable, and always including those that refer specifically to African literature and African studies. These interpretations do not stand on their own but always take as their starting point a wider debate in critical theory or a subject of inquiry in humanities and/or social science research. The chapters in individual sections of the Handbook are also positioned so that each chapter can be read in dialogue with other chapters in its section (though the authors worked independently of each other), and within a larger context of critical interpretations of African literature. Because we intend the Handbook to be an instigation to further research, our method of engaging with individual sections does not so much involve summary as the elaboration of pointers indicating how chapters connect to other scholarship on African and related literatures and to other works of African literature. The description of chapters and sections that follows offers a preliminary, and by no means exhaustive, identification of apposite questions and apposite texts that might be invoked in extending and redrawing the map of areas of interest in African literary studies.

Before proceeding any further, we should point out that there are obvious omissions in the Handbook. There is only one chapter in the Handbook dedicated to the interpretation of a dramatic text (the chapter by Ying Cheng). There are no chapters presenting an examination of African poetry, much as we would have wanted to include one. Readers might be forgiven for concluding that the term African literature refers here mainly to prose narratives (the novel, short stories, fiction), and overwhelmingly to prose narratives written in English, although some chapters also consider works written in French (such as the chapters by Anna-Leena Toivanen, Jesse Arseneault and Pim Higginson). The two chapters referencing African literature in African 
languages are both in the section titled 'Literary Networks,' which do not feature interpretations of specific works. These elisions and omissions are not intentional, nor are they designed to suggest a hierarchy for African literature, with the novel written in English occupying the highest rung of the ladder. To the contrary, both happenstance and serendipity are at work in the range of contents for the Handbook. On the one hand, the specific works discussed represent particular areas of interest for our contributors. Partly, also, the omissions identified can be attributed to the constraints of time and space which prevented other interested scholars from participating in this project or from completing commissioned chapters. Additionally, however, we should acknowledge that we were not aiming for a full coverage of extant critical approaches in this single volume. What the Handbook offers, instead, is a 'Kodak moment' from the early twenty-first century indicating the directions currently being pursued by scholars located differently around the world at this point in time. ${ }^{2}$

Assembling chapters for this Handbook compelled us to also ponder the politics of the scholarly anthology and the interventions that anthologies make. If scholarship on African literature has become a global subject in the sense that it is studied around the world, the majority of critics who participate in engendering this global subject are in many respects local and localized scholars, who differ in their understanding of reasonable material for investigation, acceptable methodologies and even acceptable registers of language to deploy. Research concerns that enjoy salience in one location may be considered unworthy of attention in other locations. As critics, we belong to particular scholarly traditions and networks that are often valuable, but can also present investigative blind spots. This anthology comprising the work of differently located scholars gives some sense of the concerns that matter for individual scholars in diverse locations and how we might bring these concerns into dialogue with each other.

To facilitate cross-referencing between different chapters representing a wide spread of scholarly traditions and locations, we made a decision that all chapters would be written in the same language. We did not want a technically representative sample of scholarship from around the world where it would be possible to ignore some chapters on the basis of a lack of proficiency in the language used. We recognize that all potentially interested readers might not have proficiency in English, and hope there will be opportunities to translate the entire volume into one or more additional languages. However, and as an acknowledgment of the fact that our contributors and readers operate in different educational settings, we have left the different spellings of English used in each contributor's location intact.

\section{Mapping Political Agencies}

The chapters in the first section of the Handbook, titled 'Mapping Political Agencies' invoke the political in ways that do not necessarily reference governmentality or the state. In the current neoliberal era, which has resulted in a reorganization of the scope of the state in Africa, and in some instances, led to an actual disempowering of the state, it makes sense to interrogate other visions of the political that are not expressly premised on the expectation of direct interventions from the African state as currently constituted. In the opening chapter of this section, Monica Popescu's examination of generational differences among two Kenyan writers in their responses to the Cold War uncovers an overlooked tangent in the writings of Ngũgĩ wa Thiong'o and Binyavanga Wainaina. But also, and in foregrounding often neglected political mobilizations, Popescu's chapter draws attention to the ways in which heeding divergent and sometimes forgotten political projects might make for a remapping of the field of African literature. Drawing inspiration from Popescu's chapter, we would invite readers of the Handbook to identify other overlooked political 'master plans' in order to consider how these forgotten political agendas 
and moments complicate our reading of individual texts and our mapping of a field. While both sets of works addressed in Popescu's chapter were written by authors from a single nation, it is worth asking what insights we might gain by deploying the same model beyond the nation in an act of remapping. Supposing, for example, we read J. M. Coetzee's Disgrace alongside Ferdinand Oyono's Une Vie de boy as tales of destroyed reputations, how would this change our perception of African literary responses to actions undertaken by agents of the state across the continent?

In their chapters, both Chielozona Eze and Allison Mackey attend to questions of agency as an instantiation of the political outside the formal realm occupied by politicians. They both examine how authors, narrators and characters in literary texts achieve agential status and how the agency attributed to any of these subject positions connects to an understanding of political ethics. While Mackey focuses on the ownership of voice by the presumed narrators recounting the kind of African political crises that generate calls for humanitarian intervention, Eze's chapter works in the opposite direction in eschewing consideration of ethical choices made in what, following Njabulo Ndebele, he describes as the spectacular realm of grand political action. Mackey's chapter can be read alongside Laura Murphy's (2015a, 2015b) articles on the ownership of voice in what she characterizes as 'new slave narratives' or Dominic Thomas's (2006) work on textual ownership in African literature. Eze's chapter provides an opportunity to return to discussions among African writers themselves as well as among critics about the relationship between structural change and personal agency. In privileging the agency of the individual as Eze does here, do we run the risk of underplaying the radius and reach of systemic constructs? Should we interpret Ndebele's call for attentiveness to the ordinary as an invitation to foreground the personal and the internal over the structural?

In her chapter, Toivanen analyzes texts where authors take on a subject with obvious ramifications for political organization, namely labor, imagined here outside of a context of political mobilization. In the texts that Toivanen discusses such as Alain Mabanckou's Tais-toi et meurs, the criminal gang has supplanted the labor union and the brotherhood of men depicted with so much care in Ousmane Sembène's Les bouts de bois de Dieu. Toivanen's chapter invites us to consider African migration, not only from the perspective of Afropolitan mobility, but also from the point of view of the experiences of an ultimately servile work force. On the one hand, mobility enables a new form of resource extraction - the extraction of African labor. On the other hand, and in her discussion of Sefi Atta's $A$ Bit of Difference, Toivanen indicates how mobility awakens a new consciousness of the conditions under which servile populations toil. She mentions for example the internationally mobile protagonist, Deola noticing and wondering about the plight of her brother's workers in Nigeria. This moment in the narrative recalls a similar scene in Chimamanda Adichie's Half of a Yellow Sun (2007, 274-275) where another well-traveled protagonist, Olanna, is distressed by the way her wealthy mother in Nigeria treats the hired help. Although Adichie's novel does not make explicit the connection between Olanna's experience of international travel and her attentiveness to the exploitation of labor back at home, Toivanen's chapter would seem to indicate that even in portrayals of mobility (associated with ease) rather than migration, there may very well be important reflections about labor lurking behind the scenes. Novels such as Michael Donkor's Housegirl (published with the title Hold in the UK), Amma Darko's Beyond the Horizon, and Chika Unigwe's On Black Sisters' Street make even more explicit the nexus between migration and a reconstructed condition of servility. 


\section{Journeys, Geographies, Identities}

The chapters in this section, 'Journeys, Geographies, Identities,' consider questions pertaining to identity in African literature from a number of overlapping perspectives: travel, citizenship, vocation and avocation. The most visible identity connected to travel in African literary studies today is that of the Afropolitan. In different ways, and in their respective chapters, Ying Cheng and Rebecca Fasselt divert our attention to other kinds of travel-related identities that are not captured by the notion of the Afropolitan. Fasselt redirects critical conversation about travelrelated identities by foregrounding intra-African travel, instead of travel between Africa and the Global North in particular and the figure of the Afropolitan. Quoting Evan Mwangi (2007, 174), Fasselt remarks in her chapter that these narratives about travel within the continent exemplify a level of comfort with 'an unanchored sense of identity' but also a desire for some degree of rootedness. Other than Fasselt's chapter in the Handbook, there are relatively few scholarly discussions within African literary studies of the ways in which authors employ travel within the continent as commentary on identity and belonging within their own and other African nations. In establishing links between the construction of a certain kind of identity and intra-African travel and migration, Fasselt's chapter here complements Rebecca Jones's work (2015) on Nigerian travel writing about domestic travel in an earlier era.

Ying Cheng's chapter returns to a somewhat older critical framework in her reflections on Nigerian representation of Chinese-African encounters, and Chinese representation of AfricanChinese encounters. The scholarship on African-Asian encounters in literature has thus far focused mainly on Indian-African encounters (Gaurav Desai 2013; Dan Ojwang 2013), though and as Cheng notes in her chapter, Chinese characters are now showing up with greater frequency in newer African literature. While Cheng uses her analysis of the Chinese-authored text and the Nigerian-authored text as an opportunity to revise and contest aspects of Mary Louise Pratt's notion of the mutual gaze in a Global Southern context, the chapter also makes notable contributions to research on othering in African literature. The fact that Femi Osofisan, the Nigerian playwright, committed to fostering cooperative relations between Nigerians and the Chinese, became aware of the need to moderate stereotypes of the Chinese in his play only after receiving comments from his Chinese associates about the play, suggests that processes of othering may be lurking in unexpected corners of African literature. If we think beyond nationality and race, what other categories and modes of othering might we find in African literature and where might we find them? The distinction between the human and non-human, between the human and the animal, as well as forms of disease and disability come to mind as possible modalities for representing otherness in African literature that might be worth investigating.

Aghogho Akpome's chapter on ethnicity in twenty-first century African writing returns to a subject that can often be taken for granted as fixed or subsumed within other categories. In earlier African literature, the specifically ethnic coloration of cultural referents could be ignored and interpreted as exemplary for African culture broadly, even when they were unintelligible for many African readers. In his comments about the centrality of the West African yam in Chinua Achebe's writing and the opacity of the yam for East African readers, Simon Gikandi captures the extent to which the significance of certain literary references could remain highly circumscribed by nationality and ethnicity among others. Gikandi writes: 'for those of us growing up in the highlands of East Africa, the yam was as alien as the proverbial apple. Having never seen a yam in our lives, we were hard pressed to understand its value' $(2001,4)$. Although many researchers have already written about ethnic conflict in African literature, ${ }^{3}$ Akpome's chapter suggests that we might not always wish to accept at face value an author's affirmation or 
denial of ethnic identification within the text. Unlike the texts examined by Cheng and Fasselt, the identities in play in Akpome's chapter are not travel-related. At the same time, and as remarked by Akpome, the identities in question are dynamic rather than static. In the texts considered, ethnicity is inflected by race, citizenship and postcolonial politics among others. Several questions could be posed in response to this chapter, and most notably, what exactly does ethnicity signify in contemporary African literature? How do we determine when African literatures are actually ethnic literatures, if ethnicity is so often an avatar for other identities, or denied altogether in some instances? In what contexts might ethnicity as an avatar or in itself be considered ideologically unacceptable and associated with dangerous exclusionary impulses? Akpome's interpretations in this chapter will hopefully serve as a provocation for further reflections on the meanings of ethnicity in African literature.

In his chapter, Rotimi Fasan considers an ideological rather than an atavistic identity. We should state here that Fasan's chapter is one of several chapters in the Handbook that examine the ideological orientations, functions and strategies of African life writing (see also chapters by Were, Fasselt, Popescu, Aghogho). Indeed three of the chapters in this section of the Handbook refer to life writing, though Fasan's is the only one based entirely on an examination of life writing. The number of creative writers who have engaged in life writing is extensive and growing. Fasan suggests in his chapter that Wole Soyinka uses life writing to write back to his creative and meta-critical writing about the Yoruba mythological figure, Ogun. In responding to Fasan's chapter in the Handbook, we think it might be worthwhile to consider the different stages of their career at which creative writers produce memoirs, the purposes and audiences for which they produce these memoirs and the identities they wish to stage in these memoirs. There can be little doubt for example that Soyinka's memoirs have made his contributions to Nigerian political life more publicly accessible than his early modernist creative and critical writing. By contrast, memoirs like those of Binyavanga Wainaina and Teju Cole appear to be more focused on crafting the identity of the creative writer than that of the political provocateur.

\section{Working through Genres}

Each of the chapters in the section titled 'Working through Genres' seeks answers to questions that might be asked about works of African literature that embody a particular type, or if you will, a genre. While arguments made by Tsitsi Jaji and Lily Saint (2017), as well as Adejunmobi $(2017)^{4}$ adopt a wide-angle look at the fundamental issues to be addressed when approaching cultural practices and texts in relation to genre in African contexts, the chapters in this section respond to the matters arising with respect to specific genres or types of African writing. It is true that debates about genres have a long history in African literary studies, still we will need to expand the scope of these arguments about typology in thinking about texts published since the beginning of the twenty-first century, so as to better account for continuing experimentation with form in African writing. Whether particular typologies do or do not apply to African writing and literature, how African variants of an expansive and global type differ from related forms elsewhere in the world, and when to isolate a strand of African writing as a genre are matters for consideration. To mention one example, should we think of literary works where the named author becomes a character in the narrative as a genre? Helon Habila's Waiting for an Angel and Igoni Barrett's Blackass represent recent illustrations of this trend.

In their respective chapters, both Rebecca Duncan and Ian MacDonald investigate classifications that have been more frequently applied to literatures from Western societies than they have to African literatures: namely the gothic, and utopian literature. Drawing on the work of 
Harry Garuba, Diane Mafe, Cheryl Stobie, Brenda Cooper and Ato Quayson, Duncan brings several conversations about the nature of the supernatural in African literature into dialogue with each other. She makes a useful distinction between the association of magical elements with fear and anxiety, as a characteristic of the gothic, and the magical as manifestation of what Garuba has called an animist realism. MacDonald too pursues an interest in the magical dimensions of African literature, but specifically in its relationship to the articulation of a utopian vision within a broad stream of African fantasy and science fiction. Ever since the politics of disenchantment set in during the decades after independence, African literature has been more frequently thought of as motivated by a dystopian rather than a utopian impulse. But as MacDonald seeks to demonstrate in his chapter, locating utopia (which in Greek means 'noplace') and eutopia ('good place') is an important undertaking in Okri novels like In Arcadia and Starbook. MacDonald raises several questions with respect to these texts. For example, are Okri's less well known novels simply recycling or trying to move beyond Western conceptions of utopia? Do they put forward a programmatic vision for instantiating utopia? MacDonald's chapter here can be read alongside the work of Bill Ashcroft (2009a, 2009b, 2013) and Valerie Orlando (2016) who have also argued for a recognition of a utopian impulse in a wider range of African literature. While both Duncan and MacDonald read the magical and other non-realist dimensions of selected texts as modalities for interrogating modernity and scientific rationality in their respective chapters, other interpretations are also possible. With the emergence of a growing number of writers of non-realist fiction in the early twenty-first century (Nnedi Okorafor, Lauren Beukes, Helen Oyeyemi and Tomi Adeyemi among a crowded field), theorizing and interpreting the diverse forms of non-realist African and African diasporic fiction clearly represents an important area of growth for scholarship in African literary studies.

In their examination of self-help literature and life writing, the chapters by Marciana Were and Rebecca Jones point readers to a wider textual world and culture that encompasses but also extends well beyond literary writing. Taken together, both chapters as well as others in the Handbook challenge the notion of an African literary world relatively detached from other forms of textuality. These other genres of writing intersect with African literary writing, at a formal level, but also in terms of the purposes for which they are deployed. The fact that a literary memoir, Binyavanga Wainaina's One Day I Will Write About This Place is perhaps the most cited creative work in this Handbook is itself indicative of the imbrications between particular types of literary writing and a wider textual culture around Africa. An interest in a positioning of the text and of textual strategies for self-fashioning is to be discerned in virtually all the sections of the Handbook. Like Stephanie Newell (2008), Jones is concerned with how different kinds of texts construct the self, and what kind of self is constructed. Different genres of writing construct the self differently. Jones's chapter identifies the specific conventions of the secular selfhelp text, and how these differ from the conventions of the religious self-help text. Marciana Were draws on the growing body of work on African female autobiographies (for example Folasade Hunsu) in her chapter on two non-fictional female autobiographies. Where Duncan examines the genealogy of a genre, Were considers the functions of genealogy within a genre. In some respects, the narrators of the autobiographies analyzed by Were resemble the fully autonomous subjects that Newell $(2008$, 16) describes. But in other respects, the narrators reclaim their position within a web of familial filiations as an ideological move to pre-empt a repudiation of their positions as foreign to their birth community. The chapters by Were and Jones also reveal contrasting strategies for constructing the self in these narrative types explicitly focused on the self. If the self of self-help literature is often cut off from the past (Newell 2008, 19), the narrating and authorial self of the autobiography often seeks to reclaim the past. 


\section{The World of and beyond Humans}

The chapters in the section titled 'The World of and beyond Humans' seek to go beyond what Cajetan Iheka $(2018,2,8)$ identifies as the human-centeredness or anthropocentrism of African literary studies. In their chapters in the Handbook, Iheka and Jesse Arseneault consider the nonhuman from different perspectives. Iheka examines two novels where the search for a missing human is supplanted by the discovery of an environmental situation. If Eze's chapter in 'Mapping Political Agencies' calls for attention to the most vulnerable among us, Arsenault extends that concern to a discussion of the representation of animals in their own right, and as symbols of a certain kind of humanity. Animal studies, and the term animality is a particularly fraught subject, given the ways in which Africans have been animalized in colonial discourses. As Chris Dunton (2015) points out, Africans could in colonial discourses, be thought of as animals, and thus the obverse of humans. In Lauren Beukes's Zoo City, which rewrites this stereotype for dramatic effect, to be animaled is an often fear-inducing condition. Arseneault's attention to animal figures could also be applied to recent fantasy fiction by writers like Nnedi Okorafor, Tomi Adeyemi and Akwaeke Emezi that reprise the animal figure for a variety of purposes. Furthermore, Okorafor's The Book of Phoenix in particular and Emezi's Freshwater offer opportunities to study what Iheka $(2018,7)$ has described as 'interspecies relations.' Arseneault's chapter in the Handbook might usefully be read alongside some other recent studies of animals in their own right and animals as metaphors in African fiction. ${ }^{5}$

If Iheka and Arseneault question anthropocentrism in African literary studies, Sarah Lincoln and Ng'ang'a Muchiri focus attention on interactions between humans and other elements of the natural world, in particular, land and soil. Both contributors invite us to direct greater attention to delineating types of human interactions with a non-animate world beyond humans and what these interactions might signify. For Muchiri and Lincoln, the elements of nature in question are land, landscape and soil. If landscape is, according to W. J. T. Mitchell $(1994,1)$, 'a process by which ... subjectivities are formed,' Muchiri examines how the diverse interactions that create landscape form subjectivities in Kenyan fiction by women. In his chapter, he identifies characters who stand apart from landscape, those who travel over landscape, those who are submerged in landscape, and those who touch landscape among others. Lincoln's chapter offers an opportunity to ponder the significance of those characters that are comfortable with dirt and a tactile experience of the soil, in contrast to those who envision land as an entity but do not interface directly with soil. Her chapter complements a growing body of research on dirt in African literature and cinema by scholars like Kenneth Harrow (2013) and Stephanie Newell (2017; Newell and Green 2018) among others. Muchiri's attention to the early and later years after independence in his chapter presents an interesting parallel with Lincoln's references to the moment of Earthrise (when images of Earth as viewed from space were first circulated), also unfolding in Africa's post-independence era. Together, Muchiri's and Lincoln's chapters highlight the import of the distinctions that writers make between land and landscape, farming and gardening, especially in relation to the unspooling of different time scales (the time of independence, the time of the space race, and the time of nature among others).

In this section of the Handbook, Lincoln and Iheka also attend to the form of the narrative, its plotting, and draw a line from the novel's plotting to its focus on nonhuman life or other dimensions of nature. Iheka considers questions of audience for the literary work, not from the perspective of language or even theme, but from the perspective of the formal traits of the works, and their narrative organization. He further suggests that we read what might appear to be mishaps in form, not as aberrations, but deliberate choices intended to foreground devastation of nonhuman life. Where Iheka is interested in a narrative form that displaces attention 
from humans, Lincoln tracks a plot that foregrounds minor forms of farming in an everyday context, even as she invites us to reflect on the ethical and ecological stakes of gardening in works by African authors.

\section{Everyday Sociality}

The section titled 'Everyday Sociality' brings together two items that have attracted relatively little attention in African literary studies: the everyday on the one hand, and sociality on the other. Despite the considerable interest that Njabulo Ndebele's Rediscovery of the Ordinary (1991) has generated among some critics of African literature, reflections on the textures of everyday life in African literature are relatively uncommon. A search through the titles of articles in major journals in African literary and African cultural studies will quickly reveal how infrequent the words 'everyday' and 'quotidian' are in the titles of scholarly publications dedicated to African literature. The few books in African cultural studies that reference the everyday in their title, as for example in Karin Barber's Africa's Hidden Histories: Everyday Literacy and the Making of the Self (2006) are not actually works of literary criticism. Though it too is not work of specifically literary analysis, Ato Quayson's Oxford Street, Accra: City Life and the Itineraries of Transnationalism (2014) presents a more productive point of departure for deliberating on everyday sociality in African literature.

In this section, the two chapters by Delores Phillips and Pim Higginson address the subject of everyday sociality by reviewing practices involving ingestion in everyday life: specifically consuming food and imbibing alcohol. In her analysis of several literary texts, Phillips makes a distinction between studies of food and eating in African literature that focus on its 'gastropolitical import,' and those that focus on its 'gastropoetic import.' For Phillips, the term 'gastropoetic,' borrowed from Parama Roy, reveals the dimensions of ordinary life that depictions of everyday eating can unveil - both its pains and its pleasures. In the realm of the everyday, Phillips singles out the dinner table, to which we also add snacks and informal meals. While Jonathan Bishop Highfield (2017) has authored an insightful monograph and the most comprehensive work to date on the connections between African literature and the growing field of food studies at large, there is still much work to be done in uncovering the gastropoetic dimensions of food in African literature. Phillips's chapter builds on the work of Highfield, but also that of Njeri Githire (2014), by applying the notion of the gastropoetic more broadly to African literature. Alongside identification of the gastropoetic dimension in selected works of African literature, this chapter also initiates a project of delineating and characterizing the specific relationship between the gastropolitical and the gastropoetic in African literature.

In Higginson's chapter, drinking scenes gesture at varied socialities, some of which are quotidian, while others are not. Following up from Phillips's chapter, there is room to inquire whether the distinction between the political and poetic applies to these drinking scenes and how the significance of what we wish to call the liquorpolitical differs from the significance of the liquorpoetic in African literature. While Higginson relates the drinking scenes in the Francophone novels examined to the distinctions between modernity and tradition, his chapter suggests many other possible lines of inquiry regarding alcohol-fueled socialities. For example, the presence or absence of drunkenness and the figure of the alcoholic would be a subject for further discussion. The upsides and downsides of female figures in alcohol establishments in urban settings represent another subject for consideration, whether one thinks of the shebeen queens of southern African literature or the bar girls of West African literature. As Higginson's chapter makes clear, and inasmuch as the everyday differs from the spectacular, the everyday manifested in alcohol-related socialities, can also become a site for dehumanization. How to 
write about scenes of dehumanization for example in such novels as Peter Abraham's Mine Boy, remains a challenge.

The chapters in this section by Shirin Edwin and Fiona Moolla invoke the everyday dimensions of social institutions regulating faith and intimacy as well as reproduction. Although the consideration of marriage is not in itself a new topic in African literary studies, the contours of the marriage plot and its relationship to the everyday have yet to be fully explored. Much has been written about infertility in African literature, without necessarily identifying how this experience factors into the marriage plot in both African literature and popular culture. Still, Moolla's chapter raises as many questions as it answers. For example, do the patterns of the marriage plot that Moolla identifies in her chapter extend beyond what she calls the Anglo-Igbo novel? In earlier and more recent literary works of African literature, how is the interplay between the genealogical marriage and alternative conceptions of matrimony unfolding? Which particular socialities do novels that include the marriage plot foreground and to what end? As Edwin's chapter makes clear, the tendency to think of social practices in their institutional terms rather than in terms of their everyday dimensions is even more pronounced in matters pertaining to religious faith. Edwin's chapter extends conclusions from her own recent publications, and works in dialogue with insights provided by other scholars of literature such as Kenneth Harrow (1996), Emad Mirmotahari (2011) and Gabeba Baderoon (2014). But she also draws upon research conducted by social scientists placing religion and specifically Islam in a wider context. How to interpret any distinctions made between the everyday and the institutional and political dimensions of religious practice is an important concern in this chapter. Edwin responds to the concern by adopting a topological approach that refracts institutional engagement with a wider world through the prism of the local and the everyday. But this too raises additional questions that other critics of African literature might wish to consider, and in particular whether an everyday practice of a religious tradition in African literature is in fact always an indirect commentary on the institutional and political dimensions associated with the religion itself, or larger institutional and political forces within the society.

\section{Bodies, Subjectivities, Affect}

The chapters in the section titled 'Bodies, Subjectivities, Affect' clearly privilege the last item in the list, namely affect, while gesturing at the connection between affect and both bodies and subjectivities. Together, the four chapters here consider the affective states of desire, trauma and shame, and offer a point of departure for extending insights from such studies as Sara Ahmed's The Cultural Politics of Emotion (2004). As Madhu Krishnan (2017) has pointed out, African literature recounting suffering often seeks to engender a particular type of affective response as a basis for ethical engagement with the work. At the same time, affect in the work itself remains relatively understudied. While pain and trauma have received considerable attention from scholars of African literature (Zoe Norridge, Stef Craps, Nick Mdika Tembo), other affective states such as anxiety, grief, fear, joy, pleasure, desire, shame and others have yet to elicit significant attention in scholarship on African literature.

In her chapter, Grace A. Musila focuses on female desire as an expression of an alternative to nationalist imaginations of freedom. The chapter does several things at once. In the first place, it directs attention to the subject of freedom which has until recently been relatively undertheorized. On the one hand, Musila's pairing of female desire with the anticipations of freedom linked to the end of colonial rule can be read in tandem with Phyllis Taoua's extensive discussion of African freedom (2018). But her chapter also works as an investigation into the subject of female desire itself as envisioned by an African female writer. It is in this respect a 
helpful contribution to the expansive field of Africa and black-centered scholarship on female sexuality and gender. The meanings attached to portrayals of female desire in diverse African literature texts call for the kind of sustained examination provided here in Musila's chapter. Among possible subjects for such inquiry, one need only think of such famous African literary figures as Noria in Zakes Mda's Ways of Dying, or Ifemelu in Chimamanda Ngozi Adichie's Americanah, or Kainene in Half of a Yellow Sun, or Ken in Ken Bugul's Le baobab fou, or Ona in Buchi Emecheta's The Joys of Motherhood, to name just a few. In laying a wider scope for a discussion of female desire, this chapter furnishes an opportunity for a more detailed characterization and study of male desire in selected African literature works. In dictator novels such as those by Sony Labou Tansi and Ngũgĩ wa Thiong'o, the larger than life protagonists seem to be consumed by sexual and other appetites that can never be satisfied. Whether these appetites actually correspond to the affect of desire is a question worth weighing. And we might further contrast the dictator's seeming inability to achieve a state of satiety in novels like these with ingestion as obligation, but also detached from the affect of satiety in such novels as Tochi Onyebuchi's Beasts Made of Night.

While Musila is concerned about female desire in relation to particular conceptions of freedom, Edgar Nabutanyi takes on the subject of male desire within a context of same sex intimacy. Like Taiwo Osinubi $(2014,2018)$ who has tracked the presence of queer intimacies through responses to political life in the postcolonial African nation, Nabutanyi views Jennifer Nansubuga Makumbi's novel of the nation, Kintu, in its historical sweep as a pointed response to contemporary debates on same sex intimacy in Uganda. In this chapter, Nabutanyi contends, Makumbi brings together the politics of the nation and the politics regarding sexuality. In passing, Nabutanyi also draws attention to another dimension of Makumbi's novel that calls for further analysis, namely the description of male sexual activity for the purposes of reproduction as labor. In African literature, we less seldom encounter a direct through line from male sexuality to labor than the more commonplace association of the outcome of female sexuality with labor either through reproduction or infertility. Somewhat unusually, Kintu, a novel by a female author, concentrates on male desire, more so than on female desire, and relates male desire to the nation. The depiction of male desire in male-authored works as in a novel like Patrice Nganang's Temps de chien, almost always seems to speak to a relationship with the nation. Although Musila's chapter suggests a somewhat similar interpretation for Yvonne Vera's novels, there are grounds for questioning whether female desire advances the same ends in works by African female authors.

In her chapter, Martina Kopf studies how narratives organized around displaced witnessing of a traumatic event use the absence of the actual event and the ensuing trauma. The goal in such instances is not to solicit empathy from the reader, but to encourage the reader to make a connection between an acknowledged trauma in the past, and an unsettling situation in the present. Kopf's chapter can be placed alongside Gĩchingiri Ndĩgĩrin's (2016) article considering a different strategy for effecting distance from trauma. Kopf, like Ndĩgirĩ connects this displacement of trauma to a distinctive form of witnessing. In examining narratives that appear to sidestep a frontal confrontation with the actual events relating to a society-wide trauma, Kopf raises questions about the range of purposes for which witnessing is invoked in African literature. Other works that would be well suited for this kind of analysis include Chinelo Okparanta's Under the Udala Trees, as well as South African texts like Mark Behr's The Smell of Apples and Jo-Anne Richards' The Innocence of Roast Chicken.

In her chapter, and following up on Timothy Bewes's work (2010) on postcolonial shame, Naminata Diabate considers recent recourse to the affect of shame in African literature as a response to the failures of postcolonial liberation. Diabate's analysis of the shamelessness of 
individuals in positions of political leadership in Ngũgĩs Wizard of the Crow exposes another dimension of the characterization of dictators in some works of African literature, namely the absence of a capacity for affect. It is not just that the Ruler of Aburĩria in Ngũgî's novel does not feel shame, but that he appears to lack an actual capacity for affect of any kind. Readers of the Handbook might also wish to revisit other elaborations on shame in African literature (such as in Zoë Wicomb's David's Story) in light of the interpretations proposed in Diabate's chapter. In this section of the Handbook, Diabate's chapter is also the one that most closely concatenates affect with the body. In our reading of Ngũgĩ's novel, the depiction of grotesque bodies and bodily excess among Abũriria's ruling class serves to further underscore a state of affective deficit. It is also worth noting that the women who shame the Ruler in Ngũgî's novel do so in part by deploying the female body and scatological bodily functions. Akin Adesokan $(2012,12)$ has proposed that we view the scatological as a trend in Francophone African writing especially, and an exercise in 'courting a particular readership' (2012, 14). Whether this interpretation of a scatological dimension applies to works like Ngũgĩ's novel is up for debate. There can be little doubt that other conditions of the body such as disease, injury, mutilation, disability, corpulence, emaciation, beauty and darkness among others are deserving of additional attention in African literary studies. Scholars in African literary studies interested in pursuing such subjects will find a helpful point of departure in studies in postcolonial and African literature by authors like Ato Quayson (2007), Régine Michelle Jean-Charles (2014), Ken Lipenga (2014), and Christian Flaugh (2012).

\section{Literary Networks}

The chapters in the final section of the Handbook, titled 'Literary Networks' contribute to a slowly growing area of scholarship dedicated to mapping African literature as a cultural field sustained by regional, national and transnational networks, and involving different kinds of institutions. For us as editors, the idea of the network allows for a more comprehensive accounting of the African literary field, as a complex field studded with nodal points, involving connections as well as disconnections with other nodal points on multiple byways, facilitating movement in some directions, but not in others at different times. The network also allows for multiple narrations of African literary history following the byways of translation, publishing, language, book launches, book clubs, reading groups and other points of connection. The network suggests that even in societies facing significant infrastructural challenges, low literacy levels and reduced access to books, the literary text rarely emerges in a vacuum: it almost always abuts a byway or nodal point in one or more networks, even when it is not positioned at the acknowledged centers of any network.

The chapters by Stephanie Bosch Santana and Kate Wallis in this section bid us to rethink the kinds of connections that African readerships have with African literature by directing attention to those connections that have not been previously memorialized in academic writing. In her chapter, aptly subtitled 'Literary Networks Offline,' Bosch Santana reminds us that initiatives for publishing and initial responses to African literature do not always emanate from the Global North. Bosch Santana's chapter tracks a world of connections between creative writers, and between writers and readers in Malawi, that extends into Zimbabwe, Uganda and Kenya, as well as Sweden. In her equally incisive chapter, Wallis makes the argument that multinational publishers (like Heinemann Educational Books) did not necessarily convene the networks that their publishing depended on, they just needed to understand how to access and build their publishing out of existing networks. In their chapters, both Wallis and Bosch Santana highlight the function of book launches as opportunities for engagement between the text 
and an embodied audience through the medium of the book launch. Another dimension of the network that these chapters foreground is the deployment of the literary text in diverse acts of self-fashioning: on the part of the author, but also on the part of readers who define themselves offline but also online (as in Twitter for example) by the books that they read. In raising questions that take us beyond an interpretation of texts, the chapters by Bosch Santana and Wallis belong alongside recent publications also attending to the varied contexts and networks of African literature, including Adélékè Adéèko's Arts of Being Yorùbá (2018), and Nathan Suhr-Sytsma's Poetry Print, and the Making of Postcolonial Literature (2017).

The chapters by Sara Marzagora and Ayele Kebede, and by Doseline Kiguru, problematize the networks of African language literatures. In making sense of these literatures, both chapters invite scholars to move beyond analytical models premised on customary oppositions and construction of islets of presumed coherence. Unlike earlier works on multiple African language literatures like Albert Gérard's African Language Literatures (1981) that assigned individual chapters to discuss literatures in distinct African languages, or studies of a text in both an African and European language in the manner that we find in Tobias Warner (2016) and Jonathan Repinecz (2015), Sara Marzagora and Ayele Kebede's chapter brings together interactions between literatures in two African languages. There will undoubtedly be analogs in other African language literatures for the unstable dynamic of connection and disjunction, spilling across borders, as well as between and within literary networks that these authors find in Oromo and Amharic language networks over several centuries.

Kiguru's chapter raises questions with respect to two distinct strands in the networks governing African literature, namely the role of language and award bodies. Like other contributions in this section, Kiguru's chapter complicates longstanding perceptions of African literary networks, and most notably of a prevailing incongruence between the internally generated and the externally supported, or to borrow terms familiar in African literary criticism, between the introverted and the extroverted. Scholars wishing to revisit debates about world literary relations from Sarah Brouillette $(2017,2015)$ to Doreen Strauhs (2013) will want to think through Kiguru's account regarding three fairly recent and transnationally supported awards for Kiswahili language literature. Other than the Caine Prize, scholarship on awards for African literature is not yet extensive. ${ }^{6}$ Kiguru's contribution here opens the door for additional research on a number of matters arising: how does the financial capital associated with these more locally grounded awards compare with the cultural capital that accrues (or does not accrue) to the winners? What is the impact of the often unpredictable life span of many awards, including the international awards, on the status of the text? What happens to the work when even the internationally supported award is unable to fulfill its promise in ensuring the translation and circulation of the African language literary text? Responses to these questions call for a kind of research practice that is often unfamiliar to scholars of literature, namely field work. This is not scholarship that can be produced from afar. It requires a presence on the ground, and access to the local networks of African literature. At the same time and in instances where participants in such local networks also begin to undertake research on the same networks, they might wish to look at emerging scholarship on practice as research in order to better differentiate the arena of practice from the arena of scholarship. ${ }^{7}$

\section{Critical junctures}

It will be evident by now that there are areas of overlap among the different chapters. The works of particular authors (Wainaina, Aboulela, Ngũgĩ, Adichie) are examined in several chapters, highlighting the multiple lenses through which works by these authors can be 
addressed. The contrasts and convergences between life writing and fiction occur in several chapters. Kopf, Mackey and Popescu look at novels with Africans from one African country located in another African country. Though Fasselt engages in interpretation of selected texts in her chapter, her discussion of networks arising from migration connects to several of the questions raised in the section of the Handbook on networks. Eze's chapter could just as easily have been placed in the section on everyday sociality or in the section on bodies, subjectivities and affect, as could Lincoln's which also attends to everyday interaction with soil. Though we did not specifically ask contributors to do so, several of them reference each other's publications on related subjects. There are intersecting examinations of questions about audience in Iheka's and Kiguru's chapters. As indicated earlier in the introduction, the sections of the Handbook are not watertight. Areas of overlap do not signal redundancy, and instead point to potential avenues for additional investigation. Together, the chapters in this Handbook offer a comprehensive introduction to multiple strands of criticism in African literary studies intended to work as a provocation to further research.

\section{Notes}

1 In this respect, the Handbook differs from such fairly recent volumes as The Columbia Guide to West African Literature in English since 1945 (2008) edited by Oyekan Owomoyela, The Cambridge Companion to the African Novel (2009), edited by F. Abiola Irele, and The Novel in Africa and the Caribbean since 1950 (2016), edited by Simon Gikandi, among many other such anthologies of African literary studies.

2 In using a term like the 'Kodak moment,' which is itself undergoing obsolescence at the time of writing this introduction, we signal the anticipated transience of the critical frameworks highlighted in this volume.

3 See Nick Mdika Tembo (2012) and Chitra Thrivikraman Nair (2014) on ethnicity in Chimamanda Ngozi Adichie's Half of a Yellow Sun, for recent examples.

4 The articles by Lily Saint and Tsitsi Jaji as well as the one by Moradewun Adejunmobi all appear in a special issue of the Cambridge Journal of Postcolonial Literary Inquiry titled 'Genre in Africa.'

5 See in particular Wendy Woodward (2008), Fiona Moolla (2016), Maurice Vambe (2017) and especially Evan Mwangi (forthcoming).

6 See Doseline Kiguru (2016) and Nathan Suhr-Sytsma (2018) for more on Africa-based literary prizes.

7 See for example, Robin Nelson (2013).

\section{References}

Abrahams, Peter. 1979. Mine Boy. London: Heinemann Educational Books.

Adéèko, Adélékè. 2018. Arts of Being Yorùbá: Divination, Allegory, Tragedy, Proverbs, Panegyric. Bloomington: Indiana University Press.

Adejunmobi, Moradewun. 2017. 'Afterword: Genre Queries, African Studies.' The Cambridge Journal of Postcolonial Literary Inquiry 4(2): 258-264.

Adesokan, Akin. 2012. 'New African Writing and the Question of Audience.' Research in African Literatures. (43)3: 1-20.

Adichie, Chimamanda Ngozi. 2007. Half of a Yellow Sun. New York: Anchor Books.

Adichie, Chimamanda Ngozi. 2013. Americanah. New York: Alfred Knopf Publishers.

Ahmed, Sara. 2004. The Cultural Politics of Emotion. London: Routledge.

Ashcroft, Bill. 2009a. 'The Ambiguous Necessity of Utopia: Post-Colonial Literatures and the Persistence of Hope.' Social Alternatives 28(32): 8-14.

Ashcroft, Bill. 2009b. 'Remembering the Future: Utopianism in African Literature.' Textual Practice 23(5): 703-722.

Ashcroft, Bill. 2013. 'African Futures: The Necessity of Utopia.' International Journal of African Renaissance Studies-Multi-, Inter- and Transdisciplinarity 8(1): 94-114.

Atta, Sefi. 2013. A Bit of Difference. Northampton, MA: Interlink.

Baderoon, Gabeba. 2014. Regarding Muslims: From Slavery to Post-Apartheid. Johannesburg: Wits University Press. 
Barber, Karin. 2006. Africa's Hidden Histories: Everyday Literacy and the Making of the Self. Bloomington: Indiana University Press.

Barrett, Igoni. 2015. Blackass. Minneapolis, MN: Graywolf Press.

Behr, Mark. 1995. The Smell of Apples. New York: Picador.

Beukes, Lauren. 2010. Zoo City. New York: Random House.

Bewes, Timothy. 2010. The Event of Postcolonial Shame. Princeton, NJ: Princeton University Press.

Brouillette, Sarah. 2015. 'World Literature and Market Dynamics.' In Institutions of World Literature: Writing, Translation, Markets, edited by Stefan Helgesson and Pieter Vermeulen, 93-106. London: Routledge.

Brouillette, Sarah. 2017. 'The African Literary Hustle.' Blind Field Journal. https://blindfieldjournal.com/ 2017/08/14/on-the-african-literary-hustle/.

Bugul, Ken. 1984. Le baobab fou. Dakar: Nouvelles éditions africaines.

Coetzee, J. M. 1999. Disgrace. New York: Penguin.

Cooper, Brenda. 1998. Magical Realism in West African Fiction: Seeing with a Third Eye. Abingdon: Routledge.

Craps, Stef. 2013. Postcolonial Witnessing: Trauma out of Bounds. New York: Palgrave Macmillan.

Darko, Amma. 1995. Beyond the Horizon. London: Heinemann Educational Books.

Desai, Gaurav. 2013. Commerce with the Universe: Africa, India, and the Afrasian Imagination. New York: Columbia University Press.

Donkor, Michael. 2018. Housegirl. New York: Picador.

Dunton, Chris. 2015. 'Sara Baartman and the Ethics of Representation.' Research in African Literatures 46(2): $32-51$.

Edwin, Shirin. 2016. Privately Empowered: Expressing Islamic Feminism in Northern Nigerian Fiction. Evanston, IL: Northwestern University Press.

Emecheta, Buchi. 1994. The Joys of Motherhood. London: Heinemann Educational Books.

Emezi, Akwaeke. 2018. Freshwater. New York: Grove Press.

Flaugh, Christian. 2012. Operation Freak: Narrative, Identity, and the Spectrum of Bodily Abilities. Montreal: McGill-Queen's University Press.

Garuba, Harry. 2003. 'Explorations in Animist Materialism: Notes on Reading/Writing African Literature, Culture, and Society.' Public Culture 15(2): 261-286.

Gérard, Albert. 1981. African Language Literatures: An Introduction to the Literary History of Sub-Saharan Africa. London: Longman.

Gikandi, Simon. 2001. 'Chinua Achebe and the Invention of African Culture.' Research in African Literatures 32(3): 3-8.

Gikandi, Simon. 2016. The Novel in Africa and the Caribbean since 1950. Oxford: Oxford University Press.

Githire, Njeri. 2014. Cannibal Writes: Eating Others in Caribbean and Indian Ocean Women's Writings. Chicago: University of Illinois Press.

Habila, Helon. 2004. Waiting for an Angel. New York: W. W. Norton \& Company.

Harrow, Kenneth. 1996. The Marabout and the Muse. New Approaches to Islam in African Literature. Portsmouth, NH: Heinemann Educational Books.

Harrow, Kenneth. 2013. Trash: African Cinema from Below. Bloomington: Indiana University Press.

Highfield, Jonathan Bishop. 2017. Food and Foodways in African Narratives: Community, Culture, and Heritage. Abingdon: Taylor and Francis.

Iheka, Cajetan. 2018. Naturalizing Africa: Ecological Violence, Agency and Postcolonial Resistance in African Literature. Cambridge: Cambridge University Press.

Irele, F. Abiola. 2009. The Cambridge Companion to the African Novel. Cambridge: Cambridge University Press.

Jaji, Tsitsi and Lily Saint. 2017. 'Introduction: Genre in Africa.' The Cambridge Journal of Postcolonial Literary Inquiry 4(2): 151-158.

Jean-Charles, Régine Michelle. 2014. Conflict Bodies: The Politics of Rape Representation in the Francophone Imaginary. Columbus: The Ohio State University Press.

Jones, Rebecca. 2015. 'Journeys to the Hinterland: Twentieth-Century Nigerian Travel Writing and Local Heterogeneity in Lagos and Beyond.' Postcolonial Text 9(4): 1-19.

Kiguru, Doseline. 2016. 'Literary Prizes, Writers' Organisations and Canon Formation in Africa.' African Studies 75(2): 202-214.

Lipenga, Ken. 2014. 'Narrative Enablement: Constructions of Disability in Contemporary African Imaginaries.' PhD Dissertation, University of Stellenbosch. 


\section{Moradewun Adejunmobi and Carli Coetzee}

Mabanckou, Alain. 2012. Tais-toi et meurs. Paris: La Branche.

Madhu, Krishnan. 2017. 'Affect, Empathy, and Engagement: Reading African Conflict in the Global Literary Marketplace.' The Journal of Commonwealth Literature 52(2): 212-230.

Mafe, Diana Adesola. 2012. 'Ghostly Girls in the "Eerie Bush": Helen Oyeyemi's The Icarus Girl as Postcolonial Female Gothic Fiction.' Research in African Literatures 43(3): 21-35.

Makumbi, Jennifer Nansubuga. 2017. Kintu. New York: Transit Books.

Mda, Zakes. 2007. Ways of Dying. New York: Farrar, Straus and Giroux.

Mirmotahari, Emad. 2011. Islam in the Eastern African Novel. New York: Palgrave Macmillan.

Mitchell, W. J. T. 1994. Landscape and Power. Chicago, IL: University of Chicago Press.

Moolla, Fiona, ed. 2016. Natures of Africa: Ecocriticism and Animal Studies in Contemporary Cultural Forms. Johannesburg: Wits University Press.

Murphy, Laura. 2015a. 'Blackface Abolition and the New Slave Narrative.' Cambridge Journal of Postcolonial Literary Inquiry 2(1): 93-113.

Murphy, Laura. 2015b. 'The New Slave Narrative and the Illegibility of Modern Slavery.' Slavery and Abolition 36(2): 382-405.

Mwangi, Evan. 2007. 'Binyavanga Wainaina.' In The Columbia Guide to East African Literature in English Since 1945, edited by Simon Gikandi and Evan Mwangi, 174-175. New York: Columbia University Press.

Mwangi, Evan. Forthcoming. The Postcolonial Animal: African Literature and Posthuman Ethics. Ann Arbor: University of Michigan Press.

Nair, Chitra Thrivikraman. 2014. 'Negotiation of Socio-Ethnic Spaces: Chimamanda Ngozi Adichie's Testimonio of African National and Ethnic Identity.' Matatu 45(1): 203-215.

Ndebele, Njabulo S. 1991. Rediscovery of the Ordinary: Essays on South African Literature and Culture. Johannesburg: COSAW.

Ndĩgĩrĩ, Gĩchingiri. 2016. 'Bloodhounds at the Gate: Trauma, Narrative Memory, and Melancholia in Ngũgĩ wa Thiong'o's Memoirs of Wartime.' Research in African Literatures 47(4): 91-111.

Nelson, Robin, ed. 2013. Practice as Research in the Arts: Principles, Protocols, Pedagogies, Resistances. London: Palgrave Macmillan.

Newell, Stephanie. 2008. 'Corresponding with the City: Self-Help Literature in Urban West Africa.' Journal of Postcolonial Writing 44(1): 15-27.

Newell, Stephanie. 2017. 'Researching the Cultural Politics of Dirt in Urban Africa.' In Theorizing Fieldwork in the Humanities: Methods, Reflections and Approaches to the Global South, edited by Shalini Puri and Debra A. Castillo, 193-201. New York: Springer.

Newell, Stephanie and Louise Green. 2018. 'Putting Dirt in Its Place: The Cultural Politics of Dirt in Africa.' Social Dynamics 44(1): 1-5.

Nganang, Patrice. 2001. Temps de chien: chronique animale: roman. Paris: Les serpents à plumes.

Ngũgĩ wa Thiong'o. 2006. The Wizard and the Crow. New York: Anchor Books.

Norridge, Zoe. 2013. Perceiving Pain in African Literature. London: Palgrave Macmillan.

Ojwang, Dan. 2013. Reading Migration and Culture: The World of East African Literature. London: Palgrave Macmillan.

Okorafor, Nnedi. 2015. The Book of Phoenix. New York: Daw Books.

Okparanta, Chinelo. 2016. Under the Udala Trees. New York: Mariner Books.

Okri, Ben. 2007. Starbook. London: Random House.

Okri, Ben. 2015. In Arcadia. London: Head of Zeus.

Olaniyan, Tejumola and Ato Quayson. 2007. African Literature: An Anthology of Criticism and Theory. Oxford: Blackwell Publishing.

Onyebuchi, Tochi. 2017. Beasts Made of Night. New York: Penguin Random House.

Orlando, Valerie. 2016. 'The Transnational Turn in African Literature of French Expression: Imagining Other Utopic Spaces in the Globalized Age.' Humanities 5(2): 1-12.

Osinubi, Taiwo Adetunji. 2014. 'Hostile Witnesses and Queer Life in Kenyan Prison Writing.' Eastern African Literary and Cultural Studies 1(3-4): 152-166.

Osinubi, Taiwo Adetunji. 2018. 'Creaturely Lives and Sexual Exposure in African Prison Writing.' In Queer in Africa: LGBTQI Identities, Citizenship, and Activism, edited by Zethu Matabeni, Surya Monro and Vasu Reddy, 41-60. London: Routledge.

Ousmane, Sembène. 1971. Les bouts de bois de Dieu, banty mam yall. Paris: Le livre contemporain.

Owomoyela, Oyekan. 2008. The Columbia Guide to West African Literature in English since 1945. New York: Columbia University Press. 
Oyono, Ferdinand. 1956. Une vie de boy. Paris: Julliard.

Quayson, Ato. 2007. Aesthetic Nervousness: Disability and the Crisis of Representation. New York: Columbia University Press.

Quayson, Ato. 2014. Oxford Street, Accra: City Life and the Itineraries of Transnationalism. Durham, NC: Duke University Press.

Repinecz, Jonathan. 2015. 'The Tales of Tomorrow: Toward a Futurist Vision of Wolof Tradition.' Journal of African Cultural Studies 27(1): 56-70.

Richards, Jo-Anne. 1996. The Innocence of Roast Chicken. London: Headline Book Publishing.

Roy, Parama. 2002. 'Reading Communities and Culinary Communities: The Gastropoetics of the South Asian Diaspora.' Positions 10(2): 471-502.

Stobie, Cheryl. 2008. 'Sisters and Spirits: The Postcolonial Gothic in Angelina N. Sithebe's Holy Hill.' Current Writing: Text and Reception in Southern Africa 20(2): 26-43.

Strauhs, Doreen. 2013. African Literary NGOs: Power, Politics and Participation. London: Palgrave Macmillan.

Suhr-Systma, Nathan. 2017. Poetry Print, and the Making of Postcolonial Literature. Cambridge: Cambridge University Press.

Suhr-Systma, Nathan. 2018. 'The Geography of Prestige: Prizes, Nigerian Writers, and World Literature.' English Literary History 85(4): 1093-1122.

Tansi, Sony Labou. 1979. La vie et demie. Paris: Le Seuil.

Taoua, Phyllis. 2018. African Freedom, How Africans Responded to Independence. Cambridge: Cambridge University Press.

Tembo, Nick Mdika. 2012. 'Ethnic Politics and the Politics of Greed: Rethinking Chimamanda Adichie's Half of a Yellow Sun.' Matatu 40(1): 173-189.

Tembo, Nick Mdika. 2017. 'Reading the Trauma of Internally Displaced Identities in Goretti Kyomuhendo's Waiting.' Eastern African Literary and Cultural Studies 3(2-4): 91-106.

Thomas, Dominic. 2006. 'Intertextuality, Plagiarism and Recycling in Ousmane Sembene's "Le docker noir" (Black Docker).' Research in African Literatures 37(1): 72-90.

Unigwe, Chika. 2009. On Black Sisters' Street: A Novel. New York: Random House.

Vambe, Maurice Taonezvi. 2017. 'Playing with the Tensions between Animal and Human Allegories in Ignatius Mabasa's Novel Imbwa Yemunhu [Youdog].’ Research in African Literatures 48(1): 44-61.

Wainaina, Binyavanga. 2011. One Day I Will Write About This Place. Lincoln: University of Nebraska Press.

Warner, Tobias. 2016. 'How Mariama Bâ Became World Literature: Translation and the Legibility of Feminist Critique.' PMLA 131(5): 1239-1255.

Wicomb, Zoë. 2001. David's Story. New York: The Feminist Press.

Woodward, Wendy. 2008. The Animal Gaze: Animal Subjectivities in Southern African Narratives. Johannesburg: Wits University Press. 


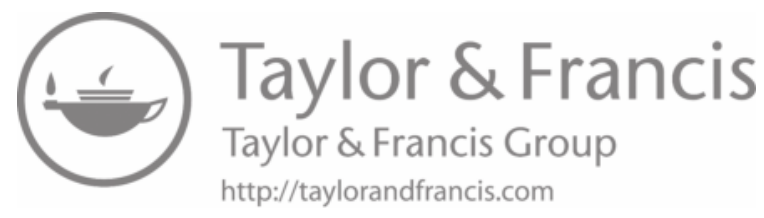


Part I

Mapping Political Agencies 


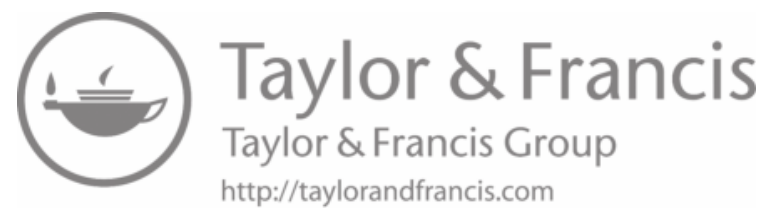




\title{
'Children of the Cold War'
}

\section{Rethinking African literary generations through the global conflict}

\author{
Monica Popescu
}

'We are children of the cold war. We came of age when it ended' states the narrator of Binyavanga Wainaina's memoir One Day I Will Write about This Place (2011b, 105). Although Wainaina proclaims the Cold War to be an integral part of his and his generation's bildung, the conflict is rarely mentioned in the same breath as African literature or, for that matter, any cultural productions from the Global South. What would it mean to revisit African literature by positioning its decolonizing ethos against the background of the Cold War and its aftermath? How does one write as a child of the Cold War? In this chapter I argue that it is possible to trace the shadow of the Iron Curtain in Africa beyond the proxy hot conflicts where the United States of America and the Soviet Union fought for supremacy (like those in Angola and the Horn of Africa). I look at Ngũgĩ wa Thiong'o and Binyavanga Wainaina as representatives of two generations of writers who, in formulating their ideological affiliation, thematic and formal concerns, respond to and transform the Cold War context and its aftermath. ${ }^{1}$ This approach repositions African writers from silent witnesses into active participants in the global Cold War discourses.

Until less than a decade ago, most literary scholars and social scientists understood the Cold War as a bipolar conflict that mainly concerned the two superpowers, the United States of America and the Soviet Union. In these studies the Global South garnered, at most, a footnote on the margin of events unfolding in the northern hemisphere. Postcolonial polities seldom featured as qualified participants, and even destructive conflicts like those involving Angola or the Horn of Africa were treated as spin-offs of events taking place in the northern hemisphere. ${ }^{2}$ In 2005 the historian Odd Arne Westad introduced the idea of a 'global cold war,' the early years of which unfolded in tandem with processes of decolonization. Yet, while historians and political scientists are warming up to the idea that events that unfolded in the Southern hemisphere should be integrated into the historical record, Cold War literary studies have largely overlooked the cultural output of postcolonial nations. Andrew Hammond has edited two path-breaking collections of essays on global literary perspectives on the Cold War (2006, 2012); however, with the exception of one essay in the first volume, African literature is not represented.

The paucity of research treating African cultural production in conjunction with the Cold War stems equally from blind spots in postcolonial studies. With rare exceptions, this field, 
which is attuned to old and new types of imperialism, has failed to link the forms of domination that emerged after the collapse of traditional colonialism with the USA's and the USSR's simultaneous scramble to augment their spheres of influence or the pushback from newly independent countries in the wake of the 1995 Bandung conference and the formation of the Non-Aligned Movement in 1961. ${ }^{3}$

Scholars of postcolonialism have treated with insight and thoroughness topics such as Ngũgĩ's condemnation of the West's continued domination of Kenya, Ousmane Sembène's criticism of neocolonialism, Nadine Gordimer's relation with Western realism and modernism, and Frantz Fanon's groundbreaking essays on the psychological effects of European racism and colonization. However, this axis of engagement prioritizes relations of emulation or contestation between the West and postcolonial nations. ${ }^{4}$ Until recently, little to no attention was paid to Sembène's training in filmmaking in the Soviet Union; Alex La Guma's extensive travels through the Eastern Bloc or his prominent role in the Afro-Asian Writers Association and his relocation to Cuba; or Lewis Nkosi's insightful understanding of the fault lines produced by the Iron Curtain from the vantage point of Poland, where he was stationed in the $1980 \mathrm{~s}^{5}$ All these cultural aspects can be properly understood only when taking into consideration the Cold War background against which they unfolded - the competing forces of imperialism unleashed by the West and the Eastern Bloc.

Three main research avenues rectify these omissions and exemplify the benefits of a Cold War scholarly framework: the identification of thematic concerns that directly reflect the Cold War in African literary works; the reconsideration of African literary history to address cultural institutions' ties to either side of the Iron Curtain, instead of privileging Western-driven networks; and the creation of new theoretical frameworks resulting from the confluence of decolonization and Cold War studies. 'Reading through a Cold War lens' (Popescu 2012b) reveals that hot conflicts labeled civil wars or regional confrontations (such as the war in Angola) were in fact proxy battlefields for the superpowers. ${ }^{6}$ Likewise, a classic of African literature like Chinua Achebe's A Man of the People (1966), can and should be reread as a novel about postcolonial nation-building influenced and sabotaged by political alliances sponsored by the Cold War superpowers (Osinubi 2014). In such a context, the prevailing thematic can be one of 'collaboration' (Osinubi 2014) rather than solidarity (Tolliver 2014).

African literary history, with narratives that accorded visibility to Western institutional networks, gets a Cold War reworking with emphasis on forms of sponsorship, such as the CIAfunded Congress for Cultural Freedom and its journals Black Orpheus and Transition (Kalliney 2015), as well as Soviet- and Chinese-supported organizations like the Afro-Asian Writers Association, and a united or divergent network of literary and film festivals (Yoon 2015; Djagalov and Salazkina 2016). A new research group focused on the Afro-Asian Writers Association, as well as a forthcoming issue of Research in African Literatures (see Popescu 2019) showcase the new directions archival research and African literary historiography can take when engaging with the Cold War.

Finally, recent work highlights new or re-conceptualized theoretical paradigms. The legacy of the Bandung movement can be usefully conceptualized against the background of the Cold War and within tricontinental solidarity networks like the Organization of Solidarity with the People of Asia, Africa and Latin America (Lee 2010). Such an approach indicates the shortcomings of vertical (North-South) relations of literary affiliation and influence or of a simplistic 'writing back' framework, replacing them with lateral patterns of exchange and influence. African intellectuals moved beyond the well-theorized routes of the Black Atlantic and engaged with their counterparts in socialist countries like Cuba and the Eastern Bloc (Popescu 2014). Alliances across the South Atlantic were equally formed among the colonized and their 
oppressors (Bystrom 2012). Reading with an eye to historical variations, research on classics of the decolonization era, such as Frantz Fanon, makes legible the very transformations within the field of postcolonial studies (Shringarpure 2015).

In the following pages I read the relations of literary filiation between Ngũgĩ wa Thiong'o and Binyavanga Wainaina to identify how cultural debates during and in the aftermath of the Cold War shaped modes of writing in Africa. Ngũgĩ's novel Petals of Blood (1977) and Wainaina's One Day I Will Write about This Place (2011b) serve as case studies for how we can reread African literature of the second half of the twentieth and early twenty-first centuries through a Cold War lens. The stakes of such an exercise go well beyond completing the body of scholarship on the two writers' oeuvre by adding a perspective heretofore absent from their corpus. Like the chemical treatment or heat applied to invisible ink, the Cold War perspective acts as the developing substance that illuminates the political and ideological forces at work in postcolonial literature, the aesthetic choices facing African writers, and even blind spots in postcolonial studies.

Writing in a realist style and discarding modernist and postmodern techniques, or embracing life writing as a genre, are never only aesthetic choices. In the landmark study Decolonising the Mind, Ngũgĩ wa Thiong'o ties his aesthetic choices to the rejection of cultural colonialism when he reflects that African peasantry and the working class should 'appropriate the novel' (1987, 68). Aimed at finding the right style, form and audience, Ngũgi's literary practice has been part of the democratizing efforts of his oeuvre as well as the rejection of aesthetic and ideological shackles created by colonization. Likewise, Wainaina's memoir and his growing corpus of essays are concerned with placing African intellectual work on a map shaped by the forces of neoliberal capitalism that attained truly global scope in the aftermath of the Cold War. The rifts and cultural alliances created by the Iron Curtain played a part in the aesthetic choices of postcolonial writers during the latter half of the twentieth century and even for the generation of writers that established themselves at the beginning of the twenty-first century.

Praised as the father of the East African English-language novel and as a Marxist writer of monumental, finely crafted, politically engaged novels that critique the old and new forms of Western colonialism in Kenya, Ngũgĩ wa Thiong'o is one of the best known postcolonial African writers. His novels recuperate the history of anticolonial resistance and address the ills of neocolonialism - and these have constituted the main lines of inquiry in scholarship on his work (Amoko 2010; Balogun 1997; Gikandi 2000). ${ }^{7}$ Of all the formal and ideological components of Ngũgĩ's works, his Marxist aesthetics and leftist politics engender numerous contradictory, and even paradoxical, responses - sometimes praised and at other times treated as an embarrassment. ${ }^{8}$ For instance, Bernth Lindfors observed that 'Ngũgĩ may have his heart in the right place, but the critical consensus seems to be that he does not always have his art where it should be' (1983, 51), suggesting that some critics perceived artistic merit as tarnished through political engagement. Even when scholars positively assessed the revolutionary aspects of Ngũgĩ's Marxist aesthetics, his support of leftist politics was seen as partisan engagement that diminished the universal appeal of his work. Therefore, scholars sometimes apologized for the writer's political engagement, pleading for a purely literary value of his work. Koku Amuzu entreats the reader:

While I do not deny the strong political nature of the novel or undervalue its social importance, I insist that regardless of the limitations from which it might suffer, Petals of Blood is foremost a literary work, an artistic creation, and if we look closely enough, we will discover its beauty. 
Attempting to save Ngũgĩ from himself, these statements are directly at odds with the writer's professed opinion on the function of literature:

any art that divorces itself from those social forces that impinge on human lives can only be an art which is denying itself its real life-force. So politics, economics - everything which has to do with the struggle of human beings - is a legitimate concern of art.

(Ngũgĩ 2006, 219)

What perspective can give us the key to such contradictory statements? Such critical evaluations are not the consequence of scholars' ill-intentioned or limited engagement with the author's works. Quite the opposite: Lindfors, Amuzu and many others are fervent promoters of Ngũgís literary oeuvre. These contradictory views of literature's function in society are clarified once placed against their historical background. The critics' unease with Ngũgî's emphasis on the political role of literature - as reflection and agent of social transformation - reveals the Cold War-era clash regarding conceptions of the function of literature that informed equally the writer's view as well as the reception of his works. I argue that by integrating a Cold War perspective with a reading that emphasizes the postcolonial elements of texts we elucidate the roots of some aesthetic, thematic and ideological choices otherwise obscured or insufficiently illuminated by a discussion of literary forms of resistance to (neo)colonialism. Furthermore, the overlaying and interpenetrating postcolonial and Cold War perspectives reveal some of the blind spots in postcolonial studies.

Petals of Blood is a narrative tour de force that redresses the silences and imbalances of colonial versions of Kenyan history. The novel gives prominence to the Mau Mau resistance to British colonialism while also detailing the post-independence disenchantment with a new black elite. It builds an intricate murder plot and portrays four convincing main characters - the teacher Munira, the barmaid Wanja, the shopkeeper Abdulla and the trade unionist Karega. Brought by circumstance to the isolated village of Ilmorog, they dedicate themselves to reviving its spirit. The quartet organize a long march to the capital when the drought decimates the farmers' cattle and already scant crops, and succeed in drawing the politicians' and entrepreneurs' attention to the region. The long-term results of economic development are, however, a far cry from what the protagonists envisioned: their initial gains are taken over by rich industrialists, the number of unemployed and the lumpenproletariat is on the rise, and those who abused the protagonists in the past are at the top of the neocolonial hierarchy. At least five or six meaning-making overarching narrative structures are superimposed, as characters struggle to make sense of the past twelve years of their lives and the place of the post-independence period in Kenyan history. What happened to the revolutionary spirit after uhuru? Why are the Kenyan peasantry and the emerging working class still struggling for basic means of subsistence if there is a black government in power? What is to be learnt from past struggles in order to achieve a different political and economic outcome in the future? These are some of the questions posed by the novel. All of these narrative arcs are concerned with the meaning of history, with linking events into causal patterns and ascribing interpretations to them.

The global conflict makes itself felt in the novel through reworked genres that reflect Cold War concerns and literary sensibilities. An author's choice of a specific narrative structure and genre is informed by the historical and political context to which the writer responds: electing to use realist, magical realist, modernist or postmodern techniques is a contextual decision partly informed by the historicity and locality of the respective genre and literary work. Ngũgi's decision to write Petals of Blood as a sweeping historical novel in the socialist realist vein (Gikandi 2000,135), a novel that nonetheless presents characteristics of a whodunit, is the result 
of his informed dialogue with, and contestation of, contemporary literary genres against the background of the Cold War.

Petals of Blood conforms to some of the requirements of the detective genre, as literary critics have pointed out (Robson 1979; Asong 2012). At the first level of interpretation, the novel is a crime mystery driven by the discovery of the corpses of the three directors of the Theng'eta Breweries. This plot element is the pretext for Munira's detailed revisiting of the past twelve years of his life, as he attempts to explain to the police, and to clarify for himself, the logical thread that led to the deaths of the three industry leaders. 'How does one tell of murder in a New Town? Murder of the spirit? Where does one begin? How to recreate the past so that one can show the operation of God's law?' (Ngũgi 1991, 45). In this chain of rhetorical questions, the emphasis shifts from homicide as the object of a criminal investigation to murder as the object of psychological and sociological scrutiny. Munira's questions illuminate a self-reflexive aspect of the literary work: Ngũgi explores the formal literary options available to him in the mid-to-late 1970s, while witnessing to the palpable deterioration of the Kenyan social fabric, the betrayal of the core ideals of the Mau Mau struggle and the exhaustion of social patience.'

In a recent study on Detective Fiction and the African Scene, Linus Asong reiterates Clifford Robson's earlier observation that 'the ostensible framework of the book [is given by] the "whodunit" element of the three deaths' (Robson as quoted in Asong 2012, 22). Ngũgĩ's familiarity with the thriller genre stems from his time as a student at Alliance High School, where he immersed himself in classics of European literature, such as Dickens and Tolstoy, while also enjoying the formally less demanding pleasures of thrillers. In fact, his first literary attempt 'was an imitation of the American thriller writer Edgar Wallace' (Ngũgĩ 2006, 103). To this intimate acquaintance with the rules of the genre we can also trace his use of the detective novel structure in Petals of Blood, where, however, the former imitative mode is transformed into a new aesthetic and political position. Observing the masterful in medias res opening of the novel, the drama and suspense created with the successive arrests of Munira, Abdulla and Karega, as well as the long paragraph dedicated to the alleged professionalism of Inspector Godfrey (the police officer investigating the case), Asong considers the novel to be a successful incorporation of the elements of the whodunit genre. 'Fortunately for Ngũgĩ,' Asong proclaims, 'the detective novel devices which he employed to hold the reader's attention to the end' $(2012,54)$ save the author from being accused of having written a polemic, an overtly ideological narrative, rather than a work of fiction (53-54). Recognizing that the detective genre is employed by Ngũgĩ to address social issues characteristic to a nascent capitalist society, including the criminalization of the poor, Asong implies that the emphasis in Petals of Blood is placed on answering the question 'whydunit?' rather than 'whodunit?'

Instead of assuming that Ngũgĩ's decision to draw on detective fiction strategies is the saving grace that lifts the novel out of literary marginalization, I ask what Ngũgĩ intended to do with this formal element and how his decision to work with, and ultimately discard, the whodunit genre is rooted in aesthetic choices that are influenced by the Cold War. As Ngũgi acknowledged in a 1996 interview:

there is nothing wrong in the writer experimenting with different forms. I myself use in Petals of Blood [a] very popular thriller structure, a mix of thriller and detective structure $[\ldots]$ or the investigative detective structure and I use that for different reasons.

(Ngũgĩ 2006, 371)

Inspector Godfrey is one of the principal semioticians of the novel, trained by his trade to put together the pieces of the social and political puzzle, the commingling and crisscrossing of 
personal histories. As he investigates the deaths of the three local tycoons, Godfrey elicits personal narratives that weave a tapestry of life in Ilmorog, from its humble beginnings as an inert village to its transformation into a humming city divided by social inequity. The personal histories that the police investigator draws out are intended to highlight the possible motives for the arson and the likely perpetrator.

Crime for him was a kind of jigsaw puzzle, and he believed that there was a law to it - a law of crime - a law of criminal behaviour - and he believed that if you looked hard enough you could see this law operating in even the smallest gestures. He was interested in people; in their behaviour; in their words, gestures, fantasies, gait: but only as part of this jigsaw puzzle. [...] From there he could work out the exact circumstances, to the minutest details, and he hardly ever failed.

(Ngũg̃ 1991, 43)

If Ngũgĩ shows interest in the narrative opportunities afforded by the traditional detective novel that, popular with the masses and familiar as a mode of structuring the plot, would have garnered him a wider audience, he does not offer his readers a praiseworthy Sherlock Holmes or Hercule Poirot figure in Inspector Godfrey. On the contrary, we can say that Ngũgĩ intentionally employs this plot device in order to reveal its flaws: though formally a correct identification of the arson author, the detective's interpretation fails to grasp the larger historical significance of what has happened. Munira was indeed the author of the arson, as Inspector Godfrey intuits. Yet Wanja had already killed Kimeria, the man who had impregnated and abandoned her many years before, and Abdulla was contemplating the same revenge against the man who had betrayed the Mau Mau movement. The arson was the response of nascent forces resisting the transformation of Ilmorog, and by extension of Kenya, into a community divided by capitalist relations of production and neocolonial interests.

'One can use popular forms and subvert [the] ideology those popular forms have been serving in the past,' the author observed (Ngũgĩ 2006, 371). Ngũgĩ suggests that an interpretation arising from a popular Western literary genre - a genre emanating from capitalist societies would confuse or, worse, willfully obfuscate, the roots of social unrest and violence in contemporary Kenya. As Simon Gikandi points out, Ngũgĩ's aesthetic 'was premised on a very specific [Marxist] understanding of the relation between society and the subject and form of literature' $(2000,278)$. The genres developed in what the author saw as capitalist-imperialist societies would not have been appropriate to represent the continued exploitation and marginalization of the Kenyan peasantry and working class.

Thus, Ngũgĩ quotes in order to criticize aspects of the detective plot, therefore critiquing not only a genre popularized in Africa by European pocketbook editions, but also a genre that responded to Cold War concerns. Literary scholars like Ann Douglas (1998, 75-76) and Allan Hepburn (2005, xiv) call attention to the flourishing of the detective and espionage genres in fiction and film during the Cold War, arguing that it is tightly connected to the perceived uncertainty of knowledge, the compulsion to read between the lines, and the mistrust of others (and even oneself) that characterized the conflict in the West. Hence, with this reference to detective fiction, Ngũgĩ criticizes what he perceives as a failed epistemological mode arising from nineteenth-century Western literature that found renewed popularity during the Cold War. Countering the bourgeois worldview embodied by the detective genre, he introduced elements of socialist realism. ${ }^{10}$

Ngũgĩ has been praised for his leftist narrative patterns, the Lukacsian development of plots and the recourse to social (or even socialist) realism in the depiction of the condition of the 
peasantry and the proletariat in post-independence Kenya. ${ }^{11}$ At the end of the novel, Karega questions the reasons for the paradoxical impoverishment of a recently decolonized people and links local events to the larger canvas of insidious neocolonial forces:

From Koitalel to Kimathi it had been the peasants, aided by the workers, small traders and small landowners, who had mapped out the path. Tomorrow it would be the workers and the peasants leading the struggle and seizing power to overturn the system and all its prying bloodthirsty gods and gnomic angels, bringing to an end the reign of the few over the many and the era of drinking blood and feasting on human flesh. Then, only then, would the kingdom of man and woman really begin, they joying and loving in creative labour.

(1991, 344-345)

Karega's teleological interpretation announces the inevitable triumph of workers' and peasants' efforts to engender a second coming of the revolutionary spirit of the Mau Mau anticolonial fighters, this time led by the proletariat and directed at the neocolonial forces that have taken control of Kenya through the mediation of a local comprador class. The conclusion of the novel highlights the leftist thematic in Ngũgĩ's literary and nonfiction works of this period. However, beyond a preference for Marxist teleology, this passage also reveals the influence of Soviet genres and narrative patterns on his work.

Critics have paid attention to the role British, and generally Western, literature has played in shaping Ngũgĩ’s earlier view of literary craftsmanship, as well as his later integration of Gĩkũvũ oral narratives, leading up to his decision to renounce English as a literary language (Gikandi 2000; Balogun 1997). Yet, despite the interest in Ngũgĩ’s literary Marxism, scholars have failed to establish a relationship between Ngũgĩ's leftist vision and his 1975 writing vacation in Yalta at the invitation of the Soviet Writers' Union, or his admiration for Russian literature and the general Cold War context. In fact, in the same way in which Western literature has played a formative role in Ngũgĩ's development as a writer, we can equally speak of the role of the Eastern Bloc (and especially Russia) in Ngũgĩ's cultural imaginary. M. Keith Booker and Dubravka Juraga (1997) highlight the similarities between the historical novel in Africa and in the USSR. In both situations we deal with post-revolutionary texts that are 'inherently political' (276) and therefore need to be evaluated according to different aesthetic principles than those promoted in the West; the authors argue that such literature aims to seize historical interpretation from the hands of the bourgeoisie and recast the meaning of the past in order to open up new possibilities of political action (277-280). Therefore, the emphasis on socialist realism and the orientation towards the future are sometimes the result of African writers' deliberate departures from Western literary models and intentional dialogue with narrative strategies practiced in the Eastern Bloc, which they see as more compatible with the people's struggle. What then are the forms and the implications of Ngũgĩ's admiration for the Russian historical novel? How does he transform the socialist realist form to suit his aims?

Ngũgĩ's interviews underscore the influence of Russian writers, from the masters who shaped the global development of prose in the nineteenth century (Leo Tolstoy, Ivan Turgenev, Fyodor Dostoevsky) to the Soviet novelists who emphasized the tribulations and historical victories of the peasantry and the working class (Maxim Gorki, Mikhail Sholokhov). ${ }^{12}$ This dialectical vision of history, which Ngũgĩ had assimilated from reading Marx's Grundrisse and the German Ideology (Gikandi 2000, 278), accounts for his understanding of the relationship between the economic structure of society, the forces of production and the generation of cultural forms specific to each economic system. Based on this correlation, he identifies a kinship between the 
social transformation ushered in by the Russian Revolution and the liberation of the Kenyan people from British colonialism:

What I liked with his [Sholokhov's] novel And Quiet Flows the Don was his mastery in depicting human beings being pulled, being torn, if you like, in the context of the Russian Revolution. This reveals his deep understanding of what you may call the dialectics of life. Really, I must have been under the spell of his And Quiet Flows the Don when I came to look at Kenyan history. I read his works at the same time I was writing $A$ Grain of Wheat and later, before I wrote Petals of Blood. So I think his world outlook, his artistic rendering of the struggles of people, had a definite effect on me.

(Ngũgĩ 2006, 221)

A dialectical view of history, tracing the forces of progress (the working class and the peasantry) and the forms of consciousness engendered by the transition from one social order to another, connects two apparently disparate events - the Bolshevik revolution and the Mau Mau uprising (Ngũgĩ 1981b, 81). They led to a similar radical transformation of people's social consciousness, opening up the vision of freedom and equality, and simultaneously engendered the cultural instruments of liberation. However, although Ngũgĩ perceives the Mau Mau uprising as an unfinished transformation, interrupted by the installation of an insidious neocolonial regime, he does not question whether the Soviet narrative of triumphant equality and participation in the new political structures gives a complete story of the state of affairs in the USSR.

Novels like Petals of Blood borrow from earlier Soviet narrative models, like the early twentiethcentury socialist realist genre, by latching onto an imagined temporal structure specific to Russia and the Eastern European socialist countries. It is imagined because it subsumes all the unwieldy historical material to a teleological narrative arc. This temporal structure imagines the victorious march forward of progressive social forces that defeats even the constraints of time itself. Post-Perestroika research on the USSR has shown that such a temporal structure, while invoked in official documents, was a projection oftentimes directly at odds with the reality experienced by the Soviet people in the late 1970s. For the purposes of this argument it is irrelevant whether, during his 1975 sojourn in Yalta or when he traveled to the Soviet Union to attend the 1973 Afro-Asian Writers' Association conference in Alma Ata, Kazakhstan, where he was distinguished with the Lotus award, the writer was able to get an accurate understanding of the economic, political and cultural situation in the USSR. Shepherded by translators and closely monitored, foreign guests were oftentimes prevented from interacting with a disgruntled populace. What merits attention is the Kenyan writer's choice of literary forms that he borrowed from Soviet writers as well as the cultural routes traveled by these literary techniques during the Cold War. ${ }^{13}$

Ngũgĩ borrowed some aesthetic preoccupations and the attending revolutionary vision from the first generation of socialist realist writers like Gorki and Sholokhov, yet he also tailored these features to speak to aspects of Kenyan society after independence. For instance, most Soviet socialist realist novels of this period foreground the consciousness of a 'positive hero' whose life is patterned to represent 'the forward movement of history' (Clark 2000, 46). ${ }^{14}$ However, despite Ngũgĩ's embrace of the genre, his polyphonic novel is fragmented by the diverging views of the four main characters and fraught with contradictions. The text ends with the imprisoned Karega's hopeful anticipation of 'tomorrow' (Ngũgi 1991, 345), a word that announces both a renewed workers' strike to be held the following day as well as a future horizon of fulfillment for the downtrodden of Kenya. Thus, the novel appears to endorse Karega's leftist worldview that largely coincides with the author's political views as stated in 
essays and interviews. However, in embracing the conflicting perspectives of all four protagonists, the author distances the reader's sympathies from Karega who, led by revolutionary ardor and a mechanistic understanding of class conflict as the driving engine of history, ignores Wanja's sentiments and inadvertently hurts her. Instead of showing understanding for her suffering, Karega lectures her on historical lessons. Furthermore, Abdulla rejects Karega's workerist view of historical change and class conflict; instead, he emphasizes the role small traders and the unemployed might play in shaping the future of Kenya. As it is Abdulla who fathers Wanja's child and acts as the symbolic progenitor of a new generation, his perspective carries interpretive weight, counterbalancing Karega's leftist view at the close of the novel.

Critics have read Petals of Blood as an example of detective fiction, on the one hand, and socialist realism, on the other, yet only a Cold War lens allows for an interpretation that accounts for the author's choice and deployment of both genres. Ngũgi used the detective novel structures only to discredit the genre's epistemology: Inspector Godfrey, representing individualist capitalism, cannot comprehend the clash between neocolonialism and progressive forces in Kenya. Similarly, the author borrows from the Russian historical novel and socialist realist techniques yet adjusts them to specific Kenyan concerns: Karega's Marxist view is complemented by that of the ex-Mau Mau fighter turned destitute small trader Abdulla. Like numerous other African texts, Ngũgî's novel does not merely repeat Western or Eastern Bloc formal literary concerns but develops new genres adapted to the local cultural heritage that afford a better understanding of both the Kenyan and global dimensions of the Cold War. Neither the epistemology of the detective novel nor that of the socialist realist text completely fit his aims - the former is discarded as inadequate; the latter adapted to fit the Kenyan context. Ngũgĩ invites a cultural and political triangulation that includes the West, the Global South and the East.

This triangulation reemerges a generation later, in Wainaina's memoir One Day I Will Write about This Place. The book is a direct challenge to the idea that the Cold War was a distant conflict, disputed between two remote superpowers, the USA and the USSR, which had little or no impact on African countries. To come of age with the last breath of the Cold War entailed, among other things, coming to terms with the conflicting desires for activist engagement in the tradition of leftist anticolonial intellectuals while also displaying the American-style coolness embraced by his generation. 'I will make very good decolonized advertisements for Coca-Cola' (2011b, 92) Wainaina's younger self, an avid reader of Ngũgĩ's Decolonising the Mind, promises himself. The irony embodied by this contradiction reflects the convoluted allegiances and partitioned cultural landscapes transected by the Iron Curtain even far away from what was supposed to be this conflict's battlegrounds.

As the title promises, One Day I Will Write about This Place is concerned with much more than the memories of a child and young man finding his way in the world. The bildung experience is connected to the growing pains of a relatively new state, Kenya, followed from its second to its fourth decade of existence. ${ }^{15}$ Personal experiences point to larger social patterns, and adolescent moments of rebellion and assertiveness obliquely give voice to the national concern with cultural independence paradoxically combined with longing for the seeming cohesion and flair of Western culture. The memoir ends with the cautious recognition of cultural harmony beyond the cacophony of multiple Kenyan voices exacerbated by new forms of factionalism: 'We fail to trust that we knew ourselves to be possible from the beginning' (253). This convoluted, almost paradoxical formulation, along with all the other self-contradictory impulses of the work, announces that the memoir will not let itself be packaged into national allegory, as Fredric Jameson (1986) controversially argued about the work of Wainaina's literary forebears. The formal and ideological tensions that manifest themselves in the memoir are the product of a post-Cold War retrospective glance at the global conflict. 


\section{Monica Popescu}

If its author suffers from the anxieties of a 'child of the Cold War,' the text displays the literary sensibility of a complex world which is no longer characterized by the relative transparency of old dichotomies (colonizers versus colonized; capitalists against communists) that informed works a couple of decades earlier. The sensitive, thoughtful and timid self, projected by Wainaina, is terrified of being 'hijacked by patterns' (2011b, 65). This statement simultaneously represents his anxiety at having his daily activities and preferences reoriented by the influence of strong personalities like those of his siblings, and, at a second level, his literary angst about finding a voice of his own. A tension develops between the narrator's concern with finding his own voice and the counterpointing drive of Binyavanga-the-young-reader to succumb to the 'patterns' of other writers, to become immersed in the world of the novels that he enjoys.

This tension between the lure of alternative styles of writing and the pressure to find his own voice is connected with an indirectly stated concern with modes of writing in a post-Cold War world. In what genre and what style does a Kenyan writer who lived in South Africa and the United States express his experiences at the turn of the millennium? How does one find both a local and global audience yet resist the pigeonholing effect of literary prizes and academic recognition? Seen through the lens of aesthetic choices, and also in view of the instantaneous celebrity it brought its author, Wainaina's well-known essay 'How to Write about Africa' (2006) is not just a text that debunks (neo-)colonialist clichés, but also a cri de coeur against the literary 'patterns' demanded of successful postcolonial writers. If Ngũgĩ expressed the similarity between the social function performed by the African and Eastern Bloc writer by indigenizing the structures of the socialist realist historical novel, Wainaina articulates the transition from Cold War to neoliberal capitalist era by attending to the continuous search to find his own writing 'patterns.'

The young Binyavanga - the memoir's narrator - draws attention to a difference of substance between his peers and their predecessors. To the young man, the generation of intellectuals preceding him, whether Marxist or pro-Western in ideological orientation, appear steadfast in their vision of the future, a future in which they see Kenya playing a clear role in the world. However, while admiring their commitment, the uncompromising stance of Ngũgĩ's generation does not resonate with the young Binyavanga:

Ngũgĩ wa Thiong'o is a writer and a playwright, a Kenyan playwright, and people say he says that women should not perm their hair or wear lipstick. I have permed my hair. I like it. Ngũgĩ wa Thiong'o is Kenya's most famous writer and was arrested by Moi in the early 1980 s and imprisoned. He is in exile now, and he is trying to bring down the government. His books are banned in Kenya. He is a communist and says that to decolonize we have to write our literature in our languages. I don't like Moi - but if those people take over the government, what music will we listen to? Nyatiti?

$(2011 b, 88)$

The suspicion with which Binyavanga (and by extension his generation) regard Ngũgĩ's commitment springs from a perceived (and generally romanticized) belief in resistance to neocolonialism through authenticity. The narrator perceives the turn towards traditional instruments (the nyatiti), native tongues and an identity uninfluenced by Western technologies of self-fashioning (the perm) as anachronistic and practically impossible to sustain. There is no original language for the young Wainaina to return to: a product of the new Kenyan middle class, conversant only in English and Kiswahili, the young man knows nothing of his father's Gikuyu, or his mother's tongue, Kinyarwanda. As for embracing an authentic, uncontaminated self, he decrees 
it to be a purist fantasy; its make-believe is betrayed by his generation's thirst for everything American: break dance, Michael Jackson, nasal accents, hair-styles and 'diversiddy.' 'Even Ngũgĩ is in America' (92), concludes the narrator, highlighting the naivete of faith in such an uncontaminated self. However, American culture is not embraced without suspicion: the structural adjustment programs imposed by the IMF and the World Bank ruined the meritocratic education system in Kenya, which had allowed poor and middle class students to forge a future for themselves through the power of their intellect.

His own generation, unmoored from the political faith strictures of an older generation of intellectuals, merely performed and ventriloquized Americanness and Russianness, reducing them to a style. This style could embrace both the flexibility of American break dance as well as the thrill of rebelliousness evoked by the drink provocatively named 'Black Russian.' On the eve of his departure to study business in South Africa, Binyavanga is enticed by a sophisticatedlooking, cosmopolitan woman to order the beverage (89). A person who drinks 'Black Russians,' the name of the drink promises, is a revolutionary individual who discards shackling norms. Later in the memoir, when he is in South Africa, the narrator orders 'another Black Russian,' with his arm protectively wrapped around the shoulders of a woman called NomaRussia, an isiXhosa name that means Mother of the Russians (99). ${ }^{16}$ Wainaina's peers are 'children of the Cold War' because they still long to fuse an idealized Marxist Russian identity and black revolutionary attitude, in a latter-day replication of the alternative solidarities established during the Cold War. Indeed, the imagined identity of 'Black Russians' appeared in Ngũgi's novel Petals of Blood. There it was the product of the transformation of nineteenthcentury news through oral narratives: when Kenyan peasants heard of Russians defeating the British in the Crimean War, they wondered if these distant avengers were black and colonized like themselves.

The memoir oscillates between the longing for an uncompromising political affiliation and the realization that such a reality never existed. Such yearning is a romanticized view of a simple Cold War world where people were either pro-Western or pro-Eastern Bloc, either capitalist or socialist, or, if neither, they were firmly Non-Aligned. The bar scene evoked earlier is elucidating: the narrator experiences disappointment when the woman's cosmopolitan identity, redolent of revolutionary mystique, peels off to reveal 'tribal marks' insufficiently concealed by her make-up. This recognition of kinship beneath Soviet-tinged difference is a confirmation that, for Wainaina's generation, deeply politicized identities - whether Marxist or Westernized - are difficult to embody. Unlike Ngũgĩ's idealized generation, the young Binyavanga is disappointed with 'the children of the Cold War' who, instead of actually committing themselves to revolutionary politics merely ventriloquize a style.

Looking back at his memories of the early 1980s, the narrator acknowledges the cacophony of political positions, opportunistically invoked by politicians to achieve their purposes:

Moi and his cronies are on the radio daily [in 1984]. It is in the papers every day. These are dark days, we are told. There are dissidents everywhere. We have to all unite and silence the dissidents. From the radio, we know that foreign influenzes are invecting us, secret foreign influenzes are infringing us, invincing us, perferting our gildren, preaking our gultural moralities, our ancient filosofies, the dissidents are bushing and bulling, pringing segret Kurly Marxes, and Michael Jagsons, making us backliding robots, and our land is becoming moonar handscapes. They took the rain away, the Marxists, the Ugandans, wearing Western mini sguirts, and makeup, they are importing them, inserting them inside invected people, these dissidents, like Ngũgĩ wa Thiong'o, and that man called Raila Oginga Odinga. 
In this cacophonous, accented English performance of nationalism, the effectiveness of Marx's analyses has been removed, while the historical figure has been coiffed into a Kurly Marx (a reference to the 1980s Kenyan teenagers' obsession with Afros) and rubs shoulders with Michael Jackson. In the search for scapegoats, the 1980s paranoid nationalist discourse in Kenya borrows epidemiological overtones and blends the threat of opposing ideologies (Marxist socialism and consumerist Western capitalism) into a composite figure.

In the memoir, the young Binyavanga coins a word that reflects this cacophony: it is kimay, a language name formed with the prefix 'ki' (denoting language in Kiswahili) and a stem full of the potentiality of the unknown (all that may inhabit a different linguistic or ideological universe). The tentative conclusion of the memoir returns to the idea of kimay, as it suggests ideological cacophony as the root of the confusion experienced by Kenyans, a confusion that leaves them vulnerable to being hijacked by the 'patterns' of various ideologies. As Americanness, Marxism, Christianity, nationalism and tribalism all mix together to produce dissonance, Wainaina implies that the condition of being 'a child of the Cold War' is that of being assaulted, tempted and seduced by these coexisting discourses. The writer's function, then, is to historicize the production of Cold War kimay, its competing ideologies, and the performance of various styles in relation to the formation of Kenyan nationhood. This historicizing approach brings a further benefit: it explains the appeal of certain styles of writing at specific historical conjunctures, such as Ngũgi's historical novels in the 1970s and 1980s and postcolonial memoir in the new millennium.

In his book Postcolonial Life-Writing (2009), Bart Moore-Gilbert poses questions about the borders of the postcolonial memoir genre and Non-Western narrative resources of life-writing. As he observed in an interview, these concerns were at the heart of Wainaina's efforts:

I wanted to try to write a riskier book. I felt like I'd been writing a lot of safe short stories for a while, and I wanted to go a bit crazy and take some risks with form and language. I was feeling a little cramped with all these new expectations - you know, to write a big Africa book that fulfills the Postcolonial Condition and so on.

(Wainaina 2011a, 52)

In other words, he wanted to break both the literary mold expected of a winner of the Caine Prize for African Literature, or of writers anthologized, read and proclaimed by the academic community in the West to embody a new wave of African writing, and as 'the patterns' that hijacked 'children of the Cold War.'

It is only by restituting the Cold War as the background and shaping element of the decolonization struggles and the post-independence engagement with neocolonialism that we can grasp the full significance of the aesthetic and ideological choices made by African writers, their resistance or acquiescence to the polarization of the world, and their contributions to the global discourses informing the latter half of the twentieth century. ${ }^{18}$

\section{Notes}

1 In this chapter I spell Ngũgĩ's name with a tilde, but follow the spelling used by referenced authors whenever I quote them or mention the titles of their works.

2 As an example of such omission, see Winkler (2000); the only reference to Africa is in relation to the Suez Canal crisis (77).

3 For pioneering approaches linking the two fields see Pietz (1988), Brennan (2001), and more recently Prashad (2007) and Lee (2010). 
4 Even when Marxism was the object of research, the Cold War connection with the Eastern Bloc is not explored. See Gikandi (2000), Gugelberger (1985).

5 For articles addressing these perspectives see Woll (2004), Djagalov and Salazkina (2016), Lee (2010), Popescu (2012a).

6 For a treatment of regional aspects of the Cold War in Southern Africa see also Baines and Vale (2008).

7 For a discussion of diverging trends in Ngũgĩ's aesthetics see also Amoko (2000, 2, 71-72).

8 For features of Ngũgís Marxist aesthetics see Balogun (1997).

9 Gikandi speaks of Ngũgĩ's continuous reevaluation and reinvention of the novel genre to address the demands of post-independence Kenya (2000, 13).

10 Gikandi $(2000,143)$ and Amoko $(2010,12-13)$ point out that Ngũgi challenges the ideology of the novel as a bourgeois genre and of Western literature in general.

11 Balogun discusses the transformation of Ngũgĩ's art from a nationalist to a Marxist aesthetics (1997, 20).

12 Ngũgĩ makes repeated references to his admiration for nineteenth-century Russian novelists (2006, 50, 220). See also Williams (1999, 5-6).

13 In the Preface to Detained Ngũgĩ distances himself from direct Soviet or Chinese influences that could be reductively understood as forms of ideological indoctrination (1981a, xvi-xvii).

14 Despite official narratives that subsumed socialist realist fiction to direct filiations to Maxim Gorki's Mother, the authors' practices and views were quite divergent (Clark 2000, 28).

15 For the altered role of the bildungsroman structure in postcolonial fiction see Slaughter (2007).

16 This translation for the name NomaRussia appears in Zakes Mda's novel The Heart of Redness (2000, 63).

17 Scholars like Mukoma wa Ngũgĩ (2014) have suggested that such awards and institutions pigeonhole African literature, reducing it to formulas even when it strives against those formulas.

18 With the permission of the editors, this chapter incorporates reworked parts of my earlier essay 'Aesthetic Solidarities: Ngũgĩ wa Thiong'o and the Cold War,' originally published in 2014 in The Journal of Postcolonial Writing. Insight Grant funding from the Social Sciences and Humanities Research Council of Canada has allowed me to complete the research for this chapter.

\section{References}

Amoko, Apollo Obonyo. 2010. Postcolonialism in the Wake of the Nairobi Revolution: Ngugi wa Thiong'o and the Idea of African Literature. New York: Palgrave.

Amuzu, Koku. 1997. Beyond Ideology: Literary Technique in Ngugi's Petals of Blood and Devil on the Cross. London: Minerva.

Asong, Linus T. 2012. Detective Fiction and the African Scene: From the 'Whodunit?' to the 'Whydonit?' Mankon, Cameroon: Langaa Research \& Publishing CIG.

Baines, Gary and Peter Vale. 2008. Beyond the Border War: New Perspectives on Southern Africa's Late Cold War Conflicts. Pretoria: Unisa.

Balogun, Odun F. 1997. Ngugi and African Postcolonial Narrative: The Novel as Oral Narrative in Multigenre Performance. St-Hyacinthe, QC: World Heritage.

Booker, M. Keith and Dubravka Juraga. 1997. 'The Reds and the Blacks: The Historical Novel in the Soviet Union and in Postcolonial Africa.' Studies in the Novel 29(3): 275-296.

Branch, Daniel. 2011. Kenya: Between Hope and Despair, 1963-2011. New Haven, CT: Yale University Press.

Brennan, Timothy. 2001. 'The Cuts of Language: The East/West of North/South.' Public Culture 13(1): 39-63.

Brennan, Timothy. 2006. Wars of Position: The Cultural Politics of Left and Right. New York: Columbia University Press.

Bystrom, Kerry. 2012. 'Reading the South Atlantic: Chile, South Africa, the Cold War and Mark Behr's The Smell of Apples.' African Studies 71(1): 1-18.

Clark, Katerina. 2000. The Soviet Novel: History as Ritual. 3rd edition. Bloomington: Indiana University Press.

Djagalov, Rossen and Masha Salazkina. 2016. 'Tashkent '68: A Cinematic Contact Zone.' Slavic Review 75(2): 279-298.

Douglas, Ann. 1998. 'Periodizing the American Century: Modernism, Postmodernism, and Postcolonialism in the Cold War Context.' Modernism/Modernity 5(3): 71-98.

Gikandi, Simon. 2000. Ngugi wa Thiong'o. Cambridge: Cambridge University Press. 


\section{Monica Popescu}

Gugelberger, Georg M., ed. 1985. Marxism and African Literature. Trenton, NJ: Africa World. Hammond, Andrew, ed. 2006. Cold War Literature: Writing the Global Conflict. London: Routledge.

Hammond, Andrew, ed. 2012. Global Cold War Literature: Western, Eastern, and Postcolonial Perspectives. New York: Routledge.

Hepburn, Allan. 2005. Intrigue: Espionage and Culture. New Haven, CT: Yale University Press.

Jameson, Fredric. 1986. 'Third-World Literature in the Era of Multinational Capitalism.' Social Text 15: 65-88.

Kalliney, Peter. 2015. 'Modernism, African Literature and the Cold War.' Modern Language Quarterly 76(3): 333-368.

Lee, Christopher J., ed. 2010. Making a World after Empire: The Bandung Moment and Its Political Afterlives. Athens: Ohio University Press.

Lindfors, Bernth. 1983. 'Petals of Blood as a Popular Novel.' In Contemporary African Literature, edited by Hal Wylie et al., 49-55. Washington, DC: Three Continents.

Mda, Zakes. 2000. The Heart of Redness. New York: Farrar, Straus and Giroux.

Moore-Gilbert, Bart. 2009. Postcolonial Life-Writing: Culture, Politics and Self-representation. Oxford: Routledge.

Mukoma wa Ngũgĩ. 2014. 'Beauty, Mourning and Melancholy in Africa39.' LA Review of Books, November 9. https://lareviewofbooks.org/article/beauty-mourning-melancholy-africa39/.

Ngũgĩ wa Thiong'o. 1981a. Detained: A Writer's Prison Diary. Oxford: Heinemann.

Ngũgĩ wa Thiong'o. 1981b. Writers in Politics: Essays. London: Heinemann.

Ngũgĩ wa Thiong'o. 1987. Decolonising the Mind: The Politics of Language in African Literature. Harare: Zimbabwe Publishing House.

Ngũgĩ wa Thiong'o. 1991. Petals of Blood. New York: Penguin.

Ngũgĩ wa Thiong'o. 2006. Ngñgĩ wa Thiong'o Speaks: Interviews with the Kenyan Writer, edited by Reinhard Sander and Bernth Lindfors. Trenton, NJ: Africa World.

Osinubi, Taiwo Adetunji. 2014. 'Cold War Sponsorships: Chinua Achebe and the Dialectics of Collaboration.' Journal of Postcolonial Writing 50(4): 410-422.

Pietz, William. 1988. 'The "Post-Colonialism” of Cold War Discourse.' Social Text 19-20: 55-75.

Popescu, Monica. 2012a. 'Lewis Nkosi in Warsaw: Translating Eastern European Experiences for an African Audience.' Journal of Postcolonial Writing 48(2): 176-187.

Popescu, Monica. 2012b. 'Reading through a Cold War Lens: Apartheid Era Literature and the Global Conflict.' Current Writing: Text and Reception in Southern Africa 24(1): 37-49.

Popescu, Monica. 2014. 'On the Margins of the Black Atlantic: Angola, the Eastern Bloc, and the Cold War.' Research in African Literatures 45(3): 91-109.

Popescu, Monica. 2019. 'African Literature and the Cold War: What Is at Stake?' Introduction to forthcoming special issue of Research in African Literatures, edited by Monica Popescu and Bhakti Shringarpure, 50(3).

Prashad, Vijay. 2007. The Darker Nations: A People's History of the Third World. New York: The New Press.

Robson, Clifford B. 1979. Ngũgĩ wa Thiong'o. New York: St. Martin's Press.

Scott, David. 1999. Refashioning Futures: Criticism after Postcoloniality. Princeton, NJ: Princeton University Press.

Shringarpure, Bhakti. 2015. 'The Afterlives of Frantz Fanon and the Reconstruction of Postcolonial Studies.' Journal of French and Francophone Philosophy 23(1): 113-128.

Slaughter, Joseph R. 2007. Human Rights, Inc.: The World Novel, Narrative Form and International Law. New York: Fordham University Press.

Tolliver, Julie-Françoise. 2014. 'Césaire/Lumumba: A Season of Solidarity.' Journal of Postcolonial Writing 50(4): 398-409.

Wainaina, Binyavanga. 2011a. Interview with Bob Spillman. BOMB 116 (Summer): 50-55.

Wainaina, Binyavanga. 2011b. One Day I Will Write about This Place. Minneapolis, MN: Graywolf Press.

Westad, Odd Arne. 2005. The Global Cold War: Third World Interventions and the Making of Our Times. Cambridge: Cambridge University Press.

Williams, Patrick. 1999. Ngugi wa Thiong'o. Manchester: Manchester University Press.

Winkler, Allan M. 2000. The Cold War: A History in Documents. Oxford: Oxford University Press.

Woll, Josephine. 2004. 'The Russian Connection: Soviet Cinema and the Cinema of Francophone Africa.' In Focus on African Films, edited by Françoise Pfaff, 223-240. Bloomington: Indiana University Press.

Yoon, Duncan. 2015. “Our Forces Have Redoubled”: World Literature, Postcolonialism and the AfroAsian Writers' Bureau.' The Cambridge Journal of Postcolonial Literary Inquiry 2(2): 233-252. 


\section{Ethics and the politics of the ordinary in African literature}

Chielozona Eze

In the past three decades, there has been increased attention paid to the place of ethics in literary scholarship. Martha Nussbaum's 'Flawed Crystals' (1983) and Love's Knowledge (1990) broke new ground in this regard, as did Adam Newton's Narrative Ethics (1995). The Turn to Ethics, edited by Marjorie Garber et al. (2000), brings together some of the most important thinkers on the issue. In African writing, as in literary scholarship, there has been a noticeable shift away from the postcolonial impulse to write back to the empire. There is now more emphasis on everyday practice and the body, especially the degree to which it feels pain. Of relevance in this regard are Zoe Norridge's Perceiving Pain in African Literature (2013) and my Ethics and Human Rights in Anglophone African Women's Literature (2016). Cynthia R. Wallace's Of Women Borne (2016) highlights the redemptive place of suffering in narrative and the need for readers to acknowledge and respond to that with humility. Joseph Slaughter's discussion of the genre of the bildungsroman in his Human Rights, Inc. (2007) makes a persuasive argument for the power of narrative to script human rights. Cajetan Iheka in Naturalizing Africa: Ecological Violence, Agency, and Postcolonial Resistance in African Literature (2018) extends the ethical inquiry in literature to the area of ecology.

Interest in ethics in African studies scholarship is not restricted to literature. Rijk van Dijk, Astrid Bochow and Thomas G. Kirsh $(2017,447)$ provide an insightful anthropological reading of ethics in Africa that encompasses people's everyday struggles. In particular, they examine how organizations and social movements in Africa, such as the NGOs, state agencies, labor unions and religious organizations, act as agents of the good in society and propagate ideas about how people can lead good, prosperous lives (250-252). Theirs is a useful way to understand ethical agency in Africa, with which I fully agree. Literature takes us in a different direction and provides us with opportunities for introspection, especially regarding our relation to ourselves, to others and to reality. Working from the assumption that ethics is about the individual's response to the practice of the everyday, and how to conduct oneself, especially in relation to others, this chapter seeks to map out the contours of ethical agency in African literature. It examines the question of ethics and the politics of the ordinary in literature.

Literature is highly individualized, in its production, its consumption and in the subjects represented; this remains the case even when a literary text takes up concerns that affect a larger group. In one of its many forms, such as narrative, literature addresses the world primarily 
through imaginative representation. It is this that separates literature from polemics or political tracts, which are appreciated for advancing specific arguments, but not essentially for their expressiveness. Whereas texts produced for other professional purposes might offer an opportunity to pursue an interest in ethics as ideals in practice among discrete social groups, literature (stories, poems, drama and so on) tends to focus on individuals, and how these individuals relate to themselves, to the other and to society in general. Given that literary works are conceived as ends rather than as means, it might seem contradictory to speak of the potential of the literary for ethics. But it is also true that being a highly individualized intervention does not make the creation of literature an isolationist act, nor does it consign the reader to a monastic, meditative quietude.

The literary text, as an intervention that can address the details of everyday practice, necessarily calls for some form of responsibility in society. This responsibility comes about because the attention to everyday practice delivers the other to us as vulnerable. To be sure, how people will respond in the face of other people's vulnerability cannot be determined ahead of time; but it is also true that there is responsibility in that response, or lack thereof. In this way, therefore, paying attention to the ordinary in our everyday lives uncovers many ethical and political opportunities. For one, it raises awareness of the power of individuals to script the texts of their lives and the implication that the hitherto unknown moral agency has on other lives and on society.

The ethical and political implications of attention to the ordinary in literature involve, among other things, two interrelated ideas: firstly, recognizing oneself and others as conditioned by our common humanity, and secondly, relating to oneself and others accordingly. In exploring the ethical implications of attention to the ordinary in human interactions in literary texts, this chapter seeks to answer the following questions: what are the implications of the presentation of ordinary, everyday actions as ethical for our understanding of the polis? How might literature contribute to a different understanding of what the polis is and what our responsibilities are as members of the polis? In engaging the above issues, I discuss Petina Gappah's 2015 novel The Book of Memory and Ayobami Adebayo's Stay with Me from 2017. I argue that some works of literature depict ordinary and everyday actions as a space for ethical and therefore political action, and the fact of extending ethical recognition to other humans as a political intervention. The ethical stakes in a literary work can be understood on two levels: in the relationship between characters, and between the narrated world and the reader.

Gappah's The Book of Memory tells the story of Memory, a girl living with albinism in Zimbabwe. Neither black nor white, she is the object of ridicule because of the color of her skin in a land of black people. Ironically, Lloyd, a wealthy white professor adopts her. Lloyd sees his own fate as a white man in Zimbabwe reflected in her condition. Members of a nationalist band kill Lloyd, but frame Memory for the murder and she is condemned to jail. While awaiting trial, she tells her story in the hope that the presiding judge will be lenient after hearing it. In Adebayo's Stay with Me, which is set in Nigeria, Akin (the husband) and Yejide (the wife) are ostensibly in a loving marriage. Yejide is distressed because of her failure to conceive after years of marriage. Her mother-in-law arranges a new wife for Akin. But the cause of their childlessness is Akin's inability to consummate the marriage. Yejide does not comprehend this, because, having married as a virgin, she has little understanding of what sexual intercourse between a man and a woman actually entails. Akin arranges for Dotun, his younger brother to have a sexual relationship with his wife in order to impregnate Yejide. The two children born as a result of Yejide's liaison with Dotun both inherit a congenital disease, sickle cell anemia, and die in childhood, leaving Yejide racked with guilt over her acts of adultery. Yet she is pregnant with a third child. After learning from Dotun that his sexual involvement with her 
was not accidental, but instigated by Akin, Yejide feels betrayed by Akin. When her third child, Rotimi, ${ }^{1}$ becomes sick shortly after her first birthday, Yejide leaves Akin in the belief that her third child will also die. But Rotimi does not die; she survives. Yejide returns to the family unit several years later for the funeral of her father-in-law, and must then fight to gain her surviving daughter's love and trust.

These two novels are ethical and political, not because they address matters of political malfeasance or urge the populace to engage in political activities, but rather because they focus on how the choices made by individuals in their daily lives affect other people. My analyses will concentrate on significant encounters and choices in the narratives, and the degree to which they help our understanding of ethics and political agency. My use of the term politics differs from the popular understanding which refers to the act of engaging in partisan political activities. While I do not explicitly dismiss this reading of politics, my notion of the term relies on Hannah Arendt's Aristotelian definition as 'the human condition of plurality,' in which the exercise of free speech in the open arena is possible (Arendt 1958, 7). I will discuss this more fully in the subsequent sections of the chapter.

\section{Literature, the ordinary and ethics}

There are certain elements in Aristotle's definition of tragedy in his Poetics to which every understanding of narrative as ethics returns directly or indirectly: an 'imitation of an action' that 'arouses pity and fear' and thus affects a 'katharsis of such emotions' (Aristotle 1996, 6). Stories, which are recreations of people's actions or encounters, are typically told to arouse a response (perhaps not exactly pity and fear) in the listener/reader. In this way, stories establish a relationship between two worlds: the narrated world and that of the reader. Lawrence Buell $(2000$, 6) believes that the meeting point of ethics and literature is the relationship 'between texts and readers.' But this is not just a casual meeting. In texts, readers are asked to imagine the lives of people (characters) they will never meet; the ethical dimension at the heart of an encounter with the literary text lies in this act of imagination. It is in this light that David Palumbo-Liu (2012, 3-9) argues that literature delivers the lives of others to us and challenges us to respond and to relate to them. The encounter between the reader and the people he or she will never meet becomes truly ethical when the relation is initiated in the form of identification with characters, worldviews or events, or rejection of the same. Either way, judgment is involved precisely because one weighs the positive and negative aspects of what one identifies with or rejects. It is, of course, possible to identify with something out of pure instinct, or out of loyalty to one's tradition, but even that implies acceptance of the decision behind the forming of that tradition. Every judgment implies responsibility. Ethics as transmitted in literature, as Adam Newton $(1995,12)$ argues, 'signifies recursive, contingent, and interactive drama of encounter and recognition, the sort which prose fiction both crystallizes and recirculates in acts of interpretive engagement.' The phrases 'drama of encounter and recognition' and 'interpretive engagement' capture the essence of literature as ethics, which is rooted in the relation of one character to another, or of readers and the world that is presented to them. In literary works, a representation of the everyday lives of characters offers a particularly apt opportunity for observing the drama of encounter and recognition.

Njabulo Ndebele is perhaps the most famous African philosopher and literary scholar to draw attention to the everyday and ordinary in literature as a space for ethical and political intervention. $^{2}$ Though he addressed apartheid-era South African writing, his arguments apply to much of African post-colonial writing. In his essay 'The Rediscovery of the Ordinary' (1986), he critiques the apartheid-era South African writers who adopted protest literature as a means of 
confronting apartheid. Ndebele terms the approach of these writers 'spectacle' because they produced 'spectacular representations of reality' (144) and failed to focus on the practice of everyday life of black South Africans. Like spectacle, their writing preferred 'the larger issues of society in our minds, obliterating the details ... It is the literature of the powerless identifying the key factor responsible for their powerlessness. Nothing beyond this can be expected of it' (149-150). For Ndebele, this attention to the ordinary and the everyday is also a form of selfmaking, which is a necessary precondition for creating a flourishing community.

The Oxford English Dictionary (Simpson and Weiner 1989, 165) defines spectacle as 'a piece of stage display or pageantry, as contrasted with real drama ... an event or scene regarded in terms of its visual impact.' In regard to politics and the human condition, spectacle is often taken to mean whatever is staged, which would include the act of inflicting gratuitous pain in order to maintain power. In general, the spectacular paints reality in broad strokes. ${ }^{3}$ Ndebele notes some of the major characteristics of the spectacular, especially in narratives: 'it provokes identification through recognition and feeling rather than through observation and analytical thought; it calls for emotion rather than conviction; it establishes a vast sense of presence without offering intimate knowledge' (1986, 149-150). Spectacle fails to pay attention to the details of the human condition of pain and pleasure; it acts through the prism of ideology. Ndebele argues that rather than the spectacular events of history such as colonialism, apartheid, military dictatorship, the 'ordinary day-to-day lives of people should be the direct focus of political interest [in literature] because they constitute the very content of the struggle, for the struggle involves people not abstractions' (156). This, to be sure, is counterintuitive. Why should writers not take a spectacle such as colonialism or military dictatorship head-on? But herein lies the irony. The moment narratives engage the large issues rather than the minutiae of people's interaction, they replicate the ideological flaws of the spectacle, which then obliterates analytical insight.

To further appreciate Ndebele's notion of the spectacular and its implications for ethics in literature, it helps to consider Martin Buber's notion of an 'I-Thou' relationship. Buber (1970, 50) differentiates between experience and relation. One experiences the world of things but stands in relation to the world of humans. When we relate to people, we cease to see them through the lens of utility; rather we begin to understand that they make our existence whole. Relation is not a one-way attitude; it is reciprocity, and reciprocity recognizes the dignity of the other. Experience, for Buber, is 'remoteness from you,' but relation reduces that remoteness (60). If the remoteness between me and you is nullified, there is then the possibility of encounter, which is the basis of actual life (62). In this encounter, the individual, 'I,' could meet the other, You, as 'my You.' The phrase 'my You' seeks to present the other, who is otherwise an indifferent 'You,' as very close to the subjectivity of 'I' to the degree that there is no longer an estranging distance caused by abstractions such as ideology. Spectacle is like ideology because of its focus on generality rather than on individuality, on an exteriority rather than an interiority; it prevents an 'I' from relating to the other as 'Thou'; rather, the 'I' relates to the other as an 'It' - a thing to be used.

\section{The ordinary as the political}

According to Arendt $(1958,3)$, politics is a defining aspect of the human condition, and it can be reduced to one simple act: speech. She states, 'Wherever the relevance of speech is at stake, matters become political by definition, for speech is what makes man a political being. ${ }^{, 4}$ Speech thus has meaning only within the context of democracy, government of the people (demos), of equals; their equality is rooted in the human condition. ${ }^{5}$ For Arendt, three fundamental human activities form the basis of the human condition: firstly, there is labor, the activity which entails 
the 'biological process of the human body' (7) that is activated in the sustenance of life. Secondly, there is work, the activity through which humans produce the artificial 'world of things, distinctly different from all natural surroundings.' Finally, there is action, which is 'the activity that goes on directly between men without the intermediary of things or matter'; and which 'corresponds to the human condition of plurality' (7). Without action, the human condition would not be possible; this is the condition 'of all political life' (7). Arendt states that, 'action has the closest connection with the human condition of natality' (9). The fact of being born reduces all to a common denominator; being born underscores the individual's vulnerability and therefore his or her dependence on others. As Arendt states: 'To be political, to live in a polis, meant that everything was decided through words and persuasion and not through force and violence' (26). The implication is, of course, that no human should be considered a tool or means to other humans' ends.

In the remaining parts of this chapter, I discuss The Book of Memory and Stay with Me in the context of action, and of being born. I focus specifically on childlessness and albinism, both of which highlight the centrality of the body in the discourse of the ordinary. Ultimately, the goal is to answer the question of how literature sharpens our ethical awareness and exposes the political structure of the ordinary.

The issue of childless marriages has occupied African women's writing, from the work of pioneer Flora Nwapa in Efuru (1966), to an early-twenty-first-century enunciation by Lola Shoneyin in her The Secret Lives of Baba Segi's Wives (2010). Nigerian professor of Gynecology and Obstetrics, Friday Okonofua (1997), Ghanaian Professor of Nursing, Ernestine S. Donkor (2007) and others have discussed the social and cultural repercussions of childlessness in African societies. Typically, childlessness in marriage is seen as a curse. Furthermore, women in childless marriages suffer because they are believed to be responsible for the condition of infertility, even when that is not the case. Adebayo's Stay with Me explores this issue and raises questions that have profound ethical resonance. What is the value of an individual to society? Or more pointedly, what is the value of a woman's body to her family? Do men and women occupy an equal ethical and political space within a given community? Akin marries Yejide, knowing that he is incapable of consummating a marriage and impregnating a woman. Yejide has no idea what sexual intercourse between a man and a woman entails because she married as a virgin. The narrative chronicles the series of humiliating incidents that she experiences because her community considers her body to be deficient. As a woman in the depicted society, she knows that her body does not possess the same value as her husband's; her body is valued only to the degree that it serves the purpose of reproducing. The subordinate position that her body occupies emboldens people around her to make judgments about her body and determine the use to which it must be put. This condition irritates her. She states, 'A number of my in-laws had been in our home previously to discuss the same issue. Discussion being: they talked and I listened while on my knees' (Adebayo 2017, 7). In this instance and following Arendt (1958, 3), one could say that Yejide is denied speech, and thus the right to function as a political being.

Narrating in a sarcastic tone, Yejide exposes other people's meddling in her marriage and their claim to know her intimate life better than she does. In denying her freedom of speech, they give her to understand that she is there to serve a single purpose: procreation. They do not consider her as possessing subjectivity. Their relation to her is mediated by the spectacle of patriarchy. Expressed in Buber's terms, they do not relate to her; they experience her. She describes the smile she wears when she joins her husband in the sitting room where his family members are gathered to talk about her marriage to Akin. It is a smile that says, 'Even though you old people know nothing about my marriage, I am delighted, no, ecstatic to hear all the important things you have to say about it. After all, I am a good wife' (8). Her emphasis on her 
smile alerts the reader to her desire to speak, but the impossibility of doing so. Her sarcastic use of the phrase 'good wife' draws attention to the expectations for married women in this society. A good wife, like a good servant, is one who has no opinion, no desires. Her life is therefore predetermined. She is not an interlocutor or an equal partner in speech.

The ultimate humiliation of Yejide's body is that even though the reason for her inability to conceive lies with Akin, she is still viewed as the cause of the problem, and women are paraded before Akin to be made pregnant - that is, to be conferred with meaning. Akin, the man, is thus the ultimate giver of meaning. The ethical issue here is the unequal relational economy between Akin and Yejide. More particularly, it is about Akin's inability to be honest and open with the woman he calls his wife. That condition results from the fact that, to a degree, he perceives reality through a prism; he ignores the ethics of the ordinary, of relation. To be sure, this condition is equally inimical to Akin. The condition which forces Akin to be fundamentally deceptive even to himself deserves to be brought to conversation. The truth is that Akin cannot relate even to himself in an ethically fulfilling way. Living with the secret of his own sexual inadequacies and the knowledge that he orchestrated his own wife's adultery, he is not what one might call a happy person. This is because the power conferred on him by patriarchy (the power to give meaning to women's bodies), does not by itself enable him to stand in relation to the world of humans. Attention to the ordinary allows us to see the outcomes of exercising power in an unethical way.

In the belief that the problem of childlessness in Akin and Yejide's marriage lies with Yejide, Akin's family arrange a second (and hopefully more fertile) wife for Akin, Funmi. The goal is, of course, to ensure that Funmi produces a child, preferably a boy, to carry on the family name. Funmi and Yejide are considered to be the means to a predetermined end. Ironically, and typically of oppressed people, the condition to which both women have been subjected engenders unfair competition and hatred between them while Akin pretends to be above the fray. In painting these characters who are denied speech by their community, especially in matters relating to their bodies, Adebayo has constructed a microcosm of the political condition of her society, in which the privileged and the underprivileged, those who have a voice and the voiceless, exist in parallel universes even within the same spatial economy. This, of course, does not mean that her narrative is allegorical; rather, it is a portrayal of the human condition in a way that initiates what Newton $(1995,12)$ has called an act of 'interpretive engagement.'

The context of the story suggests that the second wife of a man in a polygamous marriage ingratiates herself to the first wife, so that the first wife can create a space for her in the life of their common husband. This is what Funmi seeks to achieve with gestures such as calling Yejide 'mother' (30-31) as a sign of respect. But Yejide finds both of them diminished and does not hide her contempt for Funmi. Because Yejide has no social or legal mechanism for fighting the condition that erodes her dignity, she falls back on what she believes is a proven means through which women assert themselves in African patriarchal societies such as hers: 'I simply had to get pregnant, as soon as possible, and before Funmi did. It was the only way I could be sure I would stay in Akin's life' (38). Becoming pregnant increases a woman's stake in a man's life and giving birth to a male child doubles her worth as a human being (56). The situation thus reduces her to a means and therefore increases the value and power of the man. When it becomes known that Yejide is pregnant - even though it turns out to be a phantom pregnancy - people express their wishes for the gender of the child. Her mother-in-law tells her in a burst of joy: 'You must give us twins. Two fat boys, fat baby boys' (56). In seeking to become pregnant before her co-wife does, Yejide admits her utilitarian value. It is also ironic that her mother-in-law, as herself a woman, is part of the system that diminishes the female body. Why else would she wish for two boys? Yejide's sarcastic tone draws attention to her interiority and 
challenges the reader to see reality from her perspective. She is fully aware that she is a tool in the imagined happiness of the group. Her mother-in-law is willing to admit her into 'the human condition of plurality' only if she gives birth to children, and preferably to sons. It is, therefore, no surprise that she considers herself useless when the child she does give birth to dies of sickle cell anemia (125-126). Yejide will eventually abandon her third child, Rotimi, when she fears that this child, too, will die - an ill-advised decision to which I will return later.

Thus far, in the ordinary practices of the everyday, Adebayo seeks to achieve the political goal of placing individuals at the core of interactions in society and thereby asserts that they should be taken as ends, not means. Here, consideration of the feelings of individuals replaces any ideology that is thought to serve society. Eventually, we learn that all this domestic drama plays out against the background of military coups and political turmoil (Adebayo 2017, 94). In addition to the political turmoil, there are indications that the society is also beset by high rates of violent crime. It is important for our understanding of ethics that Adebayo does not make the spectacle of the military regime the centerpiece of the narrative. Instead, she enables us to raise questions about society's relationship to its weaker, less privileged members. We see the parallels between the objectification of life in a society ruled by the military and one ruled by abstract principles, rooted in tradition, one that functions from the standpoint of human nature.

Arendt (1958, 9-27) differentiates between the human condition and human nature. The human condition surrounds the lives of individuals as part of a community, while human nature seeks to capture the general, abstract thing that is thought to be common among individuals; it seeks to establish the norm. Those who aim to define human nature seek to establish the essence or an absolute condition of things and often resort to ideology. Arendt's notion of human nature and Ndebele's conception of the spectacular have one thing in common: they are based on abstraction and involve neglect of the ordinary. Spectacle is a tool deployed by those who have a particular ideologically determined goal, in other words, by those who are beholden to their notion of human nature rather than to the human condition. They deploy it to deny others their freedom and agency; in other words, they deny them an ability to live as full members in the polis. Ideologies function under the premise of human nature, with an understanding that all humans have a certain disposition by nature. Racism, sexism, tribalism and bigotry are all results of obsession with human nature. In Stay With Me, Yejide's in-laws do not interact with her as a fellow human based on the parameters given by the fact of a shared natality. Instead, they relate to her on the basis of human nature; in their encounters with her, they do not relate to her as a 'You,' that is, in ways in which they themselves would like to be treated.

In The Book of Memory, Memory begins her story by announcing the condition that makes her a stranger and an object of ridicule in her society. She is 'murungudunhu ... a black woman who is imbued not with the whiteness of murungu, of privilege, but of dunhu, or ridicule and fakery, a ghastly whiteness' (Gappah 2015, 2). She is 'black but not black, white but not white' (7). In her understanding, her body is not deserving of admiration because it is an object of pity. She sees her ugliness reflected in another albino, 'Lameck, who had a squashed face and red, blotchy skin that broke over his arms and face' (54). Every time Memory passes Lameck, she sees 'the flies that settled on his mouth.' She is afraid of Lameck and so does not wonder that people are afraid of her (55). This condition makes her arrive at a devastating self-judgment: 'I see now, of course, that he was just as much a misfit as I was' (55).

Memory's painful honesty about herself might appear somewhat self-deprecatory, but it achieves the first goal of narratives in the realist tradition: to bring the human condition to the fore, and in regard to ethics, to elicit some degree of relation from the reader. The truth is that albinos have experiences such as those described by Memory (Brocco 2016). When Memory 
becomes honest about herself, it is to draw her listener's attention to the condition of her body as that of a fellow human. It is, at the same time, a body that had been 'othered' by society's oppressive gaze. But by giving a name associated with the act of remembering to a human rejected on account of her body, the narrative makes it difficult for the depicted society to represent its past misdeeds as mere abstractions, instead of as crimes against fellow humans.

Memory's difference from the norm poses an ethical challenge to her society. She regrets that society sees her as the other; she is an abnormality, not part of human nature as conceived by her people. People do not see her as an embodied being; they hardly imagine the pain she experiences owing to her difference, her 'white' skin. She is to her community what the 'Negro' is to the white society in Frantz Fanon's famous analysis of the lived experience of the black man (Fanon 2008, 89). Just as painful, and even more so, her mother sees her condition as a curse that can be taken care of with the help of the spirit world. It is a curse because it is not part of human nature to be born that way. She allows her relation to her daughter and to the world to be dictated by diviners and prophets (Gappah 2015, 105-103). As Memory explains, 'My mother believed in the spirits and the mediums through which they spoke. She believed in healers and diviners' (118). From Memory's perspective, religion stands in the way of her mother taking her (Memory's) body seriously; her mother sees Memory as an 'It' rather than as a 'You.' Indeed, religion conditions her mother to conceive the idea to send Memory to a foster home, a gesture that Memory interprets as being sold. This is one of the instances in which the ethical has far-reaching political relevance. Memory's mother's inability to relate to Memory in ordinary terms implies a denial of speech. Memory also observes that religion does not contribute to people's self-esteem. The opposite is the case. She tells of a church service she attended in which the preacher unleashed words that debased rather than uplifted the faithful (116). From her perspective, religion is a tool which suppresses individual speech. Ndebele's definition of spectacle as establishing a vast sense of presence without offering intimate knowledge (1986, 149-150) applies to religion; it views individuals as predetermined by their essences, derived from the religion's divine being. But that conception of humanity makes politics, understood as an act of persuasion or of speech between equals, impossible.

What was said earlier about Yejide's voice as a political act goes for Memory as well. Memory invites the reader to take a second look at her body; this second look will be achieved the moment the reader begins to listen to her story. In effect, Memory initiates what seems like a dialogue with the reader and seeks to achieve with the reader what she could not achieve with her mother. She speaks and the reader listens. With her, narration becomes not only a means of understanding the self and initiating a relation to others, it also becomes a life-saving act. Memory, who has been falsely accused of murder, narrates that Vernah, her lawyer, 'told me that I should write down every detail that I could remember, that I should record everything that could make a sympathetic case' (Gappah 2015, 10). Memory hopes that when the trial begins, the judge who had heard her story will sympathize with her. The judge stands in for the prospective reader who is asked to understand Memory's condition. Memory even refers to herself as Scheherazade from One Thousand and One Nights, who also must tell a story to live (87). The reader knows that she is not guilty of the crime for which she has been jailed. Here, then, she narrates to make her listeners see reality from her own perspective and to see her as a person with interiority, a person deserving of co-feeling. Ethics in literature takes place precisely in such moments when listeners or readers recognize the character's interiority, and when they engage in what Newton $(1995,12)$ has called the 'interactive drama of encounter.' In Memory, literature becomes fully ethical, a means of initiating relation.

Thus far, in these two novels, the protagonists' bodies are presented as fragile and vulnerable. The novels' attention to vulnerable bodies is ethical and political, and it is so without relying on 
spectacle. It does not accuse. The first task of literature that seeks to rise to the level of ethics and to dramatize a different kind of life in the polis is to defy abstraction and to focus on the ordinary; thus, in presenting their bodies as ordinary and vulnerable, Yejide and Memory pose simple questions to their immediate world: what is my body to you? What am I to you? Who am I to you? These questions and the ethical relation they imply form a template for our recognition of others. They challenge the characters in the narrative world (and by implication the readers) to take an ethical stand. Indirectly, these novels also question the understanding of politics of societies that tolerate discrimination against vulnerable bodies.

\section{Recognition and care as contours of everyday agency}

In the introductory part of this chapter, I stated that employing ethics as a political tool involves two related ideas: firstly, recognizing others as conditioned by our common humanity, and secondly, relating to them accordingly. I understand this relation as recognition and read it as an integral part of ethics in literature. In their focus on the ordinary, or what Ndebele $(1986,156)$ calls 'man-man, man-woman, woman-woman, man-nature, man-society relationships,' Stay With Me and The Book of Memory reveal the ethical demand of attention to the ordinary: recognition. Their attention to the interior lives of these characters, that is, how they felt being ignored or recognized, is a good example of how narratives effect changes in society. Specifically, Gappah and Adebayo present us with moments and characters who, in drawing attention to themselves, make us aware of the gratuitous pain society inflicts on them and how this pain robs them of their human rights and dignity. We become aware of their plight, their demand that they be heard, their demand for a right to have a say in matters related to their own bodies, and ultimately their demand for recognition.

Recognition is the immediate implication of our attention to ordinary practice. We discover one another as conditioned by our common humanity. Community is where recognition is conferred; that is, in action and speech, we recognize one another as beings without whom our existence as humans would not be possible. This, at least, is the implication of the African traditional conception of being, expressed in the saying, 'I am because we are' (Menkiti 1984, 171). As the Nigerian-American philosopher Ifeanyi Menkiti states, individuals acquire personhood only in the community. Personhood is attained not in the abstract, but in being with others, in the daily exercise of encounter and, I would add, in the practice of the ordinary with others. We are, as it were, exposed to one another, for without the other, action would not be possible.

The demand for recognition or simple human relation is at the core of Memory's wishes. She states, 'I longed to be like all the others. I tried to get as dark as the other children. I longed to belong' (Gappah 2015, 57). She is invisible in a society that acknowledges only dark-skinned people. She prays 'for God to darken [her] skin' (58) because 'If [she] could not be like the others [she] would be invisible' (59). The desire to belong is simply an expression of the most basic human need for relation; it is at the same time an expression of the most political need: the need to make one's voice heard. Memory finds some degree of recognition in her relationship with her father. In contrast to her mother, her father takes her to the hospital; he takes care of her. Memory appreciates this simple act, and she shares one of her most profound moments of recognition and affirmation. She has prepared food for her father. In gratitude, he puts his arm around her and weeps. When he lets her go, he tells her it was what he needed (131-132). Memory's father puts into words what Memory has always wished for herself: human touch. It is ironic and humanely more fulfilling that Memory's father seeks affirmation from Memory; he wants Memory to affirm him, and in so doing, he gives her a sense of worth 
and affirms her as well. Lloyd extends the ethical gesture that Memory's father began when he adopts Memory. She says, 'Lloyd and I listened to cassette tapes by Fleetwood Mac and Depeche Mode' (167). Listening to music together is a metaphor for mutual recognition; it binds them and creates some commonality and a template for shared experience. With Lloyd, Memory finds that she 'could belong' (170). Lloyd is like a father to her. Indeed, he treats her like her father did - through touch - which, in the context of Memory's difference, is an important gesture of affirmation. When Memory returns from overseas studies, Lloyd welcomes her back like a daughter, calls her name, puts his arms around her, and lifts her off her feet (208). When Memory hugs Lloyd, she completes the circle of mutual affirmation that Lloyd has initiated. In Memory, therefore, Gappah pleads for the recognition of people with albinism, who bear the most visible markers of difference and otherness in a country of dark-skinned people. She exhibits a political gesture.

Although the narrative in The Book of Memory appears to be an allegorical representation of the nation's dealing with its past, and thus with politics, we should not assume that Gappah's preoccupations in this novel relate mainly to what Ndebele views as a spectacular notion of politics. By keeping the narrative focused on the ordinary life of Memory, the author concentrates our attention on ethical responses to difference. The novel seems to suggest that even the most intractable political conundrums of the past and the present are best understood in terms of our willingness to extend recognition towards individuals, especially those bearing visible markers of difference, and our willingness to treat them as human subjects rather than as abstractions. ${ }^{6}$

I now return to the irony of Yejide abandoning Rotimi in the belief that she would die like her other two children. Adebayo does not intend Yejide to be perceived simply as a victim. Yejide consented to an affair with her brother-in-law. She, too, owes others recognition. The twist in the narrative, in regard to ethics, however, is that she is given that which she sorely needs, but which she has denied others. When she returns to Akin to take part in Akin's father's burial, she is shocked to learn that Rotimi, her daughter, is alive; Rotimi draws her into her arms and calls her 'Moomi,' a Yoruba term of endearment for one's mother. It is of profound ethical significance that Rotimi recognizes her mother in such an endearing format, given that Yejide had abandoned her in the belief that she would die. Yejide is overwhelmed by the joy of affirmation and recognition: 'I shut my eyes as one receiving a benediction. Inside me something unfurls, joy spreads through my being, unfamiliar yet unquestioned, and I know that this too is a beginning, a promise of wonders to come' (Adebayo 2017, 270).

One of the important scenes in Stay with Me is when Rotimi bonds with Akin (222). Akin happily narrates that:

one morning she (Rotimi) looked up at me one fist beneath her chin as though she was pondering what she was about to say and said, 'Baba'. She said it two more times before she went back to sleep, as if she knew that I needed to hear the word again.

This seemingly magical moment underscores the affinity between Akin and the child who is not his, but whom he now takes as his. It is of great ethical relevance that Akin accepts Rotimi as his child. In this gesture, he makes up for the flaws in his relationship with Yejide. This moment of profound encounter encapsulates the most important ethical insight in Stay with Me. The child with sickle cell anemia does not die; she stays with the man who is not her father and, in calling him father, affirms him, just as he has affirmed her. This mutual affirmation is like that between Memory, her father and Lloyd, and acts as a lineament for affirmation in society; it 
provides us with the best example of an ethics that is rooted in the ordinary. Recognition does not necessarily have a biological basis; it is our admission of our natality and vulnerability, and consequently our positive response to it. It is a revealing irony that Rotimi (a daughter rather than a son) confers recognition and meaning on Akin. This reversal of roles in a patriarchal society signals a new ethical-political trajectory in the functioning of that society.

\section{Conclusion}

In the introductory part of this chapter, I established Rijk van Dijk, Astrid Bochow and Thomas Kirsch's anthropological reading of ethics in Africa. In particular, the authors examined how groups interact with other groups in society. Whereas a religious group or NGO can prescribe to people how to organize their lives, the best works of literature are never prescriptive. They do, however, draw attention to what human flourishing is all about, and they do so by focusing on ordinary, day-to-day life. The ethical, political function of imaginative narratives of the ordinary is to dislodge the teleological frame of ideology and abstraction; it restores the dignity of the other by placing him or her within the axis of our co-feeling. The task of literature as ethics is to present humans as possessing subjectivities and to place them in action in society. Literature helps us to become aware of the nexus of vulnerability and dependency.

Ndebele $(1986,156)$ speaks of individuals as possessing interiority when he states, 'It will be the task of literature to provide an occasion within which vistas of inner capacity are opened up.' For him:

The new literature can contribute to the development of this subjective capacity of the people to be committed, but only on the basis of as complete a knowledge of themselves and the objective situation as possible. The growth of consciousness is a necessary ingredient of this subjective capacity.

I read this subjective capacity in terms of ethics. It is that which begins from the moment humans recognize one another as subjectivities that are nevertheless interconnected and mutually dependent on others, given the fact of our natality. The questions: 'who am I to you?', 'what is my body to you?' or 'what am I to you?' can therefore be approached by listening to the questioner tell who she is. If the questions have to be answered, this has to be done within the contexts established by the meeting of two worlds, that of the narrator and that of the listener. Ethics is no more than acceding to the demands of the meeting of these two worlds, the world of the 'I' and that of the 'You'; it is the admission of the interiority and subjectivity of the other, the recognition of the other as possessing dignity and a moral space.

In an earlier publication, I celebrated the fact that African literature occupies itself less and less with the Empire (Eze 2016). Led by women authors, African literary texts write back to the body, and to the degree that the body feels pain, instead of to Empire. The authors of The Book of Memory and Stay with Me belong to that new generation of authors; they are not concerned with how the West tells a single story of Africa, or how it writes about Africa. They are interested in delivering the lives of Africans to other Africans and thereby challenging them to respond ethically. It is satisfying that Gappah and Adebayo do not dwell on the most spectacular forms of life in the polis in their novels. Rather, by focusing on the ordinary, they call society's attention to the necessity of mutual recognition of one another in public spheres. 


\section{Notes}

1 The title of this novel comes from the Yoruba name and phrase, Durotimi (often abbreviated as Rotimi), which translates as 'stay with me.'

2 I have discussed Ndebele more fully in Race, Decolonization, and Global Citizenship (Eze 2018).

3 Empire and colonialism are spectacles, as is everyday corruption in a failed democracy.

4 Speech is also understood as logos, thought, or the ability to hold a formal discourse. In ancient Greece, only free men were thought to possess this ability. Women, children and slaves were not considered free and able to engage in the noble task of speech.

5 We extend the understanding of speech to include the ability and the audacity to express how one feels and what one thinks, how one wants to conduct one's life.

6 I am grateful to the editors, Moradewun Adejunmobi and Carli Coetzee, for this suggestion.

\section{Bibliography}

Adebayo, Ayobami. 2017. Stay With Me. Canongate: Edinburgh.

Arendt, Hannah. 1958. The Human Condition. Chicago, IL: The University of Chicago Press.

Aristotle. 1996. Poetics. Translated by Malcolm Heath. London: Penguin Books.

Brocco, Giorgio. 2016. 'Albinism, Stigma, Subjectivity and Global-Local Discourses in Tanzania.' Anthropology \& Medicine 23(3): 229-243.

Buber, Martin. (1923) 1970. I and Thou. New York: Simon Schuster.

Buell, Lawrence. 2000. 'What We Talk about when We Talk about Ethics.' In The Turn to Ethics, edited by Marjorie B. Garber, Beatrice Hanssen and Rebecca L. Walkowitz, 1-13. London: Routledge.

Donkor, Ernestine S. 2007. 'The Impact of Perceived Stigma and Mediating Social Factors on Infertilityrelated Stress among Women Seeking Infertility Treatment in Southern Ghana.' Social Science Medicine 65(8): 1683-1694.

Eze, Chielozona. 2016. Ethics and Human Rights in Anglophone African Women's Literature. New York: Palgrave Macmillan.

Eze, Chielozona. 2018. Race, Decolonization, and Global Citizenship in South Africa. Rochester, NY: University of Rochester Press.

Fanon, Frantz. 2008. Black Skin, White Masks. Translated by Richard Philcox. New York: Grove Press.

Gappah, Petina. 2015. The Book of Memory. New York: Farrar, Straus and Giroux.

Garber, Marjorie, Beatrice Hanssen and Rebecca L. Walkowitz, eds. 2000. The Tum to Ethics. New York: Routledge.

Iheka, Cajetan. 2018. Naturalizing Africa: Ecological Violence, Agency, and Postcolonial Resistance in African Literature. Cambridge: Cambridge University Press.

Menkiti, Ifeanyi A. 1984. 'Person and Community in African Traditional Thought.' In African Philosophy: An Introduction, edited by Richard A. Wright, 171-181. New York: University Press of America.

Ndebele, Njabulo S. 1986. 'The Rediscovery of the Ordinary: Some New Writings in South Africa.' Journal of Southern African Studies 12(2): 143-157.

Newton, Adam Zachary. 1995. Narrative Ethics. Cambridge, MA: Harvard University Press.

Norridge, Zoe. 2013. Perceiving Pain in African Literature. New York: Palgrave Macmillan.

Nwapa, Flora. 1966. Efuru. London: Heinemann African Writers Series.

Nussbaum, Martha Craven. 1983. 'Flawed Crystals: James's The Golden Bowl and Literature as Moral Philosophy.' New Literary History 15(1): 25-50.

Nussbaum, Martha Craven. 1990. Love's Knowledge: Essays on Philosophy and Literature. New York: Oxford University Press.

Okonofua, Friday. 1997. 'The Social Meaning of Infertility in Southwest Nigeria.' Health Transition Review 7(2): 205-220.

Palumbo-Liu, David. 2012. The Deliverance of Others: Reading Literature in a Global Age. Durham, NC: Duke University Press.

Shoneyin, Lola. 2010. The Secret Lives of Baba Segi's Wives. New York: William Morrow.

Simpson. J. A. and E. S. C. Weiner. 1989. The Oxford English Dictionary. Oxford: Clarendon Press.

Slaughter, Joseph. 2007. Human Rights, Inc.: The World Novel, Narrative Form and International Law. New York: Fordham University Press.

van Dijk, Rijk, Astrid Bochow and Thomas Kirsch. 2017. 'Introduction: New Ethical Fields and the Implicitness/Explicitness of Ethics in Africa.' Africa 87(3): 447-461.

Wallace, Cynthia R. 2016. Of Women Borne: A Literary Ethics of Suffering. New York: Columbia University Press. 


\section{Globalisation, mobility and labour in African diasporic fiction}

Anna-Leena Toivanen

This chapter addresses the entanglement of mobility and labour in the global era, and suggests potential ways to study these issues in contemporary African diasporic fiction. My analysis focuses on Fatou Diome's Le Ventre de l'Atlantique (2003), Alain Mabanckou's Tais-toi et meurs (2012) and Sefi Atta's A Bit of Difference (2014), which are novels set against the background of different forms of Afroeuropean mobility. The central characters' working lives in Europe - or their aspirations of having one - are important not only in the sense that they drive the plot, but also because labour is a theme that allows the texts to explore the logic of globalisation from an African perspective. In Diome's Le Ventre de l'Atlantique, a young man on a Senegalese island nurtures hopes of becoming a professional football player in Europe. The novel promotes an anti-emigration message directed at young Africans who, lacking prospects in their countries, invest their hopes in unrealistic ideas of a working life in Europe. Mabanckou's Tais-toi et meurs explores informal and illegitimate labour through the figure of an undocumented Congolese migrant in Paris. The thriller draws attention to the exploitative features of globalisation through its portrayal of a diasporic criminal underground community that profits from its countrymen's dreams of a better life in Europe. And finally, Atta's A Bit of Difference features an affluent, London-based Nigerian who works as an auditor in an international charity organisation and travels around the world because of her job. Through its upwardly mobile protagonist, the novel brings to the fore the diasporic African upper middle class and its work-related dilemmas. The novel sets cosmopolitan ethics and responsibility in the context of labour. All three works to be discussed link questions about labour to a more familiar concern with mobility.

Mobility is a theme that has intrigued African writers for decades. Bernard Dadié's Un nègre à Paris (1959) is one of the first African authored travelogues featuring the figure of the African tourist; Aké Loba's Kocoumbo, l'étudiant noir (1960) addresses African student mobility; Buchi Emecheta's Second Class Citizen (1974) discusses migration from African women's perspective; and Abdulrazak Gurnah's By the Sea (2001) represents the coerced displacement of asylum seekers. Mobility is commonly explored more generally through the migrant experience despite the fact that migration and mobility are often motivated by problems of access to adequately remunerated labour. Indeed, while there are exceptions such as Brian Chikwava's Harare North (2009), and Imbolo Mbue's Behold the Dreamers (2016), few African migration novels address the mobility-labour nexus explicitly. Labour in general is a theme that remains under-examined in 
literary studies (Connell 2017, 1); the link between mobility and labour has not received much attention in African literary scholarship either. This subject therefore represents a new avenue for studying African fiction.

Through the themes of mobility and labour, this chapter addresses the question of political agency in African literatures in the global era. The idea of political engagement has motivated African literatures from the very beginning, as attested by diverse literary articulations of anticolonial, nationalist and feminist agendas. While the nation has been the axiomatic centre of political agency for previous writerly generations, the failures of national projects and globalisation processes have started to widen the scope of politics towards new areas. As a concept, labour is inherently political. Guy Standing (2014, 964; emphasis original) defines it as follows: "labour" is done for a wage or some form of remuneration. It has exchange value and is an activity, that of devoting time and effort to working for someone else, in some position of subordination.' This definition is useful as it invokes the patterns of exploitation and control as well as the notion of political consciousness exploitation may generate (Standing 2014, 965). Works such as Ousmane Sembène's Le docker noir (1956/1973) and Les bouts de bois de Dieu (1960) or Emmanuel Dongala's Photo de groupe au bord du fleuve (2010) engage with labour in a context of political mobilisation. These novels portray labourers' struggles against exploitation, injustice and poor working conditions as they mobilise themselves socially. Political agency in these novels is represented as social solidarity. However, when it comes to the treatment of the labour-mobility nexus in the novels of Diome, Mabanckou and Atta, they address it from a comparatively apolitical perspective. There are no allusions to social movements - with the exception of police and immigration apparatuses - and no allusions to the state. Mabanckou's and Diome's novels in particular include elements that could easily lend themselves to an overtly political treatment of labour-related mobility from the perspective of social solidarity. Yet, neither of these novels not even Diome's, which resorts to emphatically political tones in its anti-migration message explores the ways in which organised social movements could redress labour-related inequalities. Agency, if there is any, manifests itself in individuals' choices. By disregarding the notion of social solidarity, the novels under scrutiny give articulation to the neoliberalist ethos that highlights individual freedom and personal responsibility (see Harvey 2005, 23). As such, these works mark a shift away from the domain of politics.

As the analysed texts do not actively represent the question of labour from the perspective of political agency and social solidarity, a reading focusing on the politics of mobility and labour must adopt another entry point. To this end, my analysis revolves around questions of what Mekonnen Tesfahuney $(1998,501)$ calls 'differential mobility empowerments', that is, who is on the move, how and why. These 'differential mobility empowerments reflect structures and hierarchies of power and position by race, gender, age and class, ranging from the local to the global' (Tesfahuney 1998, 501). The contextual backdrop for this analysis is the global world order whose cartography is informed by European colonialism (Behdad 2005, 70-71), and that is therefore motivated by capitalism and 'written in the grammar of race and ethnicity' (Munck $2010,164)$. The present chapter is, then, less an endeavour to analyse the characters' political agencies than an activity of reading the texts' representations of labour-related mobilities through a political lens. As Liam Connell $(2017,7)$ formulates this idea in his study on the precarious features of labour in the contemporary novel, 'the texts alone cannot make visible or generalise the conditions governing the characters' relations to work and that is only possible by reading the texts theoretically.'

Prioritising politics in literary analysis may run the risk of reducing works of art to sociopolitical 'proofs' or promoters of political agendas. Therefore, a nuanced analysis of 'the multiple trajectories' of globalisation and labour necessitates attention to both politics and poetics 
(Malreddy 2015, 13; see also Connell 2017, 5). In order not to deny the texts their poetics of global mobility while reading them through a political lens, my analysis pays attention to the literary means that the texts employ to represent different African diasporic labour-related mobilities. To this end, I study the texts' concrete images of mobility that embody 'local processes of daily transportation' (Hannam, Sheller and Urry 2006, 1): air travel and commuting, the Parisian metro and modern technologies. These tropes are telling of the fictional characters' mobile positions and symbolise their relation to labour. Analysing such tropes also allows for a 'multiple and intersecting' understanding of mobilities (Hannam, Sheller, and Urry 2006, 2), in particular in the sense of linking these daily mobilities to the wider context of migration. By focusing on these concrete tropes of mobility, this chapter aims at widening the scope of how mobility can be understood in the study of African literary texts.

Globalisation is a complex process and a concept that carries multiple, sometimes contradictory meanings. One of its defining elements is the 'spread of a free-market-based, capitalist style of production' (Krishna 2009, 2) that started to occur in the 1970s and accelerated after the end of the Cold War, and that entails such phenomena as the transnationalisation of production, weakening labour movements, and the multinationalisation of corporations (Connell and Marsh 2011, xiv). Besides being a phenomenon characterised by liberal capitalism, globalisation is frequently described as a process of deterritorialisation and transnationalisation in which oppositions between centres and peripheries no longer hold, and which is generated by the 'flows' of people, capital and technology (Connell and Marsh 2011, xiv). In other words, globalisation is characterised by the increase and intensification of different forms of mobility. ${ }^{1}$

Globalisation processes affect labour in diverse ways. Ronaldo Munck's (2010, 159-160) keywords 'in the lexicon of global political economy of work' include (migrant) mobility, flexibility, informality/precarisation. Munck (2010, 163-164) underlines globalisation's link to colonialism and imperialism, and notes that migrant mobility should be discussed in the context of its 'root causes [...] such as uneven development and the continued subjugation of the South by the dominant capitalist regimes, not least through the active policies of neoliberal globalization.' Liam Connell $(2017,4)$ posits that precarious labour does not refer only to the threat of unemployment or the idea that work may not guarantee good life, but also 'signals workers whose relationship to the social, whose very being is contingent or at risk'. This element is also manifest in the novels of Atta, Diome and Mabanckou, where the work-related issues seem to be detached from the socio-political.

The 'pursuit of capital' has motivated the movement of people between Africa and the Western world since the slave trade (Otiono 2011, 6). Today, this legacy can be observed in how labour mobility from Africa towards the Global North continues to be 'a form of resource extraction' (Otiono 2011, 16) - this is the case of highly skilled African workers, but also less educated migrants on whose input the low-paid service sector increasingly relies in many Western societies (Sassen 1998, 48, 87). Indeed, it can be argued that the economy of the Global North depends on migrant labour (Bauder 2006, 3). Migrants are a welcome segment of the work force because they are cheap and flexible, which renders them vulnerable to exploitation (Bauder 2006, 4). Labour migration is 'an integral aspect of a wider neoliberal economic regime' where migrants form a new international proletariat that can be used as a work force reserve (Bauder 2006, 5-6). Members of this mobile proletariat embody the unequal effects of a neoliberal global economy as 'they command a minuscule fraction of the world's wealth even though their earnings help sustain entire communities' (Ghosh 2012, 36). These global subaltern subjects are invisible not only because they often occupy the position of undocumented migrants, but also because they become 'consumed and erased while producing value through their labor' (Ghosh 2012, 36). 
Prior to becoming part of a foreign work force, aspiring migrant workers must cross national borders. The period after World War II until the mid-1970s saw a 'migrant labour boom' in Europe, but since then, migration policies have tightened (Cohen 2006, 138-139). Further, while globalisation has eased the transnational movement of goods, capital and information, human movement across borders is increasingly controlled (Behdad 2005, 73). This has implications for labour-motivated mobilities. By performing processes of inclusion and exclusion in the context of labour mobility, borders play a central role 'in producing the times and spaces of global capitalism' (Mezzadra and Neilson 2013, 3-4, 20-21). The selective role of borders underlines the fact that mobility is an unevenly distributed resource (Cresswell 2006, 178) and as such, crucial to the unequal processes of globalisation (Sheller 2014, 49). Obviously, exclusionary politics and the uneven distribution of the resources have not stopped migration without documents towards the global North, nor has it slowed down informal labour practices in the Global North. Unauthorised migration and the labour of underprivileged, racialised and gendered mobile subjects have contributed to a phenomenon of 'shadow globalisation' (Penttinen 2008). Shadow globalisation, according to Elina Penttinen $(2008,7)$ refers to:

activities that have been made possible by global flows of information, technology, finance and people, [and] that are taking place in informal and illegal ways [...] in the shadows in terms of otherness of the domain of subjectivity of global world economy.

The phenomenon of shadow globalisation attests to how globalisation produces 'new forms of precarity, marginality and subalternity' that fall beyond the scope of the normative category of wage-labour (Malreddy 2015, 2, 8) and the current division of labour motivated by racial and gender differences (Cohen 2006, 158). Given the multiplication of borders that destabilises traditional centre versus periphery binaries, these global subaltern classes can be found anywhere on the globe (Mezzadra and Neilson 2013, 64, 85). This trend disturbs - without entirely undoing - the 'residual effects of colonially organised geopolitics' (Loomba et al., 2005, 8).

While it is true that 'global cultural flows are [...] dominated by [...] coerced migrants rather than free-willing cosmopolitan subjects' (Gikandi 2010, 28), one should also be wary of promoting the stereotypical idea of African mobile subjects as underprivileged victims. 'The leisured postcolonial class' and 'connoisseurs of global culture' - as reads Gikandi's (2010, 22) portrayal of privileged mobile Africans - also form one segment of global African labour mobility. The concept of middle class has been applied to the African context only recently, and it is sometimes difficult to define who belongs to it (Jacquemot 2012, 3). African middle classes also remain invisible in the study of African literatures (Adenekan and Cousins 2014, 1; Knudsen and Rahbek 2016, 106). For an analysis of fictional African labour-related mobilities, it is important to take into account class - privileged ones included - as it is one of the major factors that enables or limits one's physical and socio-economic mobility.

What is literature's role in the globalised African context? Even if literature only rarely features in discussions concerning globalisation, it can contribute to them. The 'slowness' of narrative fiction and its attention to character development may allow for an in-depth treatment of phenomena generated by globalisation (Connell 2017, 5). Narrative fiction may render visible experiences that would otherwise remain invisible - this is the case for informal labour (Dawson 2009, 139), but the same also goes for the labour of African middle classes which has not gained much critical attention in literary research. Moreover, and since literary texts have the capacity to produce 'narrative constructions of the numerous discourses or "fictions" of globalisation' (O'Brien and Szeman 2001, 604), fiction is well placed to embody the complexity and contradictoriness of the processes of globalisation. 
Diome's Le Ventre de l'Atlantique is a modern classic addressing migration from Africa to Europe from a bilateral perspective (Garnier 2004, 19). Salie, the protagonist, has left her native island Niodior in Senegal and emigrated to France. The novel draws attention to the intertwining of mobility and labour not only in a diasporic, but also in a local African setting. The local dimension is approached through the figure of Madické, Salie's brother who wishes to pursue a professional football career in Europe. For the uneducated young men of Niodior, football is the ultimate career goal: it involves physical mobility from Africa to Europe, which for them promises socio-economic mobility. As pointed out by Dominic Thomas (2006, 195), the world of football is in itself a symbol for globalisation. While for the unemployed young Africans, football represents 'l'issue de secours idéale' (Diome 2003, 240) ['the ideal emergency exit' (172)], ${ }^{2}$ the industry sees the bodies of these aspiring players as raw material to be used and disposed of (Thomas 2006, 196; Nyawalo 2011, 98). This exploitative logic is embodied in the figure of Moussa, whose football career came to an abrupt end, driving him to a life of secrecy, illegal residency, human trafficking, deportation and suicide. Moussa's short adventure in the football industry can be read as an allegory for the neoliberal world of labour which relies on profit seeking, precariousness, competition and lack of solidarity. Moussa's expectations about a sports career contradict the reality: 'Du sport, en dehors de la promesse de réussite, Moussa n'en attendait qu'une franche camaraderie et le respect mutuel. Il ne trouva que calculs sordides et mépris' (Diome 2003, 99) ['Beyond the promise of success, Moussa expected only honest camaraderie and mutual respect from sport. He found only sordid calculation and contempt' (66)]. Once he is discharged from the football team as an unprofitable investment, he ends up doing forced labour to pay his debt for the headhunter - the expiration of his residence permit renders him vulnerable to exploitation. There is no-one to help him in his distress, and he even starts to think that 'après tout, ce n'était pas si mal d'être logé et nourri' (105) ['after all, it wasn't so bad; he was fed and had a roof over his head' (70)], which signals his resignation to the situation.

The aspiring football players refuse to take Moussa's alarming example seriously. They do not see their own complicity in this exploitative system, and are ready to serve as the raw material for the business of soccer as they see it as their only opportunity to embrace upward socioeconomic mobility. Interestingly, for most of the aspiring athletes, football is nothing more than a 'simple prétexte pour atteindre l'Occident' (115) ['means of reaching the west' (78)] in their 'désir d'embourgeoisement' (116) ['desire for the good life' (79)]. It turns out that the young men would be ready to accept any job to get to Europe. Unlike these young men - and, for that matter, Salie who exercises the strongly gendered and racialised profession of a cleaner Madické stubbornly holds on to his unrealistic dream for his professional future and in this way rejects the position of the low-paid migrant doing the menial jobs that Europe has reserved for him.

The novel shows how migrants are used as a reserve work force for low-skilled, low-paid jobs in Europe. Besides Salie who works as a cleaner, the text lists 'des experts du ménage qui s'habillent chez Tati, des gardiens de magasin qui se musclent aux nouilles, des touristes qui visitent Paris sur des camions à benne, des arroseurs de jardin qui coupent des roses pour Mme Dupont' (37-38) ['domestic goddesses who dress at Tati, ${ }^{3}$ for shop security guards who build up their muscles on noodles, tourists who visit Paris huddled on dumper trucks or gardeners who cut roses for Madame Dupont' (21)]. The novel discusses in more depth the figure of 'l'homme de Barbès', a been-to who now leads a comfortable life on the island after having worked in France. His success story hides less glamorous details of his stumbling career path: menial jobs, no residence permit, informal labour and fixed-term contracts before ending up as a guard in a shopping centre - a typical 'migrant job', that is.

Diome's novel also produces its own poetics of global mobility. From the perspective of Madické's professional dreams, the most important vehicles of mobility are the television and 
the telephone - they allow him to engage in imaginative and communicative travel. While these mobile technologies link Madické to global flows, he sees them as unsatisfactory substitutes for physical human mobility, and they underline his immobility in this respect. These modern technologies - which, since the publication of the novel in 2003, have become overtaken by ITC-mediated mobilities - play a key role in his professional aspirations. The television keeps Madické connected to the world of football and thus provides him with the material for his dreams, which his telephone conversations with his sister further consolidate as Salie regularly ends up buying - with her cleaning lady's salary - the sports material Madické asks for. The television becomes a vehicle for imaginative travel that is intertwined with the transnational movement of capital and consumer culture. It promotes dreams of consumerism that seem to be available only to those who work in France. The fact that the television breaks down in the middle of the football match Madické is watching portends the likely failure of his unrealistic ideas about migrant working life in France and also conveys the unattainability of his consumerist aspirations. Further, the telephone conversations between Madické and Salie structure the novel and contribute to its poetics of global mobility. Mouhamédoul Amine Niang (2011, 239) suggests that the novel can be read as an updated version of the epistolary. Niang points out that the telephone turns into 'a medium of psychological and social pressure on the migrant' (2011, 243; my translation) as witnessed by Madické's repeated requests for sports material. As such, mobility enabled by the telephone not only connects distant places, but also creates financially motivated power structures between migrants and those who stay.

Le Ventre de l'Atlantique promotes an articulate agenda regarding transnational labour mobility. Salie, by convincing Madické to abandon his ideas about a football career in Europe and to establish a small business on Niodior with the money she sends him, is the mouthpiece of Diome's 'antiglobalisation narrative' (Coly 2010, 83). In what comes across as a personal mission, Salie fights the unrealistic ideas of France that the young men of Niodior cherish. While this anti-emigration/-globalisation agenda is an important gesture in highlighting the possibilities of the local (Thomas 2006, 200), the way in which this political message is constructed is unconvincing. As pointed out by Robert Nathan $(2012,77)$, the contradiction lies in Salie's own position: while she 'condemns the insensitivity that comes with the free movement of transnational capital under a neoliberal world economic framework, her own solution to the migration problem also involves the free movement of capital across international borders' (Nathan 2012, 78). What adds to this contradiction is the fact that Salie manages to establish herself as a published author in France - if she can succeed, why not her brother? The novel is curiously torn between its anti-globalisation/-migration agenda - which relies on the opposition between the local and the global and on the romanticised idea of the island as self-sufficient (Nathan 2012, 78) - and its representation of the entanglement of the local with the global through different forms of mobility. The novel's failure to promote a consistent political message vis-à-vis mobility and labour in the context of neo-liberal capitalism betrays the complexities that inform Africa's relation to globalisation. It is equally significant that the solution to Madické's dead-end situation comes from a family member and that the postcolonial nationstate remains entirely indifferent to his distress. This suggests that the state or nation do not have any relevance or credibility as a domain for political agency. This is partly because the state actively sabotages labour movements, as suggested by the fact that Ndétare, a fervent union activist, has been reassigned by the government to a teaching post on the isolated Niodior as he was considered to be 'un agitateur dangereux' (Diome 2003, 65) ['a dangerous agitator' (41)].

Mabanckou's Tais-toi et meurs foregrounds informal elements of mobility and labour in a diasporic, criminal global underground setting. The protagonist Julien Makambo leaves CongoBrazzaville for Paris with a forged passport arranged by Pedro, his nephew's father. In Paris, he 
is supposed to work for Pedro, who has established himself as the 'big brother' of the community exercising its own 'économie parallèle' (Mabanckou 2012, 145) ('parallel economy') ${ }^{4}$ on the fringes of French society. The novel thus shifts away from the hegemonic conception of work as wage labour towards an understanding characterised by informal/illegal elements. The underworld context of the novel is disconnected from the surrounding society in such a pronounced way that this illegal-informal space becomes the norm. This is conveyed in the way in which characters trivialise their criminal activities by referring to these as work.

The protagonist does not have any expectations of what awaits him in Paris, and slips rather smoothly into the role of a petty criminal. He shares Pedro's one-room apartment with seven compatriots. The young men have ended up in the criminal milieu after their professional dreams have failed them. Unlike in Diome's novel, their career aspirations are not per se unrealistic; they dream about working as estate agents, car mechanics or musicians. Their failure to gain entry into such seemingly banal professions suggests that the situation of migrant workers in the formal sector is challenging. Indeed, as one of the father figures of the 'milieu' claims, there were times when 'on venait chercher les immigrés dans les foyers pour leur proposer du travail' (37) ('they came to get immigrants from their homes to offer them jobs'). These words refer to the migrant labour boom in France and elsewhere in Europe between 1945 and the mid-1970s. In the narrative present, the demand for migrant labour has decreased as neoliberal capitalism makes migrants compete for jobs with citizens. Difficulties of finding work in the formal sector have contributed to the establishment of the exploitative 'filière congolaise' (146) ('Congolese network'). The 'little brothers' owe their diasporic lives to the father figures who have introduced them in France; the recurring notions of debt, loyalty, secrecy and hierarchy actually point at human trafficking. Yet, the narrator does not see himself as a victim - not even when, a few days after his arrival, Pedro tells him that 'Paris c'est Paris, tout le monde doit bosser' (58) ('Paris is Paris, everyone has to work'), and sends him to sell falsified travel passes. This is an offer the protagonist cannot turn down; as a clandestine newcomer, he has no idea where and how to look for a job on his own.

Tais-toi et meurs is a fast-paced novel tracing the events that have led to the protagonist's imprisonment in the narrative present. He has been imprisoned in the aftermath of a 'mission' in the course of which a woman got killed - a murder for which he is made the culprit by his community. Such key attributes of the thriller genre such as detection, conspiracy and in/visibility (Primorac 2013) drive the plot forward, and the narrative regularly links the protagonist's experiences to imagery used in the thriller genre. The thriller form is an integral part of the novel's representation of clandestine and criminal labour in the global underground. The protagonist is constantly on the run, and the anxiety-informed thriller form captures his futile attempts at escape from the authorities and his exploitative community. While the protagonist is a victim of conspiracy orchestrated by his community, the roots of this conspiracy lie in a wider context of global inequality. The text's thrilleresque qualities and the first person narration immerse the reader in the gloomy world of shadow globalisation (Penttinen 2008) that is without prospects for the undocumented migrants and is detached from and invisible to the surrounding society.

In the aftermath of the murder, the protagonist is drawn from invisibility to hyper-visibility: his flight from the crime scene has several witnesses as he wears an extravagant, bright green suit. Moreover, his case is followed by the media which places the murder in the context of political discussions on migration. The green suit becomes a trope that conveys the idea of how a clandestine migrant without residency papers becomes visible when $\mathrm{s} /$ he wishes it the least and when it serves the purpose of anti-migration discourses. The unwelcome hypervisibility associated with the green suit also suggests that the protagonist's consumerist aspirations, 
manifested in the form of Congolese dandyism, la Sape (Société des Ambianceurs et des Personnes Elégantes; 'Society of Ambiance-Makers and Elegant People'), characterised by a passion for luxurious designer brands, eventually turn against him. He drifts into this shadowy setting at the mercy of the laws of the global underground, unable to identify or challenge the fact that he is being exploited. The novel explores how globalisation generates forms of exploitation that may not even be identified as such - let alone resisted - by those exploited until they find themselves in the ultimate cul-de-sac like the protagonist. The thriller plot conveys this lack of agency and social marginalisation perfectly (see also Dawson 2009, 129). In the protagonist's world, there is no room for political agency or even solidarity between 'colleagues'. The milieu's competitiveness could be read as a dystopian allegory of the neoliberal labour market which engenders competition between workers, undermines social solidarity, and which is characterised by precariousness and exploitation.

The novel displays a variety of mobility-related imagery, of which the Parisian underground network is the most central. Reading Tais-toi et meurs is like reading the map of the Parisian metro: names of the stations and their interconnections recur frequently as the protagonist heads for his missions. This underground cartography of Paris symbolises the shadow milieu in which the protagonist and his 'brothers' operate. In this respect, a very powerful scene features in a chapter in which Pedro sends the protagonist on a mission to test his loyalty. As usual, the protagonist takes the underground without buying a ticket. This does not go unnoticed by the inspectors, who pursue him in the labyrinth of the underground station. The protagonist wears expensive designer shoes which are not made for running - again, a detail suggesting that his consumerist aspirations have made him an easy prey. His panicky marathon leads nowhere: all he comes across are 'no exit' signs, dead ends and metro carriage doors closing right in front of his nose. When he finally thinks he has escaped the inspectors, it turns out that he is yet again in a cul-de-sac, with the triumphant black inspector - for whom catching the protagonist is a sort of a personal mission - exclaiming, 'Fils de bâtard, tu croyais connaître cette station mieux que moi, hein?' (Mabanckou 2012, 70) ('Son of a bitch, did you really think you knew this station better than I do?'). This passage captures the protagonist's impossible situation as an undocumented migrant working in a criminal milieu, and conveys the idea of how his subservient position renders him an outsider even where he is supposed to be 'at home'. The veil of secrecy and demands for loyalty that inform the global underground milieu create an extremely limited world, attesting to the multiplication of borders typical of the globalised era (Mezzadra and Neilson 2013), and preventing him from seeing the wider picture of his situation. In his clearly bordered world, Mabanckou's protagonist belongs to the class of new, 'politically dispossessed' global subaltern (see Malreddy 2015, 5). On a broader scale, however, the fact that the clandestine migrants in the novel have created their own parallel reality and economy in the margins of society suggests that at least for the father figures, the 'filière' represents an opportunity to reject the position of the low-paid migrant worker that the global economy reserves for many Africans in Europe. The father figures are not simply victims of globalisation but do claim some agency, albeit in a form that subjects their fellow Africans to exploitation.

Unlike Diome's and Mabanckou's novels, Atta's A Bit of Difference addresses privileged labour-related mobilities. The Nigerian protagonist Deola Bello lives in London where she works as an auditor of an international charity organisation. The novel opens with a scene in which Deola's flight from London has just arrived at Atlanta airport. By describing her as 'an arriving passenger' who wears a 'pin-striped trouser suit' (Atta 2014, 1) and carries a laptop, the narrative positions the protagonist as a business traveller, and thus foregrounds the link between mobility and labour. When the protagonist is on the move, there is often a work-related motive to it: she travels abroad for business and commutes between her London home and work place. 
With its allusions to commuting and international business travel, the novel draws an itinerary of its middle class protagonist. Her class status is conveyed in how she travels. In her diasporic life, she enjoys somewhat banal middle class comfort. Thanks to her British passport, she can travel in Europe as she pleases. When going to work from her London home, she can either use public transport or drive her own car - that it is an old, small Peugeot suggests that she is not interested in showing off her success, unlike many of her fellow Nigerians in the novel. Commuting, often portrayed as an alienating, boring and frustrating form of mobility (Edensor 2011, 189), embodies the idea of Deola Bello's banal, yet relatively comfortable working life, and portrays her as part of the anonymous masses of commuting Londoners whose lives are structured by work. As such, her inter-city mobility stands in a stark contrast to Mabanckou's protagonist's anxious mobility in the Parisian underground network. When back in Lagos with her well-off family, her conditions of mobility undergo an upgrade: she travels in air-conditioned SUVs driven by a chauffeur. It is in Lagos, sitting in the back seat of these relatively luxurious cars, that the protagonist is most aware of her privilege.

It is not only the protagonist's profession that is highlighted in the narrative: whenever her friends or family members feature in the text, attention is quickly drawn to their careers, and their discussions often revolve around work-related issues. Labour, then, plays a central role in defining the characters' ways of being in the world both globally and locally. With the exception of some of her friends working in the creative sector, the protagonist's circle of acquaintances consists of upper middle class people working as doctors and lawyers, or in finance. In this sense, the world of labour in Atta's novel differs drastically from those narrated in Diome's or Mabanckou's novels: like Deola Bello - daughter of a successful Lagosian banker - Atta's characters belong to a group of privileged mobile Africans who cannot be seen as victims of globalisation.

The class status of the protagonist is underlined throughout the narrative. When she meets a man with whom she gets romantically involved, her writer friend Bandele suspects in a tonguein-cheek sort of a way that the man must be 'a doctor, or a lawyer, or an accountant' (Atta 2014, 195). It can be argued that Atta makes a statement with a protagonist so firmly immersed in the upper middle class environment. Deola Bello does not read African literature because she does not recognise her experiences in its 'exotic' (190) imagery, finding it 'preoccupied with politics in a way she never was' (194), and feels that representations of Africa on the television fail to take into account the perspective of middle class Africans. As the narrative voice states, 'What she would give to see a boring old banker going on about capital growth, as they do in Nigeria, just for once. Why not? Don't they exist?' (291). A Bit of Difference brings these experiences directly to centre stage.

Africa in this novel is not necessarily a place to escape from, nor Europe an imagined Eldorado. The text addresses the question of brain drain, but it is not made the key issue of the novel's politics of global mobility. In effect, the narrative questions the importance of the phenomenon by suggesting that 'there are enough brains in Africa' and that resourceful people in Africa 'make the opportunities overseas look like a joke' (119). Despite the fact that the people around the protagonist form a homogenous group in terms of class, she is clearly conscious of how privilege has affected her life. This consciousness is thrown into relief during her travels to Nigeria where the class divide is flagrant. After having lived abroad her entire adulthood, the protagonist pays attention to the fact that she and her family are surrounded by housemaids and chauffeurs. During her stay in Lagos, she notices her brother's chauffeur eating lunch in her mother's garage, and observes: 'She might not have noticed him had she not lived overseas and had the experience of being ignored at work' (176). As these words suggest, the protagonist's experiences as a black African worker in Europe have subjected her to marginalisation. She has 
learned how to adjust her accent in order not to come across as incompetent. Her braids have been deemed 'unprofessional' (211), and once, at her arrival at a bank for an auditing, she was told that 'Deliveries are through the side entrance' (211). These experiences of racist belittlement she discusses with her Nigerian friend Subu who works as an investment banker. Both Deola and Subu seem somewhat resigned to the racial biases of the European work life but lack tools to address these flaws. Moreover, while Deola Bello is now a holder of a British passport, she still cannot allow herself to criticise aloud the border control procedures at an airport because of her skin colour. By drawing attention to such elements of unease, the narrative points out that even the mobilities of privileged African workers are not as unproblematic as one might think. Race and nationality continue to matter in the allegedly borderless global world of labour.

The protagonist's experiences of racial marginalisation have generated a feeling of professional discontent. The beginning of the novel finds Deola working in a charity organisation where she has been for three months, after 'a lacklustre stint' (4) in a consultancy firm, and yet there is no 'indication that she intends to remain here' (25). She wonders why she has 'ended in a dreary office' (27), and considers her career 'banal and unsatisfying' (40). While such feelings could be dismissed as the complaints of a privileged professional who could easily secure a new job, the protagonist's dissatisfaction drives the narrative in the sense that it is one of the reasons that leads her to consider returning to Nigeria. Her professional dissatisfaction, experiences of 'rivalry' (4) and her somewhat erratic work history point at the precarious nature of labour in the global era. It also suggests that there is a 'mismatch between the promise of success [that work is supposed to entail] and the feelings of insecurity', which Connell $(2017,3)$ considers to be one of the main dilemmas of contemporary work life.

As an auditor, who is involved with the financial rather than the humanitarian dimension of the charity industry, the protagonist is painfully conscious of the risk of corruption that charity projects may run. Her particular concern is the bad reputation of Nigeria - she refers to the phenomenon as 'Africa's self-sabotage' (Atta 2014, 218) as it reinforces Western stereotypes of the continent as corrupt. Her position places her in a difficult situation: when she suspects corruption in a Nigerian NGO, she is reluctant to share her suspicions with her Western colleagues as she believes it will feed their stereotypical views and jeopardise the funding of noncorrupt organisations. Deola Bello is suspicious not only of the way in which the charity business represents Africans in a sensationalist, stereotypical light, but also of the very philosophy of the industry grounded on the idea of Africa as 'a charity case' (205). Her growing inability to accept the politics of the organisation she works for - culminating in her superior's dismissal of her suggestion of moving from charity to microcredit - leads her to resign. When she announces her resignation, she tells her managers that she wants to fight the brain drain as she thinks it is what they want to hear. Deola Bello sees her own role in a wider context of global politics and is able to make a choice that is in line with her moral convictions.

Through the figure of Deola Bello, A Bit of Difference gives voice to cosmopolitan ethics. While a privileged mobile position does not automatically lead to a cosmopolitan vision of the world, Deola Bello's experiences as a diasporic African in Europe allow her to adopt a stance informed by cosmopolitan ethics. Her cosmopolitanism is much more than her travels in business class or her being an 'Afropolitan commuter' (Knudsen and Rahbek 2016, 90). Nor is it a mere question of style or a self-congratulatory personal attitude as cosmopolitanism is often defined (Calhoun 2017, 192-193). Instead, this cosmopolitan stance can be observed in the protagonist's critical understanding of her own privileged positionality and her ability to see things from a perspective that is freed from nationalist parochialism (Toivanen 2017, 198-199). Cosmopolitanism is commonly considered a condition of being 'at home in the world'. Yet, critical distance to cultural tokens that lies at the core of cosmopolitanism can be seen to result 
from a certain 'homelessness' that allows one to value and criticise different phenomena from an outsider's perspective. In $A$ Bit of Difference, this critical detachment is paired with a pronounced sense of national belonging and affinity: Deola Bello's strong national identity does not prevent her from criticising the flaws of her society. This criticism and detachment translate into an ironic narrative voice that surfaces in particular when she comments on phenomena that she considers as 'typically Nigerian'. Irony, as Cyrus Patell $(2015,6)$ points out, is a literary strategy that conveys a critical cosmopolitan position by allowing one to place one's feelings of belonging in a global perspective. Cosmopolitan ethics inform Deola Bello's acknowledgement of her responsibility for being part of a global business that bolsters stereotypical images of Africans and reduces them to dependent victims. In this way, the novel places cosmopolitan ethics in the global context of labour. Consequently, Deola Bello's resignation can be read as an ethically and politically motivated gesture that embodies the idea of affluent "cosmopolitans" responsibilities towards those who are more urgently subjected to the unequal effects of globalisation (see Calhoun 2017, 191, 198).

Attention to subjects with political ramifications in contemporary African literatures may not always be as explicit as in texts by previous generations of writers. Atta's and Mabanckou's texts are cases in point: Tais-toi et meurs resorts to the popular genre of thriller, and $A$ Bit of difference refuses to make obvious politically motivated issues such as the brain drain its core agenda. The novels by both Atta and Mabanckou do engage with issues that have political ramifications, but they are far from being political texts. Through the figure of Deola Bello, the criticism $A$ Bit of Difference articulates is multidirectional and subtle, drawing the reader's attention to the complexities informing her position as an African upper middle class professional working in Europe in the charity industry. Mabanckou's novel relies even more on the reader's willingness to read the text politically; the narrative itself does not directly engage in a critique of globalisation because it builds on the protagonist's limited vision of his own situation. When it comes to a political response to exploitation, neither of these works addresses it in the form of social solidarity in the traditional sense. The global underground in Mabanckou's novel is characterised by ruthless competition. The characters form an exploitative community in which there is no room for solidarity, and the global underground milieu they inhabit is totally disconnected from a world in which constructive communal action is possible. In Atta's novel, expressions of solidarity with regard to labour are located within the private sphere; the characters discuss their problems between family and friends. In this way, $A$ Bit of Difference, too, performs the gesture of turning away from politics. Deola's way to fight against the inequalities that she believes her work generates is to resign.

Compared to Atta's and Mabanckou's texts that gesture only indirectly at the political underpinning of labour in the global economy, Diome's more overt political agenda may come across as the expression of a position that has been overtaken by events, especially in Europe. In effect, the contradiction that lies at the heart of Diome's anti-globalisation/-emigration discourse derives in part from the fact that the neat distinctions between the local and the global have become blurred and from the fact that xenophobia is rapidly becoming the new face of anti-globalisation itself. Yet, when it comes to political agency, Diome's novel is equally marked by a gesture of turning away from the domain of politics: resolution to problems related to labour and mobility lies less in social solidarity than in the individual's initiatives and choices. Underprivileged Africans cannot rely on the state in their predicament either locally or in the diaspora, and acts of social solidarity are limited to the private realm. All in all, the novels analysed in this chapter detach the issues of mobility and labour from what is traditionally conceived as the domain of politics. For different reasons, they see no room for political agency and reflect the neoliberal ethos of the global world order. 


\section{Funding acknowledgement}

This project has received funding from the European Union's Horizon 2020 research and innovation programme under Marie Skłodowska-Curie grant agreement No 701238.

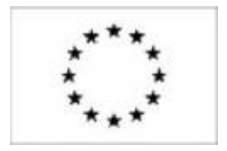

\section{Notes}

1 While increased mobility is one of the characteristics of globalisation, different mobilities have long been a central aspect of both historical and contemporary existence, of urban and non-urban locales, of Western and non-Western experience' (Sheller 2014, 48). Mobility studies is a field whose focus is less on globalisation per se than on the complex intertwinement of different forms of mobility and the ways in which power relations affect and produce (im)mobility (Sheller 2014, 48).

2 English quotes are from The Belly of the Atlantic, translated by Lulu Norman and Ros Schwartz.

3 Tati is a French budget clothing store.

4 Translations from Tais-toi et meurs are mine.

\section{References}

Adenekan, Shola and Helen Cousins. 2014. 'Class Online: Representations of African Middle-Class Identity'. Postcolonial Text 9(3): 1-15.

Atta, Sefi. 2014. A Bit of Difference. London: Fourth Estate.

Bauder, Harald. 2006. Labour Movement: How Migration Regulates Labour Markets. Oxford: Oxford University Press.

Behdad, Ali. 2005. 'On Globalization, Again!' In Postcolonial Studies and Beyond, edited by Ania Loomba et al., 62-79. Durham, NC: Duke University Press.

Calhoun, Craig. 2017. 'A Cosmopolitanism of Connections'. In Cosmopolitanisms, edited by Bruce Robbins and Paolo Lemos Horta, 189-200. New York: New York University Press.

Chikwava, Brian. 2009. Harare North. London: Jonathan Cape.

Cohen, Robin. 2006. Migration and its Enemies: Global Capital, Migrant Labour and the Nation-State. Aldershot: Ashgate.

Coly, Ayo A. 2010. The Pull of Postcolonial Nationhood: Gender and Migration in Francophone African Literatures. Lanham, MD: Lexington.

Connell, Liam. 2017. Precarious Labour and the Contemporary Novel. Basingstoke: Palgrave Macmillan.

Connell, Liam and Nicky Marsh. 2011. 'Introduction'. In Literature and Globalization: A Reader, edited by Liam Connell and Nicky Marsh, xiii-xvi. London: Routledge.

Cresswell, Tim. 2006. On the Move: Mobility in the Modern Western World. New York: Routledge.

Dadié, Bernard B. 1959. Un nègre à Paris. Paris: Présence Africaine.

Dawson, Ashley. 2009. 'The People You Don't See: Representing Informal Labour in Fortress Europe'. ARIEL 40(1): 125-141.

Diome, Fatou. 2003. Le Ventre de l'Atlantique. Paris: Anne Carrière.

Diome, Fatou. 2006. The Belly of the Atlantic. Translated by Lulu Norman and Ros Schwartz. London: Serpent's Tail.

Dongala, Emmanuel. 2010. Photo de groupe au bord du fleuve. Paris: Actes Sud.

Edensor, Tim. 2011. 'Commuter: Mobility, Rhythm and Commuting'. In Geographies of Mobilities: Practices, Spaces, Subjects, edited by Tim Cresswell and Peter Merriman, 189-203. Farnham: Ashgate.

Emecheta, Buchi. 1974. Second Class Citizen. London: Allison \& Busby.

Garnier, Xavier. 2004. 'L'exil lettré de Fatou Diome'. Notre Librairie 155-156: 19-23.

Gikandi, Simon. 2010. 'Between Roots and Routes: Cosmopolitanism and the Claims of Locality'. In Rerouting the Postcolonial: New Directions for the New Millennium, edited by Janet Wilson, Christina Şandru and Sarah Lawson Welsh, 22-35. London: Routledge. 
Ghosh, Nandita. 2012. 'Footloose Labor: Understanding Globalization and Migrancy Through Literature'. WorkingUSA: The Journal of Labor and Society 15: 35-50.

Gurnah, Abdulrazak. 2001. By the Sea. London: Bloomsbury.

Hannam, Kevin, Mimi Sheller and John Urry. 2006. 'Editorial: Mobilities, Immobilities and Moorings'. Mobilities 1(1): 1-22.

Harvey, David. 2005. A Brief History of Neoliberalism. Oxford: Oxford University Press.

Jacquemot, Pierre. 2012. 'Africa's “Middle Class"'. Afrique Contemporaine 244(4): 17-31.

Knudsen, Eva Rask and Ulla Rahbek. 2016. In Search of the Afropolitan: Encounters, Conversations, and Contemporary African Literature. London: Rowman \& Littlefield.

Krishna, Sankaran. 2009. Globalization and Postcolonialism: Hegemony and Resistance in the Twenty-first Century. Lanham, MD: Rowman \& Littlefield.

Loba, Aké. 1960. Kocoumbo, l'étudiant noir. Paris: Flammarion.

Loomba, Ania, Suvir Kaul, Matti Bunzl, Antoinette Burton and Jed Esty. 2005. 'Beyond What? An Introduction'. In Postcolonial Studies and Beyond, edited by Ania Loomba, Suvir Kaul, Matti Bunzl, Antoinette Burton and Jed Esty, 1-38. Durham, NC: Duke University Press.

Mabanckou, Alain. 2012. Tais-toi et meurs. Paris: La Branche.

Malreddy, Pavan Kumar. 2015. 'Introduction'. In Reworking Postcolonialism: Globalization, Labour and Rights, edited by Pavan Kumar Malreddy, Birte Heidemann, Ole Birk Laursen and Janet Wilson, 1-15. Basingstoke: Palgrave Macmillan.

Mbue, Imbolo. 2016. Behold the Dreamers. New York: Random House.

Mezzadra, Sandro and Brett Neilson. 2013. Border as Method, or the Multiplication of Labour. Durham, NC: Duke University Press.

Munck, Ronaldo. 2010. 'Globalization, Migration, and Work: Issues and Perspectives'. LABOUR. Capital and Society 43(1): 156-177.

Nathan, Robert. 2012. 'Moorings and Mythology: Le Ventre de l'Atlantique and the Immigrant Experience'. Journal of African Cultural Studies 24(1): 73-87.

Niang, Mouhamédoul Amine. 2011. 'Croisées narratives ou nouvelle translation du vécu spatial de l'immigré: Le post-épistolaire et le mémoriel dans Le Ventre de l'Atlantique de Fatou Diome'. In Frictions et devenirs dans les écritures migrantes au féminin: Enracinements et renégociations, edited by Anna Rocca and Névine El Nossery, 235-252. Sarrebruck: Editions Universitaires Européennes.

Nyawalo, Mich Yonah. 2011. 'La France inventée en Afrique: Un discours sur l'imaginaire collective'. Journal of the African Literary Association 6(1): 89-103.

O'Brien, Susie and Imre Szeman. 2001. 'Introduction: The Globalization of Fiction/the Fiction of Globalization'. South Atlantic Quarterly 100(3): 603-662.

Otiono, Nduka. 2011. 'Tracking Skilled Diasporas: Globalization, Brain Drain, and the Postcolonial Condition in Nigeria'. Transfers 1(3): 5-23.

Patell, Cyrus R. K. 2015. Cosmopolitanism and the Literary Imagination. New York: Palgrave Macmillan.

Penttinen, Elina. 2008. Globalization, Prostitution and Sex-Trafficking: Corporeal Politics. New York: Routledge.

Primorac, Ranka. 2013. 'Introduction: In/visibility and African Thrillers'. Journal of Postcolonial Writing 49(1): $71-73$.

Sassen, Saskia. 1998. Globalization and Its Discontents: Essays on the New Mobility of People and Money. New York: New Press.

Sembène, Ousmane. 1960. Les bouts de bois de Dieu. Paris: Le Livre Contemporain.

Sembène, Ousmane. 1973. Le docker noir. Paris: Présence Africaine.

Sheller, Mimi. 2014. 'Sociology of the Mobilities Turn'. In The Routledge Handbook of Mobilities, edited by Peter Adey et al., 45-54. London: Routledge.

Standing, Guy. 2014. 'Understanding the Precariat through Labour and Work'. Development and Change 45(5): 963-980. doi:doi:10.1111/dech.12120.

Tesfahuney, Mekonnen. 1998. 'Mobility, Racism and Geopolitics'. Political Geography 17(5): 499-515.

Thomas, Dominic. 2006. Black France: Colonialism, Immigration, and Transnationalism. Bloomington: Indiana University Press.

Toivanen, Anna-Leena. 2017. 'Cosmopolitanism's New Clothes? The Limits of the Concept of Afropolitanism'. European Journal of English Studies 21(2): 189-205. 


\title{
Towards an ethics of the humanitarian imagination
}

\author{
Allison Mackey
}

The writing and reception of literature in human rights contexts relies on a public circulation of affect that divides the world into 'comfort zones' and zones of risk, vulnerability and disposability. Humanitarian narratives about Africa are largely produced for the consumption of English-speaking readers in the global North in the interest of drawing attention to - and garnering support for - efforts to engage in humanitarian relief efforts. Given that at 'any historical moment, only certain stories are tellable and intelligible to a broader audience' (Schaffer and Smith 2004, 32), victims of humanitarian crises often need humanitarian groups to speak for them. Even when personal stories of suffering are called upon to do specific political work within human rights networks, the complexities of self-representation do not always line up easily with the cultural work that these narratives are expected to do in terms of rights discourse. Personal narratives that have been taken up within the field of human rights illustrate a wide variety of writing strategies and goals, and include genres such as testimonio, examples of postcolonial bildungsromane, 'stolen generation' and AIDS memoirs, child soldier and refugee narratives, as well as more recent sites of narration enabled by the use of social media and other digital technologies. In each instance, acts of 'personal storytelling' motivate the 'rights movement' and become the ground for political action and social change (Schaffer and Smith 2004, 3). When storytelling is implicitly linked to human rights claims it is important to consider the consequences and complexities of this pressure to 'represent oneself' (Gilmore 2001, 19) on the world stage. Given that such narratives operate within an already existing economy it is difficult to avoid their absorption into transnational culture industries where they are fetishised as commodities of cultural difference or cultural ambassadors of human suffering. ${ }^{1}$ Keeping in mind the market- and consumer-logics within which these stories tend to circulate, in this chapter I am concerned with identifying what is at stake in iterations of humanitarian narratives about Africa and in how we approach them: what do these kinds of story do for their authors and for their readers?

When it comes to humanitarian narratives about Africa, there is pressure to produce narratives along certain discursive lines in order to make the story available to a particular culture of reader, who in turn comes to the story with pre-formed assumptions about 'Africa' and 'Africanness' (Wainaina 2006). Within the humanitarian imagination, distinctions between legitimate 'victims' worthy of humanitarian sympathy or 'threats' that must be contained through 
increasingly global processes of securitisation, are centred around the notion of vulnerability, mapping vulnerability onto certain bodies rather than others and distributing 'human physical vulnerability' 'across the globe' in 'radically different ways' (Butler 2004, 57). The dominant narrative about Africa - what Manthia Diawara (2010) calls 'humanitarian Tarzanism' and Teju Cole (2012) has called 'the white-savior-industrial complex' - depicts Africans as helpless, voiceless and 'in need of salvation by the West' (Adichie 2008, 44). The media apparatus colludes with humanitarian marketing strategies in order to 'generate a matrix of indistinct stereotypes, prejudices and theoretical elaborations to form a gallery of performances that have now become part of the collective imagination of Western societies' (Musarò 2013, 8). This salvation narrative has been a constitutive element of the humanitarian imagination from its religious to its more secular incarnations, and sometimes clashes - but often meshes easily - with militaristic and economic interventions (Ferguson and Gupta 2002, 993). When reading humanitarian narratives about Africa it is important to ask: whose vulnerability is being referenced? Is it the vulnerability of marginalised subjects whose stories are being marketed and consumed, or the (often paranoid) vulnerability of the privileged subjects who are consuming them? In whose interests do narrative acts constitute or repair intersubjectivity, and what relations of power are at work?

In the interest of exploring the potential role of storytelling as a catalyst for understanding the humanitarian imagination as more than a matter of sympathetic self-projection - or a 'posthumanitarian' response (Chouliaraki 2011, 364) that overwrites the political agency of the writing subject - I look at Chimamanda Ngozi Adichie's novel Half of a Yellow Sun (2006), Dave Eggers' 'fictional autobiography' of Sudanese 'Lost Boy' Valentino Achak Deng, What is the What (2006) and Evelyn Amony's 2015 autobiography I am Evelyn Amony (edited by Erin Baines). I query to what extent the adopted storytelling strategies in these very distinct texts amount to an empowering of the vulnerable subject, such that they are more or less able to exercise political agency under particular conditions. Schaffer and Smith argue that if the "ethic of engagement' with stories within human rights frameworks is 'visceral', it is not enough to stop there: it is important to pay attention to the 'political and relational forces that motivate people's capacity for critical responsiveness to an other' $(2004,232)$. To what extent do the storytelling strategies adopted by each author enable them to move the reader beyond responses based on sympathetic self-projection, and to what degree do they challenge and/or perpetuate 'the existing relations of power between the West and vulnerable others' (Chouliaraki 2011, 364)? Each text signals the problem of circulation and reception of stories by intentionally drawing attention to the complexities of (self)representation. Accordingly, I identify and map some of the strategies that these authors use to side-step or trouble generic and market expectations, and link these strategies to an ethics and politics of telling and consuming tales about and across difference.

These case studies reveal writing and reading in humanitarian contexts to be relational and self-problematising acts. I have deliberately chosen to look at fictional and (more or less loosely) autobiographical texts in order to foreground the distinct questions they raise about market and generic expectations of differently located readers, as well as about the problematic demand for truthful accounts of personal experience. If the question of vulnerability and literary engagement with it is both political and contextual, how do the respective identities of the (co-) authors matter in this context? Both What is the What and I am Evelyn Amony are co-written, creative collaborations between writers/academics of the global North and the African subjects of their narratives. Yet how are we to interpret what seems to be Eggers' 'blackface' (Murphy 2015) appropriation of Deng's voice in order to write a 'true' yet at the same time 'fictional' account of his life, or Baines' editorial decision to frame Amony's personal tale with extensive contextual material? Adichie was born and grew up in Nigeria, but moved to the USA as a 


\section{Allison Mackey}

young woman: how does her position as an Igbo Nigerian whose parents lived through the Biafran war influence questions of ownership of voice and authentic experience in Half of a Yellow Sun? Albeit in different ways and to varying degrees, each text throws into question the relationship between constitutive structures of address, on the one hand, and the way that narrative vulnerability is consumed and contested within the framework of human rights and 'minority' literatures, on the other. Even though they are embedded in and conditioned by a global literary marketplace, these stories are at the same time being deployed in order to mobilise complex political projects of bearing witness across generational, linguistic, epistemological and national divides.

As Joseph Slaughter suggests in his influential study of the role that literary form played in the drafting of the Universal Declaration of Human Rights, "while the tools may not be able to dismantle the master's house, they are useful for prying open its doors and windows' (2007, 315). Despite their inevitable collusion with humanitarian rights regimes and patterns of literary consumption, these narratives also challenge complacent readings in order to draw attention to the acute difficulty 'with speaking and with being heard' (Egan 1999, 120), supporting - as well as testing the limits of - generic conventions and expectations. It is not only a matter of native informants contributing to the consumption of 'authenticity' and neatly packaging it for Western consumption: emphasising local as well as global forms of relationality, they place writers and readers as situated (and implicated) within unequal global cultural, social and economic networks. While the explorations of human rights that occur in these texts can be consumed as spectacles of difference, I argue that they go beyond spectacle in order to make ethical and political demands upon readers.

What is the What is the story of Valentino Achak Deng, a Sudanese 'Lost Boy' who survives war, famine and refugee camp life before being chosen for resettlement in the USA, where he encounters a whole new set of difficulties. Framed as a 'fictional autobiography', the story is written by Dave Eggers, a writer and publisher known for founding the human rights nonprofit 'Voice of Witness'. Taking into account power differentials when it comes to possibilities of political agency, what does it mean when a white man from the suburbs of Chicago appropriates the voice of a young Sudanese refugee in order to construct a 'fictional autobiography' of his life in the generic form of a novel? Lee Siegal (2007) interprets Eggers' act of personification as a form of violence, saying that the 'eerie, slightly sickening quality' about the text is that 'Deng's personhood has been displaced by someone else's style and sensibility - by someone else's story. Deng survived his would-be killers in the Sudan, only to have his identity erased here.' However, I suggest that Eggers' fictionalisation of Deng's life story does more than just exploit Deng's vulnerable social location by allowing a tension in the text between making the story available to readers and forestalling its easy consumption. Specifically, the text flags the problematic circulation and reception of stories of trauma by drawing attention to the pressure to produce narratives along certain discursive lines, simultaneously invoking and evoking the "crisis of truth' (Felman and Laub 1992, 6) in contemporary autobiography and eliciting uncomfortable or even perplexed responses from readers. True and not true, it purposefully draws attention to the difficulty of truth-telling in human rights contexts and raises important questions about the market demand for personalistic accounts of vulnerability and suffering.

The importance placed on testimony when it comes to advancing human rights claims through personal narratives signals a more general problem of life writing: that is, the often messy distinction between truth and fiction. In genres of testimony, the expectation is for an individual writer or speaker to present the reader with authentic experience, yet a deliberate playfulness when it comes to 'truth' in What is the What critically draws the reader's awareness to his or her own fascination with and desire for true stories about suffering others. In the Preface, 
Deng tells the reader that the novel is born out of his desire to let the world 'know the whole truth of my existence' (xiii), and there are para-textual inclusions, such as a map of the region where Deng's experiences take place, that lend an aura of historical authenticity. At the same time, from the outset the reader is invited to doubt the veracity of the story: the seemingly oxymoronic subtitle on the front cover reads: 'The Autobiography of Valentino Achak Deng: a Novel'. Deng says that 'it should be known to the readers that I was very young when some of the events in the book took place, and as a result we simply had to pronounce What is the What a novel', even though 'all of the major events in the book are true ... I told Dave what I know and what I could remember, and from that material he created this work of art' (xiv). Collaborative life writing is not new, but while such narratives challenge official generic expectations by straddling the boundary between autobiography and biography, unlike What is the What they do not at the same time claim to be fictional. How can this book be 'the soulful account' of Deng's life (xiii) and at the same time be a work of fiction? What happens when 'memory and imagination combine to form a historical record' (Gilmore 2001, 47), especially when the 'memory' belongs to one person and the 'imagination' to another? Since the 'culture of the individual, the belief in the individual's uniqueness and unique story, and his or her individual rights, has gained international currency' (Schaffer and Smith 2004, 24), what happens when the 'self is deliberately fashioned by a 'not-self? Especially given the tendency for 'survivors' to 'tell the stories the sympathetic want' (Eggers 2006, 21), perhaps it is important to keep in mind that the 'demands that trauma and the self make upon each other might require alternative forms through which to represent both' (Gilmore 2001, 143). Precisely what is at stake when (auto) biography becomes a kind of cross-cultural project that bears multiple witness?

What is the What casts suspicion on the Western valuation of objective, personalistic and factdriven truth by emphasising relational structures of address. Through the narrative deployment of second-person voice, in particular, the text can be read as an extended meditation on what Adriana Cavarero calls the 'language of the you' (2000, 92). From 'TV Boy' - 'Have you seen the beginning of a war? Picture your neighbourhood, and now see the women screaming, the babies tossed into wells. Watch your brothers explode. I want you there with me' (Eggers 2006, 73) - to Julian the nurse, to the photographed faces of the (more-or-less) well intentioned members of the fitness club where he works, Valentino's 'you' wanders from person to person, searching for someone who will hear him. His attempts to find an interlocutor constitute a 'creative act of establishing witness' (Felman and Laub 1992, 87), yet even 'You have no ears for someone like me' (Eggers 2006, 142). Like his plea to the 'Christian neighbours', who in Valentino's mind will 'feel the guilt in knowing that they could have done something sooner had they only been listening' (162), what is being demanded of readers is more than just empathy: unable to ignore the web of global relations, readers participate in the larger community of what Slaughter calls the 'implicated reader' (2007, 292). Valentino has survived the Sudanese war in order to step into another (albeit less obvious) state of war and abandonment: the neoliberal state that turns against its most vulnerable residents, most notably youth of colour. Far from the prototypical immigrant narrative of happy assimilation and able appropriation of the American dream, his relocation to the USA places him within already existing (if unnamed) racially configured relationships, of which the reader - and (co-)writer - also form a part.

Siegal (2007) suggests that Eggers is the 'sincere young father of post-postmodern half-irony call it sincerony'. Beyond what Lilie Chouliaraki understands to be a 'post-humanitarian' response (2011, 364), I suggest that irony in What is the What functions as a way of sneaking past generic border patrols and stereotypical readings, 'signposting' that which is 'culturally occluded' (Chambers 2004, 37). The implicated reader is thus 'smuggled into the conversation' (21) in an indirect - but still unsettling - form of critique. For example, Valentino expresses confusion 


\section{Allison Mackey}

about Western cultural behaviour like the world's reaction to the death of Princess Diana, the 'taste for TV', the thoughtless circulation of 'superficial pleasantries' and the indignation of Atlanta fitness club members who are 'determined to work out' but 'cannot do it on the timetable they have planned' (Eggers 2006, 259, 467, 504, 503). An ambiguity of (auto)biographical tone means that the reader is not sure whether to read these moments as earnest or ironic: is Valentino genuinely confused about this behaviour, or is Eggers purposively staging his confusion in order to defamiliarise audiences about what is being taken for granted? Whose voice are we meant to be paying attention to here, Deng's, Eggers' or both simultaneously? As a strategy of indirection, irony allows for such ambiguities to remain in play and invites a more nuanced second reading of the story (as something beyond the expected performance of refugee gratitude). The reader is compelled to see his or her geographical and/or epistemological position reflected critically, and the assumed priority and 'goodness' of the values of this position are significantly displaced. By transforming the generic merger of fiction and memoir, the text bears witness to the reader's own unknowing, uncertainty or even willful refusal, by pointing to new contexts that shift older registers of truth, transparency or value.

Resonating with Butler's suggestion that giving an account of oneself is always directed toward an 'addressee' who 'might receive the story and in receiving, alter it some', representing the 'prospect that the story might be given back in a new form, that fragments might be linked in some way, that some part of opacity might be brought to light' $(2005,80)$, Eggers acts as interlocutor, patiently listening to a story that has been told to him over a period of several years. But he is also the teller and shaper of the tale, putting Deng's story into words for him and offering them back to him in a new way. And as a novelist, he is also offering these words to us as readers on behalf of them both. In the last paragraph of the novel, the wandering 'you' shifts one last time:

Whatever I do, however I find a way to live, I will tell these stories ... I speak to these people, I speak to you because I cannot help it ... How can I pretend that you do not exist? It would almost be as impossible as you pretending that I do not exist.

(Eggers 2006, 535)

Rather than wonder who is the 'who' of the narrative voice (Eggers or Deng), the reader is encouraged to consider who is the 'you'. In the final paragraph this 'you' has finally settled on you, on me, on us as readers. This is not only the story of Deng, or even of Eggers' relation to him: this is also the story of humanitarian imagination's readerly (ir)responsibility. In seeking to rhetorically unsettle complacent readings by breaking down generic expectations, the narrative invokes the Sudanese community while at the same time refusing to allow the larger community of implicated readers off the hook. Direct questions - like why 'every international body that monitors or provides for the displaced, customarily place their refugees in the least desirable regions on earth' (Eggers 2006, 454) - remain unanswered, inviting readers to critically reconsider contemporary global processes that occur in the name of humanitarianism. The novel does not lose sight of the unequal relationship of each party to dispossession and/or vulnerability. It is not a question of getting rid of conflict or tension, but of deliberately gesturing toward it in indirect yet insistent ways. While personal narratives provide 'avenues for empathy' (Felman and Laub 1992, 6) there are no guarantees about how such stories might be taken up by individual readers. ${ }^{2}$ Refusing to occupy a reified space of political agency or resistance, the collaborative space that is being created between Eggers and Deng equally has the potential to miss its mark.

Chimamanda Ngozi Adichie's Half of a Yellow Sun alternates between historical periods, before, during and immediately following the Biafran war (1967-1970). The story is 
interspersed with eight fragments of a book in progress and is told in the third person voice from the perspective of three different protagonists, inviting readers to identify, however imperfectly, with Richard (a British writer), Olanna (a Nigerian academic) and Ugwu (a rural houseboy) simultaneously. Resonating with Wainana's advice about 'how [not] to write about Africa', even though the novel is set during the war and all major narrative events are directly related to it, the reader is made aware of historical details only obliquely, since public events are filtered through the daily and affective lives of the protagonists. An English writer who travels to Africa in order to write a book about Igbo art, Richard functions as 'a marker for how colonial epistemology constructs and shapes Africa as an object for consumption' (Novak 2008, 40). The epistemological violence of colonialism is especially explored in the shifting nature of Richard and Ugwu's relationship to one another and in the relationship that they each have to the act of writing.

The novel challenges readerly presumptions about the knowing subject versus epistemological object by problematising ownership of voice and agency, especially in the circumstances surrounding the production of the metafictional book-within-the-book. Throughout the novel, readers are led to believe that the fragments of writing that are interspersed in the novel are being written by Richard, since they usually appear in sections of the story being told from his perspective, their detached tone is markedly different from that of the rest of the narrative, and each one begins with an action verb attached to a male pronoun: 'He recounts ...' (Adichie 2006, 103), 'he discusses ..' (146), 'he writes ...' (195), 'he argues' (256). At dinner parties before the war, Richard 'come[s] into the kitchen to ask Ugwu questions', mining him for information about his village, and jotting 'his answers down in a small book with a leather cover' (109). When Richard condescendingly asks Ugwu 'What are you writing now?', Ugwu answers, 'A small thing, sah' (508). It is not until the very last line of the novel that readers find out that the 'small thing' that Ugwu has been 'scribbling' will, in fact, 'be part of a big book' $(495,530)$. By the end of the novel there has been a complete transfer of author/ity (understood as both authority and authorship) from Richard to Ugwu. Our surprise upon realising that the 'he' or active writing agent has been Ugwu all along places us in a similar position to Richard; however, as readers we are invited to move beyond being 'amused' about Ugwu's 'ambition' (495) in order to question our surprised response, not to mention what this reveals about our own preconceived assumptions about writerly authority.

When Ugwu takes 'the sheets of paper from Mr. Richard' (531) he also (re-)appropriates his book title: The World Was Silent When We Died. Ugwu's seventh fragment is a poem about how Western media plays into and perpetuates consumable images of suffering, alluding to the way that media photographs of starving children in Biafra sparked unprecedented global concern that transformed the Biafran War into the epitome of humanitarian crisis in the Western imagination. The poem parallels a central scene in the novel where 'two American journalists' snap photographs of children suffering from severe malnutrition while exclaiming, 'that's a lovely smile!' (464). The title of the poem mirrors the title of the metafictional manuscript, but is presented in the form of a question: 'Were You Silent When We Died?' The titular 'You' serves as counterpart to the 'We' in the book title and, like the second-person address in What is the What, directly implicates readers: 'You needn't imagine. There were photos / Displayed in gloss-filled pages of your Life. / Did you see? Did you feel sorry briefly. / Then turn around to hold your lover or wife?' (470). Formulated as a question, the title of the poem reverses relations of epistemological vulnerability: turning the tables, so to speak, the reader is caught out as 'voyeur', and is invited to take responsibility for his or her own response - or lack thereof. It is not enough to know about the suffering of others, or indulge in sympathetic acts of imaginative projection that would make 'oneself a surrogate victim who has a right to the victim's voice or 


\section{Allison Mackey}

subject position' (Novak 2008, 78). The reader as 'addressee' is encouraged to 'move beyond an empathic response that relies on identification with the victim' (78) and recognise global patterns of vulnerability and responsibility.

A series of losses reduce Richard to a mere 'shadow' of himself (Adichie 2006, 537) by the end of the novel. Tortured by uncertainty regarding his place in Biafra (not to mention the 'we' of his failed book) Richard eventually admits: 'the war is not my story to tell, really' (530). How does Richard's resignation to the passivity of the 'voyeur' (211) square with the possibility of regenerating a humanitarian imagination, beyond sympathetic self-projection or a throw-upyour-hands kind of cynical relativism, in the face of real human rights abuses? Read alongside the transfer of author/ity in the novel, Richard's citation of Rimbaud's 'I is someone else' (386) might be a clue that, more than a resignation to passivity in the face of unimaginable suffering, Richard's renunciation might be understood as an act of vulnerability that resonates with Butler's call for an emergence of an ethics 'based on our shared, and invariable, partial blindness about ourselves' $(2005,27)$. Richard's dwindling selfhood portends an ethics of a passive, non-emphatic ego grounded not on the concrete foundations of an 'I', but on being responseable - that is, quite simply, able to respond to others. ${ }^{3}$

By stepping aside as he does, Richard makes room for Ugwu to tell the story of the war from the perspective of the disenfranchised. Eleni Coundouriotis suggests that Ugwu's 'identity as a servant, which he never seems to outgrow, troubles Adichie's vision of a people's history' because the 'fragments' of the book that he is writing are written in a 'derivative' tone, instead of reflecting the alternative to colonial history he is supposed to be writing (2014, 232). This mimicry of tone might at least in part be due to technical constraints (that is, the need to tease the reader into thinking the writer is Richard until the very last moment). But perhaps viewing the fragments as a series of attempts to change the way history is written can help us to understand Ugwu's 'people's history' as not a failure, necessarily, but as a work-in-progress: Ugwu 'would never be able to depict the very bleakness of bombing hungry people. But he tried' (Adichie 2006, 498). Ugwu's decision to adopt the role of storyteller constitutes a reparative act of relational witnessing, given that the 'earnestness of his interest' when Olanna recounts her traumatic experience on the train 'suddenly made her story important, made it serve a larger purpose that even she was not sure of (512). Taking ownership for telling the story of the war, Ugwu takes on a much bigger 'ambition' than Richard originally gives him credit for.

At the level of textual production, by choosing a rural house boy to be the writer of the story Adichie is, like Richard, stepping aside and 'relinquishing her position as narrative authority in favor of a spokesman for the voiceless - which she does not claim to be' (Bryce 2008, 62). The implicit alignment between the (African) writer of the novel and the (white, Western) writer in the novel draws attention to the fact that, when it comes to voice, vulnerability and power in global literary relations, subject positions are never straightforward. Since 'nobody taught [her] about the war in school', Adichie says that her aim is to educate Nigerians of her generation about 'their history and ask questions of that history' in order to 'at least make it possible for us to collectively acknowledge what happened' (2008, 53). In crafting this polyvocal narrative, Adichie takes on the imaginative, ethical and political task of the second-generation storyteller, drawing attention to fundamental questions about voice and experience when it comes to telling difficult stories.

I am Evelyn Amony: Reclaiming My Life from the Lord's Resistance Army is the first-person account of life within the Lord's Resistance Army from the perspective of a young girl who was abducted by the LRA at the age of eleven and spent almost as many years as forced wife to Joseph Kony and mother to his children. Like What is the What, the text is a collaboratively 
produced narrative, although its engagement with questions of testimony and ownership of voice is markedly distinct. In the Editor's Introduction, Erin Baines recognises that a 'distinct disjuncture between those who respond to crisis and those who have lived through it warps what is written and known', and admits that - as a Western academic - she is herself 'part of the problematic reproduction of knowledge' (Amony 2015, Kindle Locations 236-237). Baines is well aware that she wields considerable editorial power over Amony's story by framing the deeply personal tale with extensive contextual and historical material, presumably in order to make the story available to readers from differing cultural contexts, and makes a concerted effort to allow Amony's narrative and unique voice to 'stand on its own'. One of the most interesting aspects of the production of this text is the fact that Baines gave Evelyn a digital recorder so that she could keep an audio diary at home, which she did for ten months in 2009-2010. Baines had access to a written 'text' to edit only after the stories had been transcribed and then translated into English.

In the recordings, Amony reclaims the identity that was taken away from her during the war by beginning each audio entry with the words: 'I am Evelyn Amony.' Baines underscores Evelyn's political agency by suggesting that she 'asserts herself as a subject of history, not the object of it', and that her storytelling exposes the 'fissures, disjunctures, and false truths in dominant narratives of the war by revealing the lives that exist within history and claiming the right to retell it' (Amony 2015, Kindle Locations 268-269). Baines and Stewart emphasise the importance of informal storytelling sessions within storytelling orientated cultures, since 'sometimes the story itself is the act through which people work through social tensions, misperceptions, discrimination and injustice' and might be 'just as important as pursuing formal justice goals' (2011, 260). If being compelled to speak of trauma can be felt as a form of epistemological violence, then it is important to find 'culturally safe and relevant' spaces from which to tell such stories (261). In contrast to formal storytelling venues (like trials or truth commissions) in Baines' narrative methodology researchers are not present during the sessions to direct the questioning, which means that women are free to choose to tell the stories that are most 'relevant to them' (261).

Baines tells readers that she 'critically questioned [her] own role in the production of metanarratives on the war' in the editing process (Amony 2015, Kindle Location 226), and actively strove to avoid perpetuating popular narratives about the LRA in general (and Joseph Kony in particular). This is not to say that there is no evidence of shaping in order to impose a kind of narrative coherence: the ample contextual material at the beginning and end of the book frames Evelyn's story in significant ways. This material is there to aid readers as they navigate the text, but it also inevitably steers readings in certain directions. The transition (and translation) from oral to written document also poses unique challenges, even though this process took place 'in consultation with Evelyn'. Well aware of the complexities of translation 'as a form of intervention in the text' Baines explains: 'we wanted the book to be written in English to make it accessible to all Ugandans, where English is the official language and is commonly shared across the linguistically diverse country' (Amony 2015, Kindle Location 299). Here she implies that the book is not intended primarily for Western readers even though it is translated from Evelyn's original Acholi into English, challenging presumptions about the production of academic texts for consumption in spaces of relative safety and privilege. However, as a Canadian academic whose research was conducted with assistance from major funding bodies, making sure the book could be published in English would surely have been an additional consideration. Ultimately, Baines admits that they were 'unable' to completely 'solve' these complexities, but that she merely wishes to 'bring' them 'to the reader's attention'.

The inclusion of an interview with Evelyn allows her to clarify her own personal and political reasons for wanting to produce this book: on one hand, Evelyn's storytelling is directed 


\section{Allison Mackey}

towards her family, including her own daughters. Since she 'cannot just tell them' what happened, she takes advantage of the mediating function of the text in order to communicate stories that are 'too heartbreaking' or 'difficult' to tell them orally. On the other hand, her stories are directed to the members of a community in which she struggles to find her place after reintegration: 'everything that I do, people say that I am Kony's wife ... Why do they look at me? Why do they talk so much about me?' (Amony 2015, Kindle Location 3005). Through the process of re-membering her experiences of the war, Amony is at the same time restoring, through re-storying, her place within her local community. She defends her moral integrity as an Acholi woman and repeatedly tries to counter narratives that have been imposed on her as a 'survivor', insisting that she is not to be blamed while at the same time refusing to be cast in the role of passive victim. She details the reasoning and tactical agency behind her decisions and actions, while at the same time reminding her readers of the constraints of the alternate moral space of war. One of her most impassioned anecdotes tells of being lured back to Kony after eight months in a rehabilitation centre with the false promise of finding her lost daughter: 'It was never our wish to rejoin Kony!' she insists, countering the dominant view at the time that was even held by her own mother. Implicitly addressing the popular suspicion that abductees sympathise with the armed group if they do not attempt escape, at various points in her narrative Evelyn gives detailed tactical reasons for not attempting to do so. ${ }^{5}$

Through her stories, Evelyn renegotiates 'her subject positions as a mother, wife, and ultimately a woman in Acholi society in the face of the stigma that implied otherwise' (Baines and Stewart 2011, 255). After leaving the LRA she puts herself in a place of moral authority by willingly accepting her position as Kony's 'favourite' wife and visiting his homeland to advocate on behalf of his other wives and children. At the same time, she minimises her own culpability by maintaining a certain distance from Kony: the event of her capture by the Ugandan military in 2005, just ten days after the birth of her third daughter, is re-framed in her narrative as an 'escape'. Whether or not this choice of wording is a result of selective translation or selective memory, this episode is narrated in conjunction with her expressions of frustration about people viewing her as 'Kony's wife', and thus can be read as an attempt to regain moral ground within the community. As a storyteller, Amony 'positions herself and her story in relation to the opinions and mores around her', and it is 'precisely in this relational act that her story becomes political as facts and information are secondary to the critical understanding expressed as a "provocative and principled story" (Disch in Baines and Stewart 2011, 259).

Baines' editorial and/or political motivations do not always line up with Evelyn's. In the Introduction, she tells readers that her aim is to 'better understand the experience of women forced into motherhood and the challenges of life after their return' from the bush. Given the dearth of testimonies from a woman's perspective, Evelyn's story 'contributes to the making of an historical archive on her country and attends to truths about women and war as only a firsthand witness can' (Amony 2015, Kindle Location 120). Baines' aim is to hit upon a more collective kind of narrative truth - above and beyond any one individual story - revealing a tension between individual and 'universal' experience. This tension is especially fraught since, given her relatively privileged position vis-à-vis the leader of the LRA, Amony is far from a typical abductee or child soldier. This ambiguity of perspective is compounded by the ambiguity of intended audience that I mentioned earlier: Baines suggests that Evelyn's story challenges 'readers to comprehend that to which they did not bear witness' and 'begs' them 'to suspend judgement for a time ... to listen differently, to unlearn and think anew' (Kindle Location 383). But who are the 'readers' that Baines is referring to? Is she talking exclusively about family, community members and Ugandans in general (as stated in the Introduction and in the interview with Evelyn), or can we assume that Western readers are also contemplated in 
the process of editing of the text? This ambiguity can be glimpsed when an ironic tone, similar to that in What is the What, emerges, like when Evelyn ponders why people only seem to care about the disappearance of the Aboke girls (an incident that garnered considerable Western media attention). At the same time, in a diary entry about International Women's Day, Evelyn seemingly chastises the behaviour of other women in her community. These are moments when an uncertainty regarding intended audience tugs at the margins of the text. By foregrounding Evelyn's voice and deliberately allowing (and even encouraging) ambiguities of voice and audience to remain in play, the kind of 'activist framing' that would enfold 'the narrative within the individualist, humanist and secular frameworks of Western rights, overwriting the customs and beliefs of the victims' (Schaffer and Smith 2004, 17) is at least partially elided, leaving I Am Evelyn Amony vulnerable to multiple interpretations.

Within the field of transitional justice, the personal stories that survivors tell in public forums are expected to conform to standards of historical and factual accuracy. Baines deflects the kind of accusations that have been levelled at other life narratives by telling readers in the Introduction that she 'did not edit for details that had no supporting evidence, nor did I seek to verify dates or facts', because 'to focus on the historical accuracy of her account would miss the point of this powerful personal history of the war' (Amony 2015, Kindle Location 303). Baines is aware of the importance of foregrounding Evelyn's personal voice and individual story despite her aim to allow a more universal truth to emerge, just as Evelyn 'also found courage from listening to other women who narrate their stories' (Kindle Location 178). Indeed, the power of Amony's storytelling is felt in the way she searches for not only 'truth (the facts of what happened)' but also for a universal notion of "truthfulness" (what these events mean)' (Baines and Stewart 2011, 260). Pointing away from the inadequacy of universally applied Western frameworks and toward other ways of telling and healing, this is precisely the kind of truth value that Baines and Amony are attempting to draw out in their collaborative project of informally re-storying the war. As an epigraph to Amony's tale, Baines chooses a poem by Juliane Okot Bitek: 'Here, take these words. Catch the whirlwind in your palm. Rest a bit with me ... you can sit by me and hold me up as I let the torrents out.' Storytelling in I Am Evelyn Amony can be understood as something other than an individual act of confession, artistic expression or one person's privatised tale of trauma or healing: it is also a communal, collaborative, world-making enterprise. As a way of claiming political agency, this kind of storytelling can be seen as a political act of 'social repair' and as a 'locally based practice of justice making' (Baines and Stewart 2011, 257, 247).

The texts I have examined in this chapter engage deliberately with storytelling in human rights contexts as relational acts of political agency. The shaping of each of these narratives (fictional and non-fictional) foregrounds collectivity rather than individuality, challenging the primacy of the 'authentic' subject as central to storytelling - from the negotiation of voice and audience in Baines and Amony's collaboratively produced testimony, to Richard's (and Adichie's) stepping aside to make room for Ugwu in Half of a Yellow Sun, to Eggers' enactment of his own kind of ethical disappearing act in the collaborative production of What is the What. ${ }^{6}$ In a neoliberal market that is hungry for narratives of personalistic suffering, it is important to ask: what is 'risked and gained by deposing' the 'sovereignty' (Schaffer and Smith 2004, 21) of the autonomous self? As both a process of stepping aside and of stepping into, collaborative writing strategies such as these extend beyond the writing process, since readers also form an integral part of this synergistic relationship.

By drawing attention to acts of writing (and not writing) as gestures of possession and dispossession, these texts invite readers to question the generic and cultural expectations that structure our readings. While many narratives mask their inherent contradictions in the interest 


\section{Allison Mackey}

of the important work they are meant to do in the field of human rights, the texts that I look at here employ rhetorical strategies that allow such contradictions to remain in play, participating in - while at the same time challenging - generic and market expectations. Above all, these narratives invite questions about the unequal meanings of vulnerability and dispossession in acutely unjust geopolitical contexts. It is not only a matter of whose stories are told, who tells them, when and how (and when and how we read them) but it is also about recognising and accepting the constitutive relationship between storytellers and readers as agents within the same global market. This would include an awareness of one's own (linguistic, geopolitical) place within international economic, cultural and political constellations, as well as of the reality of unequal access to publishing industries.

Pointing toward hierarchies of vulnerability and imagination, the act of writing constitutes a site of conflict, tension and also of hope. Encouraging a productive (if unsettling) kind of friction between conflicting responsibilities and identifications, narratives like these can potentially contribute to a regeneration of the humanitarian imagination by encouraging readers to move past visceral reactions and pay attention to the 'political and relational forces that motivate people's capacity for critical responsiveness to an other' (Schaffer and Smith 2004, 232). It is the task of readers to do the important work of recognising the structural patterns behind the scenes of humanitarian 'emergencies' while at the same time listening for the voices of real human beings, deserving of dignity, to emerge. Self-reflexive engagements with these kinds of question can inform how we read tales of suffering and humanitarian 'crises', while keeping the geopolitics of both imagination and vulnerability in mind.

\section{Notes}

1 Achebe famously suggested that since it is 'arguable whether we can truly know anything which we have not personally experienced', the imagination gives us the 'closest approximation to experience that we are ever likely to get' $(1998,145)$. However, according to Barnard, the kind of 'empathetic globalization' championed by the Oprah Winfrey Book Club phenomenon, for example, 'is far too closely tied to a therapeutic feel-good mode of consumption to be ethical in any serious sense' $(2006,5)$. In many cases, the reading of such narratives becomes a matter of individual consumer choice, and choice itself - including the books one chooses to read or the websites one visits - is in turn promoted and understood as a form of humanitarian activism.

2 Read in this light, the irony in the above passage comes even more sharply into focus: even though Valentino proclaims that 'you pretending that I do not exist' would be 'impossible', the events of the narrative illustrate that many people (perhaps even readers of this novel) do in fact go about their lives pretending that people like him do not exist.

3 Richard's role in Ugwu's rebirth as a writer is likened to that of a midwife when he ferries Ugwu through 'an unending journey in a car' not to his death, as Ugwu initially wonders, but back to life (Adichie 2006, 494).

4 In a process that took over a year, Baines edited 'stories for verb tense and sentence structure, while attempting to retain Evelyn's narrative voice'. She strives to communicate moments when Evelyn's narrative becomes 'less comprehensible or sounded detached' due to trauma, as well as trying to communicate 'oral pauses, sighs, and dramatic intonations', but recognises that she was largely unsuccessful: 'if storytelling reveals meaning, then we were limited in our ability to fully translate the emotional weight of each story as it was intended while spoken' (Amony 2015, Kindle Location 291).

5 Even while insisting that her agency was heavily circumscribed, Evelyn recounts small acts of resistance and disobedience during her time with the LRA. Evelyn's characterisation of her relationship with Kony is complex and ambivalently rendered in her narrative: in her stories, she alternately stands up to, protects, lies to and cleverly manipulates him for her own benefit.

6 When asked in an interview about the decision to write this book in the form of a 'fictional autobiography', Eggers replies: 'Valentino's voice is so distinct and unforgettable that any other authorial voice would pale by comparison. Very early on, when the book was in a more straightforward authorial 
voice, I missed the voice I was hearing on the tapes. So writing in Val's voice solved both problems: I could disappear completely, and the reader would have the benefit of his very distinct voice' ('Interview' 2014).

\section{Works cited}

Achebe, Chinua. 1998. Hopes and Impediments: Selected Essays. New York: Anchor Books.

Adichie, Chimamanda Ngozi. 2006. Half of a Yellow Sun. New York: Anchor Books.

Adichie, Chimamanda Ngozi. 2008. 'African "Authenticity” and the Biafran Experience'. Transition 99: 42-53.

Amony, Evelyn. 2015. I am Evelyn Amony: Reclaiming My Life from the Lord's Resistance Army. Edited and with an Introduction by Erin Baines. Madison: University of Wisconsin Press. Kindle Edition.

Baines, Erin and Beth Stewart. 2011.“'I Cannot Accept What I Have Not Done”: Storytelling, Gender and Transitional Justice'. Journal of Human Rights Practice 3(3): 245-263.

Barnard, Rita. 2006. 'Oprah's Paton, or South Africa and the Globalization of Suffering'. Safundi: The Journal of South African and American Studies 7(3):1-21.

Bryce, Jane. 2008. "Half and Half Children": Third-Generation Women Writers and the New Nigerian Novel'. Research in African Literatures 39(2): 49-67.

Butler, Judith. 2004. Precarious Life: The Powers of Mourning and Violence. London: Verso.

Butler, Judith. 2005. Giving an Account of Oneself. New York: Fordham University Press. Cavarero, Adriana. 2000. Relating Narratives: Storytelling and Selfhood. New York: Routledge.

Chambers, Ross. 2004. Untimely Interventions: AIDS Writing, Testimonial, and the Rhetoric of Haunting. Ann Arbor: University of Michigan Press.

Chouliaraki, Lilie. 2011. “Improper Distance”: Towards a Critical Account of Solidarity as Irony'. International Journal of Cultural Studies 14: 363-381.

Cole, Teju. 2012. 'The White-Savior Industrial Complex'. The Atlantic, 21 March.

Coundouriotis, Eleni. 2014. The People's Right to the Novel: War Fiction in the Postcolony. New York: Fordham University Press.

Diawara, Manthia. 2010. African Film. Munich: Prestel.

Egan, Susanna. 1999. Mirror Talk: Genres of Crisis in Contemporary Autobiography. Chapel Hill: University of North Carolina Press.

Eggers, Dave. 2006. What is the What: The Autobiography of Valentino Achak Deng, a Novel. New York: Random House.

Felman, Shoshana and Dori Laub. 1992. Testimony: Crises of Witnessing in Literature, Psychoanalysis and History. New York: Routledge.

Ferguson, James and Akhil Gupta. 2002. 'Spatializing States: Toward an Ethnography of Neoliberal Governmentality’. American Ethnologist 29(4): 981-1002.

Gilmore, Leigh. 2001. The Limits of Autobiography: Trauma and Testimony. Ithaca, NY: Cornell University Press.

Interview with Dave Eggers and Valentino Achak Deng. 2014. VADfoundation.org. www.vadfoundation. org/interview-with-the-creators/.

Murphy, Laura. 2015. 'Blackface Abolition and the New Slave Narrative'. Cambridge Journal of Postcolonial Literary Inquiry 2(1): 93-113.

Musarò, Pierluigi. 2013. “Africans” vs. "Europeans”: Humanitarian Narratives and the Moral Geography of the World'. P. Musarò and P. Parmiggiani, eds, Sociologia della Comunicazione 45: 37-59.

Novak, Amy. 2008. 'Who Speaks? Who Listens?: The Problem of Address in Two Nigerian Trauma Novels'. Studies in the Novel 40(1\&2): 31-51.

Schaffer, Kay and Sidonie Smith. 2004. Human Rights and Narrated Lives: The Ethics of Recognition. New York: Palgrave.

Siegal, Lee. 2007. “'The Niceness Racket”. Review of Dave Eggers's What is the What'. The New Republic Online. Thursday 23 April. https://newrepublic.com/article/62544/the-niceness-racket.

Slaughter, Joseph. 2007. Human Rights, Inc: The World Novel, Narrative Form and International Law. New York: Fordham University Press.

Smith, Sidonie and Julia Watson. 2001. Reading Autobiography: A Guide for Interpreting Life Narratives. Minneapolis: University of Minnesota Press.

Wainaina, Binyavanga. 2006. 'How to Write about Africa'. Granta 92: The View from Africa. https://granta. com/how-to-write-about-africa/. 


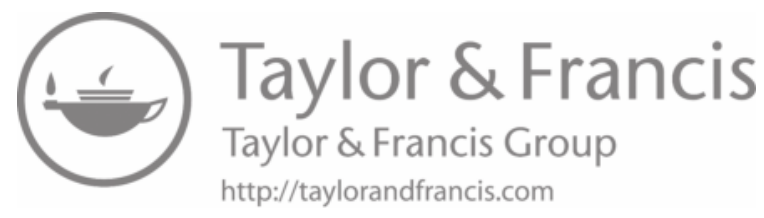


Part II

Journeys, Geographies, Identities 


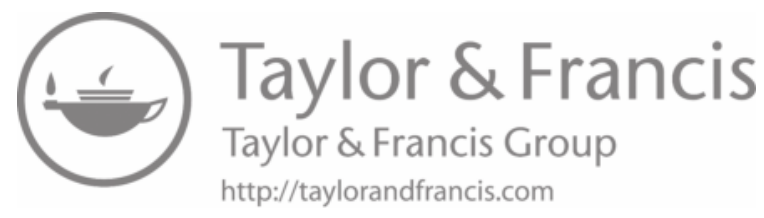




\section{Decolonising the Afropolitan Intra-African migrations in post-2000 literature}

Rebecca Fasselt

Studies on migration in Africa have repeatedly debunked the myth of an 'African exodus' to the West, emphasising the complex nature of migration into and out of Africa and the prevalence of intra-continental movements. Narrative engagement with intra-continental migration and cross-border lives is not a new phenomenon in African writing. Literary scholarship, however, has, over the past decades, predominantly focused on migratory movements from the Global South to the North and inter-continental return narratives to Africa. Negotiations of migrant subjectivities within the continent, while not entirely dissimilar, exhibit visible differences from those in the context of South-North movements. Whereas migrants' Africanness in the West is often positioned as a marker of racial, cultural and religious otherness, migrant characters in narratives of cross-African migration frequently mobilise African identity to negotiate inclusion and assert belonging. Reading three texts from different regions published after 2000, I demonstrate that contemporary African authors reposition current debates on national belonging, gender, ethnicity, indigeneity, transnationalism and Afropolitanism in the context of intracontinental movements. The chapter addresses multifaceted forms of intra-continental migration such as 'voluntary' and 'forced', while being wary of totalising categories and of the porous boundaries between different forms of migration.

The first part of the chapter analyses Leila Aboulela's historical novel Lyrics Alley (2010) set in pre-independence Sudan in the early 1950s. Focusing on the author's portrayal of the conflictual relationship between Sudan and Egypt (one of Sudan's colonisers), I suggest that Aboulela's text departs from conventional narrations of pre-independence resistance. Her protagonists partake in the nation-building process not primarily in response to the British colonial centre, but from the position of leading trans-border lives between Sudan and Egypt. I then read Unexpected Joy at Dawn (2004) by Ghanaian novelist, poet and playwright Alex AgyeiAgyiri as an example of forced migration and repatriation in the context of the Ghanaian Aliens Compliance Order of 1969 and the Nigerian Aliens Expulsion Order of 1983. The novel, I argue, dramatises the tension between nationhood and continental unity in the post-independence era, while at the same time defying narrow ethnic and national boundaries by constituting its characters as transnational African subjects. Binyavanga Wainaina's literary memoir One Day I Will Write About This Place (2011), spanning East and Southern African geographies, subverts common assumptions about African migration by primarily relating intra-continental movement 
to family and the pursuit of higher education rather than political conflict. Straddling different geographies and foregrounding diverse forms of intra-African migration, these texts critique the quasi-universality of the South-North migration axis alongside Afropolitan discourse in critical scholarship. In doing so, they forge new trajectories outside old centre-periphery relations for the study of contemporary African migration fiction.

\section{Introduction: re-framing the 'migrant novel'}

In a futuristic, satirical inversion of world power relations depicted in Abdourahman A. Waberi's 2009 (2006) novel In the United States of Africa (Aux Etats Unis d'Afrique), Africa is imagined as a 'continent of light', dominating global politics and blatantly exploiting destitute migrants from Euro-America. Waberi's dystopia not only satirises contemporary exclusionary migration regimes of states in the Global North, but through its hierarchical reversal of dominant South-North migratory patterns also foregrounds the role of African countries as host nations: 'Today even more than yesterday, our African lands attract all kinds of people crushed by poverty: trollops with their feet powdered by the dust of exodus, opponents of their regimes with a ruined conscience' (Waberi 2009, 15). It is in this way that the novel's parodic futurist positioning of Africa as an abusive host to the world's poor also, even if subliminally, exposes blatant incongruences between media discourse on Africa's 'exodus' to the West and statistics that reveal African countries as receiving nations of large migrant and refugee populations. Unveiling media biases, the novel, notwithstanding its predominant focus on binary inversion, subjects to derisive critique the purported uni-directionality of contemporary world migration to the West. It thus calls for an examination of alternative modes of migration obfuscated in critical scholarship that largely focuses on the South-North pattern.

Migration in literary criticism on contemporary migrant writing is, albeit with minor exceptions, by default assumed to follow a route from the continent to the West, a trajectory that has become the fulcrum of these texts' post-nationalist, transnational imaginaries. Focusing on subSaharan African writers in the West, Tanure Ojaide notes that 'African writers have become part of the world-wide phenomena of migration and globalization with the attendant physical, sociocultural, psychic, and other forms of dislocation' (2008, 43). Migration and transnationality have thus become the defining vectors of so-called third generation African writing or what Carole Boyce Davies (2016) terms 'the Post-Colonial/Diasporic Chimamanda Adichie Moment'. In contrast to engagements with cultural nationalism and postcolonial disillusionment in the writing of their literary predecessors, these authors, Ogaga Okuyade observes, 'seem more versatile in their thematic preoccupations and more global in their vision and style, especially in their exploration of issues like transnationality, migration, exile, war, and cultural revitalization' (2013: 7). The controversial figure of the Afropolitan, much maligned for its 'elitism/class bias', 'a-politicalness' and 'commodification' (Gehrmann 2016, 62), has become emblematic of the post-millennial 'migrant novel' by African writers. Responding to a recent debate on African literature in the post-global age, Pius Adesanmi argues that:

What the post-global really did was to create the possibility of easy assumptions on the part of the twenty-first-century African writer and critic. Such easy assumptions as the idea that narratives of origins have been overcome and cosmopolitanism is the only basis through which the African must engage the rest of the world. The itinerant, well-heeled African writer and critic, circulating in the capitals of the global north, the rootless cultural mongrel of Taiye Selasie's [sic] 'Bye-bye Barbar,' became the iconic embodiment of the mobilizing power of diaspora, immigrant, global mobilities, hybridity, heterogeneity, and every other 
identity interpellation that is cast as antipodal to 'the Africa of the [s]ixties' or 'the Africa of Makerere and the language debate.'

In a critique of the generational model and assumed uniform characteristics of third generation writing that orbit around the itinerant Afropolitan in the North, Madhu Krishnan similarly warns that these models tend to preclude other, more ex-centric, narratives that fall outside the 'fossilization of a centre-periphery model of reading' (2017, 152). More nuanced readings, she advocates, would 'consider the nodal networks and overlapping, sometimes partial, matrices that pulsate across the landscape of African literary production' (152). This crucial point pertains with equal force to the indiscriminately labelled 'migrant writer' or 'migrant writing'.

While earlier studies of African migrant fiction privilege writers living in or writing about the diaspora in the US and the UK in the Anglophone, and France in the Francophone context, more recent scholarship has begun to study works by African migrant writers in more 'marginal' European geographies, or 'new Euro-African literary spaces' (Bekers et al. 2009), such as Spain, Italy, the Netherlands, Belgium, Finland, Sweden and Germany, and in languages other than English and French (López 2008; Portelli 2006; Thomas 2014; Van Deventer and Thomas 2011). This growing body of scholarship on Afropean literature, while aware of the intricacies and problematics inherent in such an overarching approach 'given the plurality and heterogeneity within [Afropean literature]' (Brancato 2008, 4), seems a useful analytic category inasmuch as it highlights diverse migratory routes that undermine traditional conceptions of centre/ periphery and provides a larger comparative canvas within which to study migrant fictions in various languages.

Another area of focus has been return migration to the African continent, a narrative trend which has, despite a noticeable rootedness of scholarly accounts on these in domineering postnationalist frameworks, resulted in a restructuring and destabilisation of centre/periphery dichotomies. Reconfiguring the predominantly male figure of the 'been-to' in novels by earlier generations of African writers such as Chinua Achebe (1994 [1960]), Wole Soyinka (1970 [1965]), Tayeb Salih (1969 [1966]) and Ayi Kwei Armah (1969), and later feminist revisions thereof by Ama Ata Aidoo (1994 [1977]) and Buchi Emecheta (1994), more recent texts by authors such as Doreen Baingana (2005), Teju Cole (2007), Sefi Atta (2012), Taiye Selasi (2013), Chimamanda Ngozi Adichie (2013) and Yvonne Adhiambo Owuor (2013) probe the position of the continent as 'originary home' in the imaginaries of their 'global citizen' protagonists. Even if the purview of these texts remains fixed, with the exception of Owuor's Dust (2013), on North-South movements, they cast a more critical light at the idea of a rootless, hybrid post-national migrant subject. As Helen Cousins and Pauline Dodgson-Katiyo posit, 'for much contemporary African literature a return home is still fundamentally important' (2016, 8). ${ }^{1}$ Rather than figuring return migration to the African continent through the prism of mythical reconnection with a shared past and the attainment of identitarian certainty, these novels complicate 'the idea of Africa' (Mudimbe 1994) through narrative self-reflexivity and a foregrounding of the anxiety of the returnee. In these re-conceptualisations of 'Africa's centrality' (Rushton 2017, 48), 'Africa emerges as a series of diverse cultural spaces' (Knudsen and Rahbek 2017, 126) defying singular narratives of the continent.

While migratory movements to and from the West still remain pivotal in literary and cultural migration studies, critics have more recently embarked on studying African mobilities to and connections with the socialist East during the continent's decolonisation struggles in the context of the emerging field of Cold War literary studies (Popescu 2010) and South America or the South Atlantic (Bystrom 2012). South-South movements between the continent and Asia have 
garnered most critical attention in the burgeoning field of Indian Ocean Studies (Bose and Manjapra 2010; Frenkel 2011; Hofmeyr 2015; Hofmeyr and Williams 2011; Ojwang 2013; Samuelson 2010). Critical questions here relate to the ways in which understandings of Africa are reconfigured 'if we read its long history as an encounter not only with the West but also with the East' (Desai 2016, 6). It is in this sense that these alternative migratory trajectories and Southern transnationalisms contribute to the recognition of the irreducibility of migration novels to a single, South-North trajectory.

Migration within the African continent, by contrast, has largely remained outside the critical conversation in African literary studies. Migration scholarship in the social sciences, however, has, for some time, challenged the narrow theoretical focus on South-North migration patterns that assumes, 'implicitly if not explicitly, a developing-to-developed migration path' (Nawyn 2016, 165), and pointed out the need for 'theories of migration that more fully encapsulate all human movement across borders' (Nawyn 2016, 165). ${ }^{2}$ As Loren B. Landau and Oliver Bakewell remind us, 'millions of people's lives across the continent are shaped by aspirations and interactions that are more decidedly local' $(2018,3)$. These studies emphasise the 'diversity of African migration' (Flahaux and de Haas 2016, 2; Whitaker 2017), while at the same time highlighting that most African migrants move to other African countries. Critics have also questioned 'the implicit assumption that African migration is "exceptional" and essentially different from migration elsewhere' by drawing attention to the fact that 'most Africans migrate for family, work or study' (Flahaux and de Haas 2016, 2).

The preoccupation with intra-African migration is, of course, not a recent phenomenon in African literature, but has been one of its longstanding, inherent characteristics (Asaah 2007; Crush 1995) featured in works by Ama Ata Aidoo, Mariama Bâ, Modikwe Dikobe, Nuruddin Farah, Nadine Gordimer, Ahmadou Kourouma, Es'kia Mphahlele, Lewis Nkosi, Sol Plaatje and Ousmane Sembène. My intention here is to examine intra-African migration in a number of post-2000 texts to challenge universalising tendencies of the Western-centred migrant novel in contemporary scholarly readings and inscribe the study of literature and migration onto a larger, pluriversal map. ${ }^{3}$ For, as Sydoine Moudouma Moudouma contends, '[i]ntra-African migrations differ from inter-continental movements not only in the nature of boundaries that migrants cross but also in how these boundaries are defined from historical, racial, individual, as well as ethnic standpoints' $(2013,76)$. In order to move beyond the universalising impulses of figurations of the African migrant or the Afropolitan, I attempt to provide a decolonial reading ${ }^{4}$ of the migrant figure informed by the 'project of de-linking' that undergirds Walter D. Mignolo's understanding of the 'decolonial shift' $(2007,452)$. This invites us to consider further paths across a more differentiated terrain of pluriversal migration and Afropolitanism, including other narratives and geographies that co-exist with, re-work, and challenge the South-North axis. Approaching intra-African migration from diverse angles, the selected works by Leila Aboulela, Alex Agyei-Agyiri and Binyavanga Wainaina offer new vocabularies for reading migration narratives from a decolonial point of view.

\section{Pluriversal migration narratives}

Sudanese-Egyptian diasporic writer Leila Aboulela has in recent years become a prominent voice in African migrant writing. What seems most remarkable about Aboulela's fictional praxis, according to Tina Steiner, 'is that [her] [...] women characters, who are triply marginalized by being African, Muslim and female, do not succumb to the pressures of assimilation. On the contrary, Aboulela writes revisionist fiction, in which women negotiate migration on their own terms' $(2008$, 8). Shirin Edwin highlights that Aboulela's work is deeply grounded in an Islamic 
feminism that makes visible the quotidian, 'personal and emotional dimensions of an individual's behavior and actions in the enactment of her faith aspects' $(2013,60)$, rather than presenting narratives of a 'culture clash' between Islamic doctrine and Western liberalism as some critics have argued (Ghazoul 2001; Hassan 2008).

In contrast to her earlier works, The Translator (1999), Coloured Lights (2001) and Minaret (2005), which engage with the more common South-North migration axis, the plot of her third novel Lyrics Alley is set mainly in Africa. Set in the year 1953 at the dawn of Sudan's independence from the Anglo-Egyptian condominium, the novel focuses on the trans-border travel and migration of the Abuzeid family between Egypt and Sudan. The novel features two migrant characters from Egypt, Nabilah, the second wife of the successful, cosmopolitan Sudanese businessman Mahmoud Abuzeid and his son's teacher Ustaz Badr, who have settled more permanently in Sudan, as well as back and forth movement of several members of the Abuzeid family between the two countries for the reasons of family visits, travel and education.

The relationship between Sudan and Egypt, as most characters in the novel suggest, echoes Egypt's dual position as a colonised coloniser. As Alessandra Rizzo writes:

Sudan and Egypt [in the novel] represent a dual vision of Africa: two locations, geographically belonging to the same continent but enormously distant in terms of culture, language, elegance, and landscape. Indeed, the constant and dominant clash in Lyrics Alley is not between Sudan and the British Empire, but rather between Sudan and Egypt, between Sudanese and Egyptian women.

$(2012,150)$

For Nabilah 'the Sudan was like the bottom of the sea, an exotic wilderness, soporific and away from the momentum of history' (Aboulela 2012, 24), an 'untamed land' (25), a 'primitive', 'African adventure' (84) and 'a province of Egypt', the 'metropolitan centre' (38). The novel's focus on cross-border relations and movements between Egypt and Sudan as well as Britain thus triangulates the predominantly binary framework of the coloniser-colonised relationship in postcolonial studies. In A Different Shade of Colonialism, Eve M. Troutt Powell highlights 'the underlying centrality of slavery in the historical relationship between Egypt and Sudan' (2003, 219) - Sudan served as a source of slaves for Egypt until the end of the nineteenth century and Egyptians' subsequent engagement 'in a discourse of stereotypes and fantasies about the Sudan specifically and Africa in general, [was] a discourse that paralleled Orientalist imagery' (10).

The conflictual relationship between Sudan and Egypt is expressed in Aboulela's novel through the figuration of Abuzeid's two wives as national allegories of the two nations, the illiterate, 'traditional' Sudanese Hajjah Waheeba and the 'modern', educated Egyptian Nabilah. Most scholarly discussions of the novel contend that this contrast is dismantled as the narrative progresses through the trajectories of the main focalisers, Mahmoud Abuzeid, his son Nur, his niece Soraya, Nabilah and Ustaz Badr, who become 'cultural translators/migrants attempting to reconcile the modern and the authentic, the secular and the sacred, and the foreign and the native' (Abdel Wahab 2014, 230). In contrast to these readings, I argue that Aboulela also uses her characters, especially Nur and Hajjah Waheeba, to highlight how African migrant subjects can live in and move between what Harry Garuba refers to as 'two discursive and symbolic orders' $(2015,22)$ in his discussion of 'postcolonial modernity and normalisation' (16) in Chinua Achebe's Arrow of God. ${ }^{5}$ Moreover, a closer look at the portrayal of Aboulela's characters also reveals the author's critique of hegemonic discourses on hybridity in Afropolitan migrant fiction. 
Before a swimming accident that leaves Nur permanently disabled, Mahmoud perceives his son, who is educated at the prestigious Victoria College in Alexandria, as a promising heir to the family business. Largely confined to his mother's hoash after the accident, Nur begins to suffer from depression. But the writing and success of his poetry allow him to find a renewed sense of meaning and self-worth. His poem 'Travel is the Cause', in which he expresses his personal grief about his disability, is adapted into song by a popular musician and the lines, "[i]n you, Egypt, are the causes of my injury. And in Sudan my burden and solace' (Aboulela 2012, 221), are later appropriated by the Sudanese independence movement against Anglo-Egyptian rule. Contrasting with his earlier poetry, 'imitations of grand words striving awkwardly to rhyme', this poem is a 'mix of Sudanese colloquial and classic Arabic, a fusion of formal language and common everyday words [...] The words are from inside him, his flesh and blood, his own peculiar situation' (221). According to Lipenga (2018, 101, 103), Nur's poetry presents 'attempts to harmonize' the dichotomous spaces inhabited by his father's two wives, while also serving as an 'anthem of patriotism' that at the same time undermines 'the "effeminacy" that others ascribed to Nur's literary efforts'. However, rather than casting Nur as a 'hybrid' figure, Aboulela, I suggest, seems to foreground his doubleness, his participation in both discourses of cosmopolitan worldliness and cultural nationalism. Nur's worldliness, given his studies at a colonial institution in Alexandria as well as his mastery of classical Arabic, however, provides a different template for worldliness to that of the contemporary Afropolitan migrant. It reveals the limits of Afropolitanism's dual premise of being of Africa and of the world by dramatising Nur's relationship to Egypt, a colonised coloniser. At home in Umdurman, Nur moves within a different set of norms that are located in a growing rhetoric of cultural nationalism. When asked by an admirer of his poetry whether one of his poems is referencing a specific location on the Nile, Nur confirms that it is the Riviera Park in Umdurman, but also thinks to himself: 'How can one pinpoint a particular scene, a single place? The poem came from far beyond and deep within' (Aboulela 2012, 302). It is Nur's simultaneous participation in the contradictory discourses of Sudanese cultural nationalism, illustrated here by his confirmation of rootedness, and cosmopolitan worldliness critical of the singularity of places that allows him to carve out an enabling space for himself after his accident. Introducing this coeval dynamic (see Garuba 2015), the novel offers an alternative model to post-nationalist conceptualisations of migrant characters.

A celebratory elevation of the hybrid migrant figure is visible in most critical accounts that juxtapose inter-cultural retranslation to a second worldview with Hajjah Waheeba at its centre. Marked by tradition, the latter is 'deeply rooted in the parochial norms of [the characters'] provincial society and culture and strongly reluctant to welcome the cultural transformations of modern retranslations' (Abdel Wahab 2014, 230). Throughout, Hajjah Waheeba is read as 'conservative' (Rizzo 2012, 177), 'a staunch believer in Sudanese traditions and customs, including female circumcision' (Awad 2014, 79), and a 'patriarchal mother' whose illiteracy sharply contrasts with the voracious reading appetite of her niece Soraya (Abdel Wahab 2014, 238). Migration and travel here become the main signifiers of a renewed connectivity between the two countries, progressing from Egypt's negation of Africanness, as expressed in Nabilah's initial views, toward a reconciling hybridity that embraces the traditional and the modern. Like unreflective employments of 'tradition' and 'modernity', these readings seem caught in 'the conceptual teleology and binarist hierarchies of the transition narrative, which compels us to $\mathrm{read} /$ write the histories of so-called Third World societies in terms of a lack that is only rectified by an "orderly" progression toward modernity and modernization' (Garuba 2003, 262).

Waheeba's character, I suggest, needs to be read outside these strictures to establish more fully Aboulela's rewriting of the traditional migrant novel. In contrast to the frequent travels of the other Abuzeid family members for the purposes of work, holidays, family visits and education, 
Waheeba's relationship to travel is linked to her 'backwardness'. After Nur's swimming accident Waheeba travels from Umdurman to the hospital in Alexandria. The narrative voice notes that she:

came straight from the train station, her tobe incongruous in this most cosmopolitan of cities. She threw herself on Nur's bed and made a scene. Fatma and Halima had to restrain her while Mahmoud turned his back in disgust and stared out at the sea. [...] She had never left Sudan, except for the time she went to Mecca and returned a Hajjah. Now she was traumatised as much by the journey as by the cause of it. At the end, after she had worked herself into a state, slapping her face and gnashing her teeth, he managed to get a nurse to give her a sedative.

(Aboulela 2012, 105)

Within the purview of modernity embraced by Mahmoud, who acts as a focaliser here, other, non-Western, scripts for coping with grief such as Waheeba's face slapping is rendered as an incomprehensible 'scene'. Moreover, Mahmoud's conception of travel in the passage, echoed by critical accounts on the novel, establishes a hierarchy of mobility in which travel as cultural negotiation is juxtaposed to religious travel as a less valued form of cultural consolidation.

But Waheeba, like Aboulela's earlier characters, negotiates her identity within the pressurising environment of the Abuzeid home without adapting to what her husband and Nabilah conceive of as a 'modern lifestyle'. While Nabilah associates religious practice 'with the rural lower classes', 'the poor and uneducated' (283), Waheeba's religious practice is not so much a marker of her obsequious adherence to an 'unshifting tradition', but rather serves her, to draw on Saba Mahmood's work, 'as a means of organizing daily life' (2005, 44). She steps outside simple objectification by adopting so-called 'traditional' practices as means of resistance and is the first family member encouraging Nur to break away from constricting notions of masculinity that forbid him to show his pain openly. One may hold it against the author that Waheeba's perspective is silenced throughout the narrative. Yet Aboulela at the same time uses Waheeba to question the value-laden, hierarchic organisation of mobilities that tend to structure the cosmopolitan mobilities paradigm.

In contrast to Lyrics Alley, Alex Agyei-Agyiri's Unexpected Joy at Dawn is set in the postindependence era. It centres on the trans-border lives of the siblings Nii Tackie and Mama Orojo of Nigerian parentage, who grow up in Ghana until the enactment of the 1969 Alien Compliance Order under Ghanaian Prime Minister Kofi Abrefa Busia, 'which led to a mass expulsion of about 200,000 migrants, mainly from Nigeria, Togo, Burkina Faso and Niger' (Flahaux and de Haas 2016, 12). Mama Orojo and her parents are deported to Nigeria, but leave Nii behind in Ghana. Facing economic hardship in Accra where he works as an assistant bank manager, Nii travels to Nigeria fourteen years later in search of his sister who is now a successful entrepreneur in the Lagos suburb Ijase, but is confronted upon his arrival with a deportation order directing over one million Ghanaians and immigrants from other West African countries to leave Nigeria within two weeks.

Echoing earlier narratives of postcolonial disillusionment, Agyei-Agyiri's novel dramatises, to draw on Sabelo Ndlovu-Gatsheni's work on nationalism in postcolonial Africa, the 'metamorphoses and mutations if not degeneration of African nationalism from its celebrated civic principles, predicated on the slogan of "diverse people unite" into narrow, autochthonous, nativist and xenophobic forms that breed violence and conflict' (Ndlovu-Gatsheni 2013, 61). Unexpected Joy at Dawn adds the angle of intra-continental migration and displacement to the multifaceted expressions of disenchantment with the postcolonial nation state in seminal texts such as Ayi Kwei Armah's The Beautyful Ones Are Not Yet Born (2003 [1968]) in which images of dirt, 
bodily decay, disease and conspicuous consumption feature prominently as metaphors for the failures of post-independence politics and economics (Innes 1995, 1). While the re-articulation of belonging is portrayed as a constitutive element of postcolonial Ghana and Nigeria as well as of the continent at large in Agyei-Agyiri's novel, the close interweaving of the two narrative strands set in Accra and Lagos respectively as well as the constant shifts in focalisation between Nii and Mama demonstrate the novel's bold declaration of the indivisibility of the two spaces. Paralleling the deportations from both nations, Agyei-Agyiri's narrative, as Mawuli Adjei notes, 'bring $[\mathrm{s}]$ into question the whole concept of Pan-African unity and identity' $(2004,326)$, but at the same time reads as a plea for trans-African solidarity.

Narrow definitions of belonging along the lines of autochthony are ridiculed in a passage focalised through Nii that expresses his fear of 'an indigenization programme in Ghana'. $\mathrm{He}$ realises that neither his Ghanaian upbringing and name, nor his '[b]lackness' would shield him from deportation from Ghana, given his Yoruba 'tribal marks' (Agyei-Agyiri 2004, 25). Ironically, when facing Nigerian immigration officials, these do not make his claim to Nigerian citizenship acceptable either. Deprived of unequivocal belonging in either state by the practice of 'un-African, unconscionable law' (151), Nii painfully experiences the flipside of the Afropolitan's global mobility, and expresses a strong desire for belonging that straddles the boundaries of both Ghana and Nigeria.

Contrasted to this closed space of the nation are extensive references to pan-Africanism throughout the novel. Before Nii decides to leave Ghana, he bemoans the decay and closure of Kantamanto market, one of the most diverse spaces in Accra, which 'gave expression to African unity' (38). He reminisces:

One could, standing at one spot, sample the diverse races and tribes in Africa and Asia. The onion trade was the monopoly of the Gao from Mali; the Yoruba, who were known as Anago, sold dawadawa and the very best smoked mudfish, beads and animal - sometimes, they say, human - parts. Sometimes they sold fresh and dried fish and Anago or Alata soap. The Syrian and Lebanese stores overlooked the streets. The Zabrama ran a lucrative textile business. The Ibo controlled secondhand clothing.

While Adjei (2004) and Moudouma Moudouma (2013, 148) read this portrayal of the market space as a celebration of pan-Africanism and Africanity, I suggest that it rather invokes the idea of a 'decolonial' Afropolitanism given the traders' migrations from various countries of the Global South. Against the background of the continent's longstanding history of multidirectional mobilities, Mbembe $(2007,27)$ redirects the geographical South-North focus of more popular understandings of Afropolitanism. He notes:

it is not simply that a part of African history lies somewhere else, outside Africa. It is also that a history of the rest of the world [...] is present on the continent. Our way of belonging to the world $[\ldots]$ has always been marked by $[\ldots]$ the interweaving of worlds.

(2007, 28)

In contrast to 'the dominant Anglophone [theorisations] of Afropolitanism', Hicham Gourgem suggests, 'Mbembe adds the dimension of decolonization' to engagements with the Afropolitan, 'provid[ing] an account of modernity that subverts the Eurocentric logic of human history by showing that beside the European centre there stands another non-European one' (2017, 297). This sense of Africa's indivisibility from world history and its entanglements through intra- and 
cross-continental movement strongly surfaces in Nii's description of the market, which, moreover, 'gave a common base to the rich and the poor alike and successfully wiped away tribal barriers' (Agyei-Agyiri 2004, 39). This is not an Afropolitanism of the elite, but one that articulates a decolonial vision in which monotonous and uniform discourses of transnationality are disbanded in an attempt to make visible 'the multiple worlds that make up the pluriverse' (Escobar 1995, xxxiii).

At the same time, a strong sense of loss emerges from Nii's description of the market. The narrative voice mentions that the 'Kantamanto market was no more being used' and 'had become one of the things in the country being talked about in the past tense - like old Makola market and revolutions' (Agyei-Agyiri 2004, 37). In South-North migration fiction, migrants' melancholic condition is frequently addressed in relation to race (Cheng 2001). Nii's postindependence melancholia can unquestionably be located in his traumatic separation from his family, but it equally gestures to the loss of his vision of intra-continental connectivity, the cornerstone of Nkrumah's early promises to Ghanaians and Africans. Walking along the market's broken walls, Nii 'listed other "past tenses". He remembered a few important market women who dealt in used clothing' (Agyei-Agyiri 2004, 37). Badly cracked and overgrown with weeds, the market's walls, as Moudouma Moudouma suggests, come to 'represent one of many examples of the disintegration of the early Pan-African ethic of togetherness and nonexclusive citizenship' (2013, 148). But Nii's dwelling on the 'past tenses' and careful reconstruction of his memories of the market also express his refusal to abandon this ethic.

In her work on melancholia in the African American context, Sara Kaplan (2007) shows how diasporic melancholia can become an active practice of resistance. Through his focus on intraAfrican migration between Ghana and Nigeria in the 1960s and 1980s, Agyei-Agyiri re-routes these conceptualisations of melancholia to vocalise his protagonist's interminable grief for the ideal of continental unity, demonstrating the need for historical and regional specificity and warning against the dangers of a delocalised set of generic traits that can be applied uniformly to migrant fiction from across the globe. Yet similar to Kaplan's diasporic melancholia as a collective practice, 'in which the individual places herself in reciprocal relationship with a larger imagined and remembered collective, a broader history of losses yet-to-be-answered-for' (2007, 516), the novel proffers a version of post-independence melancholia that is grounded in the collective vision for a free and united continent.

Towards the end of the novel, Nii is detained with a number of 'non-Nigerian aliens' in a detention camp near the airport in Lagos. It is in this episode of abject dehumanisation that the detainees' strategic assertion of their Africanness becomes a tool of active resistance to the state's deportation orders. Nii and his friend Aaron cut themselves on their hands and use their blood to write the words '[h]ere we plant the African Unity flag' on a sheet of paper (Agyei-Agyiri 2004, 282). While the flag 'appeared faint and insignificant' (282), Nii's subsequent, even if somewhat didactic, tirade transforms it into a token of memory and pride: "We're holding it between us [...] in memory of those who are already dead in the course of the struggle for African Unity"' (282-283). In this context of collective resistance to the Nigerian immigration regime and, by extension, the existence of intra-African borders, embodied memory and past suffering also produce new communities of protest in the sense of Kaplan's understanding of melancholia that, unlike the unspeakable grief of the Freudian melancholic subject, allows for the articulation of grievance. The protesters' Africanness is utilised as an assertion of humanity in Nii's speech:

'A sense of love for your country is a sense of pride. Pride is an improved ego, which is not hateful. Look around, watch the people round about you. Same people same reaction to 
pain. Race is important but being human elevates one above all base acts of hatred. We should not allow hatred to destroy this our unique humanity.'

The notion of a 'unique humanity', it appears, arises directly from this assertion of a shared Africanness, in which Nii's and Aaron's blood symbolises the blood lost by those propagating continental unity rather than narrow national affiliations. At this moment of crisis, togetherness is articulated not through an Afropolitan ethic, but the elevation of the African unity flag. A more essentialist performance and invocation of Africanness, untainted by constricting definitions of citizenship, here becomes a means of protest against the myopic politics of indigeneity arising from increasingly exclusionist conceptualisations of Africanness in the postcolonial nation state.

Later on in the novel, Mama Ojoro, who has travelled to Ghana in search of her brother, returns home where she reunites, in a deus ex machina ending, with Nii who has escaped from the detention camp. While this final family reunion appears improbable and contrived, the narrative deliberatively seems to draw on the conventions of melodrama. For Nii the reconnection with his sister 'was like heaven opening for the first time in one's life time and one's rush $[\ldots]$ to embrace it and get lost in its ethereal fold before it disappeared', '[s]heer melodrama' (316). And the narrative voice notes that Mama 'was reaping an unexpected joy at dawn' (317). The conscious deployment of melodramatic devices for Agyei-Agyiri becomes the only means to end his novel on a more hopeful note. Yet the self-reflexive mode coupled with the melancholic strand that permeates the narrative all the more visibly reveal the constructedness and futility of this dream. Despite 'multiple cases of explicit ideological and moral intrusions' (Asaah 2007, 9), the author uses melodrama as a powerful rhetorical strategy to express his belief in a shared Africanness that transcends the private idyll.

In contrast to Aboulela's and Agyei-Agyiri's fictional engagements with intra-African migration, Binyavanga Wainaina's One Day I Will Write About This Place examines the subject from the angle of a literary memoir. Building on his Caine Prize-winning short story 'Discovering Home' (2001), the narrative chronicles Wainaina's trans-continental travels from Kenya to South Africa and Uganda for the purposes of tertiary education and family visits, and to a number of other African countries for various journalistic assignments. According to Grace Musila, Wainaina, born in 1971, belongs to the 'Redykyulass Generation', a new generation of intellectuals, writers and performers who consistently challenge 'manifestations of conservative geronto-masculine attitudes in Kenyan public life' (2010, 295). Critics have noted that this critique of older generations extends to his preoccupation with identity and migration that 'supports a more unanchored sense of identity than the one celebrated in earlier East African writing' (Mwangi 2007, 174). Yet his memoir demonstrates the significance of both roots and routes to his coming of age, challenging any straightforward demarcation between his writing and that of earlier generations.

The text, moreover, undermines common assumptions about African migration by primarily relating intra-continental movement to family and study rather than political conflict. In this sense, Wainaina rewrites the common African migration story about ' $[\mathrm{t}]$ he Starving African, who wanders the refugee camp nearly naked, and waits for the benevolence of the West', who has 'no past' and only speaks about her '(unspeakable) suffering' $(2005,93)$ that he satirises in 'How to Write about Africa'. This is not to say, however, that Wainaina negates the importance of other forms of intra-continental movement. Several of his childhood memories, even if from the safe space of his middle class home in Nakuru, aptly capture the experiences of individual forced migrants and refugees from other East African countries, specifically those 
'running to Kenya from Amin' $(2011,13)$. At the same time, his family's cross- and intercontinental movements also highlight the difficulty of neatly distinguishing between different forms of migration and categories of migrants, however not without demonstrating an awareness of asymmetries in contemporary mobility regimes. ${ }^{6}$

Like Agyei-Agyiri's novel in the West African context, Wainaina recounts the exclusionary, nationalist rhetoric in the East Africa of his childhood. His Ugandan-born mother frequently has to endure the xenophobic tirades of the coffee house owner next to her hair salon in Nakuru: 'You Ugandans spoiled your country - why do you want to come here and spoil ours?' (18). And the young Binyavanga frequently witnesses discrimination against Somali immigrants in public places (75). Countering these exclusionist articulations of identity and belonging, Wainaina asserts the multiple histories that have informed his family history: 'We are mixed-up people. We have mixed-up ways of naming too: the Anglo-colonial way, the old Gikuyu way, then the distant names from my mother's land, a place we do not know' (21). Crucial to note in this context, however, is that Wainaina's memoir does not succumb to a set of simple dichotomies between a celebratory hybridity of the migrant subject on one hand and stultifying, parochial identifications on the other.

A far more critical stance on these hierarchical oppositions emerges from Wainaina's most striking neologism in the text, kimay, a word that the child narrator first uses to describe what then appears to his ears as a cacophonous sound of people singing and playing musical instruments at President Jomo Kenyatta's funeral:

In school we were taught that all music comes from eight sounds [...] but what those people are singing and playing cannot fit those sounds. Gibberish. [...] all those gathered harambee sounds of people in the many costumes of Kenya, singing and dancing on no choir, many unrelated sounds and languages and styles and costumes, and facial expressions. They have nothing to do with each other. Ki-may. This is my new word, my secret. [...] It calls at the most unexpected moment. [...] I can speak English. I can speak Kiswahili. Ki-may is any language that I cannot speak, but I hear every day in Nakuru.

This passage illustrates on the one hand Wainaina's fascination with 'the linguistic or aesthetic that foregrounds his childish imagination and confused consciousness within the political' (Knighton 2014, 39). But, on the other, it also points toward his feeling of alienation within the plurilingual postcolonial nation. In Knighton's view, 'Wainaina's major political focus within his memoir is his stress on national unity in the face of ethnic division' (43). This point seems to be implicit in his revision of kimay at the end of the memoir as 'people talking without words, exact languages, the guitar sounds of Kenya speaking Kenya's languages. If kimay brought me uncertainty, it was because I simply lacked the imagination to think that such a feat was possible' (Wainaina 2011, 253).

Yet this richly imagined polyvocality not only extends to the Kenyan nation, but also moves beyond its borders to other geographies of the continent. While narrating the violent fissures of the postcolonial Kenyan nation most visible in the narrative's account of the post-election violence in 2007, Wainaina is equally concerned with the ways in which his trans-continental travels inform his coming of age. Kimay, therefore, becomes associated moreover with the music of other African countries, such as 'Congo music, with wayward voices as thick as honey' (33).

Kimay foregrounds, while refusing to resolve, the contradictions and multiplicities of the continent that cannot, as Wainaina shows in 'How to Write About Africa', be accommodated in a single image or narrative. 'Africa, as kimay' in his memoir, Krishnan suggests, 'is reached 
through Kenya, but Kenya itself only comes into being through its passages through Uganda, Burundi, Rwanda, and South Africa' (2014, 20-21). In this vein, kimay becomes a fluid, yet anchored, terrain of intra-continental connections and mobilities, providing a springboard for thinking about Africa-centred migration fiction. Wainaina's neologism kimay also calls for new critical vocabularies cognisant of the linguistic complexities within intra-African diasporic spaces. Narratives considering the South-North migration axis to a large extent still exhibit engagement with early traits of the postcolonial novel such as the appropriation and decentralisation of the colonial language. Wainaina's text demonstrates how different migration trajectories complicate the metropolitan migrant's encounter with the largely monolingual Western context.

The author's memoir can, moreover, be read as part of the growing body of texts by African writers from elsewhere on the continent who live and publish temporarily, or more permanently, in South Africa. In the works by Hawa Jande Golakai (2011, 2015), Simão Kikamba (2005), Jonathan Nkala (2009), Sue Nyathi (2018), Ijangolet S. Ogwang (2018), Yewande Omotoso (2011, 2016), Jamala Safari (2012), Novuyo Rosa Tshuma (2012) and others, postapartheid South Africa frequently becomes a shifting, contradictory terrain oscillating between hope and disillusionment (see also Fasselt 2015). For Wainaina, South Africa of the early 1990s, as Kangsen Feka Wakai writes, is at once an African melting pot and the embodiment of panAfrican dreams, yet somewhat seems like it is not of Africa. But in Wainaina's telling, it is Brenda Fassie's stage' (2013, 173). Having grown up with South African freedom songs, Wainaina, while surrounded by a network of family, other African migrants as well as South Africans, painfully feels South Africa's postapartheid discourse of exceptionalism. South Africa according to his uncle who lectures at the University of Transkei 'is opening up', offering opportunities and, moreover, 'is cheaper than America or Europe' (Wainaina 2011, 89). And yet Wainaina is also told every day that '[t]his is not Africa' (98) and he frequently comments on anti-immigrant violence (105). He ridicules sensational representations of refugees dominating South African discourse about Africa, but also points to the many ways in which Kenyan migrants inventively utilise these through, for instance, the construction of a 'bulletproof refugee story' (107) for their own economic survival. His final verdict of the country, however, is steeped in the language of disillusionment: 'South Africans are infatuated with their own new trajectory. Like Americans, they see the whole world in their country, and seem perpetually surprised that other people are in their country. I will always be a foreigner. Even after ten years' (182). His years in South Africa, while increasingly marked by depression and isolation, however also mark the beginning of his career as a writer, complicating singular readings of his time in the country and his reading of the South African nation as a whole.

This ambiguous notion of belonging is echoed in his account of a family reunion near Kisoro, Uganda, to celebrate his grandparent's 60th wedding anniversary. On the drive from Kampala to Kisoro, Wainaina is confronted with his childhood imaginations about Uganda and a landscape of an 'alien quality' that 'does not conform to any African topography that [he is] familiar with'. He notes, 'Mom looks almost foreign now. Her Kinyarwanda accent is more pronounced [...]. Her beauty, so exotic and head-turning in Kenya seems at home here. [...] The rest of us seem like tourists' (157). The journey to his grandparents' home again, this time from the perspective of his Ugandan family, defies the unifying myths of the nation in favour of recounting its many entanglements and interlinkages through histories of migration. Living close to the border with Rwanda and Congo, Binyavanga's maternal family has a long history of trans-border movements, with his ancestors having moved to the region of the Bufumbira mountains in the late nineteenth century from present-day Rwanda during the reign of Rwandan King Rwogerase wa Rwabugiri (160). For Wainaina who is named after his grandfather, '[b]eing Binyavanga is [...] also exotic'. He ponders, 'an imaginary Ugandan of some 
kind resides in me, one who lets me withhold myself from claiming, or being admitted into, without hesitation, an unquestioning Gikuyu belonging' (160-161). The expressive function of belonging in the memoir is, perhaps, most pointedly revealed in these lines. While Wainaina's mobility resembles that of the Afropolitan who is at home in the world and on the continent, his Africanness is an ongoing negotiation grounded in his family's history of intra-continental migration.

This hesitation moreover underlies the title of the memoir, which Wainaina mentions in the context of the family visit to Kisoro. Crucially, the title of Wainaina's short story 'Discovering Home' here is rendered more ambiguous through the use of the deictic expression in 'this place'. Even though the demonstrative is clearly anchored spatially within the body of the text, its use as the title appears central to Wainaina's narrative practice. Deictic expressions, such as “"we", "this" and "here"” (Billig 1995, 115, 94), are frequently employed in nationalist discourse. This 'homeland deixis' (105) unequivocally locates the deictic centre, referred to in Karl Bühler's (2011) work on deixis as the location of the speaker in time and place, in the homeland. The memoir moves beyond this nationalist anchoring of deixis, while at the same time disavowing an utterly de-territorialised denotation. Wainaina's Afropolitan orientation is deeply inflected with various cadences of the local as expressed through kimay and rooted, not in a specific location, but in the trans-African movements of his family.

\section{Conclusion}

If Waberi's In the United States of Africa 'has allowed us to see the absurdity of any kind of oriented globe', as Everett (in Waberi 2009, viii) contends, Aboulela, Agyei-Agyiri and Wainaina lend a pluriversal angle to contemporary migration/migrant writing. The writers clearly demonstrate the need to transcend the epistemic 'tyranny of abstract universals' (Mignolo $2007,159)$ that have come to define the post-nationalist 'migrant novel'. This is not to suggest a radically different set of characteristics or to draw a clear line between novels of intra-African migration and those focusing on movement outside the continent, but to highlight the diverse modes of mobilities and affiliation that are effaced precisely in such attempts to establish fixed parameters of 'migrant writing'.

Most crucial to Lyrics Alley is the observation that specific critical trends such as the study of the cosmopolitan/Afropolitan migrant novel often lead to the obfuscation of other, more incongruous forms of mobility and belonging. Triangulating conventional centre/periphery formations, Aboulela draws attention to the multiple affiliations of her characters who participate both in discourses of cosmopolitan worldliness and cultural nationalism. Unexpected Joy at Dawn illustrates, against the backdrop of forced migration and repatriation, the ongoing emancipatory force of pan-African nationalisms that, in post-nationalist discourse and Mbembe's understanding of Afropolitanism, are dismissed as narrow essentialism. Through his characters' mourning and invocation of a pan-African ethic in moments of crisis, Agyei-Agyiri poignantly reminds us of the imperative 'to distinguish [...] between the reactionary, reformist, or revolutionary goals of various nationalisms' (Zeleza 2006, 112-113). At the same time, the novel through its depiction of the market space invokes a decolonial inflection of Afropolitanism that challenges uniform discourses of transnationality. In his literary memoir One Day I Will Write About This Place Wainaina successfully narrates the multiplicities of intra-African movement, debunking the myth of Africa's exceptional migration patterns in comparison to other continents. The inventive neologism kimay comes to stand for a rooted form of Afropolitanism, enunciated from the specific standpoint of Wainaina's entangled East-African family history, which disavows universal premises of human migratory experiences. Moreover, the memoir also 
draws attention to South Africa as a contradictory terrain that provides a new focal point in contemporary African migrant writing. Read together, these narratives of myriad forms of intraAfrican migration, open new vistas in relation to a growing set of critical accounts within the field of African literary studies that strive to find alternatives to the strictures of the post-national and globalisation paradigms.

\section{Notes}

1 Rather than providing a nuanced analysis of continuities and discontinuities accounting for thematic and aesthetic overlaps between earlier and more recent return narratives, Knudsen and Rahbek focus on difference, arguing problematically that in contrast to more recent works "the "traditional" or recognisable African "been-to" characters - who visit the West for a shorter or longer period - can always return to a familiar place where they feel a sense of belonging and attachment' $(2017,118)$.

2 See the large body of work produced by the African Centre for Migration \& Society located at Wits University.

3 For the purposes of this chapter, I rely on Robin Dunford's reading of pluriversality in his work on decolonial ethics. A decolonial global ethics, he suggests, would defy the focus on 'individualism' and 'universality' which tends to undergird uncritical accounts of cosmopolitanism. A 'pluriversal world' in his account:' is one in which multiple options are possible - a world in which many worlds can co-exist. Whilst other options would be circumscribed insofar as they would have to accept the decolonial imperative of working towards a pluriversal world, this still leaves room for many options, many possible lives, livelihoods and cosmovisions.' (2017, 393)

4 A detailed engagement with decolonial theory is beyond the scope of this paper.

5 Postcolonial modernity for Garuba is marked by the 'simultaneous interpellation', rather than hybridity, of postcolonial subjects who have 'the ability to operate under two different discursive orders and experience them as normative' (Garuba 2015, 22).

6 For a compelling narrative exploration of the hierarchy of intra-African mobilities in contemporary migration discourse see Yvonne Adhiambo Owuor's extended short story 'Weight of Whispers' (2003).

\section{References}

Ahmed Gamal Abdel Wahab. 2014. "Counter-Orientalism: Retranslating the "Invisible Arab" in Leila Aboulela's The Translator and Lyrics Alley'. Arab Studies Quarterly 36(3): 220-241.

Aboulela, Leila. 1999. The Translator. Edinburgh: Polygon.

Aboulela, Leila. 2001. Coloured Lights. Edinburgh: Polygon.

Aboulela, Leila. 2005. Minaret. London: Bloomsbury.

Aboulela, Leila. 2012 [2010]. Lyrics Alley. London: Phoenix.

Achebe, Chinua. 1994 [1960]. No Longer at Ease. New York: Anchor Books.

Adesanmi, Pius. 2017. 'From Post-Global to Post-Truth: African Literature beyond Commonsense'. The Cambridge Journal of Postcolonial Literary Inquiry 4(2): 271-279.

Adichie, Chimamanda Ngozi. 2013. Americanah. London: Forth Estate.

Adjei, Mawuli. 2004. 'Epilogue: Unlocking the Memory Door, Purging the Collective Conscience'. In Unexpected Joy at Dawn, by Alex Agyei-Agyiri, 321-331. Accra: Sub-Saharan Publishers.

Agyei-Agyiri, Alex. 2004. Unexpected Joy at Dawn. Accra: Sub-Saharan Publishers.

Aidoo, Ama Ata. 1994 [1977]. Our Sister Killjoy. Harlow: Longman.

Armah, Ayi-Kwei. 1969. Fragments. London: Heinemann.

Armah, Ayi-Kwei. 2003 [1968]. The Beautyful Ones Are Not Yet Born. London: Heinemann.

Asaah, Augustine H. 2007. 'Pan-Africanism, Inter-African Migration and the Crisis of National Integration in the African Novel'. Research Review 23(1): 1-13.

Atta, Sefi. 2012. A Bit of Difference. Northampton, MA: Interlink Books.

Awad, Yousef. 2014. 'Writing from the Margins of the Nation: Leila Aboulela's Lyrics Alley'. Arab World English Journal 2: 69-81.

Baingana, Doreen. 2005. Tropical Fish: Stories out of Entebbe. Amherst: University of Massachusetts Press.

Bekers, Elisabeth, Sissy Helff and Daniela Merolla. 2009. Transcultural Modernities: Narrating Africa in Europe. Amsterdam: Rodopi. 
Billig, Michael. 1995. Banal Nationalism. London: Sage.

Bose, Sugata and Kris Manjapra. 2010. Cosmopolitan Thought Zones: South Asia and the Global Circulation of Ideas. Basingstoke: Palgrave Macmillan.

Boyce Davies, Carole. 2016. 'Migration, African Writing and the Post-Colonial/Diasporic Chimamanda Adichie Moment'. In Gender and Race Matter: Global Perspectives on Being A Woman, edited by Shaminder Takhar, 233-248. Bingley: Emerald.

Brancato, Sabrina. 2008. 'Afro-European Literature(s): A New Discursive Category?' Research in African Literatures 39(3): 1-13.

Bühler, Karl. 2011. Theory of Language: The Representational Function of Language. Amsterdam: John Benjamins.

Bystrom, Kerry. 2012. 'Reading the South Atlantic: Chile, South Africa, the Cold War, and Mark Behr's The Smell of Apples'. African Studies 71(1): 1-18.

Cheng, Anne Anlin. 2001. The Melancholy of Race: Psychoanalysis, Assimilation, and Hidden Grief. Oxford: Oxford University Press.

Cole, Teju. 2007. Every Day Is for the Thief. Abuja: Cassava Republic Press.

Cousins, Helen and Pauline Dodgson-Katiyo. 2016. 'Leaving Home/Returning Home: Migration and Contemporary African Literature'. African Literature Today 34: 1-11.

Crush, Jonathan. 1995. 'Vulcano's Brood: Spatial Narratives of Migration in Southern Africa'. In Writing across Worlds: Literature and Migration, edited by Russell King, John Connell and Paul White, 229-247. London: Routledge.

Desai, Gaurav Gajanan. 2016. Commerce with the Universe: Africa, India, and the Afrasian Imagination. New York: Columbia University Press.

Dunford, Robin. 2017. 'Toward a Decolonial Global Ethics'. Journal of Global Ethics 13(3): 380-397.

Edwin, Shirin. 2013. '(Un)holy Alliances: Marriage, Faith, and Politics in Leila Aboulela's The Translator'. Journal of Middle East Women's Studies 9(2): 58-79.

Emecheta, Buchi. 1994. Kehinde. London: Heinamann.

Escobar, Arturo. 1995. Encountering Development: The Making and Unmaking of the Third World. Princeton, NJ: Princeton University Press.

Fasselt, Rebecca. 2015. "Nigeria” in the Cape: Afropolitanism and Alienation in Yewande Omotoso's Bom Boy'. Research in African Literatures 46(2): 119-145.

Flahaux, Marie-Laurence and Hein de Haas. 2016. 'African Migration: Trends, Patterns, Drivers'. Comparative Migration Studies 4(1): 1-25.

Frenkel, Ronit. 2011. 'Reconsidering South African Indian Fiction Postapartheid'. Research in African Literatures 42(3): 1-16.

Garuba, Harry. 2003. 'Explorations in Animist Materialism: Notes on Reading/Writing African Literature, Culture, and Society'. Public Culture 15(2): 261-285.

Garuba, Harry. 2015. 'Postcolonial Modernity and Normalisation: Reading Chinua Achebe's Arrow of God in the Present Tense'. In Chinua Achebe's Legacy: Illuminations from Africa, edited by James Ogude, 16-29. Pretoria: Africa Institute of South Africa.

Gehrmann, Susanne. 2016. 'Cosmopolitanism with African Roots: Afropolitanism's Ambivalent Mobilities'. Journal of African Cultural Studies 28(1): 61-72.

Ghazoul, Ferial. 2001. 'Halal Fiction'. Al Ahram Weekly 542: 12-18.

Golakai, Hawa Jande. 2011. The Lazarus Effect. Cape Town: Kwela.

Golakai, Hawa Jande. 2015. The Score. Cape Town: Kwela.

Gourgem, Hicham. 2017. 'Afropolitanism: The Other Side of the Coin'. Transnational Social Review 7(3): 287-299.

Hassan, Wail S. 2008. 'Leila Aboulela and the Ideology of Muslim Immigrant Fiction'. NOVEL: A Forum on Fiction 41(2/3): 298-319.

Hofmeyr, Isabel. 2015. 'Styling Multilateralism: Indian Ocean Cultural Futures'. Journal of the Indian Ocean Region 11(1): 98-109.

Hofmeyr, Isabel and Michelle Williams, eds. 2011. South Africa and India: Shaping the Global South.Johannesburg: Wits University Press.

Innes, C. Lynn. 1995. 'Conspicuous Consumption: Corruption and the Body Politic in the Writing of Ayi Kwei Armah and Ama Ata Aidoo'. In Essays on African Writing. Volume 2. Contemporary Literature, edited by Abdulrazak Gurnah, 1-18. Oxford: Heinemann Educational Publishers.

Kaplan, Sara. 2007. 'Souls at the Crossroads, Africans on the Water: The Politics of Diasporic Melancholia'. Callaloo 30(2): 511-526. 
Kikamba, Simão. 2005. Going Home. Roggebaai: Kwela.

Knighton, Rachel. 2014. 'Refracting the Political: Binyavanga Wainaina's One Day I Will Write About This Place'. In Politics and Social Justice. African Literature Today 32, edited by Ernest N. Emenyonu, 33-46. Rochester, NY: Boydell \& Brewer.

Knudsen, Eva Rask and Ulla Rahbek. 2017. 'An Afropolitan Literary Aesthetics? Afropolitan Style and Tropes in Recent Diasporic Fiction'. European Journal of English Studies 21(2): 115-128.

Krishnan, Madhu. 2014. 'Negotiating Africa Now'. Transition 113: 11-24.

Krishnan, Madhu. 2017. 'Periodizing the Anglophone African Novel: Location(s) in a Transnational Literary Marketplace'. In Literature and the Global Contemporary, edited by Sarah Brouillette, Mathias Nilges and Emilio Sauri, 135-156. Cham, Switzerland: Palgrave Macmillan.

Landau, Loren B. and Oliver Bakewell. 2018. 'Introduction: Forging a Study of Mobility, Integration and Belonging in Africa'. In Forging African Communities: Mobility, Integration and Belonging, edited by Oliver Bakewell and Loren B. Landau, 1-24. London: Palgrave Macmillan.

Lipenga, Ken Junior. 2018. 'Voicing Marginality: Disability in Leila Aboulela's Lyrics Alley'. Journal of African Cultural Studies 30(1): 93-104.

López, Marta Sofia, ed. 2008. Afroeurope@ns: Cultures and Identities. Newcastle: Ambridge Scholars Publishing.

Mahmood, Saba. 2005. Politics of Piety: The Islamic Revival and the Feminist Subject. Princeton, NJ: Princeton University Press.

Mbembe, Achille. 2007. 'Afropolitanism'. In Africa Remix: Contemporary Art of a Continent, edited by Clive Kellner, translated by Laurent Chauvet, 26-29. Johannesburg: Jacana.

Mignolo, Walter D. 2007. 'Delinking: The Rhetoric of Modernity, the Logic of Coloniality and the Grammar of De-coloniality'. Cultural Studies 21(2-3): 449-514.

Moudouma Moudouma, Sydoine. 2013. 'Intra- and Inter-continental Migrations and Diaspora in Contemporary African Fiction'. PhD dissertation, University of Stellenbosch.

Mudimbe, Vumbi Yoka. 1994. The Idea of Africa. Bloomington: Indiana University Press.

Musila, Grace. 2010. 'The "Redykyulass Generation's" Intellectual Interventions in Kenyan Public Life'. Nordic Journal of Youth Research 18(3): 279-299.

Mwangi, Ewan. 2007. 'Binyavanga Wainaina'. In The Columbian Guide to East African Literature in English Since 1945, edited by Simon Gikandi and Ewan Mwangi, 174-175. New York: Columbia University Press.

Nawyn, Stephanie J. 2016. 'New Directions for Research on Migration in the Global South'. International Journal of Sociology 46(3): 163-168.

Ndlovu-Gatsheni, Sabelo J. 2013. 'Is Nativism a National Question in Post-colonial Africa?' In Nationalism and National Projects in Southern Africa: New Critical Reflections, edited by Sabelo J. Ndlovu-Gatsheni and Finex Ndhlovu, 60-83. Pretoria: Africa Institute of South Africa.

Nkala, Jonathan Khumbulani. 2009. The Crossing, and, the Bicycle Thief. Mowbray: Junkets.

Nyathi, Sue. 2018. The Gold Diggers. Johannesburg: Macmillan.

Ogwang, Ijangolet S. 2018. An Image in a Mirror. Auckland Park: Blackbird.

Ojaide, Tanure. 2008. 'Migration, Globalization, and Recent African Literature'. World Literature Today 82(2): 43-46.

Ojwang, Dan. 2013. Reading Migration and Culture: The World of East African Indian Literature. Basingstoke: Palgrave Macmillan.

Okuyade, Ogaga. 2013. 'Continuity and Renewal in the Endless Tale of a Continent: New Voices in the African Novel'. Ariel: A Review of International English Literature 44(1): 1-24.

Omotoso, Yewande. 2011. Bom Boy. Cape Town: Modjaji.

Omotoso, Yewande. 2016. The Woman Next Door. London: Chatto \& Windus.

Owuor, Yvonne Adhiambo. 2003. 'The Weight of Whispers'. Kwani? 1: 12-37.

Owuor, Yvonne Adhiambo. 2013. Dust. New York: Alfred A. Knopf.

Popescu, Monica. 2010. South African Literature beyond the Cold War. New York: Palgrave Macmillan.

Portelli, Alessandro. 2006. 'Fingertips Stained with Ink: Notes on New "Migrant Writing" in Italy'. Interventions: International Journal of Postcolonial Studies 8(3): 472-483.

Rizzo, Alessandra. 2012. 'Leila Aboulela's Lyric's Alley: Crossing the Sudan, Egypt, and Britain'. Textus 25(2): 165-181.

Rushton, Amy. 2017. 'No Place Like Home: The Anxiety of Return in Taiye Selasi's Ghana Must Go and Yvonne Adhiambo Owuor's Dust'. Études anglaises 70(1): 45-62.

Safari, Jamala. 2012. The Great Agony and Pure Laughter of the Gods. Cape Town: Umuzi. 
Salih, Tayeb. 1969 [1966]. Season of Migration to the North. London: Heinemann.

Samuelson, Meg. 2010. '(Un)settled States: Indian Ocean Passages, Performative Belonging and Restless Mobility in Post-Apartheid South African Fiction'. Social Dynamics 36(2): 272-287.

Santos, Boaventura de Sousa. 2014. Epistemologies of the South. Justice against Epistemicide. Boulder, CO: Paradigm.

Selasi, Taiye. 2013. Ghana Must Go. London: Viking.

Soyinka, Wole. 1970 [1965]. The Interpreters. London: Heinemann.

Steiner, Tina. 2008. 'Strategic Nostalgia, Islam and Cultural Translation in Leila Aboulela's The Translator and Coloured Lights'. Current Writing: Text and Reception in Southern Africa 20(2): 7-25.

Thomas, Dominic. 2014. Afropean Cartographies. Newcastle upon Tyne: Cambridge Scholars Publishing.

Tshuma, Novuyo Rosa. 2012. Shadows. Cape Town: Kwela.

Troutt Powell, Eve M. 2003. A Different Shade of Colonialism: Egypt, Great Britain, and the Mastery of the Sudan. Berkeley: University of California Press.

Van Deventer, Alison and Dominic Thomas. 2011. 'Afro-European Studies: Emerging Fields and New Directions'. In A Companion to Comparative Literature, edited by Ali Behdad and Dominic Thomas, 335-356. Oxford: Blackwell-Wiley Publishers.

Waberi, Abdourahman A. 2009 [2006]. In the United States of Africa. Lincoln: University of Nebraska Press. Wainaina, Binyavanga. 2005. 'How to Write about Africa'. Granta 92: 91-95.

Wainaina, Binyavanga. 2011. One Day I Will Write About This Place. London: Granta.

Wakai, Kangsen Feka. 2013. 'Benga Benga: A Review of Binyavanga's One Day I Will Write About This Place'. Transition 111: 167-175.

Whitaker, Beth Elise. 2017. 'Migration within Africa and Beyond'. African Studies Review 60(2): 209-220.

Zeleza, Paul Tiyambe. 2006. 'The Troubled Encounter between Postcolonialism and African History'. Journal of the Canadian Historical Association 17(2): 89-129. 


\section{History, imperial eyes and the 'mutual gaze'}

\section{Narratives of African-Chinese encounters in recent literary works}

Ying Cheng

Relations between Africa and China have changed rapidly in the past decades and scholars, artists and writers are seeking new ways of conceptualising relations and encounters between Chinese and Africans both in Africa and China. Travel writing, novels, biographies, adaptations and online blogs have become important forums for representing these encounters and interactions. These texts have started to document and comment on the growing engagement between Africa and China, and have complicated discussions about 'otherness'. This chapter explores the representation of African-Chinese encounters in contemporary literary works and analyses the ways in which 'otherness', difference and emerging identities have been represented, constituted and debated in African and Chinese literature.

Many existing discussions of the representation of 'otherness' privilege the analysis of Western representations of its 'others' (Said 1978; Spurr 1993; Clifford and Marcus 1986) or examine how 'other' texts 'write back' to the West (Pratt 2007). Unlike the research that prioritises the 'West and the rest' framework, this chapter takes on a different perspective by juxtaposing writers from different non-Western literary traditions alongside one another. Using examples of narratives of Africa-China encounters, I examine how non-Western texts may either strengthen or unsettle the existing Eurocentric models of othering, and provide layered representations of encounters based on a more complex understanding of self and other. I am also particularly interested in the historical and contemporary factors affecting both African and Chinese writers' interpretation of 'otherness' and 'difference'.

African-Chinese encounters in two literary works will be examined: the first is Nigerian playwright Femi Osofisan's All for Catherine (2016), a play about a Chinese family living in Nigeria, adapted from a well-known Chinese play Thunderstorm (Leiyu/雷雨, 1934) after Osofisan's multiple visits to China. The second literary work to be considered is the celebrated Chinese writer Yan Geling's Notes on Africa (Feizhou Zhaji/非洲札记, 2013) a collection of writings based on her own experiences of living and travelling in Nigeria. Osofisan's adaptation of the Chinese play Thunderstorm features an anxious critique of the exploitative nature of Chinese capital in Nigeria, while emphasising the urgency of building a new model of 
Southern-based cultural interactions and cultural politics. Yan Geling's travel writing about Nigeria sometimes appropriates the rhetoric of imperial travel writing, while it also positions her Chinese-ness as removing her from the dynamics of empire that characterise relations between Westerners and Nigerians.

These individual literary works offer important insights into the ways in which knowledge about the 'other' is constructed and reproduced in the dynamics of transcultural contacts. While linking these accounts of cross-cultural encounter to broader questions about history, race and class in the context of the Global South, the chapter develops more nuanced ways of understanding emerging identities in Africa, especially in the context of intensifying China-Africa encounters.

\section{Representing otherness: the postcolonial and the Global South}

The work of scholars such as Pratt (1991, 2007), Bhabha (1994), Fabian (1991), Hall (1997), Hallam and Street (2013), has been adopted and reinterpreted by literature scholars to reveal the connections between power dynamics and representations of difference and otherness. For the most part, these studies focus on how Western writers represent the 'other', or produce 'the rest of the world' as an object of Western knowledge in the 'contact zone' of the colonial encounter, ${ }^{1}$ where various cultures 'clash, and grapple with each other, often in contexts of highly asymmetrical relations of power' (Pratt 1991, 34). Alternatively, this line of inquiry has privileged those writers who 'write back' to the West, to resist, destabilise or subvert Western hegemony and reaffirm the other's rights to self-representation. ${ }^{2}$

The construction of a 'Civilisational Other' in opposition to the self-constitution of the West, or the subversion of the Other within established metropolitan discourses, have become the central themes in postcolonial criticism. The postcolonial critical model features binary oppositions of centre and margin, metropole and periphery, self and other, and it exemplifies the contrasting relationship between the periphery and the centre at the expense of internal heteroglossia' (Mwangi 2010, 1-4) between non-Western texts. The experience of 'the postcolonial other' (McClintock 1992, 86) is determined so overwhelmingly by his or her relation to the metropolitan centre that 'class, gender, and other local and historical and social pressures are elided' (Barber 1995, 3). In other words, despite claims to specificity, the postcolonial model blocks a properly historical, localised understanding of post-Independence literary production in Africa and beyond.

A few moves to counter this model have emerged and recognised the necessity of moving away from this Eurocentric mode of seeing and narrating. Using 'island narratives' - one of the central tropes of Western investment in otherness - as an example, Harry Garuba explores how African playwrights dwell on the issues of discourse/power and marginality 'from their own perspectives and in their own voices' (Garuba 2001, 64), rather than writing against the explorer-discoverer-coloniser. He suggests that in these works, including African adaptations of Western plays, there is a strong insistence on the historical and cultural past, as well as the lived reality of the local communities. Similarly, Rebecca Jones argues that early twentieth-century Nigerian domestic travel writing, 'offers a way to re-imagine the centres and peripheries produced and replicated by travel writing, distinct from the colonial metropole-periphery relationship often imagined to characterize the genre in its colonial heyday' (Jones 2014). ${ }^{3}$ Scholars (Garuba 2001; Osofisan 1999) maintain that not all third-world texts exist in a confrontational relationship with the Western canon, or acquire legitimacy mainly through the discourses of the West with which they engage.

This chapter joins the discussions of cross-cultural encounters within the context of 'the postcolonial other' (McClintock 1992, 86) and the South by examining representations of 
'otherness' in narratives of encounters between Africa and China. These discussions challenge postcolonial theorists' generalisations about 'all postcolonial people', which 'bind the peoples of these societies in conflictless brotherhood ... inequalities of caste and class do not exist in these societies, and ... their literary works are only about "resisting" or "subverting" the colonizer's discourses' (Mukherjee 1993, 27). An examination of Chinese-African interactions in Chinese and African literary works also offers alternatives for interrogating notions of 'intertextuality' and 'hybridity' advocated by many postcolonial theorists. The conception of postcolonial hybridity defines postcolonial literatures in terms of 'a textual contest, or a bibliographic battle, between oppressive and subversive books' (Ghandi 1998, 141). It focuses on an intentional hybridity in postcolonial literatures - understood as the 'inappropriate appropriation of Western language, conventions, and texts' (Caminero-Santangelo 2004, 2) - enabling a particularly effective form of writing back to the imperial centre. I argue that, instead of 'textual contest', the 'appropriation' or 'intertextuality' of texts between Asian and African writers is more complex and problematic than that suggested by postcolonial theory.

As David Spurr has pointed out, in imperial discourse, colonised subjects are denied the power to shape their own narrative: 'Gazed upon, they are denied the power of the gaze; spoken to, they are denied the power to speak freely' (Spurr 1993, 4). By contrast, I suggest that literary texts about non-Western encounters may provide an alternative model of 'mutual gaze'. This new model is, on the one hand, mediated by a common history of colonial oppression and anticolonial resistance in Asia and Africa and, on the other hand, shadowed by the ghosts of imperial rhetoric that often imply asymmetrical power relations within the context of the postcolonial other. In other words, the mutual gaze is not a simple lateral relation, but more of a negotiation of mutual histories and ongoing interactions. The chapter also suggests that more research is necessary in terms of understanding concepts like the 'Global South', 'Third-World', and 'China-Africa', ${ }^{4}$ entangled territories which involve multi-directional circulations and interactions, deep historical entanglements as well as intricate ongoing relations. What does the 'internal heteroglossia' (Mwangi 2010, 1-4) tell us about power relations within the South? How and why are narratives of encounters within the South mediated by northern references?

\section{Recent literary narratives of Africa-China encounter}

In relation to an exponential increase in interactions between Africa and China over the past few years, many more African literature texts have begun to portray Chinese-African crosscultural encounters on the continent. To name just a few, one might consider the Zimbabwean writer NoViolet Bulawayo's novel We Need New Names (2013), the South African writer Bongani Madondo's short story 'Jozi 2020' (2016), the Congolese writer In Koli Jean Bofane's Congo Inc.: Bismarck's Testament ([2014], 2018), and the Nigerian playwright Femi Osofisan's All for Catherine (2016). Moreover, China references or Chinese characters frequently appear in works by African writers such as Chimamanda Ngozi Adichie, Sefi Atta, Billy Kahora, Teju Cole and others. ${ }^{5}$ Characters in many writers' works, for instance, Chimamanda Ngozi Adichie's Americanah (2013, 580) and Sefi Atta's A Bit of Difference (2013, 57), express strongly worded critiques of China's potentially disruptive presence in Africa. As Teju Cole observes in his Everyday is for the Thief, 'The Chinese have arrived, and they are visible all over Lagos, as merchants, as contractors, as labourers' $(2007,144)$. Moreover, Bulawayo's chapter about a Chinese-run construction site called 'Shanghai' (2013, 42-57) reveals that the physical presence of China in infrastructure and construction, which often involves importing Chinese labour, is very significant in many African countries. These more recent representations could be understood as attempts to reflect on such issues as the neo-colonialism thesis for explaining China's 
growing presence in Africa, ${ }^{6}$ or the 'win-win' rhetoric celebrated in the official discourses about China-Africa engagement. ${ }^{7}$

It is worth noting that there is also a growing number of narratives on travelling and living in Africa by Chinese writers, for instance, Liang Zi's Ten Years in Africa (Feizhou Shinian/非洲十 年, 2012), Bi Shumi's Thirty Thousand Miles in Africa (Fezhou Sanwanli/非洲三万里, 2016), Gui Tao's This is Africa (Shi Feizhou/是非洲, 2012) and Yan Geling's Notes on Africa (Feizhou Shouji/ 非洲手记, 2016). ${ }^{8}$ These recent literary works provide examples of popular perceptions of the presence of non-Western 'Others' in Africa and China. However, and thus far, very few studies (Fan 2017; Thornber 2016) have examined these works and their subtle roles in shaping the collective imaginations of self and other. ${ }^{9}$

Alongside the flowering of literary representations of the Africa-China encounters, African studies has become a more prominent discipline in Chinese universities and institutions in recent years. In China, African literature is often seen as an important site for experiencing 'contact zones' that may refresh an understanding of 'the self and 'the other' (Jiang 2017, Chen 2016). The visibility of African studies mirrors a resurgence of discourses of 'Afro-Asian solidarity' over the past few years. ${ }^{10}$ These discourses as well as histories of the Asian-African Conference (also known as the Bandung conference) have been invoked as the foundation for historicising the recent emergence of the Global South (see also Christopher J. Lee 2010). ${ }^{11}$ Chinese scholar Chen Kuan-ksing proposes that, in order to subvert limitations in postcolonial theory, Africa-Asia, instead of Euro-America, should be considered 'as method for third-world critical thoughts' (Chen and Lang 2017). Jiang Hui (2017) argues that it is necessary for both Chinese scholars and African scholars to refer to 'the mutual historical background of modern writing in China and many African countries, and explore non-Western dominated approaches of understanding African literature'. The current chapter contributes to these discussions by posing new questions about how African and Chinese writers represent each other: in what ways do the histories of Afro-Asian political solidarity inform narratives of contemporary African-Asian encounters? Are African and Chinese writers and intellectuals able to imagine this encounter without referencing Western discourses and Western power?

\section{Femi Osofisan's adaptation of Thunderstorm}

In this section of the chapter, I plan to explore how Nigerian playwright Femi Osofisan uses adaptation to reflect on and respond to the dynamics of power relations in Africa-China interactions. The appropriation and representation of Chinese characters in Osofisan's play reveal how ambivalence towards China and the Chinese people has evolved in complex ways in recent years.

Osofisan's All for Catherine is a partial adaptation of Chinese playwright Cao Yu's most famous work Thunderstorm. ${ }^{12}$ In 2013, after a guest lecture at Tianjin Normal University in China, Osofisan was taken on a courtesy tour of the city of Tianjin where he visited the famous Chinese playwright Cao Yu's old house and theatre. Cao Yu (1910-1996) is one of China's most distinguished twentieth-century playwrights, and many consider his powerful tragedy Thunderstorm, the greatest of all Chinese spoken dramas (huaju/话剧). The play Thunderstorm was set in an unnamed city in Northern China in the years following the May Fourth Movement of 1919. ${ }^{13}$ It explores the theme of patriarchal capitalist oppression and individual emancipation. Dramatic conflict revolves around a complex, three-decades long entanglement between two economically disparate families: the Zhou family, headed by Zhou Puyuan, the head of a coal-mining company, and the Lu family, whose members have been employed by the Zhou family at one time or another. ${ }^{14}$ At the heart of the play is the rigid traditionalism and 


\section{Ying Cheng}

ruthlessness of the patriarchal Zhou Puyuan which leads to the destruction of families and individuals. The plot highlights Zhou's exploitation of subordinates, both in his family and among his employees. Zhou manipulates and represses the workers' strike at his mine, and has a fierce conflict with the strike leader Lu Dahai, who represents the radical spirit of resistance in the play.

In his adaptation, Osofisan shifted the setting for the play from Northern China to Southern Nigeria, and transformed the tragedy between two Chinese families to an equally combustible encounter between a Chinese family and a Nigerian family. Osofisan transformed the character of Zhou Puyuan, a greedy capitalist and patriarch in early twentieth-century China into Li Weiye, a Chinese businessman working and living in Nigeria in the twenty-first century. Li's lack of compassion for and exploitation of the lower class is exemplified by his conflict with Tony, a Nigerian who works in Li's rice-farming company in Lagos and leads the Nigerian workers' strike. It is not until the end that Li realizes that Tony is Li's unknown son with a Nigerian woman.

In fact, the seemingly appropriated plot of the play - a conflict between Chinese business owner Li and Nigerian worker Tony - could relate to an event widely reported in the Nigerian media in $2013 .{ }^{15}$ On the very day Osofisan arrived back home from China, one of the headlines in newspapers at the airport was about a strike that had just begun at one of the Chinese manufacturing companies in Lagos. This piece of news in local newspapers caught the playwright's attention and provided him with the inspiration for his adaptation. ${ }^{16}$

This partial adaptation seems to address one of the perceptions held by Nigerians, especially social elites, who believe that the Chinese presence in Africa represents a new form of economic exploitation and threatens the development of local entrepreneurship. The following dialogue between Tony and his younger sister Catherine, ${ }^{17}$ exemplifies this point of view:

TONY (bitterly): Look, most of these foreign employers here, especially the Chinese like this $\mathrm{Mr}$. Li, are up to no good. I've seen enough of their doings at the plantation these past few years to know them very well. They pretend they've come to help us, but they're only out to fleece us. Oh, I hate them.

CATHERINE: And what are these things you've seen?

TONY: Don't tell me you're blind, Catherine! Take even this house, this magnificent house! Will you say you don't know that it was built with the blood of workers crushed at their rice mills!

CATHERINE: Mr. Li is giving jobs to hundreds of unemployed. Every year he offers scholarships to several of our desperate youths. So what's wrong with it if he builds himself a decent home?

TONY: Of course he can afford to play the philanthropist. That's what they all do, isn't it, these rich expatriates?

CATHERINE: Mr. Li is different, can't you see? You especially! On dad's intervention, he gave you a job -

TONY: To salvage his conscience, isn't it? These grand gestures, after working so many to death! But do you see him living among us, among our people? Never! They build their separate estates, these glittering new mansions, and put a high fence round it, because they despise us!

CATHERINE: And our own people, the Nigerians too who live in these same estates?

TONY: Are no different dear sister! It isn't the colour of their skin I'm talking about! It's the cynical exploitation of the common people like you and me; the swindle that goes on with the collusion of our governments in the name of creating employment. 


\section{All the big people are in the racket, whether black or white. It's the few rich against the powerless masses.}

(Osofisan 2016, 9-10)

In this conversation between Tony and Catherine, the Chinese presence is seen as a symbol of capital. The interpretation given to Chinese activity in Nigeria echoes a perspective that views China as one element of a broader process of primitive accumulation of capital on a world scale in the context of a deepening crisis of capitalism. In the words of Tony, 'All the big people are in the racket, whether black or white. It's the few rich against the powerless masses' (Osofisan 2016, 10). This logic of equivalence is clarified by Tony in several other places in Osofisan's adaptation, including Tony's confrontation with Li. In other words, what initially appears to be a conflict of race and nationality (black and Asian, Chinese and Nigerian) turns out to be a conflict of class (capitalist and working class) thus extending the basic plot of the original Chinese play. As Stuart Hall $(1980,341)$ has observed: 'Race is thus ... the modality in which class is "lived", the medium through which class relations are experienced, the form in which it is appropriated and "fought through".'

I note that not only Osofisan, but several other African authors also feature the image of a stereotypical Chinese 'Other' in their recent works, very often as economically prosperous outsider or indifferent stranger. These works depict China as a 'sub-imperial' force leading the scramble for African resources and acting as a tributary of Euro-American hegemony. In a central scene of Adichie's Americanah (2013), Chinese citizens are mentioned in relation to the oil exploration in Nigeria that threatens the future of Nigerian sovereignty. Likewise in a 'Sinophobe' tone prevalent in South African media, Bongani Madondo's 'Jozi 2020: Made in China' imagines a futurist Johannesburg controlled by the Chinese 'red force' $(2016,372)$. Similarly, an entire chapter in Bulawayo's We Need New Names is about how the Chinese are 'taking over' Africa, and how, as one of Darling's friends puts it, the Chinese 'are not even our friends' $(2013$, 49). These narratives reveal a major transformation of geopolitical orders that is reshaping Africa-China relations: the ex-socialist, ex-colonised and ex-third world countries, including China, seem to have emerged as the leading edge of global capital in the Global South.

I suggest that Osofisan's adaptation cannot easily be classified as a literary example of the 'recolonisation' thesis accounting for the Chinese presence in Africa, mainly posited by liberal Western scholars and African mainstream media. For example, Li Weiye could have been sketched as a stereotypical Chinese neo-colonialist, a symbol of capitalism and patriarchal hegemony, but his sentimental musings on the past complicate this reading. The playwright sent the earlier versions of his adaptation to his Chinese students, colleagues and friends for their comments and made several changes to the character. They read the story in manuscript form and suggested that the image of the Chinese as neo-colonialists was becoming increasingly prevalent in African media and that Osofisan's work should be more nuanced. ${ }^{18}$ In this play that aims to promote 'mutual understanding across the geographical and racial frontiers' (Osofisan 2016, 69), stereotypical and exaggerated Chinese characters are still present, thus revealing the playwright's anxiety regarding the crisis confronting two civilisations. This adaptation itself can be interpreted as the playwright's endeavour to urge both Nigerian and Chinese audiences to dwell on the history and dynamic nature of contemporary Afro-Asian interactions.

Those who are familiar with Osofisan's work would have noticed that this adaptation fits into his on-going project of 'interwoven bi-cultural play scripts' (Osofisan in his afterword to the play, 2016, 70), for instance in his Tegonni (an adaptation of Antigone) and Wesoo, Hamlet! (an adaptation of Hamlet). According to Osofisan, this project 'creates plays - and primarily re-readings of canonical texts - for interpretations that would of necessity incorporate a 


\section{Ying Cheng}

racially mixed cast of actors'. All for Catherine (an adaptation of Thunderstorm) is the first and only non-Western text in Osofisan's 'interwoven bi-cultural' theatre project, which he created for 'promoting inter-racial understanding between China and Africa' (Osofisan 2016, 70).

Adaptations of Western plays by African writers are often read as counter-narratives to the original works (Van Weyenberg 2010; Caminero-Santangelo 2004). However, Osofisan's partial adaptation should be interpreted beyond the framework of 'counter-narrative'. Instead, and in order to fully appreciate the 'intertextuality' of his adaptation, one has to refer to Osofisan's understanding of modern Chinese theatre and its history, as well as his concerns about social relations in both China and Africa.

In order to understand the multiple layers of adaptation at work here, one needs to consider the significance of Cao Yu's Thunderstorm in the history of modern Chinese theatre. Thunderstorm exemplifies the new Chinese dramatic form of huaju, and was often considered as one of the most representative works of the Chinese huaju movement. ${ }^{19}$ From the beginning, the huaju movement in China was associated with Western theatre. In the early years, huaju performances essentially consisted of Chinese translations and adaptations of Western plays, but characters would often stand on the stage expounding on the current issues facing Chinese society, regardless of whether or not these were relevant to the plot of the source text. Although some critics point out that Cao Yu's works, including Thunderstorm, bear the marks of modern playwrights such as Eugene O'Neill and Henrik Ibsen, the characters of Thunderstorm were received among the audience as a portrayal of and commentary on Chinese society. As one of the first examples of the huaju dramatic style, Thunderstorm (1934) represents a new tendency in the Chinese perception of theatre at that time: local audiences were beginning to see theatre as a tool for social reform. Reformers in the decades after 1915 appealed to the genre of theatre, and especially modern forms such as huaju, in their mission to strengthen China through social reform' (Noble 2007, 113). Social reform remained a key aim of huaju writers at the high-water mark of this movement and was particularly crucial in the works of Cao Yu. According to the prologue written by $\mathrm{CaO} \mathrm{Yu}$, 'Writing towards the end, there seems to be a wave of emotions pushing me. I am letting out the depressed anger, and maligning families and society in China' (1936, iii). This explains why in China critics often interpret the initial play of Thunderstorm not as a family tragedy but rather as a critique of the society's unhealthy systems.

The circumstances surrounding modern Chinese theatre, especially the huaju movement led by playwrights such as $\mathrm{CaO} \mathrm{Yu}$, are not unlike the conditions for the reception for modern African drama and especially African adaptations of Western theatre classics. Scholars of African theatre like Brian Crow, Harry Garuba and Glen Odom have called for an expansion of critical perspectives in African theatre studies and the introduction of a 'historical dynamism' (Garuba 2001). ${ }^{20}$ Osofisan likewise offers a critique of postcolonial theory, arguing that it ignores the material conditions of existence in favour of theoretical abstraction:

It is no wonder, then, that [Western critics consider] the plays we write, and all the strategies we employ, as merely strategies to deconstruct the presence of colonization, as opposed to what they really are - attempts to confront $[\ldots]$ the various problems of underdevelopment which our countries are facing.

$(1999,3)$

Osofisan's interest in African theatre's capacity to instigate social change coincides with the stated goals for many works by Cao Yu including Thunderstorm discussed in this chapter. Osofisan points out that he finds striking similarities between the cultural contexts of Chinese and Nigerian literary works: 
I have observed, over the years since I have been coming here [China], that there is a growing interest, among students and faculty, in the field of African studies. This is perhaps not surprising, given the numerous similarities between our cultures - similarities which have inspired my students for instance to effortlessly undertake the translation into Chinese / Mandarin of some of the works that we studied in class; while I myself have had no difficulties at all adapting some Chinese masterpieces into the Nigerian context. ${ }^{21}$

The congruence in concerns animating modern African and Nigerian theatre and the huaju movement in China explains why Osofisan felt that the playwright's spirit suddenly 'floated up and came to speak to him', and he was 'surrounded by the ghosts of actors who once peopled his stage' (Osofisan in the afterword of the play, 2016, 71), while sitting in Cao Yu's memorial in Tianjin.

Through the resurrection of $\mathrm{Cao} \mathrm{Yu}$ and a shared history of Afro-Asian interactions, the play represents changing imaginations of China and Chinese people in African literature. ${ }^{22}$ This transformation raises new questions with respect to notions of Afro-Asian political solidarity constructed during the Bandung Conference and subsequent Non-Aligned Movement in the mid twentieth century. Throughout the Maoist period, these relations were pursued primarily with a view to promoting an ideology of anti-imperialist, Third World solidarity. Half a century after the end of colonial rule in Africa and Asia, the notion of a solidarity founded on antiimperialism is increasingly at odds with the new realities of a globalised world.

We see these tensions in a conversation between Chinese businessman Li Weiye and the Nigerian worker Tony: Li rebukes Tony and calls him a 'fire-eating young Mao' and 'Michael Imoudu' (Osofisan 2016, 55). Tony, based on the character of Lu Dahai in Cao Yu's play, is compared to two historical figures who represent the radical spirit of proletarian revolution in the twentieth century. The Nigerian workers' movement leader, Michael Imoudu, is seen by the playwright as the counterpart of Mao Zedong in China. In the author's conversation with Osofisan (August 2014), he mentioned that Mao had an ideological influence on some African nationalists and intellectuals during the 1950s and 1960s, when decolonisation and patronage from competing Cold War powers created opportunities for new alliances among people across the colonial and postcolonial world. By juxtaposing two influential socialist figures and invoking the common histories of anti-imperialism, the playwright questions the ideological disjuncture between current Africa-China relations and an earlier history of Afro-Asian solidarity during the Bandung era. Are the rising economies (including China's) with a revolutionary and antiimperialist past able to create new forms of cooperation to break the conquering and exploitative logics of capitalism, or do they simply end up reproducing what they were fighting against? In this sense, the adaptation troubles the 'Third Worldism and/or nationalism' that supposedly binds the peoples of non-Western societies 'in conflictless brotherhood' (Mukherjee 1993, 27), and the fantasy of a racially neutral encounter in Afro-Asian interactions.

Through this adaptation, the playwright also calls for further reflections on the current gaps in recent Afro-China engagements. The forgotten histories of cultural interactions, for instance the literary translation movement among Asian and African writers between the 1950s and $1970 \mathrm{~s},{ }^{23}$ constitute a stark contrast with the ongoing economically orientated engagements between Africa and China. According to Osofisan, his awareness of 'the urgent need to bridge the gap between China and Africa' (2016, 70), was what eventually brought him to Cao Yu's Thunderstorm:

True, there is a Chinatown now in Lagos and some other cities in Africa, just as there is an upsurge of African settlers in places like Guangdong province, but the unfortunate fact is 
that, as aggressive as the links may be growing on the business, agricultural and technological fronts, contacts at the intellectual and cultural levels are still lamentably poor.

(Osofisan 2016, 68)

We understand then that the playwright is not trying to simplify this encounter as an exploitative and subversive relationship through a stereotypical image of a Chinese capitalist. Instead, he reminds us that a prior pattern of engagement between China and Africa should neither be uncritically romanticised nor consigned to the dust heap of history. These earlier forms of engagement should be reactivated to allow for layered representations of a 'mutual gaze' between Africans and Chinese subjects that 'imperial eyes' would not have fostered. Despite the fact that this play has a tragic ending, Osofisan expresses his hope for future Afro-Asian encounters guided by alternative principles, involving, for instance, genuine, respectable relations between the younger generation of Chinese and Nigerians. This adaptation should be interpreted as the playwright's attempt to encourage familiarisation with specific literary and cultural histories, rather than through knowledges and narratives mediated by the West.

\section{Yan Geling's travelogue in Nigeria}

The past few years have seen an emergence of travel collections by Chinese writers who have lived or travelled in Africa. Some works document the authors' journeys in different African countries, for instance, Liang Zi's Ten Years in Africa (Feizhoushinian/非洲十年, 2012) and Bi Shumin's Thirty Thousand Miles in Africa (Feizhousanwanli/非洲三万里, 2016). Others, such as This is Africa (Shifeizhou/是非洲, 2012) by Gui Tao and Bye, Tower of Babel: When China Meets Africa (Zaijianbabieta, dangzhongguoyushangfeizhou/再见巴别塔, 当中国遇上非洲, 2013) by Chang Yuan and Yuan Qing, aim to challenge the often stereotyped images of Africa, and reflect on a growing 'cultural gap' between Africa and China. According to the authors, this is happening due to the lack of day-to-day interactions between Chinese and Africans, despite the intensifying economic and political ties. ${ }^{24}$ This section focuses on Yan Geling's book Notes on Africa (Feizhoushouji/非洲手记, 2013, 2016) and explores how these accounts complicate and problematise the postcolonial model of 'othering' as well as questioning the existing narratives of Africa-China encounters. I would like to suggest that the recent travel collections by Chinese writers reveal a rejection of the politics of imperialism and at the same time an inability to map out the positioning of Africa in relation to China without a detour through the West.

The writer Yan Geling is a prominent writer born in Shanghai, China in $1959 .^{25}$ She is one of the most acclaimed contemporary novelists and screenwriters writing in Chinese and most of her works have been adapted for the screen. She once served with the People's Liberation Army (PLA) during the Cultural Revolution of China, starting at the age of 12 as a dancer in an entertainment troupe of the army. She went to the USA for a writing programme in 1989 and married her husband Laurence Walker in Los Angeles in 1992. This book, Notes in Africa, first published in Chinese in 2013, was written during her stay in Abuja, Nigeria between 2004 and 2006. On the one hand, Yan's writing dissociates her from imperial projects and affirms her Chinese identity. On the other hand, her view of Nigeria continues to be mediated by Western references. Even her presence in Nigeria is mediated through her own personal association with Western society. ${ }^{26}$

In many respects Yan Geling's work departs from the conventions of Western travel writings, in privileging the depiction of a mobile and dynamic life in an African city. The gaze of travellers who self-identify as Western, often requires fixing Africans in a specific type of both spatial and temporal site, for instance traditional villages and natural landscapes. Africans on the 
move (both spatially and temporally) are often seen as threatening to the Western established images of Africa, "which are grounded in a long-standing fear of "unordered" and "chaotic" African space' (Dunn 2004, 483). Yan Geling dedicates lengthy paragraphs to writing about such features of life in Nigeria as the okada and the danfo, ${ }^{27}$ the bus stop, the flea market, the dye house and other everyday spaces that are not typical tropes in colonial and postcolonial travelogues.

In Yan's work, there is an insistence on the everyday which lends itself to the exposition of a specific history and specific culture. Different from Osofisan's accounts of the Chinese presence in Africa, Yan returns to the lived reality of local communities and the daily life of the people. As analysed in the section above, Osofisan's text manifests an African writer's concern with China's recent presence driven by state-led ideologies and policies. Characters like the powerful Chinese businessman in Nigeria in the adaptation, represent the symbol of aggressive stateorientated foreign capital, ${ }^{28}$ rather than a realistic depiction of the daily interactions between Africans and Chinese. By contrast, Yan Geling writes about daily encounters with Nigerians and reflects on the differences and commonalities of how people identify themselves through the frames of religion, gender, class and political ideologies. Yan recounts below a conversation with a lady who is a squatter in the neighbourhood. When the lady invites Yan to go to church, they have a long discussion on the role of religion in Nigerian and Chinese cultures.

I say I am an atheist, only believing in Darwin, truth, good and beauty. She asked where my parents go to church. I said they do not go to any church. She felt horrible, and asked: your elders are not religious? I said they believe in Marxism. She asked: What is that religion? I said you can teach it as a religion, but when it becomes a religion, I am afraid it will be worse ...

She did not quite understand what I said. She said she had never met anyone like myself, neither going to mosque nor visiting the church. I think she pitied me at that moment. Although it seems that she is a homeless squatter, metaphysically, I am spiritually homeless, not having even a single place to squat. ${ }^{29}$

(2016, 77-78)

Unlike the bulk of Western narratives of Africa, the writer does not pathologise the African world, its food, religion and values, in order to affirm her own normativity. Instead, she understands this otherness as the reference point allowing one to reflect on one's own culture and history. On the one hand, Yan seems to pity herself for being spiritually homeless, unlike the homeless squatter. On the other hand, both of her cultural references in this passage emanate from Western culture: Darwin and Marx. It is worth noting that both referents are also male figures. Here, Yan aligns herself culturally with foreign and Western males, in order to validate an African woman's perspective, but also to set up a contrast with the African woman.

The way Chinese author Yan Geling envisions her travel through Nigeria differs from the authors of many other postcolonial travel narratives. One can take, for instance, V. S. Naipaul's depictions of his travels to Africa, which could be interpreted as enacting a logic that 'enables an expression of imperialism to appear reasonable, even inevitable, despite the loss of the context of European empires' (Samantrai 2000, 50). By contrast, Yan clearly and repeatedly dissociates herself from the political project of imperialism. At the same time, her cultural references are often drawn from Western sources. And the basis for making comparisons with African society in her travelogue almost always involves a direct or indirect acknowledgement of Western references. One example can be found in Yan's discussion of the 'unique modernity' of the African city in a chapter titled 'Abuja Lying Down'. This is how she describes her observation 


\section{Ying Cheng}

of the urbanscape and urban life in Abuja during her daily walk routine. By 'lying down', she means that Abuja is a 'man-made city with infinite capacity and freedom of growth' (2016, 110). She writes about how plants, streets and landscapes change rapidly in 'an environment with great intensity'. At the end of this chapter, she writes:

Abuja does not have financial zones or dense skyscrapers blocking the sun like those in San Francisco or New York. Except for the Aso Rock, Abuja is soothing. If we say that the cities we are all familiar with are standing, then Abuja is lying down ... Getting up is inevitable, but she feels no sense of urgency about getting up and cannot see the necessity of getting up. Why can't I lie down, just because New York, San Francisco, and even Beijing are standing upright?

(Yan 2016, 110-111)

Here Yan considers how a Western-defined project of modernity has created normative landscapes where only one way of narrating or experiencing that space is allowed, while Abuja and other 'stubborn' Nigerian cities have not fallen into this pitfall of modernity. She also views the urbanscape of Abuja as a contrast to modernisation of cities like Beijing, and calls for reflection on the limitless pursuit of Western modernity in China. At the same time, Yan identifies herself with a group of people 'we' whose point of departure lies in the experience of cities like Beijing, New York and San Francisco. It is worth pointing out that the use of 'we' actually assimilates the Chinese and Westerners as equal partakers in creating cities that 'stand up'.

We can also note that as the wife of an American diplomat in Nigeria, Yan is given a unique position to observe and dwell on the dynamics of relations between Westerners and Nigerians. Some of the chapters in this book, for instance, 'Digesting Running' and 'Happy Hour' are about her observations of Westerners' lifestyles in Nigeria. The following paragraph documents her observation of the 'digesting running' activity organised by American and European embassies in Abuja:

Only once or twice, the running team passed through the streams, where beautiful young ladies from the village often wash clothes. The ladies turned their beautiful eyes on the huge white people - they could not have thought that these white people were running in the jungle driven by high cholesterol and high blood lipids. When material wealth and food abundance reaches a certain level, people start to ask for suffering. They abuse themselves either in the gym or in the wild, only for pain, sweat, and shortness of breath. People aimlessly relieving the energy from excessive food through self-abuse - this is called civilization.

(Yan 2016, 114)

Civilisation, a concept and trope through which the West locates itself and constructs the difference from its racial and cultural others, is deconstructed by Yan Geling in a satirical way. She uses her Chinese-ness to locate herself outside the dynamics of empire that characterise relations between Westerners and Nigerians. But it is also clear that this observation is less a commentary about African society than it is a reflection on Western society. Instead of ascribing bewilderment over the absurdities resulting from Western lifestyles to herself, she attributes it to an African gaze, that of the 'beautiful young ladies from the village'. Similarly, there is a sense in which this travelogue is as much a Chinese author's reflection on the legacy of the West around the world, as it is about a Chinese author's experience of life in an African country. Yan's observation of everyday life in Nigeria often runs parallel to her interpretation of the continuing 
imprint of colonialism in Nigeria. In the chapter titled 'Palace on the Earth', she criticises a colonial legacy that 'ruined' the design of modern Nigerian architecture, for instance:

The houses we live in all have a 'Boy's Quarter', which means 'homes for servants'. They are small in size, have no air-conditioners, and are extremely hot. African people have to count on the heat-resistance they inherited from their ancestors. Within the same wall, slums and mansions coexist. And the word 'boy's quarter' also makes me think: Regardless of whether they are men or women, young or old, they are all 'Boys' and it seems that people are despicable. In the eyes of superiors, they are always 'half people', 'adult boys' who do not deserve to be treated equally.

(Yan 2016, 13)

The architectural legacy of colonialism puts Yan, as an expatriate, in a unique position in her interactions with Nigerians despite her repudiation of colonialism. In another chapter of the book, she discusses the culture of 'kneeling down' among the housemaids and servants hired by American and European diplomats. She questions why Americans apply rules of 'equality' and 'independence' only within their own country but forget about these rules abroad. Once when a housemaid kneeled down in front of her, Yan blurted out, 'I am from People's Republic of China. People no longer kneel down since the year 1949. I joined the army at an early age hoping to liberate people humiliated by the kneeling culture' (Yan 2016, 154). It is worth noticing that Yan does not seem to be aware that kneeling is part of a specific Nigerian culture. It is customary in the Yoruba culture to curtsey or prostrate when greeting one's elders or people who occupy a higher social position. As part of a tradition, kneeling and greeting is a way of showing respect. It seems Yan ignores this part of local culture and simplifies kneeling as an embarrassing or demeaning behaviour, and a legacy of colonialism. The writer admitted that this claim of 'being a Chinese' was her unconscious response in that situation. The history of 'Afro-Asian solidarity' or the 'Third-world solidarity' was invoked here by the writer to imply how Nigerian-Chinese interactions are (or should be) different from relations between Westerners and Nigerians. In another chapter, Yan criticises her Chinese compatriots' racist behaviour in Nigeria. But even in this criticism of her own compatriots, the basis for the critique derives from their experience in Western society. Yan makes the following observation after watching the owner of a Chinese restaurant shouting at her Nigerian employee:

The discrimination and persecution against the yellow race by white people lasted for hundreds of years. From the 1960s to the Second World War, until the alliance of United States and China, the United States abolished the Chinese Exclusion Act ... In less than half a century, the Chinese started to repeat racial discrimination in Africa towards people with darker skin. My Chinese compatriots who were once treated as the colonized people, have already forgotten about the pain of being colonized, so fast and so completely.

$(2016,147)$

In Yan's writing, we see 'history' or 'historical selves' frequently being invoked to legitimate, criticise or interpret the present. However, the writer often finds herself in an ambivalent position: while exposing or critiquing the 'essentialism' inherent in many European representations of Africa, she is complicit in seeing the histories of African peoples only within the context of empire and thus as a continuation of that history. This ideology plays an important role in that it flattens the messy terrain of social conflicts in Nigeria into an easy formula of rivalry between Africa and the West. She attributes various social problems in Nigeria (for 
instance, traffic congestion, incomplete infrastructure, corruption and so on) to the legacy of colonial history.

One also finds that Yan's writing sometimes repeats the tropes and rhetoric of imperial travel writing. The title of the book, Notes on Africa exemplifies this tendency. Although the book is advertised by the author and the publisher as a collection of essays on travelling and living in Africa, the author Yan did not travel to other African countries apart from Nigeria. One can imagine that this title is a strategy for marketing the book in China, where the majority of the population has little knowledge about the history and culture of Nigeria or other African countries. It represents a common misinterpretation of the diversity of Africa among Chinese readers - what happens in one city or one country is very often generalised as situations prevalent on the whole continent. ${ }^{30}$

Moreover, although Yan attempts to challenge stereotypical images of Africa and African people, there are still unconscious references to the tropes of colonial writing. For instance, upon her arrival in Nigeria, Yan writes a letter to her father, an enthusiastic fan of African arts: 'With a car, I am able to go deep into Africa, visiting a tribe with more than two hundred languages, or a wildlife park with elephants and lions' $(2013,69) \cdot{ }^{31}$ In a later part of the letter, she writes, 'Africa is such a magical land. Even though people have not fed their belly, they never starve their eyes. They use their infinite vitality of art to feed the whole human mind. Without African art, there would be no Picasso.' Her first impression of the continent still involves animals, tribal life and how African arts - 'primitive idols, statues and masks with childlike, completely free imagination' (Yan 2016, 184) - have inspired Western artists like Picasso. In some other popular travelogues written by Chinese authors, for instance those by Gui Tao and Bi Shumin, although the writers invariably urge Chinese readers to reflect on the stereotypes of African culture and African people, one finds recurrent tropes and quotations taken from Karen Blixen's Out of Africa and Ernest Hemingway's Green Hills of Africa. This reveals how the Chinese writers' way of knowing the other continues to be mediated and disrupted by the hegemony of Western discourses. The ambivalence and conflicts in the literary works about Africa-China encounters have shown that, although often mediated by the discourses of 'AfroAsian solidarity', the representation of otherness is still shadowed by the rhetoric of the empire which implies the unequal power relations within this 'mutual gaze'. The continuing dynamic of unequal power relations between Africans and the Chinese give the Chinese writer Yan the privilege to move across different places and 'enjoy the cityscape from a height' (Yan 2016, 108).

\section{Conclusion}

Simon Gikandi $(2000,91)$ points out that the force of intertextuality in postcolonial texts would have to be determined by the specific circumstances in which texts were produced, the histories they invoked, and their conditions of reception. This chapter has explored how Western narratives of 'the other' have been appropriated consciously or unconsciously as the intertexts of creative writing by Chinese and Nigerian authors. In the discussion, I have argued for the importance of excavating historical and contemporary contexts in order to interpret the mutual representations of the 'the postcolonial other' within the context of the South.

An analysis of the representations of otherness in recent Nigerian and Chinese literary works suggests that, instead of being silenced, colonial and anti-colonial histories and the shadow of imperial narratives, have been functioning as the historical and political unconscious of the narratives representing contemporary Afro-Asian encounters. Creative writing from both Chinese and Nigerian writers is burdened by the 'tensions of postcoloniality', ${ }^{32}$ the inherited colonial legacies and possible future transformations that both African and Asian countries will 
have to negotiate (Lee 2010, 27). These tensions are encoded by writers in the process of representing and understanding each other, which suggests alternative approaches to studying cross-cultural interactions in our contemporary era. One needs to recognise and engage with the historical dynamism and material tensions of postcolonial societies, in order to avoid another 'single story' of Africa, and its dynamic interactions with the world outside.

\section{Notes}

1 Africa, the 'Orient' and the 'New World' have been represented as 'the other' of the West, see also Mudimbe (1988), Mignolo (2005), Said (1978), Hallam and Street (2013).

2 As I will elaborate later in this chapter, postcolonial criticism has favoured those texts 'writing back' to the centre, see also Pratt (2007), Ashcroft, Griffiths and Tiffin (2002).

3 Recent years have seen other research about how non-African people and cultures from other regions of the Global South are represented in African cultural productions. Scholars like Sarvan (1976), and Waliaula (2012) have studied how other Asian people have been represented in African literature, and pointed out that the corpus of East African literature has problematised or satirised the cross-cultural interactions by less than flattering depictions of the Asian world. In their analysis of Chinese characters in Ethiopian video-films, Jedlowski and Thomas (2017) provide an example of how Chinese characters are represented and discussed in African public spheres. Their paper suggests that stereotypical Chinese characters are mainly used as narrative devices functional in the development of inward-looking social criticism.

4 The growing relationship between China and Africa has been considered as one of the most striking geopolitical shifts of our contemporary era by media and academia. With the burgeoning of terms such as 'Chinafrica' and 'Sino-Africa', the academic literature on China-Africa relations has expanded and China-Africa has gradually been recognised as a field of study. These terms coincide with the recent emergence of the 'Global South' - a provisional term referring to what used to be called the 'Third World' or 'Asia-Africa'. In this chapter, I suggest that the understanding of literary interactions between Africa and China should be situated in these historical and contemporary contexts of geopolitical orders. Moreover, in this chapter, I privilege more neutral terms such as 'Africa-China' or 'China-Africa', instead of terms like 'Chinafrica' that seem to only emphasise China's growing access and influence throughout the African continent. Rather than a unidirectional phenomenon, the interactions between Africa and China are multi-directional and multi-layered.

5 China and Chinese appear in the celebrated African novelists' works, for instance, Chimamanda Ngozi Adichie's Americanah (2013), Sefi Atta's A Bit of Difference (2013), Billy Kahora's 'Selling World Power' (2007), Teju Cole's Everyday is for the Thief (2007) and others. In her article 'Breaking Discipline, Integrating Literature: Africa-China Relationships Reconsidered', Karen Laura Thornber (2016) provides a relatively comprehensive overview of African-Chinese encounters in African and Chinese literary works.

6 In an article with the giveaway title 'How China's Taking over Africa, and Why the West Should be VERY Worried', Andrew Malone (2008) writes, 'In the greatest movement of people the world has ever seen, China is secretly working to turn the entire [African] continent into a new colony.' David Blair (2007) asserts that China's relationship with Africa is directly comparable to Europe's Scramble for Africa, led by a 'motley collection of robber barons, imperialist ideologues, explorers, rogues and adventurers.' Media in Africa has also been influenced by the global media's imagination of China, and often affirms or promotes the stereotypes about the Chinese people. See also Sautman and Yan (2009), Huynh (2012).

7 In Chinese government discourses, China-Africa is often portrayed as a model of international partnership based on win-win cooperation. Recent scholarship (Musanga 2017; Marysse and Geenen 2009; Fijałkowski 2011) has raised new questions concerning the assumed 'win-win' rhetoric in the discussions on China-Africa relations.

8 Yan's book was first published in 2013, and a revised version was published in 2016. I will discuss in a later part how these two versions differ.

9 Scholars like Simbao (2012) and Huynh (2012) have realised the significant gap between expansive research on China-African economic or political engagement, and the lack of studies on China-African cultural interactions. 
10 The 1955 Asian-African Conference in Bandung, Indonesia (or the Bandung conference) is often seen as a symbolic moment of political solidarity between Asian and African countries during the early postcolonial period. In recent years, this history of third-world solidarity has been invoked by many Chinese public intellectuals such as Wang Hui, Dai Jinhua, Lydia H. Liu and others.

11 In 2015, Chinese scholars organised a 'BANDUNG - Third World 60 Years Initiative' in different Asian cities, taking the sixtieth anniversary of the 1955 Bandung Conference as an opportunity to reflect on the histories, trajectories and the conditions of the transformation of global geopolitics. In Africa, the inaugural Association of Asian Studies in Africa (A-Asia) Conference was held in Accra, Ghana in September 2015.

12 Initially published in Literary Quarterly/文学旬刊 in 1934, Cao Yu's Thunderstorm is considered the most famous spoken drama and the most frequently performed play in the history of Chinese theatre. Thunderstorm was adapted for film in 1938 and for dance play in 1981. Femi Osofisan started to adapt this play and named it 'All for Catherine' in 2013. Osofisan has directed staged readings of his adaptation All for Catherine at Peking University in China in 2014 and at Kwara State University in Nigeria in 2018. The Chinese translation of this adaptation was first published by Social Sciences Academic Press (China) in 2018.

13 The May Fourth Movement was an anti-imperialist, cultural and political movement by student participants in Beijing on 4 May 1919, protesting against the Chinese government's weak response to the Treaty of Versailles, especially allowing Japan to receive territories in Shandong which had been surrendered by Germany after the Siege of Tsingtao. These demonstrations sparked national protests and marked the upsurge of Chinese nationalism, a shift towards political mobilisation and away from cultural activities, and a move towards a populist base rather than intellectual elites. Many political, social and cultural leaders of the next decades emerged at this time.

14 The main characters of Thunderstorm can be divided into two groups: a businessman named Zhou Puyuan, his wife Fanyi and his sons Ping and Chong; and Puyuan's abandoned first wife Lu Shiping, her husband Lu Gui, her son Dahai and her daughter Sifeng, who works as a maid in Zhou's house. Along with the scenes around the ruthless oppression by Zhou, the play revolves around a series of tragic triangular relationships, both past and present.

15 For online discussions about this protest, see www.chinaafricarealstory.com/2013/02/nigerian-work ers-protest-conditions-at.html.

16 Interview with Osofisan in June 2016.

17 Catherine is Tony's sister by another father, a Nigerian man Etim. She works in Li's family as a housemaid and falls in love with Li's elder son.

18 Correspondence with Femi Osofisan, Sola Adeyemi, Wang Shang and Yan Gurun from August 2014 to December 2014. Osofisan had at least six different versions of the adaptation. In the process of revision, he took the readers' advice, and deleted some of the exaggerated and straightforward comments of Li Weiye about 'degenerate Nigerian youths', 'lazy, troublesome, thieving Nigerians' and so on. Moreover, in the adaptation, there is also a contrast between two generations of Chinese-Nigerian interactions.

19 The aim of this movement was to create a form of theatrical expression that was new not only in its abandonment of the conventional media of singing, reciting, acting, dancing and martial arts, but also in its adoption of the vernacular spoken language as its basic form to spread new ideas. For more on this, see also Tian and Ouyang (1963).

20 In Garuba's analysis of postcolonial drama, he suggests that, discarding the material and figural centrality of the explorer-colonist, African plays return to the lived reality of the island communities to record the daily lives of the people. There is an insistence, at every point, on a historical and cultural past of local communities.

21 Osofisan's keynote speech during China's first conference on African languages and literatures held in Peking University in May 2014.

22 In earlier literary works, we come across characters with 'ideal' qualities attributed to Chinese culture. For instance, in Athol Fugard's My Children! My Africa! (1993), Mr. M. describes himself as a black Confucius (the Chinese philosopher, 551-479 BC), and believes in education as the only way to ensure changes in a society.

23 During this period, large numbers of Asian and African literary works were translated for readers on both continents. African literary works, for instance, Achebe's Things Fall Apart, were translated and published in Chinese in the 1950s before they were widely circulated in other parts of the world. Moreover, modern Chinese literature (works by Lu Xun, Mao Dun, etc.) were introduced to Nigeria 
and other African countries. Besides, from the end of 1957 to the beginning of 1958, the first meeting of The Afro-Asian People's Solidarity Organization was held in Cairo, Egypt. In October 1958, the First Afro-Asian Writer's Conference was held in Tashkent, Uzbekistan.

24 For more on this, please see Chang and Yuan $(2013,2)$.

25 Yan is the writer's family name.

26 Yan moved to Nigeria with her American diplomat husband in 2004, and they lived in Abuja for two years.

27 Okada and danfo are public transport vehicles that play an essential role in the lives of millions of Nigerians. Okada is a motorcycle taxi. The name was borrowed from Okada Air, a Nigerian local airline. Danfo ('dánfó' in Yoruba) is the yellow minibus that normally carries approximately 16-18 passengers, or even more.

28 The Nigerian workers' strike that inspired Osofisan's adaptation happened in a state-owned Chinese company. These state-run enterprises are often accused of being inaccessible to non-Chinese and of excluding the local communities. Osofisan's adaptation is based on his understanding of these stateowned Chinese enterprises.

29 All quotations of Yan's work in this chapter are translated by the author of this chapter.

30 This is also very common in other Chinese travelogues in Africa. For instance, in Chinese journalist and travel writer Gui Tao's book titled This is Africa (2012), the author tends to generalise his observations in Kenya to represent the whole African continent.

31 This letter only appeared in the first version of the book published in 2013. It was removed in the second version published in 2016.

32 Lee points out that tensions of postcoloniality refers to the complex, and at times contradictory, set of aims and conditions situated between the rhetoric of revolution and the pragmatism of governance, defiance of the West and continued forms of economic and political need.

\section{References}

Adichie, Chimamanda Ngozi. 2013. Americanah. New York: Anchor Books.

Ashcroft, Bill, Gareth Griffiths and Helen Tiffin. 2002. The Empire Writes back: Theory and Practice in Postcolonial Literatures. London: Routledge.

Atta, Sefi. 2013. A Bit of Difference. Northampton, MA: Interlink Books.

Barber, Karin. 1995. 'African-language Literature and Postcolonial Criticism'. Research in African Literatures 26(4): 3-30.

Bhabha, Homi K. 1994. The Location of Culture. London: Routledge.

Blixen, Karen. 1954. Out of Africa. Harmondsworth: Penguin.

Bi, Shumin/毕淑敏. 2016. Thirty Thousand Miles in Africa/非洲三万里. Changsha/长沙: Hunan Literature and Art Press/湖南文艺出版社.

Blair, David. 2007. 'Why China Is Trying to Colonise Africa'. The Telegraph, August 31. www.telegraph. co.uk/comment/personal-view/3642345/Why-China-is-trying-to-colonise-Africa.html.

Bofane, In Koli Jean. 2014. Congo Inc.: Le Testament de Bismarck. Arles: Actes Sud.

Bofane, In Koli Jean. 2018. Congo Inc.: Bismarck's Testament. Bloomington: Indiana University Press.

Bulawayo, NoViolet. 2013. We Need New Names. London: Vintage Books.

Caminero-Santangelo, Byron. 2004. African Fiction and Joseph Conrad: Reading Postcolonial Intertextuality. Albany: State University of New York Press.

Cao, Yu/曹禺. 1936. Thunderstorm/雷雨. Shanghai/上海: Shanghai Culture Life Press/上海文化生活出 版社.

ChangYuan and Yuan, Qing/常远 and 袁卿. 2013. Bye, Tower of Babel: When China Meets Africa/再见巴 别塔: 当中国遇上非洲. Beijing/北京: Peking University Press/北京大学出版社.

Chen, Kuan-ksing and Lang, Jing/陈光兴 and 郎静. 2017. 'Africa as the Approach for Third-world Critical Thoughts'/非洲作为方法的第三世界思想路线 - - 陈光兴教授访谈'. China Book Review 3中 国图书评论第三期: 66-75.

ChengYing. Interviews and correspondence with Femi Osofisan in August and December 2014, October 2015 and June 2016.

Cole, Teju. 2007. Everyday is for the Thief. New York: Random House.

Clifford, James and George Marcus, eds. 1986. Writing Culture: The Poetics and Politics of Ethnography. Berkeley: University of California Press. 


\section{Ying Cheng}

Dunn, Kevin C. 2004. 'Fear of a Black Planet: Anarchy Anxieties and Postcolonial Travel to Africa'. Third World Quarterly 25(3): 483-499.

Fabian, Johannes. 1991. Time and the Work of Anthropology: Critical Essays 1971-1991. Chur, Switzerland: Harwood Academic Publishers.

Fan, Christopher T. 2017. 'Battle Hymn of the Afropolitan: Sino-African Futures in Ghana Must Go and Americanah'. Journal of Asian American Studies 20(1): 69-93.

Fijałkowski, Lukasz. 2011. 'China's "Soft Power" in Africa?' Journal of Contemporary African Studies 29(2): 223-232.

Fugard, Athol. 1993. My Children. My Africa. New York: Theatre Communications Group.

Gandhi, Leela. 1998. Postcolonial Theory: A Critical Introduction. Sydney: Allen \& Unwin.

Garuba, Harry. 2001. 'The Island Writes Back: Discourse/Power and Marginality in Wole Soyinka's The Swamp Dwellers, Derek Walcott's The Sea at Dauphin, and Athol Fugard's The Island'. Research in African Literatures 32(4): 61-76.

Gikandi, Simon. 2000. 'Reading the Referent: Postcolonialism and the Writing of Modernity'. In Reading the 'New' Literatures in a Postcolonial Era, edited by Susheila Nasta, 87-104. Cambridge: Brewer.

Gui, Tao/桂涛. 2012. This is Africa/是非洲. Beijing/北京: China Encyclopedia Press/中国大百科全书出 版社.

Hall, Stuart. 1980. 'Race, Articulation and Societies Structured in Dominance'. In Sociological Theories: Race and Colonialism, edited by Marion Patrick Jones, 305-345. Paris: Unesco Publishing.

Hall, Stuart, ed. 1997. Representation: Cultural Representations and Signifying Practices (Vol. 2). London: Sage.

Hallam, Elizabeth and Brian Street, eds. 2013. Cultural Encounters: Representing Otherness. London: Routledge.

Hemingway, Ernest. 1935. Green Hills of Africa. New York: Scribner.

Holland, Patrick and Graham Huggan. 2000. Tourists with Typewriters: Critical Reflections on Contemporary Travel Writing. Ann Arbor: University of Michigan Press.

Huynh, Tu. 2012. 'What People, What Cultural Exchange? A Reflection on China-Africa'. African EastAsian Affairs 2: 3-16.

Jedlowski, Alessandro and Michael W. Thomas. 2017. 'Representing "Otherness" in African Popular Media: Chinese Characters in Ethiopian Video-films'. Journal of African Cultural Studies 29(1): 63-80.

Jiang, Hui/蒋晖. 2017. 'Pragmatism or Westernization: What Kind of African Literature Should China Have?’‘载道还是西化: 中国应有怎样的非洲文学研究?’ Shandong Social Science 6/山东社会科学第6 期: 62-76.

Jones, Rebecca. 2014. 'Journeys to the Hinterland: Early Twentieth-Century Nigerian Domestic Travel Writing and Local Heterogeneity'. Postcolonial Text 9(4): 1-19.

Kahora, Billy. 2007. 'Selling World Power'. Kwani? 4: 350-364.

Lee, Christopher J., ed. 2010. Making a World after Empire: The Bandung Moment and Its Political Afterlives. Athens: Ohio University Press.

Liang, Zi/梁子. 2012. Ten Years in Africa/非洲十年. Beijing/北京: CITIC Press/中信出版社.

Madondo, Bongani. 2016. 'Jozi 2020: Made in China'. In Sigh, The Beloved Country: Braai Talk, Rock ' $n$ ' Roll \& Other Stories, 471-480. Johannesburg: Picador Africa.

Malone, Andrew. 2008. 'How China's Taking over Africa, and Why the West Should Be VERY Worried'. The Daily Mail, 18 July. www.dailymail.co.uk/news/article-1036105/How-Chinas-taking-Africa -West-VERY-worried.html.

Marysse, Stefaan and Sara Geenen. 2009. 'Win-Win or Unequal Exchange? The Case of the Sino-Congolese Cooperation Agreements'. The Journal of Modern African Studies 47(3): 371-396.

McClintock, Anne. 1992. 'The Angel of Progress: Pitfalls of the Term "Post-colonialism"'. Social Text 31/ 32: 84-98.

Mignolo, Walter D. 2005. 'Prophets Facing Sidewise: The Geopolitics of Knowledge and the Colonial Difference'. Social Epistemology 19(1): 111-127.

Moyo, Sam. 2016. 'Perspectives on South-South Relations: China's Presence in Africa'. Inter-Asia Cultural Studies 17(1): 58-67.

Mudimbe, Valentin-Yves. 1988. The Invention of Africa. Bloomington: Indiana University Press.

Mukherjee, Arun. 1993. 'First World Readers, Third World Texts: Some Thoughts about Theory and Pedagogy'. Gulliver 33(1): 24-36.

Musanga, Terrence. 2017. 'Perspectives of Zimbabwe-China Relations in Wallace Chirumiko's Made in China (2012) and NoViolet Bulawayo's We Need New Names (2013)'. Journal of African Cultural Studies 29(1): 81-95. 
Mwangi, Evan. 2010. Africa Writes Back to Self: Metafiction, Gender, Sexuality. Albany: State University of New York Press.

Noble, Jonathan. 2007. 'China: Modern Theatre'. In Encyclopedia of Asian Theatre Vol. 1, edited by Samuel L. Leiter, 111-119. Westport, CT: Greenwood Press.

Odom, Glen. 2015. Yorùbá Performance, Theatre and Politics: Staging Resistance. London: Palgrave Macmillan.

Osofisan, Femi. 1999. 'Theater and the Rites of "Post-Negritude" Remembering'. Research in African Literatures 30(1): 1-11.

Osofisan, Femi. 2016. All for Catherine (English version). Unpublished manuscripts (1st-6th version), courtesy of Femi Osofisan.

Osofisan, Femi. 2018. All for Catherine (Chinese version)/一切为了凯瑟琳. Translated by Yang, Mengbin/杨梦斌译. In Annual Review of African Studies in China/中国非洲研究评论, edited by Jiang, Hui/ 蒋晖编, 397-456. Beijing/北京: Social Science Academic Press (China) /社会科学文献出版社.

Pratt, Mary Louise. 1991. 'Arts of the Contact Zone'. Profession '91, 33-40. New York: MLA.

Pratt, Mary Louise. 2007. Imperial Eyes: Travel Writing and Transculturation. London: Routledge.

Said, Edward. 1978. Orientalism: Western Representations of the Orient. New York: Pantheon.

Samantrai, Ranu. 2000. 'Claiming the Burden: Naipaul's Africa'. Research in African Literatures 31(1): 50-62.

Sarvan, Charles Ponnuthurai. 1976. 'The Asians in African Literature'. The Journal of Commonwealth Literature 11(2): 160-170.

Sautman, Barry and Yan, Hairong. 2009. 'African Perspectives on China-Africa Links'. The China Quarterly 199: 728-759.

Simbao, Ruth. 2012. 'China-Africa Relations: Research Approaches'. African Arts 45(2): 1-7.

Spurr, David. 1993. The Rhetoric of Empire: Colonial Discourse in Journalism, Travel Writing, and Imperial Administration. Durham, NC: Duke University Press.

Thornber, Karen L. 2016. 'Breaking Discipline, Integrating Literature: Africa-China Relationships Reconsidered'. Comparative Literature Studies 53(4): 694-721.

TianHan and Yuqian, Ouyang/田汉 and 欧阳予倩. 1963. A Collection of Resources on the Fifty Years of Chinese Spoken Drama Movement/中国话剧运动五十年史料集. Beijing/北京: Chinese Theatre Press/ 中国戏剧出版社.

Van Weyenberg, Astrid. 2010. 'Antigone as Revolutionary Muse: Fémi Òsófisan’s Tègònni: an African Antigone'. In Interrogating Antigone in Postmodern Philosophy and Criticism, edited by S. E. Wilmer and Audronė Žukauskaitè, 366-378. Oxford: Oxford University Press.

Waliaula, Ken Walibora. 2012. 'The Asian “Other”, Frontline 29(16) (11-26 August). https://frontline. thehindu.com/static/html/fl2916/stories/20120824291609800.htm (Accessed 20 February 2018).

Yan, Geling/严歌苓. 2013. Notes on Africa/非洲札记. Beijing/北京: Beijing United Press/北京联合出版 公司.

Yan, Geling/严歌苓. 2016. Notes on Africa/非洲手记. Beijing/北京: People's Press/人民出版社. 


\title{
8
}

\section{Ethnicity in post-2000 African writing}

\author{
Aghogho Akpome
}

This chapter examines the use of ethnicity in the exploration of social subjectivities in selected African novels and memoirs published since the turn of the twenty-first century. In the opening part of the chapter, I argue that, in general, ethnicity is used in recent African writing in ways that are significantly different from many earlier texts, especially those that belong to the socalled first generation. In contrast to the largely cultural nationalist orientation of seminal African texts such as Chinua Achebe's trilogy, ethnicity is deployed in recent writing in ways that are much more fluid and ambivalent. In this regard, I argue that referents of ethnicity and indigenous African cultures can be understood in recent writing in different ways. They may operate as metonym and/or metaphor for other categories of identification and may sometimes conflate and contest the complex forms of social consciousness that characterize the postcolonial and postmodern contexts of identity (re)construction among African narrative subjects. I therefore approach references to the 'ethnic' in terms of narrative strategies that complicate a range of contemporary subjectivities including region, race, class, nation, gender and autochthony.

I consider representations of, as well as references to, indigenous African languages, customs as well as cultural practices and artifacts as de facto ethnic referents. It is these representations that I interrogate in two novels and two memoirs selected from across regions. The novels are Coconut (2007) by South Africa's Kopano Matlwa and Purple Hibiscus (2003) by Nigeria's Chimamanda Ngozi Adichie, while the memoirs are An Ordinary Man (2006) by Rwandan former hotelier, Paul Rusesabagina and My First Coup D'etat (2012) by John Dramani Mahama, who was vice-president and president of Ghana. These texts are chosen for the range of social, political, geographical and historical situations they represent as well as for their impact and significance - literary and otherwise. The combination of novels and memoirs is an attempt to extend the analysis beyond narrow narrative and aesthetic modes. While each novel is examined for its representation of ethnicity (through its use of referents from a single ethnic group), the memoirs offer portrayals of narrative referents belonging to different groups in the context of national and inter-regional politics. Together, these four texts provide scope for a robust and productive inquiry into the new paths being charted by recent African literatures that reflect the continuing significance of ethnic sensibilities.

In Define and Rule: Native as Political Identity (2013), Mahmood Mamdani provides a particularly insightful exploration of the ways in which the identities of indigenous African peoples 
(variously designated 'native' and 'tribe') became invested with enduring political force by colonial divide-and-conquer policies. Mamdani demonstrates how these policies served imperial interests and were founded upon discredited anthropological and historiographical constructs such as the infamous 'Hamitic Hypothesis' of John Hanning Speke. Using Nigeria as example, and invoking the Nigerian historian, Yusuf Bala Usman, Mamdani (2013, 105-106) contends that 'contemporary ethnic nationalities ... were actually created in the process of the formation of the colonial state in Nigeria':

[B] efore the coming into being of Nigeria, there was no ethnic nationality called 'Hausa', as was the case today. Instead, what we had were Kanawa, people of Kano; Katsinawa, people of Katsina; Zage-Zagi, people of Zazzau; Sakkatawa, people of Sokoto, etc. The same really applied to the Yoruba, who were identified as Egba, Oyo, Ekiti, Ijebu, etc.

Notions of ethnicity continued to evolve during the period of anti-colonial agitation across colonial Africa. This intensified in the periods proximate to, and especially after, independence as politicians mobilized cultural histories, affinities and geographical contiguity in forming the political alliances that provided access to state power and resources. Again, the case of Nigeria is a good example. Eghosa Osaghae and Rotimi Suberu (2005) have demonstrated the fluidity of ethnic identity in Nigeria, noting that what may be considered to be a distinct ethnic group at one stage may have been part of a different collective earlier. They also point out that 'Nigerians are more likely to define themselves in terms of their ethnic affinities than any other identity' given that 'ethnic formations are perhaps the most historically enduring behavioural units in the country, and were further reinforced by the colonial and post-colonial regimes' (8-9).

Although texts classified within what is arguably described as Africa's 'third generation' literatures increasingly foreground the fluidity and multiplicity of African identities, this chapter reveals some of the ways in which recent writing continues to reflect the enduring importance of ethnic sensibilities to contemporary African narrative subjects. This is in spite of the extremely cosmopolitan and globalized contexts of recent African literary production and circulation with an increasing number of writers born after independence and living outside their home countries (Attree 2013). Similarly, Pius Adesanmi and Chris Dunton (2008, 15-16), focusing on Nigerian literature, point out that recent writing is marked by the absence of an overdetermining 'traditionalist centre [and] the domestication-impulse' of earlier texts as well as the use of predominantly urban settings and a 'euromodernist' and globalized ambience.

Before proceeding to a close analysis of the chosen texts, I begin with the important caveat that I do not approach African literatures in general and the chosen texts as ethnic literatures. Rather, I examine them for the ways in which ethnic referents play significant roles in the exploration of modern African subjectivities. In this connection, I take Achebe's (1976, 56) description of African literature as the aggregate of the continent's 'national and ethnic literatures' to indicate the significance of nation and ethnicity as frames of reference in modern African literary expression. Achebe's earlier novels are among the most iconic works of the socalled first generation of African literatures in English. Writing in apparent response to the disparaging depiction of the colonized African subject in colonial narratives such as Joseph Conrad's Heart of Darkness and Joyce Carey's Mister Johnson, ${ }^{1}$ one of Achebe's chief successes was the rehabilitation of the individual and collective African subject through his adroit depiction of Igbo ethnic culture in Things Fall Apart. This has led to what Harry Garuba (2003, 145) describes as the novel's eventual 'hypercanonisation' ${ }^{2}$ as a repository of 'documentary evidence for anthropological studies and sociological speculations ... [and] the representative text of the African response to European colonialism and modernity'. 


\section{Aghogho Akpome}

Things Fall Apart owes its stature, in large part, to its compelling ethnography which familiarizes Igbo ethnic culture to a worldwide readership through innovative textualization of its historical traditions, language, worldviews and socio-political organization. It is indeed for this reason that it is considered as a leading example of 'Igbo literature in English' (Igboanusi 2001, 53). Sol Plaatje's pioneering novel Mhudi (1930) offers a romanticized narrative of early urbanization as well as social organization among the Barolong peoples of colonial Bechuanaland in the latter part of the nineteenth century. For his part, Wole Soyinka has provided useful sociological insight into aspects of Yoruba ethnic culture through his works, a good example being his exploration of the practice of ritual suicide by the royal horsemen of the ancient Yoruba kingdom of Oyo in Death and the King's Horseman (1975). The play was one of the works mentioned in his Nobel Prize citation in 1986 and is based on an actual incident in 1946 that baffled the colonial authorities at the time. Similarly, the Malawian poet, Jack Mapanje used his poetry to trace parallels between ethnic Chewa and Greek mythology, Kofi Awoonor's works popularized the folklore of Ghana's Ewe peoples, Ngũgĩ wa Thiongo's Weep Not Child (1964) explores Gikuyu mythology and Mongo Beti's Mission to Kala (1957) provides a fascinating exposition of Cameroon's Vimli culture of polygamy.

In the examples mentioned above, fictional ethnographic representations of African cultures served collectively - by design or default - to foreground the unique ethnic sensibilities of their respective subjects such that individual cultures become identifiable, knowable and distinguishable from one another. This is significantly different from the largely homogenizing and reductive representations offered in colonial anthropological narratives. It is important to make a crucial distinction here between the role of these texts in the articulation and creation of African and pan-African subjectivities versus their role in foregrounding the specificities of Africa's myriad ethnic and cultural identities. In this regard, it is also important to question the prevailing critical tradition of reading the protagonists of such texts as Things Fall Apart and Weep Not Child almost exclusively in terms of their perceived metonymic value of standing in for a putative generic African subject, a practice that echoes the totalizing misrepresentations of Africa in colonial narratives. Furthermore, the indigenous oral narrative traditions adapted in these novels' aesthetic modes reflect the ethnic subjectivities of their writers as well as the uniqueness of their ethnic subjects and referents. This is highlighted in Abiola Irele's $(1981,10)$ observation of the ways in which 'areas of collective awareness that have been determined by ethnic, historical and sociological factors affect and express themselves in [African] literature, marking off for it a broad area of reference' (emphasis added).

Among some of the major texts published in the years directly following independence, ethnicity featured in the literary imagination in markedly different ways as the emerging postcolonial nation-state increasingly became the dominant center of interest and frame of reference. Seminal examples include Achebe's A Man of the People (1966) and Ayi Kwei Armah's The Beautyful Ones Are Not Yet Born (1968), both of which are symptomatic of what Neil Lazarus calls the 'rhetoric of disillusion' that dominated the novels of the early post-independence period. It is quite significant that $A$ Man of the People breaks from Achebe's preceding three novels by being set not in a specific Igbo or Nigerian settlement, but in a fictional country which, while strongly resembling Nigeria, operates as a metonym for post-independence Africa. In the same vein, the absence of any specific ethno-cultural group as well as the negligible ethnic referents in the text (such as the names of characters) can be understood as avatars for Nigeria and for postcolonial African national subjects in general. ${ }^{3}$ Armah adopts a similar strategy in The Beautyful Ones Are Not Yet Born which uses a nameless protagonist to lament political corruption in post-independence Ghana. This part of the discussion of ethnic referents in postindependence African texts would be incomplete, brief though it is, without reference to texts 
belonging to what may be called 'Biafran War literature' namely the fictional and non-fictional works on the Nigerian Civil War of 1967-70. The first set of texts in this corpus was published soon after the war and some of them included considerable focus on the ethnic oppositions that formed a major part of the fratricidal war. It is safe to say that ethnic referents among these texts operate in ways that are significantly different from the trend observed in post-independence African writing in general. Detailed discussion of how ethnicity is represented in Biafran War literature is however outside the scope of the present inquiry. ${ }^{4}$

As noted earlier, one of the key features of the transnational, postmodernist and late postcolonial contexts within current African literatures is the protean nature, not only of subjecthood but also of processes of narration (Adesanmi and Dunton 2005). The analysis to follow demonstrates the multiple and ambivalent ways in which textualizations of indigenous African ethnic referents dramatize different forms of consciousness produced in different cultural contexts. I begin with Kopano Matlwa's Coconut (2002) where ethnicity is deployed as an avatar of racial difference in the novel's construction of a form of black (South) African identity produced in binary opposition to whiteness. In an apparent effort to contest and problematize official discourses of post-reconciliation ${ }^{5}$ social cohesion in South Africa, Coconut explores the profound social differences that continue to mark inter-racial relations. It does this by focusing on the identity crises plaguing some young black South Africans growing up in the country's still mutating social, cultural and political milieu. I focus on the delineation of Ofilwe, one of the novel's two main protagonists, who begins to question her suburban upbringing among white South Africans and embarks on a journey to discover her indigenous African cultural identity. It is in this regard that the novel invokes aspects of Ofilwe's ethnic Pedi culture - language, rituals - in ways which, I argue, render Pedi ethnicity as little more than a metonym for a presumed form of totalized indigenous African cultural identity.

Given the mission of this chapter, it is important to begin this discussion of Coconut by foregrounding the ways in which the novel can be understood within the specific socio-political contexts of post-reconciliation South Africa. Ralph Goodman $(2012,109)$ has demonstrated how the novel reflects the enduring effects of apartheid on race relations, and 'how structures that promote inequality and fix identity survive by skillful adaption to changing circumstances.' Gugu Hlongwane (2013, 9), for her part, considers how the delineation of the novel's characters highlights the un-abating social and economic 'power of whiteness' that results in the devaluation of blackness among young black South Africans. There is no doubt therefore that racial difference and race relations are at the very core of the novel's thematic mission. It is entirely reasonable to contemplate its other concerns in terms of how they are linked to the central questions that Matlwa raises. This consideration is a cornerstone of how invocations of ethnicity are explored in this discussion.

Set in the years following the end of apartheid, the novel explores the crises of identity experienced by two young black South African women, Ofilwe and Fikile, who are positioned at opposite ends of the country's socio-economic spectrum. Growing up in an impoverished black township and a dysfunctional home, Fikile rejects her black identity and is determined to transform herself into a white person. For her part, Ofilwe is raised in a Johannesburg suburb where she is surrounded by, and enjoys, the socio-economic privileges common to many South African whites, and seems unaware of issues of race. This changes after her brother, Tshepo, forces her to question her assumptions about race relations while pointing out that she has grown almost completely out of touch with their indigenous culture. In response to Tshepo's nudging, Ofilwe undergoes a psycho-social metamorphosis dramatized through her personal reflections on racial inequities in contemporary South Africa. During this process, she breaks up 


\section{Aghogho Akpome}

with her best friend Belinda, who is white, and commits herself to learning Pedi culture and speaking the language.

To interrogate the role of ethnicity in Ofilwe's journey towards self-realization, it is important to note that the narrative does not follow a linear temporal path but loops back and forth between the narrative present and different periods in the past to capture different important moments and stages in the transformation of her consciousness. ${ }^{6}$ And while we are not told the specific point at which she begins to reconsider her racial and ethnic sense of self, we learn of the incident whose recall triggers her psycho-social turning point. This incident, recorded towards the very end of Part One of the novel, which focuses on Ofilwe, happens when Tshepo confronts her with the fact that all the people she admired, and whose posters she had on her room walls, were white:

There was not a single face of colour on the wall, I had not noticed. Honest. It was only after he pointed it out that I saw it too. I mean, why on earth would I do something like that intentionally? What did it matter anyway? It was purely a coincidence; perhaps there were not black faces I liked in the magazines I cut out from. 'None at all?' I looked around once more and then at Tshepo. In his eyes I saw what was only to hit me many years from then. I think it was on that day that Tshepo saw me for what I was. I wish I had then too; maybe things would have worked out differently.

(Matlwa 2007, 92-93; original italics)

This passage illustrates that her growing race consciousness is the overriding motivation for Ofilwe's interrogation of her social assumptions as well as her newfound interest in her Pedi ethnicity. Another incident that reinforces this racial awakening is recorded earlier in the narrative where Tshepo forces her to defend the fact that all her close friends are white; asking: 'Who are you, Ofilwe? You do not know who you are' (42; original italics). Against this backdrop, the reflections and recollections that map Ofilwe's psycho-social metamorphosis become instructive. The following aspects of her transformation are especially important: her growing skepticism towards Christianity, her detachment from Belinda, her enhanced awareness of race relations in her society and her gradual self-conscious identification with blackness in general (31). I will examine each briefly while foregrounding their connection to this chapter's central argument on the overall deployment of ethnicity in the novel.

The first debate between Tshepo and Ofilwe that we read about is the one in which Tshepo questions the genuineness of Christianity, likening its profound socio-cultural influences to the result of sustained 'advertising' (5). When Ofilwe rejects this description, Tshepo simply says, 'All I am saying is that my skin is black' in a way that reinforces the importance of racial identity to the narrative. And although she initially dismisses Tshepo's cynicism as exuberant 'Africanism' (5), we soon find her admitting that she 'understand[s] nothing of the history of the church. I do not know what the word "Anglican" means nor can I explain how the church came to arise' (9). At about the same time, she begins to inquire about indigenous Pedi religious beliefs from her mother (9). The symbolism of the racial orientation of Ofilwe's increasing skepticism towards Christianity is borne out practically in her increasing detachment from Belinda and the eventual termination of their friendship. Amidst recollections of the development of their friendship from childhood and Tshepo's protestations that Ofilwe is merely 'the backstage crew in the drama' of the lives of her white friends, Ofilwe eventually reaches the conclusion that she was 'different' from, and 'really "better off' without them' (48).

It is revealing that Ofilwe's detachment from her links to whiteness (through Christianity and her white friends) is accompanied simultaneously by her developing of interest in race relations and ethnic Pedi culture. Her initial indifference to race gradually gives way to a strong sense of 
a collective black identity that encompasses her own suburban subjectivities and those of less privileged blacks which manifests in her lamentation that 'we may not be black in restaurants, in suburbs and in schools' (31). Upon close scrutiny of the novel's invocations of ethnicity however, there is little evidence that Ofilwe's newfound interest in Pedi culture, under the influence of Tshepo's intense intellectual stimulation, is more than a tokenist narrative gesture that operates as a signifier of her rejection of whiteness and as a badge of her blackness. The earliest references to Pedi language and culture are found in the portion of the text where she discusses Christianity with Tshepo and where she asks her mother about their pre-colonial religious beliefs. In this part of the narrative, she not only bemoans her lack of competence in the 'ageold Pedi rituals' observed during nuptial, burial and thanksgiving ceremonies, but expresses her 'reverence' for, and eagerness to learn these observances. Elsewhere in the story, she is hanging out with friends who begin to speak in some of South Africa's indigenous languages - 'IsiZulu, isiXhosa, sePedi, seTswana' - and share 'their clan names and the histories behind them' (59).

Yet, these references provide no substantial exploration of ethnic Pedi culture whether in terms of social systems, world view or history in the ways that, for instance, Sol Plaatje's Mhudi provides a romanticized portrayal of the Tswanas as a peace-loving people. When Ofilwe declares that she 'stands in reverence' absorbing the 'age-old Pedi rituals' mentioned earlier, we are left without a clue of what those rituals actually are and what actually inspired her reverence for them; neither do we learn what specific traditional values or philosophies underpin those rituals. Moreover, the fact of Ofilwe's 'Pedi-ness' contributes little or nothing of significance to our understanding of her attempts to deal with her identity crisis and to negotiate the complex social, cultural and political changes her society is undergoing. It is in this sense therefore that ethnicity operates in ways that are different from its connotation of a system of identification based on apparently unique sets of cultural features. Rather, ethnicity can be understood in this text as a metonym for multiple and often intertwined and marginalized subjectivities which are deployed figuratively to resist the assimilationist tendencies of the dominant and enduring sociocultural ethos of whiteness. In the specific context of post-reconciliation South African transition, the foregrounding of Ofilwe's ethnic and black identity can also be read as a means of problematizing the totalizing political discourses of cosmopolitan nationalism that tend to obliterate significant and enduring forms of social and cultural difference.

The discussion now turns to Adichie's well-received debut novel, Purple Hibiscus (2003) which tells the story of the Nigerian family of Eugene Achike, a wealthy philanthropist and devout Catholic who abuses his wife, Beatrice, physically and psychologically, as well as his daughter, Kambili and son, Jaja. The story is told from the point of view of the 15-year-old Kambili who adores her father in spite of his cruelty, which turns their luxurious home in Enugu into a virtual prison for everyone except Eugene. When they cannot take it any longer, Beatrice poisons Eugene but Jaja claims responsibility for the killing and goes to prison. Purple Hibiscus has elicited much commentary on its critique of the oppressive patriarchal and gerontocratic power structures that dominate Nigeria's (and Africa's) social, political and cultural landscapes (Ouma 2011).

Importantly for the argument presented in this chapter, the novel's references to and portrayals of indigenous Igbo culture has also drawn considerable critical attention (Cooper 2008). And although these critics do not explicitly identify them as such, the novel is populated by unmistakable ethnic referents, the most conspicuous being short italicized Igbo words and expressions - for example ' $n n e$ ', ' $g b o$ ', ' $k p a$ ' (Adichie 2003, 10, 13, 15 respectively) - that appear throughout dialogues. There is mention of an iconic Igbo cultural dance, 'atilogu' (9), Igbo cuisine (152, 172, 197 and others), references to the Igbo notion of the extended family, 'umunna' (74), a fairly detailed account of the traditional masquerade, 'mmиo' (83) and repeated 


\section{Aghogho Akpome}

references to Igbo Christian songs $(28,39,179)$. More significantly, the overall portrayal of Eugene, his wife Beatrice and father Papa Nnukwu as well as the young Igbo priest, Father Amadi, figure prominently in the novel's thematization of Igbo spirituality and gender attitudes.

Although Adichie offers far more detailed portrayals of ethnicity in Purple Hibiscus than Matlwa does in Coconut, there is a strong sense in which the deployment of ethnicity in Purple Hibiscus can also be understood, like that in Coconut, in terms of resistance to dominant sociocultural discourses and power structures. On the one hand, ethnicity plays an important role within the intersecting gender, class, generational, cultural and spiritual sensibilities of the protagonists of Purple Hibiscus. On the other, the novel's different ethnic referents operate in symbolic ways within its critique of the prevailing power structures in Nigeria under military rule in the 1990s and its simultaneous proposal of alternative socio-cultural paradigms. These alternatives are articulated through a range of oppositions between different sets of characters and between indigenous and Western forms of spirituality which all suggest the salience of the characters' residual ethnic subjectivities without denying their immersion in a postmodernist amalgam of identities. To highlight the role of ethnic referents in the construction of these oppositions, it is important to consider the symbolism of the novel's eponymous purple hibiscus mentioned in the opening part of the story where Kambili contrasts her luxurious home in Enugu with the home of her widowed aunt Ifeoma in Nsukka:

I lay in bed after Mama left and let my mind rake through the past, through the years when Jaja and Mama and I spoke more with our spirits than with our lips. Until Nsukka. Nsukka started it all; Aunty Ifeoma's little garden next to the verandah of her flat in Nsukka began to lift the silence. Jaja's defiance seemed to me now like Aunty Ifeoma's experimental purple hibiscus: rare, fragrant with the undertones of freedom ... . A freedom to be, to do.

But my memories did not start at Nsukka. They started before, when all the hibiscuses in our front yard were a startling red.

(Adichie 2003, 15-16)

The rare fragrant purple hibiscus in Ifeoma's home which signifies freedom is deployed as a contrast to the familiar red hibiscuses which evoke the suffocating restrictions in Eugene's home and operates as an extended metaphor for the preferred alternative social-cultural paradigms proposed in the text. This can be observed in the oppositions between the respective forms of spirituality and masculinity represented by Eugene and Papa Nnukwu as well as those between Father Benedict and Father Amadi. There is a strong sense in which some of the novel's ethnic referents operate within these oppositions in ways that are especially significant. Father Benedict, the resident priest at the Achike's home church in Enugu, is a snobbish conservative British priest who disapproves of the use of Igbo language in church,

insisting that the Credo and kyrie be recited only in Latin; Igbo was not acceptable. Also, hand clapping was to be kept at a minimum, lest the solemnity of Mass be compromised. But he allowed offertory songs in Igbo; he called them native songs, and when he said 'native' his straight-line lips turned down at the corners to form an inverted U.

These attitudes are undoubtedly connected to the fact that he remains socially disconnected from the majority of his parishioners who continue to call him 'our new priest' seven years after his arrival in the parish. In contrast, Father Amadi represents a form of liberal Catholicism that 
embraces the indigenous culture of worshippers and resonates with them. These differences are demonstrated powerfully in Kambili's mind during the visit of another young priest to their family church in Enugu. Contrary to the way they responded to Father's Benedict's 'sparse sermons' and 'pinch-your-nose monotone,' the worshippers easily connect with the young priest whose 'brown eyes pierc[e] the congregation' as he read the bible (28). When the priest starts singing an Igbo song during the sermon and is joined in the song by the congregation, Kambili notices Eugene's expression of disapproval. This reveals Eugene's alignment with Father Benedict's religious conservatism. Eugene's attitude here is consistent with his intolerance of, and estrangement from people associated with indigenous Igbo forms of spirituality such as his own father Papa Nnukwu. As several critics have noted, the liberal Catholicism of Father Amadi and Ifeoma as well as the humanism associated with the indigenous religious practices of Papa Nnukwu (and affirmed by Kambili's, Jaja's and Ifeoma's enjoyment of the masquerades) are held up in the novel as a foil to Father Benedict's and Eugene's intolerant and conservative religiosity. But this does not mean that Adichie proposes an unqualified preference for the ethnic, as Cynthia Wallace $(2012,467)$ points out:

The novel certainly participates in a critique of Christian religion, aligning colonial whiteness, conservative Catholicism, and the rule of the father, and exposing their destructive power in the psyche (and body) of the novel's young narrator Kambili as well as her brother, Jaja, and mother, Beatrice. Yet Adichie also complicates this indictment through parallel critiques of Igbo culture and through contrasting characters whose own beliefs manifest the proliferated possibilities of a secular age: no repudiation of Igbo culture or of Christianity, but a dynamic process of critique and embrace.

Perhaps the most conspicuous example of the novel's critique of Igbo culture is its depiction of the violent nature of Igbo patriarchy represented by Eugene's abusive personality and his roles as father and husband, a depiction that famously invokes that of Okonkwo in Achebe's Things Fall Apart. Another important example relates to Beatrice's apparent willingness in the early parts of the story, not only to condone Eugene's abuses, but also to praise him for not taking a second wife as is expected in Igbo custom (Adichie 2003, 20). The overarching significance of the novel's deployment of ethnic referents can therefore be understood in terms of their ubiquity in the author's parallel and simultaneous processes of critique and embrace, resistance and affirmation of existing social structures and forms of identification. In this way, ethnic sensitivities are accorded an important, even if not over-determining, role in the scheme of the range of alternative social, cultural and political possibilities available to postcolonial subjects negotiating the fluid and overlapping attachments that characterize the postmodern milieu in which they exist.

I now turn to the two autobiographical works, An Ordinary Man by the former Rwandan hotelier, Paul Rusesabagina, and My First Coup d'Etat by former Ghanaian president, John Mahama. As stated earlier, these memoirs, unlike Adichie's and Matlwa's novels, offer portrayals of referents from more than one ethnic provenance. Like Adichie, Rusesabagina and Mahama provide far more detailed portrayals of ethnicity than Matlwa. Significantly, both writers overtly seek to provide narratives that reinforce official national or political unity and that counter discourses of ethnic differences. Therefore, while they do allow the contemplation of ethnic differences, they are vigorous in highlighting areas of perceived national sameness between ethnic groups while downplaying or glossing over their differences. The political backdrop to the memoirs may account for the emphasis on sameness and similarity. While Rusesabagina writes in the context of post-conflict reconciliation after Rwanda's 1994 genocide, at the time of writing, Mahama was an active national politician as the incumbent vice-president of Ghana 


\section{Aghogho Akpome}

(2009-2012) who went on to contest and win Ghana's presidential elections in 2013. He left office in 2017 after failing to win reelection. What this means is that the depiction of ethnicity in both texts is demonstrably conditioned by the prevailing political circumstances of each country at the time as well as the writer's personal political interests.

An Ordinary Man is partly a memoir of Paul Rusesabagina and partly his account of the events upon which the fictional feature film Hotel Rwanda (2004) is based. Rusesabagina was the manager of the Hotel Milles Collines where 1,268 Rwandans - mostly Tutsis - took refuge during the Rwandan genocide in which hundreds of thousands were brutally killed following decades of violent conflicts between Hutus and Tutsis. Rusesabagina's account of his life and of his role in the extraordinary circumstances in his hotel and in the country includes a necessary background to, and explanation of, the strained relations between Hutus and Tutsis in Rwanda and neighboring Burundi where both groups make up the overwhelming majority of the population. In An Ordinary Man, Rusesabagina makes the case that Hutus and Tutsis are not actually different ethnically or culturally but that the violence of 1994, like the earlier conflicts that dot Rwanda's history, were caused by colonial divide-and-rule policies which became exacerbated under successive post-independence governments. In denying that these two are distinct ethnic groups, he provides a comprehensive portrayal of a putative undivided and mono-cultural Rwandan identity in opposition to the idea of distinct Hutu and Tutsi ethnicities. ${ }^{7}$ The effect of Rusesabagina's portrayal of ethnicity in Rwanda is thus that ethnic identity operates in opposition to national identity, which is the explanation offered for the country's episodes of mass violence leading up to the genocide in 1994.

In the spirit of post-conflict therefore, Rusesabagina's apparent mission involves the reconstruction of the sense of a unique national identity that is accompanied by the dismantling of oppositional ethnic identities. In this regard, Rusesabagina conflates different systems of kinship and identification by variously referring to Hutus and Tutsis as races, ethnicities, tribes, clans and classes. In one instance, he describes the Tutsi as 'the taller people in the tribe' while wondering whether the two 'main ethnic groups' are separate 'races' (2006, 21). Elsewhere, he refers to Tutsis as an 'extended clan of leaders' (22) and a 'special class of people' (23) while also describing both as 'caste group[s]' and 'ethnic class[es]' $(24,30)$. In this way, he highlights the multiplicity and instability of the dominant subjectivities of contemporary Rwandans while simultaneously problematizing the notion of ethnicity by drawing attention to its artificiality and ambivalence.

Rusesabagina provides a symbolic and lyrical portrayal of familial, communal and national spaces in ways that recall the cultural nationalist orientation of anti-colonial African narratives:

There was a narrow path from the main road that twisted up the side of the ridge and passed through groves of banana trees. ... It was our connection with a small village called Nkomero, which occupies the top of one of the hundreds of thousands of hills in Rwanda. The nickname for my country is 'the land of thousands of hills,' or le pays des mille collines, but this signifies a gross undercount. There are at least half a million hills, maybe more. If geography creates culture, then the Rwandan mind is shaped like solid green waves. We are the children of the hills, the grassy slopes, the valley roads, the spider patterns of rivers, and the millions of rivulets and crevasses and buckles of earth that ripple across this part of Central Africa like the lines on the tired face of an elder.

(3; original emphasis)

Like Adichie's novel, Rusesabagina's narrative contains a profusion of words and expressions from what he calls the 'beautiful language of Kinyarwanda' (2). He provides expositions of 
important cultural practices such as the game of trust known as 'igihango' (7), the brewing of 'urwagwa' (8), the iconic Rwandan banana beer and of course the controversial gacaca traditional system of restorative justice that was used to deal with the deluge of prosecutions after the genocide (11). ${ }^{8}$ More significantly, he highlights the pre-colonial patron-client relationships which theoretically enabled the peasant Hutus to transform into elite Tutsis which suggests that the difference between the two groups is one of class rather than kinship. This is an important assumption of Rusesabagina's which manifests in his decision to foreground class and occupation in his own self-introduction at the beginning of the narrative:

I was born on the side of a steep hill in the summer of 1954. My father was a farmer, my mother his helper. Our house was made of mud and sticks. We were a mile away from the nearest village. The first world I can remember was green and bright, full of cooking fires and sisters murmuring and drying sorghum and corn leaves in the wind and the warm arms of my mother.

(Rusesabagina 2006, 1)

When he states his Hutu heritage earlier, he does so in a way that highlights its constructed nature: 'I was a Hutu because my father was Hutu' (xii) and describes the cultural difference between him and his Tutsi wife as a 'trivia of ancestry' (136). This belief that Hutus and Tutsis are actually not separate ethnic groups is accompanied by, and feeds into Rusesabagina's portrayal of an organic, harmonious and mono-cultural pre-colonial 'united nation' in which Hutus and Tutsis shared a common language, common religions, 'the same children's games, the same storytelling traditions, the same government, [and] even, in most cases, the same outward appearance.' He goes on to add that both groups have always lived together in the same settlements with neither ever having an exclusive homeland (19, 20).

Echoing official narratives of the post-genocide Rwandan government, Rusesabagina argues that the historically united Hutus and Tutsis were only separated into distinct ethnic groups by the divide-and-rule policies of Belgian colonialists. In particular, the introduction of identity books in 1933 was what, according to Rusesabagina, 'crystalized' (56) the separation of the two groups along the lines of purported ethnic differences. This narrative, which has considerable historical and critical support (see Mamdani 2001, 2013), draws attention to the ways in which many of Africa's present ethnic affiliations and subjectivities were produced and/or conditioned in the contexts of colonialization and anti-colonial resistance. It also provides insight into the political salience of ethnicity and inter-ethnic relations within post-independent African nations where access to economic resources is determined considerably by ethnic affiliations traced to the legacies of colonial socio-political engineering. Rusesabagina demonstrates clearly how elites from both groups have taken turns to enjoy political and economic dominance in Rwanda's post-independence history thereby portraying both as equally opportunistic and thus jointly culpable in the cycles of misgovernance, corruption and violence that have rocked the country over the decades. In this way, he echoes Mamdani's (2001, 267-268) analysis of the cyclical nature of ethnic violence in Rwanda: 'Every round of perpetrators has justified the use of violence as the only effective guarantee against being victimized yet again. For the unreconciled victim of yesterday's violence, the struggle continues.'

Although the equivalence drawn between Hutu and Tutsi elites serves the argument that there are no intrinsic cultural differences between the two groups, it does not seem as if Rusesabagina succeeds in blunting his own sensitivity to the socio-political legacies of the country's history of the opposition. This is perhaps why, in spite of his spirited self-conscious attempts to downplay ethnic oppositions, he finds himself - towards the end of the narrative - 


\section{Aghogho Akpome}

invoking the same discourse of ethnic difference in his critique of the post-genocide government with the claim that 'the popular image persists that Rwanda is today a nation governed by and for the benefit of a small group of elite Tutsis' (Rusesabagina 2006, 244). This calls to mind the fact that even though the post-genocide government has prohibited ethnic identification in Rwanda (a decision which Rusesabagina hails), the Tutsi-led regime in power since 1994 insists, controversially, on officially describing the killings of 1994 as a genocide specifically of Tutsis and not merely of Rwandans. These contradictions may suggest that it is futile to legislate against ethnic self-expression by Rwandans (see Mamdani 2001). More significantly for this discussion, the contradictions demonstrate the extent to which ethnicity is entrenched as a form of self and group identification in the consciousness of even high-profile social actors at the forefront of efforts to promote national identity at the expense of ethnic subjectivities.

This chapter will conclude with a relatively shorter analysis of Mahama's memoir, My First Coup d'État, which, like An Ordinary Man, illustrates some of the different ways in which ethnic subjectivities and national consciousness intersect in response to the material socio-political conditions of postcolonial African states. Like Rusesabagina, Mahama is interested in promoting official discourses of national unity that marginalize or downplay ethnic differences. But Mahama is influenced by a different kind of political commitment given that at the time of the book's publication in 2012, he was Ghana's vice-president and went on to become president upon the death of the incumbent that same year. ${ }^{9}$ Furthermore, Ghana's socio-political circumstances are significantly different from the acrimonious decades-old Hutu versus Tutsi conflicts in Rwanda. While Ghana has its fair share of the ethnic conflicts that plague the majority of modern African states, it is one of the few that has so far been spared the horrors of a nation-wide civil war due, arguably, to the fact that its national politics has not been overdetermined by strict ethnic oppositions. ${ }^{10}$

The subtitle of My First Coup d'État, 'Memories from the Lost Decades of Africa,' and its dedication to the writer's father 'who lived in service to his family, his people and his nation,' advertise Mahama's coeval subjectivities - filial, genealogical, national and pan-African - and alert the reader to the interplay of these different layers of identity in his exploration of recent Ghanaian history, politics and culture. The lack of explicit reference to ethno-cultural affiliation here may not be unconnected with the relative unimportance of such sensibilities to Mahama's possible political objectives. I focus on specific sections of the text (in six or so chapters) which contain more sustained portrayals of ethnic referents and how these depictions figure in the text's overarching (re)construction of national and sub-regional subjectivities.

The introductory chapter expands on the subtitle and sets out a pan-African context to the narrative, pointing out some of the iconic African cultural artifacts that gained international visibility during the period of decolonization. These include 'dashikis, geles, fufu, and jollof rice' $(2010,1)$, standout music genres such as highlife and Afrobeat as well as the literary works that defined the emergent canon of African literature. Here also, the author declares his principal interest in the nation as a whole on one hand, and on its northern region, on the other hand, drawing attention to 'the differences between life in the northern part of the country, which remains the most underserved, and life in the southern part' (1). I suggest that Mahama's focus on these differences, which arise from the historical, economic and political dominance of the southern regions over those in the north, can be understood in the context of the salience of regional affiliations in Ghana's political calculus. ${ }^{11}$

The bulk of the text's exploration of ethnicity is thus made within the context of Mahama's discussion of the nation as a whole and in his focus on Ghana's northern regions rather than on specific ethnic groups. Indeed, he only announces his actual Gonja ethnicity about one-third of the way into the text where he provides a short account of the ancient history and religious 
diversity of the Gonja people. However, this account is ostensibly in support of the narrative of national unity in modern Ghana such that these specific ethnic referents are made to serve a metonymic purpose. According to Mahama, the history of the Gonja that he provides here reflects 'a spiritual independence in Ghanaian culture dating back to the origins of the tribes that currently exist in our country. ... We have successfully and peacefully incorporated myriad spiritual beliefs into one united nation' (89).

In this way, the author's Gonja identity is shorn of uniqueness and functions more or less as a token of his Ghanaian identity in ways that are similar, on one hand, to Matlwa's representation of Ofilwe's emergent sense of blackness in Coconut. On the other hand, Mahama's overt interest in the northern part of the country - over and above his interest in Ghana as a whole - also betrays a similar dissatisfaction with a form of national identity that might appear to totalize the disparate histories and experiences of its diverse citizens such as those that bother Ofilwe. This concern is demonstrated by the proliferation of the phrases 'in the north' and 'in the northern region' which are used to qualify, sometimes superfluously, representations of indigenous culture and life in the countryside such as traditions of courtship and child-naming traditions among ethnic groups in the north $(68,76,95)$. While this may be so, Mahama also occasionally uses representations of the northern regions to stand in for the country; for example, when he writes of Ghana's dry and rainy seasons in terms of the northern region. These representations populate the anecdotes of his growing up during the colonial era in the northern part of the country. Mahama's preoccupation with the north, along with his limited references to his native Gonja ethnic group ties in directly with his decision to identify himself primarily as a northerner:

Although I was not yet attending school in the north like my brothers, just being there also provided me with a vital education. I had moved to Accra when I was still very small, and in the process of growing up there I'd learned Ga ... and Twi, which is an Akan language that is widely spoken in the south. While I was picking up these new languages, I was also slowly losing my ability to speak my native languages, the ones I'd first learned while living with my mother in the north. Living in Tamale forced me to relearn Gonja, Dagbani, and Hausa and, as a matter of course, regain a vital part of my identity as a northerner.

Before this, he describes his father as 'a northerner through and through' who, as a former member of parliament and cabinet minister, had 'served the interests of his people in the north' (112). In this way, Mahama marginalizes his specific ethnic heritage and instead privileges a regional identity that he constructs by fusing selective political histories and cultural representations of apparently contiguous ethnic groups. The result is a homogenization of diverse ethno-cultural groups whose complex relationships have indeed been more adversarial than Mahama is willing to admit. According to Asante and Gyimah-Boadi (2004, 14), with no less than 15 ethnic groups, the northern region, like the southern region, is 'far from being homogenous' and is plagued by conflict due to:

several years of relegation of certain ethnic groups, so-called 'minority' groups to 'second rate citizens' in the traditional and political administration of the region, or attempts to by-pass some of the 'gates' in the system of rotation to the chiefship. ${ }^{12}$

Mahama's decision to be silent about these differences in an apparent attempt to construct a unified northern identity is therefore contradictory given that his own sense of 'northernness' 


\section{Aghogho Akpome}

can be understood (at some level, at least) as resistance to a similarly totalizing idea of national sameness. Whether this conflation of sub-regional and national sensibilities is deliberate may be unclear, but what is certain is that the narrative reflects the complex interplay of ethnic, subregional and national consciousness in the negotiation of contemporary postcolonial African subjecthood.

Like the three other texts surveyed in this chapter, My First Coup d'Etat reveals an apparent shift from the dominant thematic and formal uses to which depictions of ethno-cultural referents were put in earlier generations of African writing, especially in the era of anti-colonial fervor. This means that even when detailed expositions of ethnic cultures are made in recent texts, they do not appear to be deployed with the clear aim of romanticizing the postcolonial nation-state or of resisting colonial misrepresentations. Instead, ethnicity now figures in more ambivalent ways often in reflection of shifting political contingencies. In the case of Matlwa's Coconut, invocations of ethnic Pedi culture are shorn of detail as they operate, arguably, as a trope for racial difference in a post-reconciliation South Africa where young people still confront the psycho-social and economic aporias of inequality. For its part, Purple Hibiscus reveals the residual significance of ethno-cultural sensibilities among African subjects. It does this without denying the immersion of these subjects in a kaleidoscope of identities, cultures and experiences while Rusesabagina attempts to reconstruct a harmonious Hutu-Tutsi society in An Ordinary Man. In the ways explored above, these texts provide important examples of different narrative and representational strategies by which contemporary African identities are complicated in post-2000 writing.

\section{Notes}

1 See Lindfors (2009).

2 Garuba borrows the term from Jonathan Arac $(1999,778)$.

3 The novel ends with a military coup which bears an uncanny resemblance to Nigeria's first actual coup that occurred shortly after its release. Joanna Sullivan (2001) has argued that although Achebe apparently sought to portray the political situation in West African countries where similar coups had happened prior to the publication of $A$ Man of the People, the subsequent coup in Nigeria suggests that the novel might be specifically about Nigeria after all.

4 One of the key issues in some of these texts is the apparent marginalization of non-Igbo minorities in some of the main works of the time written by writers of Igbo extraction such as Buchi Emecheta's Destination Biafra (1984) (see Hodges 2009). Another issue is the problematical representation of minorities (see Amadi 1973).

5 I use 'post-reconciliation' to refer to the socio-political and literary aftermaths of the Truth and Reconciliation Commission (see Akpome 2016).

6 In many cases, different temporal frames are separated by the alternate use of italics in the text.

7 It is important to note that others have made a similar argument (see Prunier 1995; Mamdani 2001).

8 See Clark (2010).

9 He was elected president in December 2012 but failed in his reelection when his term ended in 2017.

10 This is not to say that Ghanaian national politics is devoid of ethnic influence. Indeed, the two dominant political parties since 1992 (the National Democratic Congress to which Mahama belongs and the New Patriotic Party which won the 2017 presidential elections) have been associated with particular ethnic constituencies (see Asante and Gyimah-Boadi 2004).

11 A map of Ghana's ten administrative regions appears in the front matter of Mahama's narrative. The north which he refers to is comprised of four regions, against seven in the south (see Asante and Gyimah-Boadi 2004). The predominantly Christian regions in the south are also numerically superior to the population of the mainly Muslim northern regions.

12 See also Ichino and Nathan (2013). 


\section{References}

Achebe, Chinua. 1976. Morning Yet on Creation Day. London: Heinemann.

Adesanmi, Pius and Chris Dunton. 2005. 'Nigeria's Third Generation Writing: Historiography and Preliminary Theoretical Considerations.' English in Africa 32(1): 7-19.

Adesanmi, Pius and Chris Dunton. 2008. 'Everything Good is Raining: Provisional Notes on the Nigerian Novel of the Third Generation.' Research in African Literatures 39(2): vii-xii.

Adichie, Chimamanda Ngozi. 2003. Purple Hibiscus. Chapel Hill, NC: Algonquin Books.

Akpome, Aghogho. 2016. "Towards a Reconceptualization of "(Post)Transitional” South African Cultural Expression.' English in Africa 43(2): 39-62.

Amadi, Elechi. 1973. Sunset in Biafra: A Civil War Diary. London: Heinemann.

Arac, Jonathan. 1999. 'Why Does One Care about the Aesthetic Value of Huckleberry Finn?' New Literary History 30: 769-784.

Asante, Richard and Emmanuel Gyimah-Boadi. 2004. 'Ethnic Structure, Inequality and Governance of the Public Sector in Ghana.' http://unpan1.un.org/intradoc/groups/public/documents/un-dpadm/ unpan040107.pdf.

Attree, Lizzy. 2013. 'The Caine Prize and Contemporary African Writing.' Research in African Literatures 44 (2): 35-47.

Clark, Phil. 2010. The Gacaca Courts, Post-Genocide Justice and Reconciliation in Rwanda: Justice without Lawyers. New York: Cambridge.

Cooper, Brenda. 2008. A New Generation of African Writers: Migration, Material Culture and Language. Woodbridge, UK: James Currey.

Garuba, Harry. 2003. 'The African Imagination: Postcolonial Studies, Canons, and Stigmatization.' Research in African Literatures 34(4): 145-149.

Goodman, Ralph. 2012. 'Kopano Matlwa's Coconut: Identity Issues in Our Faces.' Current Writing: Text and Reception in Southern Africa 24(1): 109-119.

Hlongwane, Gugu. 2013. “In Every Classroom Children Are Dying”: Race, Power and Nervous Conditions in Kopano Matlwa's Coconut.' Alternation 20(1): 9-25.

Hodges, Hugh. 2009. 'Writing Biafra: Adichie, Emecheta and the Dilemmas of Biafran War Fiction.' Postcolonial Text 5(1): 1-13.

Ichino, Nahomi and Nathan, Noah L. 2013. 'Crossing the Line: Local Ethnic Geography and Voting in Ghana.' American Political Science Review 107(2): 344-361.

Igboanusi, Herbert. 2001. 'The Igbo Tradition in the Nigerian Novel.' African Study Monographs 22(2): 53-72.

Irele, Abiola. 1981. The African Experience in Literature and Ideology. London: Heinemann Educational.

Lindfors, Bernth. 2009. Early Achebe. Trenton, NJ: Africa World Press.

Mahama, John Dramani. 2012. My First Coup d'Etat. London: Bloomsbury.

Mamdani, Mahmood. 2001. When Victims Become Killers. Princeton, NJ: Princeton University Press.

Mamdani, Mahmood. 2013. Define and Rule: Native as Political Identity. Johannesburg: Wits University Press.

Matlwa, Kopana. 2007. Coconut. Johannesburg: Jacana.

Osaghae, Eghosa and Rotimi Suberu. 2005. A History of Identities, Violence, and Stability in Nigeria. Working Paper 6. Oxford: Centre for Research on Inequality, Human Security and Ethnicity (CRISE).

Ouma, Christopher E. W. 2011. 'Composite Consciousness and Memories of War in Chimamanda Ngozi Adichie's Half of a Yellow Sun.' English Academy Review 28(2): 15-30.

Prunier, Gérard. 1995. The Rwanda Crisis: History of a Genocide. New York: Columbia University Press.

Rusesabagina, Paul. 2006. An Ordinary Man. London: Bloomsbury.

Sullivan, Joanna. 2001. 'The Question of a National Literature for Nigeria.' Research in African Literatures 32 (3): 71-85.

Usman, Yusuf Bala. 2000. 'The Misrepresentation of Nigeria: The Facts and the Figures.' http://waado. org/NigerDelta/Essays/BalaUsman/Usman_Misrepresentation.html.

Wallace, Cynthia R. 2012. 'Chimamanda Ngozi Adichie's Purple Hibiscus and the Paradoxes of Postcolonial Redemption.' Christianity and Literature 61(3): 465-483. 


\section{Mythopoesis of the self} Nation, textuality and the writer as political hero

Rotimi Fasan

\section{Introduction}

The status of literary fiction as a prominent mode of expressiveness in African literature is being destabilized by the increasing popularity of diverse typologies of life writings. As literary nonfiction, these life writings both challenge and serve as intertext to the reality and truth claims purveyed in and by dominant narratives of the postcolonial text. The genre-based division of literature into fiction and literary non-fiction can be considered a conceit with decreasing relevance for contemporary African literature, coming as it is under serious challenge by other modes and forms of textualities. While this is not the same thing as proclaiming the death of fiction as a textual practice in Africa, what it does underline is the ways in which other writing practices can complicate the position of fiction as a vehicle for communicating received truths and for shaping the political reputation of the creative writer. We see this happening, for example, in the writer's use of literary non-fiction to advance a political agenda that may complement the politics of their fiction, or diverge from the politics of their fiction. African writers are increasingly employing life writings as self-fashioning device to both foreground an ideological persona as well as underwrite a literary project of writing back to their own creative writings. Although an expanding phenomenon in African literature, life writing by creative writers rests on a solid tradition long established by political actors in different parts of the continent, from Nnamdi Azikiwe, Obafemi Awolowo and Ahmadu Bello in Nigeria to Jomo Kenyatta in Kenya, Kenneth Kaunda in Zambia and Nelson Mandela in South Africa. African politicians have typically written memoirs as a discursive adjunct to their performance of a political identity. A number of African writers appear to have taken a cue from this in using life writing as additional support for their political and cultural activism, as well as to bolster their own activist credentials. This chapter affirms and aims to demonstrate that at different stages of their career, the ideological preferences of the moment are for African writers now frequently recreated in appropriate images in the writers' own memoirs and autobiographies.

This chapter examines the construction of the political activist as a certain kind of heroic figure in the life writing of a creative writer. To this end, I explore the writings of Wole Soyinka, analyzing the processes through which he engages in self-fashioning of a public 
persona, as paradigmatic of how African writers employ life writing for purposes of activist self(re)representation. Through his memoirs that document his real life performance of the self as a radical, cultural aesthete and social critic in Nigeria, Wole Soyinka presents himself as a political and activist subject addressing the kinds of issues often to be encountered in his fictional work. In the novelistic resonances of his memoirs, the formal features of which are sometimes redolent of creative fiction, his entire life literally assumes the quality of a fable or mythos in which he is the sole protagonist or change agent. The can-do, Ogun-incarnate (eniogun) ${ }^{1}$ image that permeates his work projects the writer as a liminal figure residing at the transitional interstice of socio-political upheavals. He is the self-aware subject that insists on his own space, the uniqueness of his own experiences and his right of self-assertion as an individual always ready to tread a path different from the common course.

The starting point for my reflections in this chapter can be found in Achille Mbembe's 2002 essay, 'African Modes of Self-Writing,' where Mbembe rejects the so-called Afroradical and nativist perspectives of the African subjectivity discourse. Of particular interest are those aspects of Mbembe's analysis that dovetail with Wole Soyinka's seeming ambivalence about nationalism and nativism in his early creative and critical writings, ${ }^{2}$ but which would appear to be at odds with the negritudinist and Marxist inflections of Soyinka's later work, in his reaction against Euro-American philosophical and creative discourse on Africa.

In elaborating on what he has called the African mode of self-cognition, Mbembe takes issue with the sense of lamentation and victimization with which Africans have reacted to Western relegation of the African subject as enunciated through the triple legacy of slavery, colonialism and apartheid. For Mbembe, the adoption of the critical rhetoric of autonomy, resistance and emancipation, and the insistence on an essentialist, space-bound construction of identity, have been injurious to Africans, leading them into the cul-de-sac of a largely impoverished, homogenizing mode of subjectivity that is best conceived in mostly ludic, 'mobile, reversible, and unstable' terms (Mbembe 2002, 272). In order, therefore, for Africans to reassert a sense of agency and to escape the nativist and nationalist thought patterns forcing them back into the racial categories to which they had been consigned by Enlightenment thinkers, Africans will have to reject any racially motivated construction of a uniquely shared African self. In Mbembe's postmodernist reading of African identity, there is no African core shared by all. Instead, all that matters is the unique experience of individual Africans. He goes on to conclude:

there is no African identity that could be designated by a single term or that could be named by a single word or subsumed under a single category. African identity does not exist as a substance. It is constituted, in varying forms, through a series of practices, notably practices of the self.... Only the disparate, and often intersecting, practices through which Africans stylize their conduct and life can account for the thickness of which the African present is made.

(Mbembe 2002, 271-272, emphasis in the original)

It is as much for the strong advocacy on behalf of practices of the self, as for the disavowal of a unitary African identity that I refer to Mbembe for my analysis of Wole Soyinka's self-styling and mode of self-representation. However, Soyinka's relationship with nationalist/nativist discourse is fraught and needs to be qualified in terms of its temporality. While he was avowedly anti-nativist/anti-nationalist in his earliest works (1960-1970), he became something of a neonegritudinist in his later works (1974-1976). ${ }^{3}$ In his successive memoirs, ${ }^{4}$ chronicling different stages and events in his life, Soyinka does not account for these shifting ideological positions. Instead, he undertakes self-styling by writing texts that place the writer as an activist for the common good at the center of major turning points in the history of the Nigerian nation. 
In examining Soyinka's memoirs, I would like to draw additional insight from new historicism as propounded by Stephen Greenblatt (1980, 2005). In Greenblatt's new historicism, texts are ascribed equal importance, irrespective of modes and genres, with none granted privileged status as so-called high culture (in this instance, literary fiction and poetry etc.) while others are peripheralized and treated as 'low culture' (life writings and other popular forms, for example). Literature is in this sense just one mode of signification among other signifying practices, and literature is a source of history like other types of texts. We can therefore learn as much about the cultural politics of a writer from their life writing as from their other creative writing. Both Mbembe and Greenblatt provide a useful point of entry into Soyinka's life writings.

The creative writer as major actor in the nation's history that emerges from Soyinka's selfwriting bears more than a passing resemblance to the figure of the Yoruba deity, Ogun, as recreated in Soyinka's own critical writing. Based on his notion of 'relational differentiation,' Ato Quayson $(1997,68)$ deconstructs Soyinka's idiosyncratic re-interpretation of the mythos of Ogun, especially in his book, Myth, Literature and the African World. In this re-interpretation, Soyinka classifies disparate items within his mythic scheme by 'simultaneously relating it to and differentiating it from other items' (Quayson 1997, 68) within the Yoruba pantheon on the one hand, and the Western pantheon as represented in Nietzsche's postulation in The Birth of Tragedy on the other hand. By this process, according to Quayson, Soyinka succeeds in forging together three distinct myths of Ogun to create the singular figure of the god that is present in the entire body of his works. In Quayson's reading, Soyinka's theorizing is 'grounded on a number of conceptual presuppositions' $(1997,70)$. These include the Yoruba notion of time that is based on the triadic framework of three worlds of non-linear temporality: the world of the living, the dead and the unborn, anomalous spaces of liminality that, in crossing from one to the other, are imbued with danger. By a deft maneuvering within the relational concept, namely, by transferring the Yoruba myths of Ogun from the context of ritual to that of ideological discourse, Soyinka re-presents Ogun among all the other gods as the ultimate symbol of sacrifice, both for man and the gods. Thus for Soyinka, as Quayson explains, 'Ogun is a culture hero and a revolutionary and his actions map out the parameters of both hubris and creativity.... What Ogun does for the gods is a model for what culture heroes do for their communities' (70, emphasis added).

In several of Soyinka's memoirs, the creative writer as public figure typically embraces the mission of this culture hero acting on behalf of their community. Biodun Jeyifo has remarked that this heroic disposition is present in virtually all of Soyinka's fictional and non-fictional prose works. Among the attributes of these prose works:

One is the foregrounding in each narrative of lone or plural protagonists whose identities and fates are explicitly and intimately bound up with their coming to an acute consciousness of a monstrously dehumanizing and alienating social environment and accepting the challenge that this poses of asserting and expanding a humane, life-affirming ethic. This pattern corresponds to what I shall call the 'heroic mythos' in Soyinka's prose works, a mythos almost wholly absent in his dramas and found, in the entire body of his poetic writings, only in the long dramatic poem 'Idanre' and Ogun Abibiman.

(Jeyifo 2004, 172)

This chapter will examine the mythos of the hero in Soyinka's life writing, though, and as Jeyifo has observed, both Soyinka's fiction and non-fictional writing reveal the presence of what Jeyifo calls 'the heroic mythos.' In the section that follows, I first examine some of the scholarship on life writing by Africans, before proceeding in subsequent sections to draw a link 
between Soyinka's narration of Nigeria's history and his self-representation, as political actor and cultural hero, in the making of that history.

\section{Fractures, revisions and counter-discourse in the making of identity}

In recent years, scholars of African literature and African writing have taken a variety of approaches to African life writing and literary non-fiction. In their respective articles, Hedley Twidle, Jennifer Muchiri and Jane Bryce explore the relationship of life writing and literary non-fiction to factuality and to history. For Hedley Twidle (2012), fiction, particularly the novel and short story that were the dominant literary forms of the apartheid years, have yielded ground to different forms of non-fictive works as modes of expression in the years following the collapse of apartheid. Given the preponderance of life writings and their centrality in postapartheid South African literature, Twidle $(2012,7)$ calls for an end to what he sees as the delineation of an unproductive binary between fiction and non-fiction in discussions of these texts. The ability of creative non-fiction, in that context, to exceed any product of a novelist's imagination ${ }^{5}$ makes non-fiction as valuable as fiction for analyzing imaginative responses to the challenges of contemporary South Africa. This development is perhaps aided by the apparent novelization of life writings which can be seen, in Twidle's observation about the 'intensively researched, textured, character-driven, self-aware and immensely ambitious' $(2012,6)$ work that goes into the making of South African literary non-fiction. This critic therefore calls for a method of 'cross-reading' (24) or integrative reading that takes into its purview all forms of written texts, and might involve a 'clustering of fiction, life-writing, micro history and journalism' (24), as well as the prison memoir, the diary, travelogue, oral history and so on. At the core of Twidle's argument is the poststructuralist thought of the representativeness of history, which in Twidle's terms amounts to the 'tacit fictiveness, narrativity and intertextuality inherent in all kinds of discourses' (7).

With a focus on Kenya, Jennifer Muchiri (2014) explores how narrating subjects inscribe themselves into the history of the nation. She then draws a line between the historian and the biographer, observing that while historians place themselves outside or at the margins of the historical picture, autobiographers occupy the center of the picture they assemble with the clear intent of establishing the meaning of these larger forces or events, what Stephen Greenblatt (1980) calls social energy, for their own stories. While noting that autobiography may contain facts, Muchiri is careful to observe that it is not factual history about a particular time, person or event. It is this non-factual nature of autobiography that is the concern of Jane Bryce (2008) in her reading of some of Soyinka's memoirs.

Bryce's feminist critique is an exploration of the status of and relationship between memoir and fiction on the one hand, and history on the other hand. In particular, and quoting other scholars, she notes several points at which Soyinka's account of the Egba women's movement in colonial Nigeria from his childhood memoir, Ake, The Years of Childhood diverges from documented history. Bryce then proceeds to highlight the protocols through which Nigerian historiography as a masculinized, male-centered construct under-privileges the female as a subject of history or her perspective as well as interpretation of history. Bryce's study scrutinizes how women are written out of male-authored texts even when the women are the undoubted protagonists and initiators of major political interventions. Life writing, she intimates, provides us with a specific kind of history. In looking for history in African life-writing, she declares: 
I am less interested in detailing all the areas in which Soyinka diverges from historical record than in asking what this might tell us about his own view of himself and his role, as well as the narratalogical imperative that dictates how they are represented.

In words that seem to evoke Muchiri's distinction between the historian and the biographer and their use of 'historical picture,' Bryce concludes that she is more concerned with 'the metaphorical use' Soyinka makes of the facts of history and the purpose of this metaphorical use, since 'Ake is history: not the history of the Egba women's uprising, but the history of the individual postcolonial masculine public figure on the national stage' (emphasis in the original, $55)$.

Other scholars approach selected works of life writing from a perspective that is less concerned about its relationship to history. Instead, they examine these texts for their revisionism of the official discourses of the postcolonial nation, as well as their contestation of unitary national and racial identities. Aghogho Akpome's (2017) 'Re-writing the Nation: Literary Rehistoricisation and Counter-Hegemonic Discourse in Ken Wiwa's In the Shadow of a Saint and Jacob Dlamini's Native Nostalgia' falls into this category. For Akpome, both the Nigerian writer, Ken Wiwa (son of Ken Saro-Wiwa), and the South African, Jacob Dlamini, use their memoirs to question post-independence and post-nationalist accounts of African identity. Akpome's critique focuses in part on 'an auto/biographical exploration of post-independence and present forms of dictatorship in Nigeria from a peripheral socio-political point of view' (2017, 50). Wiwa, in Akpome's view, 'portrays a deeply fragmented national body politic that is a composite of multiple margins of oppositional subjectivities' (50). Wiwa's work evinces a sense of a fractured Nigerian identity that in some respects recalls, but in other respects differs from, the thrust of Mbembe's stance on African identity in 'African Modes of Self-writing.' Ken Wiwa rejects the notion of a unitary Nigerian identity, but in its place celebrates an essentialized Ogoni identity that appeals to his sense of being. With Dlamini, however, Akpome $(2017,57)$ notes a desire to subvert official discourses in post-apartheid South Africa 'that tend to totalize black identities and experiences.' In Akpome's perspective therefore both Wiwa and Dlamini employ life writing to approach the postcolonial nation state with greater skepticism than the leading texts of the first and second generation of writings from Africa and post-apartheid literature. Both authors' texts deconstruct the dominant national and official narratives of their respective polities, rejecting their historicist vision of national reconciliation following political crisis. As somewhat fictionalized accounts, these texts represent a 'creative blend of history, polemic and memoir' (Akpome 2017, 50) that delineates personal and group identities with emphasis on social difference.

In also analyzing Jacob Dlamini's Native Nostalgia and Chris van Wyk's memoirs, Shirley, Goodness and Mercy and Eggs to Lay, Chickens to Hatch, David Medalie (2016) comments on the fractured and non-deterministic nature of identity. In this commentator's estimation the social construction of identity in terms of history and social circumstance creates a picture of predictable and unfulfilled living. Both Dlamini and van Wyk would appear to be engaged in a 'discovery of the ordinary' in their portrayal of normalcy and community life within the abnormal condition of apartheid. Their insistence on the normal in their representation of township life and celebration of motherhood, and in the process writing of their mothers back into history, restores agency to victims of apartheid and rescues their account from the usual sense of suffering, deprivation and victimization that pervades stories of life under white minority rule. Their work, for Medalie, is geared towards cultural and historical retrieval. Memory for these memoirists is revisionist and their rejection of a homogenizing sense of identity 
supposedly achieved in the post-apartheid era is underscored by Medalie's conclusion that 'all memoirs are acts of reinvention rather than mimetic transcription' $(2016,52)$ which harks back to Jane Bryce's considerations of the epistemic status of truth in recollections of the past.

A common theme of the above review which underlines the commonality of emergent scholarship about life writings in African Studies is the postmodernist conception of identity as a fractured, ludic and evolving process that is best accounted for on an individual basis. There is also a strong emphasis on life writings as creative fiction, a blend of fact and history viewed in this context as a re-interpretation of life experiences. These critics reject the perception that upholds life writing as mimesis, an account of factual history as 'truth.' From this perspective, life writings are to a considerable extent viewed as revisionist or counter-hegemonic and intertextual scripts that are employed as means of reconstruction, self-styling and reinvention. Some African writers have employed autobiographies as an expression of nostalgia and a longing for the past. As Medalie argues, other writers view memoirs as a means for recreating a sense of magic about an otherwise tragic past, and for restoring agency to overlooked or marginalized figures to intervene in trying situations and thereby ensuring the sustenance of community life. Yet other writers employ life writing as a means to pursue a political agenda, to advertise their lives as worthy characters for some of the themes explored in their fictive and critical works.

Against this backdrop I explore the subjectivity of Wole Soyinka and his self-construction as political agent, social mobilizer and public intellectual in his life writing. Unlike other scholars of African life writing, I intend here to call attention to the process of hero making, especially for the African male political activist. My analysis of the manner in which the figure of the political activist is constructed in Soyinka's biographical works will be based on a close reading of two of his memoirs of adult life, namely, Ibadan: The Penkelemes Years (1994) and You Must Set Forth at Dawn (2006).

\section{Narrating the nation: Soyinka's life writings}

Although written more than ten years apart both Ibadan and You Must Set Forth at Dawn cover overlapping themes and periods in the life of the narrating subject. Essentially focused on political happenings in Nigeria, Ibadan spans a period of about two decades, between 1945 and 1965, a time when the young Soyinka left home for Government College in Ibadan and the outbreak of the civil unrest that would lead to and culminate with the Nigerian Civil War. The motivation for the memoir was Nigeria's descent into a time of repression and political uncertainty following the annulment of the June 12, 1993 election that was won by M. K. O. Abiola (Soyinka 1994, ix-x). ${ }^{6}$ However, the narrative itself stops in the 1960s, almost three decades before the political crisis triggered by the annulment of the 1993 elections. The struggle to revalidate Abiola's electoral mandate is the central subject of You Must Set Forth, it is the point where the latter work parts company with the former. Nonetheless, both memoirs actually begin with the narrating subject's return home after a five years stint in the United Kingdom as a student. You Must Set Forth provides Soyinka another opportunity to reflect on a recurrent subject of interest, namely, freedom that is here equated with motion or movement hence the title, You Must Set Forth At Dawn. In this, the author explores the existential theme of human freedom expressed as motion - a journey (irinajo) of discovery through the crucible of life. ${ }^{7}$ Soyinka's world, his life which affirms the primacy of human agency, is driven by hope of redemption from human folly and/or hopelessness, a déjà vu situation he has in a different but related context referred to as a 'sisyphean imposition' (Soyinka 2018, 22), always a consequence of a recurrent failure to learn from history. In successive memoirs, this journey takes the narrator from the world of ancestral presences associated with masquerades and spirits, starting in the 
parsonage of St. Peters' Church in Ake, to the school years in Ake and Abeokuta and, then, Government College, Apataganga in Ibadan. The journey then continues with an imaginative exploration of the outer reaches of human experience, into the excitable and highly exciting world of political contests, intrigues, skirmishes, exile and diplomacy.

His memoirs, beginning with Ake The Years of Childhood (1981) through Isara A Voyage Around Essay (1989), Ibadan: The Penkelemes Years and finally You Must Set Forth At Dawn, not excluding The Man Died (1972) have some recognizable features running through them all, in addition to sharing the same protagonist and narrating subject. Ake focuses on the world of the child with occasional glimpses through that infantile lens into the confusing, uncomprehending and incomprehensible world of adults. Isara is a child's voyage around and into the adult world of the author's father, Akiode (Essay), and his friends amid the political irruptions of the period. Ibadan matches The Man Died in its preoccupation with the politics of the Nigerian state while You Must Set Forth brings together the theme running through all of the previous efforts while opening up hitherto unread pages in the unfolding history of both Soyinka and Nigeria. This makes it the definitive account of the author's life in public. Even some of the factional characters and episodes of Isara and Ibadan take on more probable and convincing existence in You Must Set Forth.

Politics predominates in these memoirs and in Soyinka's own activities as recorded in the memoirs. In the different accounts of his life, Soyinka fleshes out the interstices between a private life and public existence and seeks to show how both intersect with the life of the Nigerian nation. These narratives hint at the life-altering potential of individual intervention, demonstrating how the individual can and does, in fact, enter into and shape the course of history. According to the memoirs, Wole Soyinka had set forth at dawn on New Year's Day 1960 in order to keep a self-assigned appointment with the new nation that would be created in October $1960 .{ }^{8}$ The episode of his return from the UK, with the stealth attached to it, opens the account of the life of his alter-ego, Maren, in Ibadan. In Ibadan, Soyinka extends by twenty years the story that ended in Ake covering the first eleven years of the author's life. This is a period which coincided with the end of the Second World War and the intensification of anticolonial politics in Nigeria. Both Ibadan and You Must Set Forth capture the fractious politics of the 1960s in western Nigeria while You Must Set Forth also recounts the turbulent politics of the early 1990s in the country.

But by far the most important political events detailed in You Must Set Forth are those connected to the period between 1993 and 1998, which for Soyinka corresponded to years of exile, spent campaigning for the restoration of democratic rule in Nigeria in Western capitals around the world, following the annulment of the 1993 Presidential Elections. While Ibadan ends with Maren's return to western Nigeria from eastern Nigeria to give himself up for arrest and trial, following a political escapade described later in this chapter, You Must Set Forth climaxes with the narrator's triumphant return from exile.

\section{Mythos and the self: Wole Soyinka, 'the perpetual dramatist ... in every drama of his own manufacture'}

Scholars like Bryce have taken note of Soyinka's tendency to identify the narration of his own life in his many memoirs with history. In fact, she considers his publication of successive memoirs as evidence of a 'drive to self-historicism' (2008, 37). In each memoir, the writernarrator recounts his presence at moments of historical significance for the Nigerian nation and his ensuing activism. This pattern in his life writing is already manifest in $A k e$, presented as an account of childhood. In Soyinka's rewriting of his own childhood in Ake, his parents laid a 
foundation for a habit of questioning received wisdom and prevailing conventions. For instance, he presents his own mother, not as a conformist to Christian dogma, but as a 'Wild Christian.' For a memoir of childhood, and as scholars like Jeyifo $(2004,193)$ have noted, Ake is relatively devoid of fully rounded child characters. Adults instead take center stage, and especially adults who are unique in various ways. Prominent figures in Nigerian political and cultural history loom large in Soyinka's account of his childhood and are more clearly portrayed than any of Soyinka's childhood companions. These include his respected uncle, the Reverend I. O. RansomeKuti, and his wife, Funmilayo Ransome-Kuti, who are also parents of the famous musical performer, Fela Anikulapo-Kuti. Similarly, this memoir of childhood highlights Soyinka's presence as a witness at major moments of political foment in Nigeria, and notably during the Egba women's movement. If this memoir of childhood is an act of self-fashioning, it is one that portrays a child with a precocious political sensibility nurtured by parents and other relatives who were not afraid to challenge the authority of institutions around them.

These same personal traits appear in the construction of the adult activist in Soyinka's memoirs. But the creative writer-activist of memoirs of adulthood also seems to exhibit many personality traits that Soyinka had himself identified with the Yoruba god, Ogun. It is worth pointing out here that Soyinka's interpretation of Yoruba mythology, and in particular his re-interpretation of the Ogun archetype, is highly idiosyncratic. In Soyinka's rendering, Ogun:

is known as 'protector of orphans', 'roof over the homeless', 'terrible guardian of the sacred oath'. He stands for a transcendental, humane, but rigidly restorative justice: ...

Ogun is also the master craftsman and artist, farmer and warrior, essence of destruction and creativity, a recluse and a gregarious imbiber, a reluctant leader of men and deities. He is 'Lord of the road' ... the knowledge-seeking instinct ... the only deity who 'sought the way', and harnessed the resources of science to hack a passage through the primordial chaos ... his was the first rite of passage through the chthonic realm.

(Soyinka 1976, 26-27, my emphasis)

Nonetheless, Soyinka starts off one of his memoirs, You Must Set Forth at Dawn, by appearing to disavow any critical commentary suggesting direct identification with Ogun. For example, in the opening pages Soyinka writes:

The suggestion that I was possessed quite early in life by the creative-combative deity Ogun is a familiar commentary of some literary critics who stretch my creative fascination with that deity, undeniable in my works, beyond its literary purlieu. If I were persuaded of that, I would have headed long ago for the nearest babalawo for the rites of exorcism!

(Soyinka 2006, 35)

Soyinka goes on to attribute his activism to 'an overacute, remedial sense of right and wrong, of what is just and unjust' (Soyinka 2006, 37). Despite this repudiation of any identification between him and the Yoruba deity, titles of sections in this memoir appear to reinforce the appearance of a willful identification with Ogun. Part I is titled 'Ogun and I,' while Part II is titled 'Ogun, Less Benign.' Soyinka's activism as expressed in his memoirs is in certain respects a project of identity-performance by a figure who combines creativity with a willingness to make sacrifices on behalf of the community. This figure is in many respects a heroic figure. And not only does this narrator appear to dramatize the actions of Ogun, he also seems somewhat aware of his own performance, as can be gleaned from his narration. In effect, these memoirs offer a 
mythopoesis of the self and of Ogun. In what follows, I provide a few examples of the involvement of the narrator-subject, namely Soyinka, in specific political events narrated in the two memoirs under review that appear to be modeled on his own characterization of Ogun. Several of the events recounted here overlap in both You Must Set Forth and Ibadan.

The snapshots from Soyinka's personal life that are included in both memoirs are those that intersect with his activism. As had been the case in Ake, his memoir of childhood, where he describes his involvement in the Egba Women's movement, Soyinka is presented mainly as a witness to and participant in the political turbulence of post-independence Nigeria in the later memoirs. In one of many examples, Soyinka recounts his involvement in the political chaos in western Nigeria that would eventually climax in a civil war fought mostly in eastern Nigeria that lasted nearly three years. You Must Set Forth describes how Soyinka became a key player in the events of this period when under the aegis of a so-called Third Force that was not aligned to either of the opposing sides in the war, he took on the task of visiting the East in a last ditch attempt to persuade the secessionist leader, Odumegwu Ojukwu and other intellectuals in the region to return to the negotiating table $(2006,128)$. This attempt to try and broker a peace would eventually lead to his imprisonment by the Nigerian government.

But even before the war broke out in 1967, Soyinka was already involving himself in highstakes political drama. During his student days in the UK, he had initially been concerned about the liberation of South Africa. But his initial fixation with South Africa soon gave way to a realization that the real battle was at home in Nigeria. Thereafter his thoughts returned home, to the activities of the emergent leaders of the immediate post-independence years. Says he, 'I was not pessimistic about the future, but extremely cautious, having come into contact with the first generation leaders in my student days in England. The enemy...was power and its pitfalls' $(2006,56)$. His own country, Nigeria, was stumbling from one crisis to another, and the Western Region which was a hotbed of opposition became a major theater of the chaos that marked governance. This followed the disputed result of the 1964 election that was considered to have been rigged by the ruling Nigerian National Democratic Party (NNDP) in coalition with the Northern Peoples Congress. It was in these circumstances that Soyinka returned home from the Commonwealth Arts Festival of 1965 where his play The Road had been produced to very warm acclaim and enthusiastic reception. But within days of his return, matters came to a head on October 24, 1964 when the premier of the Western Region and leader of the NNDP, Chief S.L. Akintola, was slated to make a radio broadcast announcing his victory in an election that was generally disputed. At this point all appeared lost as Akintola's victory had to all intents and purposes been presented as a fait accompli. But shortly before the premier's broadcast, Soyinka, executing an elaborate script in a gesture of personal defiance, would sneak into the studio of the regional radio station and at gunpoint compel the studio officer to replace the premier's recorded speech with his own pre-recorded speech of denunciation. He addressed the following words to the shocked people of Western Nigeria: 'This is the voice of the people, the true people of this nation. And they are telling you, Akintola, get out! Get out, and take with you your renegades who have lost all sense of shame'(Soyinka 1994, 362).

Soyinka would, following this, be declared wanted, and was for his effort rewarded with a charge of armed robbery - stealing at gunpoint the tape on which the premier's speech was recorded. Soyinka on his part accused the authorities of robbing the people of their voice by their subversion of the electoral process. It should also be noted that, even while this studio hijack incident was widely reported, it was in fact the second episode in Soyinka's gun wielding career. The first time this happened, the incident also had to do with him holding up a radio broadcast team at gunpoint (see Soyinka 1994, 350-354). 
Soyinka's firm belief in his ability to penetrate any space would again see him embarking on a daredevil trip into Lagos from the border with the neighboring country of Benin at the onset of the June 12 protests against the annulment of the 1993 presidential election. This journey, like the journey into eastern Nigeria in the lead-up to the civil war and the ten-hour journey on a motor-cycle pillion in 1994 that preceded his escape into exile through the same BeninNigeria border was a quixotically dangerous trip that could have turned out very badly for him. But he confesses, as earlier observed, to an 'irrational presumption' to penetrate even hostile spaces $(2006,378)$. It is instructive here that Soyinka describes the mission of breaching the security at a highly fortified radio house in Ibadan, and other audacious actions in almost exactly the same words he used to characterize Ogun's primordial plunge across the gulf of transition on the deity's journey to earth. For example, he writes of his 'foolhardy plunge into Lagos' $(2006,393,214)$. These ventures into the realm of postcolonial politics are depicted in a manner not unlike that used for portraying the challenges encountered by Ogun.

In light of the foregoing, it seems hardly a coincidence that Soyinka, who had portrayed himself as being possessed with an 'overacute, remedial sense of right and wrong, of what is just and unjust' (2006, 37), had also described Ogun as " protector of orphans", "roof over the homeless", "terrible guardian of the sacred oath" (Soyinka 1976, 26). The role of defender of justice for the unprotected is one that we see Soyinka playing even outside the realm of politics. For example, he directly intervened in cases involving defenseless individuals, as in the episode recounted in Ibadan (242-248) about an elderly female trader from Akure who was violently attacked and robbed/defrauded by a group of thugs/fraudsters. These fraudsters, masquerading as 'lucky dip' lottery operators, hit the undecided woman, a potential client of theirs, hard on the chest and dispossessed her of her money. Soyinka was on the trail of Kodak, leader of the fraudsters, for a couple of months and after three failed police raids on his haunts he would personally tackle Kodak to the ground and ensure his arrest and prosecution. After almost a year in jail Kodak would return to Ibadan where he would form a close collaboration with Soyinka in the latter's campaign against the ruling Nigerian National Democratic Party. With the assistance of Kodak and members of his group, Soyinka would take on thugs and other supporters of the NNDP that invaded the home of the economist Sam Aluko, terrorizing his family and destroying his property (1994, 212-214, 253-258). It was also with the help of Kodak, Soyinka's account in Ibadan (364-365) seems to suggest, that the west of Nigeria was turned into the infamous 'wild west' and made ungovernable in the wake of the electoral fraud perpetrated by the NNDP in 1965.

The title of You Must Set Forth alludes to a process of journeying and thus the road is to be taken as significant; indeed, Soyinka had earlier described Ogun as 'god of the road' (52). In 'Reunion With Ogun,' one of the chapters in the first part of You Must Set Forth, Soyinka writes of the special bond and very personal communion that exist between him and the road $(2006,48)$. As he traveled the length and breadth of the country discovering new dramatic forms and festivals, 'The road and I,' he writes, 'became partners in the quest for an extended self-discovery' (50). In addition to his play and poems using the road and the journey as metaphors for the postcolonial condition, ${ }^{9}$ Soyinka's most recent memoir, appropriately titled The Road Map of a Nation (2018), which recounts his involvement with establishing the first road safety corps in Africa, consolidates this web of allusions to Ogun in his life writing. The 'malformation of the national psyche' (Soyinka 2018, 28) that was at the root of the abandonment of a discernible moral compass and the need to restore a sense of 'communal responsibility' (42) in Nigerians were motivations for his decision to draw up the blueprint for the establishment of a self-policing outfit like the road safety corps in the late 1970s. In this most recent memoir, Soyinka $(2018,26)$ warns: 
let no one think that it is impossible to read the face, and the fate of the nation from the ordeals to which the roads have been subjected, and the scars that are left on them, projected from them, to give the lie to the grinning faces in our gilded metropolis.

If Ogun is the patron god of all road users, Soyinka, as chair of the road safety corps, is the one best identified with the mythic history of Ogun. In this capacity, he vowed to take over control of the road from reckless drivers and such others including military personnel he calls 'agents of mindless death' (51), through a process of re-education and, where necessary, force.

To some extent, the figure of the political activist in Soyinka's memoirs does not come across as just a heroic figure, but also as somewhat of a superhero. In his theory and performance of Ogun, Soyinka often appears to embody several attributes that Duncan Omanga ascribes to the emergent figure of the African superhero. In Omanga's words, 'the superhero is frequently dedicated to a moral goal of protecting humanity from harm' (2016, 264-265). Furthermore, says Omanga (265), 'superheroes are expressive of their unique historical moments.' If Soyinka's vision of the ideal hero is based on a re-interpretation of Yoruba myths, this would seem to be in keeping with trends in popular culture for creating an African superhero. According to Omanga (268), "the very idea of "supermen" was already present in legends as part of the folklore through which many African communities constructed their sense of identity and exceptionalism.' In addition, says Omanga (267), the construction of superheroes in African popular culture often entailed a remediation of figures from folklore and legend. Soyinka's life writing extends this principle already evident in popular culture to literary non-fiction. If remediation is the representation of one medium in another, Soyinka's deliberate self-presentation as a persona endowed with the very qualities that he had previously attributed to a figure from local mythology, amounts to a remediation of an oral medium, specifically mythic history, into both the print medium and the template of contemporary reality.

\section{Conclusion}

Some readers of Soyinka's memoirs of adulthood have been critical of his self-presentation as hero of history in these narratives. Of Ibadan, Jeyifo $(2004,198)$ observes:

While in Ake and Isara the narrativization of social struggles and movement is mediated by techniques which distance the author-narrator - who is at any rate not a participant in the experiences recounted... in Ibadan, the entire narrative seems to be driven by the authorprotagonist's excessive self-regard as the pivot around which diverse insurrectionary activities and currents resolve.

And for You Must Set Forth at Dawn, Adewale Maja-Pearce writes: 'As in the previous Ibadan: The Penkelemes Years ... this latest attempt at memoir betrays a certain degree of hubris on Soyinka's own part ... At bottom, Soyinka has fallen for his own myth ... as shaper of events in the life of post-colonial Nigeria' (2008).

The core argument of this chapter has been to affirm that some African writers are resorting to diverse modes of textual practices, particularly life writings, as discursive device, both for selffashioning and the performance of a political identity. This involves situating in the foreground of their life writing a political persona engaged in a literary project of either advancing or writing back to their own creative writings. With the example of Wole Soyinka, I have explored the process through which an African writer might engage in this enterprise of selfprojection and re-representation as political activist. In Soyinka's memoirs of adulthood, the 
writer is a political actor and an activist who embodies Soyinka's idiosyncratic version of Yoruba mythology. The political activist of these memoirs is a heroic figure, but not a tragic hero like the protagonists of the early novels of writers like Chinua Achebe and Ngũgĩ wa Thiong'o among others. As a conjunctional figure of creativity and activism, sober aloofness and raucous gregariousness, quiet morality and restorative violence, Soyinka, this chapter concludes, has in his memoirs engaged in an elaborate mode of identity performance modeled on a close identification with a mythic hero, that of the Yoruba god, Ogun.

\section{Notes}

1 Ogun is the Yoruba god of war, metal and creativity, and is Soyinka's adopted creative muse.

2 See in particular creative works like $A$ Dance of the Forests, The Strong Breed, The Interpreters, and critical essays like 'And After the Narcissist,' The Writer in a Modern African State' and others.

3 For more on Soyinka's changing positions over time, see Jeyifo (2004, 42-43). Here, I follow Jeyifo in saying that Soyinka's position has changed over time. For example Jeyifo (43) observes that Soyinka's 'works of the 1970s and early 1980s are nothing if not neo-negritudinist.' To make this point, Jeyifo quotes works by Soyinka published between 1974 and 1976. It is also worth noting that Soyinka's neonegritudinist stance is also quite evident in In a Burden of Memory, the Muse of Forgiveness, which was first published in 1999. In other words, Soyinka's position on negritude is not consistently sustained over time.

4 Soyinka's memoirs include The Man Died (1971), Ake, The Years of Childhood (1981), Ibadan: The Penkelemes Years: A Memoir 1946-65 (1989), Isara: A Voyage around Essay (1990) and You Must Set Forth at Dawn (2006).

5 This is a paraphrase of Twidle who states that: 'the current success of non-fiction in South Africa and its apparent ability to exceed the novelist's wildest imaginings was the subject of a panel discussion at the 2010 Cape Town International Book Fair' $(2012,6)$.

6 Moshood Kashimawo Abiola was a politician and the presidential candidate for the Social Democratic Party in 1983. The military government in power at the time decided to suspend announcement of election results once it became clear that Abiola had won. The action of annulling the elections in this way precipitated a political crisis in Nigeria as well as a wave of activism seeking restoration of democratic rule in the country. Soyinka wrote Ibadan as a reminder of or corrective to what he perceived as national amnesia, to remind Nigerians of the circumstances that led to the breakdown of order in the First Republic.

7 In this book, Soyinka does not specifically use the word irinajo, the Yoruba word for journey. Nonetheless, I read the title of the book in relation to his appropriation of Yoruba expressions about journeying. You must set forth at dawn could be a variation of such Yoruba expressions as Owuro lojo (The day starts at day break) or Ma faro sere (Do not tarry in the morning) which evoke movement and a sense of journeying early in the day. The journey motif is present in the title of this book, in the subject of this book, in his well known poem, 'Death in the Dawn,' in his character's name Maren, shortened from 'Maren ni jo ebi ponan' translated in Ibadan as 'You will not walk when the gods are angry' (Soyinka 1994, 18). The verb, walk, in this sentence could be a synonym for travel and journeying.

8 Nigeria's Independence Day was October 1, 1960.

9 For example, the play, The Road, and poems like 'Death in the Dawn' in the collection titled Idanre and Other Poems.

\section{References}

Akpome, Aghogho. 2017. 'Re-Writing the Nation: Literary Rehistoricisation and Counter-Hegemonic Discourse in Ken Wiwa's In the Shadow of a Saint and Jacob Dlamini's Native Nostalgia.' Scrutiny 2, 22(2): 49-64.

Bryce, Jane. 2008. “'Self-Writing” As History: Reconsidering Soyinka's Representation of the Past.' Philosophia Africana, 11(1):37-60.

Greenblatt, Stephen. 1980. Renaissance Self-Fashioning: From More to Shakespeare. Chicago, IL: University of Chicago Press. 
Greenblatt, Stephen. 2005. 'Culture.' In The Greenblatt Reader, edited by Michael Payne, 11-17. Malden, MA: Blackwell.

Jeyifo, Biodun. 2004. Wole Soyinka: Politics, Poetics and Postcolonialism. Cambridge: Cambridge University Press.

Maja-Pearce, Adewale. 2008. 'Kongi and Temporal Power: A Review of Wole Soyinka's You Must Set Forth at Dawn.' Originally published in the London Review of Books 29(15) (August 2007): 11-12. Republished in New Gong Magazine. thenewgong.com (accessed March 3, 2018).

Mbembe, Achille. 2002. 'African Modes of Self-Writing.' Public Culture, 14(1): 239-273.

Medalie, David. 2016. 'Remembering Life under Apartheid with Fondness: The Memoirs of Jacob Dlamini and Chris van Wyk.' English in Africa 43(3): 43-60.

Muchiri, Jennifer. 2014. 'The Intersection of the Self and History in Kenyan Autobiographies.' Journal of Eastern African Literary and Cultural Studies 1(1/2): 83-93.

Omanga, Duncan. 2016. "“Akokhan Returns": Kenyan Newspaper Comics and the Making of an "African" Superhero.' Journal of African Cultural Studies 28 (3): 262-274.

Omotoso, Akin, dir. n.d.Wole Soyinka: Child of the Forest. Lagos: MNET.

Quayson, Ato. 1997. Strategic Transformations in Nigerian Writing: Orality and History in the Work of the Reverend Samuel Johnson, Amos Tutuola, Wole Soyinka and Ben Okri. Bloomington: Indiana University Press.

Soyinka, Wole. 1965. The Road. London: Oxford University Press.

Soyinka, Wole. 1967. Idanre and Other Poems. London: Methuen.

Soyinka, Wole. 1972. The Man Died. London: Rex Collins.

Soyinka, Wole. 1976. 'Morality and Aesthetics in the Ritual Archetype.' In Myth, Literature and the African World. Cambridge: Cambridge University Press.

Soyinka, Wole. 1981. Ake, The Years of Childhood. London: Rex Collins.

Soyinka, Wole. 1988. 'The Writer in a Modern African State.' In Art, Dialogue and Outrage: Essays on Literature and Culture, edited by Wole Soyinka and Biodun Jeyifo, 15-20. Ibadan: New Horn Press.

Soyinka, Wole. 1994. Ibadan: The Penkelemes Years: A Memoir 1946-1965. Ibadan: Spectrum Books.

Soyinka, Wole. 2006. You Must Set Forth at Dawn. Ibadan and Banbury: Bookcraft and Ayebia Clarke.

Soyinka, Wole. 2014. 'My Life: Conversations with Wole Soyinka at 80.' The News (Lagos, Nigeria), July 21.

Soyinka, Wole. 2018. The Road Map of a Nation: A Narrative of the First African Road Safety Corps. Ibadan: Bookcraft.

Twidle, Hedley. 2012. “In a Country where You Couldn't Make this Shit up”?: Literary Non-Fiction in South Africa.' Safundi 13(1/2): 5-28. 
Part III

Working through Genres 


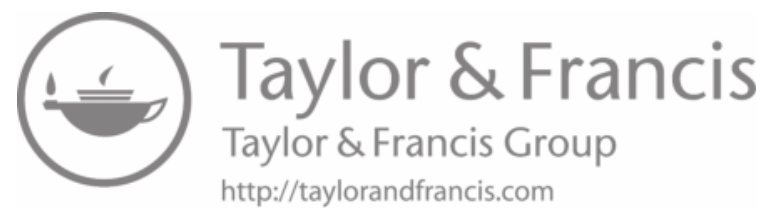




\section{How to be a writer in your 30s in Lagos}

\section{Self-help literature and the creation of authority in Africa}

Rebecca Jones

It is hard for the reader's attention not to be grabbed by the hot pink cover and cursive font of Lape Soetan's e-book, How to be a Single Woman in Your 30s in Lagos (2015b). The eye-catching book is the first of four self-help e-books by the blogger, life coach and self-help writer, who lives in Lagos, Nigeria. ${ }^{1}$ Just 14 pages long and downloadable from Soetan's website, the book explores the particular challenges and opportunities faced by single women in Lagos, where they often encounter fearsome social expectations that they should be married by the time they reach their thirties: 'It's strange (or maybe not so strange in our paternalistic Nigerian society)', Soetan reflects, 'that a single older woman is often thought to be cursed but you never hear it said that a single older man was cursed with being single' (13). Based on her own experience of being single in Lagos, Soetan guides her reader through the process of making peace with singlehood, while keeping her eyes open for true love.

Lape Soetan is far from alone in writing to address the problems African readers face in their everyday lives. Walk into a bookshop or past a market book stall in southwest Nigeria, for example, and one will likely come across an array of both locally published and foreign selfhelp, motivational or how-to books, offering advice on marriage, religion, business, writing, personal effectiveness, child-rearing and more. Such books and pamphlets are often, as Stephanie Newell puts it, 'ephemeral texts', priced affordably and sold informally at bus depots and lorry parks, as well as in bookshops. Locally published texts jostle for space with North American and European texts, especially Christian and business advice books, and the most popular self-help texts go through many reprints (Newell 2008, 16).

This boom in self-help literature is echoed across the African continent:

Pop into any bookshop in Nairobi and the shelves will be packed with paperbacks, mostly American, offering advice on how to get rich quick, deal with relationships or fasttrack careers, with titles such as The One Minute Millionaire to Secrets of Sexually Irresistible Women, 
wrote journalist Andrew England in 2005. At Nairobi's Prestige Books, manager Jitesh Upadhyay said that, '[t]here's been tremendous growth - you can see we have dedicated two whole rows to [self-help books].' Self-help texts promising wealth and success were particularly popular: 'Everybody wants to get rich quick. That's the number one on the list', explained Upadhyay. At Nairobi's BookPoint bookshop, the shop's director, Dipak Shah, estimated that '[d] uring the last three or four years, sales of self-help books have been 10 times those of novels.' Their bestselling book in 2005, selling 200 copies a month, was Rich Dad, Poor Dad by Robert T. Kiyosaki, which 'promises an insight into what the "rich teach their kids about money, the poor and middle class do not"” (England 2005, 11). In Johannesburg, meanwhile, Hilary Wilson $(2012$, 27) characterises self-help books as 'a huge publishing phenomenon', particularly amongst black South African readers who, according to one of the booksellers Wilson spoke to, favoured self-help over fiction. Kiyosaki's Rich Dad, Poor Dad was similarly the most widely read book amongst the Soweto teachers Wilson surveyed (58).

Although much of the most successful self-help literature claims to offer business success and prosperity, this is not the only advice that readers seek. In Nairobi in 2005, England encountered diverse ways of reading self-help texts:

Njoroge Gutu, a pastor, uses them to inject practical advice into the sermons he delivers. For Caroline Kenga, they provide motivation and time-management guidance as she juggles a full-time job with a university course. Moses Oburu reads them to help cope with the challenges of relationships and his dreams of making money.

(England 2005, 11)

In post-1990s Tanzania, youth turned to advice columns in magazines and self-help pamphlets for guidance on sex, relationships and love (Reuster-Jahn 2013). In early twenty-first century South Africa, Hilary Wilson (2012, 57-62) found that Soweto teachers read American self-help books and Christian devotional texts to learn how to become wealthy and in pursuit of general self-development. Meanwhile, Simphiwe Emmanuel Rens (2016, 128-129) argues that black South Africans in post-apartheid South Africa consume self-help texts and media as a "guide towards "knowing" and "finding" the self as well as granting further moral education with respect to socially-acceptable behaviour deemed vital for social harmony'. South Africa's need to 'fix' itself after apartheid and the confessional nature of the Truth and Reconciliation Commission have led, Rens argues, to a public therapeutic culture embodied in confessional television and radio shows as well as the more private consumption of self-help texts.

According to Ikenna Kamalu and Ebele Emilia Mmewu (2016, 72), self-help texts 'constitute a huge percentage of the literary production in Africa. Self-help pamphlets are one of the most prolific, widely read and commercially acclaimed book genres in pre and postcolonial Nigeria.' Such claims about the popularity of self-help literature are often anecdotal, but nonetheless they point towards general trends. While traditional literary criticism has tended to focus on 'high' literary forms, in Africa (as elsewhere in the world) other forms of writing and reading proliferate. Novels are often expensive to purchase, and so too are foreign-published self-help texts, but locally published texts and pamphlets are often much cheaper, and may hold great appeal to readers who seek educational value from their reading.

In his novella Every Day is for the Thief (2007), Teju Cole's unnamed narrator describes his encounter with self-help and religious texts at the CSS (formerly CMS) Bookshop in Lagos, where he laments how '[t]he largest section of all is devoted to "inspirational" and Christian books', in contrast to the lack of either Nigerian or international literary fiction, which occupies just one 'small' shelf - implying that 'inspirational' literature dominates contemporary Nigerian 
reading habits to the detriment of high literary culture (93). Indeed, the popularity of self-help texts has sometimes been cited as evidence of the lack of a 'serious' reading culture, or of the dominance of religious or get-rich-quick mindsets.

Literary scholars may find it useful to make similar distinctions between 'high' literature and popular texts such as self-help texts, and to take seriously the economic, social and political conditions that encourage the production and reading of self-help literature over other kinds of literary text. Nonetheless, the concerns and ideas expressed in self-help texts are not always distinct from those of either canonical literary texts or other popular cultural forms. The challenge of navigating life as a woman in the city, so vividly discussed in Lape Soetan's books, has been one of the key themes of Nigerian literary texts and popular culture, too, from highprofile novels such as Sefi Atta's Everything Good Will Come (2004) to newspaper columns such as 'Life with Treena Kwenta', published in the Vanguard newspaper in the 1980s and 1990s (Bryce 1997). The expectation that texts should educate and advise their readers, too, is shared by some readers and writers of self-help texts, popular texts and literary fiction alike, as in Chinua Achebe's notion of the 'novelist as teacher', for instance (Achebe 1975). Reading popular textual forms such as self-help texts alongside literary fiction, while still recognising the differences between them, can help literary scholars explore their shared concerns, textual conventions and readerly expectations, and avoid artificially detaching literary fiction from Africa's large, vibrant, locally produced and -circulating textual ecology (see Adejunmobi 2015, 55-57).

This chapter, then, explores the ways that literary scholars might take self-help texts seriously, through a focus on Lape Soetan's self-help e-books alongside self-help literature from across the African continent. Although this chapter focuses on 'how to' and advice guides, my definition of self-help literature is inclusive, encompassing many kinds of non-fiction text that aim to advise the reader: personal development texts; motivational and inspirational texts; Christian, Islamic and other religious advice texts; self-management and self-improvement texts; some business and management guides; and some autobiographical texts. The chapter begins by discussing the history of self-help literature in Africa, highlighting its links to other popular literary genres. It shows how self-help literature has been understood as 'problem-solving texts' produced in response to social change, and as a reflection and reconfiguration of particular ideologies, especially in relation to gender. It explores how texts imagine themselves to be creating new readerly selves, before arguing that the texts are powered by their own creation of textual, writerly and readerly authority, and ultimately, the authority of the word itself.

\section{The history of self-help literature in Africa}

While the contemporary boom in self-help literature may invite a reading of the genre as 'new', it in fact has long literary roots in the African continent. Furthermore, although North American self-help texts were the bestsellers in Nairobi's bookshops in 2005, it is not only foreignauthored texts that are making their mark in Africa's self-help publishing market. Locally published newspapers, pamphlets, books and, increasingly, e-books and blogs offer readers advice tailored to local circumstances.

Newspapers have been an important site for the publication of advice, owing to their potential for exchange between readers and writers through letters and, more recently, text messages and emails (Reuster-Jahn 2013, 69). Marriage guidance has been published from the earliest days of the West African press: in the 1880s, African-owned newspapers published pieces debating gender and marriage, such as views on ordinance marriage, 'traditional' and 'modern' marriage (Newell 2008, 18). Gustav Jahoda $(1959,179)$ describes an advice column in 
an unnamed Gold Coast newspaper of 1955. Noting that the readers' letters and advice printed in the column likely represent the views and concerns of literate, unmarried young men in the cities, Jahoda shows how the letters cluster around concerns of 'love, marriage and social change', particularly the 'persistence of traditional mores' and the 'influence of new patterns of living'.

Probably the most well-known example of advice literature published in the twentieth century African press can be found in Drum magazine. The magazine was first published in South Africa in 1951, and was home to an advice column called 'Dear Dolly' which focused on sex and relationships, reflecting readers' concerns with contemporary issues such as 'interethnic marriages, unreciprocated love, premarital sex, homosexuality' (Mutongi 2000, 3). The column sought to answer questions of everyday life from Africans across the continent, in doing so, offering what Kenda Mutongi considers a radical representation of 'ordinary Africans' and urban-dwelling Africans in the media (1-2).

The rise of pamphlets and popular literature in Africa from the 1950s has also provided a major platform for self-help literature. In Nigeria, instructional and 'how-to' pamphlets aimed at literate, aspirational urban populations formed a huge proportion of the popular literature that has become known as Onitsha Market literature. This literature was centred on city life in late colonial and newly postcolonial Nigeria, and 'the problems of a changing society in which the growth of new cultural elements has stimulated new desires, new attitudes and new values' (Obiechina 1973, 16). It has thus been read as 'a medium for the celebration of this emergence of the masses, and their discovery of their potential in the building of a modern industrial culture in Africa' (116). Alongside fictional texts addressing the dilemmas and pleasures of city life, non-fiction texts taught readers how to deal with the strains of city life, 'from how to fall in love to how to launder clothes' (16). While a number of these pamphlets addressed concerns about educational self-improvement, or making and keeping money, by far their greatest preoccupation was with love, relationships and marriage.

Mass popular culture was also the impetus behind the rise of advice columns in the postindependence era popular press. New private newspapers, radio and television stations arose in many African countries in the 1990s following the widespread deregulation of the media (Barber 2018, 137). The new popular presses embraced advice columns as a genre with huge appeal to their readerships. In Tanzania, for example, advice columns were common in the post-1980s Swahili popular press (Reuster-Jahn 2013, 70-71). Such advice columns, ReusterJahn suggests, are, like many popular cultural forms, a 'self-made literature', 'flourishing in the streets', outside the official realm of the bookshops and 'high' literature (87-89).

Self-help publishing has also been shaped by the rise of (Pentecostal) Christianity and, increasingly, reformist Islamic movements, with their emphasis on domestic relationships, gender relations and gendered forms of religious piety, and the personal encounter with the word of God (Newell 2005; Nolte 2015; Janson 2013). Although by no means all self-help texts published in Africa have a religious foundation, an abundance of 'cheap, locally published religious pamphlets' circulates across contemporary Africa: '[m]arriage guidance pamphlets, tracts and "satanic possession" testimonies are easy to obtain, sold alongside school textbooks and novels in local bookshops, displayed on street bookstalls and distributed by travelling evangelists who tour colleges and public transport depots' (Newell 2005, 297). Much African Christian self-help literature has its early roots in the influence of North American Pentecostal literature, and the use of English means that these texts can be marketed to Christians across Anglophone Africa. However, African churches have also localised the material, publishing through commercial and church printing presses (Newell 2005, 296-297, 301-302). Studies of Christian selfhelp texts dominate the scholarship on religious self-help literature in Africa, and in the late 
1990s, in southwest Nigeria at least, there were initially many more Christian than Islamic texts focused on self-help topics (Barber and Farias 2002, xiv-xvi). Today, however, Islamic texts are increasingly readily available, similarly encouraging readers to embed their relationships and personal development in Islamic principles (Nolte 2016).

Like non-religious self-help texts, religious self-help texts encourage readers to apply their lessons to everyday life, but readers 'learn to interpret their mundane experiences through the framework of their spiritual experiences' (Newell 2005, 300). However, while many Christian readers may prefer Christian texts, they are not always considered distinct from non-religious self-help literature. Hilary Wilson $(2012,70)$ argues that the teachers she surveyed in Soweto 'did not distinguish between Christian books that give practical advice and books that give advice but do not have a religious focus'. The reason for this, she argues, is that:

Their socialisation into this belief system is so thorough that any of the forms of cultural capital that they perceive to be within their grasp as a result of their reading, such as selfdevelopment, confidence building, business success and so on, are seen as entirely compatible with their religious worldview and communal dispositions.

Lape Soetan's self-help books developed out of another new phenomenon in African publishing: the rise of the online space. The ease of online self-publishing has provided a new venue for enterprising self-help authors to publish their work. Online publishers and marketplaces such as Okadabooks, the Nigerian e-publishing platform founded in 2013, sell a wide range of self-help books in electronic form. At the time of writing, Okadabooks stocked 637 selfhelp e-books, which readers can download to read via an app on their smartphones, computers or tablets. While such downloadable books may not be as accessible to mass readerships as their pamphlet predecessors were, they are certainly highly convenient for those readers who do have the money and time to get online.

The flexibility of online publishing was the impetus behind Lape Soetan's self-help writing. Soetan began writing as a hobby, through a blog which features written and video posts on travel, restaurants in Lagos and enjoying city life, as well as relationship advice. Based on the success of her blog, Soetan began writing e-books that readers could pay to download from her website, and she also works as a life coach, offering women advice on love and relationships. Soetan's self-help writing is thus part of a broader portfolio of writing built largely through the online space, alongside her face-to-face work with Lagosian women.

\section{'Problem-solving texts': self-help literature and social change}

Lape Soetan's focus on gender, love and relationships aligns her with a time-honoured tradition in African self-help literature. While business and prosperity texts are ever-popular amongst African readers, books concerned with love, marriage, relationships and sex are also published and consumed widely across Africa (Reuster-Jahn 2013, 69; Newell 2008, 17). Guides to love and relationships proved phenomenally popular amongst Onitsha Market pamphlet readers, for instance; A. O. Ude's The Nigerian Bachelor's Guide, which offers advice on marriage and romantic letter-writing, sold 40,000 copies (Obiechina 1973, 11).

Soetan's How to be a Single Woman can be read as taking off where Ude's pamphlet ends: Soetan offers advice to the Nigerian bachelor's female counterpart, updated for life in twentyfirst century Lagos. The 'single woman' of Soetan's text offers a comeback to male self-help authors' frequent worries about the deleterious influence of the 'good-time girl' of the city: Soetan's single woman is re-imagined as independent, career-minded and reflective, taking 
charge of her own happiness, whether single or married. Soetan's imagined reader is a funloving, independent Lagos woman, but she is not hunting men's cash; she finds fulfilment in work and doing things she enjoys, rather than in men or her appearance: 'A single woman in Lagos should work,' Soetan advises, 'have a hobby she can relax with after work and spend at least one day during the weekend out doing something she enjoys with people she likes around her' (9). Soetan describes holidays, restaurants and shopping, and imagines how she would spend time as a single woman going to 'art galleries, plays and bars', or travelling around the world. Soetan's readers may view these as aspirational ambitions, and even Soetan writes that 'I didn't really think I would get to do all the things I wanted' - but, she adds, 'I intended to try' (10). Thus this is a book not just about life as a single woman seeking a partner, but also about being a prosperous, independent, middle-class woman in Lagos, navigating professional and personal fulfilment.

A concern with finding happiness as a woman is at the heart of Soetan's writing: 'I just really want women to find happiness,' she explained to me in an interview, 'and I want to help them find that, whether it's through travelling, or through building their confidence no matter their marital status' (Soetan 2016a). While the focus of How to be a Single Woman is on enjoying life and seeking happiness while finding a partner, 7 Steps to Meeting the One (2015a), Soetan's second short e-book, has the same purpose but with the opposite emphasis: it helps the reader find a partner, while maintaining happiness and integrity. In a trajectory that roughly tracks Soetan's own biography, Soetan's third e-book, How to Enjoy Your First Year of Marriage (2016b), focuses on marriage. Like her other books, How to Enjoy outlines the work that a woman must undertake - but in order to secure happiness for the married couple, rather than to please the husband. Soetan's most recent book is Loving and Living as an Introvert Woman (2017). Although it focuses less directly than her other books on subverting gendered social expectations, it adopts the same theme of finding happiness on women's own terms.

Why has there been such a focus on gender, love, sex and marriage in self-help texts such as Soetan's? The scholarship on African self-help literature has shown how the genre has emerged from ideological, social, political and economic conditions of the twentieth century, particularly urbanisation and changing gender regimes. Stephanie Newell $(2008,19)$ argues that in Nigeria and Ghana, self-help texts respond to the economic and political insecurity of city life, with writers using self-help texts to reflect upon the 'moral and emotional values of people in the city', to solve the particular problems of city life and to 'adapt to the malleable social conditions of the cities'. Gender has been a particular concern for these urban writers. Emily Callaci (2017, 61), for instance, shows how in Dar es Salaam of the 1960s and 70s:

prayer guides, didactic novellas, newspaper advice columns, relationship advice books, and sex education pamphlets written for newly arrived migrant girls in the city reveal an emerging set of relationships in the city between middle-class educated women and poor and working-class 'girls'.

Callaci argues that these texts reveal the preoccupations not of the 'working girls' of Dar es Salaam themselves, but of the texts' middle-class writers, who saw the influx of young, working-class women as an opportunity to 'define their position in the city through efforts to improve the lives of poorer women'. Thus 'advice givers not only sought to affect the young women, but also sought to remake the city and their authority as reformers within it'.

Callaci's emphasis on 'remak[ing] the city' through the text reflects a broader scholarly interest in how self-help texts create and reinforce ideologies and authority. The scholarly literature on North American self-help literature has especially argued that such texts often 
reinforce (although also sometimes challenge) conservative and neoliberal ideologies, particularly in relation to gender and notions of 'hyper-individuality', although, of course, readers do not always accept the messages of these texts wholeheartedly (McGee 2012, 686; Rimke 2000, 62; Hazleden 2011). Such readings of texts as ideological tools have been influential in the scholarship on African self-help texts, too. Jana Krige and Marcelyn Oostendorp, for instance, read Drum magazine's 'Dear Dolly' column of 1984-2004 with a focus on the column's discursive construction of victims and perpetrators of sexual violence. They argue that after apartheid, the column shifted explicit blame for sexual violence from victims to perpetrators, although the continued implicit blaming of victims reflects the fact that 'conservative ideologies remain about women and their autonomy over their sexuality' (Krige and Oostendorp 2015, 14, 20). Krige and Oostendorp thus read 'Dear Dolly' as offering a 'more or less direct insight into the ideological perspectives of the magazine's readers and editors on sex, courtship and sexual autonomy', and thereby into the 'subliminal communication of norms and values' in South Africa (11-12).

Stephanie Newell $(2005,297)$ similarly positions 'how-to' pamphlets as a means through which gender ideologies are established in Nigeria and Ghana: 'evangelical and Pentecostal authors make use of their literacy to assert new domestic roles and alternative subjectivities for women and men in West African households.' However, Newell argues that the West African Christian marriage guidance texts she discusses also sometimes 'reconfigure domestic gender relations', particularly those by women authors. While texts by male authors often use the Bible as validation for patriarchal gender relations, some - though not all - women authors propose Bible-based 'inviolable gender rules and alternative, egalitarian models for the husband-wife relationship' (298). Self-help texts thus do not always reproduce dominant ideologies; they also offer potential sites for resistance or, at least, reconfiguration.

Soetan's How to Be a Single Woman, while not relying on biblical authority, also seeks to reconfigure gender relations in Lagos, through its counter-cultural assertion that (prosperous, middle-class) women can be happy even while single. In an interview, Soetan recalled how the book was received by some readers as 'scandalous', and was perceived by men as dangerous:

How to Be a Single Woman in your 30s in Lagos [...] caused some scandal. I got a few nasty comments. Mostly from men. Saying why will you be saying that? You are encouraging women to stay single. One guy now sent me a tweet saying that he doesn't want his young daughters to come across people like me, I don't want them to get married. [...] All the women who wrote to me said that they liked the book. But the men who said they didn't like it, I found it strange that they hadn't read the book.

(Soetan 2016a)

According to Soetan, the mere existence of her book and its provocative title is enough to be perceived as threatening Lagosian gender norms. Although Soetan does not use the term 'modern' to refer to the Lagosian women she imagines, these struggles between male and female readers echo disagreements over the 'modern' woman in other forms of self-help writing. Self-help literature in Africa is sometimes understood to be tussling over the encounter between 'modern' and 'traditional', or 'Western' and 'African', ways of being. In Tanzania, for example, Uta Reuster-Jahn (2013, 80-83) reads Swahili-language advice columns in tabloid magazines and pamphlets as attempting to blend 'Western' and 'African' approaches to sexuality.

However, gendered approaches to modernity suggest that both readers and writers may have different understandings of the value of the modern. Newell suggests that while the term 'modern' is sometimes used disapprovingly in relation to urban 'good-time girls', it also refers, 
in the writings of female authors in particular, to 'companionate Christian marriages based on mutual respect and gender equality'. Modernity is thus 'interpreted as liberating for women, providing them with a greater array of choices and romantic possibilities', while male self-help authors 'repeatedly associate rebellious women with modernity, and attempt to re-contain them in new "traditional” marital arrangements' (Newell 2008, 23-24). When Soetan's male readers misread her book as recommending the single life - or, as Soetan suggests, fail to read the book at all - they similarly associate Soetan's modern Lagosian woman with 'scandal' and 'rebellion', and attempt to 're-contain' women as subjects of marriage.

Concerns about gender and sexuality are, of course, not unique to self-help literature. Popular fiction has often shared the themes of self-help literature, particularly love and marriage, and has been received by readers as 'problem-solving texts', 'generat[ing] debate amongst readers on moral and behavioural issues', to the extent that Newell characterises 'what a popular novel teaches' as a key concern of West African readerships (Newell 2002, 1-5). In her study of Soweto teachers' reading habits, Hilary Wilson $(2012,70)$ found that:

'motivational' books have become the norm against which other books are measured, so that any book is termed 'motivational' by the teachers if they find them particularly relevant or inspiring, for example, biographies of famous leaders, and any literary work that deals with controversial issues or moral dilemmas, such as Shakespeare's plays.

Self-help literature thus makes this presumed educative and transformational quality of the text explicit.

\section{Creating new readerly selves by making progress}

In offering solutions to the problems of everyday life, self-help texts often encourage their readers to make progress in life. This emphasis on personal progress leads Newell to suggest that many West African self-help texts adopt a similar approach to American self-help literature, which helps the reader to imagine 'a future where a successful, self-created self exists in a happier state'. In West Africa, self-help literature similarly recognises that 'an individual often suffers alienation and urban anomie, and it looks optimistically towards individuals to take control of their environment in the near future' (Newell 2008, 19). However, while North American texts presume that readers have some control over their lives, Newell argues that 'the majority of West African texts display a lingering - often an overwhelming - sense that individual lives are determined by the invisible hand of fate', often understood as God's will, reflecting the unlikelihood of achieving full personal autonomy in difficult economic and political conditions. Self-help writers are thus 'diviners of fate' rather than architects of an entirely new readerly self: ' $[$ t]hrough reading, urban subjects can perhaps start to imagine, and enunciate, a future self, a tentative subjectivity which depends on an external power to guarantee its horizons' (20-21).

Non-religious self-help texts similarly encourage readers to imagine a changed 'future self. However, such texts are often closer to liberal North American self-help literature in their emphasis on the individual's capacity to make progress. Soetan's e-books, for instance, encourage readers to seek continual progress:

Your life is a work in progress. In this exercise, how long the process takes doesn't matter. What matters is that one makes progress every day. Every step forward will make you a better person and will bring you closer to your ideal mate.

(Soetan 2015a, 10) 
Life is a 'work in progress': Soetan's books show the reader the work and personal effort that is required to make the life the reader wants. In order to make progress, the reader must 'do the things you like and you need to do them no matter what anyone else says' (Soetan 2015b, 5). In doing so, the reader learns to rely on her own judgement: 'When it comes to taking advice, I believe you should trust yourself, Soetan explains, adding that, 'when you don't know what to do, talk to someone who you respect and who you think is objective', rather than turning to all and sundry (8). Self-discernment is imagined to result in happiness and the life the reader wants. It also, less explicitly, results in the creation of readerly subjectivity, personhood and autonomy; readers actuate their potential, move from unformed to full personhood, through this linear process of reflecting, imagining and acting.

Yet, there is an anxiety about time wrapped around this forward-looking narrative of progress. How to Be a Single Woman adopts a storytelling mode that centres on time passing. 'When I got to a particular point in my life,' the book begins, 'I wanted to write a book' (Soetan 2015b, 3). Subsequent chapters similarly open with temporal framings: 'When I was in university, I thought 27 would be a great age for me to get married' begins Chapter 1, while Chapter 4 opens with Soetan describing how 'After a few disastrous relationships, I was certain life was better single.' Age is a marker of time and of social expectation: 'I recently got married at the ripe old age of 34', Soetan tells us, remarking that her 'late' marriage did not fit with her own initial expectations: 'When I turned 28 and was boyfriend-less, I began to panic a little. How was I supposed to get married at 29 if I was still single at 28? Something was wrong here.' It also does not fit with those of the people around her: 'Later, I wondered what many people had thought that day. Perhaps it was 'Poor Lape. Dancing alone on her 30th birthday. No fiancé. No boyfriend even. $\mathrm{Na}$ wa” (3-4).

However, a key instruction of Soetan's texts is that the reader must learn to trust her internal sense of time, which relates to her own desires, instead of an externally imposed time that equates age with social landmarks, especially in relation to men and marriage: 'My point about the party is that while being single and 30 is a sad turning point for many women, I wanted to make it a happy one for me' (Soetan 2015b, 4-5). Soetan gently undermines the figure of the 'aunty' and of thirty-something women as she revels in going to nightclubs 'at a certain age':

Once, I was discussing clothes with a friend and showed her a scandalous top I had just bought. She asked where I planned to wear it. When I said 'To the club,' she said 'So you still go to nightclubs?' with a mix of pity and incredulity on her face. [...] I know what this friend was thinking: 'So this "aunty" is still going to nightclubs? No wonder she isn't married.' Said friend is younger than me and that just made me sad. If I liked nightclubs, why shouldn't I go? I always went to nightclubs with people I trusted. I enjoyed drinking at clubs. I loved dancing at clubs. What on earth was wrong with me being there? Nothing. Except that she, like many Nigerians, felt that a woman of a certain age should not be at nightclubs.

(Soetan 2015b, 6)

Marriage remains Soetan's goal, but she encourages women to find happiness even if they do not acquiesce to age-related norms, and to revel in their 'scandalous' enjoyment of life. The text thus emphasises an internal, introspective subjectivity that relies on a sense of unique personhood.

Rachel Spronk discusses a similar emphasis on self-reflection in an advice column in Nairobi's Parents magazine which, from the turn of the twenty-first century, became well known for its frank advice about sex and sexuality aimed at married couples. Spronk reads the success of the 
column as reflecting a broader emergence of 'the intimate' into public discourse in the Kenyan media from the 1990s (Spronk 2011, 145). The columns also mark a shift away from directive advice towards encouraging 'self-reflection as the most important step to solving relationship problems'. Nairobi's print media can thus be understood as 'engendering new modes of subjectivity and new discourses of personhood', embedded in a romantic understanding of sexuality and relationships (151), much as Soetan, too, imagines a new kind of woman who is able to trust her own time and self-reflection.

\section{Self-help literature and the creation of authority}

Self-help texts not only create new readerly subjectivities; they also invent new writerly subjectivities. Stephanie Newell $(2005,297-305)$ argues that Christian self-help texts often appear to limit the writer's authority by representing the Bible as the primary authorising text. Authors claim their own authority, and that of the ideologies they advocate, not from being 'originators of meaning', but from the 'incontrovertible truth of their own biblical exegeses' as they 'claim to mediate the biblical Word on behalf of readers and they connect their own locally published books with the Holy Book'.

Non-religious self-help texts sometimes use other terms to convince readers of their authority. Soetan's texts do this by asserting her experience, wisdom and age, but also adopting the persona of a relatable friend. Soetan's relationship with her reader is intimate; Soetan is 'I' and the reader is 'you', often imagined in distinction to a sometimes ambiguous 'they' who heap social pressures on the reader. However, the relationship is also directive; Soetan uses short, instructional sentences to guide the reader. Nonetheless, Soetan also encourages the reader to recognise that she has a choice about how she takes such guidance, helping her navigate the comments and judgement she is presumed to encounter as a single woman in Lagos. Even though Soetan's books are full of advice, they are also sceptical of certain kinds of it. 'Take advice with a pinch of salt' is the title of Chapter 3 of How to be a Single Woman, and Soetan reflects on how advice is a particularly gender-specific genre in Lagos:

Go to church. Don't wear revealing clothing. Don't buy a car. Don't wear expensive things. Don't get a Master's degree. And on and on. The list of things a single woman in her 30s should and shouldn't do is endless. Somehow, there's always more of this advice for women than men and the aim of the advice is always to get the single woman married.

(Soetan 2015b, 8)

Soetan explained to me her concerns about women's understanding of the right kinds of advice:

I'm coming across women who say, fine, I don't have the right relationship, I don't have love, but why do I need to be coached about it? Can't I just turn to my Bible, or turn to ... ? And I'm thinking oh wow, this is just ... I don't even know how to deal with that! So someone was telling me that you see, the people that need your help don't even know that they need your help.

(Soetan 2016a)

Soetan's books and life coaching are imagined as bringing a new kind of advice tailored to the contemporary Lagos woman, based neither on the advice of previous generations nor on that of religious authority. Soetan thus establishes herself as a textual authority on relationships, life as a woman in Lagos, and forms of advice. 
However, there is another way in which Soetan's self-help texts generate authority. Just like her imagined reader, Soetan herself makes progress: she becomes an author. How to Be a Single Woman's genesis, Soetan tells us, lay in her own desire to become an author:

When I got to a particular point in my life, I wanted to write a book. I wasn't sure what to write about or what people wanted to read so I asked a few friends and the almost unanimous answer was - write about living as a single woman in her 30s in Lagos. I was pretty surprised because that was far from what I thought they would suggest. I'm very interested in the relationship between women and their careers and have written about that a lot in the past but it seems that people are more interested in the relationship between women and men.

(Soetan 2015b, 3)

Soetan fits the book into a narrative of her own progress; becoming an author is imagined as being a way of finding happiness. Soetan thus imagines a new subjectivity for herself - the successful writer - as she does for her readers. The text may show readers how to be single women in their 30s in Lagos, but it also enables Soetan to become a writer in her 30s in Lagos.

Soetan holds an MBA, and her books are part of her broader career ambitions, as she explained to $\mathrm{me}$ in an interview:

So I do have to find the right target and the right business model. But I'm always coming up with ideas of things to write, and then sometimes I think I don't have the time to write that, or I think it's going to take me so long, should I just write a really short e-book and then let it go, and then if I'm going to write this long proper book, it may take me a year, and then am I not going to make any money for a year, what am I going to do?

(Soetan 2016a)

Soetan's emphasis on her e-books' business potential is reminiscent of Moradewun Adejunmobi's $(2014,178)$ commentary on the perception amongst Nigerian youth that mediated performance offers 'the most direct and accessible route to fame and wealth' in Nigeria's poor economic situation. Soetan's position is different from the aspirational but struggling urban Nigerian youth Adejunmobi discusses, many of whom have few formal opportunities; at the time I interviewed her, Soetan had professional employment and was building her own business on top of that. Nonetheless, while Soetan's writing does not participate in the rapid growth of performance as a strategy for social mobility that Adejunmobi stresses, I suggest that there is a similarity in that for Soetan, too, media - here, online publication - appears to offer a do-it-yourself route to building a name for oneself.

Beyond the intimate and authoritative relationship between writer and reader, other forms of interpretation and authority are invoked by some readers of self-help texts. Pentecostal Christian self-help texts, for instance, are discussed by church groups, such that '[d]uring the groupreading process encouraged by ministries, participants develop and discuss lessons about alcohol, sex, marriage, social behaviour and money' (Newell 2005, 300). New interpretations arise, beyond those envisaged by the author. I encountered a similar communal interpretation of a self-help text when a Nigerian friend visited me in London in 2016, bringing with her several copies of a self-help book called Mr Sun \& Mrs Moon: Emergence of the Seven-Star Family (2014) by Bukki Gbenro, who was my friend's pastor. The book is a Christian text which uses the metaphor of the sun and the moon to describe the complementary gender roles the author ascribes to men and women, based on his reading of the Bible. In the opening 'Remarks' 
section, Rev. Wale Adeyemo praises the book as 'an inspired body of guidelines on how to build and nurture a model family. This book is a treasure for "newly weds" and an indispensable resource for "experienced couples"' (Gbenro 2014, v). Following the book's invitation to apply its guidance to readers' own lives, my friend brought together a group of Nigerian friends and family living in London. Bukki Gbenro joined us by phone to speak about $\mathrm{Mr}$ Sun E Mrs Moon and the book's biblical framework. As the group discussed topics such as money in relationships, we re-thought our own views, based on the interpretations and experiences of others in the room, as well as those within the text.

This communal reading and reinterpretation of the self-help text is not unique to West African readers. In 1960s and 70s Dar es Salaam, Christian readers similarly formed reading groups, 'especially for women, in which members would read and discuss the Bible and other texts on themes of conjugality, childrearing and urban living' (Callaci 2017, 61). Communal reading is also not limited to Christian readerships. Male readers of Drum magazine's 'Dear Dolly' often 'read the column loudly to their male friends, commenting on and imaginatively rewriting the events in the letters in order to reveal their opinions on sexuality and courtship matters'. Female readers were more likely to read the column privately, corresponding with gendered social norms which encouraged feminine restraint in discussing sexual matters (Mutongi 2000, 3, 20). The work of interpretation involved in such communal readings makes sharply apparent a mode of reading which may also be in operation amongst those readers who read texts in private: the necessity of interpretation in order to apply, and sometimes adjust, the lessons offered by a text, and to create new meanings from the text, beyond the writer's own authority.

Although Soetan's e-books do not explicitly invite communal reinterpretation, they encourage readers to extend their interpretations in another way. Soetan's books urge the reader to interpret, analyse and reflect on their own desires and interests. 'Think about your life', Soetan instructs the reader:

Ask yourself what you like doing. Or think about times when you were doing something and felt happy. Do you get a buzz whenever you walk into a cinema? Do you love it when you snuggle into a chair with a book? Do you enjoy cooking? Do you like eating out with friends? Analyse yourself. Decide what it is that you like doing and do it!

(Soetan 2015b, 7)

This interpretive and self-reflective method becomes even more powerful as Soetan urges readers to become creators of narratives and characters for themselves: 'If you don't know what you want, how will you know it when you see it? Sit down with a pen and paper, think hard and write down a description of your ideal partner' (Soetan 2015a, 5).

For readers who prefer the imaginative to the verbal, Soetan offers another method of creation:

When I carried out this exercise, I made several lists and didn't meet my perfect partner. I then decided to stop the list-writing and instead imagine the person. So, one day, I lay down and tried to see my future loved-one in my mind. Now, I'm not a very visual person but I'm good at creating a feeling. I was more comfortable with this route. I imagined how my ideal partner would talk to me (in a caring way), how he would treat people (he would be kind), how he would think (he would be witty), how he would make me feel (he would make me feel loved) and so on. I found that this method of 'feeling' the person rather than writing down who he was made me happier and more confident that I would meet him. 
Whether you choose to write down a list or to 'feel' them, you need to come up with a description of your ideal companion so that when you spot them, you'll know immediately.

(Soetan 2015a, 6)

By imagining her ideal partner and ideal life - either through words or through 'feeling' - the reader is envisaged to bring that person or life into being: 'Now that you've come up with a list of traits your ideal partner would have, it's time to bring the person to life', Soetan instructs the reader. 'Think of a mannequin or a doll that you want to dress up', she suggests, asking the reader to create an image of her partner as if a character in a film or a novel (Soetan 2015a, 7). The reader becomes an author or film-maker of her own life:

Once you've come up with your ideal mate in your mind, recall the image or movie you made about them and revel in it every day. You can do it as you go to work, during lunch or even in a boring meeting! I find that the best time to 'watch your mind movie' is just before you go to sleep at night when you can rewind, pause and play it to your heart's content.

(Soetan 2015a, 8)

Soetan envisages the reader creating not a justifying narrative or autobiography, but a creation that engenders this life in itself. Soetan thus invests power in the word, the imagination and the visual image as forms through which one can manifest that which one desires.

This creation of the future one desires echoes a belief frequently espoused in self-help literature: if one wills something and works hard enough for it, it will come into being (Effing 2009 , 127). But the emphasis on the power of the visual and verbal imagination could also be understood as reflecting another idea sometimes encountered in West Africa: that words are imbued with power to communicate with the divine, to act on and transform the speaker, writer, reader or listener (Barber 1981; Nolte 2015). In religious contexts, words are sometimes perceived to be imbued with 'divine importance': in Christian self-help literature, 'words like "marriage", "power", "prayer" and "protection" gain a mystical significance, becoming the keys to unlock gateways through which God can enter ordinary people's lives' (Newell 2005, 302, see also Barber and Farias 2002, xviii). Even in Soetan's non-religious texts, words (and images) are imbued with a power to make things happen.

Soetan's sense of the power of words also echoes a debate about the value and authority of the writer and the written text that has long interested Nigerian writers. In the twentieth century, writers often 'make use of the text to assert the primacy of print and the superiority of literacy over other forms of authority' (Newell 2008, 24). Some Yoruba travel writers from the 1920s onwards, for instance, characterised their travel narratives as èkó (education, lessons). The process that some of these travel writers imagine is not just the transmission of lessons, but readers becoming transformed through reading - into better-informed and more cosmopolitan people, for instance (Jones 2016, 104). Soetan's texts, with their suggestion that the word and the imagination - her own, and her readers' - can transform lives, similarly affirm that wisdom and experience can be passed from text to reader. In doing so, Soetan's self-help texts, like many other self-help texts in Africa, sustain and re-imagine authority on multiple levels: in the writer; in established or new ideas about gender; in the reader's own self-reflection; in readerly interpretation; and in the word and the imagination itself. 


\section{Note}

1 Lape Soetan's website can be accessed at: www.lapesoetan.com/.

\section{Acknowledgements}

I gratefully acknowledge an ERC Starting Grant led by Dr Insa Nolte, entitled 'Knowing Each Other: Everyday Religious Encounters, Social Identities and Tolerance in Southwest Nigeria' (Grant No. 283466) based at the University of Birmingham and Osun State University, which funded some of the research for this chapter.

I also acknowledge my gratitude to Lape Soetan for giving me her time for an interview, and for her continued encouragement.

\section{References}

Achebe, Chinua. 1975. 'The Novelist as Teacher'. In Morning Yet on Creation Day: Essays, 42-45. London: Heinemann.

Adejunmobi, Moradewun. 2014. 'Stand up Comedy and the Ethics of Popular Performance in Nigeria'. In Popular Culture in Africa: The Episteme of the Everyday, edited by Stephanie Newell and Onookome Okome, 175-194. New York: Routledge.

Adejunmobi, Moradewun. 2015. 'Provocations: African Societies and Theories of Creativity'. In Rethinking African Cultural Production, edited by Kenneth W. Harrow and Frieda Ekotto, 52-77. Bloomington: Indiana University Press.

Atta, Sefi. 2004. Everything Good Will Come. Northampton: Interlink Books.

Barber, Karin. 1981. "How Man Makes God in West Africa: Yoruba Attitudes Towards the "Orisa". Africa 51(3): 724-745.

Barber, Karin. 2018. A History of African Popular Culture. Cambridge: Cambridge University Press.

Barber, Karin, and Paulo Fernando de Moraes Farias. 2002. 'An Archive of Yorùbá Religious Ephemera'. Africa Bibliography 2000: vii-xix. doi: doi:10.1017/S0266673100003974.

Bryce, Jane. 1997. 'A Life on the Women's Page: Treena Kwenta's Diary'. In Writing African Women: Gender, Popular Culture and Literature in West Africa, edited by Stephanie Newell, 47-66. London: Zed Books.

Callaci, Emily. 2017. Street Archives and City Life: Popular Intellectuals in Postcolonial Tanzania. Durham, NC: Duke University Press.

Cole, Teju. 2007. Every Day is for the Thief. Abuja: Cassava Republic Press.

Effing, Merce Mur. 2009. 'The Origin and Development of Self-help Literature in the United States: The Concept of Success and Happiness, an Overview'. Atlantis 31(2): 125-141.

England, Andrew. 2005. 'Self-help Books Take a Grip on Kenya's Middle Class'. Financial Times, 18 October, 11.

Gbenro, Bukki. 2014. Mr Sun E Mrs Moon: Emergence of the Seven-Star Family. Ibadan: Axiom.

Hazleden, Rebecca. 2011. 'Dragon-slayers and Jealous Rats: The Gendered Self in Contemporary Selfhelp Manuals'. Cultural Studies Review 17(1): 270.

Jahoda, Gustav. 1959. 'Love, Marriage, and Social Change: Letters to the Advice Column of a West African Newspaper'. Africa 29(2): 177-190. doi: doi:10.2307/1157520.

Janson, Marloes. 2013. Islam, Youth and Modernity in the Gambia: The Tablighi Jama'at. Cambridge: Cambridge University Press.

Jones, Rebecca. 2016. 'The Sociability of Print: 1920s and 30s Lagos Newspaper Travel Writing'. In African Print Cultures: Newspapers and Their Publics in the Twentieth Century, edited by Derek Peterson, Stephanie Newell and Emma Hunter, 102-124. Ann Arbor: University of Michigan Press.

Kamalu, Ikenna, and Ebele Emilia Mmewu. 2016. 'Discourse of Knowledge versus Discourse of Selflegitimation in Contemporary Nigerian Popular Literature: An Enquiry into Adebayo Bello's Self-help Pamphlets'. Mgbakoigba: Journal of African Studies 5(2): 72-84.

Krige, Jana, and Marcelyn Oostendorp. 2015. “"Too Late for Tears, Dear Sister”: Constructing Victims and Perpetrators of Rape in the Advice Column "Dear Dolly" from 1984 to 2004'. Stellenbosch Papers in Linguistics Plus 46: 7-23. 
McGee, Micki. 2012. 'From Makeover Media to Remaking Culture: Four Directions for the Critical Study of Self-Help Culture'. Sociology Compass 6(9): 685-693. doi: doi:10.1111/j.1751-9020.2012.00485.x.

Mutongi, Kenda. 2000. “Dear Dolly's” Advice: Representations of Youth, Courtship, and Sexualities in Africa, 1960-1980'. The International Journal of African Historical Studies 33(1): 1-23. doi: doi:10.2307/ 220256.

Newell, Stephanie. 2002. Readings in African Popular Fiction. Bloomington: Indiana University Press.

Newell, Stephanie. 2005. 'Devotion and Domesticity: The Reconfiguration of Gender in Popular Christian Pamphlets from Ghana and Nigeria'. Journal of Religion in Africa 35(3): 296-323.

Newell, Stephanie. 2008. 'Corresponding with the City: Self-help Literature in Urban West Africa'. Journal of Postcolonial Writing 44(1): 15-27. doi: doi:10.1080/17449850701820574.

Nolte, Insa. 2015. 'Spirit: Histories of Religion and the Word'. In West Africa: Word, Symbol, Song, edited by Gus Casely-Hayford, Janet Topp Fargion and Marion Wallace, 48-71. London: British Library.

Nolte, Insa. 2016. 'A Comparison of Gendered Repertoires in Muslim and Christian Self-help Books and Pamphlets from Nigeria'. African Studies Association of the UK Conference, Cambridge, UK, 7-9 September.

Obiechina, Emmanuel. 1973. An African Popular Literature: A Study of Onitsha Market Pamphlets. Cambridge: CUP Archive.

Rens, Simphiwe Emmanuel. 2016. "Striving towards "Perfection"?: Investigating the Consumption of Self-help Media Texts by Black South Africans in Post-apartheid'. Master of Arts (Media Studies), University of the Witwatersrand.

Reuster-Jahn, Uta. 2013. 'Sex and Relationship Education of the Streets: Advice on Love, Sex, and Relationships in Popular Swahili Newspaper Columns and Pamphlets in Tanzania'. In Popular Culture in Africa: The Episteme of the Everyday, edited by Stephanie Newell and Onookome Okome, 91-114. New York: Routledge.

Rimke, Heidi Marie. 2000. 'Governing Citizens through Self-Help Literature'. Cultural Studies 14(1): 61-78. doi: doi:10.1080/095023800334986.

Soetan, Lape. 2015a. 7 Steps to Meeting the One. Lagos: n.p.

Soetan, Lape. 2015b. How to Be a Single Woman in your 30s in Lagos. Lagos: n.p.

Soetan, Lape, 2016a. Interview with author. Lagos, 28 April.

Soetan, Lape. 2016b. How to Enjoy your First Year of Marriage. Lagos: n.p.

Soetan, Lape. 2017. Loving and Living as an Introvert Woman. Lagos: n.p.

Spronk, Rachel. 2011. "Intimacy is the Name of the Game": Media and the Praxis of Sexual Knowledge in Nairobi'. Anthropologica 53: 145-158.

Wilson, Hilary. 2012. 'The Reading of Self-help Books by Intermediate Phase Teachers in Gauteng Townships'. Master of Applied Linguistics, University of the Witwatersrand. 


\section{Gothic supernaturalism in the 'African imagination' Locating an emerging form}

Rebecca Duncan

A young Xhosa woman in South Africa is confined to a convent, a 'cure' for the spirits that she has always been able to see; a little girl in London makes friends with a Yoruba ghost, and is consequently terrorised by threatening visitations; a child in Igboland hears a voice inside her head, compelling her into the scaled arms of fanged and flesh-eating playmates. These scenarios, taken - respectively - from Angelina N. Sithebe's Holy Hill (2007), Helen Oyeyemi's The Icarus Girl (2005) and Nuzo Onoh's The Sleepless (2016) - demonstrate what I will explore in this chapter as an emerging gothic impulse currently animating strands of literary production within (to borrow F. Abiola Irele's term) 'the African imagination' (2001). But what validates the use of the term 'gothic' here, and why its attendant 'emerging' designation? African literatures have long been populated by magical and - often - terrifying figures: under what conditions do these become newly legible as 'gothic'? I address these questions in what follows, although from the outset - it should be noted that to a certain extent 'gothic' appears an appropriate category for analysis on the grounds that it is demanded by the texts themselves. Here I am referring specifically to Onoh, who is hailed - on the jacket of her Unhallowed Graves (2015) as 'the frontrunner of African horror'. ${ }^{1}$ In the coming pages, I ask what 'African horror' might look like, in formal literary terms. I attempt to situate these terms through a discussion of gothic's treatment of the supernatural, and to locate this within established analyses of magical dimensions of African fiction writing. In conclusion, I suggest that the aesthetic departures entailed in gothic form respond to conditions in African postcolonies at the historical juncture of the millennial present. To begin, however, I broach the often-elusive definition of 'gothic'.

\section{Gothic: fear, enlightenment and the supernatural}

As a term for categorising literary texts, 'gothic' first emerged in late eighteenth-century Britain to describe fiction written in the style inaugurated by Horace Walpole's The Castle of Otranto (1764): a fantastical narrative of shadowy dungeons, archaic villainy and weird, haunting apparitions. This tradition's aesthetic influence remains visible in gothic production into the present 
day. However, since Walpole, gothic has also been adapted and reformulated for a remarkable number of historical, political and geographical contexts. Along with early, Victorian and contemporary - or indeed 'post-millennial' (Spooner 2017) - gothic, contemporary criticism speaks of 'female gothic' (Wallace 2013), for example, and 'queer gothic' (Haggerty 2006), along with 'tropical gothic' (Edwards and Vasconcelos 2016), 'globalgothic' (Byron 2013), and - especially relevant to the following discussion - postcolonial gothic (Khair 2009; Wisker 2007; Punter 2003). Writing of what unites this canon - in reality much more diverse even than my sample conveys - David Punter ventures that fear is the most consistent marker of the gothic imagination (Punter 1996a, 18). Gothic texts are invested in sensations of anxiety, and, in this necessarily limited introduction, what I would like to point out in particular is that the supernatural, when it is handled in the gothic mode, is a site at which this anxiety is concentrated.

To conceptualise this relationship between fear and supernaturalism in the gothic text, it is useful to return to gothic's earliest permutations, and to recall that the eighteenth century in which Walpole writes is both the time of Enlightenment - of, ostensibly, moral, aesthetic and scientific sophistication - and the time of empire and slavery. Despite what Simon Gikandi calls the 'anachronistic'-seeming character of the latter in an Enlightened Europe, this was also a selfconsciously modern moment $(2011,20)$, one that - in Bruno Latour's formulation - defined its present by invoking a 'break in the regular passage of time' $(1993,10)$. A key effect of this break in the eighteenth century specifically was to render the contemporary period one of science (the so-called 'age of reason') and the past an epoch of superstition - a distinction that, implemented in imperial contexts, grounds the 'colonial modernist order of knowledge' via which Harry Garuba shows that indigenous knowledge systems are delegitimised and displaced $(2012,4)$. Latour goes on to summarise the modernity of the age of reason as consisting in a disentangling of the realms of human and nature, the interweaving of which characterises what, from the selfappointed 'modern' perspective, is taken to be a primitive proclivity for animating - or supernaturalising - an infinitely knowable object-world. Such a proclivity, both Latour (1993, 39) and Garuba $(2012,4)$ note, was identified by agents of empire in indigenous cultural practices across the imperial world, and marshalled, along with colonial discourses of primitivism, to align colonised peoples on the 'nature' side of modernity's human-nature dualism.

But the violent imperial/Enlightenment project of dichotomisation also produces its own limitations. What Latour calls 'hybrids' $(1993,11)$ are phenomena that resist interpretation via modernity's disjunctive logic, and it is here, at resistant sites of experience, that gothic's sinister supernatural lexicon might be located: its '[d]arkness', Fred Botting writes, 'threatened the light of reason with what it did not know' $(1996,32)$. A similar point is made by Gikandi across his Slavery and the Culture of Taste. For him, early gothic is a literary conduit for un-acknowledgeable intersections between the self-consciously humane culture of eighteenth-century Europe, and the commercial reality of slavery which undergirded and enabled this in multiple complex and layered ways. Here, Botting's 'light of reason' encompasses Enlightenment as a social and moral discourse, one that - as Gikandi shows - 'is predicated on the need ... to quarantine...social life ... from a public domain ... including the sale of black bodies' $(2011,24)$. When what Gikandi calls the eighteenth-century 'culture of taste' is made to confront this intolerable reality, the resulting fraught and contradictory experience is expressed in gothic's fantastical and fearful forms.

What Gikandi's analysis drives at, then, is a vision of the age of reason in which its culture coheres through acts of proto-repression: in which 'slavery ... [is] the great unconscious of modern identity' (121), and gothic provides a language for what rises transmogrified back up from this netherspace. ${ }^{2}$ Indeed, it is in part through reading gothic fictions that Terry Castle is able to suggest the age of reason 'invented the uncanny' $(1995,8)$. What Freud was to theorise 
in psychoanalytic terms as the 'species of the frightening that goes back to what was once ... familiar' ([1919] 2003, 124), first emerges, for Castle, in an eighteenth century where the 'urge to obtain a new and objective knowledge of the world' had the counter-effect of making the world 'all the more bewildering, inscrutable and grotesque' $(1995,16)$. Under conditions where the power of reason is presumed to be infinite, experiences not reducible to reason acquire a peculiarly unsettling quality: they are loaded with a disruptive potential that, in a world after Freud, might be associated with the uncanny as the returning repressed.

At stake in Castle's reading, then, is reason itself, and not only a culture of Enlightenment. Latour's disentangling process, through which animating spirit is exorcised from a quantifiable nature, is shown - paradoxically - to open the way for spectres of a more intensely threatening kind. The dread with which supernatural figures are imbued in gothic fiction registers such threats: gothic's superstitious vocabulary carries the weight (to return to Freud) of what should have 'remained hidden' - perhaps below the contours of an object-world - but has come 'to light' (2003, 148). This tense oppositional relationship between a rationalisable reality and its relegated, mysterious and supernatural 'other' is imprinted, like a kind of literary time-stamp, in the Gothic figure, and this - as I will go on to show - has a peculiar bearing in the context of the 'African imagination' (Irele 2001, 4).

\section{Situating gothic in the African imagination}

For Irele, the African imagination refers to 'a conjunction of impulses', which are 'grounded both in common experience and in common cultural references', and which 'have been given a unified expression in a body of literary texts' (2001, 4). It includes the 'expressions of Africans and people of African descent', the latter of which participate in the sense that they reference a 'black experience deriving from a common ... association with Africa' (20), and further deploy a 'matrix of expression' that is routed - often consciously - back to cultures of Africa (21). Irele notes the ambivalent status of white South African authors in these respects. He writes that while the novels of, for example, Nadine Gordimer, André Brink and J. M. Coetzee can 'from a thematic point of view be identified with African interests', their work 'does not display the sense of a connection to an informing spirit of imaginative expression rooted in an African tradition' (15). It is notable, then, that the majority of critical work around gothic currents in fictions of and from the African continent - work to which I have myself contributed (Duncan 2014, 2018a, 2018b) - has focused on South African literature, and has dealt most extensively (although not exclusively) with the writing of white authors. ${ }^{3}$ In part, it is these authors' connection - on which Irele comments - to a 'European literary tradition' (Irele 2001, 15) that facilitates their reading in gothic terms.

But gothic is also - as Onoh makes especially clear - currently being actively invoked within the African imagination. I am aware of several critical works dealing with this phenomenon contributions orientated largely by gothic's established relations to postcoloniality and to gender. ${ }^{4}$ In part, I draw on these relations, too; however, my interest in this chapter lies more immediately with the place and function of gothic form in texts that take sites in Africa as what Irele has called their 'cultural reference'. At its most basic level, he argues that this reference is oral literature: '[T]he assimilation of the modes and conventions of the Western literate culture' (12) notwithstanding, he identifies orality 'as the matrix of an African mode of discourse' (11). And '[i]n traditional African oral contexts,' as Ato Quayson notes, 'the dominant narrative genres that circulate have an element of the magical and the supernatural in them' $(2010,159)$. It is here, then, that we might begin to see a possible gothic connection - especially, as Brenda Cooper notes, because magical interventions in African literatures are frequently experienced as 
frightening by these narratives' characters $(1998,41)$. But the link between such moments and gothic form is also not straightforward, and cannot be assumed. While gothic supernaturalism attests to an Enlightenment logic that seeks to exorcise the world of animating spirit, Harry Garuba argues that what is frequently termed the 'magical realism' of African literatures derives from the 'logic of animist thought' $(2012,7)$.

To grasp the salience of this statement for the presence of gothic in the African imagination, Garuba's point requires some elaboration. Animism refers to the ascription of spiritual life to the object world (2003, 267): it is, Garuba writes, 'an epistemological standpoint', which 'operates basically on a refusal of the boundaries ... of modernity' $(2012,7)$. In cultures - including African cultures - in which this standpoint is central, he sees the existence of 'animist materialism', which designates a reality perceived and consequently configured via animist principles (2003, 266). All of this bears on literary expression: what has been called 'magical realism' is, for Garuba, only a subspecies of a wider imaginative inscription of animist logic, which he terms 'animist realism' (2003, 274). While 'animist realism' designates a range of narrative styles, requiring only that there occur in a text 'the materialization of ideas' (Garuba 2003, 273), magical realism is a narrower category of this broader one: within it an animist logic is vividly discernible as the interweaving of magical episodes, drawn or adapted from indigenous folklore or cosmologies, with those that speak of (colonial) modernity, and of its epistemological and material bequests. Cooper notes the equivalence that characterises this 'syncretism of disparate elements' (1998, 36). In her formulation of magical realism, '[t]he mysterious, sensuous, unknown and unknowable ... share fictional space with history' (36). The relation between esoteric and 'real' is thus lateral: the magical, as she puts it, is 'not in the subtext' (36).

Especially significant here is the sense in which, viewed through Garuba's lens, this laterality or co-existence attests to a logic that is rejected by Latour's Enlightenment programme. Where this distinguishes between human and nature, seeking to purge the world of the superstitions that entangle these, the animist principle precisely relates human and nature, spiritualising the object world, and by extension, also performing what Garuba calls a 're-enchantment' of what has been disenchanted via post-Enlightenment protocols (2003, 271). This re-enchantment unfolds in narrative as animist logic subverts ... the hierarchy of science over magic and the secularist narrative of modernity by reabsorbing historical time into the matrices of myth and magic' $(2003,270)$.

What all of this shows, then, is that magical interventions in African literatures are not consonant with those in gothic texts. These latter, as I have shown, treat the supernatural precisely as the relegated, if indelible, residue of a 'modern' epistemology. Another way of framing this distinction is to say that animist realism - and magical realism as its subspecies - registers the reenchanting work of the animist principle that Garuba calls the 'animist unconscious', which organises realities in cultures with a history of animist traditions (2003, 269). Gothic, however, might be said to register the animist as the unconscious space itself: as a kind of repository or 'receptacle' - in Garuba's terms - 'for everything that is a negation of the modern' $(2012,4)$. If in animist realism there is a horizontality or equivalence between the magical and the historical or 'real', then in gothic it might be said that this relationship is vertical, and - further - that the magical or supernatural is loaded with a disproportionate and anxious weight as it threatens (like Freud's returning repressed) to disrupt the 'reality' above it. ${ }^{5}$ Indeed, Cooper implicitly references this configuration. She writes that there is 'no gothic subtext' undergirding the magical real $(1998,36)$ - its syncretisms are explicit, rather than threateningly latent - and, thinking along similar lines, Lucie Armitt notes that the distinction between the two modes lies with the 'sinister particularity' afforded to the supernatural in gothic fictions $(2012,519)$. 


\section{The gothic prism?: verticality as a strategic relation}

In the work of Sithebe, Oyeyemi and Onoh, gothic consists in this affectively unequal and vertical relation, and - at least to begin with - each of these writers dramatises this relation as an epistemological or cosmological tension, which recalls the tension in early gothic between Enlightened or 'modern' and supernatural domains. In Sithebe's Holy Hill, for example, protagonist Nana is sent by her irate parents to the eponymous convent as a result of her sensitivity to the spirit plane. At Holy Hill, she is forbidden by the nuns - representatives of a colonising Christianity - to speak with the unborn and other spirits that she has always been able to see. Consequently, and as I have suggested elsewhere (Duncan 2018b), it is at the convent that these spirits acquire a peculiarly terrifying - and indeed recognisably gothic - inflection, materialising as floating nuns, and as graveyard spectres. In Oyeyemi's Icarus Girl, Nigerian-British Jessamy's hauntings are strongly linked to her Western upbringing, which means that she cannot speak Yoruba, and that she does not know its cosmology. She is thus terrorised by spirit manifestations connected in the narrative to a Yoruba world, which - at times - explicitly signal their association to that for which her diasporic education has not accounted. 'These ideas!', shrieks the horrifying thing that hangs from her bedroom ceiling like a bat: 'Disgusting ... shame, shame, shame. It's all been lost' (Oyeyemi 2005, 235). In Onoh's The Sleepless, child protagonist Obele is prohibited by her devoutly Christian parents from engaging with the mysterious voice she has heard in her head since birth: 'Shut up, you horrible child! Just shut your demon mouth before I kill you!', her mother rages (Onoh 2016, 49). It is Obelé, too, who is visited by the monstrous 'Ghost Girls' (143), who turn out to be the wards of Mami-Wata, and who have 'glittering eyes as green as Papa's beer bottles', 'shiny grey scales identical to ... fresh fish' (139), and 'teeth like tiny, sharp pincers' (143).

In each of these scenarios, supernatural figures associated with particular cosmologies or mythologies - Xhosa, Yoruba and Igbo respectively - are presented in gothic terms. They incarnate animist worldviews that have been excluded in realities structured by the (colonial) bequests of Enlightenment modernity, and thus, like the supernatural figures in the fiction of the age of reason, they acquire the hyper-fearful and disruptive quality of the returning repressed. All of this demonstrates the vertical relation assumed by gothic forms. Gothic in these texts implicitly situates magical materials adapted from indigenous conceptual fields as the hidden substrate of what is offered as a more prosaic reality, which is then threatened by the re-emergence of such elements from this narrative space. In short, and to reiterate, the animist or supernatural is treated here as a kind of unconscious. The magical and the real are not rendered equivalent and interwoven on a lateral plane; rather the magical has been submerged, and has transmogrified and intensified as a result.

Considered in these terms, gothic interventions in African fiction reconfigure an established relationship between magical and 'real', and - as I suggested in my introduction - it is possible to view this departure as responsive to certain material and cultural conditions. Quayson, in his Strategic Transformations in Nigerian Writing (1997), provides the conceptual framework via which to explore questions around gothic texts and African contexts. Against what he sees as a tendency to read African literatures as replications of African cultures, he offers the term 'interdiscursivity', which renders narrative a refracting, rather than a reflecting medium. Viewed with 'interdiscursivity':

The text would no longer be seen as a mirror of discrete cultural elements but rather the prismatic field of interaction between cultural discourses and literary ones with all the 
possible transvaluation of the real that this makes possible. In this light, we may describe literature as not a mere precipitate of culture but as a process of meditation upon it.

(Quayson 1997, 16)

For Quayson, the ways in which literary texts interact with what he calls the indigenous 'field of conceptual resources' (16) constitute strategic responses to the socio-economic, political and historical contexts in which these texts are produced. Paying particular attention to the 'resource base of mythopoeia' (18), Quayson charts the changing location of 'liminality' (9) between representations of 'real' and spirit domains in Nigerian writing, and explores these shifts as specific to the climates of pre- and post-independence Nigeria, and of Nigeria in the post-colonial age. I would like to suggest that gothic might be approached in these terms: as a particular strategy for organising the relationship between esoteric or spirit- and historical worlds, which in turn - I will venture towards the end of this chapter - also responds to, and provides a 'meditation' on, a particular set of circumstances.

\section{Postcolonial gothic - and beyond}

What kind of cultural 'meditation' is it that gothic forms might be seen to undertake in the narratives considered above? The first and most obvious answer to this question emerges with an agenda that can be arrogated to a now relatively established canon of postcolonial gothic fiction. From this perspective, gothic's supernatural elucidation of a suppressed substrate of indigenous culture enables a commentary on the violent cultural and material erasures of the colonial project, a key objective of which inheres - to paraphrase V-Y. Mudimbe - in the epistemological and cosmological conversion of the colonised $(1988,2)$. It is clear that the implicitly vertical arrangement of disenchanted and animist worlds in Onoh, Sithebe and Oyeyemi reflects colonising cultural transformations as a kind of repression. Indeed, it is 'the problem of repression' that Maisha L. Wester identifies as a central concern in African American gothic writing, which she sees as less interested in the terrors of what returns, than it is in the deleterious mechanics of domination $(2012,28)$. Viewed in these terms, gothic figures tell literally, in the case of Oyeyemi's bat-like apparition - of the losses incurred with the imposition of a 'colonial modernist order of knowledge' (Garuba 2012, 4), the bequests of which, the narratives suggest, have relegated animist worldviews to the netherspace from which transmogrified supernatural forms return. At the same time, and as they illuminate the colonial 'silencing of alternative visions', Gina Wisker notes that gothic avatars in postcolonial texts also enable an 'explor[ation] of how such ... hidden histories can represent themselves' $(2007,147)$. Again, Oyeyemi's haunting creature provides a salient example: as it embodies a Yoruba world from which Jess is dislocated - linking this dislocation to the power of colonising 'ideas' - it also narrates its fragmentary history of violence and loss through a mouth that, suggestively, possesses only the 'remains of a tongue' (2005, 236 emphasis in original). Silence is thus, with recourse to the gothic, made to speak.

On this account, then, the relation between magical and real in Oyeyemi, Sithebe and Onoh emerges as a means of addressing - and redressing - a postcolonial condition that is framed as one of loss. Their narratives appropriate gothic's early function as a language for what is relegated by Enlightenment protocols, and they mobilise this function to draw into focus the relegation of indigenous worldviews forcibly 'disenchanted' by these same protocols in their colonial permutations, while, at the same time, affording such histories of erasure some kind of representation. And yet, this is also not the whole story. The vertical and affectively 'bottomheavy' relationship between a real that bears the imprint of colonial bequests, and a submerged 
supernatural inflected by indigenous conceptual resources is a structural pattern through which these writers explore a complex range of tensions and histories - tensions and histories that are, in some cases, only tangentially related the colonial encounter.

\section{Gothic as a situated feminist strategy}

It is not incidental that all of the writers considered here are women, nor that each narrative focuses on the experiences of female characters. Indeed, Diana Adesola Mafe has argued that Icarus Girl should be read as 'postcolonial female gothic', allying it to that tradition, for which as she also notes - Brontë's Jane Eyre (1847) is perhaps the most illuminating example, and which focuses the material and ideological enclosures of patriarchy, while also conjuring the 'suppressed yet pervasive female agency' for which these cannot account $(2012,23)$. In her own commentary on Brontë's legacy, Cooper writes that women authors in the African diaspora are currently 'build[ing] gothic fictions ... which enable both their feminism and their blackness' (2012, 145), and Cheryl Stobie, tacitly underscoring similar gothic potentials, has called in turn for attention to the gothic dimensions of fiction 'by black South African women, who have been particularly repressed and silenced' $(2008,30)$. The implicit point here is that colonial power is both racist and gendered. As Oyèrónkẹ Oyěwùmí puts it:

African females were colonized by Europeans as Africans and as African women. They were dominated, exploited and inferiorized as Africans together with African men and then separately inferiorized and marginalized as African women.

$(1997,122)$

In her reading of Holy Hill, Stobie outlines these compound and asymmetrical relations of power as they are experienced by Nana: as privation and, frequently, as violent assault. The convent is an institution where race and gender intersect to govern the distribution of punishment and privilege $(2008,31)$ : Stobie notes, for instance, that male pupils are prioritised over female students (32), and that white sisters enjoy luxuries not available to the black nuns (34). Indeed, the education provided to Nana and her peers registers the entanglement of racism and patriarchy under conditions of apartheid, against which the convent sections of Sithebe's narrative unfold, and where - significantly - racist legislation coercively sought to produce South Africa's black populations as a labouring class. Apartheid's predominantly migrant system of labour, its roots reaching back to the mining revolution of the late-nineteenth century, meant that women were frequently required to run their households without their husbands - a situation that Anne McClintock, writing of earlier colonial formations in South Africa, has noted places the unpaid work of black women at the foundation of the country's colonial order(s) (1996, 256). In the convent, the girls acquire the skills necessary to prop up this system. They learn 'cooking, knitting, sowing, sewing, saving and managing a home', and are taught, furthermore, to accept their racialised and gendered lot: they are 'to avoid conflict, animosity, [and] public disturbance' at all costs (Sithebe 2007, 72).

But gendered repression is shown in Sithebe's narrative not to be an exclusively colonial preserve. The narrative identifies a systemic racialised patriarchy in the apartheid state, but it also explores the ways in which colonising regimes overlay and compound experiences of oppression that, while related to its mechanisms, are not wholly reducible to these. The narrative shows, for example, that Nana's convent training transforms her from a shameful daughter to a coveted household asset in her home community: 
Other mothers envied her [Nana's mother] because of Nana's obedience, such a drastic change ... There were hints from women with sons that 'the girl would make a good wife and an even better daughter-in-law. A handsome lobola of a least ten cows was almost guaranteed'.

Later, when Nana is grown up and apartheid is officially ended, her (ultimately fatal) relationship with her lover Claude locates her again in a subordinate and exploitable gendered role. Towards the end of the narrative she analyses her situation as follows: '[E]verybody, the black man and woman leading, had to stampede and trample, first over the black girl, then woman. So she knew it all. She had experienced it since birth' (198). Thus, if Nana's spiritual power psychokinesis, future sight - on the one hand suggests a resurgence of indigenous knowledge abnegated by a colonial order, then it also, on the other - and more specifically - suggests the eruption of a female agency that is elided within this structure, and which is similarly unaccounted for within the structure of the Xhosa household that Sithebe presents.

In Icarus Girl, Oyeyemi's exploration of a patriarchal order unfolds primarily - but not exclusively - in those sections of the novel that take place in Nigeria. As Mafe notes (2012, 26), it is importantly within the pointedly named 'Boy's Quarters' of Jess's grandfather's home (Oyeyemi 2005, 31) that the novel's haunting presence first appears in the form of the little girl, who Jess calls TillyTilly. Her grandfather - Gbenga Oyegbebi - presides over a substantial compound, built by his own father at the end of the nineteenth century: Gbenga 'had lived there ... right up until his father had died, and he, as the eldest son, had inherited the compound' (31). Accordingly, Jess's grandfather emerges across the narrative as the bearer of a patrilineal authority: his name, he tells Jess, means "kingship lives here" ... I am a princely man' (27). While this declaration is in part a dignifying affirmation of Gbenga's Yoruba heritage, the authority invoked in the name is also borne out in scenes where, waiting on Gbenga, Jess's mother - Sarah - appears to her daughter unfamiliarly 'like the household help' (25). Icarus Girl thus presents its Yoruba family as patriarchal in structure. While the text does obliquely situate this configuration in the wake of a colonial past - the compound is, for example, built during the colonial period - this inheritance is not offered as the wellspring of a gendered power (as it is formatively by Oyěwùmí in her Invention of Women [1997]). Rather, the aftereffects of a colonial history inflect the structure of a patriarchy that the novel identifies operating within Yoruba society.

In this inflection, formations of patriarchal authority intersect - as they do in Holy Hill - to produce particular and compound restrictions for the women in the novel. It is noteworthy here, as Mafe points out, that Jess's mother is considered transgressive by both her Yoruba father and her English husband, and her behaviour is condemned as "unnatural" by each man. Her father interprets her challenging of his paternal authority as the possible evidence of a curse, for example, while her husband betrays his Eurocentric conception of motherhood when he chastises her "Nigerian" parenting style'. 'Despite their dissimilar backgrounds,' Mafe concludes, 'both men ultimately view Sarah's behaviour as unusual and extreme' (2012, 26). Mafe goes on to suggest that TillyTilly retrieves what is excluded by these overlapping gendered visions when she spectrally appears in the disturbing-yet-maternal form of the woman whose arms are 'tentacle-like, stretching to her ankles' (Oyeyemi 2005, 70). This relationship is made especially clear in the unsettling scene where TillyTilly appears with, 'just beyond her, a pair of long, dark brown arms ... snaking through the door' (157). Moments later Sarah stands in the place where this vision has been - 'TillyTilly flew away and her [Jess's] mum came instead' (157) - and what this substitution suggests is that, in the long-armed woman, the female agency elided by Gbenga 
in his paternalistic assessment of Sarah, and the Yoruba maternity abnegated by her husband, coalesce and return.

Icarus Girl and Holy Hill thus both draw into focus contemporary configurations of gendered authority experienced as violence or restriction by their women characters, and in this sense each begins to become legible in the terms that Chielozona Eze ascribes to the 'third generation of African woman writers' $(2015,318)$. He includes Chimamanda Ngozi Adichie, Lola Shoneyin, NoViolet Bulawayo and Nnedi Okorafor (among others) in this cohort of authors (318), and suggests that in their work, these authors specifically 'respond to aspects of their cultures that they perceive as oppressive to them as women in African communities' (311). Eze makes his argument against what - drawing on Pinkie Mekgwe (2008) - he elsewhere identifies as an impulse in African feminisms to counter the reductive Afropessimism that frequently characterises representations of African women in Western discourses. This tendency gives rise to what he calls 'glossy images of the continent', which, he argues, at times entail 'outright denials of the flaws of some cultural practices' $(2008,108)$. Eze's point is that an interrogation of such practices should not be taken automatically as evidence for an alliance between African women critics and a 'neo-imperial machination against Africa'. Rather it should be viewed as articulating a 'demand [for] respect for ... body and mind' (112). In summation, Eze writes that when African women

tell stories about polygamy, the pain of childlessness, female genital mutilation, rape of women or spousal abuse, they do so not because they engage in some form of violence as pornography ...; rather they do so because they feel immense pain whether in their own bodies or, empathetically, through the bodies of women they know. We cannot afford to ignore these texts and the pains they highlight.

$(2015,317-318)$

Viewed in light of Eze's comments, the vertical structure of gothic form appears a means of interrogating gendered configurations of authority that have yet to be fully addressed. The tense gothic relation between the real and its submerged supernatural substrate becomes, in other words, the framework for excavating still-obscure historical experiences. As Sithebe and Oyeyemi deploy this structure to map formations of paternal authority in their Xhosa and Yoruba households respectively, confronting these organisations with the agencies they are shown to suppress, both writers implicitly suggest - in line with Eze - that such suppressions have been inadequately considered, that they obtain as the texture of a prosaic world, which the gothicised supernatural has a peculiar capacity for disrupting.

In Onoh's narratives, a similar strategy is discernible, and, indeed, in these texts Eze's points emerge as specifically illuminating. Of the three writers considered here, Onoh is by far the most invested in gothic's characteristic sense of fear: her narratives imbue their supernatural figures with intensely rendered anxiety, and foray frequently into the shockingly violent aesthetics of horror. Like Sithebe, Onoh also undertakes an explicit interrogation of social practices in African cultural contexts (her narratives take aim, repeatedly, at the primacy of sons in Igbo family structure), and they are further - in a direct reflection of Eze's points regarding pain and empathy - grounded in the author's own experiences, and in the experiences of women she knows. What it might be possible to see, then, in Onoh's manipulation of an especially affectively charged gothic lexicon, is an attempt to articulate a violence that is immediately and acutely felt, and to do so in terms that insist this violence not be dismissed.

In an interview, Onoh states that 'The Unclean', one of the three long tales that appear in the collection Unhallowed Graves, was 'inspired by a personal tragedy', and also by the ordeal of 
'a good family friend [who] was ... made to spend three nights in the forest with her husband's corpse' (Saulson 2015). This last is the scenario with which the 'The Unclean' closes - the corpse awakes, its phallus terribly engorged, and bears down disturbingly on the body of the protagonist - and this eventuality reiterates, in horrifying terms, the violence implied in more mundane language by the open critique of Igbo patrilineage articulated at the tale's beginning: 'As Papa was fond of telling my sister and me,' the protagonist relates, 'a woman has no name, no religion, no country, no custom, no honour except that given her a man'. Consequently, she tells that her only brother is also the only sibling in her birth family 'given an Igbo name' (Onoh 2015, 14-15): she herself is called Desdemona, which does not bode well.

Desdemona's critical assessment of patrilineage sets the tone, too, for Onoh's novel The Sleepless, to which I have already referred above. In The Sleepless, Obelé's father harbours a particular distaste for his youngest daughter (she 'didn't come out as a boy at birth' [2016, 33]), and is connected both to the paternalistic power mapped out in 'The Unclean', and with a patriarchy associated with the legacy of colonial rule: he is a pillar of the protestant church and frequent drinking partner of the wealthy white elite. He rules his wife and daughters with brutal authority, which the narrative goes on to locate within the context of gendered violences operating across the wider community. The Sleepless is unrelenting in its vision of these violences: it charts the routine sexual abuse of young girls by their teacher; tells of the protagonist's violation by a roaming soldier; narrates the ritual murder of a four-year-old girl; and opens with the analogous murder of Obelé's brother Kene, who - born with Down's Syndrome and having suffered polio - is sacrificed by her father on the grounds that he is an unsatisfactory heir.

As in 'The Unclean', then, male authority and patrilineality are presented as producing radical vulnerability, and yet, Onoh's fictions are not monolithic in their critique of the social organisations with which they deal. Like Oyeyemi, who Mafe sees as 'rearrang[ing]' patriarchal structures rather than eradicating these $(2012,31)$, Onoh interrogates, but does not entirely reject, the families and communities she considers. In part, the complexity of her critique emerges in the powerful sororal bonds that thrive within the institutions she traces. Obele is nurtured by her half-sister Ada, who - despite her father's dislike for his youngest daughter offers her guidance, refuge and comfort. A similar sustaining relationship is also extended beyond the narrative's female characters to Kene, with whom Obelé shares a particular bond, and all of these connections find their analogues in the gothic figures that give the tale its name.

'The Sleepless' are the 'Ghost Girls': those strange, fanged and scaled children, who - after some hesitation over their appearance - become Obelé's companions and protectors: 'we will play with you and never let anyone hurt you', they tell her, and make good on their word when her life is threatened (Onoh 2016, 140, emphasis in original). The Ghost Girls are also, significantly, the spirits of victims of male violence, their gothic presentation signalling their incarnation of an elided agency. In a strategy similar to the one Mafe identifies operating in Oyeyemi's novel $(2012,27)$, the Ghost Girls convert Obelés vulnerability in the face of her father's abuse into supernatural strength, bringing this to bear on their earthly aggressors, upon whom they wreak eternal vengeance. Throughout the narrative, the girls are referred to as Obelé's 'sisters' by the mysterious guiding voice she hears in her head, so that their gothic reincarnation of the powerful sustaining relationships between Obelé and her siblings is made clear.

What is being invoked here then is an agency - suppressed by the text's patriarchy - that consists in a form of sisterhood. And this is not, furthermore, the sisterhood that emerges in 'white American nineteenth- and twentieth-century family experience' (Oyěwùmí 2001, 5), and which Oyěwùmí has influentially argued is thus an inadequate model for African women's solidarity. Rather - and as Obelé's relationships with her siblings show - this is a closeness that is realised through a mutual participation in the duties of mothering. 'In many African societies, 
there is no sisterhood without motherhood', Oyěwùmí writes: 'Co-mothering as a communal ideal and social practice is not reducible to biological motherhood; it transcends it' (9). 'Comothering', furthermore, is rooted in an organisation in which 'mothers are the pivot around which ... family rotates' (9): sibling bonds in such a structure are not organised by gender, but by a shared relationship to the mother, which becomes the grounds for participation in the 'comothering' role. It is notable then, that while Obelé and Kene do share a mother, she and Ada do not - or at least not in the earthly domain: at the narrative's end, after Ada's death, she and Obelé are re-united below the surface of the Niger River, in the queendom of Mami-Wata, whose voice it is that has guided Obele since birth, and from whom she learns she is directly descended. The Ghost Girls, too, belong to this river community, and the effect of this plot trajectory is a routing of all the bonds of solidarity mapped out in the text in terms of sisterhood through the supernaturalised mother figure. In place of patrilineage and patriarchal authority, the narrative thus closes with a matrifocal organisation, which, appearing in gothic terms across the novel, is also presented as the shadow or double that inheres in androcentric formations, but for which such formations do not fully account.

\section{Why now? Gothic aetiologies of Africa's millennial present}

Onoh's extended story 'The Night Market', which also appears in Unhallowed Graves, marks a departure from the other two narratives in this collection - and from The Sleepless - in that it is the only tale to feature a European protagonist, and the only one, too, that is set in the postmillennial present. The story unfolds from the perspective of Alan Pearson, the 'commercial attaché' to the British High Commissioner in Lagos. It is Alan's job to 'negotiat[e] lucrative trade deals for British companies seeking expansion into Africa's largest economy' (Onoh 2015, 106), a role that connects him with that insidious form of capitalist (neo)imperialism, which Neil Lazarus - noting the deleterious effects of post-independence Structural Adjustment Policies - identifies as the neoliberal successor to colonial regimes past $(2011,9)$. Indeed, the text aligns Alan with what it refers to (in the present tense) as 'the empire's ulterior goals in its former colony' (Onoh 2015, 135) - skewering, in this line, the imperial nature of neoliberal geopolitics - and the tale also maps out the radically uneven socio-economic landscape to which these exploitative global relationships give rise in African contexts. Alan frequently comments on the infamous mismanagement and dramatic inequality of the contemporary Nigerian city, where he sees an elite demographic 'obscenely' staging its 'corruptly-acquired wealth' before a 'pathetically destitute' majority (114) (although he remains conspicuously silent on his own role in the production of these circumstances).

At the same time as the narrative traces the uneven contours of post-millennial Lagos, it also suffuses these materialities, subtly to begin with, with a sense of mysterious dread. From the outset, the tale suggests there are obscure forces at work in the city, which shape the lives of its inhabitants - including Alan's own. For example, when, at the beginning of the tale, Alan's driver - Olu - is forced to recalculate the route home several times, the protagonist remarks, that 'were he of superstitious disposition, [he] would've been convinced that an invisible, malevolent hand was against them' (106). Indeed, Alan's insipient superstitions are confirmed when he and Olu pick up a bedraggled hitchhiking woman, who the protagonist initially associates with 'the glaring inequalities amongst the Nigerian population', assuming these have 'consigned her to prostitution and abuse' (110). In fact, the woman turns out to be not so much poor as dead - or 'Quarter-to-Dead' (111) in Olu's phrasing - with a face like 'the mummified skull of an ancient corpse' (126). As the narrative supernaturalises the condition of poverty in this way, rendering it a mysterious state of undeath, it seems to affirm the presence of 
those obscure vectors on which Alan has speculated. The suggestion here is that to live amid the disproportionate distributions of wealth and privation in contemporary Lagos is - especially from the perspective of the destitute - akin to living at the mercy of a diffuse and violent power.

In his reading of Ben Okri's The Famished Road (1991), Quayson identifies a similar idea in action. He notes that for Okri's impoverished characters, experiences of the real are not fully separable from the esoteric: 'In the particular destitution, impoverishment and brutality in which the people in the novel are caught, the realities of existence are frequently tinged with an eerie light' $(1997,136)$. What the novel shows in its 'delineation of squalor and destitution', is thus that such conditions are 'the new seats of hallucination' (136) and it is in part Okri's specific handling of the relation between the real and the supernatural that produces this hallucinatory effect. The narrative emerges from the perspective of the abiku child Azaro, who, having access to both real and spirit worlds, enables these planes to converge across the text. Azaro's experience in a busy marketplace provides a particularly relevant example here: this is initially filled with bustling shoppers - 'mountainous women with faces of iroko, midgets with faces of stone' - but, with a blink of the protagonist's eye, suddenly becomes populated by spirit 'people who walked backwards, a dwarf who got about on two fingers ... women who had breasts on their backs' (Okri 1991, 15). This passage demonstrates an erasure of the border between real and spirit worlds, which Quayson sees as emblematic of Okri's narrative strategy, and which takes place via a 're-distribution of the anxiety-generating potential ... [of] the ghostly realm' (Quayson 1997, 137): that the market's 'real' and spirit inhabitants are all characterised in quasiesoteric terms is especially noteworthy in this latter sense. But this passage, in which Azaro is involuntarily propelled into the spirit dimension, also returns us to the insinuation of obscure controlling forces, equally salient in Onoh's tale. In The Famished Road, Quayson notes that 'shifts from one experiential plane to the other are no longer within the control of the central characters' (137), and that this in turn produces 'the suggestion that Azaro ... and existence in general, is ... partly at the mercy of those shifts' (136).

Viewed from this perspective, Okri can be seen to generate a sense of a world that is subject to processes which resist human agency, and to achieve this effect through a narrative that vacillates between real and spirit worlds, locating these as porously separated and equivalently weighted zones, which implicitly exist on a lateral plane. For Quayson, these strategies speak of an attempt to refigure realist modes of narration for the socio-economic context of late-twentieth century Nigeria: for Okri, 'the state of corruption made it impossible to write about events with the rationalism of prevailing protocols of realism' (147). That Onoh's narrative both invokes and departs from the effects produced by Okri's particular treatment of the real and the esoteric would thus seem to suggest that she writes with a different agenda, one that is - perhaps responsive to the circumstances of her own post-millennial moment. As I have shown, Onoh explicitly identifies controlling vectors in the Lagos world she represents, and she also importantly, and unlike Okri - excavates the root of these forces. It is to these expository ends that she mobilises gothic's vertical structure, tracing apprehensions in the narrative of a mysterious guiding force back to oja-ale, the Night Market: a place to which the dead lure the living in order to buy their lives.

As a spirit market, oja-ale directly recalls Azaro's own esoteric experience, mentioned above, and indeed Onoh cites Okri as key influence (Saulson 2015). However, where The Famished Road presents the marketplace as a site of real-spirit convergence or vacillation on a lateral plane, Onoh offers a different, indeed explicitly gothic, vision, which concentrates the supernatural in a particular, terrifying space. The market is said to be 'like ... a Hammer Horror film' (2015, 144), populated by shadowy, veiled figures, and in which '[e]verything [i]s silent ... eerie, scary' (143). While it is possible for living people to travel there, Onoh's characters access it chiefly in 
dreams, suggesting its status as a kind of unconscious, located below the surface world of the text. It is from this hidden, supernatural dimension, furthermore, that those controlling forces, apprehended by Alan at the outset, emanate: the various delays and route recalculations on that fateful journey home are, in fact, the strategic designs of the manipulative dead. In this sense, the revelation of the Night Market explains Alan's early apprehension of a 'malevolent, invisible hand', locating this in the machinations of a particular context, and here the covert reference to Adam Smith - on which I have remained silent thus far - becomes relevant. What this allusion begins to suggest, of course, is that oja-ale is in some sense an avatar for that brand of capitalism with which Alan himself is aligned, and, indeed, as it trades in vital force, oja-ale replicates the neoliberal drive towards what David Harvey calls the 'commodification of everything' (2005, 80). The relation between oja-ale and a (neo)imperial economy is ultimately, however, rendered explicit in the narrative when Alan justifies his desire to find the place as a matter of 'professional necessity, a need to open new markets for British business' (Onoh 2015, 164). The capitalist expansion mapped out by the protagonist thus segues seamlessly into the tale's sinister trade in human life.

From all of this, the particularities of Onoh's narrative agenda begin to shift into focus. Where Okri's interweaving of real and esoteric can be read as the 'negotiation of an aesthetic problem, in this case to do with dominant protocols of realism' (Quayson 1997, 149), it seems that Onoh's mobilisation of gothic in 'The Night Market' begins where Okri leaves off: with an apprehension of a world rendered mysterious as it is contoured unevenly by violent vectors. Onoh's narrative aetiologises this world, delving into the gothic space below its surface to expose the origins of mystifying privations and privileges. As it renders oja-ale consonant with a (neo) imperial economy, the narrative also evinces an interrogation of neoliberal capital, presenting this as the locus from which violent forces emanate. In this sense, 'The Night Market' is legible in the terms the Warwick Research Collective (WReC) ${ }^{6}$ have recently provided for reading what they call gothic's 'catachrestic' devices as these emerge in contemporary postcolonial fictions. WReC argue that gothic's particular brand of 'irrealism' registers the violent penetration of neoliberal capital into ex-colonial localities, and, further, that writers in these contexts activate gothic figures deliberately to interrogate capital's deleterious effects (WReC 2015, 96-97).

Onoh's tale thus pursues, from the narrative standpoint of Nigeria, a gothic programme that WReC identify in operation more widely across the millennial postcolonial world. For an example of a narrative that engages gothic to similar ends, we might look to the work of the South African author Lauren Beukes, whose Zoo City (2010), I argue elsewhere (2018b), precisely engages in an aetiologisation of a disorientating postcolonial present, locating the vectors of violence in textual avatars of a neoliberal economy. And this resonance is by no means superficial: Onoh cites as her inspiration for 'The Night Market' an 'urban legend' told to a friend by a 'highly educated and influential Nigerian, who advised him to steer clear of the market' (Saulson 2015). Beukes's own narrative is inspired by the figures of what Jean and John L. Comaroff have called 'occult economies' - zombies, witches, a magical trade in (human) organs - which they identity as proliferating with neoliberalisation in South Africa (1999). It is precisely the function of these magical assessments of the market - in which Onoh's urban legend can surely be included - to explain the effects of mystifying economic transformations: the perceived possibility of being reduced to zombie labour, for example, links etiology to existing orders of power and value' (Comaroff and Comaroff 2002, 799), providing a tangible account for the absence of work, for the apparently baseless enrichment of certain people. Onoh and Beukes retain this elucidating function as they mobilise figures drawn from occult imaginaries, but they also reshape these figures, and amplify their critical possibilities. Like Beukes, Onoh constructs a vertical relation between the 'real' and materials drawn from her 
esoteric resource base, implementing this structure to excavate what undergirds the anxious socio-economic conditions in her text's postcolonial Lagos.

And here we might return, finally, to Quayson's point: to text and context, to the relation between real and esoteric and the world in which it is produced. As I have shown, gothic is deployed across the narratives considered here as particular way of organising historical and supernatural domains, one that has been pressed into the service of focusing active formations of violence, which, in different ways, these texts suggest have yet to be fully interrogated in their capacity for producing pain. What 'The Night Market' suggests in particular is that - at this historical juncture - it is not only a language for the unreal realities of violence that is required, but also an origin: a source towards which dissonant action might be directed.

\section{Notes}

1 Jerrold E. Hogle summarises the criteria in terms of which works of gothic fiction are categorised as 'terror gothic' or 'horror gothic': 'The first of these holds characters and readers mostly in anxious suspense ... while the latter confronts the principle characters with the gross violence of physical ... dissolution' $(2002,3)$.

2 Hogle (2002) offers a similar, albeit broader reading of gothic as voicing a collective unconscious. For further critical discussion of gothic and histories of slavery see Paravisini-Gebert (2002) and Wester (2012). For a discussion of gothic and empire more widely see Brantlinger (1988) and Khair (2009).

3 See, for example Shear (2006) and Gaylard (2008).

4 See Illot and Buckley (2015), Cooper (2012), Cousins (2012), Mafe (2012), Wester (2012), Mabura (2008) and Stobie (2008).

5 I touch on this idea with particular reference to Holy Hill in the coda to South African Gothic (Duncan 2018b).

6 The Warwick Research Collective (WReC) is Sharae Deckard, Nicholas Lawrence, Neil Lazarus, Graeme Macdonald, Upamanyu Pablo Mukherjee, Benita Parry and Stephen Shapiro.

\section{References}

Armitt, Lucie. 2012. 'The Magical Realism of the Contemporary Gothic'. In A New Companion to the Gothic, edited by David Punter, 510-522. Chichester: Wiley-Blackwell.

Beukes, Lauren. 2010. Zoo City. Johannesburg: Jacana.

Botting, Fred. 1996. Gothic. London: Routledge.

Brantlinger, Patrick. 1988. Rule of Darkness: British Literature and Imperialism, 1830-1914. Ithaca, NY: Cornell University Press.

Byron, Glennis, ed. 2013. Globalgothic. Manchester: Manchester University Press.

Castle, Terry. 1995. The Female Thermometer: Eighteenth-Century Culture and the Invention of the Uncanny. Oxford: Oxford University Press.

Comaroff, Jean and John L. Comaroff. 1999. 'Occult Economies and the Violence of Abstraction: Notes from the South African Postcolony'. American Ethnologist 26(2): 279-303.

Comaroff, Jean and John L. Comaroff. 2002. 'Alien-nation: Zombies, Immigrants, and Millennial Capitalism'. The South Atlantic Quarterly 101(4): 779-805.

Cooper, Brenda. 1998. Magical Realism in West African Fiction: Seeing with a Third Eye. Abingdon: Routledge.

Cooper, Brenda. 2012. 'Women Dancing on Water: A Diasporic Feminine Fantastic?' Contemporary Women's Writing 6(2): 140-158.

Cousins, Helen. 2012. 'Helen Oyeyemi and the Yoruba Gothic: White is for Witching'. Journal of Commonwealth Literature 47(1): 47-58.

Duncan, Rebecca. 2014. 'Contemporary South African Horror: On Meat, Neoliberalism, and the Postcolonial Politics of a Global Form'. Horror Studies 5(1): 85-106.

Duncan, Rebecca. 2018a. 'Shades of Dissent: Notes on Haunting in South African Literary History'. In The Routledge Handbook to the Ghost Story, edited by Scott Brewster and Luke Thurston, 279-288. Abingdon: Routledge. 
Duncan, Rebecca. 2018b. South African Gothic: Anxiety and Creative Dissent in the Post-apartheid Imagination and Beyond. Cardiff: University of Wales Press.

Edwards, Justin and Sandra D. Vasconcelos. 2016. Tropical Gothic in Literature and Culture: The Americas. Abingdon: Routledge.

Eze, Chielozona. 2008. 'African Feminism: Resistance or Resentment'. Quest: An African Journal of Philosophy 20(1-2): 97-117.

Eze, Chielozona. 2015. 'Feminist Empathy: Unsettling African Cultural Norms in The Secret Lives of Baba Segi's Wives'. African Studies 74(3): 310-326.

Freud, Sigmund. [1919] 2003. The Uncanny. Translated by David Mclintock. London: Penguin.

Garuba, Harry. 2003. 'Explorations in Animist Materialism: Notes on Reading/Writing African Literature, Culture, and Society'. Public Culture 15(2): 261-286.

Garuba, Harry. 2012. 'On Animism, Modernity/Colonialism, and the African Order of Knowledge: Provisional Reflections'. e-flux 36 (July): 1-9.

Gaylard, Gerald. 2008. 'The Postcolonial Gothic: Time and Death in Southern African Literature'. Journal of Literary Studies 24(4): 1-18.

Gikandi, Simon. 2011. Slavery and the Culture of Taste. Ebook. Princeton, NJ: Princeton University Press.

Haggerty, George E. 2006. Queer Gothic. Urbana: University of Illinois Press.

Harvey, David. 2005. A Brief History of Neo-liberalism. Oxford: Oxford University Press.

Hogle, Jerrold E. 2002.'The Gothic in Western Culture'. In The Cambridge Companion to Gothic Literature, edited by Jerrold E. Hogle, 1-20. Cambridge: Cambridge University Press.

Illot, Sarah and Chloé Buckley. 2015. "Fragmenting and becoming Double": Supplementary Twins and Abject Bodies in Helen Oyeyemi's Icarus Girl'. The Journal of Commonwealth Literature 51(3): 1-14.

Irele, F. Abiola. 2001. The African Imagination: Literature in Africa and the Black Diaspora. Oxford: Oxford University Press.

Khair, Tabish. 2009. The Gothic, Postcolonialism and Otherness: Ghosts from Elsewhere. Basingstoke: Palgrave Macmillan.

Latour, Bruno. 1993. We Have Never Been Modern. Translated by Catherine Porter. Cambridge, MA: Harvard University Press.

Lazarus, Neil. 2011. The Postcolonial Unconscious. Cambridge: Cambridge University Press.

Mabura, Lily. 2008. 'Breaking Gods: An African Postcolonial Gothic Reading of Chimamanda Ngozi Adichie's Purple Hibiscus and Half of a Yellow Sun'. Research in African Literatures 39(1): 203-222.

Mafe, Diana Adesola. 2012. "Ghostly Girls in the "Eerie Bush": Helen Oyeyemi's The Icarus Girl as Postcolonial Female gothic Fiction'. Research in African Literatures 43(3): 21-35.

McClintock, Anne. 1996. Imperial Leather: Race, Gender and Sexuality in the Colonial Contest. Abingdon: Routledge.

Mekgwe, Pinkie. 2008. 'Theorising African Feminism(s): The “Colonial” Question'. Quest: An African Journal of Philosophy 20(1-2): 11-22.

Mudimbe, Valentin-Yves. 1988. The Invention of Africa: Gnosis, Philosophy, and the Order of Knowledge. Bloomington: Indiana University Press.

Okri, Ben. 1991. The Famished Road. London: Jonathan Cape.

Onoh, Nuzo. 2015. Unhallowed Graves. Lincolnshire: Canaan-Star.

Onoh, Nuzo. 2016. The Sleepless. Lincolnshire: Canaan-Star.

Oyěwùmí, Oyèrónkẹ. 1997. The Invention of Women: Making an African Sense of Western Gender Discourses. Minneapolis: University of Minnesota Press.

Oyěwùmí, Oyèrónkẹ. 2001. 'Ties That (Un)bind: Feminism, Sisterhood and Other Foreign Relations'. Jenda: A Journal of Culture and African Women Studies 1(1). www.africaknowledgeproject.org/index.php/ jenda/article/view/25.

Oyeyemi, Helen. The Icarus Girl. 2005. London: Bloomsbury.

Paravisini-Gebert, Lisabeth. 2002. 'Colonial and Postcolonial Gothic: The Caribbean'. In The Cambridge Companion to Gothic Fiction, edited by Jerrold E. Hogle, 229-257. Cambridge: Cambridge University Press.

Punter, David. 1996a. The Literature of Terror: A History of Gothic Fictions from 1765 to the Present Day. Volume 1: The Gothic Tradition. London: Longman.

Punter, David. 1996b. The Literature of Terror: A History of Gothic Fictions from 1765 to the Present Day. Volume 2: The Modern Gothic. London: Longman.

Punter, David. 2003. 'Arundhati Roy and the House of History'. In Empire and the Gothic: The Politics of Genre, edited by Andrew Smith and William Hughes, 192-207. Basingstoke: Palgrave Macmillan. 
Quayson, Ato. 1997. Strategic Transformations in Nigerian Writing: Orality and History in the Work of Rev. Samuel Johnson, Amos Tutuola, Wole Soyinka and Ben Okri. Oxford: James Currey.

Quayson, Ato. 2010. 'Magic Realism and the African Novel'. In The Cambridge Companion to the African Novel, edited by F. Abiola Irele, 159-176. Cambridge: Cambridge University Press.

Saulson, S. 2015. 'Interview with Nuzo Onoh, Author of Unhallowed Graves'. Sumiko Saulson: Things that Go Bump in my Head .... 2 June. https://sumikosaulson.com/2015/06/02/interview-with-nuzo-onoh-a uthor-of-unhallowed-graves/.

Shear, Jack. 2006. 'Haunted House, Haunted Nation: Triomf and the South African Postcolonial gothic'. Journal of Literary Studies 22(1): 70-95.

Sithebe, A. N. 2007. Holy Hill. Cape Town: Umuzi.

Spooner, Catherine. 2017. Post-millennial Gothic: Comedy, Romance and the Rise of 'Happy gothic'. London: Bloomsbury.

Stobie, Cheryl. 2008. 'Sisters and Spirits: The Postcolonial Gothic in Angelina N. Sithebe's Holy Hill'. Current Writing: Text and Reception in Southern Africa 20(2): 26-43.

Wallace, Diana. 2013. Female Gothic Histories: Gender, History and the Gothic. Cardiff: University of Wales Press.

Wester, Maisha L. 2012. African American Gothic: Screams from Shadowed Places. Houndmills: Palgrave Macmillan.

Wisker, Gina. 2007. Key Concepts in Postcolonial Literature. Houndmills: Palgrave Macmillan.

WReC (Warwick Research Collective). 2015. Combined and Uneven Development: Towards a New Theory of World Literature. Liverpool: Liverpool University Press. 


\title{
12 \\ Contested filial voice in African female-authored autobiographies
}

\author{
Marciana Nafula Were
}

\section{Introduction}

Recent scholarship on the autobiographies of Nawal El Saadawi (1931-) and Ayaan Hirsi Ali (1969-) has elaborated on the myriad ways in which filiation is established and contested through both maternal and paternal figures. In this chapter, therefore, I have chosen to examine how El Saadawi and Ali deploy the filial voice and oral traditions in their autobiographies as a technique for rewriting their own genealogical record. I consider the forms and functions of filiation in African female-authored autobiographies with an emphasis on the subjectivity of daughterhood. The chapter references four autobiographies by the two writers, namely $A$ Daughter of Isis (1999) and its sequel Walking through Fire (2002) by El Saadawi and Infidel (2007) and its sequel Nomad: A Personal Journey through the Clash of Civilizations (2010) by Ali. These texts are used to illustrate how African female autobiographers re-member and redefine their identities as relational to both maternal and paternal figures. And although El Saadawi is a creative writer, while Ali is not, both use the filial voice to similar effect in their respective autobiographies.

Scholarship on African women's autobiographies is arguably still in its infancy as critics attempt to delineate a critical tradition (Hunsu 2017). One trend in autobiographical scholarship, advanced by Western critics, highlights formal features associated with women's autobiography. ${ }^{1}$ Some of the specific attributes discussed include: intention to narrate the self, and particular notions of truth, history, memory and voice. ${ }^{2}$ In addition to these attributes, Sidonie Smith and Julia Watson $(1998,278)$ recognise relationality as a rhetorical device favoured by women autobiographers who often construct their identities around the self's interaction with their multiple selves and other selves external to them.

Other lines of scholarship on African women's autobiographical practices trace the postcolonial and decolonial responses to hegemonic discourses that define Africa and African subjects. Though varied in focus, these studies address African women's negotiation of public and private spheres as well as collective and individual selfhoods and the ensuing identity politics. ${ }^{3}$ Folasade Hunsu $(2017,319)$ takes a different approach in her work and identifies four categories of African women's life writing: fictional, and non-fictional autobiographies authored by creative writers, public figures and women who are neither creative writers nor public figures. The fictional status of the fictional autobiography distances the author from the narrator of the text. ${ }^{4}$ 
Non-fictional autobiographies are more likely to appropriate rhetorical devices intended to unify author and narrator. ${ }^{5}$ Non-fictional autobiographies by creative writers are often more nuanced than non-fictional autobiographies by varied public figures in their presentation of political concerns. ${ }^{6}$

For some scholars, the African woman's autobiography is essentially a hybrid genre. This hybridity stems, firstly, from a convergence of African practices of self-narration and Western autobiographical practices, and points to a strategy through which female autobiographers seek to contest their othering in dominant Western and hetero-normative patriarchal discursive practices (Were 2016; Alabi 2005; Hunsu 2017). Secondly, hybridity is interpreted as resulting from deliberate attempts by African women autobiographers to bypass the relegation of women to the private, domestic sphere and men to the public, political sphere (Andrade 2002; Were 2016; Azodo 1997). Thirdly, hybridity has been linked to the autobiographers' appropriation of African concepts from oral archives to subvert the authority that African and Western patriarchal discourses have conventionally exercised over women's voices, and to foreground women's agency.

\section{Reading methods and modes of re-membering filiation in African (women's) autobiographies}

Notwithstanding the genre's centrality in mapping out an African female literary tradition and modes of expression (Were 2016; Hunsu 2017), some of the commonplace rhetorical devices in African women's autobiography, such as the deployment of particular forms of relationality, have not yet received adequate attention. All autobiographies involve the strategic and sometimes unconscious selection of rhetorical devices for purposes of self-definition by autobiographical subjects and writers. This chapter focuses on the reconstruction of the filial voice and orality as rhetorical choices made by African female autobiographical narrators that inform their conception and contestation of gendered identities.

Although filiation is applicable to both sons and daughters, this chapter concentrates on daughterhood. $^{7}$ The decision to highlight daughterhood is informed by a scarcity of scholarship on this filiation in African literary studies. Chikwenye Ogunyemi $(1996,46)$ describes daughterhood as a form of subjectivity, which despite being a 'source of power [is] not fully explored, politically'. In my work, I valorise daughterhood as a departure from critical and narrative practices which reduce the complexity of African female subjectivity to debates about maternity, particularly its elevation in public (spaces) and its relationship to discourses of nationalism.

I analyse two main depictions of daughterhood, the biological and non-biological. Biologically, filiation is represented by the narrators' descent from mothers, fathers and grandparents. Filiation might, however, skip one or several generations and involve a link that is more accommodating for explicating a specific issue that is not peculiar to immediate parents. Nonbiological filiation might signal belonging to a post-independent state/nation, as in being a daughter of the nation. ${ }^{8}$ Similarly, non-biological filiation might be a way of defining ideological belonging to an ethnic, clan, institutional or intellectual community. I describe the narrating voice of these varied manifestations of daughterhood or 'childhood' as the filial voice, in this case, belonging to a daughter, a granddaughter, a female descendant of a cultural/communal mythical figure or a citizen of a nation. While the filial voice might privilege one parent over another or ancestors of one gender over another, it might also involve a co-mingling of biological descent and ideological affinity. The filial voice is, in my view, useful for autobiographical subjects seeking to negotiate and contest their position within the family, nation and community. 
Of particular interest for this chapter are the purposes for which narrators adopt a filial voice, and what these purposes entail when it comes to either embracing or rejecting different kinds of filiation.

Some African female-authored autobiographies deploy the filial voice in order to affirm filial relations, while others use the filial voice to repudiate filial ties. For example, Leah Chishugi's $A$ Long Way from Paradise: Surviving the Rwandan Genocide (2010) narrates the 1994 Rwandan genocide from an avowedly Tutsi perspective. In affirming filiation with Tutsi exiles living in Zaire as refugees, the autobiographical subject presents herself as a credible narrator of the Tutsi experience of genocide while also soliciting readers' empathy. In China Keitetsi's Child Soldier (2002), however, the nickname China, which focalises her identity as a child soldier, becomes a signifier of the problematic relationship of daughterhood to the national liberation (guerrilla) army and male figures of authority like the chief who raped her, and her father who physically abused her. As a child who was abandoned by her biological mother and mistreated by her stepmother and grandmother, the autobiographical subject uses her filial voice to deconstruct the presumption that women are inherently compassionate and caring.

The filial voice serves a variety of purposes in African female autobiographies. Some of the rationales include the reassertion of ancestry that is being contested by opponents and critics as well as the fashioning or foregrounding of a new ancestry at the expense of a known ancestry. Also important are a settling of scores with figures in one's lineage; a rejection of a dominant history and a desire to create an alternative history for the community or the self; a desire for reinsertion in history on the part of the autobiographical self; and an attempt to rescue figures in one's lineage from obscurity and marginalisation.

In examining African female autobiographies in this chapter, I shall also refer to acts of rememory. Since El Saadawi and Ali have no first-hand experience of some of the events they recount and that are attributed to maternal relatives, their narratives perform what Toni Morrison $(1987,160)$ calls acts of 're-memory'. Morrison uses the concept re-memory to explain the process by which multiple (inter/cross-generational) events are re-membered. My use of 're-memory' in this chapter applies to processes that I read as enabling El Saadawi and Ali to recall palimpsestic histories/stories/voices of women suppressed by dominant cultures, and female counter-discourses that relocate women to public memory and private-public spaces. Thus El Saadawi's and Ali’s autobiographies manifest “"[r]ememory” as [a] trope' (Rody 1995, 101) for accessing 'forgotten' histories. My use of re-memory as opposed to retelling in this chapter is deliberate. Re-memory refers to the emergence of dual voices each telling distinct but also occasionally intersecting stories, while retelling denotes an instance in which one speaking subject echoes or repeats what has been said by another speaking subject. The interwoven narration adopted by El Saadawi and Ali, merging past and present, self and other, allows for the recollection of multiple narratives concurrently, and symbolises the autobiographers' desire to reclaim not only the histories of their maternal relations, but also stories of real and legendary women in their societies.

Louise Viljoen, who has highlighted the link between the female autobiographer and her maternal relations, observes that 'in representing the (m)other, the self is implicated' $(2014,53)$. By establishing maternal relationality with various women in their autobiographies, Ali and El Saadawi are transforming these maternal figures into 'pretext[s]' for their own self-identification. The concept 'mother as pretext' has been defined by Viljoen as 'the reason or excuse for [a female autobiographer's] own writing [and invocation of] the writer of the texts preceding her own' (Viljoen, 2014, 153). While Viljoen uses 'text' to refer to a written form, I include oral forms in this definition. By choosing to incorporate their maternal relatives' oral histories into their autobiographies, El Saadawi and Ali are corroborating the oral archive as a site where 
women's stories thrive. The ensuing dialogic discourse is hybrid, relational and palimpsestic. It also creates a conundrum, for as Viljoen has noted, "[n]o discussion of autobiography which involves the biography of an "other" can avoid questions around the ethics involved in representing that other' $(2014,152)$.

\section{The filial voice's contestation and re-invention of history in El Saadawi's autobiographies}

El Saadawi is an Egyptian advocate of women's rights, politician, medical doctor and renowned writer. A Daughter of Isis (1999) and Walking through Fire (2002) are two of her life narratives. Both autobiographies express El Saadawi's disillusionment with Egypt's religious, patriarchal and political autocracy. They also archive women's historical achievements, mostly silenced in history, and their rebellions against androcentrism. The two autobiographies establish El Saadawi's filiation with her mother, father, grandparents, paternal great-grandmother, the Egyptian goddesses Isis and Nefertiti, the Egyptian nation, and ideological institutions (religious, political and intellectual). El Saadawi shifts between different subject-positions: mother, daughter, wife, doctor, writer-activist, gender-activist, freedom-fighter, which differentially encounter filiation.

A Daughter of Isis recounts El Saadawi's formative years in Egypt before she became a medical doctor but also alternates between her childhood and adulthood. Despite the story's non-linear plot, it is a bildungsroman that enables us to trace El Saadawi's growth from a state of naivety to a heightened religious, political and gender consciousness. The narration begins in present time as told by the adult El Saadawi. El Saadawi then recalls her childhood struggles and reviews the experience of filiation with her mother, father and other relatives. Walking through Fire is a sequel to $A$ Daughter of Isis. It highlights El Saadawi's adult experiences as a medical doctor and a writer living in exile. It includes an account of a brief return to Egypt, her country of birth. The story is highly nostalgic and interspersed with flashbacks as she remembers her mother, especially following her mother's death. It also provides an opportunity to recount Egypt's experience with foreign invasions by Rome, Turkey and Britain. El Saadawi's connection to this legacy is established through her parentage; her mother is half-Turkish, and represents the affluence of the aristocracy, while her father is a native Egyptian and represents the history of Egyptian peasantry and slaves, mostly erased by the colonisers. A child of both worlds, El Saadawi belongs to an Egyptian middle-class elite background. The illustrations included in my analysis draw, to a greater extent, from $A$ Daughter of Isis because this text strongly advances multiple manifestations of filiation in its representation of her turbulent relationship with the state and Islam. However, and as needed, a few examples from Walking through Fire are also referenced. The filial voice in the former autobiography serves to vocalise the narrator's disillusionment with the social, religious and political order in Egypt.

With the word 'daughter', the title of El Saadawi's first autobiography already calls attention to questions of filiation. El Saadawi further rewrites particular filiations by titling her autobiography $A$ Daughter of Isis. In Arab culture, only the man has the right to pass 'his name to the children, [and] [bestow] legitimacy and honour on them' (Saadawi 1999, 4). Thus, a female child's surname is often linked with the father's name through the prefix 'El', signifying 'daughter of a male figure. However, El Saadawi's chosen title identifies her as daughter of a pre-Islamic female figure in Egyptian culture, the goddess Isis. In defining herself through the Egyptian goddess Isis, El Saadawi would appear to be indirectly disavowing Egypt's Muslim heritage and reclaiming for herself a religious ancestry that predates Islam. In defining herself as one of the daughters of a powerful goddess in Egyptian mythology, El Saadawi also challenges her society's religious (Islamic and Christian) perception of God as male and patriarchal 
traditions that position women as inferior to men. In forgoing filiation with male religious and familial figures, as culture demands, El Saadawi makes a counter-discursive manoeuvre intended to contest patriarchal practices in defining and naming women.

In general, this autobiography shows the narrator seeking to disrupt paternal filiation, and to foreground maternal ties. El Saadawi declares that as a child, she 'loved [her mother] more than [her] father' $(1999,1)$. This filiation was established and sustained through writing. She explains it as follows:

It was my mother who taught me how to read and write $[\ldots]$. The first word I wrote was my name, Nawal [...]. It meant a 'gift' [...]. Then I learnt my mother's name, Zaynab. I wrote it next to mine. Her name and mine became inseparable.

(1999, 1)

Thus, even as a child, El Saadawi begins the process of self-definition by naming herself Nawal Zaynab. El Saadawi's conception of the inseparability of Zaynab's and her own identities points to maternal relationality as a nexus of her self-identification. Alarmed at this strong maternal filiation, El Saadawi's father reportedly attempts to erase this form of identification by crossing out Zaynab's name and replacing it with his name, Saadawi. While he does not overtly forbid El Saadawi to use Zaynab's name, he justifies his action as 'God's will' (1999, 1). This puzzled the young El Saadawi. It was years later that El Saadawi understood that while her parents' marriage was sustained by a strong bond of love for each other that fortified their relationship until they were separated by death, her father and the religion he represented conformed to patriarchal norms. Her father's actions mark El Saadawi's initial conflict with a patriarchal system's subjugation of women like her mother and it fuels her initial desire to separate herself from paternal ties. She loses her love for her father and the God 'who removed [her] mother's name from next to [hers], who abolished her [mother] as though she did not exist' $(1999,1)$. El Saadawi's doubt about this God described by her father as 'just' yet perceived by her as misogynistic (1999, 1), continues to grow strong in her adulthood, and informs her fictional works like God Dies by the Nile (1984).

As she grows older, however, El Saadawi begins to detach herself from her mother and to experience a craving for recognition from her father. For instance, while in school, her 'love [for] the letters of the language' led her to write a novel manuscript called Memories of a Child Called Sa'ad as a school assignment, a critique of her society's patriarchal justification of religious knowledge as man's prerogative. The teacher awarded her a zero for her efforts, which angered and embarrassed her. With the benefit of hindsight, she admits that although her mother applauded her talent, she craved her father's approval of her writing as at that time it was more significant than her mother's ready acceptance and praise of this novel. Thus, her mother's dismissal of the teacher as an 'idiot' weighed less in importance to El Saadawi (1999, 215), than her father's declaration that she 'really had talent' (1999, 215-216). I read El Saadawi's desire for her father's approval, despite a stated love for her mother, as symbolising the difficulty of imagining acceptable daughterhood outside paternal endorsement, and the interconnectedness of daughterhood with paternal figures. El Saadawi's conflicted relationship with the father might, however, also signify a conflicted relationship with the nation.

As she grows and witnesses the freedom her brother and father have, she longs to share in their world. This desire is shattered as her father keeps on relegating her to the kitchen, a space she hated because it 'was the place [she] knew the humiliation of being female' $(1999,46)$. El Saadawi observes that at seven years old: 
Gradually, my mother was withdrawing from my life. I no longer saw her except in the kitchen. I no longer heard her speak [...]. The distance between my mother and me grew bigger and bigger, and the distance between my father and me smaller and smaller. [...] She no longer belonged to the world which I shared with my father and my brother. Her world was another world which made me shiver every time I thought of it, the world of the kitchen.

(1999, 59-60)

Zaynab's death from breast cancer symbolises for El Saadawi the finality of separation from her mother and the end of an era. Although El Saadawi suggests that separation from her mother began when their names were separated, the narrator attempts to undo this separation. In her autobiography, El Saadawi refuses to embrace the notion of a terminal separation. Traces of a maternal relationality and the unbreakability of their bond continue to be revealed in the memories of Zaynab recounted in El Saadawi's autobiographies.

Later in life, El Saadawi's yearning for her mother returns. Memories of her mother, suppressed in her unconscious, re-emerge and she finds herself mumbling a tune from a children's song that they used to sing together, whose words she could not comprehend no matter how hard she tried. For Smith and Watson $(2001,22)$, 'the struggle with [traumatic] memories [...] necessitates the return again and again to those incomprehensible moments in the past'. El Saadawi's memories of her mother are painful because they force her to remember her mother's death. The thought of Zaynab's death makes El Saadawi 'shrink' into her clothes as she used to as a child, 'ashamed of being poor' but now 'ashamed of [her] old age' (1999, 47). By admitting to her feelings of shame, El Saadawi seems to suggests she is complicit in enforcing forgetfulness of some memories of her mother. I read El Saadawi's re-memberance of her mother through narrating Zaynab's experiences alongside her own as one way in which El Saadawi immortalises the maternal bond. In the process, El Saadawi deals with the happy and painful memories of her mother, what Rody calls the 'poetics of motherlove' (1995, 108). Zaynab's death points to regret for a lost past, a nakedness that even the clothes she can now afford cannot conceal. El Saadawi translates this loss into nostalgia for her mother, a mood that pervades her autobiographies.

Memory, say Smith and Watson $(2001,21)$, 'is always implicated in materiality [...] of sound, stone, text, garment, [...] or the materiality of our very bodies'. It is evoked by 'smell, taste, touch, sound - and encoded in objects or events with particular meaning for the narrator' (Smith and Watson 2001, 21). In A Daughter of Isis, El Saadawi seeks other stimuli that evoke memories of Zaynab such as 'smell' $(1999,30)$, which transcends time, space and the absence of the mother's body to re-establish the connection she lost in childhood and when her mother died. She remembers the 'odor of her [mother's] milk' and of the smell of foods Zaynab cooked for them. These memories bring her mother within her grasp, and she embraces them as part of herself. She writes: 'The smells of my mother's body are a part of me, of my body, of its spirit, of the hidden strength I carry within me' $(1999,4)$. She also says that she remembers the sound of Zaynab's voice to guide and protect her. This declaration is a contestation of society's allocation of the roles of protection and guidance to men, especially fathers.

Looking back, El Saadawi admits that her feelings about her mother and father as she was growing up emanated from the gender conceptions of that time. As a gender activist, she later understood that gender biases arise from cultural misogyny. Although patriarchal systems subjugate women, El Saadawi shows us that both men and women uphold these systems. In Walking through Fire for instance, while working as a medical doctor in the village of Kafr Tahla, El Saadawi observes how the dayas (women whose role it is to initiate girls into womanhood 
through circumcision, breaking of the hymen before consummation of marriage, and giving birth) had commodified women's bodies and their sexuality. She says that:

when I graduated as a medical doctor, I knew nothing about the hymen or the clitoris, or the practices related to them that were encouraged by dayas and village barbers, who made more money out of them than out of any other functions they fulfilled.

(2002, 107)

In contrast to these women, El Saadawi recalls how her own mother's courageous defiance of cultural norms ensured that El Saadawi received education and was not married off at the age of ten as custom demanded. Zaynab apparently defended her daughter's right to education, which might have been undermined by marriage. Later, when El Saadawi's father is reluctant to allow El Saadawi to go to school in Cairo, Zaynab tells him that 'Nawal has her wits about her. I trust her. You can throw her in the midst of fire and she'll come out unscathed' $(1999,156)$. This sentiment, 'throw Nawal in the fire and she will come out unhurt' $(1999,1)$, is adapted into the title of El Saadawi's second autobiography Walking through Fire as a marker of her strength. Adapting her mother's statements to a title is another strategy to sustain El Saadawi's filiation with her mother. Gender biases also influence the presentation of historical accounts. In Walking through Fire, El Saadawi says that the inclusion of women in the Egyptian independence struggle was marked by gender disparities as women were often expected to contribute either as 'nurses or entertainers' $(2002,256)$. El Saadawi refuses to comply with this ideology and having always wanted to fight for her country, she dons army 'fatigues' and undergoes militia training in arms $(2002,118)$. She is however repulsed by the great disrespect for women she witnesses in the Egyptian demonstrators who were insulting the British soldiers as 'ruled by the Mara (tart)', an army 'led by nitaya a woman's army or "bitch"” (116). El Saadawi also recalls how, when they were children, her father would narrate to her brother the history of indigenous Egyptians' resistance to British occupation in 1919, a narrative that celebrated only male heroic exploits at war $(1999,67)$. Whenever El Saadawi moved closer to listen, her father would ask her to go and help her mother in the kitchen. El Saadawi's desire to know her history was fulfilled by her grandmother Sittil Hajja, whose oral histories recounted native Egyptian women's war-time exploits.

In reproducing stories told by her female forebears, El Saadawi shows an awareness of the dialogism that exists between narratives about herself and narratives of her maternal predecessors. One way in which this dialogism unfolds is through El Saadawi's invocation of stories about female members of her family and community as told to her by her paternal grandmother, Sittil Hajja, in an act that Caroline Rody $(1995,106)$ characterises as 'history-asdaughter's rememory'. These oral histories, silenced in Egypt's official history, thrive in El Saadawi's familial oral archive. Despite this archive's commitment to memorialising all family members, women are often misrepresented and omitted from these discourses. To contest such discriminatory historical practices, El Saadawi ventures into her family's oral archive to remember stories of her maternal predecessors like her paternal grandmother Sittil Hajja and her grandmother's mother, the 'woman from Gaza' $(1999,48)$, the El Saadawi family matriarch Habasheya. I consider this process of retrieving repressed histories as a narrative 'calling [of the] [women] back into being' (Gunner 2005, 123).

The first maternal figure whose oral narrative is recalled in El Saadawi's autobiographies is the mother of her clan, Habasheya, ${ }^{9}$ who is described as the mother of Al-Saadawi, El Saadawi's 'father's great-grandfather' $(1999,26)$. In the autobiography, the young El Saadawi facilitates the recollection of this filial relation as a story told to her by her paternal grandmother Sittil 
Hajja. As we later come to discover, Habasheya's original name is practically forgotten, and her experiences overshadowed in her family's genealogy by those of their family patriarch, AlSaadawi. Sittil Hajja reclaims the memory of this almost forgotten matriarch by remembering her name as 'Habasheya', which means the Abyssinian woman (1999, 26). Habasheya's oral history, recounted to El Saadawi by her father's mother Sittil Hajja, was in turn told to Sittil Hajja by the descendants of Al-Saadawi. Although this narrative was first told by Al-Saadawi to his people, its preservation is sustained by women. According to him, Habasheya 'belonged to a noble family in Abyssinia, and owned more land and slaves than the Queen of Sheba owned in her day' $(1999,26)$. Sittil Hajja hints at a degree of exaggeration by Al-Saadawi, in her observation that 'everyone in the village believed him, except my mother' (the woman from Gaza) $(1999,26)$. One possible reason why even the family patriarch Al-Saadawi might have felt the need to magnify his maternal genealogy could be because 'he had no father' $(1999,26)$. By invoking Habasheya's Abyssinian identity, El Saadawi is also foregrounding her African rather than Arab identity as an Egyptian woman. The story that El Saadawi recalls about Habasheya is, therefore, a historical revision of dominant groups' tendencies to valorise male figures and to suppress/erase marginalised groups/communities from history.

The second woman whose story is excavated from the recesses of history in El Saadawi's autobiography is Sittil Hajja's mother, simply known as 'the woman from Gaza' (1999, 48). El Saadawi, who says that she heard many stories about the woman from Gaza from Sittil Hajja, declares that '[w]omen have an unwritten history told orally by one generation to the other' (75). According to Sittil Hajja, the woman from Gaza:

had humiliated the village headman as he stood in front of the entrance to his house surrounded by his men, and after that, one dark night he sent someone to her [...]. In the morning they found the door of her hut open [...]. She was lying on the dirt floor, her eyes wide open, staring at the heavens.

(1999, 74)

The associational link of Sittil Hajja's maternal predecessors' names to places (Abyssinia and Gaza) echoes the process described by Liz Gunner as reiteration of history through 'rewriting of the land and its names' $(2005,123) .^{10}$

The last woman whose oral history is narrated in El Saadawi's autobiographies is her paternal grandmother, identified as Sittil Hajja, or 'Al-Hajja Mabrouka' (1999, 19). 'Al-Hajja', according to Pauline Homsi Vinson (2008, 90-91), is a religious title that denotes 'one who has undertaken the religious pilgrimage (al-Haj) to Mecca'. El Saadawi's decision to use Sittil Hajja as a window to her maternal predecessors' forgotten past is important as unlike her mother's noble Turkish relations, Sittil Hajja is a peasant. In re-memorying the experiences of Habasheya, the woman from Gaza and Sittil Hajja, El Saadawi contests the historical marginalisation of peasant women. By extending these women's lived experiences across time boundaries from tales told to her by Sittil Hajja, El Saadawi's filial voice sustains an inter-generational maternal bond intended to rescue maternal figures in her lineage from obscurity and marginalisation. In fact, says El Saadawi, a key motive for writing her autobiographies was to immortalise herself and her maternal predecessors in history.

This substitute history highlights the valorisation of men over women in public discourses. According to Vinson (2008, 90): 'El Saadawi presents us with an alternative matrilineal world through the oral, peasant culture of her paternal grandmother [...] [as] an alternative history, one of defiance and survival of the subaltern in patriarchal, class cultures'. Through re-memory, El Saadawi shifts the site of historical re-telling from the public and masculine domain to the 
public-private space of autobiography and oral archive, where female subjectivities move from the margins of history to the centre. That El Saadawi learns how the power dynamics of sex and gender stifle women while sitting 'on the threshold of [their] home' $(1999,29)$ is significant because the threshold as a space of narration signifies a process of unlearning repressive cultures and relearning female-defined practices like oral narration.

It is from the same Sittil Hajja that El Saadawi discovers how, as a two-year-old, Sittil Hajja and her own mother (the woman from Gaza), collaborated with men in their people's rebellion against British occupation of Egypt in 1882 as peasants 'carrying their hoes' (1999, 73). This story, says El Saadawi, has been erased from public discourses of the Egyptian anti-colonial struggle. This is an example of stories 'told orally by one generation to the other' through which El Saadawi learns of her maternal predecessors' heroism $(1999,75)$. El Saadawi observes that the dismissal of women in history or war is sometimes legitimised by the narrative of biological essentialism that depicts women as weak compared to men. She contests this ideology by portraying her great-grandmother Habasheya's hands as big, 'bigger than that of the village headman, of the king, bigger than that of [her] father or [their] own Lord Muhammad, or [their] Lord Abraham' (1999, 75). Although this comparison might be viewed as blasphemous by some readers, I read them as a way to pay tribute to maternal strength and filiation and to elevate female forebears above notable transcendental males in religious texts.

The autobiographical subject also deploys the filial voice to unmask her problematic relationship with the state, particularly in its decision to change her name and obscure part of her identity. In A Daughter of Isis, El Saadawi condemns history's 'falsification [of her identity] in official registers' $(1999,28)$. This falsification is effected through the erasure of her name Habash from the state's 'official register' (28). El Saadawi's full name is Nawal Al-Sayed Habash El Saadawi. However, the name Habash disappeared from the state's records under unknown circumstances. El Saadawi simply says that 'somehow the name Habash disappeared on my birth certificate and my identity card and I completely forgot it was part of it' $(1999,28) .{ }^{11}$ This name was resurrected when she was arrested by President Anwar Sadat's government for writing what was considered seditious literature and belonging to an anti-state intellectual movement. Similarly, El Saadawi contests the imposition of the name El Saadawi on her selfhood, a paternal identity imposed on her by the state and her patriarchal society. She says that: '[e]ver since I was born the name of that unknown Al-Saadawi has been carried by my body [...] on the covers of my novels and books written with my ink, my sweat, my tears, my blood' (29). She later expresses a wish to have had a chance to reward her mother's contributions towards her success, saying that: 'I wish I could efface my grandfather Al-Saadawi from my name and replace it with my mother's name, Zaynab' (30).

In addition, El Saadawi uses the filial voice to expose ways in which archival practices displace female figures from official (religious and state) historical records. In Walking through Fire, El Saadawi says that the pharaohs introduced slavery to Egypt, but through their love for art and architecture, preserved the roots of matriarchy in several art forms including:

the head of Nefertiti, the painting of Cleopatra, the female goddesses and philosophers Noot, Isis, Ma'at the goddess of justice, Sekhmet the goddesses of medicine and centuries later Hypathia whose body was mutilated before she was killed by the Roman invaders who burnt her books.

(2002, 9)

Although these busts and hieroglyphs tell women's stories, the stories are told from a masculine point of view. In $A$ Daughter of Isis however, the autobiographer reclaims spiritual filiation with 
these Egyptian goddesses to subvert the position of women in male-centred religions. Furthermore, El Saadawi deliberately associates God with her mother Zaynab rather than her father, likening Zaynab's voice to 'the voice of God' (1999, 4). Furthermore, she likens her mother's bodily image to that of the goddess Isis instead of to a male Egyptian god, a narrative act that redefines her mother and by extension, Egyptian women as a source of power. This power is re-enacted in various ways, firstly through El Saadawi's juxtaposition of the memory of Isis suckling her son with her own memories of the smell of Zaynab's breast milk. Secondly, El Saadawi unifies the image of Isis and Zaynab by imagining Isis's silvery crown on her mother's forehead, thereby re-crowning her mother's selfhood as omnipresent in her own psyche. She retrieves a childhood memory which had stuck in her consciousness. In this memory, Zaynab appears with 'her head held high, a woman full of pride, a goddess like Isis a halo of light around her head, like a full moon, a silvery crown that the ancient Egyptian goddess wore above her brow' $(1999,5)$. El Saadawi adds that this demeanour by Zaynab 'taught [her] to be proud[;] to dream of better things, of a place for [her]self in this vast world' $(1999,5)$. This recollection transforms El Saadawi's mother into a figure of transcendental truth and an alternative to male religious figures. This memorial convergence also indexes El Saadawi and her maternal relations as metaphorical 'descendant[s]' of Isis and Isis's mother 'Noot' (1999, 5). Similarly, El Saadawi compares Sittil Hajja and Habasheya to 'the goddess Nefertiti [and] Queen Hatchipsut' (1999, 48). By linking her maternal relations to powerful mythical/legendary female figures from Egyptian mythology, El Saadawi resurrects their memories from the peripheries of history thereby protecting them from a collective history of subordination.

The filial memories recounted above act as the bridge to a female agency that Kolawole (1997) has identified as inherent in everyday experiences of women and located in the oral repository of their communities. Reproducing these oral narratives enables El Saadawi to bring together the public and private spheres, but also the personal and collective. In connecting the narration of her personal experiences in the Western autobiographical form, to the stories of her maternal relations excavated from the oral archive, these autobiographies also become hybrid. The 'summoning up' (Gunner 2005, 123) of El Saadawi's female relations' memories from the 'tombs' of history is a reflection of the timelessness of the oral archive.

\section{The filial voice's contestation of cultural and religious hegemony in Ali's autobiographies}

Ayaan Hirsi Ali is a Somali-Dutch-American women's rights advocate, critic of Islam, politician and polemicist. Her two autobiographies Infidel (2007) and Nomad: A Personal Journey through the Clash of Civilizations (2010) narrate Ali's biological filiation to maternal and paternal relations and her ideological filiation to Somali group identities, that is, religious and clan, especially in exile, and diasporic Somalis. Infidel documents her early life in Somalia and her family's exile first in Saudi Arabia, then Ethiopia, and later Kenya, due to her father's political activities. It follows her escape from an arranged marriage and resettlement in the Netherlands where she acquired political asylum and later Dutch citizenship. She then relocated to the United States to work with a conservative think-tank. Infidel's sequel, Nomad, is a nostalgic reflection on Ali's life in the United States after she left the Netherlands, her reunion with her family in exile (in Europe and Kenya) and her return to Kenya (where her family relocated as refugees) and Somalia (the country of her birth). It narrates her loneliness in exile and a desire to return home, however problematic such an undertaking might be.

Ali's autobiographies differ from El Saadawi's in that, while both writers reminisce about their filiation as diasporic subjects in self-imposed exile, Ali's exile is layered. To start with, she 
is forced to flee with her family from President Siad Barre's Somalia due to her father's political dissidence, but later she exiles herself to escape a forced marriage. Her first exilic subjectivity reflects the experiences of a multitude of Somali citizens who, like her, went into exile to escape political instability and war in Somalia. Ali often portrays Somali migrants as yearning for the pre-war Somalia. This search for an ideal, yet illusory, home is evident in Ali's nostalgic remembering of 'home' while in the diaspora. In order to try and lay hold of this elusive home, she retrieves from her diasporic surroundings symbols that connect her to the past, and represent a sense of belonging. These memories of the past are triggered by sights, smells or tastes that remind her of experiences from Somalia.

Unlike El Saadawi who defines herself by identifying with and celebrating maternal figures, Ali has a much more conflicted relationship with maternal figures. The representation of filiation in her two autobiographies is an opportunity to contest a particular vision of womanhood, as well as to reclaim her identity as a Somali woman. In her 1999 lectures published as Women's Lives: The View from the Threshold, Carolyn Heilbrun observes that ' $[\mathrm{f}]$ ] most daughters, mothers evoke what Aristotle recommended as the ideal response to tragedy: pity and terror. That is, pity for the mother's condition, and terror that one might resemble her' (61). Ali's experiences, especially as related in her first autobiography, Infidel, echo Heilbrun's sentiments.

The autobiographer invokes filiation with female relatives in narrating extremely traumatic events from her past like her own circumcision and the mental illness and death of her sister Haweya following circumcision. Most of these traumatic events were instigated by her maternal grandmother, Ibaado. According to Ali, her mother and especially her father had not wanted their daughters to be circumcised. But when Ibaado circumcised the girls in the absence of their parents, Ali's mother, Asha, felt 'betrayed' (2007, 34). In fact, Ali attributes Haweya's negative personality change to the trauma of circumcision, and to her grandmother's obsessive desire for her granddaughters to 'undergo the necessary and proper dignity of purification' through circumcision (2007, 31). Although Ali does not blame her mother Asha for being absent during their circumcision, Ali says that were it not for Asha's harsh treatment of Haweya during her childhood and mental illness, Haweya would not have committed suicide. When after Haweya's death Asha began lamenting in her usual manner, Ali says:

I couldn't bear that, hearing Haweya being blamed for hurting Ma. I thought of all the abuse, all the beatings my sister received when we were little. It didn't seem to occur to Ma that she might have had a role in what went wrong. I thought of how my mother had persuaded Haweya to leave her doctors and her medication in Holland and come back to Nairobi in this ugly room, this utter squalor.

(2007, 259)

Ali's re-membering of maternal filiation acts, to a large extent, as a rebuke to her grandmother's ideologies on womanhood, and to her mother's interference in Haweya's life. Ali's relationship with her mother is imbued with ambivalence since Ali's mother, Asha, mostly defers to her own mother Ibaado. At the same time, and by foregrounding her mother and grandmother in these autobiographies, Ali reaffirms her identity as a Somali woman, and pushes back against critics who claim that her stated positions amount to a rejection of Muslim and Somali identity. Ali's depiction of maternal filiation in her autobiography becomes a technique for resisting the version of womanhood performed by her mother and grandmother and for embracing alternative visions of womanhood such as Oriana Fallaci's liberal womanhood discussed below.

But Ali also uses the filial voice, and specifically maternal filiation as an indirect defence for views about Islam that might be considered as heretical by some readers. She thus links a 
growing discomfort with Islam to her own mother's experiences. Citing her mother's time in Saudi Arabia as an example, Ali observes that a male child in Saudi Arabia had more rights than an adult female. Her mother Asha, who finds herself living in the holy city of Mecca, is prevented by Sharia law from walking outside her house without a male chaperone. Ali says that to Asha's chagrin, the absence of her husband, who was co-ordinating the resistance movement against President Siad Barre in Ethiopia, forced her to depend on her ten-year-old son, Mahad, continuously. Ali remarks that Mahad:

had to act as the legal male guardian for [Asha] whenever our father was away, which turned out to be most of the time [..., ] to decipher the world for her, to protect her and us, though he was only ten. Sometimes he heard the Saudi men say lewd and ugly things to Ma such as 'slave' and 'black' and failed to interpret to Asha to protect her. Much was expected from him by his father and little affection given to him, although he was only a child.

Ali suggests that her own discomfort with these religious injunctions began not with her attempts to fit in with Western society, at a later stage in life, but with an earlier generation's experiences and with her mother's sojourn in Aden, Saudi Arabia.

Ali however also deploys the filial voice in Infidel to represent her grandmother, Ibaado, as a bridge between her female grandchildren and a more assertive tradition of Somali womanhood that Ali admires and identifies with. Ali remembers how, as children, Ibaado told her and her younger sister Haweya stories that shaped their worldview. These stories induced the young girls into gendered expectations of Somali personhood. From Ibaado, for example, they learnt that a woman should always be strong, practice caution and not trust easily. While Ali disagrees with some of Ibaado's views - like saying 'if a girl's virginity is despoiled she not only obliterates her own honor she also damages the honor of Magan, uncles, brothers, male cousins' (2007, 6) - she appreciates other insights she gained about Somali worldview from Ibaado. She also admires Ibaado's tenacity in contesting male-centred narratives that silence women's heroic exploits. It is therefore unsurprising that most oral narratives Ibaado shares with her grandchildren are about strong, brave women.

One such narrative from Ibaado that Ali recounts in Infidel is the story of Farah Goure, Ali's clan patriarch, and his wife Fadumo, the clan matriarch. Ali's transcription of Fadumo's oral narrative positions this matriarch of their clan as an important historical agent. The story is as follows:

One day, walking through the market, Farah Goure saw a young woman about his age making angello, cooking the pancakes on a charcoal brazier on the ground, rolling them up with sugar and butter, and selling them to passersby. He walked up and down smelling the angello and she called to him [...]. Farah Goure and this young woman started listing their ancestry, as Somalis always do. Both of them [belonged to the] Osman Mahamud [clan] [...]. He asked what she was doing in Kismayo [...] and Fadumo said, 'I told my parents I would leave to make my fortune and this is what I did. I have an angello stall but one day I will buy a truck. You can start an angello stall, too.' [He] said, 'Of course I can't, I'm a man.'

(2007, 99)

Ali then proceeds to recount how the couple reached a consensus to grant their respective wishes. Each day Fadumo would make Farah breakfast while he 'apprenticed himself to a 
transporter [...] [a]nd after a year or so of making angellos and renting trucks and trading between Kismayo and Mogadishu, [they] bought their first truck. Then they bought another, and a real angello stand, with employees' $(2007,99)$. Although Farah is still the dominant figure, each time 'the women of the tolka, the closest of [Ali's] Osman Mahamud clan relatives, [...] told and retold the story to [them]', they made it 'more romantic, Fadumo braver and wittier and Farah even more enchanted by her' (2007, 99-100). The patriarchal version of this story portrays Fadumo as an ideal woman 'who never caused havoc even when [Farah] married other wives' $(2007,100)$. Instead, she welcomed them and told them to 'earn [their] own money [for] the money [Goure had] married them with [was] hers' $(2007,100)$. Thus, though Fadumo's independence is recognised, her portraiture is still confined within patriarchal expectations of proper womanhood, so that she does not threaten Farah Goure's masculine privileges like polygamy. While he unscrupulously spends Fadumo's hard-earned wealth to acquire more wives, Fadumo is not accorded the same choices. Ali's version of the tale deliberately uses Fadumo's story to contest the docility implied in the masculine narrative. Her retelling is a reinvention of the oral history of her clan. By locating Fadumo at the centre of the clan's history, Ali re-positions herself as clan historian.

Having positioned herself as a transcriber of the oral histories of her community, Ali then ventures into a revision of her clan's genealogy in both her autobiographies. This enables her to re-inscribe female figures in her clan's history, but also allows her to reaffirm her own Somali identity. The opening act of Infidel, her first autobiography, positions Ali in the poetic act of chanting her genealogical roots. In the first page, Ali begins with the phrase: 'Who are you?' a question, posed by her grandmother, Ibaado, to make Ali aware of her belonging to the 'superior' Magan clan (2007, 3). The official genealogical account, however, only acknowledged male ancestry. Thus Ali would declare: 'I am Ayaan, the daughter of Hirsi, the son of Magan' $(2007,3) .{ }^{12}$ This genealogical version silences women and Ibaado contests this patriarchal practice by forcing Ali to memorise their maternal lineage alongside their paternal lineage. Thus, as she grew up, Ali extended the recitation of her family's genealogy to include matrilineal lineages and she would say: 'I am a Darod, a Hirsi, a Macherten, an Osman Mahamud. I am of the consort called the Higher Shoulder. I am a Magan' (2007, 3).

The ritualistic process of remembering this lineage is Ibaado's way of teaching Ali to honour her clan. This narrative technique fulfils different functions. Firstly, the narration of her genealogy using Somali conventions establishes that Ali is indeed Somali, born of Somali parents in Somalia. Secondly, it gives credibility to Ali's narration of Somali collective experiences as refugees in exile. This factor is important in view of Ali's mixed citizenship (Somali-DutchAmerican). Furthermore, these genealogical recitals also re-inscribe Somali women into the patrilineal familial/clan archives. In this way, Ali reclaims the memories of powerful matriarchs in her clan's lineage. However, Ali also notes that while children were encouraged to memorise their mother's bloodline, this was purely for purposes of hospitality and not identity-formation as 'a child belongs to the clan of his father' (2007, 4). It is Ibaado who teaches Ali about her maternal forebears who were not included in the family genealogy, a maternal filiation that Ali acknowledges and identifies with in her autobiography. Thus, and despite the conflicted nature of their relationship, Ibaado still plays an important role in Ali's conceptualisation of self.

At the end of her second autobiography, Ali, seemingly having understood the person she now wants to be (separate from her mother and grandmother), expresses her desire to become a mother in her own right. In the last chapter of her second autobiography Nomad, titled 'Letter to my unborn daughter' (2010, 263), Ali includes a letter in conversation with Oriana Fallaci, another female critic of Islam. Fallaci urges Ali to 'start thinking about having a child of [her] own before it is too late' $(2010,264)$. This letter serves as a reminder to Ali that motherhood 
can be a choice, an experience re-defined by women with different symbolic values to those crafted by patriarchal understandings of motherhood. Fallaci invokes motherhood as a reminder of women's need to re-inscribe their memories in other bodies, those of their children, to avoid being obliterated from history upon death. Thus, Fallaci sees motherhood as a possible experience of immortalising a woman. What is interesting regarding this is that both Ali and Fallaci were unmarried at the time and their desires for motherhood challenged social norms requiring that children be born within marriage ${ }^{13}$ Fallaci's dreams of motherhood were not fulfilled, as she lost her child through a miscarriage, and she relays her sadness to Ali for having missed out on this opportunity through a letter titled: Letter to a Never Born in memory of her unborn child, which inspires Ali to become a mother. Emulating Fallaci's example, Ali writes a letter to her unborn daughter, which demonstrates a desire to extend filiation to the next generation. This would seem to suggest that Ali favours reclaiming filiation over rejecting filiation even when filial ties are strained.

\section{Conclusion}

This chapter has argued that the African female autobiography is a text that creatively deploys the narrative techniques of the filial voice for specific purposes. Deployment of the filial voice to foreground specifically biological and non-biological maternal relationality enables the autobiographical subject to excavate silenced female figures from familial and national history. It also enables the autobiographical subject to problematise constructions of daughterhood and womanhood in African and non-African societies. The selected autobiographers, Ali and El Saadawi, both highlight female-centred narratives derived from oral traditions that often diverge from official histories. To different degrees, both writers adopt re-memorying as a narrative technique allowing them to recover and extend known female histories. Ali and El Saadawi show through their representations of self and others that re-memorying presents biases that trouble the notion of autobiographical unity. This is especially the case when a daughter like El Saadawi calls for posthumous regeneration of memories expunged, not just from written national histories, but even from the oral archives of families as in the case of Habasheya or Isis. The chapter establishes that while autobiographical re-membering may be a personal undertaking, it is also a process through which individual and collective identities are inscribed.

\section{Notes}

1 Scholars in this category include Laura Marcus, Sidonie Smith and Julia Watson, Shari Benstock, and Linda Anderson.

2 For more details, see Smith and Watson (2001) and Marcus (1994).

3 Scholars in this category include: Lisa McNee, Pumla Gqola, Marciana Were.

4 Examples of texts in this category include: Nawal El Saadawi's Woman at Point Zero (1975), Ken Bugul (Marietou Mbaye)'s The Abandoned Baobab (1982), Buchi Emecheta's Head above Water (1986) and Mariama Ba's So Long A Letter ([2008] 1989).

5 Non-fictional autobiographies by public figures comprise the majority of texts in this category. Examples include: Ellen Johnson Sirleaf's This Child Will Be Great (2009) and Winnie Mandela's Part of My Soul Went with Him (1985). Some non-fictional autobiographies by women who are neither public figures nor creative writers are: Ubax Cristina Ali Farah's Little Mother (2011) and Fauziya Kassindja's Do They Hear You When You Cry (1998).

6 Examples of non-fictional autobiographies authored by creative writers include: Grace Ogot's Days of My Life (2013), and Nawal El Saadawi's A Daughter of Isis (1999) and Walking through Fire (2002).

7 Some critical studies on filiation include but are not limited to: Alcinda Honwana's Child Soldiers in Africa (2006), Katunga Minga's 'Child Soldiers as Reflected in the African Francophone War Literature 


\section{Marciana Nafula Were}

of the 1990s and 2000s' (2012) and Edgar Nabutanyi's 'Representations of Troubled Childhoods in Selected Post-1990 African Fiction in English' (2013). Notably, not all discussions of childhood are discussions of filiation. Critics with an interest in the literary representation of children have more frequently tackled issues related to filiation. The exception is Desiree Lewis' (1999) 'Gender Myths and Citizenship in Two Autobiographies by South African Women'.

8 See Desiree Lewis (1999).

9 In A Daughter of Isis, El Saadawi recounts her paternal genealogy as follows: although Habasheya's husband is not known, she begot Al-Saadawi. Al-Saadawi had very many women, one of whom begot him a son whom he called Habash, named after his mother Habasheya. Habash married Sittil Hajja as a child bride following the death of his wife, and she begot Al-Sayed Saadawi. Al-Sayed married Zaynab and begot nine children, one of whom being Nawal El Saadawi. For more details, see: 1999, 26.

10 Abyssinia is a geographical zone in the history of ancient Northern Africa (Ethiopia), a history overwritten by various conquests.

11 El Saadawi mentions that Al-Saadawi named his son 'Habash after his mother Habasheya' so in a way it was not only a tribute to his mother (26), but a contestation of patriarchal tradition which dictated that 'the father alone gives his name to the children' (4).

12 All the names mentioned in Ayaan's genealogical recitation belong to men. She is the daughter of Hirsi (her father), son of Magan (her grandfather), son of Isse, son of Guleid, son of Ali, son of Muhammad, son of Ali, son of Umar, son of Osman, son of Mahamud.

13 Ali is currently married to the historian Niall Ferguson. Together they have a son.

\section{References}

Alabi, Adetayo. 2005. Telling our Stories: Continuities and Divergences in Black Autobiographies. New York: Palgrave Macmillan.

Ali, Ayaan Hirsi. 2010. Nomad: A Personal Journey through the Clash of Civilizations. London: Simon \& Schuster.

Ali, Ayaan Hirsi. 2007. Infidel. London: The Free Press.

Anderson, Linda. 2007 [2001]. Autobiography. New York: Routledge.

Andrade, Susan. 1990. 'Rewriting History, Motherhood, and Rebellion'. RAL 21(1): 91-110.

Andrade, Susan. 2002. 'Gender and the Public Sphere'. Agenda 54: 45-59.

Azodo, Ada Uzoamaka. 1997. 'Issues in African Feminism: A Syllabus'. Women's Studies Quarterly 25(3/4): 201-207.

Bâ, Mariama. 2008 [1989]. So Long A Letter. Reading: Heinemann.

Benstock, Shari. 1988. The Private Self: Theory and Practice of Women's Autobiographical Writings. Chappel Hill: University of North Carolina Press Books.

Gqola, Pumla. 2017. 'Winnie, Wambui, Wangari - on Being Difficult Women'. In her Reflecting Rogue: Inside the Mind of a Feminist, 145-157. Johannesburg: MFBooks.

Gunner, Liz. 2005. 'Names and the Land: Poetry of Belonging and Unbelonging, a Comparative Approach'. In Text, Theory, Space: Land, Literature and History in South Africa and Australia, edited by Kate Darian-Smith, Liz Gunner and Sarah Nuttall, 115-130. London: Routledge.

Heilbrun, Carolyn. 1999. Women's Lives: The View from the Threshold. Toronto: University of Toronto Press.

Hunsu, Folasade. 2011. 'Critical Directions in African Autobiography'. Marang: Journal of Language and Literature 12: 119-134.

Hunsu, Folasade. 2013. 'Engendering an Alternative Approach to Otherness in African Women's Autobiography'. Life Writing 10(2): 171-185.

Hunsu, Folasade. 2017. 'The Future of African Women's Autobiography'. Auto/Biography Studies 32(2): 319-322.

Kabira, Wanjiku Mukabi. 2005. A Letter to Mariama Bâ. Nairobi: University of Nairobi Press.

Kolawole, Mary Ebun Modupe. 1997. Womanism and African Consciousness. Trenton, NJ: Africa World Press.

Lewis, Desiree. 1992. 'Myths of Motherhood'. English in Africa 19(1): 35-51.

Lewis, Desiree. 1999. 'Gender Myths and Citizenship in Two Autobiographies by South African Women'. Agenda 15(40): 38-44.

Marcus, Laura. 1994. Auto/Biographical Discourses: Theory, Criticism and Practice. Manchester: Manchester University Press. 
McNee, Lisa. 1997. 'Autobiographical Subjects'. Research in African Literatures 28(2): 83-101.

Morrison, Toni. 1987. Beloved. New York: Plume-NAL.

Ogunyemi, Chikwenye Okonjo. 1996. Africa Wo/Man Palava: The Nigerian Novel by Women. Chicago, IL: University of Chicago Press.

Rody, Caroline. 1995. "Toni Morrison's Beloved: History, "Rememory," and a "Clamor for a Kiss"”. American Literary History 7(1): 92-119. www.jstor.org/stable/489799.

Saadawi, Nawal. 2002. Walking through Fire. London: Zed Books.

Smith, Sidonie and Julia Watson. 1998. Women, Autobiography, Theory: A Reader. London: University of Wisconsin Press.

Smith, Sidonie and Julia Watson. 2001. Reading Autobiography: A Guide for Interpreting Life Narratives. Minneapolis: University of Minnesota Press.

Viljoen, Louise. 2014. 'The Mother as Pre-text: (Auto)biographical Writing in Antjie Krog's $A$ Change of Tongue'. In Antjie Krog: An Ethics of Body and Otherness, edited by Judith Lütge Coullie and Andries Visagie, 133-156. Pietmaritzburg: UKZN Press.

Vinson, Pauline Homsi. 2008. 'Shahrazadian Gestures in Arab Women's Autobiographies: Political History, Personal Memory, and Oral, Matrilineal Narratives in the Works of Nawal El Saadawi and Leila Ahmed'. NWSA Journal 20(1):78-98. www.jstor.org/stable/40071253.

Were, Marciana Nafula. 2016. 'Negotiating Public and Private Identities: A Study of the Autobiographies of African Women Politicians'. PhD Dissertation, Stellenbosch University. 


\title{
'I can't go forward; I must go back' Ben Okri's (p)anachronistic utopias
}

\author{
Ian P. MacDonald
}

In 2010, Mark Bould, a key figure in the field of speculative fiction (sf), announced in his introduction to an African-sf-themed issue of the journal Paradoxa, 'If African sf has not arrived, it is certainly approaching fast' (7). The past several years have gone a long way to suggesting how fast, making it worth remarking that only a year before Bould's assertion, AmericanNigerian sf author and theorist Nnedi Okorafor (2009) asked on her blog, 'Is Africa ready for science fiction?', by which she meant, 'Is an African reading public ready to show interest in sf topics generally and in an African-themed sf in particular?' A number of examples of African sf and academic texts have since expanded the critical importance of an African sf. ${ }^{1}$ Whether a substantial African readership of sf is emerging alongside the primary and secondary academic literature remains an open question, but as Bould (2017) notes elsewhere, African sf 'by writers from Egypt, Gambia, Kenya, Malawi, Namibia, Uganda, Zimbabwe, and from across the contemporary diaspora' now dot the publishing landscape, implying increased interest both locally and globally in sf from an African perspective.

Bould's inclusion of the diaspora - works by writers like Nalo Hopkinson and Karen Lord in the Caribbean context, for example - further highlights the importance of African sf to a growing body of scholarship attending to postcolonial sf, with works by John Rieder (2008), Ericka Hoagland and Reema Sarwal (2010), Patricia Kerslake (2011), Jessica Langer (2011), Eric Smith (2012) and Ingrid Thaler (2014) representing just the crest of a wave of analyses focused on writers like Hopkinson and Lord as well as Amitav Ghosh, Minister Faust, Vandana Singh, Gerardo Horacio Porcayo, Liu Cixin and Manil Suri. Given the increased production of, and attention to, sf coming from outside the Euro-American or Russian theaters, it is worth attending to the value of the genre itself: to question not just whether there are Africans writing sf, but why it matters whether they do, whether postcolonial sf can '[transform] the rhetoric of resistance into a positive anticipation of future freedom' (Ashcroft 2009, 703). Sceptical readers, however, may still challenge the notion that science fiction, strictly defined, appears frequently enough in African contexts to merit discussion.

The twentieth century certainly saw numerous examples of African sf from white writers, primarily in South Africa and former Rhodesia. ${ }^{2}$ Nevertheless, works of black-African sf can also be identified although they were frequently mistaken for fabulism (as with much critical literature on Kojo Laing's Woman of the Aeroplanes [1988]: not entirely a misapprehension) or 
had their sf themes overlooked (as in the case of Buchi Emecheta's The Rape of Shavi [1983]: a definite oversight). ${ }^{3}$ Emmanuel Dongala's (1982) allegory of alien invasion, 'Jazz and Palm Wine,' represents a rare, explicit foray into sf, but so, one could argue, does the robotic couch that furnishes the office of Deputy Director Seth Soja in Ayi Kwei Armah's (1995, 28-29) Osiris Rising or the fact that Laing's (1992,3) Major Gentl and the Achimota Wars begins in the year 2020. Do such examples, given their relative rarity and brevity in twentieth-century African texts, require an analysis from the vantage of sf studies?

This question has motivated a host of critical works over the past decade, not only in the aforementioned issue of Paradoxa (2010) but additionally in African-sf-themed issues of African Identities (2009 [7.2]) and The Cambridge Journal of Postcolonial Literary Inquiry (2016 [3.3]); essays in edited collections such as Isiah Lavender's (2014) Black and Brown Planets; and elements of monographs like Bill Ashcroft's (2017) Utopianism in Postcolonial Literatures. As early as Ralph Pordzik's (2001) The Quest for Postcolonial Utopia, scholars have interrogated the role of properly speculative futures in African literature in terms of sf although, as in the case of Pordzik's work, such discussions frequently did so in terms of utopian writing.

Additionally, much African sf toes the line between science and localized mythopoeia. Darko Suvin $(1979,20)$ famously defined science fiction as 'the language of cognitive estrangement': a mode of submitting the intrusion of the unreal or unheimlich (what he calls the sf novum) to an empirically informed exercise of rationalization and closure. Sf, to Suvin, was 'opposed to supernatural or metaphysical estrangement' like myth and fantasy. While still influential, this view has been tempered by others, like Istvan Csicsery-Ronay (2008) and Bould, Butler, Roberts, and Vint (2009), for whom rigid generic borders are difficult to formulate and unnecessarily limiting. China Miéville, in his afterword to Red Planets (2009), notes that he felt pressured to underplay fantasy due to Suvin's claim that sf and fantasy 'are and must remain not only radically distinct but hierarchically related.' As Miéville notes:

[A]lthough [fantasy, for Suvin,] also 'estranges,' it is 'committed to the imposition of anticognitive laws,' is 'a sub-literature of mystification,' 'proto-Fascist,' anti- rationalist, antimodern, 'overt ideology plus Freudian erotic patterns.' Suvin acknowledges that the boundaries between SF and fantasy are often blurred, at the level of creation, reception and marketing, but this he sees not only as 'rampantly sociopathological,' but 'a terrible contamination.'

$(231-232)$

Such a position, Miéville continues, extends to Marxian scholars that follow in Suvin's footsteps like Carl Freedman and Fredric Jameson, with the former accusing fantasy of being 'cognitionless' and offering at best 'irrationalist estrangements,' and the latter describing fantasy as lacking sf's 'epistemological gravity' and accusing it of being 'technically reactionary' (Miéville 2009, 232).

This language - 'anti-cognitive,' 'mystification,' 'sociopathological,' 'contamination' - eerily echoes colonial-era anthropological discourse. Sf, in the above view, is 'cognitively' valid, but in the sense of cognition already conveniently validated by Western epistemology. While no doubt unintended, when Suvin and Jameson turn their critical eye to fantasy, they simultaneously describe Africa's own history of the fantastic in the works of D. O. Fagunwa, Amos Tutuola, Bessie Head, Syl Cheney-Coker, Sony Labou Tansi, Kojo Laing, Ngũgĩ wa Thiong’o, Ben Okri and others whose staging of the mythic, and often bluntly magical, intrusion into the lived world must now, it seems, be marked as reflecting 'anti-rationalist' and 'anti-modern,' 'anti-cognitive' and even 'proto-Fascist' tendencies. This is a stunning anathema aimed at an entire literary tradition. I ally myself instead with Miéville, who counters that the boundary building at play in these theorists is itself patently ideological and, more so, indefensible upon 
close scrutiny. Rather, following Wells, Miéville looks at sf as a genre that 'domesticates an impossibility' as the result of 'a strategy, or a game, played by the writer and, often, reader, based not on reality-claims but plausibility-claims that hold purely within the text' (236). Thus, the term speculative fiction allows for a broader range of content tied together by common interest in techno-scientific trends; otherworldly landscapes; fantastic devices; alternate pasts and futures; and, what concerns the remainder of this chapter, utopian, dystopian or post-apocalyptic visions.

Sf has tangibly influenced the direction of Western technology, and while art installations like Cristina Middel's Afronauts (2012) continue, however inadvertently, to portray Africans in space as a comic oxymoron, there remains enormous opportunity for Africa to transform global visions of the future: a future that must be imagined before it can arise. Bill Ashcroft $(2013,95)$ maintains that:

the vision of the future projected by African creative artists obliges nothing less than a reassessment of African modernity ... in which Africa, far from slavishly following Europe into a wealthier future, offers the potential to envision a different kind of future not only for itself but also for the world.

It is these potential futures, and the literary worlds that portray them, which mark the importance of speculative 'landscapes of hope' emerging from Africa.

\section{The utopian spectrum}

It makes sense to think in terms of sf when discussing utopias, whose calls for action aimed at effecting alternative futures embed them within the speculative imagination, and it is a rare work on sf that does not attend to them. While African literature has generally listed towards dystopic environments - unsurprising given its various histories during and after the colonial period - Ben Okri is not alone in postulating formally utopian alternatives. The style of Armah's (1995) Osiris Rising intermittently takes on the tenor of the classic utopia (108), and the aims of the novel's Ankh Society - reuniting the continent by suturing the fracture of the colonial borders by means of a repatriated Kemetic history - can certainly be seen in terms of a utopian project. Likewise, Ngũgĩ wa Thiong'o's Movement for the Voice of the People in Wizard of the Crow and the 'voices of the peasants ... students and ... other patriots singing in harmony' which drift across the river to Mũriũki in Matigari $(1987,175)$ both suggest the presence of a utopian horizon.

Unlike Armah and Ngũgĩ, however, Okri's interventions into the utopian imagination have led some critics to question his commitment to, however problematically termed, 'African' themes. ${ }^{4}$ His diverse borrowing from multiple cultural traditions and his interplay between speculative models and mythic traditions have often disarmed and flustered critics leading to regular - and, I feel, misguided - discussions celebrating Okri's postmodernism (Pordzik 2001; Fox 2005; van Niekerk 2012; Gray 2013) when his recent style might be better conceived of as a kind of meta-heuristic bricolage. ${ }^{5}$ By this, I mean that Okri's style is didactic, immanently transcendental, and structured by borrowing from whatever lies at hand. In several of Okri's recent novels - Astonishing the Gods (1995), In Arcadia (2003) and its sequel The Age of Magic (2015), and Starbook (2007) - various elements of the utopian round intersect making reading these works as a thematic unit worthwhile.

Scholars have occasionally lumped Okri's work under the umbrella of the utopian project due to its optimistic mysticism and transcendentalism. While the latter element leads Bill 
Ashcroft $(2017,87)$ to conceive of the abiku trilogy in terms of its reconceptualized 'relationship with "history", the former informs McCabe's (2005) arguments concerning New Age influences on Okri's thought. Ashcroft stages postcolonial utopianism as critical response to the 'utopian idea of the civilizing mission' embedded in imperialism (14). For Ashcroft, postcolonial utopias are distinctive in that they privilege the utopian impulse (the general principle of hope) over the utopian program (the actual, already-existing utopian site); that they imply an oracular element to memory "not as a nostalgic yearning for the past but as a "prophetic vision" of what may be possible' outside of the history of imperialism (15); and that they engage in a general rejection of the nation. McCabe, for his part, argues that rather than as postmodern experiment, or even as Nigerian mythopoesis, one should read Okri in terms of a straightforward adoption of New Age spiritual discourse - a fusion of '[s]ociocosmic millenarianism, co-creative idealism, loving monism, self-actualization, and detraditionalizing perennialism' $(2005,10)$ - a contention for which he has received substantial blowback from critics including Esther de Bruijn (2007). I contend instead that Okri attends carefully to the complex nature and history of the utopia and its multifaceted manifestations. Rather than being merely utopian in the abstract, Okri's writing intertextually engages with the literary history of the Utopia itself. "Excuse me, ma'am; excuse me, sir", Okri exclaims in an interview with Charles Rowell $(2014,221)$, “"[t]hat map doesn't have what Thomas More would call Utopia. That's a country too." That's what [artists] do, because it is not healthy for us to have a fixed map of humanity, because humanity is not eternally fixed.' Each of Okri's novels listed above traces this shifting utopian geography starting from a different sub-generic position with the aim of a practical material project notwithstanding his use of transcendentalist language. While Astonishing the Gods responds most closely to the traditional Western utopian city-state, it shares specific images and themes with Starbook (an arcadian utopia culminating in an apocalypse) and In Arcadia/The Age of Magic (a Chaucer-esque pilgrimage which dismisses any specific geographical location for arcadia) in a fashion that, seen as a four-novel whole, outlines a holistic utopian project which transcends mere "wishful dreaming' and endorses the semblance of a map to social transformation.

Okri's meta-heuristic bricolage represents an unabashed cosmopolitanism, overlaying his utopian treatments with elements from West African religious practice and oral culture (egungun [Starbook 6, 37] and ghommids [The Age of Magic 34, 41]), Western folktale (unicorns [Astonishing the Gods 157; Starbook 11, 52], knights [Starbook 138]), Greek mythology (Poseidon [Astonishing the Gods 89], Medusa [In Arcadia 15]), the poetry of Virgil, and other ingredients highlighting the spiritual motif that has remained consistent across his many books and which has drawn the aforementioned attention from McCabe and others. Okri claims he incorporates magical elements into his work to restore a prescientific language that has since been subsumed under the rhetoric of scientific rationality to the detriment of localized cultural aesthetics:

Before I left Nigeria, people spoke about the spirits and when I go back that's crushed too and no one's talking about them anymore. So everywhere there is this extra dimension of things that has slowly been murdered in the minds of people, in the minds of our children. Then the next thing you know, they start to pop up in a different way in science but given a completely different name and sanitised and not made to have any relationship with our everyday living realities.

(Quoted in Fulford 2009, 254)

This echoes Lao's observation in In Arcadia that 'We killed off the mysteries in the name of civilisation; we murdered wonder in the crucibles of barren molecules, inert space, and glorified serial killers' (Okri 2003, 47). Such an example might imply hostility to sf as a generic strategy; 
after all, in the same passage, embedded within a list of horrors filling the news alongside serial killings and child molestation, he includes 'new space missions sent out to investigate distant planets.' Nevertheless, given evidence elsewhere, it appears, rather, that Okri seeks to challenge the sterility of empiricism by infusing fabulism into the everyday world in a manner not intended to efface technological modernity but as a dialectical sublation that unifies myth and modernity in a method similar to what I have elsewhere referred to as jujutech (MacDonald 2016, 315): literary worlds in which, for example, both camera flashbulbs and lightning bolts sent by 'God ... The Great Photographer' stun or destroy nearby spirits in a similar fashion (Okri 1991, 46, 285).

In Arcadia and The Age of Magic follow a documentary film crew on a train trip from London to the Peloponnese peninsula, primarily narrated through the documentary's host, Lao. Lao and the crew - including Lao's artist partner, Mistletoe - are menaced throughout by a shadowy presence named Malasso, whose identity is never unambiguously provided. As the journey continues, especially over the course of the second book, the magical/mythic world increasingly intrudes upon Lao's narrative. In In Arcadia, while leaving London, Lao ponders the places in the world 'whose beauty was compacted into their names ... Waterloo ... Exilus ... Eden ... Paris ... Babylon ... Utopia ... Versailles ... Atlantis ... Arcadia' (Okri 2003, 18), a list that delivers an eclectic cross-section of the utopian project (Waterloo, Paris, Versailles and possibly Utopia itself), utopian impulse (Atlantis), earthly para-utopian pastorals (Arcadia), and transcendental paradises (Eden). As Sharae Deckard (2010, 104) notes, paradise differs from utopia in that the former represents a space of escapism and critique but 'cannot function as a blueprint for reality'; likewise, the celestial paradise of an Eden or even a Cockaigne (whose tales of fowl that leap pre-cooked into one's mouth belie its perceived terrestriality) differs from the geographical paradise of a Xanadu or an Arcadia.

Picture the utopian round as a circle embracing a dual axis of positive-negative and ruralurban, with utopia/dystopia on one side and arcadia/postapocalypse on the other. Whereas the utopia focuses on the creation of socio-political societies marked by hierarchies and bound to urban spaces, the dystopia inverts and deforms those spaces, often representing the utopia 'seen from the other side' (for example, in the anti-utopias of Yevgeny Zamyatin [1924], Aldous Huxley [1932], and George Orwell [1949]). On the other half of the circle, we find the arcadia - the terrestrial-Edenic space of rural plenty - and its opposite, the scarred wasteland of the apocalypse and its aftermath. The borders between these different subgenres are exceptionally permeable and mobile, with numerous available examples of the post-apocalyptic dystopia (Wanuri Kahiu's city-state in Pumzi [2009]; Mad Max: Fury Road's [2015] Gas Town) or the arcadian utopia (as Suvin [(1979) 2014, 65] has described William Morris's News from Nowhere [1890]) readily available. Understandably, diagonal elisions - the utopian post-apocalypse or arcadian dystopia - are rarer but not unheard of. (Frederick Brown's [1945] 'The Waveries' represents an example of the former.)

In looking backwards to look forward by way of utilizing utopian traditions, Okri does not idly recycle Western utopian models but discovers something integral to the utopia in the act of staging it from a postcolonial position. In his adoption of the utopia, Okri capitalizes on a structure of critique originally of the West by the West wherein the utopia, as a new sociopolitical center, challenged the norms of early-modern and Victorian Europe and the USA In order to contest the world-as-it-is with a radical vision of the new, Okri cycles through various subsystems of utopianism in a fashion that not only establishes his importance to African sf, but also in a manner that has brought him ever closer to explicit sf language. In the following section, I attend to Okri's incorporation of each of the utopian subgenres by way of indicating a material program that intersects them all. 


\section{From cloud city to white walkers}

\section{Utopia/dystopia}

Okri's Astonishing the Gods, like most utopias through the end of the nineteenth century, consists of a framing narrative initiating a physical journey to a locus of spiritual/social perfection, often located on an island or other isolated geographical space, followed by a guided initiation into the inner sanctum of the new society. (In Arcadia evokes this same framing gesture when Lao refers to his fellow travelers as 'shipwrecks and derelicts on the ruined shores of the city' [Okri 2003, 5]). The novel opens with a challenge to Hegelian ${ }^{6}$ historicizing. Upon attending school, where he learns that 'time can be written down in words,' the protagonist discovers that he was 'born invisible,' that after 'search[ing] for himself and his people in all the history books' he finds that 'he didn't exist' (Okri 1995, 3). Following this discovery, the invisible narrator 'flee[s] from home' in search of the secret of visibility. He '[runs] to the nearest port' (4), 'set[s] sail across the billowing waves and the wild squalls' (115) of 'the emerald sea,' finding himself seven years later at a 'strange port' outside of an 'empty town' (5) where he discovers an invisible civilization to which he is introduced by three guides. Entering and reentering the gates of the city several times $(31,43,126)$, he reaches its heart and discovers the city's truth - that one must not seek visibility but embrace 'a higher invisibility, the invisibility of the blessed' (159) (about which more will be said later).

In typical utopian fashion, the city is organized around a Platonic geometry of 'order' (8), 'perfection' (9) and 'symmetry' (130), yet in a manner akin to early-modern satirical utopias, the city's institutions function in ways diametrically opposed to expectation. Courts 'were places where people went to study the laws, not places of judgement'; the library 'was a place where ... [b]ooks were not borrowed' but 'composed ... and deposited.' Banks 'were places where people deposited or withdrew thoughts of well-being' (Okri 1995, 66-71). In all of these examples the didactic refusal of the 'world as it is' on the part of the utopian judge remains.

The fact that the urban facades of the City of Invisibles mirror European models ('Stainedglass cathedrals' [37], 'piazzas' [72]) reflects the older models of the utopia which motivate this treatment. Still somewhat visible, the protagonist sees past the Western utopia as not representing his utopia. Okri's 'urban landscape,' argues Sanchez-Arce $(2003,125)$ is “"oddly terrifying" presumably because it reproduces ideological structures of power - the castle, the basilica ... incorporat[ing] the self into the ideological constructs unless he can see beyond the facades.' These edifices serve metaphorical purposes, representing 'ideas, which were alive in the air' and 'seemed to him like solid things' (Okri 1995, 40), but which were '[a] dream meant to deceive the eyes of men' in that 'everything seen was intended to be visible only that it should pass away' thus indicating 'the destructibility of all things seen' (38). Okri's traveler is not visiting but passing beyond the Western utopia.

A similar interest in utopian architecture initiates Starbook, which Okri offers as an extended fable, with a storyteller relating it as a tale '[his] grandmother used to tell [him] as a child' (Okri 2007, 3). Originally utilizing the hallmarks of Western genre fantasy - a 'handsome and fair' prince (4) travels from his 'palace' (3) to woo a beautiful young 'princess' (8) who has been 'misplaced as a servant girl' (104) amidst such figures as 'fair[ies] with wand[s] of blue ... a knight in broken armour' and a 'bearded man with a shining magic sword' (138) - the novel ultimately relocates itself into a West African landscape marked by 'baobab trees' (88), 'palm-wine tappers' (55) and egungun (6). The kingdom's village, we are told: 
was built in the shape of a magnificent circle. And in the centre of the circle stood the palace of the king. Four rivers met in the forest around the village. The shrinehouse was at the edge of the village and the path that ran past it [led to an arcadian forest] dark and rich with magic and enchantment.

The novel follows the lovers' negotiation of their own place in the world until they manage to find one another and unite, only to be torn apart by dishonest politicians and the arrival of rapacious white spirits which kidnap the prince and enslave him across the ocean. We could be forgiven for seeing in Starbook's architecture what Lao describes in The Age of Magic as the 'four rivers' that 'flow into the Garden of Eden' and the 'fifth' that 'can be said to flow from Eden to Arcadia' (Okri 2015, 18). Yet, utopian architecture fails, in Okri's work, in part because it represents what Eaton $(2000,119)$ describes as 'humankind's domination of the forces of nature,' and rather than rely on the 'utopian city' as a model for progressive futures, Okri's later work seeks an escape from those quests for urban perfection. As in In Arcadia - where Lao finds himself briefly swept away by 'the complex mathematical computation' of Versailles with its 'statues' and its 'one hundred thousand and two hundred trees' realizing such edifices are 'not for the people' (Okri 2003, 169) - Starbook abandons its concern with the kingdom-as-utopia, focusing instead on a village of artists hidden behind a dimensional veil at the heart of the magical forest. In so doing, Okri moves from the utopian model of the 'city ... on a cloud' (Okri 1995, 49) to a more arcadian-utopian model.

The cities in Okri's works devolve instead into the grim, properly $d y$ stopian, realities inherent to '[t]his inferno that we call the modern world' (Okri 2003, 5) or, as in the case of Astonishing the Gods, disappears from view altogether. 'Would that architecture were the external sign of the greatness of those that dwell within' (Okri 2003, 165), Lao laments, but in the end '[d]eath' speaks through such 'geometry' (169). Okri is clear that 'The rich and powerful' cannot 'impose [Arcadia] on the world' (161). Instead one finds a 'grey suburbia' (16), with '[n]ewspapers' that bear 'notices of murders ... suicides ... ministers entangled in fraud or corruption or vice ... or nuclear waste ... poisoning the rivers' (47): a geography of 'run-down place[s]' (130) and 'shabby little rooms' (152). Further emphasizing this, in Starbook's palace, what is initially staged as utopian transitions instead to tragedy through the presence of duplicitous ministers - the king's elders - as they defend slavery, defraud the people and eventually murder the king to prevent the prince's ascension (Okri 2007, 407).

\section{Arcadia/post-apocalypse}

The arcadia, the 'dream of city dwellers' (Okri 2003, 66), occupies the second of Okri's potential sites of hope. Arcadia - as a word - suits Okri's general purposes better than utopia. Ashcroft $(2009,706)$ argues that 'the utopianism of much post-colonial literature is cyclic and recuperative' and in The Age of Magic, Lao underlines this while musing on the architecture of the word:

It began and ended with the first letter of the alphabet. Beginning with a beginning and ending with a beginning too. There was also a beginning right at its centre. ... Begin at the beginning; at the mid-point begin again; and at the end return to the beginning. Never move far from the alpha of life. Replenish yourself in the aleph.

(Okri 2015, 18) 
As with the City of Invisibles, in which 'learning what you know is something you have to do every day and every moment' (Okri 1995, 17), arcadia becomes the 'illusory goal of Arcadia' (Okri 2003, 25, emphasis mine), a paradise avenir signified by an 'ever-moving destination, unspecified except in myth, the place of absolute self-realisation and contentment which must always be just beyond the reach of the brave land, but not so much beyond reach that the people would give up in perfection's despair' (Okri 1995, 87). It is not, in other words, a place one reaches except by the act of reaching for it.

In Arcadia implies that any formally natural Arcadia, marked in Starbook as a precolonial African landscape interpenetrated by a forest replete with magic, has already become the stuff of history. In Starbook, the maiden's village houses spirits which move freely through homes and workshops that are 'rich with dreams' (Okri 2007, 105), and the village's inhabitants work with one foot planted in the (super)natural. It is a community 'absorbing' novelty in a 'high expression of gratitude that made higher creativity possible' (204): a village not just of artisans but of artists.

The novel's focus in Book Two, however, centers on the princess rather than the town from which she feels held at a certain remove and for which she represents a celestial enigma. In verbiage that touches on sf themes more explicitly than anywhere else in Okri's work, the village conceives her as being not just from another place on earth, but 'another constellation, another world,' as if she 'had found herself marooned on an odd planet where she was completely lost' (74). In her private turns of fancy, the princess:

had a sense, while staring into space ... that she returned to her real home on a distant star and lived a full life among forgotten loved ones ... Sometimes ... she was the father of a tribe ... and they could all fly, and they built things with their minds, and they loved across time and space, and they were masters of stars and galaxies.

The fact that the princess, within the apparent arcadian ideal of her village, engages in the kind of galactic dreaming that marks so much sf suggests the ways in which Okri's utopian output has begun to experiment with sf as a utopian strategy as well as highlighting the movement any lived utopia must inhabit lest it fall into fixity and decay. She dreams a utopian dream within the arcadian space suggesting that arcadia is the space in which such dreams flourish.

In the end, following the village's failure to heed prophesy, it finds itself unprepared for the arrival of 'white spirits' that violently depopulate the area. 'They were paralyzed,' Okri writes:

by the power of what they sensed ... They were like people who gazed into an abyss and no longer knew if they were still gazing or if they were falling. These were conditions which were perfect for being possessed by the abyss into which they gazed.

This abyss, and the White Wind it serves, occupy the fourth position in the utopian round: the apocalypse and its aftermath.

The rhetoric of invisibility represents a complex metaphor throughout Okri's later novels, one that is not entirely transparent. Within Astonishing the Gods, it functions as a site of erasure in both positive and negative senses. On the one hand, it represents the marginalization of black voices in Western history indicated by the opening pages. During the protagonist's first attempt to enter the City of Invisibles, he is tasked with crossing the 'bridge of self-discovery' (Okri 1995, 30) and finds himself sucked down (in language which sets the stage for the descriptions 
from Starbook, above) into an 'abyss' from which he 'heard ... voices murmuring consolations to the last man on earth, who thought himself damned.' Listening more closely, he hears the 'sweet tender choruses of the abyss calling him into the happy home of the world-effacing white wind' (20, emphasis mine), an emptiness containing 'the pure whiteness of oblivion' (22). This evocation of 'the last man' establishes the apocalyptic nature of the abyss and the 'white world' into which it draws its victims, the embracing of which represents the precise opposite of selfdiscovery. Starbook further extrapolates upon the white wind by identifying it as the herald of white spirits, who trap and bind the residents of the kingdom, put them on ships sailing to a land across the sea, sell them and force them to labor in 'fields of blood,' 'almost [creating] a desert out of a flowering land' (Okri 2007, 410). The white wind is the history of colonialism and slavery premised upon the labor of enslaved black bodies, and afterwards demanding unachievable cultural assimilation. It is literally 'the end of the world' (90). In this sense, the quest to become visible in a postcolonial world represents a negative self-effacement, a willing attempt to assimilate even though the attempt to become visible in a world committed to one's erasure will be met punitively (c.f. Ogunbayo 2012, 53).

This is what Lao, the protagonist of In Arcadia, describes as the 'invisible hell' (note the parallel to the 'inferno we call the modern world' cited above), the state of being 'reduced to colour.' To become visible in such a context is to enter a system of distrust based on the policing of 'invisible' borders that delimit nation-states. Lao becomes visible precisely at those invisible divisions that define the right of those standing on the correct side to be visible. Visibility in such a context, for Lao, reflects the consciousness of 'being automatically suspect, automatically distrusted, automatically de-humanized' (Okri 2003, 105); however, the temptation of such a visibility lies in its potential for traditional political action. As one of the figures testing the protagonist of Astonishing the Gods warns, 'In the end you'd scream for visibility and you'd flee this island, crying out for places where people have names and where you can participate in some useful struggle and where there are a thousand useful and beautiful illusions' (Okri 1995, 108, emphasis mine). But as the transcendental closure of Astonishing the Gods, and the workshop in which the princess's father creates his art in Starbook, indicate, invisibility represents not only a danger but a strategy, one representative of a different form of self-effacement.

\section{'How can I turn from Arcadia and live?'}

Near the center of In Arcadia, Mistletoe, Lao's partner who has joined the crew as a guest, sits outside a Parisian hotel room, the 'abysmal' conditions of which have induced a 'paralysis' upon the rest of the group (Okri 2003, 130). This echo to the protagonist of Astonishing the Gods sinking into whiteness is countermanded here by her own reaction to the torpor:

The gloom provided her with dark shapes, the sense of failure with Hades-inspired images, and hunger fuelled the flight of her mind into a realm of enchantment. It was a realm she was able to enter at will because she had lived a life so rich with misery, mistakes and love that she had gradually found an art of creating pleasant places in her mind where colours are astonishing, where life sings, and where possibilities lurk behind all evil shapes. Unhappiness had taught her the art of happiness. And art had taught her the saving graces of escape into the enchanted countrysides of her mind.

$(130-131)$

This passage, with its 'astonishing colours,' and 'enchanted countrysides,' evokes all the other novels discussed in this chapter, resituating the axis mundi dissolved at the end of Starbook. The 
novels become a thematic series, with Starbook, Astonishing the Gods, In Arcadia and The Age of Magic, forming a single epic tale of paradise lost, sought and regained.

To wit, at the close of Starbook, as the West African slave trade accelerates, the artists of the arcadian forest are 'captured' and '[suffer] the sea crossing' (Okri 2007, 409), where many are 'thrown overboard' (408). The protagonist of Astonishing the Gods later anachronistically sees these same people in his vision on the Bridge of Self Discovery:

whole peoples rising from the depths of a great ocean, rising from the forgetful waters. [W]ith a fixed and mystic gaze in their eyes, he saw them walking to an island of dreams. ... They built quietly for a thousand years. They built a new world of beauty and wisdom and protection and joy to compensate for their five hundred years of suffering and oblivion beneath the ocean.

(Okri 1995, 27)

The protagonist of Astonishing the Gods stands in for Starbook's prince, in whom the 'fire' is 'rekindled' and who 'escapes' his bondage 'on a great ship' and finds his way back to 'the homeland' (Okri 2007, 331), who witnesses the past emerging from the present to transform 'unforgettable suffering' into the 'bedrock of a new civilisation' (Okri 1995, 28). It is this future civilization that undergirds Lao's search as he sees through the 'facades' of the imperial utopian ideal at Versailles and seeks an arcadia that lies beyond it, and Mistletoe - ancient sacred reagent of the druids in their communion with the natural world - is the key.

The 'bedrock' of the 'new civilisation' is art. Not just its production or appreciation although these comprise the journey to the source, as indicated by the juxtaposition of the labyrinth of the City of Invisibles that brings the protagonist back again and again to the same gate with the 'labyrinths' (Okri 2003, 214) of the Louvre, that Cretan maze Lao must navigate - but rather, a return to that wisdom lost by the prince in Starbook, he who 'has no interest in creating art' but 'wants to become an art' (Okri 2007, 340): to live, in other words, as the inscription of oneself in one's art, to embody the kinds of truths normally appended to art. This role belongs to Mistletoe.

Throughout In Arcadia, as the crew negotiate each other and the demonic presence of Malasso, Mistletoe remains unflappable. Having found 'a friend in Lao,' she has begun 'a slow journey back, through art, to sanity' (Okri 2003, 81). As the crew undergoes the 'hectic ordeal' of filming, she revels in 'her freedom to conjure on paper dreams and dances ... to live in delightful reverie' (101-102). When one of the crew disappears leading to a 'tremendous sense of unease' (128), Mistletoe '[sits] at a table' drawing (129), 'becoming her own ideal' (134). While the crew debates the meaning of arcadia, Lao contemplates her 'smile of eternal happiness, of gratitude for having lived so close to the edge of personal disasters and ... found art as companion and solace' (149). Lao remarks that the 'map' to arcadia is 'not a promise ... nor an ideal embodied, nor cultivated acres' but in 'what is created, evoked, found within' $(193,166)$. Mistletoe's significance emerges in Lao's 'Arcadian' dream of her dancing in a garden with 'branches coming out of her head': a dream, she reminds him, after he recounts it to her, that was hers, one about which she had told him 'months ago' (172-173). Her dream is spreading.

It is at this point, I contend that Ashcroft's (2016, 14-15) claim that the 'defining difference' between postcolonial and colonial utopianism is 'the dominance of the utopian function over utopian form' does not apply to Okri's prismatic utopian aims. While the formal register of Okri's novels is fantastic and metaphysical, it points to something material - the immersion of oneself in the artistic process. Okri's focus on art and artistic production additionally offers a qualification to Douglas McCabe's (2005) assessment of Okri's New Age-ism. It is not enough 
simply to 'feel' the transcendental consciousness that fuels so much of Okri's philosophical output; in fact, that feeling can lead to 'seeking' in the negative sense described by Propr in In Arcadia, denoting the kind of people who want 'easy cures and easy miracles ... always joining, but never staying; always looking but never seeing ... wearing exotic clothes from Japan, Africa, India, Thailand, dabbling with Buddhism, Islam, Taoism, American Indian rituals, and the Kabbala, gulping down the latest sensational nonsense about Aztec temple prophecies' (Okri 2003, 136-137). While Propr is not held up in the novel as a source of wisdom, Lao hails this speech as 'extraordinary' (138), and it distinguishes the simple adoption of a certain kind of spiritualism (the kind attributed to Okri by McCabe) from its leveraging as artistic output. Art is utopia embodied, or perhaps, utopia is the embodiment of art. If there is a utopian project aligned with his work, it might be to reinvest globally in the arts, including, perhaps particularly, African arts like those highlighted in Starbook - sculpture, masks and clothwork, which, after the apocalypse, 'continued to appear in the land, in the world, along trade routes, in marketplaces,' produced by the 'masters' who dwelled 'in a place called no-place' until, as the decades passed, the artists became 'visible' (i.e. rationalized in the Weberian sense) ${ }^{7}$ and the work 'diminished' (Okri 2007, 419). These arts - alongside painting, prose, music and poetry provide the physical there to Okri's utopian 'Not-Yet' as indicated by the fact that, when creating for creation's sake, the masters above occupied a place called 'no-place': u-topia. In Astonishing the Gods, Okri suggests that 'Our highest acts of creativity are in the empty spaces, in the air, in dreams, in unseen realms. There we have our cities, our castles, our greatest books, our fullest sustenance' (Okri 1995, 148). The novel itself, then, can be seen here as a stand-in for the utopian project: a (literary) space in which 'cities' and 'castles' are given 'sustenance' through an 'act of creativity,' the formation of new worlds. In a parallel, non-phenotypical reading, the white abyss of history is recast for the future as the blank page: not as the erasure of cultural potential but as the womb of artistic promise.

Admittedly, Derek Wright's $(1995,330)$ critique still holds: that Okri's utopianism 'begs the question of exactly where this utopian projection occurs, except in the inward-facing consciousness of the appropriately-named "escape-artist," and how it translates into present political justice.' Yet as with so many utopias, either hypothetical or programmatic, the question is not so much when as how societal transitions can be embraced in the interest of creating the 'good place,' and Okri may, as Fulford (2009, 234-235) suggests, be seeking first to 'distinguish between "politics" as a governing ideological frame and "the political" as the potential to surpass this frame.' In centering the eutopia in the manufacture of the work of art, Okri applies a material practice to the utopia - the inherently political act of careful looking: individual commitment to the detail-oriented artistic eye, fulfilling his charge at the beginning of The Age of Magic, to 'Read slowly' (unnumbered page). As Suvin ([1979] 2016, 66-67) has noted, utopia is 'a method, not a state,' a 'heuristic epistemology,' and inasmuch as Okri dreams of a world entirely made up of artists, it is '[a] future ... to be rediscovered by all mankind' (Okri 2003, 147): a viable, if unlikely, utopia.

\section{Europe on the margins}

Ashcroft $(2009$, 106), citing Laurence Davis, suggests that utopias are 'not fantasized visions of perfection to be imposed upon an imperfect world, but an integral feature of that world representing the hopes and dreams of those consigned to its margins.' In this sense, Ashcroft sees utopias - in line with his early, foundational, work - as a form of the empire writing back. I, however, suggest an alternative formulation: rather than utopias representing marginal voices, they have always established counter-marginalizing ones. Dipesh Chakrabarty (2000, 43-44) suggests 
that part of any re-historicising project from a postcolonial perspective begins by 'provincializing Europe,' displacing a 'hyperreal Europe from the centre toward which all historical imagination currently gravitates.' Such a provincialization, he argues:

cannot be a project of 'cultural relativism.' It cannot originate from the stance that the reason/science/universals which help define Europe as the modern are simply 'culturespecific' and therefore only belong to the European cultures ... but rather a matter of documenting how ... its 'reason' ... has been made to look obvious.

Following this line of thinking, I argue that rather than being a 'quintessentially spatial and Western project' (Kesler 2012, 91), the utopia has historically served as a counterweight to modernist historicism while paradoxically also serving as its imaginative foundation. The utopia has in most cases been an act of 'provincializing Europe.' The land in Starbook, so much of which represents, in the purest imaginative form, Okri's arcadian dream, stands at the axis mundi. Its 'dancers performed their mighty dances which were reputed to have ... powers of realigning the broken axis of the world' (Okri 2007, 57) and when the White Wind eviscerates the land, Okri notes that 'the world had spun out of its axis' (406). Starbook's utopia does not represent a margin speaking back to a center, but a center itself, a 'temple at the navel of the world' (Lecoq and Schaer 2000, 50) critiquing a backward civilization which only misapprehends itself as the center: Utopia casts More's Europe into barbarism; Bacon's New Atlantis mourns the benighted lands beyond; Dr. Leete looks backwards to patronise nineteenth-century Boston; mighty Micromégas mocks the hubris of the insignificant European philosophers who contend God designed the universe just for them. This instinct guides the utopian geometry discussed above, labyrinths towards a center which represents not just the heart of the utopian city but the heart of the world.

In this sense, Okri does not reach back to borrow from Europe a method of formulating alternative futures but acknowledges that the utopia has always been located in some critical sense outside of Europe, treating the latter as peripheral and backwards by comparison to the more egalitarian center discovered by the literary utopia's protagonists. The utopia, and the genre of sf - which has borne so much of the weight of utopian dreaming since the turn of the twentieth century - represent, then, an especially fruitful strategy by which African authors can challenge neo-colonial space, effectively placing it in remission for the duration of a worldbuilding experiment that attends to the manner by which unquestioned economic globalization disjunctively juxtaposes the Global South against its own norms presented as self-evident. 'What prevents the African writer in the 21st century,' Charles Nnolim $(2006,5)$ asks, 'from reinventing Europe and from there developing an international theme in literatures ... [a] forwardlooking utopia for Africa, not the backward-looking utopia of the twentieth century that merely healed our psychic wounds?' As Okri suggests at the end of Starbook, 'Somebody has to project a story into the future' $(2007,415)$, and sf's specialty, in league with its utopian cousin, is the future.

\section{Notes}

1 For those interested in further investigating novels that deal with sf themes from an African perspective beyond those cited in this chapter, see Kojo Laing's Big Bishop Roko and the Altar Gangsters (2006), Lauren Beukes's Zoo City (2010), Deji Olukotun's Nigerians in Space (2014), N. R. A. Nyatsanza's Icho (2014), Dilman Dila's A Killing in the Sun (2014), A. Igoni Barrett's Blackass: A Novel (2015), Mohammed Rabie's Otared (2015) and Nick Wood's Azanian Bridges (2016). Nnedi Okorafor herself, perhaps more than any other single writer, has produced a daunting opus of sf marked by African elements and 
themes (The Shadow Speaker [2007], Who Fears Death? [2010], Akata Witch [2011], Lagoon [2014], Binti [2015]). The South-African literary journal Chimurenga (2008 [12/13]) released an African sf issue, and collections such as Ayodele Aribabu's Lagos_2060 (2013), Ivor Hartmann's collection AfroSF (2011), Bill Campbell and Edward Austin Hall's Mothership (2013), and Nick Wood and Tade Thompson's AfroSFv2 (2015) also introduce new works by African artists grappling with sf landscapes.

2 C.f. Doris Lessing's Memoirs of a Survivor (1974) and Shikasta (1979), Karel Schoeman's Na die Geliefde Land (1978), J. M. Coetzee's Waiting for the Barbarians (1980) and Nadine Gordimer's July's People (1981).

3 Charlotte Bruner $(1984,657)$ described the book as somewhere 'between allegory and adult fairy tale': this, despite the novel's clear introduction of a futuristic plane, the overriding context of nuclear Armageddon, and a scene describing the Euro-American scientists emerging from their crashed vehicle that could have served as a description of any number of pulp sf magazine covers figuring astronauts arising from the wreckage of spaceships in an alien environment (c.f. Emecheta 1985, 25, 30 and 32).

4 See, for example, Alfred Hickling's (2002) contention that '[w] here The Famished Road was African, expansive and generous in spirit, In Arcadia is European, thin and mean in temperament.' See also Helen Brown's review in the Independent (quoted in Fox 2005).

5 Moves to read Okri's utopian work as postmodern may stem from the tendency of some to see sf as, in Brian McHale's $(1987,59)$ words, 'Postmodernism's non-canonized or "low-art" double, its sister genre in the same sense that popular detective thriller is Modernism's sister genre.' I remain leery of celebratory postmodernity and therefore resist such moves to locate sf in toto uncomplicatedly in the postmodern theater.

6 Hegel's substantial influence on both Marxism and late-twentieth-century neo-conservatism highlights his broad relevance concerning questions of history and historical progress. Famously, however, his treatment of Africa (defined by him, essentially, as sub-Saharan Africa) in The Philosophy of History are infamously libelous. After portraying Africa as essentially still in a state of nature, he dismisses the region immediately, noting:

At this point we leave Africa, not to mention it again. For it is no historical part of the World; it has no movement or development to exhibit. Historical movements in it - that is in its northern part-belong to the Asiatic or European World. ... What we properly understand by Africa, is the Unhistorical, Undeveloped Spirit, still involved in the conditions of mere nature, and which had to be presented here only as on the threshold of the World's History.

(Hegel [1837] 1956, 99)

In this sense, then, by establishing a cogito who is aware of himself vis-à-vis the larger 'theater of history' (99) yet identifies his own absence from its texts, Okri's narrator challenges the essential Hegelian erasure of the African 'spirit.'

7 That is, subsumed into a capitalist bureaucracy, the 'rational organization of capital and labor' or 'bourgeois economic life' (Weber [1930] 2005, 111, 117). See Max Weber's The Protestant Ethic and the Spirit of Capitalism, especially Chapter 5.

\section{Works cited}

Armah, Ayi Kwei. 1995. Osiris Rising. Popenguine, Senegal: Per Ankh.

Ashcroft, Bill. 2009. 'Remembering the Future: Utopianism in African Literature.' Textual Practice 23(5): 703-722.

Ashcroft, Bill. 2013. 'African Futures: The Necessity of Utopia.' International Journal of African Renaissance Studies - Multi-, Inter- and Transdisciplinarity 8(1): 94-114.

Ashcroft, Bill. 2017. Utopianism in Postcolonial Literatures. London: Routledge.

Bhabha, Homi. 1994. The Location of Culture. London: Routledge.

Bould, Mark. 2010. 'Introduction.' Paradoxa 25: 7-16.

Bould, Mark. 2017. 'AfroSF Now: A Snapshot, Seven Novels, and a Film.' Mithila 10. http://mithila review.com/bould_04_16/.

Bould, Mark, Andrew M. Butler, Adam Roberts and Sherryl Vint. 2009. 'Introduction' In The Routledge Companion to Science Fiction, edited by Mark Bould, Andrew M. Butler, Adam Roberts and Sherryl Vint. London: Routledge.

Brown, Frederick. 1945. 'The Waveries.' Astounding Science Fiction 34(5): 126-143. 
Bruner, Charlotte. 1984. 'Review: The Rape of Shavi.' World Literature Today 58(4): 657.

Calvino, Italo. [1974] 2013. Invisible Cities. New York: Houghton Mifflin Harcourt.

Chakrabarty, Dipesh. 2000. Provincializing Europe. Princeton, NJ: Princeton University Press.

Csicsery-Ronay, Istvan. 2008. The Seven Beauties of Science Fiction. Middletown, CT: Wesleyan University Press.

De Bruijn, Esther. 2007. 'Coming to Terms with New Ageist Contamination: Cosmopolitanism in Ben Okri's The Famished Road' Research in African Literatures 38(4): 170-186.

Deckard, Sharae. 2010. Paradise Discourse, Imperialism, and Globalization: Exploiting Eden. London: Routledge.

Dongala, Emmanuel. [1982] 2017. 'Jazz and Palm Wine.' In Jazz and Palm Wine, 87-96. Translated by Dominic Thomas. Bloomington: Indiana University Press.

Eaton, Ruth. 2000. 'The City as an Intellectual Exercise.' In Utopia: The Search for the Ideal Society in the Western World, edited by Roland Schaer, Gregory Claeys and Lyman Tower Sargent, 119-131. Oxford: Oxford University Press.

Emecheta, Buchi. 1985. The Rape of Shavi. New York: George Braziller.

Fox, Alistair. 2005. 'In Search of the Postmodern Utopia.' Portal 2: 1-16.

Freedman, Carl. 2000. Critical Theory and Science Fiction. Middletown, CT: Wesleyan University Press.

Fulford, Sarah. 2009. 'Ben Okri, the Aesthetic, and the Problem with Theory.' Comparative Literature Studies 46(2): 233-260.

Gaylard, Gerard. 2005. 'Black Secret Technology: African Technological Subjects.' In World Weavers: Globalization, Science Fiction, and the Cybernetic Revolution, edited by Wong Kin Yuen, Gary Westfahl and Amy Kit-sze Chan, 191-204. Hong Kong: Hong Kong University Press.

Gray, Rosemary. 2013. " A Lucid Stream of Everywhereness” in Ben Okri's Wild: A Postmodern Perspective. International Journal of African Renaissance Studies - Multi-, Inter- and Transdisciplinarity 8(1): 143152.

Hegel, George Wilhelm. [1837] 1956. Lectures on the Philosophy of History. Translated and introduced by J. Sibree. Mineola, New York: Dover.

Hickling, Alfred. 2002. 'Tunnel Vision.' The Guardian. October 11. www.theguardian.com/books/2002/ oct/12/fiction.benokri.

Hoagland, Ericka and Reema Sarwal, eds. 2010. Science Fiction, Imperialism, and the Third World: Essays on Postcolonial Literature and Film. Jefferson, NC: McFarland.

Huxley, Aldous. [1932] 1998. A Brave New World. New York: HarperCollins.

Jameson, Frederic. 2006. Archaeologies of the Future: The Desire Called Utopia and Other Science Fictions. London: Verso.

Kahiu, Wanuri, dir. 2009. Pumzi. Focus Features.

Kerslake, Patricia. 2011. Science Fiction and Empire. Liverpool: Liverpool University Press.

Kesler, Corina. 2012. 'Postcolonial Utopias or Imagining "Brave New Worlds": Caliban Speaks Back.' Spaces of Utopia: An Electronic Journal 2(1): 88-107.

Laing, Kojo. 1992. Major Gentl and the Achimota Wars. Oxford: Heinemann.

Langer, Jessica. 2011. Postcolonialism and Science Fiction. New York: Palgrave Macmillan.

Lavender III, Isiah, ed. 2014. Black and Brown Planets. Jackson: University of Mississippi Press.

Lecoq, Danielle and Roland Schaer. 2000. 'Ancient, Biblical, and Medieval Traditions.' In Utopia: The Search for the Ideal Society in the Western World, edited by Roland Schaer, Gregory Claeys, and Lyman Tower Sargent, 35-81. Oxford: Oxford University Press.

MacDonald, Ian. 2016 “"Let Us All Mutate Together": Cracking the Code in Laing's Big Bishop Roko and the Altar Gangsters.' The Cambridge Journal of Postcolonial Literary Inquiry 3(3): 313-328.

McCabe, Douglas. 2005. “'Higher Realities”: New Age Spirituality in Ben Okri's The Famished Road.' Research in African Literatures 36(4): 1-21.

McHale, Brian. 1987. Postmodern Fiction. New York: Methuen.

Middel, Cristina. 2012. The Afronauts. Printed by Author.

Miéville, China. 2009. 'Cognition as Ideology: A Dialectic of SF Theory.' In Red Planets, edited by Mark Bould and China Miéville, 231-248. Middletown, CT: Wesleyan University Press.

Miller, George, dir. 2015. Mad Max: Fury Road. Warner Brothers.

Morris, William. [1890] 2003. News from Nowhere: An Epoch of Rest. Edited by Stephen Arata. Orchard Park, NY: Broadview.

Ngũgĩ wa Thiong'o. 1987. Matigari. Oxford: Heinemann.

Ngũgĩ wa Thiong'o. 2006. The Wizard of the Crow. New York: Pantheon. 
Nnolim, Charles E. 2006. 'African Literature in the 21st Century: Challenges for Writers and Critics.' African Literature Today 25: 1-9.

Ogunbayo, Sola. 2012. 'Prophetic Myth in Selected Fiction of Ben Okri.' Journal of Literary Studies, 28(4): 38-56.

Okorafor, Nnedi. 2009. 'Is Africa Ready for SF?' Nnedi’s Wahala Zone Blog, August 12. http://nnedi. blogspot.com/2009/08/is-africa-ready-for-science-fiction.html.

Okri, Ben. 1991. The Famished Road. New York: Anchor.

Okri, Ben. 1995. Astonishing the Gods. London: Phoenix.

Okri, Ben. 2003. In Arcadia. London: Phoenix.

Okri, Ben. 2007. Starbook. London: Rider.

Okri, Ben. 2015. The Age of Magic. London: Head of Zeus.

Orwell, George. [1949] 1977. 1984. New York: Houghton Mifflin Harcourt.

Pordzik, Ralph. 2001. The Quest for Postcolonial Utopia. Oxford: Peter Lang.

Rieder, John. 2008. Colonialism and the Emergence of Science Fiction. Middletown, CT: Wesleyan University Press.

Rowell, Charles. 2014. 'An Interview with Ben Okri.' Callalloo 37(2): 214-221.

Sanchez-Arce, Ana Maria. 2003. 'Invisible Cities: Being and Creativity in Meera Syal's Anita and Me and Ben Okri's Astonishing the Gods.' In Cities on the Margin, on the Margin of Cities: Representations of Urban Space in Contemporary Irish and British Fiction, edited by Philippe Laplace and Eric Tabuteau, 130-133. Paris: Annales Litteraires De L'Universite de Franche-Comte.

Smith, Eric D. 2012. Globalization, Utopia, and Postcolonial Science Fiction: New Maps of Hope. New York: Palgrave Macmillan.

Suvin, Darko. [1979] 2016. Metamorphoses of Science Fiction: On the Poetics and History of a Literary Genre. Oxford: Peter Lang.

Thaler, Ingrid. 2014. Black Atlantic Speculative Fictions: Octavia E. Butler, Jewelle Gomez, and Nalo Hopkinson. London: Routledge.

van Niekerk, Leigh. 2012. 'Postmodernism's Pit Stops en Route to Utopia: Language, History and Death in Ben Okri's In Arcadia.' Journal of Literary Studies 28(4): 14-24.

Weber, Max. [1930] 2005. The Protestant Ethic and the Spirit of Capitalism, 3rd ed. Translated by Talcott Parsons. London: Routledge.

Wright, Derek. 1995. 'Whither Nigerian Fiction: Into the Nineties.' The Journal of Modern African Studies 33(2): 315-332.

Zamyatin, Yevgeny. [1924] 2006. We. Translated and introduced by Natasha S. Randall. New York: Random House. 
Part IV

The World of and beyond Humans 


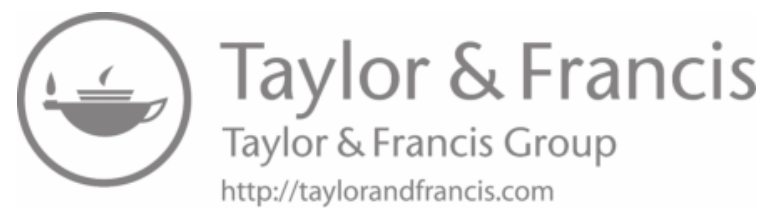




\title{
African literature, audience and the search for the (non)human
}

\author{
Cajetan Iheka
}

Recent African writings have taken up more pointedly environmental issues in ways that the earlier works did not. While earlier texts can still be read for their depictions of 'lived environments' and their mediation of 'the relationships between representations of nature and power,' as Byron Caminero-Santangelo (2014) argues, contemporary narratives enlarge the scope of characters and themes to accommodate a broader ecosystem (13). These works foreground questions of the environment, including the devastation caused by oil exploration and other extractive processes, rural and urban ecologies, agricultural economies and ecologies of war. The proliferation of environmental writing within the context of increasing attention to global warming and ecological decline has also generated critical interest in these literary productions. The growing corpus of ecocriticism in African literary scholarship has devoted attention to the rationale for the late environmental turn in African literary studies, the ways that African literature draws attention to environmental problems on the continent, and its participation in discourses on ecological sustainability (Slaymaker 2001; Nixon 2011; CamineroSantangelo 2014).

While much of this scholarship has centered on a socio-environmental justice approach to understanding the impacts of environmental problems for humans, some have spared consideration for the nonhuman world of animal/other beings and their imbrications with Homo sapiens in Africa's ecologies. In this scholarship that has focused mainly on Southern Africa, much attention has been devoted to zoocriticism, on animal subjectivities, their mistreatment in the hands of humans, and modes of positive relationship between humans and animals (Woodward 2008; Huggan and Tiffin 2010; Carruth 2011). This growing investment in the nonhuman world parallels a development in the larger fields of ecocriticism, environmental studies and animal studies, fields that have expanded consideration beyond the human and have drawn from the new materialisms to articulate the agency of nonhuman beings, including animals. Despite these similarities, it should be noted that the attentiveness to aspects of the natural environment in African literary studies derives from the primacy of nature in African cultural systems. As F. Fiona Moolla (2016) notes in the introduction to a collection of essays on ecocriticism in Africa, 'environment and animals fundamentally constitute the worldviews and lifeways that have created these cultural "texts", (9). ${ }^{1}$ Other essays in that collection pay tribute to the world beyond humans in Africa focusing on topics such as land mythologies in Shona 


\section{Cajetan Iheka}

cosmology (Musiyiwa 2016), animals in Zimbabwe poetry (Mthatiwa 2016), and 'the environment as significant other' (Mapara 2016). The reader will notice the Southern African slant of these titles which makes my own more encompassing Naturalizing Africa: Ecological Violence, Agency, and Postcolonial Resistance in African Literature (2018) a welcome addition to this corpus. Drawing on African indigenous cosmologies and new materialist scholarship in ecocriticism in this book I develop an 'aesthetics of proximity' to account for human-nonhuman relationships in literary texts across Africa, with clear attention to the conditions of the land, animals and waterscapes as well as to the agency these ecological constituents enact.

I want to explore in the current chapter a development in African literature wherein a human character goes in search of another human and, in the process, illuminates the debilitating condition of the environment. These narratives promise a search for a human being, but that premise is soon extended to reveal the prevailing state of the environment. In other words, the object of the search becomes enlarged to include the space covered in the quest. Take the case of Helon Habila's Oil on Water (2011) which introduces the search for the kidnapped British woman Isabel Floode but ends up as an exposé of the ecological devastation in the Niger Delta. Or consider Nuruddin Farah's Crossbones (2012), which depicts Ahl arriving from the United States in search of his stepson who fled Minnesota to join Al Shabaab but then turns from that depiction to illuminate the decimation of Somalia's terrestrial and aquatic spaces as a result of war. This chapter will propose that there are at least two ways to understand this narrative phenomenon. On the one hand, we can interpret the interlinking of human and nonhuman concerns in these texts as the manifestation of their entanglement or what elsewhere I have called their 'proximity' (Iheka 2018, 22-26). On the other hand, this strategy can be understood as evidence of the anthropocentricism undergirding the valuation of African literature. In this mode of reading, the human story can be said to be the hook to draw in the reader who may not necessarily be attuned to ecological questions. I argue that the ecological politics of Habila's and Farah's novels enable the authors to complicate the Africa-in-crisis expectation of the Western reader by implicating said reader in the devastation of both human and nonhuman worlds on the continent.

Helon Habila's Oil on Water follows a journalist Rufus who is on a mission to the Niger Delta creeks to ascertain the status of the kidnapped Isabel Floode, the wife of a British oil industry expatriate. On its surface, the novel looks as if it will illuminate a familiar story of kidnapping oil workers and their families and then demanding ransom from oil companies. This has become such a common occurrence that one can easily plot its ending but then Zaq's injunction to Rufus early in the novel invites a pause, a reflection as to what the novel is really about. Zaq, a veteran journalist once revered for his brilliance and professional achievements, advises Rufus to separate the story from its greater meaning. Asking Rufus, 'Tell me, Rufus, my friend, what do we seek?' Rufus replies, 'The woman, and the Professor.' In response, the older journalist offers what can be read as the navigational guide for this text primarily set on creeks and islands in the Niger Delta: 'I said "what," not "whom." Forget the woman and her kidnappers for a moment. What we really seek is not them but a greater meaning. Remember, the story is not the final goal' (Habila 2011, 5).

With this powerful statement, Zaq succeeds not only in reorienting his protégé but heightens the suspense of the reader of this novel which borrows largely from the detective genre. To find Mrs. Floode and her kidnappers, the journalists must leave the enclaves of wealth in Lagos and Port Harcourt to travel to the creeks, to the hideouts of the militants. As the novel moves from the Lagos restaurant scene where Rufus first meets Zaq to the oil enclave where James and other expatriates reside, the reader notices the stark difference between the opulence of these spaces and the abject situation in the Niger Delta, which produces the wealth that services the 
niceties of Nigeria's modernity. As Rufus travels in the creeks, it becomes clear that the Delta environment has become the 'sacrifice zone' of global modernity, if we borrow Naomi Klein's phrase $(2014,310-315)$.

As the novel unfolds, the reader learns that Isabel's initial kidnapping is unrelated to oil. Her husband had impregnated the maid who is betrothed to their driver. Salomon, the driver, is heartbroken on learning of the situation and on his friend's suggestion, agrees to kidnap Mrs. Floode for ransom to compensate for his emotional and financial loss. Matters get complicated and a bigger kidnapper, the Professor, takes custody of the British hostage. He seizes her and Salomon and invites the media to a briefing to authenticate her safety. With this unraveling, a romantic twist is added to the quest to find a missing white woman. But this love angle does not provide the greater meaning of the text either. In her review of the novel, Jennifer Wenzel (2012) points in the right direction when she writes:

One of the problems with Oil on Water is that it provides little alternative to rote voiceover. When the militants or soldiers speak to Rufus, they spout as predictably as James, offering readers exactly what they might expect from a novel about militants and soldiers in the Niger Delta. It is as if they speak in sound bites, always already in quotation marks.

In contrast, Wenzel asserts that, 'the land and water seem to speak directly, in their own voice, without quotation marks' (14). Wenzel's contrast is useful for delineating the work of the novel, for arriving at the greater meaning of the story. In other words, the clichéd handling of the human characters in the novel relegates them in favor of the more memorable, evocative rendering of the devastated environment.

Indeed, the power of Habila's prose is most evident when he describes the putrid state of the environment. In one such scene, Rufus notes:

the same empty squat dwellings, the same ripe and flagrant stench, the barrenness, the oil slick and the same indefinable sadness in the air, as if a community of ghosts were suspended above the punctured zinc roofs, unwilling to depart, yet powerless to return. In the village centre we found the communal well. Eager for a drink, I bent under the wet, mossy pivotal beam and peered into the well's blackness, but a rank smell wafted from its hot depths and slapped my face; I reeled away, my head aching from the encounter. Something organic, perhaps human, lay dead and decomposing down there, its stench mixed with that unmistakable smell of oil.

(Habila 2011, 10)

In this early passage from the novel, the stench distracts the reader from Isabel's trail and focuses on the lives, human and nonhuman, that have been rendered homeless or killed as a result of oil devastation. The habitus has lost its coherence and become uninhabitable for the people who live here. As Rufus hops from one village to another it becomes clear that the narrative is the same; before oil, these people lived in relative prosperity. As ecosystems people, who depend on the land and the river for sustenance, they have been able to survive until the interruption of their lives by oil, which has brought doom instead of the expected boom. While many communities have been pushed out and made subject to what Ogaga Okuyade (2016) terms 'dislocation from the communal web of kinship' (219), others suffer from what Rob Nixon (2011) describes as 'displacement without moving' (19). Even if they remain in their place, the land has been stripped of its homely character, of the things that make it habitable. 


\section{Cajetan Iheka}

This other form of displacement becomes manifest in their guide's plea for Rufus and Zaq to take his son Michael to Port Harcourt. It is better to hear this plea directly from the old man:

But see, wetin he go do here? Nothing. No fish for river, nothing. I fear say soon him go join the militants and I no want that. Na good boy. I swear, you go like am. Intelligent. Im fit learn trade, or driver. Anything. Na intelligent boy, im fit read and write already even though him school don close down, but him still remember how to read and write.

(Habila 2011, 40) ${ }^{2}$

In his pidgin, which enriches the linguistic ecology of Habila's novel, Michael's dad registers the impossibility of dwelling in their current location. The fish, the mainstay of their survival, have been killed by oil or driven farther in the ocean, the land has been polluted by oil spills, and the overall security of the region has been compromised by the military and militants who have taken up arms against the despoliation of the environment or for self-enrichment.

The cited passages are typical of many others that speak directly to the devastation of the environment. The perceptive power of these passages lends credence to Wenzel's observation that the land and water speak directly to the reader. Following Wenzel's conclusion and Zaq's sage advice early in the novel, we can interpret the flaws identified in the novel - Wenzel's critique of 'rote voice-over' and the excessive use of flashback are prominent examples - as strategic aberrations that foreground the environment of the text. In other words, the beneficiary of the numerous flashbacks and unwieldy plot is the environment which is rendered in powerful, poignant imagery that appeals to various senses. The devastation recounted by Rufus is primarily visual but the stench of oil and decomposing dead matter is impossible to ignore. This gripping narration of environmental decline makes it possible to shift attention from the search for the white woman - with her social and cultural capital - to the less attractive polluted landscapes and waterscapes.

As the narrative meanders through the Delta's vanishing ecosystems, Zaq's advice becomes irresistible. As the search for Isabel is punctuated at intervals and her locations change, her story takes on less structural valence. Rather the reader is oriented to the environment of the novel for the greater meaning of the story. By the time the novel ends, Mrs. Floode is still in the hands of her kidnappers while Rufus is journeying to Port Harcourt with the assurance that she is alive but, more importantly, having borne witness to the atrocities committed in the Delta. As a 'journalist-conservationist,' as Stephanie LeMenager (2014) describes him, he has the wherewithal to transmit what he has just seen to the world in a credible fashion (128). Moreover writings such as his may become the only surviving evidence of a sinking Delta where human and nonhuman beings are being 'suffocated by a film of oil' (Habila 2011, 10).

Matthew J. Christensen (2016)'s claim that 'one tactic used frequently by African detective novelists as a practice of cultural critique is to confound the genre's normative narrative resolution' (404) applies to Habila's novel, where the ending denies the closure associated with this genre. One way to interpret the irresolute ending of Habila's novel is that it inscribes the continuation of the violence being committed in the Delta, while inviting the would-be readers to be interpellated, to participate in the production of a resolution. This line of thinking will make the novel consistent with Caren Irr's delineation of a 'green novel' genre, which implies 'an ongoing and unresolved process' $(2015,90)$. For the detective genre enthusiast, the incompleteness and the unsatisfactory ending of Habila's novel rest on the fact that Mrs. Floode remains in the custody of the kidnappers. But what if we follow Zaq's lead and invest our emotional resources not in the story of the foreign hostage, but in the environment as the greater source of the meaning of the story? Shifting our attention this way can lead to a better appreciation of what 
might be read as the climax of the novel. In this scene, where Rufus regains his freedom from the kidnappers who are expecting a ransom for the release of Isabel Floode, the chief kidnapper, the Professor, pontificates:

Write only the truth. Tell them about the flares you see at night, and the oil on the water. And the soldiers forcing us to escalate the violence everyday. Tell them how we are hounded daily in our own land. Where do they want us to go, tell me, where? Tell them we are going nowhere. This land belongs to us. That is the truth, remember that. You can go.

(Habila 2011, 232)

Part command and part exhortation on the role of the journalist as objective witness, the Professor's parting words to Rufus are quite telling of the larger investment of Habila's novel. Rather than foreground Isabel, the presumed object of the search, the Professor reminds Rufus and his reader of the overarching conditions of the Delta, the flares disrupting the rhythms of the region, as well as the way oil affects the atmosphere (gas flaring), the terrestrial environment and inhabitants (land), and the aquatic creatures (oil on the water). This injunction to 'remember' is not for Rufus's benefit alone as it equally addresses the reader of the novel. In this passage, from which the novel derives its title, the Professor registers his defiance against the oil companies and government forces by insisting on their ownership of the land. If Nigeria's Land Use Decree confers ownership of land on the government, the Professor reallocates it to the people who live on it.

The discussion so far raises a question: if Floode's kidnapping is ancillary to the condition of the Delta environment, why does the novel seem to prioritize the search for her or make the quest about her? One benign way of responding to this question is that the novel is attentive to the entanglements of humans and nonhumans in the Niger Delta environment. In this reading, one can say that the novel suggests that Isabel's kidnapping is inseparable from the larger conditions of the Delta milieu, hurtful to both humans and nonhuman beings. This reading makes Habila's Oil on Water part of an oeuvre that I have described elsewhere as instantiations of the 'aesthetics of proximity,' that is literary works that link humans to the nonhumans who share spaces with them and those close to humans because of biological characteristics and shared social conditions, including victimhood in a capitalist commodification of bodies (Iheka 2018, Chapter 1). Applied to Habila's novel, Isabel's predicament arises because of her presence in the Delta environment, her sharing space with precarious subjects and victims. Moreover, the Delta that has been described in this chapter is one that commodifies human and nonhuman bodies for a small elite class. Although she is different from her kidnappers and the Delta inhabitants by virtue of race, class and nationality, Isabel's body is subject to commodification in the kidnap saga. As the driver and his co-conspirators haggle over her worth and as the kidnapper increases her monetary value, it becomes clear that her body is subject to the same economic logic that reduces everything to financial reward. Her body joins the Delta bodies - human and nonhuman - that are useful to the extent that they generate monetary compensation in a carbon economy.

Another reading is also possible, one that examines the audience of Habila's novel vis-à-vis the authorial decision to use a white woman's abduction as a plot device to showcase the destruction of the Delta ecosystem. This reading raises the question of value in the marketing of stories, and will yield substantial payoff if Farah's Crossbones is added to the discussion. As in Habila's work, Farah's novel is sustained by a quest motif. In this case, the quest applies to Ahl, a Somali-American who has returned to Somalia to find his stepson who fled Minneapolis to join Al Shabaab. Ahl's visit coincides with that of his brother, Malik, a war journalist, who has 


\section{Cajetan Iheka}

come to Somalia, his father's homeland, to research the conflict there, including the piracy for which Somalia has become well known. As both characters go, respectively, in search of a human (Taxliil, Ahl's stepson), and stories of war, clannish politics in Somalia, and the national and transnational groups affiliated with the war, their journey is anything but separate.

Since the beginning of the civil war in 1991, Somalia has become known for illustrating the failed state in Africa and has become a ready example of the view of Africa as a site of conflict and degeneration. Farah's Crossbones is a sequel to his earlier novel Links in that it continues the story of the failures of the Somali nation. While the battle between StrongmanNorth and StrongmanSouth, as well as the American invasion, take center-stage in Links, Crossbones, which 'takes its title from the Jolly Roger, the skull and crossbones pirate flag' is concerned with the continuous instability orchestrated by Al Shaabab, the Islamic Courts, and the transitional federal government in conjunction with their Ethiopian backers and Western interests (Moolla 2014, 177). In a novel that is exemplary for its network form, the piracy business crisscrosses with the lives of various characters.

Caroline Levine's claim in her work on literary form that 'we can understand networks as distinct forms - as defined patterns of interconnection and exchange that organize social and aesthetic experience' $(2015,113)$ is crucial for understanding the formal and thematic attributes of Farah's novel. Crossbones is embedded within transnational and ecological networks in its totality. The space of the novel shuttles between the United States, where Ahl lives in Minneapolis with his wife and stepson, and Somalia to where Taxliil and other youth escape to join Al Shabaab. The Somali nation is not containable within its geographical territory but has spilled into other spaces such as Minneapolis where social life reflects practices in the homeland and from where remittances that support family, friends and terrorism arrive. The routes of these foreign recruits are anything but straightforward as they travel through Abu Dhabi and Kenya before arriving at their new destination. Al Shabaab, in the novel's figuration, is not a local entity as it is implicated in recruitment and financial transactions across the world. The Somalia of Farah's fiction, as Simon Gikandi (1998) has noted, is marked by 'the multiplicity of its cultural and historical influences' that connects it to neighboring East African countries, the Arab peninsula and the Indian subcontinent, by virtue of geographical proximity and Islamic influences, as well as to European and American countries that have colonized or occupied its territory (753). These disparate links and connections to multiple locations and events are carefully threaded into Farah's Crossbones.

The novel's ecological network coalesces around piracy which has thrived in Somalia with the absence of a strong nation state capable of controlling the country's territorial waters during the civil war. To disentangle the complexities of the piracy business, Farah combines fiction and nonfiction while also highlighting the human and other-than-human lives at risk. If Habila's Delta attained notoriety for kidnapping foreigners and bombing oil installations, the image of Somalia in the international media - especially as popularized in the Hollywood film, Captain Phillips - is of a country of pirates and terrorists who seize foreign vessels at sea. This image situates the Somalis as criminal elements and Westerners as their victims in the same way that the initial view of Mrs. Floode in Habila's work positions her as the victim of criminals in the Niger Delta. Just as Habila explodes this image, interpellating the reader to view the foreign oil companies as looters and destroyers of the Delta environment, Farah's novel adds an interesting twist to the Somali-as-pirate tale. Putting piracy at the heart of the novel, pushing at the limits of fiction with Malik's work as a journalist and the incorporation of research evidence including scholarly and journalistic sources cited within the text and in the novel's acknowledgments, Farah portrays piracy as a complicated business implicating Western vessels for the threat they pose to the Somali maritime environment. 
Whereas the story of a kidnapped white woman is the lure in Habila's work, a Somalia reeling from war and criminals basking in piracy are the thrilling elements that will appeal to the foreign reader of Crossbones, the same reader who Malik is supposed to regale with stories of war in his commissioned pieces. As Farah's narrative unfolds, though, Malik's research and his brother's search for his stepson return them to the same circle of characters, including Fidno, a development that F. Fiona Moolla (2014) aptly refers to as 'the interconnected histories of its characters' (178). With Fidno's help, Taxliil is found but not before Ahl arranges for Fidno to be interviewed by Malik for the commissioned pieces. Fidno and other Somalia-based characters debunk the idea of a lucrative piracy business. In his interview with Malik, Fidno states:

Through the combined efforts of the community and the fishermen who were affronted by the mechanized fishing that was causing not only damage to the environment but the loss of livelihood to the fishermen, the people of Puntland established a coast guard, initially with the sole aim of stopping illegal fishing in our waters. When these efforts resulted in failure, because the foreign fishing vessels employed strong-arm tactics and used guns to intimidate the communities, a handful of former fishermen resorted to 'commandeering' the fishing vessels owned by the nations fishing illegally and in an unregulated manner.

(Farah 2012, 367-368)

Fidno, like the Professor in Habila's novel, seeks to reject the banditry associated with Somalis, shifting the criminal label to operators of foreign vessels whose nets catch mature as well as young fish therefore threatening the marine ecologies of Somalia and the livelihoods of the community. The harm done to sea life is compounded by another problem that is repeated throughout the novel, the dumping of toxic waste in Somalia's territorial waters. Jeebleh, Malik's father-in-law, reveals that 'the country profile compiled by the United Nations' own Food and Agricultural Organization in 2005-2006 confirmed that not only were these vessels plundering Somalia's marine resources but many of them were also dumping rubbish - nuclear and chemical waste' (73).

There is a shady quality to Fidno and some of the other characters interviewed by Malik that may cast doubt on their reliability and credibility; yet the consistency of their views on piracy, the inclusion of news items and scholarly materials supporting their oral submissions as well as the aforementioned United Nations' report render their viewpoint believable. As Bile, who hosts Malik and Jeebleh, explains, 'it was common among ancient Greeks to pursue thievery at sea as a lucrative vocation. Here, "piracy" started only after the wholesale robbery of our sea resources' (75). The Somalis in this novel agree on very little but one issue on which they remain consistent is their description of 'piracy' as a strategy of protecting the environment from assault.

In her essay on Farah's subversion of crime fiction codes in Crossbones, Kamil Naicker (2017) contends that 'having set up Taxliil as the narrative's ostensible quarry, Farah then transgresses from the norm by allowing Taxliil's story to recede and remain largely untold. The narrative therefore moves further and further away from cohesion and the possibility of closure' (9). Rather than see it as the 'ostensible quarry,' I would like to ask: what if Taxliil's story is seen as subordinate to the narrative's greater meaning? The repetition of the redemptive vision of piracy and the narrative space devoted to the subject make it possible to interpret the human search in the novel as incidental, as a disguise for the larger preoccupation with the environment - both aquatic and terrestrial. The terrestrial devastation manifests itself in bombings and charred landscape as well as decomposing bodies of animals and humans that the novel references. The novel prepares the reader to appreciate its work of disguise with at least two 


\section{Cajetan Iheka}

passages. One is at the beginning, where Cambara remarks about YoungThing, a young Al Shabaab operative who is in town to prepare for an attack: 'Maybe he is passing himself off as someone he is not, just as she puts on the body tent just before leaving the house, as part of her disguise' (Farah 2012, 2). Cambara lays out the disguise quality of Farah's work in material forms, in her clothing sanctioned by the Islamic rulers and in the vulnerable boy who tries to pass as mature and brave. Qasiir, who assists Malik in his work in Somalia, builds on Cambara's point later when he notes that 'Nothing seems as it appears' (154). I would argue that these moments challenge the reader to be attentive to other disguises in the work. In fact, one benefit of reading Farah's novel with Habila's is that Zaq's admonition to look beyond the story for the greater meaning is foregrounded by Farah's investment in disguises and what lays underneath them.

If transcending appearance, the story in Habila's work, involves looking beyond the fate of Isabel Floode to consider the way that, in the words of LeMenager, she "brings to the surface numerous other victims, mostly nonwhite or nonhuman and dead' $(2014,127)$, a similar move in Farah's novel will look beyond the search for Taxliil and the conventional understanding of Somalis as sea bandits to uncover the precarity of the oceans. Farah's work, as John Masterson (2013) observes, maps the sea as a site where 'questions of jurisdiction, surveillance and punishment are complicated' (296). The sea is positioned in this novel as a site of capitalist exploitation and manipulation of the Other, with the Other here including the humans who depend on this ecosystem for survival and the other-than-human lives that fall victim to the operators of the foreign vessels. Looking beyond the disguise means paying attention not only to the immediate consequences of war on Somalia's landscape but to those long-term consequences that may be slow in the making, those elements of 'slow violence' with the capacity to imperil already fragile ecosystems in the long run (Nixon 2011, 2).

So far, I have discussed the human search in Habila's and Farah's works as entryways into understanding the devastation caused by extractive processes in Nigeria's Delta and of the impacts of war in Somalia. I suggested that linking Mrs. Floode's predicament to the putrid state of the Delta is one way that the novel underscores their interconnection, a technique that is illustrative of an 'aesthetics of proximity.' This argument also holds for Farah's novel to the extent that it portrays humans and nonhumans as casualties of war. Beyond this point it is possible to explore the ramifications of the novels' framing for their intended audience. In other words, why would Farah and Habila structure their novels in this way and why is the environment made secondary to the human search in the novels' presentation?

Evidence of de-privileging the environment can be found in the blurbs for both books. Habila's reads

in the oil-rich and environmentally devastated Niger Delta, militants have kidnapped the wife of a British oil executive. Sensing the opportunity for his first break, Rufus, a young journalist, takes the assignment to find her and negotiate her release. Paired with his former hero, Zaq, whose journalistic heyday has passed, the two embark on a journey full of danger and unintended consequences.

The environment is evoked here but it is the kidnap of the British executive's wife that gains emphasis in the blurb, which is usually a marketing tool. This blurb suggests that the novel's attraction and therefore its marketing revolves around the British woman. Farah's blurb is too long to reproduce here but the environment does not feature at all. Rather it tells of Malik's, Jeebleh's and Ahl's visits to Somalia making sure to emphasize 'zealotry, corruption, and civil war' and 'the derailments of war.' 
This excursus into the novel's readership is warranted, especially considering the Professor's parting words to Rufus in Habila's novel; and in Farah's, Fidno's comment to Malik. It is remarkable that both characters, implicated in the environmental politics of the novels, are addressing a journalist. In the passage already quoted earlier, the Professor addresses Rufus, 'Tell them about the flares you see at night,' among other things. He repeats 'tell them' three times in this brief passage where he enjoins the journalist to 'write only the truth.' Who are the 'them'? 'Them' refers to the journalist's readers, who can also be Habila's readers. In a similar vein, Fidno, who laments the misrepresentation of the piracy issue in the media, tells Malik, 'What the rest of the world has been made to believe is untrue. Please, please write that down' (Farah 2012, 367). Like the Professor, Fidno believes in the representational power of Malik's pen to correct the misconceptions in the minds of his reader. His repetition of 'please' emphasizes the effort to persuade Malik to tell their story.

Who is Malik's reader and by extension who constitutes the audience of Habila's and Farah's novels? Following Eileen Julien's well-known essay on the African novel, the two narratives would qualify as instances of what she calls the 'extroverted novel,' which primarily address Western audiences before they circulate on the continent. According to Julien, extroverted novels address a 'nation's “others" and elites' $(2006,683)$ and are differentiated by a number of factors including, 'publishing house, place of publication, and explicit engagement with - or a capacity to be read as engaging - broad critical debates' (681-682). ${ }^{3}$ A novel published by a major publisher in New York (W. W. Norton) and written by an expatriate Nigerian, the audience of Habila's novel is primarily a Western one. Habila's novel participates in the global discourse surrounding unrest in the Delta and its implications for foreigners in the region and oil prices in the international market. Considering Farah's linguistic mode of address and the fame he has attained in the Western literary sphere, it makes sense to argue that his work is addressed primarily to a Western audience. The novel's appearance in English exemplifies a willingness to compete in a global literary marketplace just as its publishing location and storyline buttress this interest. All considered, the novels court a particular audience, and from recent scholarship in African literary criticism, this readership demands a particular brand of African story, of war and the crises of postcoloniality.

The logic of that scholarship goes thus: that contemporary postcolonial writers, including African ones, depict negative and exotic aspects of postcolonial societies in a bid to court a Western readership. Versions of this argument have appeared in Graham Huggan's work on the 'postcolonial exotic' (2001), Sarah Brouillette's writing on 'authorial self-consciousness' (2007), and more recently, Akin Adesokan's work on what he terms 'new African writing' (2012), which names 'works of fiction written by mostly young Africans and marketed primarily outside the continent' (2). In Adesokan's telling, part of the delineating features of new African writing, whose marketing primarily outside the continent aligns with Julien's extroverted novel, is its labor 'at courting a readership invested in the representation of contemporary Africa as a site of perennial political and humanitarian emergencies' (11). I argue that Habila and Farah balance the imperative to meet this market-demand with illuminating the physical setting of their novels, that is, the condition of their human and nonhuman ecologies, which are then deployed for critiquing this audience's complicity in Africa's ills.

To be sure, Habila's novel delivers the African space as one of darkness, as a space of disintegration for Mrs. Floode who had originally gone to Nigeria to rescue her marriage. In his notebook, Rufus writes of 'the abandoned villages, the hopeless landscape, the gas flares that always burned in the distance' (Habila 2011, 26). The description of the 'hopeless landscape' from one village to another is indistinguishable in the emphasis on blight. The reader who comes to the work for a Conradian take will not miss the parallels with the portrayal of the 


\section{Cajetan Iheka}

Congo river in Heart of Darkness; yet Habila's novel amplifies the accomplishment of a more complex writer by locating the devastated ecologies within the context of an oil economy that has impoverished Delta communities since oil was discovered there in commercial quantities in 1956. The novel is careful to locate the source of the miasma in the activities of oil companies and the government that enables them. In one meeting between Rufus and James Floode, the oil executive and husband of the kidnapped woman, Habila through Rufus critiques the Western perception of corruption in Africa and the paternalistic attitude toward the continent. In response to Mr. Floode's talk about corruption in Nigeria and of 'the people [who] don't understand what they do to themselves' by bombing oil installations and kidnapping, Rufus educates him on the 'suffering to their lives' brought by oil 'leaking into the rivers and wells, killing the fish and poisoning the farmlands' (103). Rufus uses a passage underscoring the poisoning of the nonhuman world to refute Mr. Floode's suggestion that the activities of the oil companies are beneficial to the people. Rufus speaks back to James, and the reader of the novel who comes to the novel to castigate the Niger Delta people. As Caminero-Santangelo (2017) notes in his reading of this scene, 'Rufus makes visible what the industry's rhetoric represses' (366). Moreover, the movements and meanderings in the novel are a reminder of the movement of oil from the Delta to international commodity markets, to refineries elsewhere in the world, and to the gas tanks of cars, most of these in the West. Foregrounding the ecological crimes of the oil companies as well as the complicity of the oil consumer in this scene and the novel more broadly, Habila's work undercuts the readerly expectation of the African novel at the point that it rises to meet the demand for an Africa-in-crisis.

The legacy of ecological excavation shared with Habila's work enables Farah to problematize the image of a crisis-ridden Africa as well. Where Habila utilizes a journalist to achieve credibility and push at the boundaries of fiction, newspapers, magazines and scholarly publications are incorporated into Farah's fiction to give it a semblance of the real or in Moolla's terms, 'to open up a more profound truth in his novel' $(2014,183)$. This 'real' character is crucial for the novel's work of reconfiguring the narrative of delinquent Somali youth seizing ships on the high seas. The extra-literary documents woven into Farah's work enable a shift in perspective, one that sees the Somalis as protectors of endangered ecosystems threatened by the operations of foreign vessels. In the words of Michele Levy (2012) in a review of the novel, Crossbones 'plumbs the murky depths' and in the process 'critiques the standard Western depiction of the pirate situation as simplistic and self-serving' (57). It is the environmental politics of the novel, its drilling of the crevices of ecological systems that make possible the radical break from conventional perceptions and the enthronement of Somalia as a site of grassroots mobilization in an era of decline. This literary revaluation of Somalia also reveals that much of the money from piracy remains abroad in the pockets of the major beneficiaries, the insurance companies and agents, among them.

\section{Conclusion: African literature, the critic, and the greater meaning}

My reading of Habila's and Farah's novels challenges the priority of the human in the valuation of African literature. I argue that due to this privileging, Isabel Floode's kidnapping and Taxliil's disappearance are necessary for the apprehension of the nonhuman world in the two texts. In other words, both authors need the disappearance of human characters to reveal the state of the environment. This prioritizing of the human has resonances in the field of African literary criticism which has just started to grapple seriously with the ramifications of a world beyond humans in African literature. The move in the two novels from the search for the human to the discovery of the nonhuman world mirrors the emphasis on the human condition in African 
literary criticism and the gradual uncovering of nonhuman ecologies in recent scholarship. This belated start is significant considering that Africa's social ecologies have always paid tribute to human-nonhuman entanglements, and positioned this interconnection at the heart of their living practices.

Critics of African literature may be better served heeding the advice of Zaq, a fellow reader and writer in Habila's novel, on the importance of attending to the greater meaning of the story. In this mode of reading, the receding of human characters that is evident in Habila's and Farah's novels will not be treated as formal aberrations, but regarded instead as stylistic maneuvers with rich implications for illuminating the conditions of the nonhuman world, both for its own sake and for the promise it holds for the world of humans. In our search for the greater meaning of texts, for their deeper meaning, the story of the human world is not the only one at stake. We can hold on to this story but at the same time seek the greater significance of the more-than-human world for enriching our understanding of African literary texts and the wonders of the African worlds they depict.

One other lesson to be taken from the novels discussed in this chapter is the need to consider the complexities of those narratives deemed written for the pleasure of the Western gaze due to their portrayal of a negative Africa. Helon Habila compares such texts to 'poverty porn' in his review of NoViolet Bulawayo's We Need New Names (2013) because of their representations of 'child soldiers, genocide, child prostitution, female genital mutilation, political violence, police brutality, dictatorships, predatory preachers, dead bodies on the roadside.' Habila's novel includes some of the characteristics he condemns but as my reading suggests, his narrative is a more complex treatment of the challenges of the postcolony and its implication for understanding global processes. Overall, the work of this chapter invites a reconsideration, and a revaluation, of contemporary African writings for the ways they indict the assumed Western audience and complicate Africa's place in the world.

\section{Notes}

1 For further discussion of this worldview, see Sule Egya (2016).

2 But see, what will he do here? Nothing. There is no fish in the river. I fear that he will soon join the militants and I don't want that. He is a good boy, an intelligent boy. The boy can learn a trade or learn to become a driver. He can read and write although his school is closed (translation mine).

3 For further elaboration of the extroverted novel, critiques of the concept and an updated article on the subject by Eileen Julien, see the special issue on the topic in Journal of African Cultural Studies 30(3), 2018.

\section{References}

Adesokan, Akin. 2012. 'New African Writing and the Question of Audience.' Research in African Literatures 43(3): 1-20.

Brouillette, Sarah. 2007. Postcolonial Writers in the Global Literary Marketplace. New York: Palgrave.

Caminero-Santangelo, Byron. 2014. Different Shades of Green: African Literature, Environmental Justice, and Political Ecology. Charlottesville: University of Virginia Press.

Caminero-Santangelo, Byron. 2017. 'Petro-Violence and the Act of Bearing Witness in Contemporary Nigerian Literature.' In A Global History of Literature and the Environment, edited by John Parham and Louise Westling, 363-376. Cambridge: Cambridge University Press.

Carruth, Allison. 2011. 'Compassion, Commodification, and the Lives of Animals: J.M. Coetzee's Recent Fiction.' In Postcolonial Ecologies: Literatures of the Environment, edited by Elizabeth M. DeLoughrey and George B. Handley, 200-215. New York: Oxford University Press.

Christensen, Matthew J. 2016. 'African Detective Fiction, Mysteries, and Thrillers.' In The Oxford History of the Novel in English: The Novel in Africa and the Caribbean Since 1950, edited by Simon Gikandi, 393-408. New York: Oxford University Press. 


\section{Cajetan Iheka}

Conrad, Joseph. 1990. Heart of Darkness. Oxford: Oxford University Press.

Egya, Sule. 2016. 'Nature, Animism and Humanity in Anglophone Nigerian Poetry.' In Natures of Africa: Ecocriticism and Animal Studies in Contemporary Cultural Forms, edited by F. Fiona Moolla, 257-275. Johannesburg: Wits University Press.

Farah, Nuruddin. 2012. Crossbones. New York: Penguin.

Gikandi, Simon. 1998. 'Nuruddin Farah and Postcolonial Textuality.' World Literature Today 72(4): 753-758.

Habila, Helon. 2011. Oil on Water. New York: W.W. Norton and Co.

Habila, Helon. 2013. 'We Need New Names by NoViolet Bulawayo - a Review.' The Guardian. June 20. www.theguardian.com/books/2013/jun/20/need-new-names-bulawayo-review.

Huggan, Graham. 2001. The Postcolonial Exotic: Marketing the Margin. New York: Routledge.

Huggan, Graham and Helen Tiffin. 2010. Postcolonial Ecocriticism: Literature, Animals, Environment. London: Routledge.

Iheka, Cajetan. 2018. Naturalizing Africa: Ecological Violence, Agency, and Postcolonial Resistance in African Literature. Cambridge: Cambridge University Press.

Irr, Caren. 2015. 'The Space of Genre in the New Green Novel.' Studia Neophilologica 87: 82-96.

Julien, Eileen. 2006. 'The Extroverted African Novel.' In The Novel, edited by Franco Moretti, 667-700. Princeton, NJ: Princeton University Press.

Klein, Naomi. 2014. This Changes Everything: Capitalism vs the Climate. New York: Simon \& Schuster.

LeMenager, Stephanie. 2014. Living Oil: Petroleum Culture in the American Century. Oxford: Oxford University Press.

Levine, Caroline. 2015. Forms: Whole, Rhythm, Hierarchy, Network. Princeton, NJ: Princeton University Press.

Levy, Michele. 2012. 'Crossbones by Nuruddin Farah.' World Literature Today 86(4): 56-57.

Mapara, Jacob. 2016. 'The Environment as Significant Other: The Green Nature of Shona Indigenous Religion.' In Natures of Africa: Ecocriticism and Animal Studies in Contemporary Cultural Forms, edited by F. Fiona Moolla, 1-26. Johannesburg: Wits University Press.

Masterson, John. 2013. The Disorder of Things: A Foucauldian Approach to the Works of Nuruddin Farah. Johannesburg: Wits University Press.

Moolla, F. Fiona. 2014. Reading Nuruddin Farah: The Individual, the Novel and the Idea of Home. Woodbridge, UK: Boydell \& Brewer.

Moolla, F. Fiona. 2016. 'Introduction.' In Natures of Africa: Ecocriticism and Animal Studies in Contemporary Cultural Forms, edited by F. Fiona Moolla, 77-96. Johannesburg: Wits University Press.

Mthatiwa, Syned. 2016. 'Animals, Nostalgia and Zimbabwe's Rural Landscape in the Poetry of Chenjerai Hove and Musaemura Zimunya.' In Natures of Africa: Ecocriticism and Animal Studies in Contemporary Cultural Forms, edited by F. Fiona Moolla, 276-304. Johannesburg: Wits University Press.

Musiyiwa, Mickias. 2016. 'Shona as a Land-Based Nature-Culture: A Study of the (Re)Construction of Shona Land Mythology in Popular Songs.' In Natures of Africa: Ecocriticism and Animal Studies in Contemporary Cultural Forms, edited by F. Fiona Moolla, 49-76. Johannesburg: Wits University Press.

Naicker, Kamil. 2017. 'Going to Pieces: Narrative Disintegration in Nuruddin Farah's Crossbones.' Social Dynamics 43(1): 8-18.

Nixon, Rob. 2011. Slow Violence and the Environmentalism of the Poor. Cambridge, MA: Harvard University Press.

Okuyade, Ogaga. 2016. 'Negotiating Identity in a Vanishing Geography: Home, Environment and Displacement in Helon Habila's Oil on Water.' In Natures of Africa: Ecocriticism and Animal Studies in Contemporary Cultural Forms, edited by F. Fiona Moolla, 212-234. Johannesburg: Wits University Press.

Slaymaker, William. 2001. 'Ecoing the Other(s): The Global Green and Black African Responses.' PMLA 116(1): 129-144.

Wenzel, Jennifer. 2012. 'Behind the Headlines.' American Book Review 33(3): 13-14.

Woodward, Wendy. 2008. The Animal Gaze: Animal Subjectivities in Southern African Narratives. Johannesburg: Wits University Press.

\section{Filmography}

Greengrass, Paul. 2013. Captain Phillips. USA: Scott Rudin Productions, Michael De Luca Productions, and Trigger Street Productions. Distributed by Columbia Pictures. 


\title{
Dirty ecology \\ African women and the ethics of cultivation
}

\author{
Sarah L. Lincoln
}

This chapter identifies African women's literary gardening as a mode of dirty ecology, an environmental praxis that models a form of dwelling - what Greg Garrard calls living ethically toward the earth 'in a relation of duty and responsibility' $(2004,108)$. Whereas proximity to dirt has long signaled underdevelopment, indignity and dispossession in Africa, in colonial, anticolonial and postcolonial treatments alike, the novels of Bessie Head that I consider below reclaim soil and other wastes as occasions for (and expressions of) contact, relation and community. As Patricia Yaeger points out, dirt reminds us both of our corporeal vulnerability and of the destruction that results from our possessive impulses; and gardening forces us to contemplate the environmentally, socially and politically violent implications of Westernized modernity's fetishization of the clean, the hygienic and the technological.

Head's fiction reveals how the rhythms, temporalities and relations of gardening demand different narrative forms and styles. Reading the novels in light of Ursula K. LeGuin's 'carrier bag theory of fiction,' I propose that African gardening also reveals new ecocritical and ecoliterary forms, forms of storytelling attentive to the 'ordinary,' the small, the incremental and the contingent. If Rob Nixon (2011) identifies 'slow violence' as a representational challenge for activists and witnesses, then gardening helps highlight the ecocritical value and significance of slowness as an orientation toward ethical dwelling.

In Bessie Head's georgic novels, texts that depict and celebrate agricultural life in rural Botswana, cultivation of the soil comes to serve as a foundation, and potent metaphor, for postcolonial community building, critiques of power, and new modes of living in relation to nature. The centrality of gardening, or minor forms of farming, of plants and the soil in these texts complicates the traditional Western treatment of the garden as a pastoral retreat from alienated urban modernity, where nature is domesticated and aestheticized. Head's work confronts broad ecological questions of how we ought to live, and live well, with the land. The inhospitable environments of rural Botswana that feature in When Rain Clouds Gather and $A$ Question of Power force characters (and readers) to contemplate the tensions between humans' need for sustenance and our ethical obligations toward soil, plants and other natural resources. This tension is resolved, to some extent, in Head's emphasis on gardening over farming: that is, on a feminine, small-scale approach to cultivation that retains an element of the nomadic, 
itinerant sensibility while enabling characters to root themselves in place and community, even when these places and communities are temporary and vulnerable. Such gardening also becomes a practice through which power relations are challenged and renegotiated, and a site where 'ordinary' narrative forms and stories can emerge.

\section{I.}

Within postcolonial studies, the centrality of botanical concepts like 'hybridity,' 'transplantation,' 'rhizomes,' 'diaspora' and 'deracination' have enjoyed much critical attention. But the connection between cultivation and (post)colonialism is more than purely metaphorical. In her essays on gardening, Jamaica Kincaid (2001) points out the myriad lines of complicity and material cross-fertilization that exist between colonialism and botany in the Caribbean and Pacific Islands. Kincaid, along with scholars including Susie O’Brien (2002), Jill Casid (2004), John Thieme (2016), Sonya Posmentier (2017) and Cajetan Iheka (2018) have begun to draw attention to the functional and symbolic importance of gardens to understanding the ways colonial modernity shapes, and is shaped by, human relationships to the environment. Yet the majority of these interventions have been focused on Caribbean and American contexts, where the advance of scientific investigation often took the form of appropriation, dissection and renaming of plants: powerful metaphors for the processes of colonial domination and symbolic violence exercised on both human and natural bodies (see also Grove 1996). Little scholarly attention has been devoted to the place of gardening in Africa, or to the ways in which African gardeners (literary and otherwise) are contributing to efforts to experience and theorize new forms of relation between the human and nonhuman world. (I make a preliminary contribution in Lincoln 2018.)

Perhaps the most famous literary example of South African gardening is J. M. Coetzee's 1983 novel Life $\mathcal{E}$ Times of Michael $K-$ a rich and valuable text for exploring the relationships between cultivation and power, the garden and the camp, in a colonial context. Yet it is also a novel that ends with its protagonist-gardener dying alone on a concrete floor with a pocketful of seeds, fantasizing dimly about a second attempt at cultivating his distant plot of land - this time, he imagines, with the help of a companion. Gardening, in Michael K, is ultimately a solitary pursuit and, in many respects, a suicidal one; K's unwillingness to inflict harm upon the earth or other life-forms leads to his capture, institutionalization and eventual death by starvation.

The solitary and ultimately sterile experience of gardening depicted in Michael $\mathrm{K}$ contrasts vividly with its representation in the work of some African women writers, for whom this mode of cultivation often serves as a basis for community; who treat gardening as a vital and complex set of relationships amongst human and more-than-human life forms; and for whom digging in the earth constitutes a provisional basis for dwelling, even as it works to complicate potentially violent and exclusionary logics of property and possession. Though this chapter focuses on the work of Bessie Head, a fuller archive of African literary gardening must include Tsitsi Dangarembga's Nervous Conditions and The Book of Not; Jayne Galassi's Cactus Letters; Zoë Wicomb's Playing in the Light; and Aminatta Forna's Ancestor Stones, amongst many others. Such an approach also invites further consideration of the ecological and ethical stakes of cultivation in other works of African literature more broadly, a feature of these texts that is often overlooked by scholars. Authors like Chinua Achebe, Chimamanda Ngozi Adichie, Ngũgĩ wa Thiong'o, Ivan Vladislavic, Wangari Maathai and others offer abundant potential for extending my analysis of the gender politics of farming and gardening, and the literary implications of the 'dirty ecology' I describe here. 
In many of these works, the distinction between 'farming' and 'gardening' serves as a marker of gender difference: men farm; women garden. As in Western culture, this binary frequently serves in African letters to privilege masculine activity over women's work. Farming is seen as productive and important, whereas gardening is trivial, even wasteful, a distinction that overlooks the reality that women provide up to 80 percent of daily foodstuffs in sub-Saharan Africa (FAO 1996; see also Moyles 2018). African women writers' appropriation and reworking of this gendered vision of gardening links these writers and their female characters to a long, transnational tradition of women who cultivate the earth. In African-American writer Alice Walker's essay 'In Search of Our Mothers' Gardens,' she recalls the beauty and passionate creativity of the flower beds her mother nurtured in each of their rural homes. Marveling at the energy her mother brought to this endeavor, despite the family's poverty and the many exhausting claims on her time, Walker remembers that 'because of her creativity with her flowers, even my memories of poverty are seen through a screen of blooms - sunflowers, petunias, roses, dahlias, forsythia, spirea, delphiniums, verbena $\ldots$ and on and on' $(1994,408)$. The essay situates the garden as one example of a broader history of black women's 'muzzled and often mutilated, but vibrant, creative spirit,' a fugitive archive of artistic achievement that includes quilts, songs, stories and spiritualism through which these women kept their souls alive despite the suffering they endured (406). Each of these women, whom Walker calls 'our grandmothers,' was 'an artist,' she insists, 'who left her mark in the only materials she could afford, and in the only medium her position in society allowed her to use' (407).

The garden is an especially vital figure for this hidden, subterranean creativity that Walker excavates, since it exemplifies what she sees as the 'low' qualities of this female genealogy. Whereas women, and particularly black women, have long been largely absent from the highcultural canons of artistic and literary achievement, their creative legacies in fact fall beneath the visible threshold of hegemonic culture: in searching for the traces of powerful, creative, yet invisible women in our history, she points out, '[w]e have constantly looked high, when we should have looked high - and low' (Walker 1994, 406). This shift in perspective, from 'high' to 'low,' from the rich and powerful - those who feature in narratives about history, or heroic literatures of struggle and achievement - to the small, minor and seemingly impotent, is one that gardening itself also demands.

Gardening thus offers not only an opportunity to think about ecology, and African women's work, from a new, 'low' perspective, but also an occasion for new forms of environmental writing. As Rob Nixon points out, environmental discourse, particularly in the West, is often galvanized by the spectacular and sublime: the fragility of planet Earth, seen from space; the magnificence and terror of superstorms, oil spills and wildfires fueled by climate change; the vulnerability of charismatic megafauna like tigers and polar bears threatened by human environmental depredations (2011, 3). Even Africa-centered environmentalism has often focused, as Byron Caminero-Santangelo and Garth Myers observe, on the effects of ecological violence (both spectacular and 'slow') rather than on the complexities of everyday human interactions with the natural world, or on alternative forms of engagement with nature, particularly when these are too local, small-scale and minor to attract the attention of international environmental activism $(2011,13)$. Cajetan Iheka similarly sees African environmentalism as typically neglectful of 'the interlinking of human and nonhuman lives in African societies represented in literary works' $(2017,2)$. 'Postcolonial ecocriticism,' he continues, 'has not sufficiently addressed the entanglement of human and nonhuman lives in Africa or the value that indigenous African communities confer on other-than-human lives' (7). As a practice that straddles the border of 'nature' and 'culture,' gardening provides a valuable case study for investigations of African literature's place within ecocritical and environmentalist discourse. 
Caminero-Santangelo and Myers call for the development of an 'African ecocriticism,' one specially attuned to the historical, political and environmental contexts of contemporary life on the continent. They emphasize the importance of storytelling, literary representation and other forms of discourse in shaping approaches to African ecological issues. Within their collection one of the first works devoted to the question of African literature and the environment - Mara Goldman points out that 'change and continuity in African environments has always involved storytelling' (2011, 95). And yet, the editors observe, 'African stories are often ignored or marginalized in constructions of the African environment' (2011, 15).

Ursula K. Le Guin's 'The Carrier Bag Theory of Fiction,' responds to this problem by challenging our definition of storytelling, and of stories, as such. Tracing the origins of modern storytelling to a masculine history of conquest and violence, she argues for a concept of narrative not as a spear or weapon - a tool for making a mark - but rather as a 'carrier bag,' a container for the ordinary objects and experiences of daily survival (1996, 151). Against the 'killer story' populated by heroes and their spectacular deeds that passes for storytelling in our culture, Le Guin positions 'a fundamentally unheroic kind of story ... full of beginnings without ends, of initiations, of losses, of transformations and translations, and far more tricks than conflicts, far fewer triumphs than snares and delusions' (152-153). Le Guin associates this 'new ... and yet old' kind of story with the patient, repetitive work of cultivation: the feminine labor of gathering wild oats and separating seed from husk, the sort of activity that's hard to tell a gripping story about. It's not easy to craft a thrilling tale of gardening, either, since its motions are typically slow and repetitive, its action unfolding gradually and often invisibly, its plot governed (as Kincaid's essays on gardening frequently reveal) by wrong turns, disappointments and failures.

Le Guin's 'carrier bag theory' therefore contests the privileging of large scale and sublime events that defines traditional, patriarchal and anthropocentric modes of thought. The experiences that Le Guin foregrounds not only operate on the incremental timescale that defines parenting, cultivation and other 'feminine' tasks; they also take place in the small, marginal and interpersonal - 'low' - spaces that typically fall beneath the threshold of visibility that determines what counts as 'event,' and thus challenge traditional storytelling's preoccupation with humans' antagonistic relationship toward nature. As we shall see, African women writers like Head articulate a slow literature - a mode of storytelling that patiently and incrementally works to destabilize the boundaries between the self and its others, drawing on images of dirt, soil and exposure as it challenges the hierarchies and borders that define hegemonic power structures.

At the time of her death from cancer in 2014, Patricia Yaeger was at work on a study of our disposable culture and human relationships with the nonhuman world. Though the manuscript remained incomplete and unpublished at her death, Yaeger's argument emerges in several shorter pieces she published or presented: in particular, a talk at UCLA in 2009 on 'Throwaway Robots' and an essay on Beasts of the Southern Wild that appeared in Southern Spaces in 2013. In the latter publication, Yaeger plays with the concept of 'dirty ecology,' calling for us to 'dirty ecology, the science of whole environments, with myths, fictions, half-truths, dirty imagery' (2013, n.p.). 'Dirty,' like 'trash,' functions as both adjective and verb, a descriptor for the residual, polluting and valueless, and a practice that destabilizes or erodes boundaries.

I take inspiration from Yaeger's argument for the cultural and ecological significance of waste, and redirect her term to describe what I see as an ecological vision emerging from texts that portray and indeed celebrate the kind of proximity to and contact with dirt that hegemonic 
discourse typically disdains. Dirty ecology, in my approach, signals an openness to dirt, both material and symbolic, and an embrace of the exposure to otherness that it signifies. In the fiction of African women gardeners, dirt marks both the limit of social order, and a metaphor and means for relation between the self and embodied others, both human and nonhuman. As Rita Barnard observes, dirt is often despised or feared precisely because it represents 'the mark of the other,' a reminder of the presence and proximity of others $(2012,86) .^{1}$ 'Dirty ecology,' in this respect, articulates a mode of environmental dwelling that imagines the contamination of self by otherness - not as a source of anxiety or crisis, but as a starting-point for ethical relation. Specifically, and appropriately enough, given Yaeger's own passion for gardening, in these texts it is the work of cultivation that fosters the emergence of this 'dirty ecology': working the soil, caring for plants and immersing themselves in the rhythms and temporalities of vegetal life, these fictional gardeners embed themselves in the social and natural ecologies of their environment. The vulnerabilities they witness and to which they are exposed by the 'dirt' that threatens to erode the boundaries of selfhood ultimately bring these subjects into closer relation with one another and with other lifeforms, while also promoting what Yaeger elsewhere $(1989,191)$ calls 'the female sublime': a sublime 'not of mastery but of undoing' ('Obituary' 2014). This version of the female sublime accords powerfully with Le Guin's call for a 'carrier bag theory of fiction': a reorientation of storytelling from the heroic, masculine narratives of sublime violence, to the more minor, dirty and intimately sublime experiences of ordinary life.

\section{II.}

The modern environmental movement is often dated to 1968, the year the famous photograph of Earth from space, an image known as 'Earthrise,' first provided a different perspective on the world. Snapped from the Apollo 8 spacecraft on December 24, 'Earthrise' has been identified as 'the most influential environmental photograph ever taken' (Potter 2018, n.p.): an image that captured the beauty and fragility of the planet and inspired a new popular consciousness of global climate change, environmental degradation and sustainability. That same year, Bessie Head published her first novel, When Rain Clouds Gather, a text that depicts life in a remote Tswana village struggling to survive amidst an unforgiving landscape. Head had left her native South Africa four years before, on the infamous apartheid-era 'exit permit' that allowed her to depart the country on condition that she surrender her passport and any right of return. In her novels and memoirs, Head documents the psychic crisis that resulted from her condition of 'permanent exile,' a feeling of being an unwelcome outsider in Botswana yet simultaneously, as a 'Coloured' woman, despised and rejected by her home country. Though most of her life in South Africa had been lived in cities, her new life in Botswana entailed adapting to the small, remote village communities to which she was assigned. And while she struggled in many ways with the transition, she found rich material for her fiction in the apparently barren landscapes and minor political and social conflicts that shaped the human environment. As studies of rural life, her novels are preoccupied with agriculture and other forms of cultivation, and deeply concerned with the interrelationship between human and nonhuman lives - the efforts of the people of these villages to find ways of dwelling or being-in-place that are not destructive or exploitative. As Elspeth Tulloch observes, Head's work consistently explores what it means to 'live well on the land,' a feature that leads Tulloch to identify Head's work as part of the georgic tradition of literary treatments of agricultural life $(2012,138)$. Yet, while her interest in the politics of space and the complexities of boundary-crossing are often highlighted by critics (see, for example, Kapstein 2003; Talahite 2005; Nixon 1993; and Campbell 1985), Head's fiction has rarely been considered by those exploring the environmental aspects of African literature 
(for some notable exceptions, see Tulloch 2012; Darlington 2007; Goodhead 2017). She is not often included on lists of 'environmental' writers, or taken seriously as a theorist of environmental ethics. When her work is read in this light, scholars are often critical of her depiction of human relationships to the natural world, and of her apparent endorsement of Western models of agriculture over indigenous methods (see, for example, Caminero-Santangelo [2014, 84] and Highfield [2010, 103]).

This ecocritical neglect is perhaps, in part, because the intensely local scope of her fiction seems incommensurate with the sublime valences of global environmentalism, exemplified in the iconic 'Earthrise' photograph. ${ }^{2}$ The place of the sublime in environmentalism has been relatively understudied. In his groundbreaking essay 'The Trouble with Wilderness,' William Cronon points out how modern literary treatments of nature have often relied on sublime registers to privilege the 'unspoiled' reaches of mountains, waterfalls, national parks over spaces like swamps, grasslands and gardens. Less 'sublime' or elevated nature becomes less worthy of concern and conservation. Donald Pease (1984), on the other hand, shows how the sublime preoccupations of nineteenth-century American literature seemingly authorized environmental destruction, and we could say the same of European colonialism in Africa and other colonial sites, where celebrations of awesome natural grandeur and abundance paradoxically coincided with, or even helped justify, hunting, deforestation and other forms of violence. While the ecstatic stage of the sublime, in which the human subject is overwhelmed by the height and grandeur of nature, reinforces human 'humility, mortality and dependence' (Hitt 1999, 611) in the face of nature, the instrumental application of the sublime has tended either to justify human violence against nature, or to promote feelings of impotence and apocalyptic despair, as in most contemporary cli-fi movies.

By contrast with this hegemonic environmental emphasis on the sublimity of nature, Bessie Head's perspective on the environment, and human relations with the nonhuman world is not distant but proximate, emphasizing the small, marginal and minor over large-scale forces and experiences. If the 'sublime' has, since Longinus, been a register of height ('hypsous'), then the 'low,' more or less by definition, cannot achieve the transporting effects of sublimity. Such elevated perspectives have traditionally corresponded with, and helped reproduce, masculine, bourgeois subjectivity, as critics like Yaeger (1989) and Anne Mellor (1992) have shown. An investment in the low, therefore, might be seen as a counter-hegemonic perspective that deconstructs the hierarchies of patriarchy, anthropocentrism and other political structures, and of the narrative modes that correspond to these. By attending to Head's literary interest in gardening, therefore, we can uncover a form of minor or 'dirty' ecology, one that is especially concerned with women's cultivation, women's community and women's storytelling. While the distinction that features in Head's writing, between farming and gardening, appears in other works of African fiction, here it becomes a specifically ecological difference: in transforming the power dynamic between men and women, gardening also becomes a different way of thinking about, relating to, and treating soil and plants. Her novels' attention to gardening not only affirms the value of smaller-scale engagements with the natural world; it also deploys forms of narrative and representation that decenter heroic individualism, masculine agency and environmental discourses' reliance on the sublime.

When Rain Clouds Gather focuses on Makhaya, a refugee from South Africa who crosses the border to escape the apartheid state's persecutions and, more importantly, to his mind, to find himself a wife (Head 1972, 26). A fugitive and a refugee, Makhaya is psychologically and physically adrift, longing for a sense of place and belonging (a characteristic ironically highlighted by his Zulu name, which means 'one who stays home' [3]). Taken in by Dinorego, a friendly old man he encounters on arrival in the first village, Makhaya joins the small 
community of Golema Mmidi, a village of 400 people notable for its emphasis on agriculture. It is 'one of the very few areas of the country where people were permanently settled on the land,' a distinction reflected in the town's name ('to grow crops') (16). While some villagers own cattle, which are grazed on distant stations attended by men and boys, most of the food is produced by women agriculturalists, who eke out a subsistence crop from the unforgiving Botswana soil, degraded by years of drought and by unsustainable farming practices.

In the village, Makhaya joins forces with Gilbert, an idealistic British expatriate determined to transform rural poverty into prosperity through modern farming techniques and cooperative farmers' associations. These ambitions bring him into conflict with the village chief, Matenge, whose economic and political status is threatened by the socialist aims of the cooperative. Winning the support of the village women for the project, Makhaya pilots a tobacco-growing experiment that ultimately persuades the men, too, of the value of cultivation, after the settlement's cattle stocks are decimated by drought. Makhaya's growing appreciation for nature and his relationship with Gilbert, Dinorego and especially the women - including his eventual wife, Paulina, along with her young daughter, and an elderly woman, Mma Millipede - gradually transform his bitter, mistrustful attitude, scarred by the effects of apartheid violence and social anomie in South Africa's townships. He and Gilbert each marry one of the village women, and the novel ends with the promise of social and environmental rejuvenation, with men returned to their families and the soil enriched by sustainable techniques.

The novel's treatment of agriculture is complicated, as in many African texts, by the political, economic, cultural and environmental contexts of rural Botswana, where traditional and modern legal frameworks and gender norms shadow efforts by individuals to feed themselves and their families and imagine new ways of being in relation to the natural world. Yet it is the natural landscape that becomes the focus of the novel, and the redemption of the soil and other nonhuman lifeforms proves a source of healing for damaged subjects as well. Head's prose goes beyond 'nature writing' to a deep consciousness of ecological interrelation and a foregrounding of nonhuman agency and value. Her careful attention to the smallest details of the landscapes, trees and fauna she describes (like the 'pale olive-green leaves' [11] that grow at the base of the thorns on the ubiquitous thornbush, or the communication strategies of vultures) render a powerful sense of a living landscape, one ultimately beyond the comprehension or control of human actors. This descriptive detail contributes to Head's unique style, one in which events are ultimately secondary to the slow, intensive experiences of readers and characters of the natural and social world. The new, more sustainable approach to agricultural development that Makhaya and Gilbert learn from the women who participate in their tobacco-growing scheme is, above all, defined by slowness. 'Things happen slowly here,' Dinorego warns them (19), and indeed the novel features very little in the way of conventional plot: its most important events like the emergence of new green shoots from the previously 'barren earth' (111) - unfold gradually and without fanfare. When Rain Clouds Gather privileges, we might say, the plot over the plot, the temporalities of cultivation (repetitive, patient, expectant but vulnerable) over the heroic rhythms of conventional narrative. As such, given the deep affective power of natural encounters in the novel, its focus on gardening as a site for human/nonhuman encounter invites a reconsideration of the sublime registers of environmental discourse.

For Head, encounters with nature precipitate responses ranging from conventionally sublime terror to poignant gratitude and appreciation. The novel's opening invokes the traditional association of the sublime with both existential terror and exhilarating freedom. On the first page, we find Makhaya, a political fugitive on the run from the South African police, hiding in a cramped hut near the Botswana border. Once he climbs the fence and crosses into Botswana, Makhaya's dizzying sense of freedom is intensified by the terror he feels when he is surrounded, 
in the thorn-bush darkness, by 'unearthly-sounding bells,' 'tinkling and tinkling with a purposeful, monotonous rhythm' (5). As in classical Romantic visions of the sublime, terror and an exuberant sense of human freedom coincide in this transgressive moment when Makhaya violates the political and symbolic borders of colonial space. Disoriented in the 'overwhelming darkness,' he looks to the stars, whose silent grandeur and persistent celestial order restore him to himself. Though he anxiously recalls legends of 'tribal societies and their witch doctors who performed their ghoulish rites by night,' he reassures himself that 'witch doctors were human, and nothing, however odd and perverse, need be feared if it was human' (5). As in Romantic visions of the sublime, human subjectivity here wins out over the ecstatic terrors of nature.

But his subsequent experiences of natural wonder, particularly in Golema Mmidi, instead come to exemplify what Yaeger calls 'female' or relational encounters with the sublime. Instead of confirming his rational capacities or the domination of others (nonhuman or human), these moments embed Makhaya more firmly in 'the sociable, the convivial' (Yaeger 1989, 195) leading him into deeper relation with others rather than reinforcing his masculine individuality. On his first morning, the beauty of sunrise in the Botswana bush almost overwhelms him. Though the sudden emergence of the sun, 'a single white pulsating ball,' takes him by surprise and seemingly accords with conventional sublime privileging of the grandiose and elevated, it is in fact smaller and less majestic sights that move him most profoundly: the 'thousands and thousands' of tiny birds, whose 'flight into the deep blue sky was just like so many insects'; the 'short low tufts' of trees that resemble wild grass; and the 'vast expanse of sand and scrub' that extends as far as the eye can see (Head 1972, 11). Finding the scant, low Botswana bush 'bewitchingly beautiful' (11), his response is neither terror, nor existential crisis, nor masculine power, but 'love':

perhaps he simply wanted a country to love and chose the first thing at hand. But whatever it was, he simply and silently decided that all this dryness and bleakness amounted to home and that somehow he had come to the end of a journey.

The love he feels for landscape itself comes to represent an act of defiance. He celebrates the 'dirty' proximity to nature and affective possibilities of a settlement like Golema Mmidi, where, unlike South Africa, 'women walked around all day with their bare feet and there were no notices up saying black men could not listen to the twitter and chatter of birds' (133). Perhaps as a result of this colonialist prohibition on black subjects inhabiting or appreciating natural spaces, he reflects that 'his own culture lacked, almost entirely, this love and care for the earth and had all its interest directed toward people' (131). By contrast, the development of Makhaya's intense affection for the soil, plants and landscapes of Botswana parallels (and indeed precedes) his romantic involvement with Paulina, two relationships where 'love' comes to be defined in terms of 'generosity' and mutual vulnerability. In the anomic world of apartheid's urban modernity, Makhaya regarded love as a source of exploitation: 'if love was basically a warm fire in you,' he recalls bitterly, 'you attracted all the cold people who consumed your fire with savage greed leaving you deprived and desolate' (27). As a result, he has arrived in Botswana lonely, isolated and determinedly independent, a 'separate particle' (76), fiercely protective of his autonomy. Typically, for this modernized man, contact or emotional intimacy with others is metaphorized through dirt, as when Makhaya ponders whether one can ever restore trust 'once it has become soiled and tainted' (126).

But it is through contact with the soil - and the relationships that develop through his work with the cooperative garden - that Makhaya is restored to connection and intimacy. The dirty 
ecology of When Rain Clouds Gather embraces the presence and proximity of embodied others, both human and nonhuman. The 'trust and affection' (78) that characterize these bonds are figured through natural imagery and forged through encounters with nature: Makhaya thinks of his love as a 'warm outflowing stream which could not be dammed up' (124), and contemplates the generosity that defines nature, even in thirsty environments like this one:

No doubt the sun knew why the clouds formed and why the wind blew and why the lizards basked in its warmth, and all this immense knowledge made the sun gay and bright, full of trust and affection for mankind. But there were shut-away worlds where the sunlight never penetrated, haunted worlds, full of mistrust and hate, and it was about this side of life that Makhaya was particularly well informed.

As in these passages, the sun is a powerful symbol throughout, exemplifying the logic of generosity that Makhaya comes to recognize as the basis for 'the peace of the world' (120). It is telling, therefore, that Paulina, the woman he eventually grows to love and prepares to marry by novel's end, is often associated with the sun. The first time she notices him, he has come to watch the glorious sunset near her home. Though they do not meet on this occasion (and though, in fact, Makhaya snubs the greetings she sends through her young daughter), he does notice her skirt, 'a vivid sunset ... of bright orange and yellow flowers' he finds 'momentarily captivating' (74). Later, when they first properly meet, he again sees her skirt, 'the same flaming colour as the sun, which was about to go down,' and admits that 'both were beautiful to him' (113).

Just as his contemplation of sublime sunsets are interrupted by the more quotidian sight of Paulina's bold skirts, so too is he distracted from such visions by what he humorously describes as the 'great drama' of thornbush seeding. Makhaya responds to the ejection of bean-like seeds from the coiled pods that cover the thornbush with 'amazement,' a term more typically associated with the conventional sublime that seems incommensurable with this scene. His gardening work with Gilbert and the women has effected a shift in perspective, allowing him to notice and find meaning in the 'details of life'; indeed, this attention to the minor details becomes one of Makhaya's chief characteristics and sources of pleasure, as 'it often pleased him to turn careless or insignificant ideas into something quite their opposite' (107).

As with Le Guin's carrier bag theory of fiction, the shift in perspective that defines the female sublime entails a similar recognition of the significance and affective power of the details of life.' When Makhaya transgresses gender roles by building a fire, toward the end of the novel, he accords even the dead sticks a reverent attention that astonishes Paulina: 'He treated each stick as a separate living entity, and because of his respect for each stick, he moved his hands slowly, with many pauses, placing the firewood down at carefully calculated angles' (135-136). Similarly, the miniature village that Paulina's daughter constructs from mud and other natural materials fascinates and 'delight[s]' Makhaya, perhaps because it so readily reflects the microcosmic scale of the farming project in Golema Mmidi. That the huts, cattle, goats and people are all constructed of mud reinforces the significance of soil in the social, economic and environmental development of the village: the novel reveals that all life is ultimately sustained by soil, and the health of the earth is both a symptom of, and a foundation for, the sustainability of all other lifeforms.

In other words, though Makhaya is a man, we can read Head's efforts to reconceptualize human experiences of the natural world, through cultivation, as examples of Yaeger's 'female sublime.' This is, after all, a novel that intertwines environmental concerns with critiques of 
African patriarchy and a celebration of women's experience, a connection Tulloch (2012) highlights through her focus on the text's themes of 'husbandry.' Its privileging of the 'ordinary' and everyday expresses both an ecological ethic of local, material experience and a feminist rewriting of the hegemonic modes of narrative that Le Guin regards as implicated in masculine ideologies. The region's inhospitability and environmental degradation parallel the breakdown of family structures and women's vulnerability in colonial modernity: Botswana has become 'a country of fatherless children,' where 'every protection for women was breaking down and being replaced by nothing' (Head 1972, 115). The rejuvenation of women's solidarity and knowledge through the agricultural project not only works to restore the soil and natural ecosystems in Golema Mmidi; it also fosters the emergence of new stories and narrative modes, while destabilizing the traditional patriarchal power structures and attitudes that have led to environmental and social infertility. Once the women have piloted the tobacco-growing project, their husbands, 'flushed with pride,' react 'the same way the ancient hunters of history must have reacted when they came back from hunting trips and found their wives had cultivated the wheat and domesticated a few wild animals for their meat' (170). The success of their efforts, and the devastating loss of the village's cattle due to drought, impels the men to return home from the cattle stations to become settled agriculturalists and family men, a poignant restaging of the origins of human culture.

Similarly, the two men who initially envision the transformation of Golema Mmidi through their modernizing efforts ultimately find themselves transformed by their time in the village, and particularly by their relationships with women. While their respective romantic entanglements are the clearest examples of this, it is also the influence of Mma Millipede, Paulina's daughter and other women that effect this shift in perspective for both Gilbert and Makhaya. The two lonely bachelors not only become settled family men, happily doomed to be 'entangle[d] ... with marriage and babies and children' (185) by novel's end; they also change their perspectives on nature, development and political practice as a result. While Gilbert's initial dream for Golema Mmidi seems to reflect a developmentalist vision of the material prosperity that might result from commercial farming, and while Makhaya himself initially determines to become a 'millionaire' (139) through his involvement with the farming project, these ideals gradually give way to smaller, more 'ordinary' hopes (166), tempered by consciousness of environmental concerns and the influence of women. Contemplating his original insistence on 'the need for a poor country to catch up with the Joneses in the rich countries,' and his vision of grand houses, cars and material goods to replace the bare feet and poverty of the 'men with no shoes,' Makhaya acknowledges the environmental unsustainability of this consumerist ideal:

Who would eat then if all the gold and pomegranates went into the house of Solomon? Who would bathe if all the water went into his forty bathrooms? Who would have time to plough if everyone had to join the parade to watch Solomon pass by in his Chevrolet of molten gold, his top hat and silk shirt, glittering in the African sun?

The Biblical imagery that mediates Makhaya's reflections culminates in his recognition that God inheres in 'the way he smelled the summer rain on the far, flat horizon, four or five months before the first, fat globs of raindrops fell two by two, three by three on the parched earth,' that a divine presence lives 'where he always had - in the small brown birds of the bush, in the dusty footpaths, and in the expressions of thin old men in tattered coats' (182). The divine is, here, no sublime transcendence, but rather a presence experienced through the small and quotidian. 
Though the work they undertake remains mostly the same, this shift in the men's perspective exemplifies, we might say, the project's change from farming to gardening. The 'smallness' of the gardening project reflects the scalar shift that defines their time in Golema Mmidi. '[Y]ou had to start small,' Gilbert observes. This approach is explicitly identified as a function of the often overwhelming effect of the countryside, where:

the great stretches of arid land completely stunned the mind, and every little green shoot that you put down into the barren earth just stood there, single, frail, shuddering, and not even a knowledge of soils or the germinating ability of seeds or modern machinery could help you to defeat this expansive ocean of desert.

Thinking small becomes, in this context, a deliberate strategy of psychological and environmental healing. Gilbert proposes thinning the villagers' large cattle herds to focus on improving quality and reducing the need for wide-ranging cattle stations. Recognizing the deep ecological significance of a small, unattractive annual known as carrot-seed grass, Gilbert protects the grass from destruction by goats or human footprints, and quickly finds that it plays an integral role in improving the quality of soil and preparing the ground for other species. This sort of attention to the low, often microscopic life forms that exist at the margins of ecosystems exemplifies Gilbert's approach, one that treats people, the soil and other beings not as means toward an end, but with 'humility and tenderness' (99).

The novel's emphasis on feminine forms of relation to land and soil, and on feminine modes of storytelling, thus aligns it with other literary treatments of African women's gardening, and with more quotidian practices of ecological relation than those privileged by Western environmental discourses. Dirty ecology here represents both a form of social stewardship, forging affective and material bonds amongst community members, and an alternative kind of interaction with the soil, the plants and the other life forms that make up the community's milieu.

\section{III.}

Head's interest in the garden as a site of ecological, psychological and social healing is continued in her third novel, which again focuses on the problematics of dwelling in a political context defined by property and borderlines. In A Question of Power (1974), Elizabeth is a transgressive figure, one who crosses boundaries and destabilizes the 'proper' places of colonial cultures predicated on the firm policing of categories and spaces. Like Head herself, Elizabeth is a 'Coloured' woman whose very existence violates apartheid strictures against interracial contact. Having fled South Africa on an 'exit' permit, she finds herself in rural Botswana with her young son, struggling to find a sense of belonging and selfhood amongst Tswana villagers suspicious of outsiders. Elizabeth's alienation as a permanently temporary refugee in Botswana only intensifies the 'permanent condition of strayness' (Kapstein 2003, 76) that characterized her relation to place in South Africa. She undergoes several nervous breakdowns, suffering through extended periods of hallucinatory anguish in which she is tormented by male and female figures with images of brutal sexuality and violence. The psychological crisis precipitated by this disorienting sense of being a perpetual fugitive is marked throughout by a preoccupation with filth, excrement and other wastes, signs of transgression for a system devoted to the hygienic separation of bodies and spaces.

What ultimately brings Elizabeth back from the brink of complete psychological breakdown is her recognition of the value and significance of the 'ordinary': that is, of the practical activities 
of everyday life; of human relationships based on generosity, humility and mutual respect; and a tolerance of boundary crossing in all its forms. For Elizabeth, this is experienced first and most immediately through the work of the cooperative gardening project. While her unconscious is violently assaulted by voices that shame and degrade her for her inability to conform to apartheid's classificatory systems, her gardening work celebrates and facilitates the individual's interdependence on other people and on nature. Her healing begins with a gift: the pumpkin her friend Thoko brings one day moves Elizabeth so profoundly that she asks to work in the community garden run by the town's local industry project. As she learns cultivation methods from the local children and expatriate volunteers who run the garden, Elizabeth finds not only a sense of purpose but also a new appreciation for the humanity, generosity and compassion of other people. 'It is impossible to become a vegetable gardener without at the same time coming into contact with the wonderful strangeness of human nature,' she reflects (Head 1986, 72), and the relationships she develops through her work tending to plants help her reconnect to others and to herself, even as it fosters a sense of belonging in the alien environment of the village. The cooperative ethos of the project contrasts vividly with the greed, violence and selfish consumption that her troubled unconscious associates with apartheid, racism and 'power-worship' more generally (33); the kindness and humility that members of the collective display toward her and one another provide concrete examples of the 'vast and universal love' she comes to see in ordinary people. 'Any assumption of greatness leads to a dog-eat-dog fight and incurs massive suffering' (34), she muses, whereas 'ordinary people have never mucked up the universe. They don't have that kind of power, wild and flaring out of proportion. They have been the victims of it' (190). As in When Rain Clouds Gather, the lesson of gardening seems to be that only humility and cooperation yield abundant results.

The multinational, multiracial, gender integrated gardening project affords dignity to ordinary people and ordinary labor, and its goal is not to accumulate wealth or resources but to feed the community in its broadest sense. This goal of feeding people becomes a tangible and symbolic expression of love, and life. Sello's observation that 'love is two people mutually feeding each other, not one living on the soul of the other like a ghoul' (213), an insight Elizabeth holds onto as a 'lever out of hell' (213), is exemplified in meals and cups of tea she shares with her friends, and in the tender care she and her colleagues devote to the vegetables. 'Love' is the term she gives to the recognition of ordinary equality - 'when a people wanted everyone to be ordinary it was just another way of saying man loved man' (223) - a form of friendship that is based on mutuality and generosity, not greed or selfishness. Hoarding resources, or greedily consuming the results of labor, are seen by the villagers as 'working for death' (166); investing in the community, by contrast, promotes and supports life, whether individual, social or environmental. The flow of resources represented by the garden reflects and promotes the 'flow of feeling from people to people' that so astonishes Elizabeth when she first arrives in the village (14). Her friend Tom, a kindly European volunteer, sees Elizabeth's empathy for the vegetable crops as indicative of her capacity for universal love: 'This is one hell of a girl. Ha, ha, ha, how does she know what vegetables like? Isn't that love, not only for people but vegetables too?' (202). In the face of the dehumanizing effects of power that have so brutally damaged Elizabeth's mind, spirit and body, the work of cultivating plants becomes a democratizing force of transformation guided by the force of love, against which 'thrones and kingdoms were of no account' (51).

The 'ordinary' encounters through which Elizabeth experiences love are predicated on touch - that is, on physical intimacy and affection. The practical experiences of sharing food, exchanging physical affection with others, and laying hands on the ground are key to Elizabeth's recovery. The voices of 'power' that threaten to drive her mad see the contamination of self by others, a preoccupation indexed in the filth and excrement that pervade her waking 
nightmares, as shameful and repellent. But this 'ordinary' ethos is comfortable with dirt. Despite her normally immaculate housekeeping, Elizabeth comes to enjoy Tom's habit of washing his face and neck in her sink, spilling water onto the mud floor and stomping his boots around in the mess $(118-119,127)$. She relishes the work of transplanting seedlings, including 'exotic' varieties that she helps thrive in the heat and drought of Botswana. Rejecting 'the idea of being that kind of farmer who earned her year's supply of food in breakneck battles with dangerous wild animals' (58), Elizabeth embraces a newfound openness to the touch of the earth, a relationship based on cooperation and interdependence rather than violent conflict or a longing for mastery. This is exemplified in the new home constructed for her near the garden:

The slowly drifting closeness to the soil was increased by living in a mud hut. It was like living with the trees and insects right indoors, because there was no sharp distinction between the circling mud walls of a hut and the earth outside. And the roof always smelled of mouldy grass, and all kinds of insects made their homes in the grass roof and calmly deposited their droppings on the bed, chair, table and floor.

$(58-59)$

The very porosity and impermanence (that is, dirtiness) of the mud structure exemplify the kind of dwelling that Elizabeth strives for by the end of the novel - one that is not defined by possession and permanence, but by interdependence. Whereas 'power people needed small, narrow, shut in worlds' (33), Eugene kindly suggests that 'too much isolation isn't a good thing' (54).

Finally, Elizabeth's ethos of ordinary life, friendship and touching intimacy leads her to a new appreciation for forms of 'low' storytelling. The differences between this approach to narrative and the 'high art' of hegemonic literature recall Le Guin's longing to develop 'new, and yet old' kinds of stories to express the experiences of ordinary, unheroic, forgotten people in their relationship with nature. The Danish volunteer Camilla at one point proclaims the singular value of Danish literature: 'In our country culture has become so complex,' she boasts, 'this complexity is reflected in our literature. It takes a certain level of education to understand our novelists. The ordinary man cannot understand them' (79). Even reading and writing have become, in other words, an experience of power and elitism - a boundary fence between the 'ordinary' people and those who claim political and cultural authority. By contrast, children in Motabeng write compositions about 'Life in Botswana' that focus on the most quotidian, practical aspects of their experience: 'When the rain rains we go to the lands to plough. We plough with oxen. The cow is a very useful animal. We use every part of it. We sell its skin for leather. We sell its bones. Glue is made from its hooves' (66). Though in the midst of her psychological crisis Elizabeth despairs at the lack of magic, hope and imagination she sees in these essays, she ultimately comes to see storytelling differently. The novel's concluding sense of tentative hope is emphasized by the book she picks up and prepares to read: The Gift of a Cow by Premchand, a 'classic Hindi novel that exalted the poor' (222), a text that sets itself in opposition to traditional Indian literature's celebration of 'amazing ... adventures of high-born heroes and heroines' (Le Guin 1996, 223). Like Elizabeth herself, the English language, and its narrative forms, are reclaimed and adapted in Botswana, being remade and made to seem at home by ordinary people: "It's all right, Tom," she said. "Wherever English travels, it's adapted. That's Setswana English”" (Head 1986, 132).

Adaptation comes to serve as the guiding principle of love and the 'ordinary' that guides Elizabeth out of madness. Indigeneity, authenticity and purity are revealed in the novel as logics of power, whether colonial or postcolonial; Elizabeth is able to make herself at home in a foreign space by putting down roots, developing rhizomatic connections with others, and by 
nurturing a sense of ecological and social generosity. In this respect, she is symbolically associated with the Cape gooseberry plants she introduces to the community garden. Though the gooseberry is not indigenous to Botswana, the plants flourish magnificently and produce an abundant harvest of fruits. Elizabeth and Kenosi distribute leaflets touting the health benefits of gooseberries, sharing recipes for jam, and celebrating the potential of the fruit for the home industries project. Eventually Elizabeth herself comes to be called 'Cape Gooseberry' by the local women, a name that highlights her similarity to this 'complete stranger' which 'settled down and became a part of the village life of Motabeng' (163). The successful transplantation of the gooseberry, and the other experimental crops and methods deployed in the garden, mark the community garden as a hybrid space, one where hegemonic strictures against cultural, racial and biological mixing are transgressed and contested. Foreign crops like tomatoes, tobacco, broccoli, peanuts, peas and pumpkins all grow successfully side-by-side; permaculture techniques are borrowed freely from European and African traditions; and the garden becomes a site of 'bonding and desire between women' (Talahite 2005, 142). In this respect, the garden serves as a tactical space where the sites and discourses of power, both colonial and patriarchal, are poached upon. When the history teacher at Motabeng school insists that the women plant barley (and rotten barley, at that), for example, Elizabeth responds not by refusing directly, but by deflecting and rewriting his efforts to control their work: "Never mind," Elisabeth had replied. "Let's dig up that bed and plant carrots. When Rodney comes again tell him the carrots are barley. He doesn't know anything about vegetables because he teaches history" (174). Though the women lack Rodney's social status, their skills as gardeners enable them to open an 'interval of freedom' from the patriarchal and colonial power that the teacher represents (De Certeau, Girard and Mayol 1998, 255).

Like Makhaya's, Elizabeth's careful tending of the soil represents more than an effort to feed the body or keep oneself busy. Gardening here entails a deliberate immersion of the self in the dirt, which is to say, in the mark of the other - the traces of history, memory, loss, love and community that trace subterranean routes of connection between the self and its others. Head's novels' celebration of the ordinary tactics, relations and narrative modes of those on the margins of dominant culture and politics, and their emphasis on adaptation, transplantation and hybridity over purity and indigeneity, affirm gardening's oppositional qualities in the face of the traumatic violence and rigidity of power. The everyday practice of gardening helps make habitable even the most inhospitable and contingent of spaces, forging underground networks of desire, love and generosity that root individuals in place and in community, even when these places and communities are temporary, vulnerable and perpetually shifting. The novels thus invite us to read gardening as a form of 'dirty ecology,' an environmental relation that does not privilege conservation, purity or separation between humans and nature. This mode's emphasis on the feminine and ordinary deconstructs Western environmentalism's reliance on sublime registers, articulating instead a 'female sublime' of intimacy and relation. Bessie Head's fictions of gardening therefore serve as valuable case studies for a broader exploration of the ethical, literary and environmental stakes of cultivation in African contexts.

\section{Notes}

1 For some classic studies of the cultural and political work of dirt, particularly in colonial and postcolonial contexts, see Mary Douglas (2002); Anne McClintock (1995); and Warwick Anderson (1995). For more recent approaches, see Sarah Lincoln (2008); Kenneth Harrow (2013); and the special issue of Social Dynamics on 'The Cultural Politics of Dirt in Africa,' edited by Stephanie Newell and Louise Green (2018).

2 I expect readers to be generally familiar with the sublime as a term that explains an aesthetic experience in which the encounter between self and aesthetic object results in an overwhelming, even terrifying 
sense of the self's vulnerability and diminution. The sublime object is, typically, elevated, massive and powerful. The Romantic tradition (which I also refer to as the 'conventional sublime'), exemplified by Kant and Wordsworth, emphasizes that the encounter ultimately confirms the power of reason and human imagination to transcend the sublime experience. 'Humility is thus transformed,' as Christopher Hitt describes, 'into self-apotheosis, validating the individual's dominion over the nonhuman world' (608). Environmental thinkers like Hitt (1999) and Cronon (1995) have critiqued the Romantic understanding of the sublime, proposing that ethical potential resides in the experience of awe and estrangement that characterizes the self's encounter with nonhuman otherness; while feminist critics like Yaeger (1989) and Mellor (1992) have invited us to consider the sublimity of low, domestic and humble experiences and objects. For a useful introductory overview of the concept, see Shaw (2017).

\section{References}

Anderson, Warwick. 1995. 'Excremental Colonialism: Public Health and the Poetics of Pollution.' Critical Inquiry 21(3): 640-669.

Barnard, Rita. 2012. Apartheid and Beyond: South African Literature and the Politics of Place. New York: Oxford University Press.

Caminero-Santangelo, Byron. 2014. Different Shades of Green: African Literature, Environmental Justice, and Political Ecology. Charlottesville: University of Virginia Press.

Caminero-Santangelo, Byron and Garth Myers, eds. 2011. Environment at the Margins: Literary and Environmental Studies in Africa. Athens: Ohio University Press.

Campbell, Elaine. 1985. 'Bessie Head's Model for Agricultural Reform.' Journal of African Studies 12(2): 82-85.

Casid, Jill. 2004. Sowing Empire: Landscape and Colonization. Minneapolis: University of Minnesota Press.

Coetzee, J. M. 1983. Life and Times of Michael K. New York: Penguin Books.

Cronon, William. 1995. 'The Trouble with Wilderness.' In Uncommon Ground: Rethinking the Human Place in Nature, edited by William Cronon, 69-90. New York: Norton.

Dangarembga, Tsitsi. 2004. Nervous Conditions. Banbury, UK: Ayebia Clarke.

Dangarembga, Tsitsi. 2007. The Book of Not. Banbury, UK: Ayebia Clarke.

Darlington, Sonja. 2007. 'The Significance of Bessie Head's Response to "The Call of the Global Green".' Journal of the African Literature Association 1(2): 97-107.

De Certeau, Michel, Luce Girard and Pierre Mayol. 1998. The Practice of Everyday Life, Vol. 2: Living and Cooking. Minneapolis: University of Minnesota Press.

Douglas, Mary. 2002. Purity and Danger: An Analysis of Concepts of Pollution and Taboo. New York: Routledge.

Food and Agriculture Organization of the United Nations (FAO). 1996. 'Women Feed the World.' World Food Summit: Food For All. www.fao.org/docrep/x0262e/x0262e16.htm\#p.

Forna, Aminatta. 2007. Ancestor Stones. New York: Grove Press.

Galassi, Jayne. 2010. Cactus Letters. Cape Town: David Philip.

Garrard, Greg. 2004. Ecocriticism. London: Routledge.

Goldman, Mara. 2011. 'Keeping the Rhythm, Encouraging Dialogue, and Renegotiating Environmental Truths: Writing in the Oral Tradition of a Maasai Enkiguena.' In Environment at the Margins: Literary and Environmental Studies in Africa, edited by Byron Caminero-Santangelo and Garth Myers, 95-120. Athens: Ohio University Press.

Goodhead, Dokubo Melford. 2017. 'The Discourse of Sustainable Farming and the Environment in Bessie Head's When Rain Clouds Gather.' Legon Journal of the Humanities 28(1): 30-45.

Grove, Richard. 1996. Green Imperialism: Colonial Expansion, Tropical Island Edens and the Origins of Environmentalism, 1600-1860. Cambridge: Cambridge University Press.

Head, Bessie. 1972. When Rain Clouds Gather. London: Heinemann.

Head, Bessie. 1986. A Question of Power. London: Heinemann.

Iheka, Cajetan. 2017. Naturalizing Africa: Ecological Violence, Agency, and Postcolonial Resistance in African Literature. Cambridge: Cambridge University Press.

Kapstein, Helen. 2003. “A Peculiar Shuttling Movement”: Madness, Passing, and Trespassing in Bessie Head's A Question of Power.' In Critical Essays on Bessie Head, edited by Maxine Sample, 71-98. Westport, CT: Praeger.

Kincaid, Jamaica. 2001. My Garden (Book). New York: Farrar, Strauss, \& Giroux.

Harrow, Kenneth. 2013. Trash: African Cinema from Below. Bloomington: Indiana University Press. 
Highfield, Jonathan. 2010. "'Relations with Food”: Agriculture, Colonialism, and Foodways in the Writing of Bessie Head.' In Postcolonial Green: Environmental Politics and World Narratives, edited by Bonnie Roos and Alex Hunt, 102-117. Charlottesville: University of Virginia Press.

Hitt, Christopher. 1999. 'Toward an Ecological Sublime.' New Literary History 30(3): 603-620.

Le Guin, Ursula K. 1996. 'The Carrier Bag Theory of Fiction.’ In The Ecocriticism Reader, edited by Cheryll Glotfelty and Harold Fromm, 149-154. Athens: University of Georgia Press.

Lincoln, Sarah L. 2018. 'Notes from Underground: Fugitive Ecology and the Ethics of Place.' Social Dynamics 44(1): 128-145.

Lincoln, Sarah L. 2008. Expensive Shit: Aesthetic Economies of Waste in Africa. PhD dissertation, Duke University.

McClintock, Anne. 1995. Imperial Leather: Race, Gender, and Sexuality in the Colonial Contest. New York: Routledge.

Mellor, Anne. 1992. 'Domesticating the Sublime.' In Romanticism and Gender, 85-106. New York: Routledge.

Moyles, Trina. 2018. Women Who Dig: Farming, Feminism, and the Fight to Feed the World. Regina: University of Regina Press.

Newell, Stephanie and Louise Green, eds. 2018. 'The Cultural Politics of Dirt in Africa.' Social Dynamics 44(1): $1-178$.

Nixon, Rob. 1993. 'Border Country: Bessie Head's Frontline States.' Social Text 36, Autumn: 106-137.

Nixon, Rob. 2011. Slow Violence and the Environmentalism of the Poor. Cambridge, MA: Harvard University Press.

'Obituary: Patricia Smith Yaeger.' 2014. The University Record, University of Michigan, August 29. https:// record.umich.edu/articles/obituary-patricia-smith-yaeger.

O'Brien, Susie. 2002. 'The Garden and the World: Jamaica Kincaid and the Cultural Borders of Ecocriticism.' Mosaic 35(2): 167-184.

Pease, Donald. 1984. 'Sublime Politics.' In The American Sublime, edited by Mary Arensberg, 21-50. Albany, NY: SUNY Press.

Posmentier, Sonya. 2017. Cultivation and Catastrophe: The Lyric Ecology of Modern Black Literature. Baltimore. MD: Johns Hopkins University Press.

Potter, Christopher. 2018. 'Behind the Most Famous Photograph Ever Taken.' Literary Hub, February 26. https://lithub.com/behind-the-most-famous-photograph-ever-taken/.

Shaw, Philip. 2017. The Sublime. 2nd ed. New York: Routledge.

Talahite, Anissa. 2005. 'Cape Gooseberries and Giant Cauliflowers: Transplantation, Hybridity, and Growth in Bessie Head's A Question of Power.' Mosaic 38(4): 141-156.

Thieme, John. 2016. 'After the Bounty: Botany and Botanical Tropes.' In Postcolonial Literary Geographies: Out of Place, 41-76. London: Palgrave Macmillan.

Tulloch, Elspeth. 2012. 'Husbandry, Agriculture and Ecocide: Reading Bessie Head's When Rain Clouds Gather as a Postcolonial Georgic.' European Journal of English Studies 16(2): 137-150.

Vital, Anthony. 2008. 'Toward an African Ecocriticism: Postcolonialism, Ecology, and Life \& Times of Michael K.' Research in African Literature 39(1): 87-121.

Walker, Alice. 1994. 'In Search of Our Mothers' Gardens (1972).' In Within the Circle: An Anthology of African-American Literary Criticism from the Harlem Renaissance to the Present, edited by Angelyn Mitchell, 401-409. Durham, NC: Duke University Press.

Wicomb, Zoë. 2006. Playing in the Light. New York: The New Press.

Yaeger, Patricia. 1989. 'Toward a Female Sublime.' In Gender and Theory: Dialogues on Feminist Criticism, edited by Linda Kauffman, 191-212. New York: Basil Blackwell.

Yaeger, Patricia. 2009. 'Luminous Trash: Throwaway Robots in Blade Runner, The Terminators, A. I. and WALL-E.' Paper presented at UCLA Center for the Study of Women. https://soundcloud.com/ willburdette/patricia-yaeger-luminous-trash.

Yaeger, Patricia. 2013. 'Beasts of the Southern Wild and Dirty Ecology.' Southern Spaces, February 13. http s://southernspaces.org/2013/beasts-southern-wild-and-dirty-ecology. 


\section{African fictions, animal figures and anthropocentric frameworks}

Jesse Arseneault

\section{Introduction}

There is that great proverb - that until the lions have their own historians, the history of the hunt will always glorify the hunter. ... Once I realized that, I had to be a writer. I had to be that historian. ... It's not one person's job. But it is something we have to do, so that the story of the hunt will also reflect the agony, the travail - the bravery, even, of the lions.

(Achebe 1994, para. 11)

The above quotation offers a fruitful start for thinking about the place of animality in African literature, especially since it signals a long history of animal figures entering the continent's oral forms (Monye 1996). In offering this much-cited quotation, this chapter's aim is not to reinstate Chinua Achebe's already powerful position within the field of African literature given its currently heterogeneous array of themes, voices and geographies. The chapter's primary effort is to consider what stories have been told in and about Africa, especially since animal studies has furnished literary scholarship with intensified attention to nonhuman life. Achebe's use of the proverb echoes both an impetus in the continent's literatures - one that would later be taken up in Chimamanda Ngozi Adichie's 'The Danger of a Single Story' (2009) - to tell stories that are not or have not been told, and foregrounds how dominant stories or ways of telling facilitate the erasure of others. The statement also centralizes a small subset of animal lives, lions, as its proverbial referents. Discerning readers might suggest that Achebe's statement is not about animals at all, instead using them as mere figures for African (hi)stories having been occluded by Europe's colonial apparatus when he began to write. If, however, we can read the metaphoricity of the proverb form as being located somewhere between the literal and the figurative, more possibilities arise where animal lives are concerned. One notable feature of the quotation is that, while Achebe has done much to emphasize colonialism's dehumanizing practices, it does not necessarily humanize Africanness in such a way that reifies Eurocentric dichotomies between human presence and animal absence. The proverb allows for the African human and animal (both of whom embody interlinked forms of absence in the colonial imagination) to jointly emerge as concerns in its drawing together of the literal animal body and figurative currency it wields. Indeed, the very possibility of the proverb applying to Europe's negation of 
African stories rests on the intimation that lions may have their own to tell. The proverb suggests that the absence of stories about certain lives is not a testament to an essential incapacity for those lives to occupy stories, but an effect of the powerful to - recalling the necropolitics of colonial sovereignty - kill the very possibility of that story's emergence and those who may tell it.

The above passage foregrounds both the possibilities and limitations of stories about animals to reach beyond the human. On the one hand, the proverb opens a space for nonhumans but, on the other, its allegorical inflection risks subordinating animality to its symbolic function in relation to anthropocentric systems of meaning and exchange (i.e. language). There may, however, be more to even the figurative where animal stories are concerned in that '[f]igures are not representations or didactic illustrations, but rather material-semiotic nodes or knots in which diverse bodies and meanings coshape one another ... where the biological and the literary or artistic come together with all the force of lived reality' (Haraway 2007, 4). The affective traces of human-animal contact may thus remain in figurations that give them narrative life. This gets more complicated where African literature is concerned in that animality has also been a powerful symbol for depriving African and especially Black bodies of humanity and sovereignty in the colonial imagination (Comaroff and Comaroff 2010; Mbembe 2001), and these metaphors also occur in vermin-laden languages for violence, for example in Hutu Power's rendering of Tutsis as cockroaches in the Rwandan genocide (Arseneault 2013), as well as Robert Mugabe's famous comparison of queer Zimbabweans to 'dogs and pigs' (Shoko 2010). Animal figures thus merit some scrutiny where African literature is concerned.

This chapter considers how animal figures emerge as concerns within African fictions, and consults three texts for the different tropes of animal and human-animal relations they engender, varied in their geopolitical context and thematic content precisely to give a broad survey of these concerns. The first text is Alain Mabanckou's Memoirs of a Porcupine, a novel that wields its titular 'autobiographical' speaking animal to foreground not only the stakes of co-opting nonhuman figures into modes of communication such as language, storytelling and history, but also for the ways that text destabilizes the ascendency these processes bring to human culture against the ostensible absence that characterizes animal life. The second, Buchi Emecheta's Second Class Citizen, addresses species hierarchies that position African and especially Black bodies in relation and often subordinate to animals. Pushing beyond the figurative use of animals, this text also emphasizes the active role that specifically dogs play in tactics of colonial policing and governmentality as they themselves are subjected to the colonial gesture of domestication. But in its refusal to reduce Blackness to its colonial meanings, that text offers possibilities for identification between subjugated human and animal figures in ways that disrupt the absolute hierarchical categorization of such bodies. The third text, Njabulo Ndebele's journalistic essay, 'The Year of the Dog,' is likely the most radical in its insistence on concern for nonhuman life. Though nonfictional, it nonetheless tackles some of this chapter's inquiries into fictional animals. That text's affective pull, I suggest, emerges from its movement between the imaginative possibilities of textual animals and the fleshly vulnerability of the material animal body. In so doing, it draws attention to the vulnerability that fleshly beings - including humans - share.

Animals in African literature, I argue, far from being peripheral to its human actors, are central to many of the field's concerns, particularly where postcolonial worldviews and their relationship to anthropocentrism are concerned. In that anthropocentrism 'functions to include only a select subset of human beings ... while simultaneously excluding ... the vast majority of human beings and ... animals' (Calarco 2014, 418), a view toward its processes might enliven a critique of its relation to colonial dehumanizations or even expose the colonized human's 'constitution in a broader domain of biosocial life' (Ahuja 2016, 8). The literatures cited here may not radically do away with anthropocentrism, as the postcolonial itself has sometimes been 
marked by human-centric worldviews (Armstrong 2002). To avoid hastily discounting postcolonialism as essentially anthropocentric, however, there is arguably no discursive zone from which to 'accomplish ... the revolution in language and thought ... needed to come to grips with the issues surrounding animal life' (Calarco 2007, 6). ${ }^{1}$ While this chapter is motivated by the call of global anti-anthropocentric thinking in an effort to dispel human-animal binaries and the hierarchies of concern that place human lives above animals, it is also holds that the literatures examined here expose that certain venues of concern for animals actually give vitality to colonial anthropocentrism and Whiteness in their reliance on racialized and species hierarchies of being. Rather, the literatures cited here offer up ways that human and animal lives are enmeshed in colonized worlds, and ponder the limits and possibilities of concern for nonhuman life in the unique context of postcolonial African writing.

\section{Framing African animals: African oratures and cultural debates}

Any attention to nonhuman lives in African literature will find precedence in its long history of orature. $^{2}$ As I have argued elsewhere (Arseneault 2016), Khoi animal poetry lends itself to postcolonial readings that blur the division between human and animal oppression. ${ }^{3}$ Elsewhere, animals frequently enter the continent's folklore, sometimes as anthropomorphic commentaries on the human world, but simple distinctions between human and animal qualities are more complicated than they appear and anthropomorphism might not involve a total erasure of animality. Refuting the ways in which African oral stories have been divided into categories such as 'animal tales, human tales, and fairy tales' (1992, 181), Isidore Okpewho insists that there is more to be gained by thinking human and animal stories alongside one another, though for Okpewho this is because they offer commentary on human worlds and thus are not devoted to the lives of animals themselves. Nonetheless, he emphasizes an ethical imperative in these stories to 'represent every animal as much as possible in its peculiar mannerisms,' and stresses that 'the experiences of ... animals are meant to have some relevance or message for us' (181). Drawing on the complex and contradictory figure of the tortoise in Yoruba mythology - often discussed as a trickster figure (Lawuyi 1990) - Okpewho suggests that efforts at separating human and animal ignore 'numerous instances of tales in which fairies, humans, and animals interact with one another' (181).

Ngũgĩ wa Thiong'o's generative contributions on African literary history also stress the centrality of human-animal interaction in African pre- and postcolonial literatures. Decolonising the Mind recalls precolonial African literature's 'mixture of animal characters, of half-man-half-beast and of human beings all intermingling and interacting in a coexistence of mutual suspicion, hostility, and cunning, but also occasional moments of co-operation' (1981, 65). The text also describes the author's childhood in Kenya prior to that nation's independence, recalling Gĩkũyũ animal stories being told around the fire and later recounted while working in the fields for 'European and African landlords.' Of these, he emphasizes that the struggles of animals with their environment or other humans or animals 'reflected real-life struggles in the human stories' (10). For Ngũgĩ, the struggles found in such stories emerge from the possibility and acknowledgment of animals' own struggles. Although these stories might 'ascribe to [animals] language and attitudes peculiar to human beings' (Okpewho 1992, 181), there is nonetheless an interplay between human and animal worlds that troubles stable anthropocentric binaries.

Numerous scholars have also delved into the unique place of animality in African literatures and cultures. A cursory search will likely find a disproportionate amount of work devoted to South African texts, particularly those by J. M. Coetzee such as The Lives of Animals and Disgrace, but animality and human-animal relationships have found representation in other domains 
as well. The cetacean protagonist of Zakes Mda's The Whale Caller is a frequently cited favorite amongst animal studies scholars, and Mia Couto's body of novels and stories contain numerous cryptic animal fables. Wendy Woodward has also produced a large body of work on animals in African literatures, culminating in her book, The Animal Gaze (2001), which unearths archives of human-animal kinship in Southern African fiction. While her text's emphasis on the affective bonds between human and nonhuman lives offers a compelling venue for challenging the species binary at a relational level, others have emphasized a structural critique of the associations between animality and Africa's experience of colonization. More recently, Jason D. Price's Animals and Desire in South African Fiction (2017) emphasizes fictional animals' resistance to the biopolitics of South Africa's colonial apparatus. My own work has also explored Africa's historical association with animality in the colonial imagination, as well as the ways in which authors across contemporary African literatures and cultures reinforce and challenge such meanings of nonhuman life (Arseneault 2016).

Although it centralizes animal life, the current inquiry offers no fiction of utopic humananimal relationality on the continent, cognizant of multiple conflicts between each's interests currently underway. ${ }^{4}$ These include South African president Jacob Zuma's vociferously critiqued 2012 comments on the keeping of domestic dogs as a legacy of 'white culture' and colonial history (Baderoon 2017, 349). While many South Africans took issue with these comments, there is certainly literary precedent for casting a skeptical eye toward the ways that racial hierarchies have frequently rendered pets more valuable than Black South Africans in the settler imaginary. The eponymous dog-lover in Es'kia Mphahlele's story 'Mrs. Plum,' for instance, is a character who 'loved dogs and Africans' $(1967,164)$, and did so 'in that order' (MacKenzie 2008, 244). Beyond the realm of South Africa, numerous conflicts between conservationist NGOs have erupted across the continent in ways that pit the interests of animals against those of local humans, rendered precarious or displaced to make way for the Western desire to conserve African animals and natures, though such desires often erroneously equate unpeopled landscapes with biodiversity. ${ }^{5}$

My hope is that these assertions do not sidestep the question of whether humans and animals should be ranked comparably in hierarchies of concern, but expose that hierarchies themselves offer only one way of conceptualizing human-animal relationality. A bold insistence on hierarchization would depend on a clean separation between what are human and what are animal concerns. While there is little doubt that the lives of humans do and will frequently trump animals', the literatures cited here - even in mere gestures toward nonhumans - offer more complex frameworks for reading interspecies lives and relations than species hierarchies allow. This chapter is motivated by a desire to promote more widespread justice for nonhumans, but it is also sceptical of those modes of liberal benevolence that centralize the agency of the human and its capacity to intervene in the lives of others, echoing critiques of liberal humanitarianism's deployment of figures of the African to buttress Western supremacy (Razack 2004). More central to this chapter are the ways in which stories that are sometimes about humans, in their use of animal figures, carry with them a residue of a world that is both other than but intermingled with the human in their gesture toward the affective traces animals leave on the lives of humans and the structures that govern both.

\section{'The autobiographical animal': the story of the nonhuman in Alain Mabanckou's Memoirs of a Porcupine}

The problems with animals-as-figures outlined above, alongside many other questions over the boundary between human and animal, are taken up in Alain Mabanckou's Memoirs of a 
Porcupine (2012). The text's narrator is the titular porcupine, recalling a few other novels offering up anthropomorphic animal voices, such as Patrice Nganang's Dog Days or Mia Couto's Confession of the Lioness. The narrator had been, up until the novel's start, the spiritual double to a man named Kibandi. In focusing on this human-animal duo, the novel draws on 'Congolese cultural inferences which serve as the framework of ... narration,' borrowing primarily from the 'spiritual concept of souls [which] accepts that a person is explicitly connected to an external animal counterpart or co-essence' (Omonzejie 2013, 73). However, the novel begins after Kibandi's death, the event that spurs the porcupine into telling his own story. He notes that, although he had been 'stuck with [his] role as a double, as a turtle is stuck with his shell' (Mabanckou 2012, 4), he is not the type of 'peaceful double' that would 'follow his [human master's] every move until his dying day, when' the animal double is also meant to 'lie down and die' (6). Though the novel focuses on the relation between human and animal in considering the porcupine as double to the human, the narrator's propensity for storytelling offers an animal narrative untethered from that of the human. Indeed, as the porcupine suggests, 'I'd have no tale to tell if I'd been a peaceful double, with no particular history' (7). The porcupine's memoir, spoken to a baobab tree against which he sits, thus occurs in the space between two nonhuman actors to which the reader is privy. In occupying its own story but relaying it in human language, this text emerges between the linguistic realm of human narrative and the supposedly alinguistic realm of animal life.

The opening of the novel explicitly troubles the knowability of animal figures from the vantage point of an anthroponormative framework. The narrator's first words to the reader are:

so I'm just an animal, just a dumb, wild animal, men would say, though if you ask me most of them are dumber and wilder than any animal, but to them I'm just a porcupine, and since they only believe in what they can see, they'd see nothing special in me, just one of those mammals with long sharp quills, slower than a hound dog, too lazy to stray from the patch where he feeds.

The porcupine is acutely aware of animality as a site of negation when he emphasizes that he is 'just a dumb' animal, though the novel subverts this alleged dumbness with the porcupine's paradoxical propensity for speech. Indeed, if under the human's gaze the porcupine's identity is cultivated through negation, the text also refutes the limited scope of that gaze, one which has determined multiple hierarchical relations between human and animal (Derrida 2008). Interrogating the frequently presumed unidirectional gaze of the human, Wendy Woodward emphasizes that ' $[t]$ he trope of the unknowability of animals ... is surely indicative not of the inscrutability of the animals themselves but of the humans' inability to respond to being addressed by a nonhuman animal' (Woodward 2001a, 165-166). The animal, it might be said, is that being which is looked at, but is not granted the capacity to look back. What is remarkable about Mabanckou's novel is not that it subverts the human gaze in favor of the animal's, but that it rejects the apparent stability of the empirical or visual as a mode of apprehending the world and species alterity. Though a human might see 'nothing special' in the porcupine, the ensuing narrative, in that it individuates this particular animal and thus contests the fungibility of those within the category of animality or porcupineness, suggests that this animal is very special indeed.

Nonetheless, the text challenges any easy apprehension of animal knowledges by emphasizing to the reader that this is a mediated text. Complicating the spontaneous emergence of the animal voice is the text's framing narrative, detailed in a fictional letter to the publisher in the novel's appendix. The closing note reveals that the text had originally been a notebook 'found 
in a thicket down by the river Tchinouka' (Mabanckou 2012, 152), and attributes the memoir to the eponymous narrator of Mabanckou's previous novel, Broken Glass (2005), since that character's body had been dredged out of the very same spot that the current text was found. The letter itself is composed by the bartender from Broken Glass, Stubborn Snail, and he insists that the text is 'an allegorical version of [Broken Glass's] last wishes. As he sees it, the world is just an approximate version of a fable which we will never understand as long as we continue to take account only of the material representation of things' (154). The novel's closing thus questions Stubborn Snail's efforts to ascribe to the text a clear origin in its emphasis on looking beyond apparent realities, privileging the realm of the figurative which I have read above as more than a form of empty signification. Read this way, the porcupine's narrative marks a zone of indistinction (Calarco 2014, 416) where meanings are unmoored from a singularly human or animal body, and instead occur in the space between.

In that the text is titled a memoir, its handling of this particular speaking porcupine echoes Jacques Derrida's consideration of the autobiographical animal. In The Animal That Therefore I Am Derrida discusses 'those among humans, writers, and philosophers whose character implies ... the irresistible sense of or desire for autobiography' (2008, 49). He also troubles the philosophical 'asinanity' (31) to narrate the human same against a generalized animal other. Though frequently negated, the animal is also 'capable of affecting itself' and able 'to track itself, to trace itself or retrace a path of itself (50). He describes the 'most difficult problem' as 'the fact that it has been refused the power to transform those traces into verbal language' (50). Mabanckou's text, as a memoir that translates into language the animal capacity to trace itself, offers a potential antidote to Derrida's problem: a porcupine bildungsroman that chronicles the history of an animal's emergence without recourse to autobiography being a solely human property.

The ability 'to retrace a path of oneself (Derrida 2008, 50) preoccupies the porcupine, emerging in his troubling of the human capacity to historicize. It is not so much that the text contests history as the exclusive faculty of the human and opens up the possibility of animal histories - though it certainly does that - but that it questions the supposed ascendancy that knowledge of the past brings to the human. This skepticism is perhaps also a subtle nod to the way that Africa has been imagined in the colonial mindset as devoid of history (Mudimbe 1994). The porcupine refers to humans as 'monkey cousins' in the text (Mabanckou 2012, 31), an oblique nod to the human's evolutionary kinship with the primate that emphasizes, brought far back enough, human history is animality. The porcupine still considers history to be a central component of human identity, where he states, 'the way I see it, confidence between humans comes from a shared knowledge of the past' (85). History might be a source of human commonality, but the text is awake to the ways in which it also generates exclusion. This realization occurs when the porcupine narrates the death of his human's mother, Mama Kibandi, who had until the moment of her death been considered an outsider in the town of Séképembé to which she and her son had earlier moved following her husband's death. '[I]t's not like in our world,' the porcupine argues.

[A] long established group of animals might view the arrival of an unknown beast with suspicion, animals are organised too, I know that from experience, they have their territory, their governor, their rivers, their trees, their paths, it's not only elephants have graveyards, all animals are attached to their own world.

Articulating the key difference between human and animal, he insists that 'with the monkey cousin it's strange, there's an emptiness, a shadow, an ambiguity about the past which breeds 
suspicion, even, sometimes, rejection, and that's why not many locals came to Mama Kibandi's burial' (85). The porcupine, disrupting conventional anthropocentric hierarchies, positions animal societies at the center of his knowledge system in his consideration of human-animal difference.

If history has been one faculty through which the West and the 'human' have cultivated a sense of presence against the imagined absence characteristic of animality and Africanness, the porcupine's statement crucially inverts that assumption, casting knowledge of the past instead as a kind of absence; that knowledge is 'an emptiness, a shadow.' The text contests the metaphorics of presence on which the human grounds its ascendancy by emphasizing the exclusionary properties that the capacity to historicize engenders. The familiarity of human community in the text emerges only through the simultaneous creation of an outside that excludes Mama Kibandi. Moreover, in that the text is a memoir emerging from a figure of the animal, it imbues the animal with presence, thwarting anthropocentric knowledges that would render animal life a mere accessory to the story of the human. Nonetheless, there remains the possibility of Mabanckou's animal being an essentially anthropomorphized figure. With that in mind, the texts examined below return the reader to the animal body in its materiality.

\section{Wildness and civilization: the African body in the imperial center in Buchi Emecheta's Second-Class Citizen}

Set in Nigeria and post-war Britain, Buchi Emecheta's 1974 novel Second-Class Citizen follows the Obi family's move from Lagos to London. It chronicles primarily the life of Adah Obi, a young Igbo woman 'born during the second World War' (7), for whom moving to England represents 'the pinnacle of her ambition' (16). In Lagos, she marries Francis Obi and the two occupy a high social position before he leaves Nigeria and she follows shortly after. Once in Britain, Adah experiences abuse at the hands of Francis who - consistently failing in his pursuit of academic study and as family provider - condemns Adah to being the primary earner and caregiver to their five children. Although Francis is early on 'a seemingly ambitious and modest young man,' upon Adah's move to meet him in England he becomes 'one of the most unredeemable villains in African Literature' (Porter 1988, 128). Despite Adah's earlier optimism, London itself, like her husband, proves unwelcoming, confirming - as the title portends Adah's subjugation under colonial racisms that render her life less valuable than White Britons whose citizenship is assured. Adah is limited by her double oppression under her husband and the racializing rhetoric of the postwar British state. The novel, showing Adah gradually achieve independence, is an exploration of both the experience of a subset of African bodies in contact with the imperial center as well as an expression of Adah's own agency in the limited context she occupies.

The novel contains numerous references to animals who index Adah's social position, recalling historical ties between race and species. As Sara Salih argues, 'it is impossible to discuss the history of race and racism without taking account of formulations of species distinction in which the putative boundaries between animal and human were (and continue to be) asserted' (2007, 95). In the novel, animals reveal the limits of citizenship for Black bodies in Britain's imperial geography, and explore convergences of race, gender and species. Animals in this context might be convenient metaphors for London's migratory histories in which Black women 'have been defined in less than human terms' (Carby 1999, 67), though such metaphors also depend on the animal occupying subhuman status. The novel's animalities, not easy signifiers of subhumanity, confound such figurations; as encountered by Adah, animals' movements often appear as sources of identification and comfort in ways that expose the limits of London's policing of African bodies. 
In its handling of the ties between race and species, the novel reveals the limits of citizenship in one passage where Francis is chased by British dogs. After getting a job as a postal worker, Francis comes home and regales Adah with a harrowing account of 'English dogs' as the 'most frightful business of post office jobs' (Emecheta 1974, 128). Postal workers' fears of dogs is a common and much-parodied trope, but Francis's anxiety reveals the particular vicissitudes of racial citizenship in post-war Britain. 'They love dogs, the English do,' he says. 'Yes, they love their dogs ... they would rather the dogs butcher a black man, than let the black man kill the dog' (128). The affective ties between dogs and their people in London accentuate for Francis his absolute exclusion within the city and delimit the constraints placed on the movement of Black bodies. This passage also perhaps reveals some limitations to the rhetoric of companion species articulated by scholars such as Donna Haraway in that the term might mark a historically whitened zone of interspecies intimacy. As the object of both the consumptive desire of dogs (who are in turn under the ownership of humans) and the ridiculing gaze of the white Londoners, Francis's story positions him as not merely a sub-category of humanity in Britain's racist cityscape, but below even those animals who find a degree of belonging - if only through their subjection to ownership - in its geographies.

This account of the relation between the Black body and white-owned dogs recalls Nicole Shukin's account of 'feeling power' as a mechanism of biopower whereby animals, especially dogs, are co-opted into the policing mechanisms of the state. She insists on thinking 'of other species as subjects of and subject to, governmentality,' citing 'the participatory spirit that seems to animate other species' involvements in modern states of war and peace' $(2013,178)$. The interpellation of nonhuman life into systems of governmentality is perhaps nowhere more evident than in colonial geographies, where dogs have been and continue to be used to police Black bodies across Sub-Saharan Africa, a trope also taken up in Tsitsi Dangarembga's Nervous Conditions (1988) and its handling of guard dogs. ${ }^{6}$ Shukin's work offers a way to view both the racist policing evident in human-canine relations in Emecheta's text, but also a consideration of how animals as more than passive bodies under human domination become co-opted into such regimes.

While Francis's experience illustrates the abjection of the Black man in London, descriptions of Adah in the text rely on animal signification - specifically wildness - that exceed colonial imperatives to contain her body. One passage from her youth in Nigeria details her being immobilized by 'four tough-looking boys' as the headmaster of her school disciplines her with 'a cane to her posterior.' In response, she bites into one of the boy's shoulders so deeply that 'fragments of his flesh were stuck between her teeth. She quickly spat them out and wiped her mouth, looking at them all wide-eyed' (Emecheta 1974, 20). This scene is striking for its emphasis on the violent and domesticating force of the educational state. It is worth noting that education itself is one of those hominizing 'institutions of culture,' but is also 'inhuman because it does not happen without constraint and terror' (Lyotard 1991, 4). Moreover, the passage strikingly inverts associations between meat and women's bodies - famously demonstrated by Carol J. Adams (1990) - in the visceral depiction of the male body's vulnerable flesh; under Adah's bite the boy 'scream[s] loudly' and 'wriggle[s] in agony." The text's foregrounding of Adah's momentary wildness breaks away from norms that position women's and nonhuman animals' bodies as available for consumption.

Adah's own body is described as 'wild' multiple times in ways subversive of the conventional colonial exercise of power on the supposedly uncivilized African body. Early in the text when under the admonishing gaze of her family when she misspends money she displays a 'wildness in her eyes [that has] a way of betraying her' (Emecheta 1974, 21), marking her body as a resistant subject to even her own efforts to interpellate it into familial norms. Later in the text, in a 
heated conversation with Francis, Adah begins 'speaking in their Igbo language and that meant gesticulating in the air. The gesticulations were wild' (121). Wildness here emerges as Adah shifts into Igbo. Wildness, then, while it might reify colonial accounts of the African body as that which is uncivilized and undomesticable might also be read as a space for the preservation of an alternative to such knowledges, a refusal of domestication. Domestication is after all a term that has 'defined the relationship of humans with certain animals but also intrahuman relationships between groups defined on the basis of race and gender' (Anderson 1997, 465). Indicating wildness as a form of resistance, in one passage we read about Adah coming under the gaze of a doctor who moralistically dismisses her attempts to get an abortion. In the moment when she falls under his pathologizing gaze, she recoils from him 'like a frightened snake, but again, like a snake, she was gathering all her energy ready to attack' (Emecheta 1974, 154). The snake metaphor might animalize her, but it also offers a venue for a kind of formidable resistance in a moment when her body is the object of institutional power.

This paradigm of wildness extends to encounters in London with animal bodies whose undomesticated pleasure refutes colonial accounts of wildness as absence. When walking to a public bath, she encounters a bird, 'great, small, solitary but contented in its solitude ... happy in its lonely freedom' (140). This description of the bird contrasts with her own experience of anything but freedom and solitude in London. In that she encounters the bird on the street, its uncordoned freedom of movement juxtaposes her containment within gendered and racial norms. She is 'intrigued by the creature,' and the encounter between them spurs her into thinking about the time 'less than a year before [when] she had seen wilder birds [in Nigeria], all gaudy in their colours, all wild in their songs' (140). This moment becomes for Adah an extended consideration of the place of the African in the colonial imagination, and offers her potential to upset that positioning. Banishing notions of 'the black man [as] lazy because of his over-abundant environment which robbed him of the ability to think for himself,' Adah concludes that ' $[\mathrm{h}]$ er children were going to be different. They were all going to be black, they were going to enjoy being black, be proud of being black, a black of a different breed' (140141). If domestication renders both animality and the Black body the uncultivated other of the colonial imaginary's anti-Blackness, Emecheta's text insists on preserving an aspect of wildness as that which is inscrutable to such negating comparisons.

Wildness and Blackness, such as they are in Emecheta's text, are described in relation to animality in terms of a metaphorics of presence. Borne out of the futurity with which her children are imbued, the text marks the beginnings of an alternative temporality of Blackness. Animality and Blackness as co-constructed in the text are thus no longer mere others, no longer empty signifiers for the normative human, but positionalities that contest the knowability of 'other' bodies from the vantage point of the colonial dichotomy between domestication and wildness.

\section{Notes on the finitude of lives: Njabulo Ndebele and the vulnerability of flesh}

If Emecheta's text subtly carves out a place for animality and Blackness to mean something other than their subhuman figurations, Njabulo's Ndebele's journalistic essay, 'The Year of the Dog,' takes up that project in a more direct fashion. Collected in Fine Lines From the Box (2007), the text takes his reader on a narrative 'journey of the imagination' (251) that considers the figure of the dog for its racialized meanings in postcolonial South Africa. The author situates the text amidst the political climate of the nation at the time, following Jacob Gedleyihlekisa Zuma's dismissal as deputy president of South Africa, when Zizi Kodwa - described as 
'spokesperson of the ANC youth league' - called for 'the dogs to be beaten until their owners and handlers emerge' (251). These dogs are not actual canines, but a reference to 'political enemies' of Zuma in the wake of his rape trial (Baderoon 2017, 352). Ndebele's essay includes an impassioned plea to devitalize this particular image of dogness, and imagines a redemptive scenario in which Kodwa declares 'we have had enough of violence! For too long we have used the dog as a symbol of abuse. This must now stop. The dog, comrades, is a special animal' (Ndebele 2007, 253). Ndebele asks, furthermore, 'How did we come to view as debased an animal known for its intelligence, empathy, loyalty, dependability, courage, protectiveness, sensitivity, and caring? ... How come an animal we own has become such a pervasive symbol of our own violence?' (255). Ndebele argues that Kodwa could 'not have been aware of the full, brutal implications of his call. He could not have been aware of the full history of violence he was invoking' (255), and so Ndebele drives home its realities through a story of a dog being beaten.

But the text makes a crucial move that dispels animality as the abject figure for the other of the normative human; refuting the figurative currency of dog slurs, he returns the reader to the materiality of flesh in a visceral account of the dog's death. This move recalls Coetzee's Elizabeth Costello and her insistence on the capacities of literature not to prize the metaphysical but to 'ask us to imagine our way into that way of moving, to inhabit that body' $(2001,51)$. Ndebele tells the reader, 'Imagine that you are witnesses to the beating of a dog.' The story goes on to say, 'Imagine Kodwa leading a crowd that has found a dog to beat and is surrounding it,' rendering the dog a kind of scapegoat in the context of postapartheid South African revolutionary politics. The graphic narrative that ensues foregrounds not the political imperatives of the crowd, however, but the suffering of the dog, stating, "The surrounded dog is terrified, helpless. There is no escape. Its eyes wide open, it watches the crowd inevitably closing in' (Ndebele 2007, 251). Much like in Mabanckou's text, Ndebele focuses not on the gaze of the human under which the animal is objectified, but the gaze of the animal itself. In foregrounding the dog's vulnerability in this moment, the text recalls what Anat Pick has characterized as a 'universal mode of exposure' shared by living beings $(2011,5)$. The massacre continues, imagining Kodwa giving 'the first blow. ... It is a powerful blow. It cracks a rib. The dog howls in pain' (Ndebele 2007, 251). Two paragraphs below, the dog's

spine is broken, the dog lies on its side, a bloody mess, still trying to raise its head, until a well-aimed knobkerrie blow smashes its skull. This silences the dog forever. The crowd continues, without a sound, to pound the dead dog's body. You hear only the dull thud of blows on the marshy body.

If we have not yet reached the revolution in language and thought necessary to consider the place of the animal, as Calarco's above-cited comment suggests, it is my argument that Ndebele's story of a violent revolutionary politics materialized in the death of a dog comes close. Indeed, this account, unlike Mabanckou's for example, does not assimilate the animal into the anthropocentric symbolic structure of language, but instead returns the reader to the material. More than that, the text generates a kind of sympathy for the animal in focusing not on the fervor of the crowd - though it does, in the text's multiple references to South Africa's dehumanizing colonial history, emphasize the constellation of politics that produce this violence but instead on the vulnerability of the animal. As the dog's rib and spine are broken, its skull crushed, and the blows fall into its 'marshy' body, the text foregrounds fleshly vulnerability, that substance that forms the matter of every mammalian body, including humans'. In that the account moves the reader away from Kodwa's figurative use of the dog toward an actual dog's 
body, it brings us into proximity with an animal in a way that even Mabanckou's story perhaps could not. But it is the finality of Ndebele's language when he marks the blow that 'silences the dog forever' that foregrounds to the reader the 'shared embodied finitude' of all forms of life (Stanescu 2012, 568). In this way, Ndebele's text offers a mode of encountering animality that puts in place the conditions of possibility for an interspecies concern to emerge, articulated alongside rather than as external to the 'human' zone of politics within South Africa.

\section{Conclusion}

Animal figures are tricky things, sometimes subordinated to their symbolic function in relation to the human but always, in that their movements may never be fully assimilable in the meanings that humans make of them, gesturing toward that other zone - that zone beyond the human where animal bodies live and move in spite of anthropocentrism's structural and global domination. Still, the 'beyond' here might overestimate the possibilities of animal life to exist outside frameworks of human domination and oppression, and I have suggested that human and animal in the few African literatures cited here jointly occupy the precarity and possibility of postcolonial worlds. I have also argued here that, even while literature itself may not yet be able to abandon fully its human-centered modes of circulation, animal presences in the texts cited here indicate a collection of beings who merit attention, both for the ways that they grant further understanding to the lives of humans, but also for - to recall Ndebele's text - their shared vulnerability in the crises that mark colonized worlds.

\section{Notes}

1 Though Calarco renders language and thought typically anthropocentric, this is not an indication of animals being 'prediscursive' bodies. As Shukin (2013) shows, animal lives - for example, police dogs are frequently incorporated into the discourses of human governmentality.

2 African animisms, often celebrated as alternatives to the fictions of Western modernity, are also a crucial source for this work (Garuba 2013).

3 Many Khoi animal poems were translated by Wilhelm Bleek in 1864's Reynard the Fox in South Africa, though Herman Wittenberg insists that Leonhard Schultze's 1907 Aus Namaland und Kalahari offers a text 'less tainted by the operations of colonial censorship' $(2011,8)$.

4 Drawing on some of these, Kai Horsthemke has recently declared 'traditional African morality [as] essentially anthropocentric' $(2015,148)$, though that argument relies on hierarchical claims of the ostensibly 'more enlightened stance' of animal advocacy (155). Paul Riesman's analysis of cattle in Fulani society is perhaps more complicated in its specific analysis, emphasizing cattle's high value, but stipulating that 'they are not integrated into [society] in the same way as men are' $(1998,159)$.

5 James Ferguson's Global Shadows (2006) details the conflicting desires of Western conservationism against the livelihood of people in the vicinity of African game reserves. More recently, Clapperton Chakanetsa Mavhunga's Transient Workspaces (2014) details the precarious lives of poachers in the global economy of the Zimbabwean hunt. For work on the positive correlation between population density and species richness, consult Balmford, Moore, Brooks, Burgess, Hansen, Williams and Rahbek's (2001) work. Gretchen Vogel (2001) troubles the assumption of a negative correlation between human population and species richness.

6 There is a rich body of literature tackling the associations between dog life and human life, ones that detail the millennia-long biological and social history of the so-called Canis Africanis (Gallant 2002). Lance van Sittert and Sandra Swart's (2008) multi-author collection, Canis Africanis, features a range of scholarship pertaining to human-canine relations, whether on the precolonial domestication of the African dog or the use of dogs to police colonized populations in Southern Africa. For relations between whiteness and domesticated animals, refer to Grace Musila's chapter 'Farms in Africa: Wildlife Tourism, Conservation, and Whiteness in Postcolonial Africa' in A Death Retold in Truth and Rumour (2015), as well as Nicholas Mirzoeff's work (2018). 
7 'Meat' and the notion of consuming animals indexes another kind of incorporative human/animal relation, often overlooked by rights-based animal studies scholarship, but present in African literature where domesticated animals or those deemed inappropriate to be eaten are subject to consumption in moments of precarity. Consider, for example, animals being eaten in Chimamanda Ngozi Adichie's Half of a Yellow Sun, Ousmane Sembène's God's Bits of Wood, or Dave Eggers' What is the What.

\section{References}

Achebe, Chinua. 1994. 'Chinua Achebe, The Art of Fiction no. 139.' Interview by Jerome Brooks. Paris Review 36(133). www.theparisreview.org/interviews/1720/chinua-achebe-the-art-of-fiction-no-139chinua-achebe. Accessed May 14, 2018.

Adams, Carol J. 1990. The Sexual Politics of Meat: A Feminist-Vegetarian Critical Theory. New York: Continuum.

Adichie, Chimamanda Ngozi. 2006. Half of a Yellow Sun. Toronto: Vintage Canada.

Adichie, Chimamanda Ngozi. 2009. 'The Danger of a Single Story.' TED. www.ted.com/talks/chimama nda_adichie_the_danger_of_a_single_story?language=en. Accessed May 14, 2018.

Ahuja, Neel. 2016. Bioinsecurities: Disease Interventions and the Government of Species. Durham, NC: Duke University Press.

Anderson, Kay. 1997. 'A Walk on the Wild Side: A Critical Geography of Domestication.' Progress in Human Geography 21(4): 463-485.

Armstrong, Philip. 2002. 'The Postcolonial Animal.' Society \& Animals 10(4): 413-419.

Arseneault, Jesse. 2013. 'On Canicide and Concern: Species Sovereignty in Western Accounts of Rwanda's Genocide.' English Studies in Canada 39(1): 125-147.

Arseneault, Jesse. 2016. 'Toward an African Animal Studies: On the limits of Concern in Global Politics.' PhD thesis, McMaster University.

Baderoon, Gabeba. 2017. 'Animal Likenesses: Dogs and the Boundary of the Human in South Africa.' Journal of African Cultural Studies 29(3): 345-361.

Balmford, Andrew, Joslin L. Moore, Thomas Brooks, Neil Burgess, Louis A. Hansen, Paul Williams and Carsten Rahbek. 2001. 'Conservation Conflicts Across Africa.' Science 291(5513): 2616-2619.

Calarco, Matthew. 2007. Zoographies: The Question of the Animal from Heidegger to Derrida. New York: Columbia University Press.

Calarco, Matthew. 2014. 'Being toward Meat: Anthropocentrism, Indistinction, and Veganism.' Dialectical Anthropology 38(4): 415-429.

Carby, Hazel. 1999. Cultures in Babylon: Black Britain and African America. New York: Verso.

Coetzee, J. M. 2000. Disgrace. New York: Vintage Books.

Coetzee, J. M. 2001. The Lives of Animals. Princeton, NJ: Princeton University Press.

Comaroff, Jean and John Comaroff. 2010. 'Africa Observed: Discourses of the Imperial Imagination.' In Perspectives on Africa: A Reader in Culture, History, and Representation, edited by Roy Richard Grinker, Stephen C. Lubkemann and Christopher B. Steiner, 31-43. Malden: Blackwell.

Couto, Mia. 2004. The Last Flight of the Flamingo. Translated by David Brookshaw. London: Serpent's Tail.

Couto, Mia. 2012. Confession of the Lioness. Translated by David Brookshaw. New York: Farrar, Strauss, and Giroux.

Dangarembga, Tsitsi. 1988. Nervous Conditions. Emeryville, CA: Seal Press.

Derrida, Jacques. 2008. The Animal That Therefore I Am. Translated by David Wills. New York: Fordham University Press.

Eggers, Dave. 2007. What is the What. New York: Vintage Books.

Emecheta, Buchi. 1974. Second-Class Citizen. New York: George Brazilier.

Ferguson, James. 2006. Global Shadows: Africa in the Neoliberal World Order. Durham, NC: Duke University Press. Gallant, Johan. 2002. The Story of the African Dog. Scottsville: University of Natal Press.

Garuba, Harry. 2013. 'On Animism, Modernity/Colonialism, and the African Order of Knowledge: Provisional Reflections.' In Contested Ecologies, edited by Lesley Green, 42-55. Cape Town: HSRC Press.

Haraway Donna J. 2007. When Species Meet. Minneapolis: University of Minnesota Press.

Horsthemke, Kai. 2015. Animals and African Ethics. New York: Palgrave Macmillan.

Lawuyi, Obafemi. 1990. 'Is Tortoise a Trickster?' African Languages and Cultures 3(1): 71-86.

Lyotard, Jean-François. 1991. The Inhuman: Reflections on Time. Translated by Geoffrey Bennington and Rachel Bowlby. Palo Alto, CA: Stanford University Press.

Mabanckou, Alain. 2005. Broken Glass. Translated by Helen Stevenson. London: Serpent's Tail.

Mabanckou, Alain. 2012. Memoirs of a Porcupine. Translated by Helen Stevenson. Berkeley, CA: Soft Skull Press. 
MacKenzie, Craig. 2008. 'Orality and the South African Short Story: Es'kia Mphahlele's "Mrs. Plum".' Alternation 15(2): 244-253.

Mavhunga, Clapperton Chakanetsa. 2011. 'Vermin Beings: On Pestiferous Animals and Human Game.' Social Text 29(1): 161-176.

Mavhunga, Clapperton Chakanetsa. 2014. Transient Workspaces: Technologies of Everyday Innovation in Zimbabwe. Cambridge, MA: MIT Press.

Mbembe, Achille. 2001. On the Postcolony. Berkeley: University of California Press.

Mda, Zakes. 2005. The Whale Caller. New York: Picador.

Mirzoeff, Nicholas. 2018. 'It's Not the Anthropocene, It's the White Supremacy Scene; or, the Geological Colour Line.' In After Extinction, edited by Richard Grusin, 123-150. Minneapolis: University of Minnesota Press.

Monye, Ambrose Adikamkwu. 1996. Proverbs in African Orature: The Aniocha-Igbo Experience. Lanham, MD: University Press of America.

Mphahlele, Es'kia. 1967. 'Mrs. Plum.' In In Corner B, 164-208. Nairobi: East African Publishing House.

Mudimbe, V. Y. 1994. The Idea of Africa. Oxford: James Currey.

Musila, Grace. 2015. A Death Retold in Truth and Rumour: Kenya, Britain, and the Julie Ward Murder. Woodbridge: Boydell and Brewer.

Ndebele, Njabulo S. 2007. Fine Lines from the Box: Further Thoughts about Our Country. Cape Town: Umuzi.

Nganang, Patrice. 2006. Dog Days: An Animal Chronicle. Translated by Amy Baram Reid. Charlottesville: University of Virginia Press.

Ngũgĩ wa Thiong'o. 1981. Decolonising the Mind: The Politics of Language in African Literature. Nairobi: East African Educational Publishers.

Okpewho, Isidore. 1992. African Oral Literatures: Backgrounds, Character, and Continuity. Indianapolis: Indiana University Press.

Omonzejie, Eunice E. 2013. 'Retelling Human and Non-Human Affiliations in Alain Mabanckou's Mémoires de Porc-Épic: A Zoocritical Exploration.' Bhatter College Journal of Multidisciplinary Studies 3: 71-82.

Pick, Anat. 2011. Creaturely Poetics: Animality and Vulnerability in Literature and Film. New York: Columbia University Press

Porter, Abioseh Michael. 1988. 'Second Class Citizen: The Point of Departure for Understanding Buchi Emecheta's Major Fiction.' The International Fiction Review 15(2): 123-129.

Price, Jason D. 2017. Animals and Desire in South African Fiction: Biopolitics and Resistance to Colonization. New York: Palgrave.

Razack, Sherene. 2004. Dark Threats, White Knights: The Somalia Affair, Peacekeeping, and the New Imperialism. Toronto: University of Toronto Press.

Riesman, Paul. 1998. Freedom in Fulani Social Life: An Introspective Ethnography. Chicago, IL: University of Chicago Press.

Salih, Sara. 2007. 'Filling Up the Space between Mankind and Ape: Racism, Speciesism, and the Androphilic Ape.' Ariel 38(1): 95-111.

Sembène, Ousmane. 1960. God's Bits of Wood. Translated by Francis Price. Oxford: Heinemann.

Shukin, Nicole. 2013. 'Security Bonds: On Feeling Power and the Fiction of an Animal Governmentality.' English Studies in Canada 39(1): 177-198.

Shoko, Tabona. 2010. "Worse than Dogs and Pigs?": Attitudes Toward Homosexual Practice in Zimbabwe.' Journal of Homosexuality 57(5): 634-649.

Stanescu, James. 2012. 'Species Trouble: Judith Butler, Mourning, and the Precarious Lives of Animals.' Hypatia 27(3): 567-582.

van Sittert, Lance and Sandra Swart, eds. 2008. Canis Africanis: A Dog History of Southern Africa. Leiden: Brill.

Vogel, Gretchen. 2001. 'No Easy Answers for Biodiversity in Africa.' Science 291(5513): 2529-2530.

Wittenberg, Herman. 2011. 'Notes towards a History of Khoi Literature.' English Academy Review 28(1): $5-22$.

Woodward, Wendy. 2001a. The Animal Gaze: Animal Subjectivities in Southern African Narratives. Johannesburg: Wits University Press.

Woodward, Wendy. 2001b. 'Dog Stars and Dog Souls: The Lives of Dogs in Triomf by Marlene van Niekerk and Disgrace by J. M. Coetzee.' Journal of Literary Studies 17(3-4): 90-119.

Woodward, Wendy. 2007. "The Killing (Off) of Animals in Some Southern African Fiction, or "Why Does Every Animal Story Have to be Sad?"' Journal of Literary Studies 23(3): 293-313.

Woodward, Wendy and Susan McHugh. 2017. Indigenous Creatures, Native Knowledges, and the Arts: Animal Studies in Modern Worlds. New York: Palgrave MacMillan. 


\title{
Depictions of Kenyan lands and landscapes by four women writers
}

\author{
Ng'ang'a Muchiri
}

Since the mid-Sixties, women writers from Kenya have demonstrated sustained interest in depicting land and landscapes. This chapter surveys the representation of land and landscape by Kenyan female authors starting from the early years after independence till the twenty-first century. It also argues that the more recent publications by Kenyan female authors tend to portray landscapes as dynamic and embodied. Grace Ogot's The Promised Land (1966) and Margaret Ogola's The River and the Source (1994) represent landscapes as deeply contested and as a communal heirloom, respectively. Muthoni Likimani's Passbook Number F. 47927: Women and Mau Mau in Kenya (1985), on the other hand, attends to the land's material aspect: soil as an object that one can touch, smell, taste and even ingest. It is in Yvonne Owuor's Dust (2014), however, that we perceive the culmination of land as not only tactile, but also animate. This chapter examines Owuor's portrayal of geographic spaces alongside depictions of terrain by Ogot, Ogola and Likimani.

I wish to begin by defining my use of two important terms: land and landscape. James Graham's Land and Nationalism in Fictions from Southern Africa (2009) successfully attends to the inherent tension in competing definitions of the land: land as terrain, versus metaphors of land which suggest identity, belonging and Black nationalism. This chapter will expand on his discussion of land and its role in the literary 'symbolic economy' (Graham 2009, 8). By contrast, my use of the term landscape emerges from the seminal essay 'Landscape in Africa: Process and Vision' by Ute Luig and Achim von Oppen. In Western thought, Luig and von Oppen (1997, 15) identify two primary understandings of the term, one using landscape to refer to spatial units, and the other associating landscape with ways of seeing the natural environment. With the second understanding in mind, they further argue that landscape is best understood as an ongoing praxis - one continuously mediated aesthetically, historically, politically and imaginatively (Luig and von Oppen 1997, 38). In an introduction to the landmark publication Landscape and Power, W. J. T. Mitchell (1994) upends conventional readings (and sightings) of landscapes. Contrary to previous scholarship which thought of landscapes as objects, Mitchell foregrounds, instead, an understanding of landscape as a "process by which social and subjective identities are formed' $(1994,1)$. He is particularly keen on unveiling landscape as an 'instrument of cultural power,' especially within the rise of imperialism in the nineteenth century (Mitchell 1994, 2). What Mitchell, Luig and von Oppen successfully lay out is that landscape is best 
understood as cultural, creative and ideological labor, manifest on geographical terrains. Writing about representations of landscape in South African literary and visual arts in the long nineteenth century, J. M. Coetzee focuses on the elision of black labor. Afrikaner settlers needed to demonstrate their husbandry over colonial spaces to justify occupation; since evidence of black labor shaping South African landscapes undermined Afrikaner claims of land ownership, Boer nationalism systematically erased this proof, preferring to highlight landscape instead of land (Coetzee 1998, 3).

Discussions of land and landscape in Kenyan literature are not in themselves new. For instance, Glenn Hooper invokes the idea of landscape in juxtaposing Ngũgĩ's Petals of Blood alongside Frantz Fanon, describing the colonial landscape as an accurate 'metaphor for the regimented life of the colony' (Hooper 1998, 47). However, and for most of his article, Hooper's focus is on the depiction of land as agricultural resource and land as place of residence, rather than on landscape. As Tirop Simatei $(2005,86)$, cogently argues, colonial relationships to pre-colonial territories were marred by epistemic violence which required the erasure of indigenous knowledge and conceptions of landscapes. According to Simatei, in order to justify this epistemic violence to particular territories and their inhabitants, Kenyan authors depicted colonizers who preferred to think of this violated land as empty landscape. Thus, in Ngũgî's Ilmorog, ${ }^{1}$ global capital assails the land in the guise of a trans-continental highway. Local activists, however, re-shape the landscape to fulfill the aspirations of the Kenya Land and Freedom Army, otherwise known as the Mau Mau. Similarly, Dustin Crowley foregrounds how terrains or land in Ngũgís texts are inherently connected to the global movement of capital and culture. Land is examined here as a political, economic and cultural asset. Overall, Kenyan understandings of landscapes in Ngũgî's writing are dynamic, advancing or withdrawing in relation - or reaction - to inflows and outflows of people, finance, technology and power.

In this chapter, Owuor's novel Dust best represents a new kind of engagement with land and landscape on the part of Kenyan female writers. To investigate Owuor's representations of the land as tangible and sentient, my chapter attends to her novel's female figures and their relative detachment vis-à-vis Kenyan vistas and the Turkana geography. ${ }^{2}$ This, I argue, differentiates Owuor from other Kenyan female authors and speaks to the disparity between subordinated persons and the postcolonial African nation-state. Much of the current interest in Owuor's Dust addresses the psychological makeup of the novel's characters and the elements that contribute to their sense of place. To this end, Christina Kenny explores recollection, emotions and language as key motifs which underline important thematic concerns such as belonging, homecoming and nationhood. Kenny identifies a fundamental paradox: characters exhibit an 'insatiable desire for home' even as they consistently resist 'borders and nationalist monoculture' (2017, 4). Tension often follows after characters migrate - either far from Kenya's metropolis, Nairobi, to Turkana or across the Atlantic to Brazil. Hence, this internal conflict can also be understood as a 'mobility-induced anxiety about place and about self' (Knudsen and Rahbek 2017, 118). Amy Rushton also attends to journeys away from a character's natal location; these voyages inspire questions regarding identity, indigeneity and the importance of rigidly holding onto an immutable image of what home should be. Throughout Dust, home is indeed a problematic notion. Home is simultaneously 'troubled and mutable' (Rushton 2017, 52) and also 'desired yet feared' (53). Scholars have convincingly argued that Owuor's protagonists view home from two opposing, perhaps irreconcilable, perspectives. Home is not only a refuge to escape to, but also a danger to escape from (Rushton 2017, 50; emphasis mine).

The inability of characters to lock the idea of home into a specific location also tends to unsettle long held assumptions about human agency. In this respect, Russell West-Pavlov 


\section{Ng'ang'a Muchiri}

(2017, 295) has explored the manifestation of a 'nonhuman agency of timespace' in Dust. What is especially fruitful in this engagement is a recognition of landscape's power to influence and indeed manipulate human lives. For West-Pavlov, geographical terrains are not simply passive bystanders bearing the brunt of human intervention, but rather active participants in the creation of reality. However, scholarly studies on Dust have yet to explore the ways in which the landscapes themselves come alive. Despite recognition of 'elemental substances' in the text - as for instance, in the descriptions of terrains as dust - there has been no sustained engagement with the animated nature of landscape (Kenny 2017, 6).

Before undertaking a more sustained examination of land and landscape in Owuor's novel, I will first review the portrayals of land in three other works of literature by Kenyan female writers, starting with The Promised Land by Grace Ogot. The Promised Land, I argue, deploys folklore to construct narratives of belonging within Kenya's Luo community. In this novel, the male protagonist, Ochola, learns that Luo farmers are migrating to Tanganyika in search of fresh land, but his wife, Nyapol, remains skeptical. Despite Nyapol's reluctance, and a family intervention asking him not to leave, Ochola and Nyapol make the journey - first by bus to Kisumu and then by ferry across Lake Victoria. Once in Tanganyika, Ochola symbolically claims land using a traditional Luo gesture: a ring of grass with a stone placed on top of it. With time, Ochola's relations with his Zangazi hosts sour. One villager is particularly bitter that Ochola and other Luos act as though they 'were born to rule' (Ogot 1966, 93). Tragedy strikes when Ochola suffers a mental breakdown. He runs off into the bush, only to re-emerge later, his body resembling a porcupine and covered with thorns. Ochola's mysterious illness defeats not only Magungu, a famous medicine man, but also experts at a colonial hospital. Finally, Magungu returns with oils and ointments which cure Ochola's skin warts. The price for treatment, however, is that Ochola's family must vacate their home before dusk. Ochola, incensed at having to leave his wealth behind, has to be physically dragged out; Nyapol is grateful to finally depart from a place harboring much misfortune. The couple and their children return to Kenya, but without Ochola's beloved dog. Ogot ends the story asserting that although Ochola's body returned to his Seme home, his soul was left in Tanganyika (193).

Ogot depicts and foregrounds landscapes as entities in their own right. Both men and women repeatedly stand back to admire their surrounding vistas. Luo country is 'peaceful,' according to Nyapol, or 'peaceful and undisturbed,' in her husband's words $(22,42)$. Abroad, in Tanganyika, Ochola's surveying eye is exceedingly satisfied by the terrain to which he has migrated. The Zangazi countryside is described as fecund, hilly and 'very beautiful' (85). Despite these calming re-assurances, however, there is something ominous in the background and the text outlines a variety of threats. For instance, there are toxic fungi that Luo toddlers are taught never to pick (22). Aside from a hostile ecosystem, the landscapes are steeped in a history of armed skirmishes. In other words, the investment in landscape on Ochola's part is not unconnected from battles over land as terrain and territory.

I argue, then, that landscapes in Ogot's The Promised Land (TPL) represent conflict - at a physical and narrative level. Nyapol's and Ochola's Luo forefathers gave up their lives to wrestle territory from Nandi pastoralists. In Nyapol's view, this history makes migration away from home tantamount to sacrilege. According to Luo folklore, the Nandi community was 'driven away to the mountains' while Luo victors took over fertile pasture and farmlands (Ogot 1966, 22-23). That numerous war heroes were never properly laid to rest, 'drowned by the angry river in the depth of the lake,' adds to the cultural angst (23). Evidently, there is deep attachment to the Luo ancestral home, and as the writer demonstrates, this connection has been forged by the blood of conquerors. Thus, although Nyapol sees the country as calm and serene, 
she also recognizes that it has been inexorably shaped by a history of war. The landscape unfolds to her gaze exactly as it does due to the lives lost, and communally honored.

Ogot recycles this motif of physical conflict, underlining the extent to which violence is a key marker of Luo landscapes. In recent memory, presumably after Ochola's ancestors had ousted the Nandi, two Luo factions clashed. Gem wanted to 'drive the people of Seme to the steep hills ... But the Seme overpowered the people of Gem and killed many of their great warriors' (Ogot 1966, 42). Once more, this history of bloodshed is deployed to suggest deeper ties to the land. Hence, Ochola is anxious that his desire to migrate betrays his grandfathers. Eventually, his ambition for fresh farmland and great wealth wins over his cultural obligations to a Luo constellation of heroes. The text does suggest, however, that Ochola and Nyapol must return home - as indeed happens by the end of the novel.

Ogot's use of local mythology not only transmits history, but also signals how violence is embedded at the level of narrative. First, the narratives of battles as told by Nyapol and Ochola re-victimize the Nandis and the Gem, respectively. Each time the story of Luo, and Seme, hegemony is re-told, the communities are that much further removed from peaceful reconciliation. The tales are both memory, and justification, of the wars. Second, this history of conquest fuels future Luo expansionism in Tanganyika. Luo fantasies of unoccupied Zangazi land are in direct conflict with indigenous land rights. Hence, in the last half of The Promised Land, Ogot's portrayal of landscapes and violence serves as an indictment of settler colonialism. Using communities of Luo immigrants and indigenous Tanganyikans - the Zangazis - Ogot stages a conflict about settlement between black Africans that allows the reader to imagine questions of otherness outside the colonial paradigm. She does this to highlight the violence that accompanies settler colonies, especially at the outset when justifications for domination are manufactured. Consider, for instance, when Ochola fantasizes about 'Tanganyika, where the land was fertile ... [and immigrants] owned large farms of maize and millet, beans and vegetables and were producing quantities of milk and ghee' (13). Luo migrants are, supposedly, better skilled, better equipped and more motivated than the Zangazi peasants amongst whom they live. This familiar dichotomy is what European settlers deployed when, for instance, they carved out prime East African farmland and demarcated it the White Highlands. ${ }^{3}$ Thus, we have to read Ogot with much irony when she writes that Ochola was convinced when Luo migrants 'said that wide expanses of the land were virgin territory. You could take as many acres as you could cultivate' (14). Approximately five decades before publication of The Promised Land, similar narratives had been employed when discussing not just East Africa, but other areas of the African continent.

Ogot uses disputes over ancestral land ownership connected to nascent colonial projects as a way of countering similar undertakings associated with European imperialism on the African continent. Beyond that, Ogot's text examines narrative-induced conflicts about land. Competing, and incompatible, folklore about geographical spaces - settlers view the land as empty, autochthons see the same space as their rightful home - leads to physical violence. The Promised Land's use of narrative interrogates contemporary understanding of land rights. On the one hand, communities produce explanations that privilege emptiness and the potential for settler occupation while, on the other, simultaneously offering tales that foreground communal ownership of ancestral land. As I demonstrate, complications arise when competing sets of narratives - from the native versus settler point of view - are applied to the same land/space. How Ochola and his community establish ownership of various spaces, both at home and abroad, offers an opportunity for a deeper investigation of land possession. Evidently, narrative forms a core mechanism in communal and individual efforts to either disenfranchise others or safeguard one's land rights.

Nyapol, the female protagonist in The Promised Land, stands apart from the landscape; this detachment molds her in two critical roles. First, as a transmitter of communal lore, Nyapol asks 


\section{Ng'ang'a Muchiri}

herself 'How could anyone think of leaving this land?' (Ogot 1966, 22; emphasis mine). In truth, Nyapol is questioning Ochola's audacity displayed in his willingness to betray ethnic solidarity; she is positioned as an educator, teaching Ochola - and the reader - about Luo heroes. To successfully perform this task, not only must Nyapol be steeped deeply in Luo political history, she must also adopt a stance outside of this chronology. That vantage point enables her to evaluate the merits of Luo mythology - versus the Nandi's - and the importance of preserving it. Significantly, Nyapol reconciles this pedagogical - and ideological - enigma while still a young bride, and before she becomes a mother. Presumably, what she learns from this experience will add to her repertoire as a mother-teacher once she and Ochola have offspring. In the first half of The Promised Land, then, Nyapol supports the inter-generational transfer of ethnic myths.

By the end of the novel, however, it is increasingly clear that Nyapol's relationship to landscape is not merely that of chronicler, but also of dissenter. This emerges as her second posture: participant in Kenya's post-independence democracy. In the midst of Ochola's mysterious skin illness, Nyapol demands they move back to Seme, re-establish a home amongst their extended families, and leave a place that has caused them much trouble (175). A little later, when two babies fall ill, Nyapol admonishes Ochola that 'All these misfortunes have befallen me because you have refused to return home. How many times have I pleaded with you to let me take the children away from this country back to the land where they belong?' (178). In Nyapol's critique of Ochola's vision for their family's future, Ogot presents the outlines of a role for female figures in shaping Kenya's postcolonial project.

In Kenya, for instance, the tastiest fruits of independence (matunda ya Uhuru) were reserved for wealthy, well-connected men who often displayed this largesse by presiding over polygamous households. Women, youths, ethnic minorities and the poor were largely sidelined in the business of running the nation. Nyapol's actions, just three years after the advent of Kenya's self-governance, map out future roles for women in the political sphere. Future disciples of Nyapol will not only lead the nation out of political tight spots, they will also engage in strategic thinking to determine the best policies for the nation. Although Nyapol is confined to the home, the disagreement with her husband over their relationship with territory in different places has serious implications for the family's future.

While Ogot portrays Kenyan landscapes as multiply contested, Margaret Ogola's fiction explores the custodial nature of communal land. The River and the Source (1994) is a tale about four generations of women. Akoko Obanda, the matriarch, is born around Lake Victoria as Britain colonizes East Africa, and her life is closely intertwined with European settlement. Not only does she lose her first son to World War I, she also relies on the colonial administration to protect her late husband's property. Other significant interactions with imperialism are facilitated by her daughter, Maria Nyabera. Maria, after several unhappy marriages, turns to Catholicism for solace and comfort. Witnessing her mother's suffering, Maria urges Akoko to accompany her to a Christian mission and to start life anew. Elizabeth, Maria's daughter, goes on to provide much needed progeny. A teacher, Elizabeth marries and bears seven children. Ogola notes that the river which began with Akoko, and which 'at one point had trickled to a mere rivulet in danger of petering out ... was [once again] gathering momentum' $(1994,190)$. Akoko's descendants, through Elizabeth, intermarry with members of various ethnic and racial groups in post-independence Kenya - including the country's expatriate community. Both by tracing the lives of several generations of Africans, and by deploying the motif 'the dead have no use for the living who have eventually to tear themselves away so that the business of life might somehow continue,' Ogola expertly depicts Kenya's colonial-to-postcolonial transformation (288). She demonstrates the socio-political changes that indigenous communities in Britain's East African colony have endured and (to various degrees) transcended. 
Ogola's The River and the Source foregrounds landscape's two key attributes: as divine bequest, and as communal heirloom. In other words, Ogola imagines geographical terrains as a vital heirloom - bequeathed by god - and passed on from one generation to the next. She achieves this by deploying oral traditions and repeatedly invoking their educational role to pass on communal wisdom. Through Akoko, Ogola offers her readers the following piece of tribal lore:

Were is a great spirit. He saw that the world needed more than spirit forms. So he created Ramogi and his brothers who were men. Man has a form which is spiritual. Were sent the men he had created to various parts of the world to settle in it. Ramogi he sent to the country around the great lake which was a great favour for he had more spirit than his brothers. The wife whom Were gave him was called Nyar Nam who embodied the spirit of the great lake. They had many children including Rachuonyo, Sakwa, Asembo, Yimbo, Gem, Uyoma, Nyakach, Seme and Ugenya among others who settled around the lake, tilling land, taming animals and catching fish. These are the children of Ramogi from whom we all arise.

(1994, 74)

Akoko's myth of Luo origin validates claims of land ownership in several ways. First, it establishes direct communion between a deity and Ramogi, the first man, and also the first inhabitant of this part of Kenya. Simultaneously, this claim invokes right of ownership via divine gift, as well as right of first occupancy. The Luo community owns the land around Lake Victoria precisely because they did not dispossess any prior residents - in contrast to the Luo-Nandi conflict described in Ogot's The Promised Land. Furthermore, the names of Ramogi's children, among them Sakwa and Gem, all coincide with the names of various regions where Akoko's community lives. This rather convenient pattern makes it clear that the rightful owners (and heirs) of this land are those who have exercised their right to name places. ${ }^{4}$ Ogola's rhetorical move can be traced back to the writing produced by Jomo Kenyatta and Oginga Odinga, in the late Thirties and Sixties, respectively. ${ }^{5}$ Kenyatta's work on Gikuyu culture, and Odinga's on the Luo community, both reference myths of origin and their centrality in communal wisdom. In addition, of course, both writers use these stories to allude to the ancient nature of African communities and justify why colonial incursions encountered resistance. What Kenyatta's, Odinga's and Ogola's texts have in common is that they establish the native/settler binary and argue for inalienable land rights on behalf of aboriginal communities.

Akoko Obanda is neither submerged into, nor is she positioned apart from, landscapes; rather, her most important relationship to landscape is that she travels extensively across it. As an aggrieved young bride - insulted by her husband's mother - Akoko abandons her children and journeys back to her natal home (Ogola 1994, 33); later as a widow, she walks to Kisumu seeking justice over a thieving brother-in-law (76). Decades after her death, Akoko's personality reincarnates in the mannerisms of her granddaughter, Vera (256). Evidently, Ogola's protagonist is dynamic, and a vibrant life force. In each odyssey, Akoko is brave, spirited and a champion of what is just. She repeatedly stands up for herself, and those like her who are marginalized and powerless. In late pre-colonial Luo-land, newly wed women and widows were close to the bottom of the social hierarchy. ${ }^{6}$ Hence, their in-laws could abuse them with impunity. Akoko Obanda, daughter of great Chief Owuor Kembo, does not brook such behavior; she resists by relying on the Jodongo, the Luo council of elders, or the colonial District Officer. A similar moral compass can be identified in Vera, who is described by her mother as wise 'beyond her years' (256). Centered around strong women, Ogola's work underlines their social role in advancing equality in the face of regressive patriarchal norms. 


\section{Ng'ang'a Muchiri}

Women's peregrinations lead to fierce criticism of colonial or homegrown hegemony. Ogola's text serves many purposes in the aftermath of colonial projects in Africa, one being the chronicling of life in indigenous societies and institutions, much like Chinua Achebe and Ngũgĩ wa Thiong'o have done. In addition to re-telling history, The River and the Source marshals aesthetic conventions to demonstrate indigenous land rights. This desire parallels earlier acts of resistance in which narratives served as political tools for demanding increased individual (or communal) agency. My reading of Ogola identifies the novel's engagement with a colonial imagination of East Africa as empty land. Ogola not only demonstrates the voiding of African customs as perpetrated by European officials but she also responds to the imperialist rhetoric embedded in colonial texts. Further, she reveals how various social binaries - male/female, settler/native - influenced patterns of land ownership. For one, the British fabrication of Kenya as a tabula rasa inspired an equal and opposing effort to prove ancestral ownership of land. Her fiction privileges oral storytelling as a way to pass on key knowledge about landscapes. These processes foreground non-text-based ways of knowing, in direct opposition to a production of information that centered on literacy. Ultimately, Ogola's fiction foregrounds land as an intergenerational bequest. Like the oral stories which litter her text, land is handed down from the ancestors via a custodial relationship - temporarily held in trust by the living and to be passed on to the unborn.

Unlike Grace Ogot and Margaret Ogola, Muthoni Likimani - a former freedom fighter - is much more interested in the material aspect of land; in other words, her focus is on land rather than landscape. ${ }^{7}$ Muthoni Likimani's Passbook Number F.47927: Women and Mau Mau in Kenya (1985) is a multi-genre text. The title refers to Likimani's own passbook document when she lived in colonial Nairobi, suggesting that her fiction is, simultaneously, autobiographical. Beyond fiction and memoir, however, Passbook Number F.47927 also crosses into cultural studies. The book was first published in 1985 as part of the Women in Society series. ${ }^{8}$ Other titles in this list include: Women and Crime, Women in Ireland, Women and Sport and Women and Spirituality. Hence, the text is deliberately positioned as critical scholarship on women's experiences and involvement in the struggle for Kenyan self-rule. This image is further cemented by Jean O'Barr's introductory essay and Likimani's own expositions which precede each story. The chapter with the title 'Passbook Number F.47927' recounts how Nairobi women struggled to acquire the essential passbook. Without it, they were liable for deportation back to their villages, and they could not seek employment. The rural areas were no more benign, as narrated in 'Forced Communal Labour.' This chapter demonstrates the extent to which colonial infrastructure projects - building roads and bridges, and soil conservation work - placed extra burdens on women. The chapters titled 'Kariakor Location,' 'Komerera - Lie Low' and 'Unforgotten Flames' feature female characters who despite risks to their lives and great odds, support the fight for independence. Finally, 'The Interrogation Camp' and 'Vanishing Camp' explore life in detention - a colonial invention meant to rehabilitate Mau Mau rank and file.

In Passbook Number F.47927, the soil is a physical object that characters connect with variously. Likimani deploys land as a material object, instead of landscape as metaphor for humans' relationships with the land. In 'Komerera - Lie Low,' Likimani conveys 'the strong feelings all [Kenyans] had for the soil, for the land taken by the whites. The soil was their lives, giving them strength as they grasped handfuls, smelling it as if a precious perfume and repeating "The soil is ours"' $(1985,92)$. I am particularly drawn to the tactile nature of these contacts with dirt. Likimani's Kenyans depend on their senses of touch, smell and even taste, to demonstrate connections to their motherland. Mumbi, the protagonist in 'Unforgotten Flames,' establishes her Mau Mau credentials by bending, taking a handful of soil, smelling it, putting some in her mouth and chewing it while repeating 'The soil is ours' (119). This helps to identify her as a 
friend of the movement - someone ready to risk everything to supply guerillas with food, shelter, medicine and ammunition.

Passbook Number F.47927 chronicles women's roles in the anti-colonial struggle and on this basis claims space for female agency in the post-independence public sphere. The text highlights women's contributions to pre-colonial economic activities. Mau Mau slogans, like 'The soil is ours,' underlined subsistence farming and pastoralism as the primary economic activities of Kenyan communities (Likimani 1985, 119). Women's labor supported this productivity and was a significant factor in the formation of polygamous households. Through Nyakio, one of the main characters in 'Komerera,' Likimani exemplifies women leaders who sustained the anti-British campaigns. Indispensable to the anti-colonial crusade, women fed guerillas, hid them from security forces, scouted and passed on information; women were also instrumental in supplying the Mau Mau with medicine, guns and ammunition. Nyakio is a seasoned guerilla. Nyakio, Njeri and Nduta embark on a quest to locate their husbands in Nairobi (96). Each missing spouse is variously employed in the colonial capital; one is a railway handyman, another is a cook at a European sports club, and the last works as a chef in a leafy suburb. Likimani explores the breakdown of familial ties that happened in the run-up to Kenyan independence. Not only did family members disappear, but many were simply separated for long stretches of time. This had repercussions for the communal links of kith and kin that bound individuals. Nyakio's expedition, navigating 'forests, crossing big rivers, climbing steep hills, walking down steep valleys,' is representative of the turmoil women suffered (92). Female figures in Likimani's text travel widely, and the result of these physical journeys is a psychological metamorphosis. These cross-country expeditions suggest women's fundamental transformation - from subjects of pre-colonial patriarchy (and colonial surveillance), into battlehardened veterans with inalienable rights in a newly democratic Kenya.

Evidently, Likimani's depiction of land privileges the tangible over the figurative. The people's connection to the soil is not merely ideological - by ingesting it, the people become one with the terrain. And of these interactions, the most significant are instances where the earth helps to rejuvenate and to strengthen. Scooping soil from the ground, inhaling its rich aroma and chewing it are key gestures for a community resisting a stronger occupying force. Swallowing the dirt not only renews their commitment to the struggle, it also serves as a unifying act that distinguishes friend from foe. For instance, the symbolic deed of consuming dirt frames the farewell between Nyakio, Njeri, Nduta and a group of Mau Mau with whom they share a meal (102). Here, Likimani demonstrates how her characters deploy this powerful performance to say goodbye and wish each other luck - amidst endless loss of lives. With death a common occurrence during Kenya's State of Emergency, eating the soil connects the living to the dead buried in the same terrain - and to the unborn - future generations who will reside on the same landscapes. The community transcends the horrors of armed conflict by simultaneously linking itself to the ancestors and the not-yet-born. Following Gikuyu custom, women buried their newborns' umbilical cord - welcoming the child into the world of the living, while also connecting it to ancient blood lines. ${ }^{9}$ The role of the soil as a conduit into the world of the living burying the umbilical cord - or into the world of the dead - burying a corpse - is thus redeployed in the Mau Mau oaths that asked adherents to grab a handful of dirt, to chew on it and to swallow. ${ }^{10}$

If in Likimani's narrative, a connection to the materiality of soil signifies a commitment to liberating land and territory, in Yvonne Owuor's novel, Dust (2014), the landscape is embodied in the lives of diverse characters and this in turn serves as a metaphor for the kinds of relationship that differently positioned Kenyan subjects have with the Kenyan nation. In this novel, Owuor is representative of contemporary writers who depict Kenyan landscapes as not only 


\section{Ng'ang'a Muchiri}

animated, but also dissimilar from the women inhabiting these spaces. Unlike some other authors, Owuor does not dwell on ownership of land, and also does not feminize landscapes. In this chapter, I read the dissonance between women and landscapes in female-authored texts like Owuor's Dust as a metaphor for the power gap between marginalized citizens and postcolonial African nations. Dust starts off as Moses Ebewesit Odidi Oganda (henceforth referred to as Odidi) re-possessing a vehicle from his former business associate, is shot dead on a Nairobi street. Nyipir Oganda, Odidi's father, and Ajany Oganda, Odidi's sister, retrieve his body from the city morgue on the day Kenya erupts into the 2007 post-election unrest. At the same time, a British national, Isaiah Bolton, sets out on a journey from England to Wuoth Ogik, the Oganda home, in search of information regarding the whereabouts of his father, Hugh Bolton, who had been a colonial settler in Kenya. Isaiah undertakes this journey even though Selene, his mother, has begged him not to. He has been summoned by Odidi who sent him a book, and a nude painting that the colonial settler Hugh Bolton had done of Akai Ma, Odidi's mother. The novel ends with love. Akai Ma walks off into the Northern Kenya drylands with a longtime admirer. Nyipir, alongside a man who was once his captor and torturer, embarks on a pilgrimage to Myanmar, where his elder brother and father died in wars fought on behalf of the colonizer. Ajany and Isaiah, now openly in love, form the second generation of Oganda-Bolton family ties.

Owuor's Dust speaks poignantly against the conceptual twinning of femininity and ecologies - both perceived by patriarchy as passive and pliable - into the concurrent projects of anticolonial resistance and post-independence nation building. Dust's East African setting in general, and Turkana in particular, is long-suffering and enduring. The Turkana vista can be either nurturing or lethal, suggesting the cyclical rhythms of life in Northern Kenya. Owuor's trilogy of female protagonists - Akai Ma, Ajany and Selene Bolton - are depicted variously as aggressive, fragile or resilient. These multi-dimensional identities are also recognizable in the geographical spaces they occupy.

In many ways, Akai Ma Lokorijom's character is constructed as non-motherly and gender non-conforming. This is despite Akai imitating expectations of femininity through her emotive grieving over Odidi's death. When her son's body is returned to Wuoth Ogik, Akai reaches into Odidi's coffin 'rocks her son, strokes his face, rocks her son,' mimicking motherly gestures (Owuor 2014, 35). Dust, however, further complicates this maternal figure. Akai Ma wields an AK-47 and threatens to use it on a mourning and clingy Ajany - a rather unmotherly act (33). Reaching for the gun is not an impulsive reaction to her son's tragic death. Akai has a history of carrying things socially reserved for men; previously, she was known to walk with a headrest and a club - items that are generally located within the purview of Turkana masculinity (39). At the same time, Akai is deeply connected to the land. Her movements seem to flow 'from the root of the world,' and she is described as 'made of and colored by the earth itself (33). In her personality, however, she is not just connected to the land, but is, as it were, an extension of the land. Akai Ma is depicted as 'ferocious'; randomly, and for no apparent reason, 'she might erupt with molten-rock fury, belching fire that damaged everything it encountered. Akai was ... dark, difficult, and dangerous' (33). Akai's most important relationship to the land is not that she is similar to it, but that she moves expansively across it - as a teenager, a student, a lover, a mother of twins and finally as Odidi's bereaved parent $(315 ; 342 ; 348 ; 362)$. It is meaningful that she embarks on these journeys as an unaccompanied woman, across spaces that have witnessed armed violence since the late colonial period. Akai's physical expeditions invite the reader to reflect on the nation-state's propensity to circumscribe its subjects. By crisscrossing the landscape, Akai pushes at multiple borders that limit citizens; these boundaries include nation, territory, culture, gender, race and ethnicity. Akai's disregard for propriety - for instance, living 
as Hugh Bolton's mistress then reacting with disdain to her parents' horror - hints at the restrictive nature of social mores.

Ajany, Akai's sole surviving progeny, stands apart from the landscape, perhaps signifying her initial alienation from the Kenyan nation. Ajany is depicted as the prophetic voice whose visions of hope inspire salvation. Despite four live births, Akai has suffered the misfortune of burying three of her children: the twins Ewoi and Etir, while still a young mother, and now Odidi. Ajany, having witnessed her parents' sorrow, responds to it through the creative arts. Reacting to the unbearable grief of losing Odidi, Ajany muses on how 'she could paint this: hold the brush as a stabbing knife ... Coloring in landscapes of loss. She could draw this for him, this longing to hear his particular voice' (18). The tragic death of her elder brother, a confidant, role model and unparalleled storyteller, is particularly hard for Ajany to accept; transcending this sorrow can only be done through painting, paintbrushes and canvas. Growing up, her relationship with Akai Ma was strained. Ajany retrieves this emotional anxiety and channels it creatively; nostalgia for her mother's affection re-emerges as artwork - Ajany 'could paint this. Could even paint the nothing' (37). Nyipir and Ajany, while much closer, are still plagued by her father's lack of emotiveness. Ajany regards him variously as a 'chiseled stone icon,' a 'stone sculpture melting,' or as a 'stone Nilote' $(23 ; 45 ; 290)$. Referring to Nyipir Oganda as rock hints at his inability to open up, be vulnerable and communicate his inner struggles. But it also represents his lack of affect in terms usually reserved for describing the physical geography of a terrain. Seemingly, while Owuor detaches her female figures from the landscape, she assimilates some of her male characters into the landscape. Ajany has previously used her artistic eye to approximate her father's true emotions. It is not until the end of the novel that Nyipir learns to open up and rely on friends and family. The refrain 'She could paint this,' as well as allusions to Ajany's art, are both repeated throughout the book $(18 ; 23 ; 37)$. By the end, Ajany's art is a harbinger of peace. Alongside a landscape in full blossom, Ajany's canvases are a key element in the forgiveness that the Oganda and Bolton families have yearned for over many decades.

Selene Bolton, a female English settler largely overlooked by critical studies on Owuor's novel, displays an antagonistic relationship towards the landscape. Against Hugh Bolton's obsession to possess as much of Kenya as possible, Selene is more cynical. Her husband surveys his surroundings and applies the possessive 'my' to items - hunting trophies, places, the Kenya colony - as well as to varied persons - a hunting guide, a chef, a carpenter, a boat rower and a spouse (94). Hugh exhibits the imperialist desire to claim, own and dominate. His wife, however, is much more aware of Kenya's resistance against this colonial gaze. Selene perceives something sinister about the land as well as a particular vision of landscape and she is skeptical about the merits of Britain's East African project. Selene recognizes that the Kenya colony 'chose its prey. Seduced them, made them believe they owned it, and then gobbled them down, often in the most tender of ways - like a python' (100). Selene's fear is inspired by her recognition that colonial settlement is short-lived and untenable. While Hugh and the rest of the British community revel in their version of tropical paradise, complete with innumerable domestic servants, Selene awaits the inevitable insurrection. She barely manages to escape from Kenya, saving herself and her unborn son, Isaiah (115). Hugh, she reluctantly acknowledges, is lost to her forever, unknowingly consumed by the same terrain he sought to dominate.

Dust spotlights landscapes singularly. Through a third person narrator, Owuor describes Odidi's nostalgia for home. Odidi remembers 'desiccated terrains ... bleating goats ... far mountains,' and the Turkana skies resembling an 'endless dome' (Owuor 2014, 5). Here, at the onset of her text, Owuor clearly lays out her focus on landscape. In Dust, landscapes are a dynamic force, and they come alive. By demonstrating how people, and the land they live on, 


\section{Ng'ang'a Muchiri}

share a desire for longevity, Owuor anthropomorphizes the landscape and paints it as a living entity - articulating how 'transient' geographic features can 'disappear' or even 'crawl back' (364). After a sudden rainstorm in the arid Turkana lands, the soil 'gulps down' as much refreshment as possible, stockpiling water through underground aquifers in anticipation of another long dry spell (364). I read the earth's reaction to blessings of rain as a survival tactic, necessitated by the extremely arid conditions of Northern Kenya.

Dust illustrates a clear causal relationship between the well-replenished earth and thriving flora and fauna. After the desert storm, birdlife sings, herbivores roam freely, flowers blossom and trees flourish into a wall of green (364-365). By framing landscapes as subjects, Owuor invites the reader's reflection on how organisms - human and non-human - are dependent on each other. Landscapes are instrumental in rejuvenating diverse forms of life, both plants and animals. Owuor's unique aesthetics, delivered via poetic language, foreground agency in climactic elements. For instance, the winds featured in Dust are particularly potent. Owuor's illustration of the breeze is couched in captivating verbs; the wind roams, ambushes, flanks, blunders and swivels (365). Aside from demonstrating the frequent transformations of Northern Kenya's weather patterns, this language images how terrains are shaped and re-shaped by atmospheric conditions. Moreover, by highlighting the effect of winds, thunderstorms, flash floods and drought - phenomena over which humans have little control - Owuor undermines human assumptions about influence on, and ownership of, the landscape.

In Owuor's Turkana, physical and psychic landscapes are symbiotically connected - none thrives without the other. Besides landscapes' central role in Owuor's work, they serve as depositories for psychological suffering. For instance, Akai Ma retrieves personal narratives she had hidden deep 'in the earth' (362-363). By sharing these memories with Ali Dida Hada who in turn offers his own biography - Akai Lokorijom transcends the decades of inner turmoil she had previously endured. Both Akai and Ali move beyond their individual tragedies. As Nyipir instructed Ajany, it is vital that the Oganda family learns to re-generate hope, and how to breathe again (361). Owuor's description of Akai Ma's psychosomatic burdens as being hidden 'in the earth' nudges us to see the connection between a Turkana terrain that nurtures animal and plant biodiversity and its human inhabitants who have, finally, attained a semblance of inner peace.

Owuor's representation of landscapes outlines the extent to which history haunts the present. Dust demonstrates how the past is manifested in the present. This is especially true in relation to political unrest. While the 2007-2008 post-election violence was the most traumatic in Kenyan post-independence history, Owuor reveals a long and ominous history of such conflict. She parallels a man's beheading - with digits stained by voter's ink - to the political assassinations of the Sixties and Seventies that ended such illustrious lives as Pio Gama Pinto's, Tom Mboya's and Kung'u Karumba's (41; 23). ${ }^{11}$ Truly, with Mboya's 1969 murder, the 'dying had started long ago'; to survive, the masses adopted a way of life characterized by 'not hearing, not seeing, [and] never asking, because sound, like dreams, could cause death. Sound gave up names, especially of friends' (23). As aberrant as the 2007-2008 cycle of bloodshed was, it can be viewed as merely one episode in a drama that has lasted since Kenya's late pre-colonial period and Britain's anti-Mau Mau efforts. Dust suggests that connections exist between the loss of life for political reasons in 1963 and the loss of life for political reasons in 2007 (24). The victims from 1963 have not been publicly acknowledged, nor have their perpetrators been brought to justice; but no amount of willful forgetfulness will eradicate these ghosts who continue to haunt the political present. Owuor's novel proposes that what is required, instead, is an overhaul of how power interacts with the people: nothing short of a third liberation will suffice. Initially, independence wrested self-rule from Britain in 1964, while the 1992 liberation brought the 
advent of multi-party politics into what had been a one-party autocracy. A third revolution will entrench the rule of law and end impunity.

By displacing critical parts of the narrative away from the capital city towards regions considered barren and infertile, Dust re-arranges Kenya's perceived cartography and de-centers Nairobi's importance within the national imaginary. Owuor unsettles mechanisms of regional inequality, prejudiced against Luo and Turkana communities. Hence, Gikuyu and Kalenjin chauvinism in the first and second republic - buoyed by ethnic affiliations to former presidents Jomo Kenyatta, Daniel Arap Moi and Mwai Kibaki - is challenged (274). Owuor does this by centering the plot in Turkana, often thought of as a drought-ridden frontier where (colonial and post-independence) civil servants are exiled for insubordination (14; 206; 313). Dust challenges popular imaginations of Kenya, with metropolitan Nairobi - situated next to the original Gikuyu home - positioned cartographically and rhetorically at the nation's heart. As Dustin Crowley in his Africa's Narrative Geographies argues, challenges about belonging and socio-economic inequity are 'inextricably fashioned by the where of Africa and its specific geohistorical conditions and spatial relations' (2015, 2; emphasis mine). Crowley's supposition about the continent as a whole can be applied to locales within particular nation-states. Patterns of economic disparity between the center and the periphery are identifiable at multiple levels: England versus the Kenya colony, before 1963, and metropolitan Nairobi versus far-flung Turkana, after independence.

Owuor, using a plot timeline that moves back and forth, underlines this critique of postindependence map-making and problematizes chronological approaches to history. The novel begins with a 'Prologue,' which relates the circumstances of Odidi's death. Chapters one through three are chronologically arranged, but chapter four shifts between funeral arrangements in the present, Ajany's return to Nairobi a week before, and her sojourn in Brazil over the last few years (48). Chapter nine is similarly structured but goes farther back in time incorporating the 1950s arrival of Hugh and Selene Bolton in Kenya (91). Other chapters share this narrative style: chapter twelve, for instance, recounts the tragic death of a woman and her children eleven years before (130). Overall, Dust's reverse chronology helps to reinforce the idea that history has perceptible effects on the present. In other words, a character's deeds in the past have a profound influence on their decisions and fate in the present - for example Nyipir Oganda's role in disposing of Mau Mau bodies, in relation to the extrajudicial killing of his son (47; 17). The novel successfully shows that this cause and effect is also visible in the real Kenya outside of the novel. Moreover, challenging a uni-directional view of history undermines the rhetorical fallacy of a center, from where history, progress, modernity and civilization radiate to the margin. The fundamental insight is that Owuor's Dust must be read alongside others including Ogot, Ogola and Likimani. The four writers discussed in this chapter explore, from multiple perspectives, an ongoing conversation on land, landscape and women in East Africa.

\section{Notes}

1 In his novel, Petals of Blood.

2 The word Turkana refers to an ethnic group and the district where they reside in northern Kenya.

3 Caroline Elkins' Imperial Reckoning: The Untold Story of Britain's Gulag in Kenya (2005) and David Anderson's Histories of the Hanged (2005) both elaborate on the creation of settler colonialism in Kenya. The White Highlands, named as an exclusively European area of settlement, were fertile and temperate terrains around Kenya's Rift Valley. Both Elkins and Anderson also recount the violent efforts to defend this project in the face of increasingly militant agitation for indigenous self-rule.

4 Naming is a recognized convention to display ownership, as discussed in If this is Your Land, Where are Your Stories? by Edward Chamberlain (2003). Aboriginal communities in Canada and Australia 


\section{$\mathrm{Ng}^{\prime}$ ang'a Muchiri}

enshrine their land rights in the kinds of narratives they tell about their environment, its geographic features, fauna and flora.

5 Jomo Kenyatta and Jaramogi Oginga Odinga were Kenyan politicians in the Forties through the Seventies. They both led efforts to oust British colonial rule from Kenya and went on to form Kenya's first post-independence government. Kenyatta, while studying in the UK under B. Malinowski wrote Facing Mount Kenya (1938), an anthropological work on Gikuyu culture. Odinga wrote Not Yet Uhuru (1967), a memoir that also included history about the Luo community, after his fall from Kenyatta's grace and much political rivalry between them.

6 See also 'Marriage Customs of the Luo of Kenya' by E. E. Evans-Pritchard (1950) for an explanation of how young men and women started a family.

7 Likimani trained as a teacher and pursued a career in broadcasting. She accompanied her husband, a medical doctor, to various colonial detention centers in Kenya. It is during these visits that she secretly served as a letter courier, delivering messages from Mau Mau detainees to their families.

8 The Women in Society series was commissioned by Palgrave Macmillan.

9 For further reference, see Kenyatta (1938) on Gikuyu rituals about birth, marriage and death.

10 Mwanzia Koster's The Power of the Oath (2016) offers a comprehensive discussion of Mau Mau oaths and their utility in creating the Kenya Land and Freedom Army.

11 Pinto, Mboya and Karumba were prominent political activists in the anti-colonial struggle as well as in the first Kenyan republic. Their tragic deaths, though officially unexplained, were publicly understood as political assassinations and instilled fear.

\section{References}

Anderson, David. 2005. Histories of the Hanged: The Dirty War in Kenya and the End of Empire. New York: W. W. Norton.

Chamberlain, J. Edward. 2003. If This is Your Land, Where are Your Stories?: Finding Common Ground. New York: A. A. Knopf.

Coetzee, J. M. 1998. White Writing: On the Culture of Letters in South Africa. New Haven, CT: Yale University Press.

Crowley, Dustin. 2013. “"A Universal Garden of Many-Coloured Flowers”: Place and Scale in the Works of Ngũgĩ; wa Thiong'o.' Research in African Literatures 44(3): 13-29.

Crowley, Dustin. 2015. Africa's Narrative Geographies: Charting the Intersections of Ecocriticism and Postcolonial Studies. New York: Palgrave Macmillan.

Elkins, Caroline. 2005. Imperial Reckoning: The Untold Story of Britain's Gulag in Kenya. New York: Henry Holt and Co.

Evans-Pritchard, E. E. 1950. 'Marriage Customs of the Luo of Kenya.' Africa: Journal of the International African Institute 20(2) : 132-142.

Graham, James. 2009. Land and Nationalism in Fictions from Southern Africa. New York: Routledge.

Hooper, Glenn. 1998. 'History, Historiography and Self in Ngugi's Petals of Blood.' Journal of Commonwealth Literature 33(1): 47-62.

Kenny, Christina. 2017. "'She is Made of and Coloured by the Earth Itself": Motherhood and Nation in Yvonne Adhiambo Owuor's Dust.' In Proceedings of the 39th African Studies Association of Australasia and the Pacific (AFSAAP) Annual Conference, 5-7 December 2016, 15-22. Perth: The University of Western Australia.

Kenyatta, Jomo. 1938. Facing Mount Kenya. New York: Vintage Books.

Knudsen, Eva Rask and Ulla Rahbek. 2017. 'An Afropolitan Literary Aesthetics? Afropolitan Style and Tropes in Recent Diasporic African fiction.' European Journal of English Studies 21(2): 115-128.

Koster, Mwanzia. 2016. The Power of the Oath: Mau Mau Nationalism in Kenya, 1952-1960. Rochester, NY: University of Rochester Press.

Likimani, Muthoni. 1985. Passbook Number F.47927: Women and Mau Mau in Kenya. New York: Praeger.

Luig, Ute and Achim von Oppen. 1997. 'Landscape in Africa: Process and Vision. An Introductory Essay.' Paideuma 43: 7-45.

Mitchell, W. J. T. 1994. Landscape and Power. Chicago, IL: University of Chicago Press.

Mwangi, Evan. 2009. 'Gender and the Erotics of Nationalism in Ngũgĩ wa Thiong'o's Drama.' The Drama Review 53(2): 90-112.

Ngũgĩ wa Thiong'o. 1977. Petals of Blood. London: Heinemann.

Odinga, Ajuma Oginga. 1967. Not Yet Uhuru: The Autobiography of Oginga Odinga. London: Heinemann. 
Ogola, Margaret. 1994. The River and the Source. Nairobi: Focus Books.

Ogot, Grace. 1966. The Promised Land. Nairobi: East African Publishing House.

Owuor, Yvonne Adhiambo. 2014. Dust. New York: Vintage.

Rushton, Amy. 2017. 'No Place Like Home: The Anxiety of Return in Taiye Selasi's Ghana Must Go and Yvonne Owuor's Dust.' Etudes Anglaises 70(1): 45-62.

Simatei, Tirop. 2005. 'Colonial Violence, Postcolonial Violations: Violence, Landscape, and Memory in Kenyan Fiction.' Research in African Literatures 36(2): 85-94.

West-Pavlov, Russell. 2017. 'From the Spatial Turn to the Spacetime-vitalist Turn: Mahjoub's Navigation of a Rainmaker and Owuor's Dust.' In The Routledge Handbook of Literature and Space, edited by Robert Tally Jr, 291-302. New York: Routledge. 


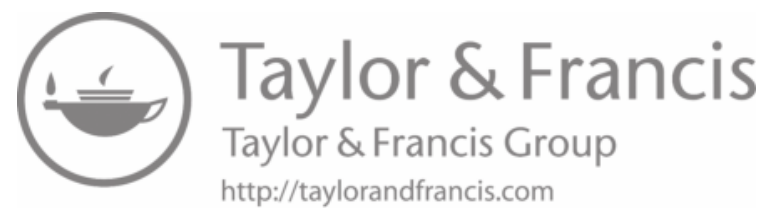


Part V

Everyday Sociality 


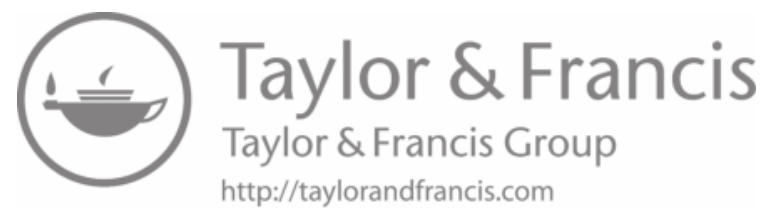




\title{
Geopolitical and global topologies in fiction
}

\author{
Islam at the fault lines in Africa and \\ the world
}

Shirin Edwin

In his study on Islamophobia, Andrew Shryock (2010) observes the absence of the term 'Islamophobia' before 9/11 and the surge in scholarship on 'Islamophobia' in the decade following 9/11. Similarly, in their study on Christian-Muslim relations in Nigeria, Insa Nolte, Olukoya Ogen and Rebecca Jones state that 'since the Cold War and especially since September 2001, religion has been recognized as an increasingly important factor in personal and group identification and mobilization ... tensions between Islam and Christianity have become especially salient' $(2017,1)$. However, a closer look at literary fiction reveals that both established and emergent writers from Africa illustrated, decades before 9/11, and continue to represent, the quotidian socio-spiritual salience of Islam. Islam's longstanding presence in African society is well documented in African history. This longstanding presence of Islam in fiction is best captured topologically. The obvious danger of using $9 / 11$ or the Cold War as starting points of an analysis of Muslims lies in the erroneous ascription of the importance of Islam in the daily lives of Muslims to the occurrence of a spectacular political event. Such studies often reveal the intellectual's own bias when tracing the subject's itinerary in that a topic exists only insofar as it is relevant to the representing intellectual's preference. This chapter reads Islam in African society as a topological presence - the configuration or relationship of different constituents and components. Doing so highlights the crucial idea that the presence of Islam in African society did not abruptly gain salience with the occurrence of a handful of political events, as did the scholarship on Islam in Euro-American circles following 9/11. Gayatri Spivak warns against scholarly expediency about topics that gain critical and scholarly salience:

[T] he intellectual's solution is not to abstain from representation. The problem is that the subject's itinerary has not been left traced so as to offer an object of seduction to the representing intellectual ... The question becomes, how can we touch the consciousness of the people, even as we investigate their politics?

(1999, 272) 
The politics of representing and investigating a particular topic illustrates the study of Africa and its relationship to the rest of the world. Concomitant with this oversight is the exclusion of Islam in Africa as seen when dating the importance of Islam and ascribing critical salience to it in the shadow of the terrorist attacks on the United States of America on September 11, 2001.

In his foundational book, African Religions and Philosophy, John Mbiti famously states that for most Africans, religion more than anything else shapes their social participation $(1969,256)$. Other scholars of African religions have commented that religion diffuses every aspect of social life - funerals, birth, naming, marriage, even fishing and trading. Kwame Gyekye notes that to practice religion in Africa is to participate in the rituals of the community $(1996,4)$. These rituals are not socially or spiritually hermetic. They unfold, as I demonstrate, topologically or through relationships with other systems. Religious identity thus may be individual but it is nursed by socially anchored rites and rituals. This core element of religious practice is essential to understanding Islam in Africa as social rituals and community participation expose a topology of interrelated constituents as Islam, Islam in Africa and Africa's place in the world.

This chapter focuses on everyday Islamic practice in established and emergent African fiction as a topology - the configuration or relationship of different constituents. The constituents of such sociality - individual, local, communal and even global - cannot be understood by simplified relationships of just tolerance or conflict; peace or violence. Nor can they be understood in isolation from other systems of belief and politics. Benjamin Soares rightly draws attention to ambiguity when studying Christian-Muslim interactions by warning that examining religious relations as conflictual or tolerant subsumes hidden layers of interactions that include conversion, appropriation, adaptation or even avoidance (Soares 2016). Within the dialectic of local and global, however, the relationship I examine is not about sizes - small or large. I aim to show that everyday sociality is at once a microcosm of wider systems and it also produces, reproduces, subverts, refracts and even instructs wider contexts, thus paving the way for reading Islam as a topology of diverse constituents. Seen this way, Islam's relationship to other social systems of belief and politics instructs the wider context of Africa's relationship to the rest of the world. A multitude of uneven patterns lies embedded within and between African communities and societies, where a topological framework becomes useful for instructing our understanding of Islam both in local and wider contexts. Topology also prevents the foreclosure of relationships into inflexible dialectics. I emphasize the topology of local relationships as a way of metonymically dealing with wider debates about Africa; its relationship to the world; Islam in Africa; and its relationship to Islam in the world. A topological understanding of local communities as metonyms of wider frames ensures a fuller engagement with one's place in the world just as the fiction I examine grapples with questions about Islam's place in African systems of sociality and politics. With these two objectives in mind, I approach the configuration of the quotidian in established and emergent African fiction as it unfolds in relation to other social systems of belief and politics, and inflects global issues to think about such themes as Islamophobia, Islamophilia and uneven relationships between Africa and the rest of the world through fiction. Decades ago, Mariama Bâ commented on the character of differences and divisions in Africa, '[B]ut Africa is diverse, divided. The same country can change its character and outlook several times over, from north to south or from east to west' $(1989,42)$, thereby interpellating a reading of Islam in Africa, and by extension in the world, as a topology of different and everchanging constituents.

To these ends, I focus on writers who centralize the everydayness of Islam as a topology. I study Cheikh Hamidou Kane's Ambiguous Adventure; Mariama Bâ's So Long a Letter, Ken Bugul's The Abandoned Baobab; Chimamanda Ngozi Adichie's short story 'A Private Experience'; and Leila Aboulela's short story 'The Boy from the Kebab Shop.' 
This fiction increasingly reduces the global gap by metonymizing geopolitical or local interactions in global contexts. Folded into this metonymy of local instantiations of interactions with wider discussions is the widely discussed topic of 'Africa's place in the globe,' as James Ferguson aptly coins the expression $(2006,3)$. By pointing up religious interactions more as a topology an assemblage - these writers recover lost meanings and broaden our understanding of such topics as Islamophobia, Islamophilia, religious intolerance and by extension, Africa's place in the globe. I ask the following questions to foreground topology in my analysis. What are the spaces where sociality occurs? What are the actions through which sociality occurs? How does the work deploy instances of sociality, to build solidarity or to deconstruct solidarity? Which institutions and types of people facilitate sociality? The writers I study instructively illustrate Islamic habits as interconnected assemblages at various times - colonial and post-colonial - to express Africa's place in the world. By approaching the following questions as topological arrangements of different religious constituents - how do writers illustrate the relative insertion or absence of Islam in daily life? How do these illustrations converse and connect with local and wider issues that concern Muslims, Islam and Africa's place in the globe? - this chapter centralizes Islam in Africa as a way of understanding Africa's place in the world. The following theoretical overview highlights the topological basis for the study of Islam, as I propose in this chapter, in African literatures.

\section{Local and global topologies: Islam in Africa; Africa in the world}

Without explicitly naming it as such, post-colonial, women's and literary studies topologically tackle a wide range of such relationships, including power asymmetries between colonizer or colonized; dominant or dominated; and even relationships between two or more systems of belief or religions, regions and languages. The literary critic Sahar Amer, for instance, has shown that topological elements in the notion of 'borders' are not elements of separation or division, but 'fluid spaces of cultural exchange, adaptation, and collaboration' (2008, ix). Amer's 'doublereading' of two literatures and cultural traditions (French and Arabic) recovers meanings that are obscured or distorted, and calls 'into question long-cherished paradigms' (x). With regard to Islam in African literature, Kenneth Harrow expresses a similar idea where the literary representation of Islam in African literature is 'not the perplexing one of what Islam is (to author, to reader, to discourse), but the straightforward notion of a religious/cultural tradition that represents itself in orature and in literary texts' (1991, 4, emphasis added).

In examining women's experiences and conditions, gender and sexuality, African feminists frequently grapple with the challenge of inclusion and exclusion, especially in geopolitical and global conceptualizations of gender. As a formidable challenge facing African feminist theorizations, Naomi Nkealah pinpoints the tensions of balancing inclusivity and exclusivity. One the one hand, the narrow focus on African cultural particularities risks excluding African women in the diaspora. On the other, as Nkealah notes, we risk excluding collective feminisms if we breed only geopolitical or local actions:

Theorising that focuses on the interests of one group of women can easily alienate another group. Moreover, it creates and/or deepens dichotomies (continental/diasporic, black/ white, young/old, educated/illiterate, etc.) that breed fragmentation rather than collective action. On the other hand, an all inclusive theory becomes handicapped by lack of a definitive constituency to put its principles into practice within the delineated context. 
As a possible solution, Nkealah suggests a simultaneous approach that closely examines the varied nature of relationships between different constituents or a topology. She recommends, 'making room for another while simultaneously asserting one's authority and ideological stance. (West) African feminisms can apply this principle by acknowledging the varied orientations in their feminist praxis' (71).

The second objective of this chapter - metonymizing local relationships between Islam and other systems of belief and politics to instruct our understanding on wider debates about Islam centralizes a common concern in African Studies about Africa's place in the world and its relationship to the rest of the world. In his book Global Shadows: Africa in the Neoliberal World Order, James Ferguson examines the well-discussed topic of the exclusion of Africa from global discussions on politics and economics, and the treatment of Africa on the margins of global processes or as his title suggests, 'the neoliberal world order' (2006, 3). Ferguson's use of the word 'shadows' in the title of his book unmistakably signals the perception of Africa's place on the globe, on the margins of global discussions - inseparable from the world but not fully acknowledged. Just as there is a 'shadow' government, a shadow economy and a shadow social order accompanying the formal sectors of the economy and political systems in Africa, that we incompletely grasp, Africa itself serves as a shadow to the world, never quite centralized in discussions about the world. Briefly, Ferguson examines the trope of the shadow both internally and externally as regards what it means to the world order. This twin relationship of internal or local processes and their inflections externally or globally highlights the preoccupation with 'Africa and its place in the wider world,' of broader questions or large-scale issues (6). Ferguson writes:

essays in this book are all attempts to speak in an explicitly non- or supra-ethnographic way about broader questions concerning the category that is Africa and its place in the world ... And they all in one way or another seek to use a consideration of this question as a way to think about such large scale issues as globalization, modernity, worldwide inequality, and social justice.

Likewise, we may think about Islam in Africa as interconnected with other systems of sociality and of the topology of this sociality as Africa's interconnection with the wider world. Inversely, to study African Islam and Muslims through key words like inequality, aspiration and rank in the world is to recognize that this lexicon, as Ferguson underlines, is also widely employed to allude to Africa and its place in the globe (19). Perhaps the most influential and useful notion of encounter and interaction as metonyms of wider contexts is found in the powerful idea of relationality, proposed by the Caribbean critic and philosopher, Edouard Glissant. Glissant explains relations in the context of his suspicion of a totalizing narrative or a narrative that subsumes local issues. For Glissant, relationality is a space where relationships flow - a site of topological configurations. In particular, the topology of relationality subverts the West or the global through what he calls 'relation' (1997, 218). Describing the onslaught of colonialism, Glissant notes that just as sameness began with colonialism, diversity began with the rebellion of the colonized peoples. However, as I would like to suggest, this dialectic between sameness and difference is not limited to resistance and conflict. Relationality, as I argue, comprises of the instances of connections as a way of inflecting wider contexts.

In a more specific reference to Islam in Africa, in Faces of Islam in African Literature, Kenneth Harrow points to the ever-present topology between various systems of belief and politics, especially in Africa - 'Mysticism and legalism, Baraka and scripture, marabout and faqih (legal 
scholar) are often at odds with each other' $(1991,7)$ - as examples of opposing relationships. Colonialism, continues Harrow, brought an 'additional element' into the pattern of struggles (7). In other equally compelling analyses on Islam in African literature, critics use 'biliteracy' or multiple traditions, sources and modes of knowledge that writers conscript in their illustrations of an African-Islamic or African-Islamic feminist text (Edwin 2016). When reading Islam and other such forces as race, colonialism, slavery and even apartheid, Gabeba Baderoon engages with the various forms of sociality in Islam among South African Muslim communities in unusual places - cookbooks, emblems, travel guides and narratives - attesting to the embeddedness of Islam in South African society. But this intricate tapestry of sociality is best read as a topology, for as Baderoon makes clear, her aim is not to 'insert Muslims into South African history and culture, but to bring to the fore the role of slavery in the formation of South African culture' (2014, 23, emphasis added). Doing so points up Islam's neglected and undervalued role in the formation of South African history and culture. The purpose, furthermore, as she continues, is not to portray Muslims as 'exemplary' or 'impossibly pure' figures at the risk of becoming invisible or excluded, but to suggest an uneven and asymmetrical mosaic of the nature of Islam in South African culture, 'certain representations of Islam resonate strongly with the history of images ... others do not align with it, and some contest it' (24). Here, topology exposes the unevenness of alignment, contestation and resonance; asymmetrical relationships through which hidden networks between Islam, slavery, apartheid and South African history powerfully rise to the top. Emad Mirmotahari's study on Islam in Eastern African literatures, Islam in the Eastern African Novel, is an equally compelling inquiry on the intricate varieties of ways in which Islam lies embedded in the social fabric of Eastern African societies. Mirmotahari's study of Abdulrazak Gurnah's, Moyez Vassanji's and Nuruddin Farah's novels focuses on the salience of Islam precisely because their fiction engages with 'authoritative narratives of Islam that incorporate scrutiny and criticism' (2011, 14). Foregrounding a topological approach, Mirmotahari shows that Islam appears at times as a tool for patriarchy, colonized religion, austerity and dictatorship, among its other purposes (14). Ultimately, Islam, secularism and even modernity, avers Mirmotahari, are understood through the various topologies or relationships of dissonant voices, narratives, histories and cultures embedded within African novels.

In Beyond Religious Tolerance: Muslim, Christian and Traditionalist Encounters in an African Town, Insa Nolte, Olukoya Ogen and Rebecca Jones similarly discourage a binary reading of interfaith relations to recommend a study of the nature of relationships between different faiths. As the authors note, their study aims at 'challenging the notion that Muslim-Christian difference is inherently conflictual' (2017, 257). These critics refute the 'either Muslim or Christian' context and argue for a closer analysis where meaning can be created both by 'religious expression and by the absence of other forms of expression' (4). They argue that the politics of the global North, especially following the end of the Cold War, did not adequately capture the complexity of politics in societies in the South, and studies treated Africa merely as a 'reservoir of raw fact' (1). In their ethnographic study of Christian-Muslim and traditionalist interactions in the Yoruba town of Ede in Nigeria, the authors describe the ways in which religious encounters 'are put to work within the town of Ede,' in the form of a wide range of interactions beyond spiritual practices, including clothing, educational practices and even daily rituals (259). Such a complex undertaking underscores the fluid, ever changing and ambiguous nature of Christian, Muslim and traditionalist encounters in Ede (264). It suggests a topology: 'how individuals draw on the knowledge and experience of religion other than their own to navigate their lives, authority, gender and social identity more generally cannot be captured by a focus on one religious community alone' (4). In a study in the same collection, Ogen's and Balogun's analysis of education in Ede examines Islam and Christianity as topological assemblages, where a 
Baptist school employs Muslim teachers and a Muslim school employs Baptist teachers (Ogen and Balogun 2017). But in Ede itself, the playing field is not level, 'Christians still dominate the education sector, they also still have a relative advantage,' states Nolte (Nolte, Ogen and Jones 2017, 168). Such unevenness, coupled with a study of daily rituals and habits in both Christian and Muslim communities, thus mirrors wider configurations of similar anxieties about power asymmetries in Christian-Muslim relationships. The fiction I examine instructively presents such local and global assemblages. Using this topological model where constituents enjoy a variety of relations that are continually 'at odds,' I want to point up a constantly shifting relationship between the various constituents of Muslim communities captured topologically with the aim of recovering details that may be obscured if we limit our understanding of Islam and other faiths in purely tolerant or conflictual shades, of Muslims as purely exemplary or notorious individuals in African history. Then, I turn this topology externally to examine Muslims in connection with such wider processes as globalization, westernization and colonialism, thereby mapping these local topological interrelations onto a wider canvas of issues facing Muslims and non-Muslims, Africans and non-Africans alike.

\section{Established and emergent fictions on Islam: topologies over time}

Cheikh Hamidou Kane's Ambiguous Adventure (1961) was one of the first post-colonial African novels to highlight the tension between local spiritual practice and a lifestyle under threat by a different system of beliefs in Sub-Saharan Africa. It presents Islam in Africa as a topological relationship in that the foreign, invading influence of the colonizer met with uneven responses and reactions from the Diallobe community. Kane situates the sociality of Islam in Northern Senegal, in the Diallobe community, whose lifestyle is anchored in Islamic beliefs. He introduces the earliest form of sociality in Islam in the Qur'anic school, where children are initiated into the Qur'an and into the social community or umma of believers connected by the belief in the oneness of God (Hefner and Zaman 2007; Ware 2014). Kane also introduces the primary agent of Islamic schooling or sociality, the Qur'anic teacher, a 'formidable man,' who devotes his life 'to the education and molding of the young people who had been confided to his care' (Kane 1963, 7). But the satisfaction of imparting Islamic education must straddle an uneasiness in the Qur'anic teacher's mind at the thought of the 'assault of strangers come from beyond the sea' (23). This tension at the core of daily Muslim life is best understood as a topology that reveals social hierarchies in the nobility, military, clergy and peasantry in the Diallobe community. The devout Qur'anic teacher reminisces about the 'vanished days' before the birth of the noble classes as he underscores the topology of Islam locally through these class differences. In the Qur'anic teacher's view, 'nobility is the exaltation of man, faith is before all else humility' $(23,24)$. It is within this topological configuration that Kane places the 'great clamor' to which the 'entire black continent' awakens - alluding to the arrival of French colonialism - as yet another element in this topology of different social and belief systems. Kane echoes Ferguson's double idea of Africa's rude awakening to the colonial onslaught and the exposure of the West to the context of Africa's spiritual systems, setting in motion a topological configuration between Islam, Africa and the colonial encounter. Equally, Kane's topological illustration evokes Nolte, Ogen and Jones's idea about the dominant relationship as the colonizer in the novel leaves the Diallobe community no choice but to adopt Western education.

The initiation to the Qur'anic school at the start of the novel, in fact, sets the tone for a number of social facts about Muslims. First, a school is one of the earliest sites of education. It is also the earliest site of social relationships, camaraderie and membership of a community. A Diallobe child's sociality is shaped in Islam at the Qur'anic school, for it serves as the 
multi-layered site of social, religious and educational knowledge and relationships. Kane describes the camaraderie and interactions between the pupils of the Qur'anic school. The fabric of this sociality is threatened by the arrival of the colonist. Most critical analyses have centered thus on the crisis born out of the anxiety of losing one's way of life to another belief system. The daily interactions and forms of sociality both in relation to local hierarchies and external forces such as colonialism that Kane describes in detail, especially at the start of the novel, tend to be overlooked in favor of a simplistic dialectic between Islam and Western culture. In fact, Kane presents two moments of sociality to understand Islam - one local with the Diallobe and their internal differences and voices varying on the presence of Islam; and the other with the external system or colonial presence and non-Islamic modes of social knowledge and education and religion.

Similarly, Mariama Bâ's landmark novel So Long a Letter (1979) highlights Islam as a configuration in Senegal, connecting varying degrees of Islamic practice and observance with other systems of belief and politics. One of the most overlooked details of her sociality and education is her allusion to the Qur'anic school, appearing in the second paragraph of the novel. Like Kane, she mentions the Qur'anic school to emphasize the earliest site of social relationships for Muslims. Boys and girls alike are initiated into religious education as Bâ's novel shows. The protagonist of the novel, Ramatoulaye, writes to her friend to reminisce their deep friendship, 'we wore out wrappers and sandals on the same stony road to the Koranic school' (Bâ 1989, 1). She reminisces about her earliest form of education and knowledge along with her most precious social connection and contact in the same breath. But in so doing, she is also quick to note the abiding presence of the European school, thus alluding to the quotidian sociality of Islamic beliefs in a topological relationship where the everydayness of Islam - social contacts, early friendships and forms of knowledge - unfurled for Ramatoulaye and her friend as a configuration with a host of other systems of belief and politics. But the detail about Islam that has enjoyed the most critical attention is the Qur'anic concept of 'mirasse' or disclosure as critics focus on Ramatoulaye's disclosure of her personal details of pain and suffering. For most critics, the starting point of the novel and of Ramatoulaye's Islamic identity is found in her evocation of mirasse. The study of Islam appears more amenable to such critical inquiries that centralize the religion's problems, conflicts and crises. But details of formative sociality such as the brief allusion to the Qur'anic school in the opening paragraph that also occupy a crucial place in shaping Islamic identity and social relationships is not adequately analyzed in the study of Islam in predominantly Muslim societies.

Even preceding her allusion to the mirasse - the most commonly accepted gambit for analyzing Islam in Senegal and Ramatoulaye's Islamic beliefs - Ramatoulaye reveals the deep insertion of Islam in Senegalese society. She details Islamic funeral rites:

Comforting words from the Koran fill the air; divine words, divine instructions, impressive promises of punishment or joy, exhortations to virtue, warnings against evil, exaltation of humility, of faith. Shivers run through me. My tears flow and my voice joins weakly in the fervent 'Amen' which inspires the crowd's ardour at the end of each verse.

She also details how 'The seven meters of white muslin, the only clothing Islam allows for the dead, are carefully placed in a new basket. The Zem-Zem, the miracle water from the holy places of Islam religiously kept by each family' (5), to reveal not only her intimate knowledge of Islam and her personal piety but that religious observances are deeply intertwined with forms of social relationships and interactions. She braids these minute details of Islamic rituals with social 
customs and ties, for her husband's funeral draws a 'buzzing crowd' (5). Ramatoulaye's own social position attracts a large group of acquaintances, 'As I come from a large family in this town, with acquaintances at all levels of society, as I am a schoolteacher on friendly terms with the pupils' parents, and as I have been Modou's companion for thirty years' (6). And again, she observes, 'Afterwards comes the procession of old relatives, old acquaintances, griots, goldsmiths, laobés with their honeyed language' to underscore the conflation of Islamic spiritual practice with social kinship ties manifested at the funeral (7). Embedded within these ties are Ramatoulaye's own critique of the unabashed display of ostentation and superficiality. Accompanied by the religious rituals, the reading of the Qur'an and Ramatoulaye's own knowledge of the meaning of a host of funeral rites and her recognition of the social ties of friendship, family and acquaintances, is her astute critique of the excessive material display of wealth at the funeral:

'One hundred thousand francs from the father's side.' 'One hundred thousand francs from the mother's side.' She counts the notes, blue and pink, one by one, shows them round and concludes: 'I have much to say about you Falls, grandchildren of Damel Madiodio, who have inherited royal blood. But one of you is no more. Today is not a happy day. I weep with you for Modou, whom I used to call "bag of rice", for he would frequently give me a sack of rice. Therefore accept this money, you worthy widows of a worthy man.' The share of each widow must be doubled, as must the gifts of Modou's grandchildren, represented by the offspring of all his male and female cousins. Thus our familyin-law take away with them a wad of notes, painstakingly topped, and leave us utterly destitute, we who will need material support.

She mentions 'Christmas eve parties' and places associated with Catholic rituals: 'Here, Sindia, and to the left, Popenguine, where the Catholics celebrate Whitsun,' to underscore the topology of a predominantly Muslim society with a minority Catholic population $(8,27)$. These observations convey varying degrees of spiritual maturity as austere religious rites are duly received, understood and acknowledged by the sober Ramatoulaye, but the crowd of noisy women remain indifferent to the spiritual tone of the Qur'anic verses. They seem more interested in the latest gossip:

In the women's corner, nothing but noise, resonant laughter, loud talk, hand slaps, strident exclamations. Friends who have not seen each other for a long time hug each other noisily. Some discuss the latest material on the market. Others indicate where they got their woven wrappers from. The latest bits of gossip are exchanged. They laugh heartily and roll their eyes and admire the next person's boubou, her original way of using henna to blacken hands and feet by drawing geometrical figures on them. From time to time an exasperated manly voice rings out a warning, recalls the purpose of the gathering: a ceremony for the redemption of a soul. The voice is quickly forgotten and the brouhaha begins all over again, increasing in volume.

She juxtaposes Islamic rituals and funeral rites with ostentation to expose a topological relationship between religious observance (funeral rites in Islam) during such important social events as marriage, births and funerals; the display of excessive material wealth and social kinship ties that bring scores of mourners to condole her husband's death. She continues to foreground the topology of this complex weave of social ties and widely practiced social customs during 
important religious events with her personal rejection of many of the popular and widespread religious practices.

When persuaded by friends and relatives to consult marabouts or resort to witchcraft that would make her husband return to her household, Ramatoulaye firmly rejects the pressure to consult what she calls 'charlatans' with 'supernatural powers' (6). Bâ illustrates the thickly woven social bonds around the determined concern from a friend and the power of numinous traditions, elevated to a science:

People talked of bewitchment. With determination, friends begged me to react: 'You are letting someone else pluck the fruits of your labour.' Vehemently, they recommended marabouts, sure in their science, who had proved themselves by bringing husbands back to the fold, by separating them from evil women. These charlatans lived far away. Casamance was mentioned, where the Diola and Madjago excel in magic philtres. They suggested Linguere, the country of the Fulba, quick in vengeance through charms as through arms. They also talked of Mali, the country of the Bambara, with faces deeply scarred with tribal marks.

$(48-49)$

She cites her personal spiritual outlook, 'reared on its strict principles' as the reason for resisting the well-meaning pressure of her friends (48-49). She nevertheless describes the heft of such widespread practices on local Muslims as the topological conflation of 'antiquated rites with religion' (28). Similarly, she details the local ritual by Muslims who pour milk into the Sine 'to appease the invisible spirits,' to protect from the 'evil eye,' and to 'attract the benevolence of the tours' or 'invisible companions' to underline the topology of the practice of Islam by contrasting such praxis with the actions of Muslims such as herself who are reared on its strict principles (28). These immensely popular practices - whether to maintain or manipulate relationships, as in the case of Aissatou's conniving mother-in-law who inserts a young and unsuspecting cowife to sour Aissatou's marriage - nevertheless undergird sociality as they are primarily marshalled in the service of social bonds, operating within intricate networks between friends, families and well-wishers. This is furthermore evidenced by Ramatoulaye's griot friend, Farmata, who unerringly predicts her young daughter's premarital pregnancy by reading cowries:

Farmata, the griot woman of the cowries, very cleverly led me to this discovery. ... Every day Farmata would insist a bit more on the 'young pregnant girl' of her cowries. She would show her to me ... She was eloquent: 'Look, I say, look! This separate cowry, hollow side turned upwards. Look at this one, adjusting itself to the other, white side up, like a cooking pot and its cover lid. The child is in the belly. It forms one body with its mother. The two groups of cowries are separated: This indicates an unattached woman. But as the cowries are small, they indicate a young girl.' And her hand threw down, again and again, the gossipy cowries. They fell away from each other, collided, overlapped. Their tell-tale chink filled the winnowing fan, and the same group of two cowries always remained separate, to reveal distress. I followed their language dispassionately. And then, one evening, annoyed by my naiveté, Farmata said boldly: 'Question your daughters, Ramatoulaye. A mother must be pessimistic.' Worried by the relentless repetition, anxious, I accepted the proposition.

In this long passage, Ramatoulaye again exposes a topological relationship as her strict religious principles resist belief in cowries. She admits that it could just be Farmata's keen observation but 
nevertheless details the reading of the cowries to reiterate the nature of relationships between strict adherence to Islam and recognition of supernatural powers. Underlying these two kinds of beliefs within Islam is a strong sense of sociality as Farmata is Ramatoulaye's friend who helps her as a single mother, knows of her unfortunate situation, and exposes the girl's pregnancy to avoid public shame and rumor. Underlying Ramatoulaye's illustration of the configuration of Senegalese socio-spiritual practices - a strict observance of Islam by herself; a syncretic practice for the wider majority who consult spiritual intermediaries; antiquated rites, along with the presence of a small Christian community in the allusion to Christmas eve parties and Whitsun is a topology to study Islam in Africa.

Ken Bugul's novel The Abandoned Baobab (1982) is equally illustrative of the topology of Islam and other such systems and processes of belief as faith through spiritual intermediaries, colonization and transnational globalization. The conflicts that pervade the narrative foreground the importance of reading Islam as a topology in the crisis of identity of a Black woman, a colonized woman and an African Muslim woman. Like Bâ, Bugul opens her novel with an explicit reference to the Islamic ritual of aqiqa or baptism; an allusion that is easily missed in favor of the larger crises of colonization and racism in post-colonial Africa in the novel. Bugul sets the tone for her background as a 'traditional Moslem family' (Bugul 2008, 126). First, Ken mentions rather distinctly her Islamic background through a ritual that marks important social events like birth. Next, she reveals her personal stance on Islam by identifying her spiritual teacher and his Qur'anic instruction. She also stresses that she learns the Qur'an meaningfully, 'Thierno Alassane Ba, taught me the Koran differently from the blind way in which it used to be taught. And so when I wasn't studying for classes, I'd escape with the Koran' (117). Reading such influences on Ken's life as a topology prevents their oversight as she poignantly evokes in the novel's epigraph, 'the obliterated shall be remembered.' But this personal relationship with Islam is disturbed by the arrival of French colonialism. She refers to French colonial influence that 'undermined the sacred foundations, had dismembered them,' and recounts post-colonial onslaughts on Africa as she lives in Belgium and faces racism and objectification (85). Ken describes the 'world festival of Negro Arts': 'what still remained of the Black people was displayed in a show of entertainment between the conquered and the conquerors, in their participation in the process of humanity's march of history' $(129,130)$. Moreover, Ken is sexually and racially objectified as inferior, and told that she is Black, beautiful and meant for consumption, 'You are a Black woman' (104). In this transnational intersection of race and gender, a topology maps Islam onto Ken's multivalent experience and identity (101). Ken's narrative thus urges us to read French colonialism, the aftermath of colonial violence and their impact on a Black, African and Muslim woman as a topology to avoid critical and political minimization.

This psychological violence underlying Ken's confusion unleashed by the French school, and then in post-colonial Belgium, echoes with Ferguson's allusion to Africa's place in the world and the attempt to address large-scale issues when Ken tries to situate herself as a Black, African and Muslim woman in a wider context. Schooled on such false notions as 'our ancestors the Gauls' and the depiction of Africans in the 'blackest of inks' as Ken remembers her French textbooks - a fear that Kane pointed out in the Diallobe community who anticipated the loss of their education system and values - Ken's realization that she, as a Black woman, is meant for consumption underlines the same shock at being excluded, vilified and ridiculed, condemned to the margins of History (90). She tries to revive her story - 'Ken's Story' as the second section is entitled - to illustrate the engagement that Ferguson sees in an entire continent that is addressing large-scale issues. The local bonds of sociality and kinship, as Ken's father chooses to settle in a city to be close to his friend and spiritual guide, nurse and mobilize socio-spiritual ties. In turn, these local practices mirror important lessons on the multivalence of identities that are 
more often than not obliterated as Ken's history on multiple counts - Islam and African - are erased in a post-colonial context. On a global stage then, Ken's narrative punctuates the wider narrative in many places - gender, Islam and Africa - thus reifying Ferguson's articulation of Africa's engagement with a number of such broader issues as globalization, modernity and Africa's place in the world.

While Ken describes her personal praxis of reading the Qur'an and the meaningful teaching she receives from Thierno Alassane $\mathrm{Ba}$, she points to the social ties that Muslims forge with their spiritual teachers for all matters of spiritual and practical guidance in life. The social significance of such ties is furthermore elaborated in Ken's illustration of her father's socio-spiritual ties with his own guide. Such ties cover all manner of social bonds - friendship, respect, devotion and assistance. They prompt people to move and settle in places to solidify ties. Religion, in this sense, is indistinguishable from social relationships and the pursuit of knowledge. Ken calls it 'Vision':

We were a traditional Muslim family. The father, temporal and sacred guide, had settled in Ndoucoumane out of friendship for a great man. They had sworn to each other that they'd never abandon each other and the pact was signed ... when the spirits stood guard. Together they devoted themselves to Knowledge and from there to Vision, inside the virtues of Islam, inside the depository of all Knowledge which is the Koran.

Ken's remembrance of her Muslim background, the impact of Islam, French colonization and her transnational experience as a Black Muslim woman facing post-colonial racism in Belgium topologically emerges as a configuration of interrelated experiences.

As Kane, Bâ and Bugul frame Islam in a topological framework of the various constituents spiritual intermediaries, strict precepts, Islamic schooling, colonialism, post-colonial racism, and other systems of politics and belief - emergent fiction from Africa also depicts Islam's topological patterns of everyday sociality. Written in 2008, Chimamanda Ngozi Adichie's short story 'A Private Experience' weaves the everydayness of Islam in interfaith tensions, Islamophobia and extremism. An ethnic mob in a marketplace in a town in northern Nigeria serves as the political backdrop of this short story, where Chika, a Christian university student in her early twenties, and an older Muslim woman, a vegetable vendor, take refuge in an abandoned shop.

Beyond the visible markers of religion - Chika's cross and rosary beads and the Muslim woman's tribal scars and her headscarf - the story topologically frames individual or personal and class or social stereotypes and prejudices about religion, thereby metonymizing such perceptions to reflect wider contexts of religious misunderstandings, extremism and violence. While the story is told by a Christian, affluent, educated and purportedly emancipated Chika, suggesting the discursive authorship on Islam and Muslims to expose the dominant stereotypes and prejudices about Muslims, the introspective gaze of the Christian, educated and affluent woman reveals not just the internalization of such stereotypes but also their rebuttal. I read the meeting of these two women as Adichie's effort to conflate two faiths, classes, levels of education and gender priorities in the examination of similar issues on a wider scale. The riot outside the abandoned shop where the two women meet directly alludes to the geopolitical problem of Christian-Muslim violence in the region. The most recognizable and well-known feature of this conflict is said to be the ascension of Boko Haram. But Adichie makes no mention of Boko Haram in the story, nor does she explicitly tie the local events to such wider problems as Islamophobia. This absence itself underlines two things: a topological context between more than two faiths as Adichie refuses to foreclose the women's interactions as one of conflict or 
understanding. By framing the women's private encounter within the shop whose only outlet is the window (also a frame), Adichie places it as an assemblage of two viewpoints or constituents. Simply, Adichie sketches several frames that strongly point to a topological reading, going beyond the simpler relationship of tolerance and conflict that aims at 'challenging the notion that Muslim-Christian difference is inherently conflictual' (Nolte, Ogen and Jones 2017, 257). Andrew Shryock's insistence on the study of Islam beyond the politics of enemy or friend is particularly useful in conceptualizing the topology that Adichie demonstrates in this story (Shryock 2010), for she draws no such conclusions of reconciliation or revision, leaving open the space where two women have interacted with one another and experienced cycles of introspection, self-doubt and self-knowledge to face their own stereotypes, prejudices and shortcomings.

I emphasize two examples of interfaith assemblages in the story. The first example refers to the Muslim woman's ablutions by a rusty tap she finds in the store and her use of her scarf as a prayer mat. Adichie describes the prayer as Chika sees it:

'I wash and pray,' the woman says, ... the woman clumsily washes her hands and face at the tap, then removes her scarf from her neck and places it down on the floor. Chika looks away. She knows the woman is on her knees, facing Mecca, but she does not look. It is like the woman's tears, a private experience, and she wishes that she could leave the store. Or that she, too, could pray, could believe in god, see an omniscient presence in the stale air of the store.

$(2009,52)$

Chika observes the private act of praying and the ritualistic steps taken to fulfil this spiritual obligation - the ablution that precedes the act of prayer and the facing toward Mecca that comprise the correct way of offering the prayer. This multi-layered spectatorship holds multiple connections - the private experience of the vendor's spirituality; a revelation of Chika's prejudices, and more importantly, the variance between this private experience and observation of spirituality and the resultant knowledge about the other, and the riotous violence on the street outside the store. On the one hand, the conflation of the personal and the public enables an overturning of the public and impersonal act of violence between two communities. On the other, it also challenges the observer's (Chika's) own assumption about Muslims. Adichie's double-edged depiction of private and public spheres offers a way of thinking about geopolitical and global interfaith relations as local and personal experiences produce, reproduce, subvert and even instruct global contexts.

The second example undergirds a similar topology as pertinent to individual and class differences. Chika is studying medicine in university and the woman is an illiterate vendor: 'Chika wonders if the woman even knowns what going to university means' (49). The Muslim woman is more concerned about her vegetable stall that she leaves hurriedly in the riot, wondering what will happen to it. The vendor narrows the gulf between the two classes, though not without revealing her own prejudices about upper-class women. On learning that Chika is studying medicine, the vendor, who is nursing, shares a personal problem, 'my nipples have been burning ... my nipples have been burning like pepper. Will you look at them?' (54). Chika looks on surprised as the woman pulls her blouse up leaving Chika to stare at the vendor's cracked nipples, as her patient feels no inhibition in baring her body to the doctor. Chika suggests some remedies to the woman and this unexpected disclosure of her problem and the remedy forge a bond between the two women. Both examples - class stereotypes and the woman's commitment to pray even when she feels anxious about her daughter's whereabouts - 
foreground the topology of class and religion. The personal conflict of stereotypes and prejudices does more than to metonymize the political conflict of violent riots and ethnic mobs. It reinforces a topology of two faiths, layered with class differences. While the private experience inside the shop clears stereotypes, the public experience on the other side of the window subverts this clarification as both women may have lost a family member. The relationship between two faiths thus remains a topological one as the assemblage of class, politics and personal prejudices inflects the encounter between two faiths both in individual, local and global frames.

The Egyptian-Sudanese writer Leila Aboulela's fiction frequently presents the topological assemblage of different faiths, genders, classes and cultures. Her short story 'The Boy from the Kebab Shop' (2005) is particularly representative of the topological configuration of Islam as Aboulela mobilizes a host of interconnected and overlapping assemblages that introduce additional elements to pre-existing relationships and unravel an asymmetrical mosaic of the various constituents (Harrow 1991, 7; Baderoon 2014, 24). Aboulela embeds the daily practice of Islam that exposes the relationship between local and wider contexts, transnationally, in her characters, themes and storyline. Like the transnational that interconnects two or more national and cultural boundaries, the characters' backgrounds (Muslim, Christian, Arab, Scottish, African) expose local and wider assemblages, including the 'additional element' (Harrow 1991, 7) of the refugee crisis in Kosovo that Muslim students at a Scottish university raise funds for, thus revealing an ever-widening assemblage of habits and beliefs that involves local and wider processes. Such a configuration mobilizes a topology in understanding the ways in which Islamic sociality unfolds at various levels of politics and culture.

The main protagonist, Dina, is of mixed descent - Scottish and Egyptian. Her mixed descent or metissage conflates two cultures, beliefs and habits. It enables Dina to compare, contrast and debate the daily habits that she identifies as characteristic of the two cultures - Islam (prayer, greetings, social work, social awkwardness and isolation) and Scottish (football, beer and boredom) - through habits and the daily unraveling of the religion in the lives of Muslims. Dina scrutinizes the two cultures by closely observing another protagonist of mixed heritage, Kassim, who is half Scottish and half Moroccan. The eponymous hero of the story, a revert and a metis like Dina, struggles to learn about Islam. While Dina's ties with Islam are 'fragile,' Kassim himself shares a distant relationship with the religion as his mother is Scottish (Aboulela 2005, 53). But it is through 'daily contact' with his employer that Kassim begins to 'live Islam' (57). 'It was working with Basheer, day in day out, through the mundane and the significant that had made Islam a rhythmic reality, a feasible way of living' (57). It is often through social ties with co-workers, casual acquaintances at mosques and such spiritual centers that Muslims forge their ties to faith. In her long and short fiction, Aboulela recurrently employs the trope of faith and sociality in Islam at such sites as the mosque and social welfare centers through such agents as social aid workers, embalmers at funerals, students at universities, in student associations, as network sites and channels for building personal spirituality in Islam (see, for example, Minaret [2005], The Translator [1999], Coloured Lights [2001]). One such mundane habit that emerges at the cusp of this newfound fascination with Islam by Dina and Kassim is the customary greeting 'Salaamu Alleikum' that Muslims utter as a spiritual practice (59). Dina is not accustomed to this quotidian greeting. It makes her feel 'self conscious ... new words she was not used to' (59). But when she utters it for the first time to greet Kassim's employer, the self-consciousness wears away (60). The mundane greeting thus reveals itself in a topological relationship between two cultures, two characters with varying degrees of spirituality, as initiates adjust to an Islamic way of life and sociality. The second form of everyday habits appears in the story when Dina stumbles upon Kassim praying. She feels the invitation to 'her faith' in this daily habit that unsettles her (63). The ordinariness of the prayer that Kassim performs in the backroom of the 
Kebab shop is understood when conflated with the front of the store - 'customers milling round, barbecue smoke and the happy ring of the till' (63). The rhythmic reality of Islam that Kassim tries to connect with unravels in Dina's observation of these daily habits of greetings and prayer. These quotidian attempts at acquiring socio-spiritual habits are embedded within the characters' own interconnectedness with wider processes such as the event organized by the Muslim Students Society to help refugees in Kosovo.

I have read Islam as it emerges in forms of sociality - schools, prayer habits, spiritual guides, teachers, friends, co-workers - and at social events (births, funerals, transnational communities) that unravel a topology. The quotidian sociality in Kane's novel rises to a state of crisis in relation to the assault posed by the 'additional element' or the colonial system, introduced within the Diallobe community, thus setting in motion a topology of multiple constituents, including the internal differences within the Diallobe community with regard to the arrival of the colonist (Harrow 1991, 7). Likewise, in Bâ's novel, Ramatoulaye's description of her spiritual practices and rituals and social events or in social situations often occur in relation to her critique of practices such as the consultation of marabouts, the practice of worshipping the graves of saints or the use of witchcraft and spells. These forms of spirituality in Islam are also conflated with Ramatoulaye's own strict beliefs of refusing such forms of spiritual habits. Adichie also presents the topology of Islam and Christianity where she reveals the quotidian embeddedness of the two religions in the form of prayers, daily rituals, identity markers such as the cross, the rosary, the headscarf and facial scars. She juxtaposes these identifiable signs with the internal monologue that reveals hidden reservations of both protagonists - a Muslim vegetable vendor and an upperclass educated Christian. For Bugul, reading Islam topologically exposes the displacement of a background by colonial and post-colonial confrontations that involves her identity as a Black woman in post-colonial Europe suffering great blows. For Aboulela, mixed identities, instances of prayer and daily greetings and salutations in multilayered contexts enable a reading of Islam that emerges in a topological framework. Such topologies emphasize the sociality of Islam in relation to other systems of belief along with internal and local practices and perceptions about other faith systems and their practitioners. Such relationships in turn reflect the locality and the globality of Islam to produce, reproduce, subvert but also instruct on solutions for approaching Islam and Islam in Africa, in particular, as topological configurations without foreclosing relationships as conflictual or tolerant.

In not explicitly naming Islamophobia or extremism, these writers insist on Islam and its quotidian sociality as a topology that opens up a way for reading Islam in relation to wider processes. Just as locally, Islam interacts on multiple levels with local constituents, it inflects wider contexts - colonialism, post-colonialism, modernity and globalization - in multiple ways. In Kane's novel, the local tensions between the Diallobe community and other constituents antecedent to Islam in Senegal, mirror the same tensions of acceptance and resistance of colonial education. A similar topology emerges as Ken reveals her traditional Muslim background, enters the French school, and then travels abroad to experience great shock on account of her race and gender. Bâ weaves her personal spiritual practice with a critique of social bonds and spiritual customs of varying degrees of spirituality. Such topologies of class, race, gender and Islam enable a nuanced understanding of both colonial and wider post-colonial contexts. Both Adichie's and Aboulela's stories provide instructive contexts for interfaith relations that map onto wider relationships globally. As Adichie illustrates the topology of private clarifications of the other, she contrasts this experience with the mayhem outside to figuratively portray the lessons such a local experience may contain for external and even global violence. Aboulela's characterization of mixed backgrounds embeds systems of belief, cultures and politics in her characters themselves to produce a wider context of a topological reading. Moreover, these writers map this 
topology onto a wider arena and urge us to rethink the negative perception of Africa as 'the dark side of the globe' (Ferguson 2006, 1). The central question then, not posed by studies on Muslim and Christian interactions, is what does the interaction tell us about the local and then the wider context of such systems? My reading has pushed this question beyond the descriptive conclusions of fluid and ever changing interactions to understand the lessons that this metonym of interfaith encounters has for wider contexts.

\section{Works cited}

Aboulela, Leila. 2005. 'The Boy from the Kebab Shop.' In Coloured Lights, 53-63. London: Polygon.

Adichie, Chimamanda Ngozi. 2009. 'A Private Experience.' In The Thing Around Your Neck, 43-56. New York: Anchor.

Amer, Sahar. 2008. Crossing Borders: Love between Women in Medieval French and Arabic Literatures. Philadelphia: University of Pennsylvania Press.

Bâ, Mariama. 1989. So Long a Letter. Translated by Modupe Bode Thomas. Portsmouth, NH: Heinemann.

Baderoon, Gabeba. 2014. Regarding Muslims: From Slavery to Postapartheid. Johannesburg: Wits University Press.

Bugul, Ken. 2008. The Abandoned Baobab. Translated by Marjolijn de Jaeger. Charlottesville: University of Virginia Press.

Denny, Frederick. 2016. An Introduction to Islam. London: Routledge.

Edwin, Shirin. 2016. Privately Empowered: Expressing Islamic Feminism in Northern Nigerian Fiction. Evanston, IL: Northwestern University Press.

Ferguson, James. 2006. Global Shadows: Africa in the Neoliberal World Order. Durham, NC: Duke University Press.

Glissant, Edouard. 1997. The Poetics of Relation. Translated by Betsy Wing. Ann Arbor: University of Michigan Press.

Gyekye, Kwame. 1996. African Cultural Values: An Introduction. Accra: Sankofa Publishing Company.

Harrow, Kenneth, ed. 1991. Faces of Islam in African Literature. Portsmouth, NH: Heinemann.

Hefner, Robert and M. Q. Zaman, eds. 2007. Schooling Islam: The Culture and Politics of Modern Muslim Education. Trenton, NJ: Princeton University Press.

Kane, Cheikh Hamidou. 1963. Ambiguous Adventure. Translated by Katherine Woods. Portsmouth, NH: Heinemann.

Mbiti, John. 1969. African Religions and Philosophy. Portsmouth, NH: Heinemann.

Mirmotahari, Emad. 2011. Islam in the Eastern African Novel. New York: Palgrave Macmillan.

Nkealah, Naomi. 2016. 'Challenges Facing (West) African Feminisms.' Journal of Literary Studies 32(2): 61-74.

Nolte, Insa, Olukoya Ogen and Rebecca Jones, eds. 2017. Beyond Religious Tolerance: Muslim, Christian and Traditionalist Encounters in an African Town. London: James Currey.

Ogen, Olukoya and Amusa Saheed Balogun. 2017. 'The Baptist Church in Ede: Christian Struggles over Education and Land.' In Beyond Religious Tolerance: Muslim, Christian and Traditionalist Encounters in an African Town, edited by Insa Nolte, Olukoya Ogen and Rebecca Jones, 151-172. London: James Currey.

Shryock, Andrew, ed. 2010. Islamophobia/Islamophilia: Beyond the Politics of Enemy and Friend. Bloomington: Indiana University Press.

Soares, Benjamin, ed. 2016. Muslim-Christian Encounters in Africa. Leiden: Brill.

Spivak, Gayatri. 1999. A Critique of Postcolonial Reason: Toward a History of the Vanishing Present. Cambridge, MA: Harvard University Press.

Ware, Rudolph. 2014. The Walking Qur'an: Islamic Education, Embodied Knowledge and History in West Africa. Chapel Hill: University of North Carolina Press. 


\title{
19 \\ Appetite and everyday life in African literature
}

\author{
Delores B. Phillips
}

While African literary criticism has engaged food as political index, the connection between food and everyday life has, until relatively recently, largely eluded critical attention. The thematics of the kola nut in Things Fall Apart are well documented. The troubled dinner table in Tsitsi Dangarembga's Nervous Conditions stands as an ur-text interrogating the treatment of colonial power in Zimbabwe. Achille Mbembe's (2000) fat autocrat and Jed Esty's (1999) work with Mbembe's earlier theories position the African 'big man' prominently as a figuration for abusive largesse and imbricate him in the everyday life of Africans who mock him. Mbembe's analysis of Cameroonian despotic appetite contravenes the notion that Africa is a nation of no food and is, rather, a continent where appetite and privilege can be linked to the broader field of food literary scholarship - an area which has not received much attention. Meanwhile, food scholarship in African contexts comprises of thousands of anthropological, ethnic and economic studies of the problem of African food security. This means that the kola nut, the obese autocrat and the hungry millions dominate how academics begin to talk about food in Africa.

Studies of food in African literature have:

rarely focused on food in its ordinariness, in the labour that goes into the production of its ingredients, the ways and means through which it is prepared, the way it mediates social relationships, or even quite simply the pleasures that it gives.

(Ojwang 2013, 65)

In other words, while literary criticism of African texts adeptly targets food's gastropolitical import, little attention is paid to its gastropoetic promise, its ability to paint a vividly colored, richly textured portrait of everyday African life across the continent. Food's gastropolitical referents eclipse its ordinariness. A turn to gastropoetics reveals the dimensions of ordinary life that depictions of everyday eating can unveil - both its pains and its pleasures. Parama Roy's analysis of 'the haunting and occasional deconstructive intimacies of food, autobiographical and gustatory memory, and gendered indigeneity' in South Asian women's culinary writing (Roy 2002, 476) provides a gastropoetic template for thinking about food in African literary contexts as achieving or thwarting intimacy, encoding cultural norms and memory, and negotiating cultural claims both on the continent and outside it. Her reading of the gastropoetics of Indian 
food writing is 'particularly attentive to the metaphorical and allegorical logics that govern the crafting of lives and recipes' (Roy 2002, 476). This same question flits about the depictions of food in African literary contexts. In his analysis of South Asian Africans writing in diaspora, Dan Ojwang asks, "What does the symbolism of food tell us about the contests that characterize the lives of the African Indians and in what way does food enable writers to imagine possible worlds beyond such contests?' (Ojwang 2013, 66). These questions do not completely set aside the gastropolitical interests that dominate the prevailing understanding of food in African literature. Rather, they suggest that thinking gastropoetically reveals dimensions of African life that gastropolitics only narrowly circumscribes and can allow imaginings of other worlds beyond the political contests that characterize that life.

This customarily limited view of the African culinary imagination therefore demands a new approach. Lisa McNee (2003) invites food studies scions such as Brillat-Savarin (1825; qtd. 176) and Penny Van Esterik and Carole Counihan (1997; qtd. 176) (and, without naming her, Susan Leonardi [1989]) into conversation with African philosophical and cultural paradigms - but without leaning on their words, resisting the gravitational tug of Western culinary philosophy by banishing them to notes, references or oblique allusions. Her work's structural alliance with these thinkers connects food to cognition and ontology, tracing etymological roots in English and vernacular languages to assert the primacy of cultivating local food customs and knowledges in the service of a pan-African philosophical tradition, one that, after the fashion of Dipesh Chakrabarty (2000), provincializes Europe while asserting Africa as a glocal site of multicultural exchange. McNee shapes this pan-African approach to 'food for thought' following four axioms: 'local knowledge is profoundly pragmatic and adaptive in nature' $(2003,166)$; 'locating knowledge also involves locating power' (168); 'food culture is the nexus for the creation of cultural identities, as well as local knowledges, and thus plays a role in the affirmation of proprietary claims to knowledge' (171); and 'knowledge is transferrable and grows through exchange' (174). Applying these axioms to culinary writing, oral traditions and kitchen practices across the continent, McNee finds that the presumed absence of philosophy parallels the presumed absence of food and food traditions in Africa. Consequently, a short-sighted view of African thought and African life emerges, one based on a misrecognition of everyday life practices. African 'denrée mentale' or 'mental food' demonstrates a 'pragmatic pluralism' that imbricates it in global flows that nourish the production of vernacular cuisines, and philosophical permutations that serve local communities.

Asking about the locations of national cuisine and questioning the identities of who is involved, Igor Cusack observes that the:

main driving force for the creation of national cuisines in Africa appears to come from the West, and in particular from African-Americans ... As certain dishes become 'national dishes,' the very mention of these will reinforce any sense of national identity.

(Cusack 2000, 216)

McNee resists this argument by laying claim to vernacular culinary formations. Furthermore, McNee points toward the continent's global flows as a response to Cusack's claims that external pressures impel cookbook writers to nationalize African cuisines, to package them in readily commodifiable forms, and to deploy them to solidify the cultural character of African nation-states. In answer to Cusack's question, whither Africa? McNee suggests that Africa is present in the culinary records of cookery books, the songs sung by local children and the adages taken as local wisdom.

Shirin Edwin's (2008) study of African literature reveals the difficulties of a strictly gastropolitical approach even as it valiantly attempts to introduce an African culinary lexicon to the 
broader field of food studies. Reading African literature gastropolitically, Edwin's study of West African Francophone novels analyses 'the ways in which food is engaged in by the writers [she studies] to unmask sociopolitical problems' (2008, 40). Edwin forges an uneasy marriage between seminal food literary studies texts such as Cooking by the Book (Schofield 1989) which largely uses American women's culinary writing, and anthropological studies of West African culture. According to Edwin, literature therefore verifies anthropological observations and is gastropolitical in its most vulgar sense, confirming the role of food writing in African literature's larger political function.

Dan Ojwang's (2013) study of three key East African Indian authors and the displacements that their works interrogate complements Edwin's work in key ways. Applying Arjun Appadurai's $(1981,1988)$ definitions of gastropolitics, a lens developed to view South Asian culinary writing as contributory to nation-building, he begins with this premise: 'Food and eating have most memorably appeared in African literature and popular culture as metaphors for political corruption, the greedy acquisition of material goods, and the social inequality engendered by the latter in both the colonial and postindependence eras' (Ojwang 2013, 65). Citing James Ogude (2009) and Eleanor Schmitt and Werner Graebner (1992), Ojwang (2013) observes that depictions of food are embedded in larger referendums of corrupt postindependence politics and urban poverty. Achille Mbembe's, Ayi Kwei Armah's, Ngũgĩ wa Thiong'o's and Francis Imbuga's corpulent, flatulent men who eat well and starve others serve as staples of these depictions of dysfunctional postcolonial Africa (Ojwang 2013, 65). This suggests that Ojwang's view of African gastropolitics builds on the ethnographic and economic studies that dominate search results when investigating African food; the tendency to foreground sociopolitics trickles into African literary criticism. However, Ojwang seeks to press beyond these confines by turning to questions attendant to everyday life:

How does food, in literary senses, encode histories of resistance, accommodation, and also cultural exchange in contexts marked variously by racialism, violence, communal expulsions, and inequality? Why do the writers find in food a useful tool for mediating personal and communal stories, making it in the process an important focus of feelings of nostalgia, loss, and longing? How do food and drink inscribe communal boundaries or act as indices of social status, personal character, or even gendered power?

$(2013,70)$

Ojwang connects to 'food's political character' concerns that Roy would ascribe to the gastropoetic: the use of food as 'material reality and symbol,' and its placement in East African Indian fiction as a medium to negotiate the mundane power dynamics between self and community, self and culture, and self and nation, and its pleasures as a vehicle of intimacy and care (Ojwang 2013, 70).

Considering the gastropoetic does not merely entail attention to everyday life and sociality. It also attends to formal questions of how literary modes and mechanisms depict its pleasures and perils. Julie Huntington's (2015) study of African cookbooks offers the clearest example of a gastropoetic engagement with food literature, and not just because she focuses on the bonds that connect family members, friends and members of local community groups. The gastropoesis that interests her in her study consists of the different entanglements of form. Of the cookbook authors in her study, she writes 'there are multiple means through which [they] contextualise and interpret [the] cultural, historical, and aesthetic significance' of ceebu jën, a dish that she connects to Senegalese sovereignty and multiculturalism (Huntington 2015, 125-126). ${ }^{1}$ Huntington reads Senegalese cookery in the company of other nonverbal artistic forms such as 
jazz and percussion. More critically, she argues that not all dimensions of the 'oral, instrumental, and cultural components of culinary folklore' translate easily, as some are 'preserved and celebrated in some instances, but also transformed and/or compromised in others,' with omissions and alterations proving as revelatory as inclusions and transmissions (Huntington 2015, 134). For Huntington, these elisions suggest the appropriateness of applying literary praxis to culinary writing (136) in addition to applying nonliterary techniques that focus on the oral and the instrumental.

Jonathan Bishop Highfield (2017) provides a needed panoramic critique of the role that food plays in African literature across the continent and into diaspora, beginning with Sunjata's epic, ${ }^{2}$ continuing through colonial culinary writing, and then moving through analyses of writers such as Bessie Head, Chimamanda Ngozi Adichie, Yvonne Vera and Ben Okri, and concluding in exile with M. G. Vassanji and cookbook writers Marcus Samuelsson and Pierre Thiam. ${ }^{3}$ Highfield's work enjoins literary studies and food studies to take seriously African literature's longstanding interest in feeding and the culinary traditions and forms of sociality that cascade from it. His work connects the gastropolitical and the gastropoetic: African folk stories bookend the text that examines a range of literary modes. The book considers the connections between food and the epic, food and labor, food and sustainability, food and violence, food and global capital, and food and exile. In his argument he deconstructs the tidy divisions that distinguish gastropolitics from gastropoetics and shows that literary depictions of food and foodways enact African history from the precolonial to the postcolonial to the global, even as the preparation, gifting and consumption of food trope the intimacies of everyday life across African letters' myriad forms.

This chapter positions itself as a response to Cusack's and Highfield's calls to consider culinary writing and national literatures in their plurality, and extends McNee's thinking about the culinary into the realms of the aesthetic by considering the complex relationship between gastropolitics and gastropoetics in African novels. It reinforces Ojwang and Roy's insistence that food is an everyday practice and so its depictions can work allegorically and metaphorically to encode the body's entanglements with culture, interpersonal intimacy and interior life. The reductive maxim that 'food is power' applies (enacting McNee's second axiom): by no means is this maxim exclusive to African literature, but African food scholarship's absorption by famine, food aid, food supply management, food production, and despotic excesses and largesse suggests that the axiom proves particularly potent in African contexts. However, McNee's thinking recommends a productive entanglement between the gastropolitical and the gastropoetic by thinking about the concomitance of the everyday and the political backdrops that animate its contexts. This chapter offers only the gentlest corrective to Ojwang's study and to Edwin's work by introducing notions of the gastropoetic that both Ojwang and Edwin overlook, considering them to complement the gastropolitics that both scholars interrogate (even as Ojwang's work explicitly references gastropoetic interests). It broadens Ojwang's scope by considering works from across the continent, although this chapter's focus (for lack of space) does not consider the African minority literatures that interest Ojwang.

Zakes Mda's (2002) Ways of Dying suggests that the insistent everydayness of eating and its pleasures can offer solace, a refuge from social chaos and the hard life of the itinerant poor in South Africa. Toloki is a self-employed professional mourner, the first of his kind. He makes his home on outdoors benches where he sleeps, the beaches where he showers and, eventually, a shack that he builds in the township with Noria, a childhood neighbor grieving for two dead sons and hailing from the village where Toloki was born. With the noteworthy exceptions mentioned below, meals taken with others in the novel generally represent opportunity thwarted by disappointment and the cruel caprice of those in power, as the novel reveals food's 
gastropolitical dimensions. After leaving the village for the city, Toloki enters a small town, tired and hungry. Refusing charity and vowing reimbursement - as he will repeatedly throughout the novel - Toloki receives a meal of fat cakes and milk from a man in overalls who also arranges a job unloading maize and mealie-meal for a milling company (Mda 2002, 60-1). This first job is marred by trouble over food, as his predecessor is ousted by false implication in a mealie-meal reselling racket (62-63). Toloki's first business is cooking and selling boerewors on rolls and mealie-pap and steak (121-122). Toloki's prosperity is short-lived: one day, he leaves his cart to resupply after running out of meat, only to find it gone when he returns, confiscated and destroyed by the city. The investigation into his cart's disappearance never ends nor is the matter ever closed, as the officers to whom he complains cannot cite the regulations he violates nor supply the name of the official who gave the order. Toloki loses his clientele and is again jobless (121-123). The loss of the food trolley reveals the inefficiency and indifference of urban South African bureaucracy, as well as the state-sanctioned cruelty that prevents upward mobility for the working poor, no matter how inventive or hardworking they might be.

Food can also comfort, and these moments unveil the novel's commitment to a gastropoetics of succor that shelter characters from gastropolitical havoc. Toloki enjoys eating an unorthodox combination: Swiss cake topped with a relish of green onions (Mda 2002, 14-15). He delights in his snack: 'He takes a bite first of the cake, and then of the green onions. His eyes roll in a dance of pleasure. He chews slowly, taking his time to savor each mouthful. Quite a tingling taste, this delicacy has. It is as though the food is singing in his mouth' (15). He enjoys his delicacy for its vivid flavor as well as for the 'aura of austerity that he associates with monks of eastern religions that he has heard sailors talk about' (15). The cakes fantastically transport Toloki and Noria as he shares them with her, fetching them from a fantasy oven and serving them on fantasy china stored in an imaginary sideboard that furnishes the house that Noria and Toloki conjure through the magazine pages pasted on the walls of the shack he helps her build. Noria observes the strangeness of the combination, to which Toloki replies: 'It is what I eat when I really want to spoil myself. It is not the kind of food I can afford every day' (114). Except for the meal that Noria prepares, the cakes and onions stand as the only food that provides unalloyed pleasure, as this odd culinary invention of Toloki's connects the luxuriousness of the cake and the piquancy of its relish to his invented vocation and the aura of sanctity that accretes to it. The cake provides the setting for intimacy and sociality between friends that ameliorates rough handling by a society that cannot offer the upward mobility proffered in the magazine pages pasted to the walls of a shack. The sharing of the cake foregrounds the productive communal ties that Toloki forges in the novel's closing pages and the promise of his future happiness as a beloved member of that community.

Aminatta Forna's (2010) The Memory of Love advances the themes of state-sanctioned cruelty, addressing them metaphorically and against the backdrop of the civil war in Sierra Leone. The novel bears close similarity to the themes and progression of Chimamanda Ngozi Adichie's Half of a Yellow Sun. The personal costs in The Memory of Love are high, as people attempt to use narrative to heal wounds inflicted on both body and psyche. Both novels depict the middle class under assault, the ambition and failure of the professoriate in a time of mass uprising and political dissidence, the crumbling of personal passions, and a gastropoetics of political duress. Half of a Yellow Sun depicts everyday food habits in famine-wracked Biafra to sketch daily life under political pressure. The novel's gastropolitical preoccupation with food is unavoidable: the novel is set during the Biafran famine; and it is Ugwu, Odenigbo's servant, who ultimately tells the story, and his duties chiefly keep him in the kitchen. His sparring with Odenigbo's mother for command of that space (Adichie 2007, 94-99), the 'real meals' with boiled yam and 'boh-tah' that he misses when visiting his family in the village (121) and the food waste about which 
Olanna reminisces at the height of famine (285) yield to the exigencies of starvation as Biafra suffers one of the worst humanitarian crises of the twentieth century. The product of Ugwu's hands is where the novel's gastropolitics and gastropoetics collide: in contrast with the lush meals that prompt jealous badinage with his sister early in the novel (119-121), Ugwu must prepare hated relief food that is of low quality and difficult to cook well (283). However, he bends ably to the task, preparing powdered eggs that Baby craves once she falls ill (267). A gastropolitical reading would focus exclusively on the relief center's insertion into the family's life, the eggs as synecdochic of the blockade and its effects. However, a gastropoetic reading introduces the notion of Baby's pleasure in the face of the 'slow look' that Ugwu casts at Mrs. Muokelu as he goes into the kitchen to fry the dried egg yolks in red palm oil (267). The fried egg yolks and the cake that he lovingly prepares for the family (283) represent sustained efforts to allow the family to eat well every day against the backdrop of daytime food theft and the peril of abduction. The egg yolks reveal the need for culinary creativity in the face of deprivation.

If the ratio of gastropolitics to gastropoetics tilts toward the gastropolitical in Half of a Yellow Sun, the formula is inverted in The Memory of Love, in which food is tied intimately to remembrance and feeling. A frame narrative takes place at the hospital and the university, two sites of public service that surface repeatedly in African fiction as metrics of the fragility of the state, the novel follows twin temporal threads. Adrian, an English doctor who works in 'the Third World,' listens to the last testament of Elias Cole, an elderly academic dying of pulmonary fibrosis. Adrian's work as a psychotherapist alongside surgeon Kai Mansaray heals people suffering in Sierra Leone's civil war; Elias's confessional takes place in the years after independence as democracy's decay anticipates the oppressive military regimes that will eventually fill the hospital where Adrian and Kai serve. Sociality in The Memory of Love breaks down: characters die alone or suffer betrayals that splinter their relations with one another. Kai and Adrian's friendship collapses. Kai raises Mamakay and Adrian's daughter as his own and without her father's knowledge. Elias has spent his life shrugging off responsibility for Julius's death and then resenting him for standing between Elias and Saffia even in death. Mapping a gastropoetics of sociality under sustained assault, food reverberates in Forna's narrative.

Comfort in cooking marks cultural acumen. Kai is at home in his nation and in Adrian's kitchen. Food also marks degrees of assimilation for Adrian, whose palate is tested in his early days by the spicy stew served to his black co-workers (Forna 2010, 23) and then later by the ants he shakes from his bread (128), ants that had bitten him viciously in the novel's opening chapters (25). When they first meet, Kai makes a breakfast as Adrian looks on: 'Watching the newcomer move around the kitchen, his kitchen, as though he were a man entirely alone in his own space, it is Adrian who feels like the intruder' (28). Kai's breakfasts become a part of Adrian's routine, but Kai's enjoyment of cooking is not located in the act of feeding. Instead, it is located in the acts of cooking itself, as '[h]e loves the routine and rhythm of preparing food. It brings him to a feeling of peace' (123). He is also 'an opportunistic eater' who rummages through cupboards 'purely out of habit' because he has known hunger (217). Marking a moment of rejection, Kai does not fill Adrian's empty stomach on the afternoon when Mamakay dies giving birth to Adrian's child. Instead, Adrian soothes his hunger pangs with whiskey, as they 'come without the accompanying desire for food.' It is at the same table where Kai serves his meals that he tells Adrian: 'Go home' (21-422). Even after Mamakay dies and Adrian returns to the apartment to live during his last days in the country, it is Kai who cooks (439).

Two foods are linked to trauma in the novel and reveal the entanglement of gastropolitics and gastropoetics: meat and cake. Adecali's trauma splinters his experiences into discrete fears 
that Adrian treats in his therapy. In addition to the nightmares, fear of fire and incontinence he suffers, Adecali also smells something that is not there: 'I smell roast meats. I hear screaming and banging. And then I smell roasted meat' (Forna 2010, 317). Adrian attributes the hallucinations to a lack of education that robs Adecali of the facility to talk about them. (He will come to learn that Elias too uses silences and elisions to deal with his own traumas, and that Adrian is implicated in them.) Adrian learns that Adecali's dread of fire and the smell of roasted meat are flashbacks from his time as a rebel in the paramilitary Sensitization Unit, and that Adecali's job was to burn families alive in their houses (372). Like the roasted meats in Chris Abani's GraceLand (2005, 74, 207, 213) that I analyse elsewhere (Phillips 2012), the delicious flavor of cooking flesh in The Memory of Love tropes the atrocities that haunt their perpetrators and the guilt that lays mundane claims to everyday affective life.

Cake, however, serves as a figuration of different forms of complicity with state power and quieter implication in its crimes. The morning of Elias's arrest, he has bought a cake in a box for his breakfast (Forna 2010, 187), and Johnson asks him what is in the box during a terrifyingly mundane interrogation. Forced to wait to go to the bathroom as his need urgently presses, Elias understands that ' $[t]$ he man was a small-time sadist, pedantry his weapon of choice' (192). As the questioning goes on, Elias is diminished and infantilized by his interrogator: 'I was aware of Johnson's eyes on me, regarding me as though I were a querulous child. I felt petulant and aggrieved. My head ached and I experienced a strange and sudden urge to cry. He had even stolen my cake' (193).

The gastropoetics of the theft of the cake on the table trope the 'vast, fearsome power' of the state as it inflicts its cruelty casually on citizens in its power, adding dimension to Elias's torture. In The Politics of Cruelty, Kate Millett (1995) describes the subject's powerlessness when confronted by the state's power to torture its citizenry, withdrawing any rights to which they feel entitled. She exactly describes Elias's predicament, his trembling compliance and eventual obsequiousness, his humiliation and hurt, the 'leaking away' of his pride, and the role that the need to eliminate plays in the infliction of psychic injury (Millett 1995, 3). Elias eventually bends beneath the pressure of Johnson's voice (Forna 2010, 193). He can feel the insult of state power viscerally in the theft of the cake. He becomes a child oppressed by an abusive adult, the citizen betrayed by the state.

The cake also symbolizes Elias's own comprised ethics. He is more aggrieved by the loss of the cake than he is by his own culpability in Julius's death, from which Elias profits by winning the hand of Julius's widow. In his first telling of his interrogation, he focuses on the theft of the cake and his own feelings of powerlessness. Later, as he repeats his confession to Adrian, he begins with Johnson stealing the cake and abandoning him for hours (Forna 2010, 407). He then elaborates that he is imprisoned close enough to Julius to witness what was probably his death, and that he turns over his detailed notebooks to Johnson and the Dean in return for his own freedom (408-409). Elias does and says nothing as he listens to Julius wheeze and die: he alters the course of a life with '[t]he silent lie. The act of omission' (410). Adrian understands this as 'The fragmentation of the conscience ... [Elias] absolved himself of responsibility for the greater crime and yet it could not have occurred without him. There are millions of Elias Coles the world over' (410). The cake is a feint, a focus for Elias's indignation, a symptom of the diminishment of his spirit and his capacity for ethical agency.

In Adichie's Purple Hibiscus (2003), the havoc in the novel is confined within the family, as observed by Highfield (2017, 114-115), but food performs the same gastropoetic work as in The Memory of Love. In this precursor to Half of a Yellow Sun, Adichie pays close attention to the dynamics at the family table, much in the same fashion as Tsitsi Dangarembga does in Nervous Conditions, and to similar effect. Eating is anxious: Kambili's father tyrannizes the family with his 
faith, throwing a missal when Kambili's brother Jaja does not take communion (Adichie 2003, 6-7), viciously beating his wife and children when Kambili eats a bowl of cereal before mass (100-102), and making mealtimes a gut-twisting misery with his anger. When a coup threatens, Eugene sends the family to live with his sister Ifeoma, an academic who lives hand-to-mouth in Nsukka. Kambili is often so tense that she cannot enjoy food, although the family's meals are rich, flavorful and skilfully prepared $(12 ; 38-41)$. The family must often uphold a fiction of filial happiness, complimenting the drinks and the biscuits that Papa's factory makes $(12-14 ; 40)$, a fiction that generally fails.

Connected to uncomfortable meals, scalding tea works as a cruel semiotic throughout the novel. The gastropoetics of boiling water and blistering flesh depict the private calamity in the home, but also reference psychological derangement suffered at the hands of the colonial educator. The sips of tea from Papa's cup, called 'love sips' and taken only on his invitation, burn Kambili's tongue, but she accepts the pain because 'when the tea burned my tongue, it burned Papa's love into me' (Adichie 2003, 8). The immediate import of this moment is that she and Jaja are not invited to sip when Jaja refuses communion at the novel's opening, and this denial underscores the depth of Papa's displeasure with his family. However, Papa will burn his love into Kambili when he accuses Kambili of 'walking into sin.' She fails to report her grandfather's presence in Nsukka and her punishment is that a kettle of boiling water is poured over her feet, passing down punishment Papa endured at St. Gregory's when a 'good father' steeped his hands as punishment for masturbation (193-197). The teacup will resurface at the novel's end, when Kambili learns that her mother had been using it to poison her father's tea. Kambili immediately thinks back to the sips of Papa's tea, 'love sips, the scalding liquid that burned his love onto my tongue.' The tainting of the tea is sacrilegious despite Papa's many abuses, and Kambili screams at her mother, 'Why did you put it in his tea? Why in his tea?' (290). Even though the poisoned teacup offers the relief that Kambili will never seek as Papa's abuses scale in cruelty, Kambili still views the tainting of the tea as an encroachment upon a space where Papa communicated his love.

Meanwhile, Kambili's meals at Aunty Ifeoma's house nourish both body and spirit, even as Aunty Ifeoma must economize in ways that Kambili finds unfamiliar, a coupling of gastropoetics and gastropolitics to depict state institutions under duress. Nevertheless, the family finds pleasure and sociality despite enduring precarity and want. A comforting meal of soybean milk and okpa reveals the climbing price of dried milk that Aunty Ifeoma can no longer afford (Adichie 2003, 233). When power outages ruin the meat, Aunty Ifeoma does not see waste, but instead sees opportunity (246). Even the petrichor smells appetizing:

There was a smell of freshness in the air, that edible scent the baked soil gave out at the first touch of rain. I imagined going into the garden, where Jaja was on his knees, digging out a clump of mud with my fingers and eating it.

Kambili eventually learns cookery skills: her cousin Amaka teases her inability to economize when peeling yams and shows her own skill in producing a single, 'soil-studded ribbon' of yam peel (134). Later meals will have Kambili and Jaja better able to help in the kitchen, and Amaka and Kambili will find sorority there. Of this, Highfield (2017) writes: 'The simple act of preparing a meal with her cousin is Kambili's first real moment of community. It gives her a sense of a possible life not lived in fear' (120).

The study of food in African literature places Tsitsi Dangarembga's Nervous Conditions (1998) at the center of collective attention; food plays as critical a role in its sequel, The Book of Not 
(2006), which picks up the thread of the narrative by following Tambu to boarding school. There, her chilly motivations shape her responses to the war for independence, race relations and class difference between student cohorts, and the constant jockeying for position as head girl of her class. Describing the novel's trajectories, Rosanne Kennedy writes: 'The novel dramatizes the narrator's struggle to break out of a repetition compulsion, manifested in her obsessive desire for recognition, which continually leaves her deflated and depressed,' treating legacies of colonialism and race in ways that dodge the taboos that prohibit speaking about them (Kennedy 2008, 87). After segregation interferes with her ability to learn at the same pace as the white students, Tambu suffers a fall from grace that she quickly internalizes - her poor marks are indicative of her insufficiency rather than structural racism. Upon leaving Babamukuru's home as a failed student unqualified for university, Tambu gains employment as a copywriter of an advertising agency, a job she ends up losing. Tambu concludes the novel unemployed, possibly homeless, her quest for unhu (personhood) in doubt. The text ends similarly to Chris Abani's GraceLand (2005) but is even bleaker as Tambu experiences no epiphany to allow her to understand her place in the world.

Dangarembga's (2006) novel relegates Nyasha to a minor character whose disordered body surfaces and then vanishes in the text, transformed from an avatar of anticolonial resistance to a warning against personal weakness. Tambu, an antisocial individual, assesses her failure to fit into the world and regards her as a family malady who must be treated, a model of feebleness and inadaptability. Kennedy (2008) argues that the novel treats the traumas of postcolonial subjectivity as animated in everyday struggles and triumphs (89). Food is one of those everyday sites of struggle: the pain and agitation food tropes effect disappointment, small defeats, everyday indignities that perhaps fall far short of the cataclysmic losses Forna describes in The Memory of Love yet matter no less to those who suffer them.

In its opening chapter, the novel links the consumption of traditional food to political alignment in a gastropoetic fashion, as everyday eating tropes these alignments and then, in Tambu's case, symbolizes their failure. Netsai's sadza wins her the heart of a freedom fighter with whom she falls in love (Dangarembga 2006, 5). Tambu's mother couches her demands for tribal, familial, and racial loyalty in culinary innuendo, calling Tambu 'wekuchirungu [people from European places]' and asking: 'Do you still like matumbu [intestines], Tambuzai! Can you white people eat mufushwa [dried vegetables] with peanut butter?' (7). If Tambu has trouble eating, it is not because her mother tests her political and filial loyalties - it is because Tambu finds loyalty itself burdensome and diminishing. As Tambu takes small bites and sips of sadza and sourmilk, her mother 'derisively' observes: 'It's difficult, isn't it, the eating's difficult.' Tambu responds by taking a 'a large gulp so as not to answer':

I could not tell her what was difficult. It was not the food. It was her ... It was the nothingness upon which she stood as upon the summit of her life, from which she clawed about for the gleanings from other women's husbands, such as Babamukuru. I shuddered, spilling the sourmilk. What could make a woman so avaricious and hollow? Oh, how to become more of a person!

(Dangarembga 2006, 7)

Tambu's principal loyalty is to her own self-expansion. The sadza serves as an index of Tambu's allegiance, measured by her mother in terms of her hesitancy: a faithless daughter is a fussy eater. Like Nyasha's anorexia in Nervous Conditions, Tambu's refusal to eat in accordance with parental demands of appetite marks out terrains of resistance and self-assertion in The Book of Not. The family pathologizes Nyasha's extreme response in Dangarembga's first novel; in the sequel, 
Tambu's careful eating describes a careful path as she navigates the demands placed upon her by her family members. For both young women, food maps the difficult terrain of sociality that they fail to successfully navigate.

Meals throughout the novel serve as sites that expose inequity and highlight social status, conforming to the gastropolitics of class and race that bring Tambu to the table, as well as conforming to a gastropoetics of everyday failed sociality. While the novel rarely states overtly that Tambu's black skin segregates her from others and entices the white nuns and nannies to treat her differently, Dangarembga speaks racial discrimination in a code that is simple enough to decipher. The nannies who serve at meals 'move fluidly' as they bear food from the kitchens, 'but when they set a jug or a plate before Ntombi or me, they smack it down with a jut of the chin and spills, as though slapping a hard, crushing thing down on obnoxious, crawling objects' (Dangarembga 2006, 46). Black servants treat black students poorly yet exhibit servility toward their white counterparts. This poor treatment continues as a free Zimbabwean tea-boy named Raphael slams down cups and berates Tambu for not being at her desk during service. Her dilemma is whether to drink: her curdled stomach marks out her difficult circumstances as she is too queasy to enjoy the tea that he disrespectfully serves her (Dangarembga 2006, 220).

Touching food and cleanliness also mark racial and class differences among the girls, exemplified by Bougainvillea's chocolate (Dangarembga 2006, 38-40) and the oily, squashed paper bags of food that must be eaten in the dormitory (41). The food named 'tuck' marks race and class, visibly designating levels of privilege and mobility, as food maps a regimented sociality, vertical in its arrangement. If Nyasha's nervous condition in the previous novel is disordered eating, then Tambu's nervous condition is the neuroses that accompany the delectation of food brought into the school from outside and the concomitant judgment of her peers. At a meal, Ntombi casually asks for some of Bougainvillea's Nesquik, her hand hovering over the 'tin of taste,' 'the sign of our classmate's superiority' (38-39). The casual nature of the request reveals racial and class tensions in the group, as Tambu holds her breath, awaiting the answer: 'Did Ntombizethu really have the stamina to pull that tin over and serve herself from it? Or was she in the end going to give in and sell something fundamental for the taste of chocolate?' (39). In the standoff, systems of oppression also bind white feminine privilege: '[P]oor Bougainvillea's options were limited. If she dragged the container out of Ntombi's reach she could be blamed for being stingy, or even worse, a racist' (40). Bougainvillea resolves the dilemma by serving Ntombi herself (42). Kennedy reads this moment, as well as the slammed plates and jugs, as tropes for " $\mathrm{t}]$ he absurdity of the relations between the black and white students produced by the allegedly "equal" but in practice inferior position of the black students' (95-96). The table marks ambivalent spaces of belonging for all who eat.

The hungering self undertakes the uneasy navigation of these spaces as it moves away from the continent and into diaspora; the family table offers a setting where characters negotiate shifting frames of sociality. It is Calixthe Beyala's How to Cook Your Husband the African Way (2000) that offers the clearest depiction of the gastropoetics of diasporic longing filtered through the body's plural appetites. The novel features a protagonist suffering from an eating disorder; who holds up the slim-boned bodies of white women as an unachievable aesthetic ideal and who finds power in rejecting them in favor of an intimate sociality between man and woman. However intimate this relationship may be as Aissatou attempts to pare down her neighbor Bolobolo's circle of relations to focus exclusively on her, it serves as a metonym for her relationship with the continent of her birth. Aissatou lives in diaspora in Paris and devotes her attention and her labor in the kitchen to winning Bolobolo's affections as he enters the novel involved with another woman. Aissatou ensnares him with her cooking, preparing dishes that their shared heritage recognizes, seducing his palate and prying him away from Bijou, a French 
woman of mixed race. Food forges the marriage, as it is the plinth on which Aissatou erects their union. Despite his many betrayals - that result in a child born outside their marriage Aissatou manages to tame his wayward tendencies and transform him into a faithful, dutiful husband. The narrative ends with this observation: 'This is the way you cook your husband the African way' (Beyala 2000, 1278). The novel, punctuated by recipes between chapters, reveals itself to be a cookbook that instructs in the construction of a satisfying, placid marital life.

Prior to the commencement of her project to seduce and then marry Bolobolo, Aissatou starves herself in a vain attempt to be desirable to men who prize whiteness. She notes the frail tautology that binds race to body size: 'to be white you've got to be thin' but to be thin, you must be white (89). She strips her body of its curves, subjecting it to the torsion of a pareddown diet, and observing that a 'beautiful woman is flat as a pancake, thin as a rake or a slice of Melba toast.' As she notes the fragility of the Melba toast body - its desiccated brittleness, 'crickle crackle' - she considers the paradox of feminine beauty and the primacy of the male gaze in determining what it entails. A beautiful woman has trimmed her body of its markers of femininity, flattening its 'geometries,' rendering it two-dimensional and assessing it using the brutal arbitrariness of a tape measure around the waist (89-92). The paradox of the beautiful white woman who strips her body of feminine features becomes the syllogism of the "white Negro' woman alienated from her own body and, by extension, her cultural identity, thwarted sociality excarnated (181-184). The novel grapples with the alienation of the exiled body in ways that refract Njeri Githire's (2014) readings of illness and purgation in diasporic Caribbean writing: 'pressed to assimilate to the national body' Aissatou, 'the guest (the im/migrant)[,] defies assimilation/annihilation through food and (non)eating activities' (1585-1586). The novel posits that the sociality of assimilation carries with it the threat of annihilation, and so Aissatou must choose. She understands the unsustainability of working toward the ideal of being a "white Negro' woman and learns that the prize of a white man's love is not worth the work. She turns her back upon this strange method of winning a man, revisiting African cookery as a means of achieving a glossy, plump, well-nourished sexual strength and achieving a realignment of body, gender, race and culture. Her response to the pressure of diasporic displacement is a return to African traditions because she 'know[s] how to cook a husband the African way without losing [her] soul' (Beyala 2000, 591-592). She turns toward a romantic relationship as part of a realignment toward homeland.

Cooking a husband the African way involves a pan-African approach: the novel's recipes represent the Ivory Coast, Cameroon and the French-speaking DRC. The word for okra in Bantu languages appears in two recipes, and maffe is a Central and West African name for chicken with peanuts. If the tuck at Tambu's lunch table points outward from Zimbabwe and toward South Africa (or toward local street vendors) then the Parisian table points toward the entire continent, in keeping with Igor Cusack's observations about the gastropolitics of African national cuisines. The novel never indicates which country in Africa is home: instead, all of Africa is home for the homeless woman whose emaciated form crackles her alienation from her origins. Her return to these origins predictably offends her neighbors as Beyala writes of the smells that emanate from Aissatou's apartment: 'Those blacks. How can they eat stuff which stinks so much?' (Beyala 2000, 654). This is the conventional complaint about ethnic kitchens, one that appears in diasporic literature across cultures (Native Speaker by Chang-Rae Lee [1996]; 'Mrs. Sen's' by Jhumpa Lahiri [1999]). Rather than let it shame her into compliance, she glories in the effusive odors that flood from her home and into the houses of others. She even observes: 'If the way the blacks eat is destroying nature, the way the whites live is killing human beings with its mechanized madness, I say' (Beyala 2000, 884-885). Aissatou practices kitchen magic (troped in similar ways by Haitian-American writer Edwidge Danticat [1996] in 
her short story collection Krik? Krak!). Aissatou surrenders one mode of sociality - assimilation into Parisian culture - to gain another that is far more precious and pertinent to her. Her measure of success is the eagerness of Bolobolo's multiplied appetites. Her greatest compliment is the enthusiasm with which he greets the meal (Beyala 2000, 841-843). Although Aissatou arouses Bolobolo's greed and massages his hungers, her cooking and her body can only do so much, as her work in the kitchen cannot keep Bolobolo from straying. Aissatou confesses, 'I cooked to keep us together because he cheated on me with the prettiest girls around' (12321234). Her patient suffering and the ginger juice she serves finally work to secure his faithfulness at the novel's conclusion.

The gastropoetic stands opposite the gastropolitical, following the structure of the relationship between the aesthetic and the sociohistorical that remain otherwise inaccessible, as Fredric Jameson argues in The Political Unconscious. The division separating gastropolitics and gastropoetics is not tidy: rather than view African politics as connected to powerful figures and voiced in a specific, narrow lexicon of poverty and exploitation, food images grant insight into how these instances are embedded in everyday life in much more complex ways. Even more critically, the gastropoetics of African literature animate food as a means of communion, as a site where characters find, lose or exercise agency, and as a place where, against the backdrop of political calamity, private exercises of culinary creativity can create spaces of solace and sociality or foreclose those spaces from others.

\section{Notes}

1 Huntington offers the following delicious description of ceebu jën, along with the multiplicity of its naming conventions: '(alternatively spelled thieboudienne, theibou dienn, tiep bou dienn, tiébou dienne, and tiebou dieune, among others), a sumptuous stew made with fresh fish stuffed with herbs and spices, accompanied by a variety of colorful vegetables, and served atop a bed of broken rice' (124).

2 The Manding epic of Sunjata tells the story of the consolidation of the Mali Empire under the leadership of the culture's greatest hero. Rather than surviving as a written text, a jeliw sings the epic, often accompanied by instruments and arousing response from a naamu-sayer (Condé 2004, xviii). The interactive, cooperative storytelling tradition and the prominence of the Condé bards who tend to the story support the endurance of African oral traditions and Manding cultural values. Highfield's analysis focuses on the baobab fruit in the epic. Both he and this chapter rely on Gordon Innes' (1974) transcription of three of Gambia's leading bards, Bamba Suso, Banna Kanute and Dembo Kanute. I gently supplement Highfield's thorough research of the epic with David C. Conrad's (2004) translation of Djanka Tassey Condé's storytelling and the introduction Conrad provides.

3 Highfield's analyses of these authors comprises treatment of the following: Bessie Head's The Collector of Treasures, A Question of Power, Serowe: The Village of the Rain Wind, Tales of Tenderness and Power, When Rainclouds Gather, A Woman Alone and her collected letters in A Gesture of Belonging; Yvonne Vera's The Stone Virgins; Ben Okri's The Famished Road, Infinite Riches, and Songs of Enchantment; M.G. Vassanji's No New Land; Marcus Samuelsson's Aquavit and the New Scandinavian Cuisine, his memoir titled Yes, Chef and his cookbook The Soul of a New Cuisine; and Peter Thiam's Senegalese cookbooks titled Yolele! Recipes from the Heart of Senegal and Senegal: Modern Senegalese Recipes from the Source to the Bowl. Highfield's study shares this chapter's interests in Chimanda Ngozi Adichie's Half of a Yellow Sun and Purple Hibiscus.

\section{References}

Abani, Christopher. 2005. GraceLand. New York: Picador.

Adichie, Chimamanda Ngozi. 2003. Purple Hibiscus: A Novel. New York: Anchor Books.

Adichie, Chimamanda Ngozi. 2007. Half of a Yellow Sun. London: Harper Perennial.

Appadurai, Arjun. 1981. 'Gastro-Politics in Hindu South Asia.' American Ethnologist 8(3): 494-511.

Appadurai, Arjun. 1988. 'How to Make a National Cuisine: Cookbooks in Contemporary India.' Comparative Studies in Society and History 30(1): 3-24. 
Beyala, Calixthe. 2000. How to Cook Your Husband the African Way. Translated by David Cohen. Peach Publishing. Kindle Edition.

Brillat-Savarin, Jean Anthelme. 1825. Physiologie Du Goût, Ou, Méditations De Gastronomie Transcendante: Ouvrage Théorique, Historique Et À L'ordre Du Jour. Paris: Gabriel de Gonet.

Chakrabarty, Dipesh. 2000. Provincializing Europe: Postcolonial Thought and Historical Difference. Princeton Studies in Culture/Power/History. Princeton, NJ: Princeton University Press.

Condé, Djanka Tassey. 2004. Sunjata: A West African Epic of the Mande Peoples. Translated by David C. Conrad. Indianapolis: Hackett Publishing Company.

Cusack, Igor. 2000. 'African Cuisines: Recipes for Nation-Building?' Journal of African Cultural Studies 13 (2): $207-225$.

Dangarembga, Tsitsi. 1998. Nervous Conditions: A Novel. New York: Seal Press.

Dangarembga, Tsitsi. 2006. The Book of Not: A Novel. Banbury: Ayebia Clarke Publishers.

Danticat, Edwidge. 1996. Krik? Krak! New York: Vintage Books.

Edwin, Shirin. 2008. 'Subverting Social Customs: The Representation of Food in Three West African Francophone Novels.' Research in African Literatures 39(3): 39-50.

Esty, Joshua D. 1999. 'Excremental Postcolonialism.' Contemporary Literature 40(1): 22-59.

Forna, Aminatta. 2010. The Memory of Love. New York: Atlantic Monthly Press.

Githire, Njeri. 2014. Cannibal Writes: Eating Others in Caribbean and Indian Ocean Women's Writings. Chicago: University of Illinois Press.

Head, Bessie. 1974. A Question of Power. Oxford: Heinemann.

Head, Bessie. 1977. The Collector of Treasures. Oxford: Heinemann.

Head, Bessie. 1981. Serowe: The Village of the Rain Wind. Oxford: Heinemann.

Head, Bessie. 1986. When Rainclouds Gather. Oxford: Heinemann.

Head, Bessie. 1989. Tales of Tenderness and Power. Oxford: Heinemann.

Head, Bessie. 1990. A Woman Alone. Oxford: Heinemann.

Head, Bessie. 1991. A Gesture of Belonging: Letters from Bessie Head, 1965-1979. Edited by Randolf Vigne. London: SA Writers.

Highfield, Jonathan Bishop. 2017. Food and Foodways in African Narratives: Community, Culture, and Heritage. Milton Keynes: Taylor and Francis.

Huntington, Julie. 2015. 'There's More than One Way to Make a Ceebu Jën: Narrating West African Recipes in Texts.' In Renée Brenda Larrier, editor. Writing through the Visual and Virtual: Inscribing Language, Literature, and Culture in Francophone Africa and the Caribbean. In the series: After the Empire: The Francophone World and Postcolonial France. Lanham, MD: Lexington Books. 123-148.

Innes, Gordon, trans., ed. 1974. Sunjata: Three Mandinka Versions. London: School of Oriental and African Studies.

Jameson, Fredric. 1981. The Political Unconscious: Narrative as a Socially Symbolic Act. Ithaca, NY: Cornell University Press.

Kennedy, Rosanne. 2008. 'Mortgaged Futures: Trauma, Subjectivity, and the Legacies of Colonialism in Tsitsi Dangarembga's The Book of Not.' Studies in the Novel 40(1-2): 86-107.

Lahiri, Jhumpa. 1999. 'Mrs. Sen’s.' In Interpreter of Maladies: Stories, 111-135. Boston: Houghton Mifflin.

Lee, Chang-rae. 1996. Native Speaker. New York: Penguin Random House.

Leonardi, Susan J. 1989. 'Recipes for Reading: Summer Pasta, Lobster À La Riseholme, and Key Lime Pie.' Publications of the Modern Language Association of America 104(3): 340-347.

Mbembe, Joseph Achille. 2000. On the Postcolony. Translated by A. M. Barrett et al. Studies on the History of Society and Culture, Vol. 41. Berkeley: University of California Press.

McNee, Lisa. 2003. 'Food Cultures and Food for Thought: Cultivating Local Knowledges in Africa.' Pretexts: Literary and Cultural Studies, 12(2): 165-177.

Mda, Zakes. 2002. Ways of Dying: A Novel. New York: Picador.

Millett, Kate. 1995. The Politics of Cruelty: An Essay on the Literature of Political Imprisonment. New York: Norton.

Ogude, James. 2009. 'The State as a Site of Eating: Literary Representation and the Dialectics of Ethnicity, Class and the Nation State in Kenya.' Africa Insight 39(1): 5-21.

Ojwang, Dan. 2013. Reading Migration and Culture in Context: The World of East African Indian Literature. New York: Palgrave Macmillan.

Okri, Ben. 1991. The Famished Road. New York: Doubleday.

Okri, Ben. 1993. Songs of Enchantment. New York: Doubleday.

Okri, Ben. 1998. Infinite Riches. London: Phoenix House. 
Phillips, Delores B. 2012. “'What Do I Have To Do With All This?”: Eating, Excreting, and Belonging in Chris Abani's GraceLand.' Postcolonial Studies 15(1): 105-125.

Roy, Parama. 2002. 'Reading Communities and Culinary Communities: The Gastropoetics of the South Asian Diaspora.' Positions 10(2): 471-502.

Samuelsson, Marcus. 2003. Aquavit and the New Scandinavian Cuisine. Boston, MA: Houghton Mifflin.

Samuelsson, Marcus with Veronica Chambers. 2012. Yes, Chef: A Memoir. New York: Random House.

Samuelsson, Marcus, with Heidi Sacko Walters. 2006. The Soul of a New Cuisine: A Discovery of the Foods and Flavors of Africa. Hoboken, NJ: John Wiley and Sons.

Schmitt, Eleonore, and Werner Graebner. 1992. 'Sukumawiki: Food and Drink in the Nairobi Novels of Meja Mwangi.' Matatu 9: 133-151.

Schofield, Mary Anne, ed. 1989. Cooking by the Book: Food in Literature and Culture. Bowling Green, OH: Bowling Green State University Press.

Thiam, Pierre. 2008. Yolele! Recipes from the Heart of Senegal. New York: Lake Isle Press.

Thiam, Pierre with Jennifer Sit. 2015. Senegal: Modern Senegalese Recipes from the Source to the Bowl. New York: Lake Isle Press.

Van Esterik, Penny and Carole Counihan, eds. 1997. Food and Culture: A Reader. New York: Routledge.

Vassanji, M. G. 1991. No New Land. Toronto: M\&S.

Vera, Yvonne. 2002. The Stone Virgins. New York: Farrar, Straus, Giroux. 


\title{
'Foundational fictions'
}

\section{Variations of the marriage plot in Flora Nwapa's early Anglophone-Igbo novels}

\author{
F. Fiona Moolla
}

Be you as beautiful as a mermaid, the beauty

of a woman is to have a husband.

Be you one who has been to the land of white

people, the beauty of a woman is to have a

husband.

If a woman does not marry, her beauty declines.

One who is beautiful is best to be in her

husband's house.

When you get to your husband's house, have

A baby.

After you look after the child, the child will

look after you.

(Igbo marriage song, transcribed and translated by Ifi

Amadiume in Male Daughters, Female Husbands,

1987, 72)

The Igbo marriage song recorded by Ifi Amadiume (1987) in her influential ethnographic study of the Nnobi in Southeastern Nigeria is a reminder of the cross-cultural, trans-historical significance of some form of marriage in the establishment of some form of family as the foundation and guarantor of survival and stability of the social. One might cite any number of world socio-anthropological studies, or, more to the point, innumerable African studies which support the contention that marriage, conventionally considered, is the cornerstone upon which the social is constructed. ${ }^{1}$ It is a convenient research 'shorthand', however, simply to refer to John S. Mbiti (1975) whose magisterial overviews seem usually to capture the fundamentals. Mbiti suggests that:

It is believed in many African societies that from the beginning of human life, God commanded or taught people to get married and bear children. Therefore marriage is looked upon as a sacred duty that every normal person must perform. Failure to do so means in 
effect stopping the flow of life in the individual, and hence the diminishing of mankind upon the earth.

This view of marriage, given the integration of Africa into globalised economies and globalised culture, of course, is subject to multiple variations. Late-modern Anglo-American social and cultural transformations, notably contraception (separating sex from marriage) and medical technologies (separating parenthood from marriage), have led to the decline of marriage traditionally considered, but where marriage has been replaced by a range of new, fairly flexible family arrangements (Lewis 2001). (Through globalisation, such social transformations in the global north doubtless will impact the wider world in locally complex ways.) In the context, however, of Southeastern Nigeria that comes most under focus in this chapter through the setting of Nwapa's novels, changes in interpersonal relations have not yet led to a drop in the marriage rate. Daniel Jordan Smith, doyen of the study of contemporary transformations of Igbo intimacies, finds that as a consequence of urbanisation, among other factors, even though premarital sex has vastly increased, 'the overwhelming majority of young women seek marriage and parenthood as the ultimate expression and fulfilment of their ambitions for themselves as persons' $(2010,126){ }^{2}$

The Nnobi song used as an epigraph also acts as a convenient index of the most significant concerns of Efuru (1966) and $I d u$ (1970), the early novels of Flora Nwapa, the first major Anglophone African woman writer. The song identifies women in what for constructivist approaches would be considered essentialised conceptions of both wifehood and motherhood. The refrain, 'the beauty of a woman is to have a husband' presents marriage as an inevitability and a duty which, at the same time, is framed as a desired, albeit gendered, dimension of selfrealisation. In the song in translation, the word 'beauty' may be read expansively, I believe, to encompass individual physical attractiveness, but, more significantly, social moral fulfilment through the status of marriage. In a few lines, the song captures the most important stages of female rites of passage which echo, in an Igbo context, the cycle of life in most cultures across time. Procreation, furthermore, is presented as the crux of married life - '[w]hen you get to your husband's house, have / A baby' - where the future generation is one's 'insurance' against the infirmities of old age - '[a]fter you look after the child, the child will / look after you.' (This age-old assumption is radically destabilised in the transformed social landscape presented in The Joys of Motherhood (1979), Buchi Emecheta's very well known novel, which interpellates Efuru (1966), Nwapa's first novel. Emecheta's novel will be referred to again later.) The life cycle described is not one that is inward looking. The woman who has been to 'the land of the white people', whether literally through travel or figuratively through mental and conceptual expansion of consciousness, is a woman who, by implication, is more experienced and wiser than the woman who has not ventured out. The song also, in the opening line, alludes to Mammywater (or Mami Wata), the contemporary designation of the pantheon of water goddesses linked with the deity, Idemili, who lies at the heart of Nwapa's extended creative project, and who is referred to in her fiction for adults and children variously also as Uhamiri, Ogbuide or The Lady of the Lake. One of the benedictions for the bride for whom the song is sung is that she be as 'beautiful as a mermaid', conjuring up visual images of Mammywater, siren-like in her loveliness, half fish, half human, sometimes with blonde hair, embraced by the sacred python. Although the wedding song would appear to endorse and enforce strict gender roles, the import of Ifi Amadiume's study of the Nnobi is to show the flexibility or adaptive intelligence of Igbo cultural norms, a tradition of flexibility that Nwapa creatively expands in her fictions. Amadiume shows that even though the Nnobi system of social organisation was based 


\section{F. Fiona Moolla}

on a strict division of gender roles and institutions, nevertheless, gender concepts were manipulated and mediated, allowing the unexpected categories of, for example, 'male' daughters, who could continue the family line in the event of procreation failure, and female 'husbands' who married wives allowing accrual of wealth and status among leading women in a celibate marital arrangement.

The Igbo nuptial song, which is used synecdochically to suggest the cultural ubiquity of marriage virtually throughout time, may be contrasted with the overriding impression one gleans from reading many European novels where there is no 'classic' novel of happy marriage, ${ }^{3}$ and the novel where happy marriage is a formal element of closure is twinned at the outset with the novel of marital breakdown in adultery. ${ }^{4}$ In some ways, as we shall see, in Nwapa's early works the marriage-adultery dyad is not an inevitability in the late and uneven engagement of modernity figured in Nwapa's novels - in fact, marriage seems to be paired not with its dissolution in adultery, but instead with procreation failure. The dyad that emerges in Nwapa's early novels is a marriage-procreation, rather than marriage-adultery dyad. The well-represented novel of unhappy marriage in the Anglo-American tradition, beginning in the late nineteenth century, may also be contrasted with parts of Nwapa's first novel Efuru since the causes of unhappiness are different. Unhappy marriages in the Anglo-American novel are the outcome of oppressive, hierarchical, gendered relations, while the most significant cause of marital tension in Nwapa's novels is procreation failure, exacerbated by transformed social contexts.

\section{Plotting marriage: Anglophone-Igbo approaches}

Analysing the gender dynamics of marriage is a focus of a vast number of feminist studies of African literature. Isidore Okpewho in 'Understanding African Marriage: Towards a Convergence of Literature and Sociology' (1987) contrasts the picture of marriage that occurs in African cultural expression (ranging across oral and print forms), with marriage as it emerges in anthro-sociology. Okpewho finds that African literatures and oratures significantly complicate the somewhat rigid and reductive picture of African marriage contracted exclusively for structural social reasons that emerges in anthro-sociological scholarship. The work of Senegalese author, Mariama Bâ, has encouraged attention specifically to marriage through her meditations on monogamous, plural and intercultural marriages in her novels So Long a Letter (1980) and Scarlet Song (originally published in 1981) (Makward 1986 and Nnaemeka 1997 among others). African literary representations of marriage have, furthermore, been put into diasporic comparison in the study of Francophone African and Caribbean writing by Cécile Accilien (2008). This chapter seeks to further develop these approaches, which in the main foreground women's self-realisation through a feminist lens, by a closer attention to the formal implications of inflections of the marriage-plot in Nwapa's early novels, which establish a paradigm for subsequent Igbo-Anglophone, and West African novelists more generally.

Flora Nwapa, often designated the 'mother' of African literature, was the first African woman writer to be published internationally, as she was the first woman to establish a publishing house, namely, Tana Press. Nwapa was well acquainted with Chinua Achebe, who was the editor of the Heinemann African Writers Series at the time. Nwapa sent the manuscript for Efuru to Achebe, which then was published in 1966, eight years after Achebe's now canonical Things Fall Apart. Nwapa, as one of the second wave of Nigerian writers (Peters 1993, 13), portrayed in her work a complementary representation of female subjectivity as a response to the more male-centred fictions of male writers like Achebe, who had preceded her. Nwapa's first two novels, Efuru and Idu (1970), continue the tradition of what Judith Gleason in This Africa (1965) was the first to identify and term the 'village novel'. The 'village novel' is a well- 
exemplified sub-genre in Nigerian literature, but for the purposes of the focus of this chapter, I would like to juxtapose Nwapa's village novels with those of only two other authors, namely, Chinua Achebe and Elechi Amadi. The contrast with Achebe will be brief and the comparison with Amadi a little more detailed since Amadi's and Nwapa's novels have significant commonalities. The Concubine (1966), the first novel of Elechi Amadi's village trilogy, is remarkably similar to Nwapa's Efuru both in plot structure and characterisation. By contrast, marriage is not the central concern of Achebe's village novels, Things Fall Apart (1958) or The Arrow of God (1964). But marriage is part of a very well-defined social backdrop, especially in Things Fall Apart, strategic to Achebe's 'writing back to Empire', through the intimations of Igbo/African social life through nuptial rituals, and especially through the dynamic of the network of the polygynous and extended family. Romantic love may easily be overlooked in Achebe's first novel, embedded as it is in the pre-history of Ekwefi, Okonkwo's second wife, who abandoned her husband for Okonkwo, her first love and grande passion. Okonkwo's wives, who are secondary characters in Things Fall Apart, become the focus of attention, and are writ large in both Nwapa's and Amadi's village novels where affect in relation to marriage is the centre of narrative attention. Thus romantic love, which was treated only incidentally in Achebe is underscored in the work of the later authors. James Olney, who compares Achebe's fiction with Igbo autobiography on the questions of 'Love, Sex and Procreation' (1973, 157-203) reinforces the centrality of procreation in marriage in Achebe's village novels, superseded completely by the love-marriage ethic in A Man of the People (1966). Olney is not, however, alert to the references to love and marriage in the incidental subplots in Achebe, which is a focus that Nwapa's fiction expands.

Romantic love lies at the heart of Amadi's oeuvre, chiefly in its connection with marriage. Eros is alluded to in Nwapa's Efuru and plays a very significant role in Idu. By contrast, in both Efuru and Idu unlike Amadi's novel, the link between motherhood and marriage is stressed over the connection between love and marriage. Despite the difference of focus, it is almost impossible not to compare Nwapa's and Amadi's first novels, as Eldred Durosimi Jones and Eustace Palmer were the first to do in early reviews of the novels. Published in the same year, 1966, and striking for the similarity of their characterisation and the influence of the supernatural, both Efuru and The Concubine feature heroines who are the apogee of Igbo physical and moral perfection. The heroines of both novels, however, are tragically fated never to achieve happiness in the social world because of prior and privileged relationships with divinities that supersede their marital relationships with mortals.

Nwapa and Amadi have frequently been compared, most often in a valorisation of one author over the other. The comparison at the outset was centred mainly on questions of literary aesthetics. In the feminist retrieval and counter-canonisation of Nwapa's novels, scholars have often resurrected and challenged the early critiques of Efuru by Eustace Palmer (1968) and Eldred Durosimi Jones (1967). Naana Banyiwa-Horne in 'African Womanhood: The Contrasting Perspectives of Flora Nwapa's Efuru and Elechi Amadi's The Concubine' (1986) and Florence Stratton in Contemporary African Literature and the Politics of Gender (1994), ascribe value to Nwapa's treatment of female characters, while critiquing their subordinate role and instrumental use in Amadi's novels. Banyiwa-Horne suggests that Amadi's female characters are 'inferior and subordinate to men' $(1986,123)$, while Stratton finds that, unlike Nwapa, Amadi projects onto female characters 'a rabid, dangerous, and ever-present sexuality' (1994, 86). Curiously, this is not a view endorsed by Nwapa who, in an interview with Marie Umeh, confirms her appreciation of Amadi's work and commends, specifically, the deep understanding of female subjectivity displayed in Estrangement (1986), the novel by Amadi published at around the time that the interview was conducted (Umeh 1995, 27). However, rather than drawing 


\section{F. Fiona Moolla}

the selected authors into an agonistic relationship, as scholarship has often tended to do, this chapter will adopt a different approach. In considering West African permutations of the marriage plot, the study will regard the narratives of these two authors, Nwapa and Amadi, as the unique thought experiments of each writer on the question of marriage in a period of unprecedented velocity of transformation of social relations as a consequence of colonial modernity, but will return to Nwapa as the 'progenitor' of a line of novels that alter dominant conceptions of the marriage plot.

In order to bring into relief Nwapa's approach to the marriage plot, her village novels, Efuru and $I d u$, will be contrasted with The Concubine, the first of Amadi's village trilogy, given the strong similarities of thematic approach, plot and characterisation, noted above. But in order to highlight the specificities of the Igbo-Anglophone novels, it becomes necessary as a counterpoint to compare Nwapa's and Amadi's approaches with marriage-plot conventions in the Anglo-American tradition, even though their narratives in no way are a studied riposte to metropolitan conventions. Both authors were, no doubt, familiar with this tradition through their background in colonial education systems, and integration into British imperial and later global cultural networks by virtue of their exposures through higher education and their positions as members of the Igbo intellectual and political elite. (In fact, Emmanuel Obiechina (1972, 21-23) draws our attention to the fact that a significant number of readers only functionally literate in English would have been familiar with the English 'classics', evident from the allusions to these novels in the popular genre of the Onitsha market chapbooks.) While both Nwapa and Amadi would have been au fait with liberal ideals of intimacy spread through what Elizabeth Povinelli (2006) has termed the 'Empire of Love', their work gives no indication of 'writing against', or even in any other way engaging the dominant global normative and normalised approach to marriage. Amadi's thought experiment is even more radical than Nwapa's in this respect since it projects a timeless village, using the narrative conventions of formal realism, that is hermetically sealed off from the influences of colonial modernity, but whose realism extends to the spirit or cosmic worlds. Spirits and gods actively and realistically exist and intervene in the material world to shape the fate of the denizens of the world. The presentation of marriage, in particular the significance of romantic love in relation to marriage is, therefore, in terms of Amadi's thought experiment, wholly Igbo. This contrasts sharply with Nwapa's Oguta, where her novels are set in the 1940s and 1950s. Oguta is the town situated on Oguta Lake, home to the goddess Ogbuide, another name by which Mammywater is known. Nwapa's Oguta is repeatedly represented as experiencing the ambiguous and complex impact of colonial modernity through the tensions created by Christianisation, formal Western-style education, transforming social relations, and colonial legal and economic regimes. Nwapa's village novels do not reveal personal relations as being riven by the tradition-modernity binary, but they do present personal relations that undermine the assumptions of the dichotomy; and they present personal relations in a state of unprecedented flux which, nevertheless, the adaptability of Igbo social norms accommodate.

Nwapa's and Amadi's marriage plots may be contrasted with the Western marriage plot, explored in most detail by Joseph Allen Boone (1987). For Boone, the novel is the form in which the literary ideal of romantic wedlock may be most clearly tracked, symbolised by the novelistic happy ending in companionate nuptial harmony, exemplified most distinctly in the novels of Jane Austen. But for Boone, the mutualism implied in the happy ending masks a hierarchy based on male dominance and female suppression that gets challenged in a counter tradition, which in various ways tries to show up or escape marriage as a 'primary shaping influence and potent symbol of order in the novel' (5). In the novels of the late eighteenthcentury British novelist Jane Austen, however, the idea of love as the sine qua non for marriage 
achieves its normalised European Enlightenment modern apogee, albeit with the hidden subtext of the inescapability of exchange relations, which are generally held to define and critique 'utilitarian' marriage in a non-modern context - expressed bluntly, Austen's heroines always marry for love, but they also always, very conveniently, marry for money. (And marriage for money seems to fall outside the range of self-reflexive critique of Austen's irony.) The romantic marriage plot that for Boone exerts the strongest influence on the form of the novel thus, by affirmation or rejection, tracks the protagonist's courtship, beset by obstacles both external and internal that constitute narrative drive, until closure in companionate marriage, proclaiming a unity in mutuality. (The study of the marriage plot in Nwapa's early fiction forms part of a larger project that considers romantic love in African cultural forms more generally. The project engages a broader cross-cultural and trans-historical backdrop against which to identify the specificities and universalities of African approaches to eros.)

The move tracked in the novel that makes romantic love the only acknowledged basis for marriage in the modern West is supported also in the sociological studies of, among others, Lawrence Stone (1977), Niklas Luhmann (1986, 2008), and Anthony Giddens (1992). The geographical expansion of the love-marriage ideology has been extensive, and its impact is widely attested (Wardlow and Hirsch 2006), and it has had significant influence in the cultural context of Southern Nigeria (Okonjo 1992; Smith 2010).

\section{Amadi's The Concubine and the embedded love-marriage plot}

What contrasts do the Anglophone-Igbo village novels present to the Anglo-American lovemarriage plot? And in what ways are Nwapa's variations on the pattern distinct from Amadi's? Amadi's The Concubine is the story of the ill-fated heroine, Ihuoma, who, it is revealed at the end, unknown to herself or anyone else, is in fact a water divinity married to the Sea-King. Since she is the favourite wife of the polygynous aquatic god, her act of disobedience, which sees her ascending to the world of mortals, displaying her curiosity and agency, is leniently punished by the Sea-King. She is destined on earth only ever to be the concubine or mistress of mortal men since she remains wedded to the god. Although the brief plot summary gives the novel the air of a folk tale, its narrative style is defined by a meticulous formal realism, a realism that extends to the depiction also of the supernatural, which unlike in Nwapa's novels, where Mammywater is alluded to in the background, the Sea-King in The Concubine very actively intervenes in the human world. The narrative opens not with the encounter of the hero and heroine, as one comes to expect of the Anglo-American romance novel, followed by courtship and finally marriage, but with Ihuoma's very happy marriage to Emenike. Like Nwapa's heroine, Efuru, Ihuoma is the epitome of Igbo conceptions of beauty, virtue and grace. Unlike Nwapa's heroines, Ihuoma's misfortune is not that she is unable to have children - she is surrounded by her children in her happy home in the opening scenes of the novel. Ihuoma's curse is that the jealous Sea-King strikes down any man that marries her. Shortly after the narrative opens, Emenike dies under somewhat mysterious circumstances, possibly as a consequence of a fight with Madume, the village bully and longstanding rival for Ihuoma's affections. Madume moves to marry the widowed Ihuoma and is himself killed when poisoned by a spitting cobra. The greater part of the narrative, however, is dedicated to the budding romance between Ihuoma and the son of a neighbour, Ekwueme. This portion of the narrative bears great similarity to the classical Anglo-American love-marriage plot, following the template established in the novels of Jane Austen, and perpetuated in contemporary romance literature. But unlike the normative romance novel, the hero dies at the end subject to the dictates of the vindictive SeaKing. The Concubine does not 'write back' to Empire either by rejecting or claiming as 


\section{F. Fiona Moolla}

autochthonous the love-marriage plot. Instead, it embeds a transformed love-marriage plot into a complex network of affective relations informed by an Igbo epistemological approach to its worlds. The love-marriage exists cheek-by-jowl with 'utilitarian' forms of marriage which apparently serve only social ends rather than the fulfillment of individual desire.

Thus what we see in The Concubine is a transformed conception of the love-marriage, which, while not the primary form of marriage in this culture, nevertheless is accommodated in a flexible extension of norms rather than the alternative of confrontation and inevitable collapse of social conventions. The love-marriage plot, furthermore, is embedded in a wide network of alternatively construed intimate relations, which include polygyny in the world of humans, and polygyny and polyamory in the realm of the Igbo gods and goddesses.

\section{The marriage-procreation plot in Nwapa's Efuru and Idu}

'Motherhood' is a concept that has come under intense scrutiny in the scholarship of African society and literature. Debates on motherhood form part of many feminist socio-anthropological studies, but two key edited volumes specifically on the topic are Marriage, Fertility and Parenthood in West Africa (Oppong et al. 1978) and Gender, Sexuality and Mothering in Africa (Falola and House-Soremekun 2011). The general debate in the broader literature shuttles between the absolute valorisation of biological motherhood as a source of power in, for example, Catherine Acholonu's idea of 'motherism' (1995) as an African alternative to feminism, and critique of such notions which highlight the role of racist and patriarchal discourses in figurings of the 'black mother' (Lewis 1991). Obioma Nnaemeka's edited volume, The Politics of (M)othering (1997), is probably the best known literary engagement of the question of the mother in Africa, while Carole Boyce Davies addresses the question in the context specifically of early Igbo writers (1986). But perhaps it is the work of Oyèrónké Oyěwùmí on age-inflected (rather than gender-inflected) Yorùbá conceptions of personal roles and status, and the significance of 'matripotency' as a concept wider than procreation that is most pertinent here. Oyěwùmí asserts an alternative Yorùbá epistemology that is not grounded in biological gender. She suggests further that it is the empowering, non-somatocentric concept of motherhood that defines Yorùbá personal positionality. Thus for Oyěwùmí motherhood is the salient nexus in Yorùbá society rather than Western feminist contestations around the subordination of wifehood in monogamous marriage (see Oyěwùmí 2015). Although Nwapa's cultural context is Igbo rather than Yorùbá, where gender roles appear to be more clearly defined (though flexible) than Oyěwùmí's presentation of a largely non-gendered Yorùbá world, the foregrounding of motherhood in her marriage-plots suggests significant overlap with the thrust of Oyěwùmí's study. In contrast with Oyěwùmí, Nwapa highlights the tensions that arise when biological motherhood fails. Nwapa's early novels are 'foundational fictions' in the sense that they link marriage with the obstruction of failed procreation (rather than romance and its obstruction leading to marriage) in a transformed marriage plot in the genre of the novel. (The expression 'foundational fictions' is borrowed from Doris Sommer's Foundational Fictions: The National Romances of Latin America (1991) which shows how nineteenth century romance novels played a significant role in the nation-building projects of modernising South American countries.)

Nwapa, like Amadi, does not challenge the love-marriage plot, so much as to destabilise and re-frame it completely, without appearing to write back to the neoliberal 'Empire of Love' (Povinelli 2006). Unlike the 'autological' subjects of the European novel, Nwapa's heroines remain 'genealogically' embedded in the social and ethical horizons of their constitution. In other words, Nwapa's heroines do not imagine they transcend the tradition and culture in which they are formed as subjects, and they continue to defer to the shared, but transforming, 
precepts upheld in common. I shall use these terms, 'autological' and 'genealogical', in the sense of their use by Povinelli, where autological refers to the cultural trajectory privileging selfmaking, sovereignty, individual freedom and contractual relations, while genealogical suggests cultural traditions where the social constraints of various inheritances are acknowledged by embedded persons. Unlike the traditional pattern of courtship, and obstruction finally resolved in marriage, Efuru and $I d u$ begin with the heroines already married and, in both cases, narrative drive is provided by the 'obstruction' of infertility, rather than the obstructions to the union of lovers first identified in the seminal study Love in the Western World by Denis de Rougemont (1939). The problem presented in both novels by Nwapa is the problem of procreative failure, instead of obstacles to love.

Efuru, the daughter of a wealthy Igbo man of status, stretches the conventions of her community by eloping with a feckless, inconsequential fellow because she has fallen in love - a classic case of love at first sight:

One moonlit night they went out. They talked of a number of things, their life and their happiness. Efuru told him that she would drown herself in the lake if he did not marry her. Adizua told her he loved her very much and that even the dust she trod on meant something to him.

(Nwapa 1966, 7)

The focus of the novel, however, does not fall on the impediments to love, as it does in most other love stories involving a transgression of accepted boundaries and a challenge to parental and social authority. The couple is at liberty to elope with relative rapidity and ease: 'They were going to proclaim themselves married and that was that' (7). In this context, Efuru enjoys the autonomy that allows her to fulfil personal desire relatively easily, but significantly, as we shall see, it is a pursuit of happiness accepted only grudgingly by her family and community and, more importantly, one that nevertheless observes social conventions through the absolute requirement that her bridewealth be paid. In fact, it is only some time later, when the necessary nuptial rituals are performed and the dowry is paid, that 'the two felt really married' (24). Efuru thus, in her love-marriage, appears to place affect, privileged in liberal economies of sociality, above exchange, the impetus for marriage of genealogical societies, which autological societies retrospectively constitute through the modern historical break where exchange as one basis of marriage is wholly rejected. It is only when love becomes the only acknowledged, but usually not sole basis of marriage, that, by contrast, the prior marriage regime is cast as utilitarian. Effaced utilitarian concerns, however, remain the subtext of the autological marriage. But Efuru subsequently (and only paradoxically if one accepts the dichotomy of socialities at face value) insists that her bride price, an index of a genealogical conception of marriage, is paid, suturing the social breach, and ensuring, when later the marriage breaks down, she has 'insurance' allowing her to return to her father's household. Ironically, Efuru's bride price is essentially paid by herself, again confirming the convention in its contravention, since Efuru is a gifted trader, acquiring the wealth her husband cannot.

While, as noted above, there appear to be few novels of happy marriage in the AngloAmerican tradition, Nwapa presents us with 'one and a half novels of happy marriage - all of $I d u$, and a significant part of Efuru. Adizua is so besotted with his wife that he cannot bear to be out of her company, not even to pursue his livelihood on the farming land some distance from their home: 'he thought so much of her that he no longer wished to be away from her' (20). Domestic happiness in the extended family of the Igbo context of the period in which the novel is set involves not only husband and wife, as in the nuclear family, but also the husband's 


\section{F. Fiona Moolla}

extended family relations. Efuru's warm relationship with her husband is equalled by the closeness and the supportiveness of her relationship not only with Adizua's mother, but also his aunt. Unlike the novels of marital stalemate and disillusionment in the Anglo-American tradition, in the first half of the novel, tension is created not through the realisation that the apparently companionate marriage remains hierarchical and patriarchal, but through the misfortune that Efuru cannot bear a child. If Efuru is socially gendered male in paying her bridewealth herself, she is also gendered male through her apparent 'barrenness'. Efuru's actions and the fact of not giving birth are associated with being male not female. The everyday sociality of the exchanges with neighbours allow the reader insight into the norms of the society:

Neighbours talked as they were bound to talk. They did not see the reason why Adizua should not marry another woman since, according to them, two men do not live together. To them Efuru was a man since she could not reproduce.

The novel thus confirms what is repeatedly attested in the cultural expression of significant parts of the African continent - namely that procreation is an urgent imperative felt by men, but disproportionately felt and borne by women. In an earlier agrarian context, children were survival, children were wealth, and children, as they continue to do, represented the continuation of blood lineages and generations across material and spiritual worlds. (As noted earlier, some aspects of the value of children are disputed in The Joys of Motherhood by Buchi Emecheta, a novel which takes its title from the closing lines of Efuru, and which continues the foundational conversation begun by Nwapa on the marriage-procreation plot.)

Despite the altered economic and social conditions, which may make motherhood a trial rather than a joy, procreation appears to continue to be the foundation of marriage in the world Nwapa represents, rather than romantic love. The need to bear children is felt so greatly that Efuru would happily consent to her husband's taking a second wife to produce a child, which would be a testament to rather than a betrayal of the love Efuru has for her husband. But Adizua's love appears to be exclusive and monogamous; thus he proclaims after hearing that Efuru has been to visit a dibia about their childlessness:

I am happy that you went to see the man. But please don't think that it will make any difference to me whether you have a baby or not. You know I will be the last person to do anything that will hurt you, my wife. You know I cannot exchange you with a wife who would give me twenty sons.

(We discover later, ironically, that Adizua's monogamous affection is rather suddenly overtaken by what Obioma Nnaemeka in the context of an analysis of Mariama Bâ's So Long a Letter has referred to as men's 'polygamous instincts', when he enters into an adulterous affair.) Narrative tension in Nwapa's novel is dissipated when in the third year of marriage Efuru gives birth to a daughter, but is generated again when Adizua becomes an 'absent' husband, where neither romantic love nor a child appears to be sufficient to the well-being of the once happy marriage.

From this point on the narrative presents the husband's apparently inherited disposition to be like his father who abandoned his wife, Adizua's mother. On the birth of their daughter, ironically, the bond between the couple is stretched and finally snaps when the husband disappears, leaving Efuru to handle the tragedy of the daughter's eventual death. Thus, given that she has borne a child, it is not the fact that Efuru is barren that causes her husband to abandon 
her and take up with another married woman. Bearing in mind the social acceptance of polygyny in this community, the husband's adulterous relationship with a woman who is also an adulterer, is exceptional and scandalous, and is an index of the rending of the social fabric. The marriage breaks up for a number of vaguely defined reasons. It may be in Adizua's 'blood' to be a bad husband, or it may be because of the general male 'polygamous instinct'. The fine and paradoxical balance in the novel between autological love-marriage and genealogical exchange is highlighted when Efuru returns to her father's home, where she is maintained by the bride price she insisted on paying herself despite her elopement.

To the end of the novel, Efuru remains in love with her first husband, but genealogical incentives to marry kick in when she agrees to wed a second husband, Gilbert. Paradoxically, the marriage to the Christianised, Western-educated Gilbert, is a marriage based not on love, as one would expect given Gilbert's exposure to the modern regime of love-marriage, but on social expectations and personal convenience. Love is not once mentioned in this second marriage. Gilbert says to Efuru that he will make her 'happy', that he will be 'faithful' to her and that if 'God wills it', they will be 'rich' (122). Efuru agrees to marry Gilbert because he 'talks so responsibly' (124) and, at a party with his friends, Gilbert is further persuaded to marry since the men praise Efuru for her culinary skills and her astonishing success at trade. Efuru thus marries Gilbert since, unlike Adizua, Gilbert seems steady; and Gilbert marries Efuru since he will have his personal needs met, and since Efuru's trading achievements will guarantee family prosperity. The utilitarian marriage, like the love-marriage, is initially happy, but even the 'genealogical' marriage is tested by procreation failure.

In Nwapa's early narratives it is the conversations that are part of everyday socialities at the stream or at the market that reflect the social 'debates' which identify cultural norms and conventions, their infringements and the limits of their transformation. The mutual joys of the utilitarian marriage are publicly expressed by people's remarks about Gilbert and Efuru's inseparability, especially their affectionate swimming together in the stream. The 'gossip' of the 'people' outlines the social horizon of the culture:

'Seeing them together is not the important thing.' ... 'The important thing is that nothing has happened since the happy marriage. We are not going to eat happy marriage. Marriage must be fruitful. Of what use is it if it is not fruitful?'

When Efuru is confirmed as 'barren', she encourages Gilbert to take a second wife, and then also a third since she is dissatisfied with the character of the second wife. But, after a series of betrayals by Gilbert, most notably his absence at her father's funeral, Efuru eventually returns to her father's house, dedicating her life to the worship of the Goddess of the Lake, whose acolyte she has always unknowingly been. This accounts for her misfortunes in marriage and motherhood, but success in trade, since the goddess has claimed Efuru as her worshipper. Contrasted with the wedlock plot which presents the teleological progress of the sovereign heroine negotiating various courtship obstacles from her father's house in a pas de deux with the hero, culminating in companionate marriage in her husband's house, Nwapa's narrative presents a heroine relatively freely and autonomously leaving her father's house for the houses of her two husbands, where she is the significant breadwinner, to return on both occasions to her father's house, where she is maintained by the bridewealth, in the first marriage paid by herself. Efuru finally solely dedicates herself to the Lake Goddess, who alone in Nwapa's creative portrayal is able to offer the childless woman in this society social standing, personal peace and contentment. Rather than adopting the dominant European love-marriage plot in a different cultural 


\section{F. Fiona Moolla}

context or presenting a genealogically driven, culturally inflected alternative to the European love-marriage plot, Nwapa's disorientating novel destabilises the autology-genealogy dichotomy, reframing the wedlock plot to encompass both freedom and obligation, eros and exchange in marriages which privilege procreation, but also provide alternatives when procreation fails.

Nwapa's second novel, Idu, also begins with marriage rather than courtship, and again the narrative presents a happy marriage of devotion and love, to which the entire novel is given over. Again, it is through the everyday socialities of the marketplace and at the stream which accommodate 'small talk' that the novel collectively tells rather than shows significant ideas relevant to the marriage plot, in this case revealing the love that exists within marriage rather than the love that precedes marriage. Women at the stream reflect on the affection of the couple after meeting Idu: 'Sometimes when I see them, I am filled with happiness. Have you ever seen two people so happy before?' $(1970,2)$. Again, tension in the novel is generated out of the loving couple's childlessness, which sees Idu, out of love for Adiewere, her husband, and concern for his well-being, arranging a second wife whom the husband, by various strategies of indirection that make it uncomfortable for the young girl to stay, obliges finally to leave the household. Idu eventually gives birth to a child, a son, who, unlike Efuru's daughter, survives. When the husband, whose premature death is foreshadowed in the conversations of the women from the beginning of the novel, dies, Idu wills herself to death after him. Some interpretations of the novel suggest that Idu dies in order to avoid the levirate, that is, the system whereby widows are inherited by the remaining patriarchal head of the family. But Idu, it would appear, dies for love, putting love in marriage in this case ahead of procreation, even though procreation remains the sine qua non of the marital relationship. The question of procreation is considered also from the angle of male sterility in a subplot of the novel. Reflected in village talk, Idu's friend Ojiugo is presented as justified in leaving her sterile husband for another man in a plural, very productive marriage, where she soon after has a child. The impact of procreation failure is such that it is understandable when the husband, Amarajeme, commits the abomination of suicide. Nwapa's novel glosses over the Igbo practice of tacit impregnation by a male relative in the case of sterility of the husband, a practice that has been common elsewhere in Africa, as a creative non-medical resolution for childlessness. (See, for example, the study by L. E. Ugwueye and I. L. Umeanolue (2015) which contrasts Christian and Igbo responses to childlessness.)

Despite the early critiques that Nwapa writes novels with poor plots, closure in $I d u$ is expertly managed. Adiewere's death comes after the disappearance of their child and Idu's frantic response proves how precious her son is to her. The child, it is revealed, had gone to the uncle's home. Because of confusion that arises out of the foolishness and general lack of foresight and responsibility of both the brother- and sister-in-law, Idu is not informed of her child's visit. Adiewere's death also comes after Idu has 'adopted' the orphaned son of her business friend. It emerges that after a long period of infertility, Idu has become pregnant. The plot sequence thus shows that for Idu, the levirate is no option since Ishiodu, her brother-in-law, is incompetent and unreliable - she does not need him even to serve the utilitarian ends of marriage. She objects to shaving her hair as is customarily required of widows, indicating that she does not see herself as permanently parted from her husband, only that she needs to make a journey to follow him to the spirit world. When Anamadi, Idu's sister, discovers Idu's corpse, she says, "'Come, let's prepare for the funeral, don't you see she is dead? She kept her word. She has followed her husband to the land of the dead"' (218). The plot thus artfully foregrounds the idea that while children are crucially important in marriage, the importance of the love between two people can sometimes take priority over childbearing. Idu makes her journey to the land of the dead despite having a healthy son, and an 'adopted' son, and despite the fact that she is pregnant with another child. 
Despite the thematic similarities and similarity of characterisation between Amadi's and Nwapa's village novels, a marked difference exists in the style of narration. While Amadi's narrative is marked by tight management of plot and the impression of impersonal, distant control through mostly third person narration, Nwapa's village novels are highly idiosyncratic in their distinctive adaptation of conventional forms of dialogue. Nwapa's innovative use of conversation in her novels has paradoxically been both critiqued and commended. Florence Stratton very ably responds to Eldred Jones's criticism of the language dimension of Nwapa's novels. Stratton rebukes Jones for describing Nwapa's novel as being 'full of small talk' instead of employing proverbs judiciously as Amadi does. For Stratton, 'small talk' is code for the conversations of women, where such conversation is nothing more than 'idle chatter, chit-chat, prattle-prattle, gossip' (1994, 83). By contrast to Jones, Elleke Boehmer reads Nwapa's minutely detailed realism of interpersonal exchange as a formal strategy for portraying a woman's world that uses 'choric language to dramatise and empower her representations' $(2005,96)$. Boehmer continues:

In this way ... [Nwapa] creates the effect of a women's verbal presence in the text while at the same time bringing home her subject matter by evoking the vocality of women's everyday existence. ... [The novels clear] the space for the elaboration of another kind of narrative entirely - a highly verbalised, collective women's biography, 'transsubjective, anonymous', transgressive.

$(2005,96)$

If the marriage-procreation plot is Nwapa's main thematic concern, given the centrality of marriage in the establishment of the social, then the style of the language in the novels, foregrounding the day-to-day conversations of women, highlights the significance of everyday socialities in rehearsing Igbo conventions regarding interpersonal relations. The women's everyday exchange presents what is normative, and the challenges and tensions within these norms, as they adjust in altered contexts. The women's daily conversations in the course of their daily activities stage the possibilities and limits of adaptations of norms within a shared and culturally coherent horizon of accommodation. More to the point, women's 'small talk' in the novels, as we shall see in the analysis below, acts to inform the reader of customs regarding marriage, the ways in which custom is challenged by an era of rapid transformation, and the degree to which Igbo social elasticity may be stretched without things falling apart. The everyday female socialities at the marketplace and at the stream, the daily visits, storytelling, work and other songs act as a barometer of Igbo cultural vitality and adaptability - and also of the limits of change captured in the negative views of malicious gossip-mongers and know-it-alls who feature in each of the novels.

\section{Conclusion}

Through writing a culturally alternative marriage plot, Flora Nwapa's early novels present a view which complicates the assumption of a progression of intimacies from exchange to eros, presenting exchange and eros instead as indivisible parts of a complex and shifting range of marriage practices. The focus in the novels moves from obstructions to the union of lovers and on to the sometimes debilitating demand on men but, more especially women, that marriage must produce children. All of this is set against the backdrop of the everyday socialities of women whose exchanges outline the normative horizon of intimate relations and show the reader how these horizons change in a shared view. The marriage-procreation plot outlined by 


\section{F. Fiona Moolla}

Nwapa was extended in Buchi Emecheta's The Joys of Motherhood, but plays a significant role also in the work of other Igbo-Anglophone novelists like Onuora Nzekwu, Akachi AdimoraEzeigbo and Chika Unigwe, in whose writing the marriage-procreation plot is foregrounded. Chimamanda Ngozi Adichie's Half of a Yellow Sun (2007) is probably the most well-known recent iteration of the 'marriage'-procreation plot in an Igbo cultural setting. Since the heroine Olanna cannot conceive, she adopts the daughter of her partner Odenigbo, whose intercourse with a young village girl is cleverly orchestrated by his mother's desire for male progeny to continue the family line. The foregrounding of marriage and fertility has been extended further in the Anglophone Nigerian novel more generally, namely in Lola Shoneyin's The Secret Lives of Baba Segi's Wives (2010) and Ayòbámi Adébáyò's Stay With Me (2017). The marriage-procreation plot emerges also in a wider West African context as a recent study of Gambian fiction shows (Gomez and Ndow 2015). The continued development of the marriage-procreation plot is an index of the centrality of the questions first creatively explored by Flora Nwapa.

\section{Notes}

1 There are several continental African anthropological surveys specifically of marriage, which gird the idea of the centrality of marriage to constructions of the social. They include the following edited volumes: Alfred Radcliffe-Brown and Daryll Forde's African Systems of Kinship and Marriage (1950), Arthur Phillips's Survey of African Marriage and Family Life (1953), Christine Oppong, Gemma Adaba, Manga Bekombo-Priso and John Mogey's Marriage, Fertility and Parenthood in West Africa (1978), David Parkin and David Nyamwaya's Transformations of African Marriage (1987), Caroline Bledsoe and Gilles Pison's Nuptiality in Sub-Saharan Africa (1994), Themba Sono's African Family and Marriage Under Stress (1994) and Toyin Falola and Bessie House-Soremekun's Gender, Sexuality and Mothering in Africa (2011), which addresses women's concerns in marriage. There are also a vast number of studies of Africa by region or of specific African cultural groupings that reinforce the idea of the importance of marriage.

2 Scholarship of Igbo marriage, apart from Ifi Amadiume's study which is cited in the chapter, includes Victor Uchendu's The Igbo of Southeast Nigeria (1965) which contains a section on marriage, and Kamene Okonjo's 1992 study, 'Aspects of Continuity and Change in Mate-Selection among the Igbo West of the River Niger'. Most recently Daniel Jordan Smith's work has covered marriage and related topics such as sexuality, romantic love and infidelity in several essays (see, for example, Smith 2000, 2001, 2009).

3 A. O. J. Cockshut's study of English fiction across two centuries confirms the absence of the novel of happy marriage in the British context.

4 Tony Tanner's influential study of adultery in the European novel observes that the novel of adultery originates virtually contemporaneously with the 'romance' novel that ends in happy marriage (1979, 369-371).

\section{References}

Accilien, Cécile. 2008. Rethinking Marriage in Francophone African and Caribbean Literatures. Lanham, MD: Lexington Books.

Achebe, Chinua. 1958. Things Fall Apart. Oxford: Heinemann.

Achebe, Chinua. 1964. Arrow of God. Oxford: Heinemann.

Achebe, Chinua. 1966. A Man of the People. Oxford: Heinemann.

Acholonu, Catherine Obianju. 1995. Motherism: The Afrocentric Alternative to Feminism. Owerri: Afa Publications.

Adébáyò, Ayòbámi. 2017. Stay With Me. Edinburgh: Canongate.

Adichie, Chimamanda Ngozi. 2007. Half of a Yellow Sun. London: Harper Perennial.

Amadi, Elechi. 1966. The Concubine. London: Heinemann.

Amadi, Elechi. 1986. Estrangement. London: Heinemann.

Amadiume, Ifi. 1987. Male Daughters, Female Husbands: Gender and Sex in African Society. London: Zed Books.

Awunobi, Ola. 2015. Love's Persuasion. London: Ankara Press. 
Bâ, Mariama. 1980. So Long a Letter. Translated by Modupé Bodé-Thomas. Oxford: Heinemann.

Bâ, Mariama. 1986. Scarlet Song. Translated by Dorothy S. Blair. New York: Longman.

Banyiwa-Horne, Naana. 1986. 'African Womanhood: The Contrasting Perspectives of Flora Nwapa's Efuru and Elechi Amadi's The Concubine'. In Ngambika: Studies of Women in African Literature, edited by Carole Boyce Davies and Ann Adams Graves, 119-129. Trenton, NJ: Africa World Press.

Bledsoe, Caroline and Gilles Pison, eds. 1994. Nuptiality in Sub-Saharan Africa: Contemporary Anthropological and Demographic Perspectives. Oxford: Clarendon.

Boehmer, Elleke. 2005. Stories of Women: Gender and Narrative in the Postcolonial Nation. Manchester: Manchester University Press.

Boone, Joseph Allen. 1987. Tradition Counter Tradition: Love and the Form of Fiction. Chicago, IL: University of Chicago Press.

Cockshut, A. O. J. 1977. Man and Woman: A Study of Love and the Novel 1740-1940. London: Collins.

Davies, Carole Boyce. 1986. 'Motherhood in the Works of Male and Female Igbo Writers: Achebe, Emecheta, Nwapa and Nzekwu'. In Ngambika: Studies of Women in African Literature, edited by Carole Boyce Davies and Ann Adams Graves, 241-256. Trenton, NJ: Africa World Press.

De Rougemont, Denis. 1939. Love in the Western World. Translated by Montgomery Belgion. Princeton, NJ: Princeton University Press.

Emecheta, Buchi. 1979. The Joys of Motherhood. Oxford: Heinemann.

Falola, Toyin and Bessie House-Soremekun, eds. 2011. Gender, Sexuality and Mothering in Africa. Trenton, NJ: Africa World Press.

Giddens, Anthony. 1992. The Transformation of Intimacy: Sexuality, Love and Eroticism in Modern Societies. Cambridge: Polity Press.

Gleason, Judith Illsley. 1965. This Africa: Novels by West Africans in English and French. Evanston, IL: Northwestern University Press.

Gomez, Pierre and Isatou Ndow. 2015. Gendered Voices from the Gambia: A Gendered Perspective in Selected Gambian Books. Leicester, UK: Global Hands Publishing.

Jones, Eldred. 1967. 'Locale and Universe: Three Nigerian Novels'. Journal of Commonwealth Literature 2(1): 127-131.

Lewis, Desiree. 1991. 'Myths of Motherhood and Power: Reflections on "Black Woman" in Literature'. Paper presented at the Conference on 'Women and Gender in Southern Africa', University of Natal, January.

Lewis, Jane. 2001. The End of Marriage? Individualism and Intimate Relations. Cheltenham, UK: Edgar Elgar.

Luhmann, Niklas. 1986. Love as Passion: The Codification of Intimacy. Translated by Jeremy Gaines and Doris L. Jones. Cambridge: Polity Press.

Luhmann, Niklas. 2008. Love: A Sketch. Translated by Kathleen Cross. Cambridge: Polity.

Makward, Edries. 1986. 'Marriage, Tradition and Woman's Happiness in the Novels of Mariama Bâ'. In Ngambika: Studies of Women in African Literature, edited by Carole Boyce Davies and Ann Adams Graves, 271-281. Trenton, NJ: Africa World Press.

Mbiti, John S. 1975. Introduction to African Religion. London: Heinemann.

Nnaemeka, Obioma. 1997. 'Urban Spaces, Women's Places: Polygamy as Sign in Mariama Bâ’s Novels'. In The Politics of (M)othering: Womanhood, Identity and Resistance in African Literature, edited by Obioma Nnaemeka, 163-192. London: Routledge.

Nwapa, Flora. 1966. Efuru. Oxford: Heinemann.

Nwapa, Flora. 1970. Idu. London: Heinemann.

Obiechina, Emmanuel. 1972. 'Introduction'. In Onitsha Market Literature, edited by Emmenuel Obiechina, 3-27. London: Heinemann.

Okonjo, Kamene. 1992. 'Aspects of Continuity and Change in Mate-Selection among the Igbo West of the River Niger'. Journal of Comparative Family Studies 23(3): 339-360.

Okpewho, Isidore. 1987. 'Understanding African Marriage: Towards a Convergence of Literature and Sociology'. In Transformations of African Marriage, edited by David Parkin and David Nyamwaya, 332-345. Manchester: Manchester University Press.

Olney, James. 1973. Tell Me Africa: An Approach to African Literature. Princeton, NJ: Princeton University Press.

Oppong, Christine, Gemma Adaba, Manga Bekombo-Priso and John Mogey. 1978. Marriage, Fertility and Parenthood in West Africa. Canberra: Australian National University.

Oyěwùmí, Oyèrónké. 2015. What Gender is Motherhood? Changing Yorùbá Ideals of Power, Procreation, and Identity in the Age of Modernity. Basingstoke, UK: Palgrave Macmillan. 


\section{F. Fiona Moolla}

Palmer, Eustace. 1968. 'Elechi Amadi: The Concubine and Flora Nwapa: Efuru'. African Literature Today: A Journal of Explanatory Criticism 1: 56-58.

Parkin, David and David Nyamwaya, eds. 1987. Transformations of African Marriage. Manchester: Manchester University Press.

Peters, Jonathan A. 1993. 'English-Language Fiction from West Africa'. In A History of Twentieth-Century African Literatures, edited by Oyekan Owomoyela, 9-48. Lincoln: University of Nebraska Press.

Phillips, Arthur, ed. 1953. Survey of African Marriage and Family Life. London: Oxford University Press.

Povinelli, Elizabeth. 2006. The Empire of Love: Toward a Theory of Intimacy, Genealogy, and Carnality. Durham, NC: Duke University Press.

Radcliffe-Brown, Alfred R. and Daryll Forde, eds. 1950. African Systems of Kinship and Marriage. London: Oxford University Press.

Shoneyin, Lola. 2010. The Secret Lives of Baba Segi's Wives. 2010. London: Serpent's Tail.

Smith, Daniel Jordan. 2000. “"These Girls Today Na War-O”: Premarital Sexuality and Modern Identity in Southeastern Nigeria'. Africa Today 47(3-4): 98-120.

Smith, Daniel Jordan. 2001. 'Romance, Parenthood and Gender in a Modern African Society'. Ethnology 40(2): 129-151.

Smith, Daniel Jordan. 2009. 'Managing Men, Marriage and Modern Love: Women's Perspectives on Intimacy and Male Infidelity in Southeastern Nigeria'. In Love in Africa, edited by Jennifer Cole and Lynn M. Thomas, 157-180. Chicago, IL: University of Chicago Press.

Smith, Daniel Jordan. 2010. 'Promiscuous Girls, Good Wives and Cheating Husbands: Gender Inequality, Transitions to Marriage, and Infidelity in Southeastern Nigeria'. Anthropological Quarterly 83(1): 123-152.

Sommer, Doris. 1991. Foundational Fictions: The National Romances of Latin America. Berkeley: University of California Press.

Sono, Themba, ed. 1994. African Family and Marriage Under Stress. Pretoria: Centre for Development Analysis.

Stone, Lawrence. 1977. The Family, Sex and Marriage in England 1500-1800. New York: Harper and Row. Stratton, Florence. 1994. Contemporary African Literature and the Politics of Gender. London: Routledge.

Tanner, Tony. 1979. Adultery in the Novel: Contract and Transgression. Baltimore, MD: Johns Hopkins University Press.

Uchendu, Victor. 1965. The Igbo of Southeast Nigeria. Chicago, IL: Holt, Rinehart and Winston.

Ugwueye, L. E. and I. L. Umeanolue. 2015. 'A Critical Assessment of Christocentric Reaction to Childlessness in Afro-trado Cultural Marriage'. Researchers World: Journal of Arts, Science and Commerce 6(3): 70-76.

Umeh, Marie. 1995. 'The Poetics of Economic Independence for Female Empowerment: An Interview with Flora Nwapa'. Research in African Literatures 26(2): 22-29.

Wardlow, Holly and Jennifer S. Hirsch. 2006. Modern Loves: The Anthropology of Romantic Courtship and Companionate Marriage. Ann Arbor: University of Michigan Press. 


\title{
Drinking scenes
}

\section{Alcohol in the Francophone African novel}

\author{
Pim Higginson
}

Between presentations of precolonial palm-wine, beer, whiskey and champagne, alcohol consumption has been ubiquitous in African literature from its earliest decades. In the Anglophone African tradition Amos Tutuola's inaugural 1952 novel The Palm-Wine Drinkard is, as the title suggests, almost exclusively about imbibing. ${ }^{1}$ The Francophone novel, on which the present chapter focuses, adheres to this trend: elaborate drinking scenes appear in early narratives from the 1920s on. In Félix Couchoro's L'Esclave (1929), among the first Francophone novels, alcohol serves multiple economic and symbolic functions. The inaugural deflowering scene, for instance, where community members wait for the protagonist to lose her virginity, is accompanied by 'vin de palme en jarres, alcool, vin rouge, vin blanc en dames-jeannes, liqueurs en bouteille' [palm wine in jars, spirits, red wine, white wine in demijohns, bottled liqueurs]. Couchoro identifies alcohol as an important facilitator of community and ritual gathering as well as an effective way of displaying wealth (Couchoro 2005, 29). Just as importantly, alcohol immediately emerges as a powerful trope in the Francophone African novel.

Thus, the abundance of intoxicating beverages provides a preliminary sense of their meaning and function within the works to follow. Subsequent writing only confirms the pervasiveness of alcohol as a socio-cultural marker and as a metonym for the fluid relationships between colonizer and colonized. ${ }^{2}$ Beyond the 1930s, literary drinking scenes proliferate, marking a preoccupation with situations, characters and milieux involving alcohol that persists to the present day. This chapter will critically address this recurrence in the Francophone African novel by examining two exemplary cases set half a century apart: Cruel City (Ville cruelle, 1954), by Cameroonian author Eza Boto (Mongo Beti, born Alexandre Biyidi-Awala), and Congolese author Fiston Mwanza Mujila's Tram 83 (2014). Both narratives feature drinking scenes that underscore the heterogeneous social and ideological functions of alcohol while illustrating drinking's function as a narrative strategy. In bookend fashion, Cruel City and Tram 83 show where this trope has remained stable as well as how 'drinking scenes' have evolved over the decades to enable new literary techniques and ideological content.

Despite the prevalence of drink in Francophone African fiction, and despite its mediating function in the (post)colonial worlds that fiction depicts, literary critics have overlooked this key device in the French-language African novel. In what follows, I explore how alcohol - in its many forms - serves as a site simultaneously of conflict and productive encounter, of social 
coalescence and disaggregation, of economic independence and exploitation. It has, in sum, no singular function. Indeed, as will be evident in Cruel City, the role of drinking is protean. At the same time, its ability to express various protagonists' relationship to the postcolonial theme of tradition vs. change - to emergent modes of capitalist consumption, and to escapism - remains surprisingly consistent. Paying attention to alcohol in the Francophone African novel affords a valuable point of entry to authors' diverse representations of their world while also providing a more granular understanding of how they deconstruct its defining parameters. ${ }^{3}$ That is, literary drinking presents a multi-faceted meditation on experiences of social structure and hierarchy in (post)colonial cities. Likewise, the choice of this particular site of mediation as an interactive phenomenon suggests its peculiarly literary persistence.

As Robert Dudley shows in his 2014 book The Drunken Monkey, the consumption of alcohol extends back to pre-humanity as a particular form of adaptation: our distant ancestors developed the ability to metabolize the alcohol that occurred naturally in rotting fruit. Indeed, they increasingly foraged on the forest floor (rather than in trees), where such nutrition was particularly abundant. In this sense, alcohol played a fundamental evolutionary role in creating the conditions that produced Homo sapiens as a ground-dwelling primate. Therefore, it is unsurprising that alcohol should play a marked role in the cradle of humanity. To the extent that humanity came out of the African continent, drinking, as a quasi-ubiquitous human phenomenon, began there too. ${ }^{4}$ Even in those places or in those religions where alcohol isn't allowed, the taboo testifies to its existence as a temptation. ${ }^{5}$ It is not surprising, then, that, as books such as Iain Gately's Drink: A Cultural History of Alcohol (2009) and Thomas M. Wilson's Drinking Cultures: Alcohol and Identity (2005) show, alcohol consumption is global, reaching, in some form or another, virtually every corner of the world.

In the case of West Africa, alcohol had a long history that both preceded European colonization and played a significant role in the colonial enterprise. Indeed, alcohol facilitated the transition from the precolonial to (post)colonial era, as it became a common material and existential point of understanding between the soon-to-be-colonized and the colonizer. As Gately explains:

In the case of the Wolofs, who occupied what is now Senegal, the best articles of trade were wine, weapons, and horses. The Wolofs were a sophisticated culture, nominally Muslim, who maintained links with other members of their faith through a trans-Saharan land trade route, but had chosen to disregard the Koranic ban on drinking. They had a number of native beverages, including palm wine and millet beer, and these two drinks were found to be common throughout sub-Saharan Africa. Indeed, at every point of the continent where the Portuguese landed, they found alcohol to be present and to have been integrated into the customs and rituals of the peoples with whom they made contact.

$(2009,95)$

The Wolof had an alcohol culture that predated colonization. Just as noteworthy, however, is that alcohol constituted a significant element of the Portuguese/Wolof scene of encounter: it became a basis of comparison, of difference or similarity, around which contact - that is, a palatable communication - might occur. As a result, it would become one of the fundamental articles used for trade (along with guns and metal) as the Atlantic triangle trade took hold. ${ }^{6}$

Alcohol consumption is not only imbricated in the cultural habitus of individual social clusters (such as ethnic and linguistic communities), but also passes through and across identifying boundaries, increasing (or assuring) their porosity. Recent texts such as Charles Ambler's 'Alcohol and the Slave Trade in West Africa, 1400-1850' convincingly establish how distilled 
spirits lubricated the channels of the slave market and added to its already substantial profits: 'From fragmentary evidence, it is clear that alcohol served various uses in trade as both a commodity and a currency. Ship captains certainly made direct payments of alcohol for some services' $(2003,78)$. This source of revenue would only increase as dealing in black bodies gave way to imperial expansion and the colonial enterprise. Whereas alcohol's penetration of the continent originally happened through the relatively limited channel of the slave port, with colonization, the distribution of alcohol reached every corner of the continent.

In the case of the French, drinking had (and has) perhaps a greater role in defining class, gender, age and even regional belonging than any other social ritual - a reality underscored by François Rabelais's (1494-1543) repeated and detailed scenes of drinking in Pantagruel (1532) and Gargantua (1534) as well as in Michel de Montaigne's (1533-1592) discussions of wine and drinking in the Essays (e.g. 'On Drunkenness'). This preoccupation has continued through the more recent thoughts of Roland Barthes (1915-1980) in, for example, the essay 'Wine and Milk,' in his Mythologies and Michel de Certeau's discussion in 'Bread and Wine' in the second volume of The Practice of Everyday Life. Thus alcohol in general and wine in particular have preoccupied French thought since the earliest vernacular writings of the Humanists and continues, as Amy B. Trubek beautifully demonstrates in her de Certeau-inflected study, $A$ Taste of Place: A Cultural Journey into Terroir, to be a significant part of French socio-cultural identity to this day - and this more so, perhaps, than any other marker of French belonging, other than, perhaps, French writing itself.

It is within this mixed - and vexed - legacy of alcohol use - as contrasted with drinking in France (and in French literature) that Cameroonian Alexandre Biyidi-Awala (Mongo Beti) (1932-2001) set his 1954 novel Cruel City, written under the pseudonym Eza Boto. Boto recounts the story of a young man, traveling from the countryside to the city to sell his cocoa crop, hoping to use the proceeds to marry. In describing the protagonist's travails, the novel explores this unnamed country's experiences of industrialization and social upheaval. In particular, Cruel City directly addresses colonial relationships; a major feature of its fictional world is the encounter between tradition and modernity, between invisible and unnamed colonial forces, and a past whose specificity can no longer be recreated. Indeed, Eza Boto, unlike most authors before him and many who followed, refuses to sustain a potentially essentializing dichotomy, recognizing instead that, having touched every facet of African life, colonial modernity had blurred the contrast between the past and the future beyond recognition. Instead, he places his narratives along a continuum where modernity itself is the result of the moment(s) of contact between 'the West and the Rest, ${ }^{7}$ and of the multitudinous movements within and across 'empires.' Among the noteworthy commodities, signifiers and symptoms of these converging pasts and futures, traditions and modernities, he identifies is alcohol. Various forms of drink stand simultaneously as Cameroonian cultural signifiers and as mediating sites in which a comparison is being made between his text and the French literary tradition to which it will invariably be compared. ${ }^{8}$

Drinking scenes in Cruel City provide a gauge of the protagonist's relationship to tradition, to the present, and to an imagined future beyond the boundaries of the narrative where the relationship with the colonizer will somehow be resolved. In the process, these scenes explore in detail how alcohol functions as a symbol, a symptom and a material component of social evolution in an unnamed African country during the colonial era, while also claiming a place within the longer tradition of the French-language novel where alcohol has always played a uniquely powerful role. The first passage simply introduces the part of the titular 'cruel city' (Tanga) that houses the 'native' population. Among the most salient features of this space is drink: 
In North Tanga, one out of five huts served as a bar: watered down red wine, poorly stored palm wine, and corn meal beer - usually the best choice - flowed liberally. Those in the know also could find Africa Gin, a famous local beverage with a very high alcohol content. The administration had officially made the pretense of outlawing its sale ... and its distillation. An illegal network of distribution, purchase, sale, and transportation of this rare beverage had accordingly been set up. In any case, they couldn't effectively prohibit its fabrication since no one would ever look to see what was happening in the forest.

(Boto 2013, 13)

This passage anticipates what will follow. At first glance, (excessive) imbibing metaphorically and literally illustrates the abjection of Africans' experience of modernity and the colonial situation. Tanga is a place of depravity and poverty, that one might compare to Emile Zola's (1840-1902) The Gin Palace (1877) and likewise the painful reminder of a convulsively emergent modernity. Nevertheless, in Cruel City, the dispersal of these bars among the living spaces, for better and worse, also makes them vital sites of socialization; they are privileged places for testing and affirming nascent social protocols, for exchanging information, and for venting the accumulating pressures of a subaltern existence.

Despite being at the heart of seemingly debauched urban spaces, the bars are also intimately connected with and juxtaposed to the peripheral space of the forest - the space initially identified with 'tradition.' 9 Thus, the novel appears strung along a predictable axis of tradition and modernity. Yet this binary inadequately explains the protagonist Banda's experience. His movements confuse the boundaries that might sustain any legible opposition between past and future, tradition and modernity, forest and city (or again, the French and African novel). From the outset, the presence of alcohol has already suggested as much, since the most potent (and therefore, potentially desirable) form available to the inhabitants of Tanga is 'Africa Gin,' a beverage distilled not in the city where it is consumed, but in the very space of 'tradition,' 'the forest,' where 'no one would ever look to see what was happening.' This detail is all the more intriguing in that distillation is an imported technology. Distillates were first brought by European slavers but remained an important commodity during the colonial era. Thus material histories and literary tropes inform each other but also converge and diverge in important ways.

While Africans' purchase of imported spirits filled the empire's coffers and its consumption often precipitated the disaggregation of traditional social ties, clandestine distillation instead represented a potential form of resistance to colonial hegemony. It constituted a parallel economy premised on a technology stolen from the oppressor, just as it also grafted itself to capital circulation as a kind of lumpen-industry. That this illegal fabrication should thrive in the forest underscores that 'tradition' is capable of usurping - and contributing to - modernity's modes of production. Thus, the forest, a space the novel repeatedly constructs and deconstructs, cannot be given a singularly positive valence nor identified with some putative untainted origin. Rather, Cruel City demands that it be recognized for its mitigated relationship to (and participation in) the formation of localized expressions and experiences of modernity and by extension, its own paradigm for the novel. The forest, like the city resists a singular interpretation of what modernity might be for the African subject and his/her literary self-representation.

Interestingly, in telegraphed form, the passage above speaks to the very points Emmanuel Akyeampong makes in his seminal text Drink, Power, and Cultural Change: A Social History of Alcohol in Ghana c. 1800 to Recent Times (1996). There are no similar studies of alcohol in a Francophone African context. Thus, though focused on Anglophone Ghana, Akyeampong's analysis provides a uniquely effective instrument for analyzing Boto's Francophone universe. Akyeampong methodically tabulates alcohol's functions as a mediating instrument between 
colonizer and colonized and how it operates as a continuous symbolic and social factor from the precolonial period to the long postcolonial present. This ground-breaking text makes several important points. The first is that fermented beverages (various forms of beer and palm wine) occupied spiritual functions long before colonization. Further, control of alcohol and its consumption lay in the hands of powerful elders and pitted this elite against women, youth and broadly, the lower castes. '[A]lcohol,' the author notes, was connected to 'patronage, wealth, and power' (41). He also explains that, in the Ghanaian context and across multiple ethnicities, there existed 'socially approved uses ... [that] ... strengthened the community ... through social interaction among the living and through communication with the spiritual world' (41). Alcohol could, therefore, have both productive and destructive effects, and the assessment of its benefits or detrimental influence depends on perspective.

In sum, where European contact was established and the colonial relationship developed, distilled spirits were used within and against a society where relatively weak fermented beverages already had complex functions. In the process, two symbolic systems converged. Certainly, change resulted from the fact that spirits, unlike local beer and palm wine, could be stockpiled and thus became transformed into a mode of capital accumulation. ${ }^{10}$ But perhaps more significant were the new hybrid cultures that emerged around the colonial trade counters and, increasingly, the urban centers such as those depicted by Boto in Cruel City and, in more post-apocalyptic form, by Fiston Mwanza Mujila in Tram 83 (discussed below). According to Akyeampong, in these spaces, traditions were to a degree preserved, but social structures were also stretched to - if not beyond - their breaking points. Whereas 'access to palm wine in precolonial southern Gold Coast mirrored the control of male elders over land and people' $(1996,49)$, for example, in the context of the cities, 'drinking circles replaced the family and the kin networks abandoned in rural areas' (53), and 'communal drinking' helped to 'assuage anxiety, created by hard industrial labor [and] was encouraged by the absence of kin and family networks in the new colonial towns' (60). Literary representations of these phenomena would thus become a way of representing, both literally and metonymically, the proliferation of located struggles that constituted the move from colonial to postcolonial sociabilities.

Equally noteworthy, bars and clubs became the birthplace of a popular culture (a hybrid of traditional and modern practices), variants of which exist all over the continent - a culture which would, as Tram 83 certainly demonstrates, impact everything from music and dance, to literary productions. ${ }^{11}$ All the while, alcohol, most notably spirits, remained (and remains) a vast source of revenue for import merchants, for local governments and for (neo)colonial economic interests. ${ }^{12}$ Accordingly, a tremendous amount of energy was expended, both during and after colonialism, in repressing what Ghanaians call akpeteshie, the locally (and mostly illicitly) distilled liquor that Boto refers to as 'Africa Gin.' Further, because the manufacture, distribution and consumption were controlled by the most disinfranchized, both colonial masters and traditional elders agreed that local brewing and distillation should be eliminated. It thus remains a target of those in power.

Cruel City's drinking scenes depict the evolution of alcohol consumption and suggest that many of the points made by Akyeampong transcend imperial-linguistic boundaries. The first such scene in the novel occurs when Banda enters a beer shop, and shows that alcohol plays a crucial role in the transformation of a rural society to an increasingly urban one, while also underscoring how both worlds are merging into something new. Later, the sixth chapter provides a sociology of this urban space and vacillates throughout between a lament that the inhabitants of the city have been lured from a meaningful existence into this den of iniquity and a fascination with the new world that is coalescing in the space of the bar: 
One drank corn-beer there, the specialty of the house ... Patrons sat on bamboo or wooden beds, on step-ladders, or empty boxes. To rest their glass, they had the choice between the ground or a single long table... Most of them were men... Before sitting down, each new arrival went around the room and warmly shook the hands that were extended, even those he didn't know.

(Boto 2013, 47)

The room is principally designed for drinking, yet, a new sociability emerges as the patrons make the rounds shaking hands. This is done, as the passage emphasizes, 'warmly.' Further, this place is not dedicated to the drinking of imported beverages, but to 'the specialty of the house,' namely corn-beer, which has its own distinct production process, flavor, manner of consumption and terms of sale. Thus, the very modern urban bar houses the consumption of a traditional beverage drunk within evolving rituals that (re)combine old and new ways of socializing. The narrative's own ambivalence about the bar reflects an inability to decide what Africa's relation to the urbanization and modernity ought to be. Thus, it becomes the synecdoche for the greater questions about where Africa is headed.

Indeed, the convergence of old and new in the novel makes it difficult to ascertain whether this is a positive or corrupted space. In the context of this tension, some customers face particular scrutiny. These appear 'preoccupied,' have 'a smirk etched on their face' and sport 'a vague and condescending expression.' Further, 'these folks discriminated as to whose hand they shook' (48). What distinguishes these characters, we learn, is that they are 'little shop owners who had recently made money' (48). Their behavior establishes a distinction between those corrupted by capital and those retaining a sense of community. This encounter between urban drinking types also echoes Akyeampong's identification of drinking establishments in Ghana as sites where the sculpting of class identities occurred. The beer hall is a hybrid space where men and women meet, where class boundaries bend and merge, and where the country and city form an eerie stew. What is clear is that the moneyed classes (here, small merchants and the comprador intermediaries of Tanga's various industries) are deeply suspect.

A second drinking scene occurs at the threshold of the forest. Banda, the protagonist, ambles along the path home to Bamila, pondering the difference between life in the country and in the city. People in the country, he muses, 'spent the whole day in the forest. When they weren't working their fields, they were there to drink palm wine in peace or to hunt or engage in activities that the law deemed unacceptable, and for which the forest provided its maternal protection' (130). The life described is one of apparent freedom, in contrast to the drained and downtrodden workers that populate Tanga. Drinking palm wine as one of the activities in which the 'free person' of the forest indulges and which the law seeks to repress.

As if to prove Banda's point, only a few lines later, someone comes up behind him on the road and calls out:

Who are you to not even turn around when you're called? Don't you want a little of our good palm wine? ... Don't disdain my wine ... Today, we've decided to offer it to any stranger we like ... Oh! You know, if you miss this opportunity, it's just your loss. In any case, the closest village is Bamila; and they won't offer you wine ... They lack in hospitality over there. I've heard it's that they're overly jealous about their women, heh heh heh.

Banda is once again drawn into a drinking ritual but we discover shortly that there is, potentially, at least, more intimacy here. To begin, the person calling him is an acquaintance. In 
addition, in the first scene, Banda simply wanders in. Here, the appeal to drink is a gesture of hospitality, an ethos that is connected throughout the novel to tradition. At the same time, the man mocks Bamila for its lack of hospitality, though it is still further along the road into the 'countryside.' Though we should be moving towards the more hospitable space of tradition, we are, as throughout the novel, situated instead in a hybrid space that blurs the boundary between city and country. This new 'middle-ground' reminds us that neither space (city or country) corresponds neatly to the essentializing stereotype with which it is so frequently connected. ${ }^{13}$ In addition, as with the previous scene, to the extent that such essential categories are preserved at all, neither is unequivocally praised. Thus, each drinking scene inevitably melds, or recognizes as indistinguishable, the categories of pre- and postcolonial, pre-modern and modern.

While the drinking scene at the forest's edge mirrors the earlier beer-hall scene in multiple ways, it is also essential to understand its distinguishing features. Perhaps the most noteworthy is the contrast the later scene underscores between corn-beer and palm-wine. Palm-wine is the domain of men who form castes of (male) 'palm-tappers.' Once tapped, the sap spontaneously ferments after a few hours. Beer, on the other hand, demands preparation, and its production is traditionally the domain of women. Thus, as Banda's friend's comment about Bamila men's jealousy suggests, women play a significant role as mediating agents between past and present, or rather, as reminders that these categories are not only impossible to maintain, but sustain oppressive hierarchies of which gender is one of the most significant. Just as significantly, the city, or 'modern' pole of the binary, proves far more progressive for women than the traditional space represented here. Thus, the beer-hall confuses social classes and gender roles and acts as a site where women effectively enter the emerging global economy. At the same time, the person making and serving the beer in North Tanga is a businesswoman principally interested in capital accumulation, albeit on a small scale. Conversely, Banda's friend is not involved in mercantile activity. Hospitality and socialization motivate him. 'Banda,' he tells him, 'you should drink something with us, just to forget your woes ... Come and have a drink ... Follow me brother' (131). Again, no instance or space of drinking has unequivocally positive (or negative) valence. Rather, drinking scenes provide a unique opportunity to express the impossibility of speaking about Francophone African spaces in binary terms while underscoring how popular cultures cope with and improvise upon the emerging conditions of the (post)colony.

In the forest scene, Banda dozes, half listening to what is going on around him, only to emerge from his reverie when he hears discussions of a Greek couple's car that has been traveling up and down the roadway. While the car has a specific plot function, it also binds the worlds of the novel together. Banda's drinking buddy represents an older way of life. At the same time, even he is aware that this way of life is disappearing, that 'to drink palm wine in peace or to hunt or engage in activities that the law deemed unacceptable, and for which the forest provided its maternal protection' is no longer possible. The Greeks' car therefore reminds us that the forest and city are now irremediably connected, by a road, by an economy, by a history that can't be rewound, and this in a manner that demands new ways of storytelling as well, such as the novel. Thus, the relative gap between the two drinking scenes can only ever be just that: relative. The distance separating them may be a delimited zone of flux and movement, but the endpoints themselves are always already pushed towards each other, such that their differences become cosmetic, or a question of degree. At the same time, the literary medium, as represented by Eza Boto's inaugural text, is also struggling with the shape it will take as it meanders back and forth between the circular patterns of oral narrative and the forceful advance, the 'progress,' of the modern Western novel.

The second scene is less troubled by the effects of lucre and the desperation that drives the participants to drink. Nevertheless, its nostalgic refrains, recited between rounds of symbolically 
charged palm wine, suggests that this space is also flawed. Indeed, the car, passing back and forth, reminds us that this world is long gone (if it ever existed), and that Banda and his friend locking themselves in this space (or escaping to the ever-shrinking forest) cannot regain some putative or imaginary past. Banda, lost in thought, is brought to his senses by the drinkers debating the meaning of the car. Even they, who might represent the simpler ways of the country, aren't immune to the car's incursion into their territory. Or rather, the car's presence reminds Banda, the other drinkers and the reader that there is no territory that capital and modernity, or writing, don't modify - that the very notion of tradition demands modernity as its counterpart and therefore has no meaning as soon as its unique valence is posited, since it only becomes relevant (or even possible) in the moment of its disappearance - as mourning, as nostalgia. ${ }^{14}$

Such distinct temporal moments seem to disappear entirely in Fiston Mwanza Mujila's 2014 novel Tram 83. Nothing really happens, though there is, apparently, a kind of revolution at the end, the outcome of which remains entirely uncertain. Cruel City mapped out an elaborate geography tracing the ebbs and flows of modernity's relative influence as the literary form of the modern novel slowly tried to find its way over the course of the narrative, and this within a series of vignettes (village, church, bar, Greek merchants' stores, etc.). The same can be said for various material signifiers (cultural and economic) such as cocoa, women and, of course, alcohol, which in Cruel City are treated as distinct objects of analysis even if they converge to form an overall narrative and existential coherence. By contrast, Tram 83's narrative occupies vague zones anchored at their center by the eponymous Tram 83, the bar where all crucial activity in the 'City-State' takes place. The city itself, is nowhere in particular, and the exact moment when the action takes place is even less clear. ${ }^{15}$ All we know is that beyond its walls lie the hinterlands, undefined and undesirable, the mines, indistinct residential neighborhoods and the police station. The result is that, even as alcohol remains a metonymic trope, drinking is no longer, as it remained in Cruel City, a peripheral or even symbolic activity that might stand in for hybrid economies and/or other forms of sociability; nor is it a reminder of traditional rituals of community. Rather, it is ubiquitous and appears, at least at first, to be largely emptied of any function. It now serves to fend off the meaningless - even hopeless - existence that lies beyond the walls of the nightclub. As blogger, critic and author Robert Neuwirth (2016) notes in his beautiful (and beautifully efficient) reading of the novel, 'in this novel, there's no reason to engage in palaver about the way things were and the way they might been. There's only the way things are.' Invoking 'palaver,' in this case, reminds us of the 'oraliture,' with which Eza Boto's novel was so clearly contending and which Neuwirth suggests is no longer part of the (post)modern African space of Tram 83. Ironically, and in contrast to Neuwirth's implicit claim, the language of Tram 83 is very distinctly oral: the entire novel, though more vulgarly carnal, retains a genetic and generic connection to the oral tradition of the 'griot,' (to whom it is no doubt tacitly making reference) through its circular structure and insistently vernacular register.

Despite its ubiquity in Tram 83, alcohol never occupies a position on its own as it does in Cruel City. That is, no scenes are exclusively dedicated to explaining drinking culture per se and as such it becomes, perhaps, less a trope than a simple fact of the vernacular existence the novel describes: nothing here is sacred. Rather, everything is debased and derivative. Drinking is almost always bundled in with music (generally unoriginal covers played badly) and sex, which only happens in the form of prostitution. Wherever people gather, even when it is a site of death and mourning, a whole ecosystem immediately emerges of which alcohol, music and women are inevitably a part. For example, on 'Gravedigger Street,' as soon as the coffin sellers lay out their wares, their trade draws 'so-called businesswomen who [erect] straw shacks from 
which they [sling] grub, hemp, and traditional beer, which in turn [draws] musicians, babychicks [i.e., very young prostitutes]' (Mujila 2014, 73-74). The Tram 83 nightclub accomplishes the same thing without the gradual, quasi-organic build-up of this market scene. Instead, all the necessary components are available for immediate consumption. What did men do in the Tram 83? 'They hit on the baby-chicks and the ageless-women, identified with the jazz, and drank beer till they threw up' (78). Drinking may sometimes be the emphasis, but 'not all nights had the same chronology of beer, music, dance, single-mamas in the first flush of youth, dog kebabs, and madness' (176). Instead, a more radical and seemingly irredeemable form of corruption exists. What remains stable, therefore, is the overwhelming sense of a world in full deliquescence; just as the narrative itself neither begins nor really satisfyingly ends. Just as there is no meaning to the lives being lived, there is no adequate novelistic form to represent it aesthetically.

To the extent that there is a story, it revolves around Lucien, who has returned from the hinterlands to rejoin his sometimes rival, friend and enemy, Requiem. Lucien is a self-delusional writer working on a revolutionary play whereas Requiem is a schemer, one of the new protean types capable of adapting to any and all situations, largely empowered by his total lack of ethics. The Tram 83, where the two long-separated friends spend their first evening together, is perfectly suited to Requiem's Weltanschaunn:

FIRST NIGHT AT TRAM 83: NIGHT OF DEBAUCHERY, NIGHT OF BOOZING, NIGHT OF BEGGARY, NIGHT OF PREMATURE EJACULATION, NIGHT OF SYPHILIS AND OTHER SEXUALLY TRANSMITTED DISEASES, NIGHT OF PROSTITUTION, NIGHT OF GETTING BY, NIGHT OF DANCING ... THAT ENGENDERS THINGS THAT EXIST ONLY BETWEEN AN EXCESS OF BEER AND THE INTENTION TO EMPTY ONE'S POCKET.

There are many such lists and diatribes throughout the novel. Most are directly connected to the Tram 83 and its inhabitants. Indeed, the first and most substantial of these enumerates 'all sorts of tribes' that overrun 'Tram 83 in search of good times on the cheap' (8). The clientele is entirely masculine and, as in the spontaneous markets, the principle attractions are the 'EXCESS OF BEER,' the vast array and number of prostitutes who interrupt the flow of the narrative every few minutes, usually with the interjection, 'do you have the time?' and the music that plays in the background. Whereas Cruel City offered some hope, albeit inchoate and distant, Mujila's novel appears to abandon any such pretense. Cruel City describes an atopia whose meaning remains to be established; Tram 83 instead appears more radically and fundamentally dystopic, a shore on which the dregs of the global economy have washed up and where the inhabitants cobble together a present out of the flotsam of Western material culture and their own shattered history. It is in this context of narrative and existential bricolage that alcohol appears: it is simultaneously more ubiquitous than it is in Cruel City, and also far more difficult to pin down as a sociological instrument of analysis or as a stable literary trope. It is one of a few pieces of cultural debris that remains adequate to this forsaken place.

The first time Lucien and Requiem are served together, the important and yet vexed meaning of alcohol is already evident:

A sullen-faced waitress finally came. Spitefully, she placed on the table the two bottles of beer she was supposed to have served them an hour and a quarter ago. They paid the check but she stood there waiting for her tip. ... She ... cunningly refused to open the 
merchandise. ... To close the case, they decided to open the bottles with their teeth. ... They began to drink straight from the bottle.

The beer- and palm-wine drinking rituals structured around exchange (whether verbal, financial or ritual) of Cruel City are ironically recycled as the immediate need for gratification in Tram 83. No character here is thinking about the social contract constructed and reaffirmed by drinking. Rather, the waitress wants her tip and the drinkers, particularly Requiem, are only interested in what is immediately before them. As the indirect discourse of the narrator notes:

as the beer flowed, they held fast to the obvious. The backwash had cleared the way for them. They could no longer sing from the same hymn sheet. They were just two life forms adrift in a city become a state by force of Kalashnikovs.

The flow of beer reminds them that a coherent life is no longer possible (if it ever was) and that drinking is one of the principal activities of which this aimless existence consists. Every gesture is self-interested and is directed towards forgetting, surviving or profiting from the present. Accordingly, the bottles no longer testify to the sediment of history, but simply become revenue for the waitress and diversion for the two consumers. As the drinkers refuse to tip, the waitress in turn refuses to remove the caps or provide glasses, thus reducing the scene to its barest terms. When the friends wind up opening a bottle with their teeth and drinking from it, they signal the disappearance of ritual and the reduction of drinking to a commodity and source of drunkenness.

Liquor consumption was of prime importance in Cruel City, as a social artifact in its own right, as a gauge of the exact social situation of those partaking, and as a literary theme around which variations could productively be composed. As noted, even in the relatively corrupted space of Tanga, protocols were salient and a certain conviviality and residual empathy remained. Humanizing details instead prove elusive in Tram 83 and the apparent lack of symbolic meaning attached to alcohol is one more reminder of the hopelessness of this cosmo-colonial dystopia. Here, global interests play out at the expense of the most vulnerable and the moldering remains of a coherent Francophone African literary project that would 'write back,' to the French literary canon seems to breathe its last. Getting drunk (perhaps like writing itself) is simply another activity where one is always warily looking out for oneself.

When Lucien, for example, having awoken with a wicked hangover, returns to the club, he finds a man, '[a]lone with his cigarettes and a fine row of bottles, portents of an inveterate alcoholism' (40). The narrator clarifies why the man is surrounded by empties: '[w] hen you got wasted,' we are informed, 'you didn't return empties in order to avoid misunderstandings,' the reason being that, when it comes time to pay, the 'waitresses and busgirls were inclined to tell you ten bottles instead of three or five you actually ordered' (40). Thus, it was not unusual 'to come across a guy with fifty empty bottles on his table and even the floor' (40). Again, drinking is a process designed exclusively to arrive at inebriation and is done alone (even when in a group). Further, it is done defensively, in a way that recognizes that one is always surrounded by others ready to pounce. This scene illustrates perfectly how debauchery in general and drinking in particular function throughout the novel: as a simple and unvarnished form of escape from the quotidian that retains a defensive posture vis-à-vis those who might profit from any sign of vulnerability. Meanwhile, the waitresses single-mindedly focus on their own self- 
interest, as the consumers they are serving do the same. Sociability and common purpose have been dissolved in the acid of posthistorical capitalism and neocolonialism.

While it is true that alcohol is used throughout the story with a seeming lack of focused meaning, some important interpretive refinements need to be made. For, while alcohol at first seems relatively neutral in Tram 83, one more signifier of a broader existential malaise, it also works as a particular and peculiar signifier of social power that moves the narrative in a slightly different direction than might at first appear. In the first beer-drinking scene of Cruel City, when the man offers a round of drinks, there is an empathy for Banda's situation that is apparently absent in Mujila's text. Likewise, in Tanga it is understood that a round of drinks offered will be answered in kind. The impulse, though it can lead to excess, is social and communal. In Tram 83, various individuals instead take over the responsibility of paying for all the drinks, in a demonstration of largesse that immediately draws attention to the big spender. Thus, Requiem, as a sign of his victory over the editor Malingeau, 'couldn't help ordering rounds for the entire Tram' (185). Malingeau, just a few pages later, believing that he has now vanquished Requiem, responds in identical fashion, shouting out: 'But now, time for beer and music. Drink till dawn! It's Malingeau picking up the check!' (200). A few pages later still, a foreign power, what the novel refers to as 'for-profit tourists,' now pays for rounds of drinks: 'The national team had won the game. The Chinese tourists ordered rounds for the whole Tram 83 with a view of combining business with pleasure' (202). Thus, there is a certain grim irony to these demonstrations of generosity, since in every case they appear - unlike the rounds paid for by the patron in Tanga at the beer-bar, or Banda's friend's offer of palm-wine - to be entirely egotistical gestures.

Equally noteworthy is that, whereas particular types of alcohol in Eza Boto's novel spoke, albeit ambiguously, to distance from or proximity to a vaguely defined point of origin (an idea of tradition already substantially challenged in and by the novel), any such imagined or imaginary precolonial space is completely absent from Tram 83 . The effect on the narrative is that types of alcohol (to the extent that they have any meaning at all) signal social standing rather than a particular relation to one's 'roots.' The most common beverage throughout the novel is beer. Indeed, 'Drinking beer isn't drinking. It's like drinking water' (104), one character says, even if beer is 'the water of the poor' (98). Indeed, beer appears dozens of times throughout the story because most of the inhabitants of the city (and patrons of the club) are poor, rather than because it has cultural and/or symbolic valence. Thus, when someone else is buying, the 'diggers, the baby-chicks, and the students, as well as the poor tourists, always ordered wine whenever they chatted with the for-profit tourists' because, according to the former, 'it's classy' (91). The 'for-profit tourists,' for their part, drink 'fizzy wine' and 'whisky' (98), apparently the most expensive beverages in the house. In sum, because the world has become entirely commodified and class-identity is inextricably linked to purchasing power, performances of class are expressed, perhaps more than in any other way, through the alcohol one orders. The overarching sensation is of hopelessness accompanied by a hallucinatory descent into the Bourdieusian idea of 'distinction.'

Despite this pessimistic reading, there remains a glimmer of hope of which alcohol is an integral part. As the novel closes, the 'dissident-General' has tried to raze the Tram 83 but failed. Lucien, Malingeau and Requiem, each with a price on his head, try to sneak off. As they go to the train station, they pass by the Tram 83 - since 'all paths lead to Tram 83' (210) where they note with some regret that the party continues unabated. Their impending departure thus happens to a soundtrack echoing off the walls of an unfinished and bombed out colonial era structure: 
In two beats, the drums ... echoed through the station with its unfinished metal structure, gutted by artillery, train tracks, and locomotives that called to mind the railroad built by Stanley, cassava fields, cut-rate hotels, greasy spoons, bordellos, Pentecostal churches, bakeries, and noise engineered by men of all generations and nationalities combined.

It appears nothing has changed, that the decadence continues: these three men forming three different ways of confronting (or incarnating) the past have failed and, by extension, so has the 'city-state,' and the African continent as well.

However tempting it might be to read them this way, the city-state and Tram 83 are not to be taken as metonymies for Africa any more than Tram 83 should be read as another iteration of the 'Francophone African novel' and its endless attempts to be taken seriously by and within the criteria of the French literary canon. They are 'engineered by men of all generations and nationalities combined': Tram 83 is the world where capital matters more than people just as the novel circulates across linguistic and national boundaries, beyond the binary relationship of center and periphery, Paris and its (post)colonial empire(s). The novel is an example and dissection of a world where new trans- or postnational economies dominate and where new terms of engagement are taking hold. It is in this sense that, despite (and because of) the apparent irony of the story, something tentative but profound emerges. As was noted at the outset of this chapter, humans adapted (socially and metabolically) to alcohol consumption in ways that assured the survival of the species at its very beginnings. Accompanying this adaptation was the pleasure alcohol provided. This introduced something new into the equation, particularly as the need for alcohol as a form of nutrition disappeared: the frivolous, the unproductive, the supplemental nature of drunkenness that, perhaps more than anything, distinguishes the human. Tram 83 is a fraught space, most dramatically for the women who are given virtually no voice or power. Yet it contains a striking will-to-frivolity, to unproductive pleasure that, even in this diminished and corrupt world, simmers throughout and beneath the text. Alcohol is perhaps frivolity's most ubiquitous symbol. In this sense, the novel refuses the high-seriousness that ultimately determined the existence of a text such as Cruel City. Mujila's narrative is notably difficult to identify ideologically precisely because it offers so few traditional points of entry, whether in terms of narrative or aesthetic logic - it is neither a realist novel nor is it a highmodernist experiment - or again as a recognizably French or Francophone text. It sits, like the world it describes, in a world of its own making, unconcerned with debates about 'Francophonie.' Significantly, alcohol becomes a vector for this tactical unmooring because of its sustained importance as a literary trope and its potentially frivolous superfluity as a social and organic modality of human consumption.

My purpose here has therefore been to examine drinking scenes as sociological phenomena but just as importantly, as a literary device. In closing, there is an intimate connection between the ubiquity of alcohol in Tram 83 and the novel's drunken prose. The constant interjections, changes of style, shifting voices and disturbing details forego logic for an ethics of frivolity and of waste, both in the story told and in its style. 'There are cities which don't need literature: they are literature. They file past, chest thrust out, head on their shoulders. They are proud and full of confidence despite the garbage bags they cart around' (96). But this novel (and city) are literature not 'despite the garbage bags they cart around' but literally inasmuch as they are composed of that refuse, of that surplus, of that excess. Nothing can happen here. But from that nothingness emerges the strange and drunken laughter of a people who are wasting time in an endless stream of drinking scenes in a writing that likewise endlessly repeats patterns, not with some final goal in mind but simply because, in the face of a shattered world, all that is left is to 
waste narrative ink. Nevertheless, this disorientingly festive despair finds its roots in texts such as Cruel City. Cruel City's oddly wandering prose and richly developed drinking scenes already showed that its young African author, Alexandre Biyidi, was at a loss in the face of an emerging postcoloniality yet believed that alcohol might offer some form of salvation. Alcohol became and remains the privileged means of expressing despair and hope, a willingness to seize the present in order to grin in the face of the future's grim prospects, all with the vague sense that it is this particular posture that might just save that future from oblivion.

In closing, it should be clear that this chapter has only sketched the vaguest outlines of a vast problematic that merits much closer scrutiny. If, within the domain of Francophone African literature, we have seen where the literary function of 'alcohol' may have begun, and where it ultimately may have led, there remains the six-decade gap between Cruel City and Tram 83. Much can be said about alcohol in the works of authors such as Ferdinand Oyono, Mongo Beti, Cheikh Hamidou Kane, Ken Bugul, Alain Mabanckou, Abdourahman Waberi, Bessora and so many others. Each treats it differently, and yet in each, it plays a key role. The authors also pose important questions and ask for further consideration of the role of class, gender, locale, time, ideology and literary considerations that the present chapter has only begun to explore. First and foremost, it has been the goal of this chapter to demonstrate that such questions are worth asking, and to indicate in the process future veins of research on alcohol that merit pursuing.

\section{Notes}

1 It should be emphasized that the present study, while relevant to those working on the Anglophone African novel, focuses on the Francophone African novel and the 'drinking scenes' specific to it. Thus, while much could be said about works from Amos Tutuola and Chinua Achebe, through Wole Soyinka and Chimamanda Ngozi Adichie, these authors are outside this chapter's purview.

2 This is true even in cases of its marked absence, such as in Senegalese author Ousmane Socé's Mirages de Paris (1937). When the Muslim protagonist refuses an aperitif, alcohol's importance is underscored in the refusal.

3 I explored another way in which African authors have deconstructed their worlds, through the genre of the crime novel, in my The Noir Atlantic: Chester Himes and the Birth of The Francophone African Crime Novel (Higginson 2011). In particular, I identified a tool I called the 'frivolous literary,' which challenged the Sartrian imperative of an ideologically engaged literary project by making use of popular literary forms such as the crime novel or 'thriller' genre. The inclusion of alcohol, with its Dionysian implications, works in a similar (if not identical) fashion.

4 No matter what the origins of human alcohol cultures are, there is a danger in identifying Africa with drunkenness, as to do so appeals to stereotypes associating Africans with unbridled animality.

5 It should be noted that there are exceptions to this rule: before colonisation, for example, there was no alcohol consumption throughout most of Oceania.

6 'Les manifestations pathologiques liées à l'alcoolisme se retrouvent historiquement avec l'introduction des boissons manufacturées ou conditionnées en Europe, en particulier le rhum qui servait de monnaie d'échange au moment de la traite des esclaves' [The pathological manifestations connected to alcoholism appear historically with the introduction of beverages manufactured and conditioned in Europe, in particular rum, which was a common medium of exchange during the slave trade] (Klotz, Guisset and Laroche 1992, 3).

7 I borrow this expression from Niall Ferguson's entirely unironic and decidedly reactionary (not to mention crypto-racist) book Civilization: The West and the Rest (2011).

8 As Eza Boto knew, the market for Francophone African books was principally in France, where most of these books were published.

9 And in this, Ville Cruelle significantly deviates from the facile reductionism of Zola's depiction of alcoholism as a uniquely modern urban phenomenon.

10 The almost unlimited shelf life of spirits encouraged an ethos of accumulation that the short shelf-life of locally brewed products made impossible. 
11 See, for instance, Anthony Mangeon's unpublished 2014 essay on bars in the Francophone African novel, 'Contes et comptoirs: Le bar africain, un lieu de littérature pour les diasporas noires.' Achile Carlos Zango's 'Quand le bar devient miroir des mutations sociales post-coloniales dans Temps de chien de Patrice Nganang' appeared in a 2015 special issue of the journal Ponti/Ponts, also on bars in the Francophone novel. Zango examines the space of the bar from a sociocritical perspective: '[L]e bar Le Client est Roi,' he tells us, is 'représentatif ou révélateur de toutes les mutations sociales et même linguistiques du Cameroun. C'est donc un "lieu-thermomètre" du social' [The bar The Customer is King is representative or revealing of all the social and even linguistic mutations Cameroon faces. It is therefore a 'gauge-place' of the social] (11). Though Zango's essay is not specifically on alcohol, there is nevertheless much in it that overlaps with the broader claims I make about alcohol in the African novel. For similar 'Afro' bars in literature, see Alain Mabanckou's Verre Cassé and Black Bazaar.

12 It is worth noting that while local brewing practices remain, the bulk of the alcohol drunk today, whether in the form of beer or distilled spirits, whether made locally (as is the case for most beer drunk on the continent) or imported, is under the control of multinational alcohol conglomerates.

13 I'm thinking here of Homi Bhabha's now canonical The Location of Culture, where hybrid space isn't necessarily or exclusively productive of resistance just as it also deconstructs the 'poles' from which it derives. For Bhabha, everything, in essence, is ultimately 'hybrid.'

14 In a sense I am also speaking here, in a slightly modified form, of the 'postcolonial melancholia' that Paul Gilroy posits in his book by the same name: the idea that there could be a culture (whether African or European) untainted by the moment of contact. This nostalgic residue remains in the comparative analysis of tradition and modernity that Boto (Beti) so unrelentingly deconstructs.

15 It is worth noting that the introduction to the English translation of Mujila's text informs us that the action takes place in Lubumbashi, Republic of Congo. No such information is actually in the narrative and, while there is plenty of information to allow for such a conclusion, nothing indicates this in the French original.

\section{References}

Akyeampong, Emmanuel. 1996. Drink, Power, and Cultural Change: A Social History of Alcohol in Ghana c. 1800 to Recent Times. Portsmouth, NH: Heinemann.

Ambler, Charles. 2003. 'Alcohol and the Slave Trade in West Africa, 1400-1850.' In Drugs, Labor, and Colonial Expansion, edited by William R. Jankowiak and Daniel Bradburd, 73-87. Tucson: University of Arizona Press.

Barthes, Roland. 2013. Mythologies. New York: Hill and Wang.

Bhabha, Homi. 1994. The Location of Culture. London: Routledge.

Boto, Eza [Mongo Beti, Alexandre Biyidi-Awala]. 2013 [1954]. Cruel City: A Novel. Translated by Pim Higginson. Bloomington: Indiana University Press.

Couchoro, Félix. 2005 [1929]. L'Esclave. London: Mestengo Press.

de Certeau, Michel, Luce Giard and Pierre Mayol. 1998. The Practice of Everyday Life, Volume 2. Living and Cooking. Minneapolis: Minnesota University Press.

de Montaigne, Michel. Essays. Book 2, Essay II. www.gutenberg.org/files/3600/3600-h/3600-h.htm (consulted March 7, 2018).

Dudley, Robert. 2014. The Drunken Monkey: Why We Drink and Abuse Alcohol. Berkeley: University of California Press.

Ferguson, Niall. 2011. Civilization: The West and the Rest. New York: Penguin.

Gately, Iain. 2009. Drink: A Cultural History of Alcohol. New York: Gotham Books.

Gilroy, Paul. 2005. Postcolonial Melancholia. New York: Columbia University Press.

Higginson, Pim. 2011. The Noir Atlantic: Chester Himes and the Birth of the Francophone African Crime Novel. Liverpool: Liverpool University Press.

Klotz, Francis, Michel Guisset and René Laroche. 1992. 'Alcool et pathologie en Afrique noire.' Médecine d'Afrique Noire 39(3): 201-203.

Mabanckou, Alain. 2005. Verre Cassé. Paris: Seuil.

Mabanckou, Alain. 2009. Black Bazar. Paris: Seuil.

Mangeons, Anthony. 2014. 'Contes et comptoirs: Le bar africain, un lieu de littérature pour les diasporas noires.' Unpublished essay.

Mwanza Mujila, Fiston. 2014. Tram 83. Paris: Métaillé. 
Neuwirth, Robert. 2016. 'Do You Have the Time?' Blog post, January 14. http://grandhotelabyss.blogsp ot.com/2016/01/do-you-have-time.html (consulted November 9, 2017).

Rabelais, François. 2006. Gargantua and Pantagruel. Translated by M. A. Screech. New York: Penguin Classics.

Trubek, Amy T. 2009. A Taste of Place: A Cultural Journey into Terroir. Berkeley: California University Press.

Wilson, Thomas M. 2005. Drinking Cultures: Alcohol and Identity. Oxford: Berg.

Zango, Achile Carlos. 2015. 'Quand le bar devient miroir des mutations sociales post-coloniales dans Temps de chien de Patrice Nganang.' Ponti/Ponts 15, 'Bars, Cafés, Buvettes': 11-28. 


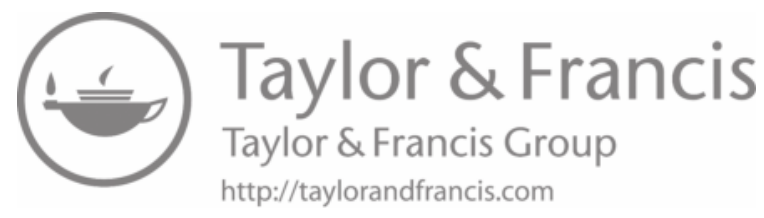


Part VI

Bodies, Subjectivities, Affect 


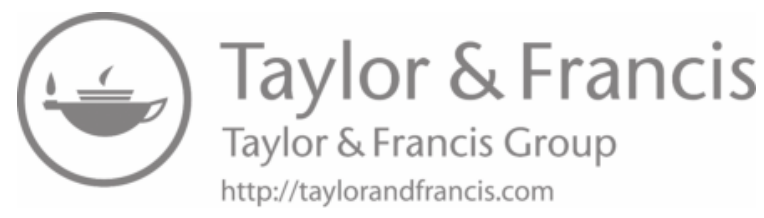




\title{
Desire and freedom in Yvonne Vera's fiction
}

\author{
Grace A. Musila
}

This chapter reflects on the female body as a site of conceptualisation of female freedom and desire in the work of Yvonne Vera. Through a reading of 'Independence Day', Butterfly Burning and The Stone Virgins, I explore Vera's constructions of self-love and the erotic as important vectors in women's conceptions of their bodies and thoughts as sites of articulation of desire and freedom which variously map onto, and against, the grain of nationalist moral-political grids of desire and freedom. I suggest that Vera recalibrates hegemonic nationalist historiographies of Zimbabwe to create space for inscriptions of women's bodies as thinking, desiring subjects who reconfigure nationalist cartographies of desire and freedom with courageous embrace of both failure and success. Through elliptical, poetic narratives, Vera imagines Black women's bodies as variously scaling contours of thought, pain and pleasure with uncompromising conceptions of themselves as thinking, desiring subjects in pursuit of freedom.

An academic, one time director of Bulawayo's national gallery, and prolific writer - she published five novels and a short story collection in nine years - Vera's writing has been described as poetic, taboo breaking 'feats of the imagination' that grapple with 'the weight of the past and how to bear it' (Ranger 2002, 203-204). Her work offers salutary 'celebrations of freedom and space [through] a new spiritual and psychological cartography of female consciousness' (Muponde and Taruvinga 2002, xi-xii). Vera's writing is often set at key moments in Zimbabwe's nationalist history, but consciously widens the lenses with which we read these historical moments, by centring ordinary people's desires and disappointments, pleasures and pain. Historical moments in Vera's writing - 1896-97 and the hanging of the eponymous spirit medium in Nehanda; 1977 at the height of the anticolonial war explored in Without a Name; 1979 on the cusp of independence in Under the Tongue; the 1946 public hangings of anticolonial resistance figures in Butterfly Burning; 1981-86 and the Matabele massacre in The Stone Virgins - Muponde and Taruvinga argue, 'recall not the historian's emphasis on dates, facts and occurrences, but certain imaginative and spiritual journeys of a colonized and oppressed people' (xi). Through her reimagining of the spirit medium Nehanda; her meditations on the sexual assault of women by fathers and freedom fighters in Without a Name, Under the Tongue and The Stone Virgins; and her sensitive portrayal of a young woman's tragic pursuit of self-determination in Butterfly Burning, Vera repeatedly breaks the taboos of silence around various forms of sexual violence, while imagining more hospitable versions of history for these women who, as 
historian Terrence Ranger writes, have been victims of history; Vera herself included, as a survivor of rape, abuse and incest (Ranger 2002, 204-205). Vera's engagement with the silences that haunt lives scarred by incest, rape, abortion and infanticide - coupled with her lyrical prose, her critique of masculinist nationalist metanarratives, as well as her celebration of Zimbabwean urbanity - has inspired rich scholarly meditations, including two influential essay collections: Robert Muponde and Mandi Taruvinga's Sign and Taboo: Perspectives on the Poetic Fiction of Yvonne Vera (2002) and Emerging Perspectives on Yvonne Vera (2012) edited by Helen Cousins and Pauline Dodgson-Katiyo. One thread that runs across much of this scholarship on Vera's work is women's placement in what Meg Samuelson calls 'the unstable space between subjecthood and subjection' $(2007,159)$. Vera's women's articulations of desire and freedom in this unstable space form the focus of this discussion, which meditates on what Elleke Boehmer, reading Tsitsi Dangarembga's Nervous Conditions, terms configurations of desire and vocabularies of aspiration (2003, 135).

Despite women characters' presence in African writing from its very genesis, it was a while before narratives celebrating the erotics of Black female bodies and their aspirations as legitimate modes of subject formation became normalised. Two factors account for this: firstly, in male writing, women's erotic desires and their dreams of freedom were considered coincident with heteropatriarchal male desire and nationalist freedom dreams respectively. Across the canonical oeuvre of Chinua Achebe, Ngũgĩ wa Thiong'o, Ayi Kwei Armah and Peter Abrahams for instance, women's desires and conceptions of freedom are folded into heteronormative male desire and the nation project's vision of freedom. Thus, Mumbi in Ngũgĩ's $A$ Grain of Wheat is largely an object of desire for the various male characters, while her own desires remain sublimated to her literal and symbolic role as mother of the nation. Her one expression of autonomous sexual desire in the novel is in ecstatic celebration of news about her husband Gikonyo's release from prison delivered by the community's public enemy, Karanja, the pro-British homeguard. A deliriously happy Mumbi has sex with Karanja, and the narrative punishes this indiscretion by making her conceive from this fall from the chaste waithood expected of what South African scholar Mamphela Ramphele (1996) would later term political widows. Equally, Achebe's most strongminded and complex female character, Beatrice in Anthills of the Savannah, remains a behind the scenes feminine presence that holds together the friendship between Chris and Ikem; and her sexual encounters with Chris are overshadowed by her spiritual side, betraying narrative anxiety about female erotic experience. Secondly, the restraint in depictions of female desire evident in early generations of Black women's writing may be understood as overdetermined by perceptions about Black female bodies, against which women writers felt inclined to write.

In her exploration of sexual love in women's blues music, Angela Davis notes that blues women indexed the sexual freedom that came with emancipation, where Black people could, for the first time, exercise choice in sexual relationships $(1988$, 4). But 'given the extent to which representations of black inferiority [...] were bound up with notions of racial hypersexualisation', there was much pressure to embody sexual purity and 'almost entirely deny sexual agency' (44), in pursuit of hegemonic respectability. This anxiety of respectability as a counter to long histories of exploitative hypersexualisation may equally explain African women writers' abstinence from narrative celebration of female sexuality and embodied pleasures, as the same discourses used to legitimise white male sexual access to Black women's bodies were duplicated in colonial Africa, alongside feverish Black peril anxieties about the imagined danger Black men posed to white women. (In Kenya for instance, British and American fiction writers obsessed about the threat of rape Mau Mau posed for white women, even though there is no historical evidence of this. On the contrary, there is historical evidence of both rape and consensual 
relations between white men and local women, most famously the case of British troops accused of decades of rape of Maasai women in Laikipia region - see Day and Patterson (2003)). It is unsurprising then, that while love stories make an earlier appearance in the African canon, female sexual desire would be a late entrant to the page, primarily spurred on by queer discourse across the continent - which centred female sexual desire and pleasure - coupled with the uptake of chick lit by African writers, a genre which takes women's desires seriously, even though it continues to be treated as the aesthetically poor cousin to canonical literature. Thus, in canonical African letters, while Buchi Emecheta's Joys of Motherhood (1979) features a transgressive Ona, and Rebeka Njau's Ripples in the Pool (1978) addresses queer desire through Selina, the full narrative possibilities of women like Ona and Selina who occupy their respective sexual bodies transgressively would be largely postponed by decades. These women would be reincarnated in figures like Akai Ma in Yvonne Owuor's Dust, who embraces her sexuality, moving in and out of hetero-patriarchal intimacies at will, with full authorial endorsement. Increasingly, a growing body of male- and female-authored African writing foregrounds women's sexual desire and their conceptions of freedom as primary concerns. Lola Shoneyin's The Secret Lives of Baba Segi's Wives (2010) is a sustained meditation on women's desires and conceptions of freedom pursued within the cracks of heteropatriarchy's institutions of polygamy and compulsory motherhood. Equally, Chimamanda Ngozi Adichie's Ifemelu in Americanah (2013); Ayobami Adebayo's Yejide in Stay with Me (2013); and Folasade in Taiye Selasi's Ghana Must Go (2013) are examples of what the later novel terms dangerous dreamer-women "who looked at the world through their wide dreamer-eyes and saw it not as it was, "brutal, senseless," etc, but worse, as it might yet become [...] insatiable women' (Selasi 2013, 48-49).

It is important to reiterate that even though earlier African writing offered limited options for insatiable dreamer-women, contemporary dreamer-women, to some degree, trace their lineage back to flashes of desiring women in earlier writing. In this regard, I see Yvonne Vera's Phephelaphi in Butterfly Burning - whom I discuss in detail shortly - as a descendant of Muthoni in Ngũgĩ wa Thiong'o's The River Between. Keguro Macharia reminds us that Muthoni's two memorable utterances in the novel both revolve around her desire to determine her identity and sense of self. In the first instance, she whispers to her sister, Nyambura: 'I-I want to be a woman. I want to be a real girl, a real woman, knowing all the ways of the hills and the ridges' (Ngũgĩ 1965, 26). In the second, her last utterance before she dies, she addresses Waiyaki, the novel's protagonist: 'tell Nyambura I see Jesus. And I am a woman in the tribe' (53). It is possible to read Muthoni as prefiguring Vera's Phephelaphi in Butterfly Burning, as a woman similarly trapped between colonial modernity's patriarchal prescripts and indigenous patriarchy's assumptions about the scope of women's aspirations. Like Phephelaphi, Muthoni's attempts to articulate her aspirations by braiding together the two value systems reach a fatal cul-de-sac, but their respective gestures of reaching for freedom on their own terms remain indelible.

My chapter's coupling of erotic desire, love and articulations of freedom takes its cue from the work of Robin G. Kelley, bell hooks and Keguro Macharia, as three scholars who variously insist on the erotic as liberating. For bell hooks, contrary to popular perceptions of political desire for change as separate from everyday longings and passions, 'our desire for radical change is intimately linked with our desire to experience pleasure, erotic fulfilment, and a host of other passions' (1990, 13). In similar vein, Robin G. Kelley's meditation on historical movements' fashioning of Black freedom emphasises the place of joy, pleasure or what he calls the ecstatic, in crafting 'cognitive maps of the future' $(2002,10)$. The ecstatic, Kelley writes, creates 'a world of pleasure, not just to escape the everyday brutalities of capitalism, patriarchy, and white supremacy, but to build community, establish fellowship, play and laugh and plant seeds for a different way of living' (11). On his part, Keguro Macharia emphasises the centrality of love to 
liberatory politics: 'fights against injustice are also fights against the lovelessness that buttresses injustice' $(2015,68)$. Yet Macharia cautions that 'images of idealized loving' in the shape of 'the white, middleclass family,' are central to the technologies of 'policing love [while] establishing and sustaining claims about difference'. These technologies 'hierarchize loving and lovability, imbuing dominant groups with the capacity to elicit, cultivate, and embody love while claiming that minoritized groups do not know how to love properly, if at all' (68). Describing love as a leaky, promiscuous concept that 'interrupts the ostensible distinction between the public and the private, the personal and the social', Macharia echoes Fanon's and hooks's caution on the impossibility of love in contexts of inequality (69), and by extension, unfreedom. In this vein then, as Phyllis Taoua would remind us, following Orlando Patterson, the idea of freedom 'emerged from the depths of unfreedom, as an aspiration held by those dispossessed of this most precious human right' (Taoua 2012, 13); a right that, in colonial Africa, was deemed 'the prerogative of "civilised" people' (Young cited in Taoua 2012, 14).

One of the ironies of the culture of modernity, Simon Gikandi writes, is that 'even in the era of colonization and enslavement, it sought to promote a universal narrative of freedom and rights, even as it recklessly promoted ideologies of difference' $(2000,24)$. These ideologies of difference form the bedrock of Sylvia Wynter's meditation on the idea of the human as synonymous with the Western bourgeois Man, and what she calls Man's overrepresentation. Wynter unpacks this irony by outlining the shift in European thought from medieval theocentric definitions of the human to what she calls the secular globally hegemonic ethnoclass Man, sustained by the trinity of 'African enslavement, Latin American conquest and Asian Subjugation' (Wynter 2003, 263). This ethnochauvinist definition of the human transformed the indigenous peoples of the Americas and enslaved Africans into 'the physical referents of its reinvention of medieval Europe's Untrue Christian Other to its normative True Christian Self, as that of the Human Other to its new "descriptive statement" of the ostensibly only normal human, Man' (265). In effect, if colonial modernity's selective distribution of 'universal' freedom and rights is paradoxical, as noted by Gikandi, this paradox is definitive of the succour drawn by colonial modernity from discourses and institutions of difference whose fictive universality had to be maintained by compelling the excluded to aspire to its ostensibly universal ideals, freedom being core among these.

In the face of the unfreedom that was colonial subjection and its de-humanisation, it is unsurprising that Black nationalism across the Third World was understood as articulating 'the all-embracing crystallization of the innermost hopes of the whole people' (Fanon 1967, 119). Indeed, Wynter nods to anti-colonial movements as the first phase of the struggle to redescribe the human 'outside the terms of the present descriptive statement of the human, Man, and its overrepresentation' (Wynter 2003, 268); a struggle that was coopted and compromised, but nonetheless remains historic.

Commenting on the power of oppressive systems to co-opt our capacity to nurture what he calls 'freedom dreams', Kelley concedes that often, 'what we are against tends to take precedence over what we are for', in part because 'the conditions of daily life, of everyday oppressions, of survival, not to mention the temporary pleasures accessible to most of us, render much of our imagination inert' $(2002,10-11)$. Yet the capacity to imagine different futures remains indispensable to the project of freedom: 'the most radical art is not protest art but works that take us to another place, envision a different way of seeing, perhaps a different way of feeling' (11). In this chapter, I build on the scholarship explored in the preceding discussion, coupled with Audre Lorde's ideas on the power of the erotic and elements of affect theory to illustrate the ways in which Yvonne Vera's engagements with the freedom dreams of nationalism and its betrayals offer a radical imagination of alternative futures for her women characters. 
In 'Independence Day', a brief vignette about what the end of colonial rule meant for Zimbabwean men and women, Vera narrates the day's ceremonies through the eyes of an unnamed man and woman, who meet on the streets on independence day, waiting to see 'the Prince who had come from England to give their country back to them' (Vera 1994, 26). Watching the dancing women and the policemen controlling the crowds on the streets, the woman repeatedly 'takes shelter in the green space in her head' (26), already alienated from the euphoria of ostensible freedom. Later that evening, at the man's house, they watch the ceremony on TV, where the new Prime Minister promises change: 'jobs and more money. Land and education. Wealth and food' (28). The man's anticipation of this magical future is palpable. He carefully choreographs his personal celebration of independence to parallel the ceremony unfolding on TV:

He was going to celebrate Independence properly: with cold beer and a woman. Now it was ten minutes to midnight. She must take her clothes off. The screen flashed the ticking minutes. The Prince and the new Prime Minister walked to the large flagpole in the middle of the stadium. The old flag was flapping in the air, the new one was hanging below. The man pushed the woman to the floor. He was going into the new era in triumph. She opened her legs. It was midnight, and the new flag went up. The magic time of change. Green, yellow, white. Food, wealth, reconciliation. When he was through he sent her home. When he awoke he preferred the whole house to himself.

If we glance backward to Vera's portrait of Zimbabweans' longing for freedom the height of colonial subjection - where 'the people walk in the city without encroaching on the pavements from which they are banned; [understanding] something about limits and the desire this builds in the body' (Butterfly Burning, 1998, 6); and buildings' corners, ekoneni, form rendezvous spots for lovers who 'cannot meet inside any of the buildings because this city is divided; entry is forbidden to black men and women' (The Stone Virgins, 2002, 11) - then we will immediately note that the woman in the story, lowered to the ground in step with the old flag, remains trapped in pre-independent unfreedom, albeit under a new flag, while the man triumphantly welcomes the promised magic time of change. The flag pole, whether holding the old flag or ushering in the future, remains a phallic witness to male conquests and defeats embodied by the tripartite fraternity of the Prince, the new Prime Minister and the man. In Vera's last novel The Stone Virgins - set in the years immediately after Zimbabwe's flag independence, Sibaso, a veteran soldier who joined the anti-colonial war fuelled by nationalist dreams of freedom, returns from the forest in 1981 with a terrible appetite for harm. In the tense moments preceding what would come to be known as the Matabeleland massacres, Sibaso attacks two sisters in the Matabeleland village of Kezi, raping Nonceba and beheading Thenjiwe. Sibaso, 'a predator, with all the fine instincts of annihilation' (Vera 2002, 69), is a broken variant of the man in 'Independence Day'; sexually spewing the traumas of anticolonial war that have left his mind 'perforated like a torn net' (82) onto Nonceba's body. Independence exacts an exorbitant price on both the woman's and Nonceba's bodies; reminding us that women, in Meg Samuelson's phrasing, 'bear the symbolic [and literal] weight of nationalism' $(2007,2)$.

The man's staging of his personal theatre of power, freedom and pleasure on the woman's body is hardly new in the pages of the African literary canon and beyond, in the social world. The man's ancestry stretches from Peter Abrahams's Udomo and Mhendi in A Wreath for Udomo (1956) whose anticolonial struggles are rewarded with sexual access to the bodies of young women; to Ousmane Sembène's El Hadji Abdou-Kader Beye in Xala (1976) who is struck with 
erectile dysfunction on the night he takes his third bride to celebrate his ascent in the chamber of commerce; all the way to David Lurie's sexual misadventures in J. M. Coetzee's Disgrace (1999). Cutting across racial, regional and temporal contexts is the phallocrat's predatory conscription of women into sexual transactions from which their desires are exiled; a trend that has in recent years seen various predatory figures of authority in arts and culture - including a prominent man affiliated with the Nobel Prize Committee and Pulitzer Prize winning novelist Junot Diaz - named, under the \#MeToo movement against sexual harassment. ${ }^{1}$ Equally, Desiree Lewis observes, 'ascendant manhood has come to signify reclaimed pride of the entire community' while polygyny stages a 'theatrical display of patriarchal authoritarianism' (2011, 211-213), most recently in the shape of South African president Jacob Zuma's and his Swaziland counterpart King Mswati's penchant for marrying. In these scenarios, state power gets framed in phallocratic registers, all centred around male sexual performance and pleasure. What Simon Gikandi has termed 'arrested decolonization' (2000, 99) in his reading of Ngũgĩ wa Thiong'o's $A$ Grain of Wheat, is often understood as the betrayal of collective freedom dreams, to borrow Kelley's term; but for women, the seeds of this betrayal were already germinating within liberation movements, as Shireen Hassim's (2004) work, as well as a growing body of biographies of women's experiences of sexual violation and silencing within anti-colonial movements such as the African National Congress, illustrates. Given long histories of Black women's sexual energy being appropriated by white and Black men alike, at will, what does freedom mean to women? What scope exists for women's self-inscription in erotic encounters? How does the erotic articulate their conceptions of freedom?

In 'Independence Day', Vera already begins to problematise men's and women's divergent conceptions of freedom; underlining women's exile from the freedom that comes with flag independence as too deeply infused with the toxic cocktail of British and indigenous African patriarchies. The richly allegorical layers of the story lay the groundwork for Vera's subsequent meditations on this exile of women's desires from both sexual encounters and nationalist conceptions of freedom. I propose that in her subsequent writing - most remarkably Butterfly Burning and The Stone Virgins - Vera repeatedly returns to this woman and paints different versions of the possibilities she envisions in the green space she retreats to in her head, crafting different registers with which to articulate her ideas of freedom. Vera further recalibrates the woman's stake in the sexual encounter, rescripting her as a subject who conceptualises freedom through a delicate balance between a still-nascent practice of self-love and erotic encounters with men who are variously invested in the nation project and its promised patriarchal dividends. The rescripted woman's attempts can hardly be termed successful; in Muponde and Taruvinga's words, 'what survives is not necessarily the freedom seeker herself, but the memories of the struggle' (2002, xi).

\section{Exiles from the future}

In her critique of Frantz Fanon's portrayals of women in his work, bell hooks laments that 'not only is the female body, black or white, always a sexualized body and not the body that "thinks," but it also appears to be a body that never longs for freedom' (1996, 84). Even as sexualized bodies, various discourses at different historical junctures have conspired to alienate Black women from the three conventional possibilities of sexual encounters - reproduction, pleasure and intimacy - by prioritising male enjoyment of all three, underwritten by varied combinations of racist, capitalist and patriarchal systems. As Nkiru Nzegwu explains, Western intellectual traditions of the erotic privileged men's desires, reducing women to objects, rather than subjects, of pleasure; and producing the virtuous woman as 'pure, chaste and monogamous 
[while making] eroticism and sexuality a basis for women's moral anguish, conflict and downfall' (2011, 254-255). This lay the foundation for not only Christianity and chattel slavery's projections of lasciviousness on Black bodies - thus rendering them legitimate targets for sexual and other forms of violence - but further, imperialism racialized sexuality worldwide, and colonialism, apartheid and corporate globalization reconstituted only white women into paragons of purity and beauty and deserving of love and affection, and fetishized non-white bodies as expendable and worthless' (255). In Kate McCullough's phrasing, Black women became 'the cultural repository of all of the white bourgeois lady's denied sexuality' (1996, 22). Black women found themselves doubly alienated from their sexual desires by the legitimisation of sexual violence against them and projections of sexual purity as a prerequisite for affection and respect.

To a large extent, hooks's assessment above holds true for much canonical African writing, whose representations of Black women - sharply critiqued by Florence Stratton for its textualisation of women's lives and struggles as allegories of national narratives - rarely imagines female thought, desire and personal freedom; and when it does, it is rarely conceptualised outside the hetero-patriarchal parameters of nationalist thought. Indeed, as Desiree Lewis remarks, 'discourses of national belonging have been anchored in familial scripts and the invention of nations as biological families [through whose] familial frame the "natural" reproduction of communities and the "rightful" belonging of individuals within collectivities are assured' (2011, 211). Predictably then, in much of post-independence Africa, women's and sexual minorities' full citizenship and enjoyment of the much-anticipated freedom remained indefinitely postponed. The irony of this situation lies in the sacrifices of women's lives and bodies - both literally and metaphorically - to the anti-colonial pursuit of freedom. Yet women's desires broadly, and particularly their desire for freedom, has consistently been exiled from the frame of the nation project. This is remarkable when we remember, with Susan Andrade, that despite its 'defensive engagement with cultural nationalism, African feminist literary criticism has always included within its self-understanding a strong component of the advocacy of cultural nationalism' $(2011,72)$.

Signe Arnfred's introduction to her edited essay collection Re-thinking African Sexualities notes the limited attention sexual pleasure and desire - and particularly female sexual pleasure - has received, considering the centrality of sexuality and desire 'in establishing the very notion of Africa and Africans' (2004, 20). Elsewhere, in her mapping of the intertextual conversation between Mariama Bâ's So Long a Letter and Sembène's Xala, Susan Andrade emphasises Bâ's contention that 'romantic idealism and faith in and practice of true love is the only way out of the brutal economy of commodification, the buying of labor and traffic in desire [and] vulgar materialism' $(2011,96)$ that Sembène satirises in Xala. Important to note here is that this emphasis on love, desire and its ethics remains invested in the fate of the collective, rather than celebrating an individualist ethos; since, Andrade writes, 'Bâ appears to diagnose the nation's ills as stemming not from social structures, but from the individual venality of powerful men with insufficient love for the country's people' (95). This bridging of romance, love and the nation, both within and outside a nationalist allegorical framing, is important in the ways it counters the tendency towards trivialisation of affect and desire as either too personal to be of political relevance, or too individual, and, implicitly, too 'feminine', to register as valuable in a largely hetero-patriarchal value system. In this context, I am struck by the ways in which Bâ, like her literary daughter, Vera, rejects the dichotomy and equally strongly counters the excising of women's affect and desires from intellectual transactions on freedom.

Yvonne Vera is one of the first canonical African writers to foreground the erotic as holding the promise of personal freedom and self-love for women, in and of themselves; and not as 
symbols of the nation, nor as metaphors for moral and economic degeneracy as in the ubiquitous prostitute trope in African writing. Given the aforementioned history of discourses that have swirled around Black female sexuality - whether as excessive and therefore in need of taming; or as metaphors that celebrate (maternal) female sexual purity - and given the feminist battle for women's lives to be understood through both the mind and the body, as opposed to the previous Cartesian split that locked women's lives in a corporeal closet, embracing and defending the erotic and forms of self-love as part of a radical project of freedom represents a fascinating break with much of the existing and accepted discourse on Black women's sexual bodies continentally.

Fanon's answer to his question - what does the Black man want? - posed in Black Skin White Masks (1967) - takes different shapes at different points in his work. Remarkable for our purposes is his implied response to this question in The Wretched of the Earth: 'the look that the native turns on the settler's town is a look of lust, a look of envy; it expresses his dreams of possession - all manner of possession: to sit at the settler's table, to sleep in the settler's bed, with his wife if possible' (Fanon 2001, 29). The all-inclusive 'dreams of possession' seem central to the Black man's envisioning of freedom. But for the Black woman, this vision of freedom becomes as difficult to render across the gender line, as the racial equation 'not only must the black man be black, he must be black in relation to the white man' (Fanon 1967, 110) is, in Fanon's thinking, impossible to conceptualise in reverse. If Black women's freedom dreams remain interdicted in colonial-style discourses about their bodies and absent futures as 'Independence Day' eloquently illustrates, then a partial answer to the question - what does the Black woman want?- might not be all manner of possession, like the Black man, but rather, self-possession, as Vera proposes. And while Vera's female characters are yet to articulate their desires with the same eloquence as Fanon's Black man's dreams of possession, their imagination is clear about the quality of freedom they desire and their willingness to pay the price. This selfpossession becomes a particularly urgent task not only given the much-lamented nationalist prioritisation of the race's freedom over gendered freedom, but also in view of Audre Lorde's reminder about the kinds of gendered vulnerabilities that attend the solidarities of (nationalist) struggles, what she calls the 'the fear of the ex-comrade':

When a people share a common oppression, certain kinds of skills and joint defenses are developed. And if you survive, you survive because those skills and defenses have worked. When you come into conflict over other existing differences, there is a vulnerability to each other which is desperate and very deep ... when you share a common oppression you have certain additional weapons against each other because you've forged them in secret together against a common enemy. [This] is the fear of the ex-comrade.

(1984, 99-100)

Lorde's cautionary note here in some senses materialises in Vera's writing, with tragic results; particularly when women register their disillusionment with the framings of freedom around relationships to land and state power that disarticulate with their conceptions of freedom; and if anything, often end up displacing the hitherto shared colonial violence onto women's lives and bodies, in the shape of patriarchal violence. In effect, the fear of the ex-comrade renders women exiles from the future - a different kind of exile from the one envisioned by Sol Funaroff's poem 'The Bellbuoy' (2002) in the lines 'I am that exile from a future time / from the shores of freedom / I may never know.' Funaroff had in mind freedom fighters' unshakeable conviction about the rightness of the cause they fought for, even when they knew they were unlikely to live to experience these futures. I riff off his poem to think about Black 
women as exiled from the promise of freedom, right from Independence Day, not because they don't live to see it, but because the threads of their betrayal are already woven into the fabric of the free future as envisioned by cultural nationalism. They remain beached in colonial time and its unfreedom.

\section{What is freedom to me? Nostalgia for the future}

Contemporary scholarship on affect theory disrupts the Cartesian binary between emotion and rationality, by reminding us that 'affect and cognition are never fully separable - if for no other reason than that thought itself is a body, embodied' (Seigworth and Gregg 2010, 3). For the longest time, affect as a mode of knowledge provoked much anxiety in both Black and feminist circles, in large part because of this Cartesian hierarchy between rationality and emotion. 'Emotions,' Sara Ahmed writes, 'are associated with women, who are represented as "closer" to nature, ruled by appetite, and less able to transcend the body through thought, will and judgement' $(2014,3)$. It is therefore remarkable that two constituencies against whom affect was marshalled as a technology of prejudice - Black people and women - have sought to reclaim affect as a legitimate cognitive resource. In African literary circles, Senegalese poet and thinker Leopold Sédar Senghor remains the foremost proponent of Black affect, most memorably in his lyrical poem 'To New York' which juxtaposes a coldly mechanised Manhattan with the lifeaffirming warmth of Harlem. Senghor's racialised dichotomy between reason and emotion came in for sharp barbs from Fanon:

I had rationalized the world and the world had rejected me on the basis of colour prejudice. Since no agreement was possible on the level of reason, I threw myself back toward unreason. It was up to the white man to be more rational than I ... Emotion is completely Negro as reason is Greek.

(Fanon 1967, 124, 127)

An equally firm critique could be made of Audre Lorde's remark that 'the white father told us, "I think therefore I am," and the Black mother within us - the poet - whispers in our dreams, "I feel, therefore I can be free"' $(1984,38)$; but her thoughts on the reclamation of affect for women remain instructive.

In 'The Uses of the Erotic', Lorde defines the erotic as 'a resource within each of us ... firmly rooted in the power of our unexpressed or unrecognized feeling' (1984, 53), systematically distorted by oppressive systems which recognise its transformative energy. For Lorde, racist and patriarchal systems have encouraged women to suppress their erotic power in exchange for the promise of strength which is nonetheless illusory precisely because this ostensible strength is patriarchally defined (53). Lorde insists that the erotic has been used against women - 'we have been taught to suspect what is deepest in ourselves, and that is the way we learn to testify against ourselves, against our feelings' (102) - precisely because once acknowledged and honestly explored, women's deep reserves of creativity, power, emotion and feeling:

become sanctuaries and spawning grounds for the most radical and daring of ideas. [Within] living structures defined by profit, by linear power, by institutional dehumanization, our feelings were not meant to survive. Kept around as unavoidable adjuncts or pleasant pastimes, feelings were expected to kneel to thought as women were expected to kneel to men.

('Poetry Is Not a Luxury', in Lorde 1984, 36-39) 
Lorde's observations on the erotic chime with Seigworth and Gregg's insights on affect. Their definition of affect as 'visceral forces beneath, alongside, or generally other than conscious knowing ... that can serve to drive us toward movement, toward thought and extension' $(2010,1)$; coupled with their insistence on affect's propensity to 'exceed the contexts of their emergence, as the excess of ongoing process' offers fine resonances with Lorde's perspectives on the erotic.

If as Lorde has it, the erotic 'is an internal sense of satisfaction' to which we can aspire because 'having experienced the fullness of this depth of feeling and recognizing its power, in honor and self-respect can require no less of ourselves' ('The Uses', 1984, 54), then Phephelaphi, the protagonist in Yvonne Vera's Butterfly Burning, experiences this depth of feeling, which compels her to imagine different registers of freedom beyond what is considered accessible for women in colonial Bulawayo.

Set in Bulawayo in the 1940s, Butterfly Burning is a tragic love story between an ambitious young woman, Phephelaphi, eager to chart a life path that precludes dependence on men through sex work, and an older man, Fumbatha, descended from a revolutionary paternal lineage which he is keen to continue by having children with Phephelaphi, even though this will foreclose her dreams of getting into nursing school. Born in 1896 - the same year his father is hanged alongside sixteen other men - a message is whispered into Fumbatha's clenched hand: 'a single seed gives birth to seventeen more, to a thousand more' (Vera 1998, 13). This prophesy of regeneration pertains to progeny and the spirit of resistance, both of which Fumbatha fails to reproduce. When, at the age of fifty he meets and falls in love with the nineteen year old Phephelaphi in Makokoba Township, Bulawayo, Fumbatha wants to hold her with the same desperate passion with which he wants the land beneath his feet (34). She soon moves in with him, and they spend two passionate years together in his tiny one room home. In the same year they meet, 1946, the state lifts the ban on Black women training as nurses; and Phephelaphi decides to apply for this opportunity, much to Fumbatha's displeasure: 'We are happy together. I work. I take care of you. It is not necessary for you to find something else' (70). But unknown to Fumbatha, she nurses what she variously describes as a burning longing, a desire, a hunger, an ache, which she initially cannot name, except to note that 'Fumbatha could never be the beginning or end of all her yearning, her longing for which she could not find a suitable name' (74). In the end, she names it: 'finding herself, that was it. [She] wanted a birth of her own' (74).

On her occasional visits to the neighbourhood shebeen owned by a notoriously courageous woman named Deliwe, Phephelaphi is introduced to Kwela music, the soundtrack of urban Bulawayo in the late 1940s; and she is drawn to Deliwe's defiance against the police and the township's commonsenses alike. On her first visit, the young woman is transfixed by 'the bliss, the ecstasy, the freedom spreading its wide wings over Phephelaphi's body as she stood watching [Deliwe]' (63). The soundtrack of the city is a simultaneous encoding of resistance and surrender which somewhat mirrors Deliwe's tough embrace: 'Kwela. This word alone has been fully adapted to do marvelous things. It can carry more than a word should be asked to carry: rejection, distaste, surrender, envy. And full desire' (6). Lizzy Attree emphasises this contradictory yet elusive capacity of Kwela music as 'suggesting a relentless grasping of the promise of future happiness, an escape in music and dance that transforms space, body and mind' $(2002,73)$.

The shebeen and Kwela music are central to Phephelaphi's gradual articulation of self-love as an important facet of female conceptualisation of freedom. The woman Phephelaphi believes to be her mother is a sex worker named Gertrude - but known to her white policeman lover who shoots her dead, as Emelda. Unknown to Phephelaphi, her birth mother is Zandile, Gertrude's colleague and friend, who generously welcomes the nineteen year old to the home she shares with her current boyfriend, Boyidi. As she learns later, her birth mother gave her away in 
protest against this baby who did not want to be born; who had to be surgically removed from her womb, leaving her with a scar that would always stand between her and her future intimate partners.

Long before the notion of self-love had become the cliché phenomenon it is now, Yvonne Vera was exploring the links between self-love and female conceptualisations of freedom. On one of her visits to the shebeen, during which the stylish migrant labourers newly returned from Johannesburg swoon at her beauty, one of the men flirtatiously shares his views on love:

The man in the green suit said a woman is for loving. If you love a woman enough she will unburden herself. That is the sweetest woman there is, a woman who has been loved well enough. [He] looked at her directly and spoke to her alone. She looked away. She wanted to raise her voice loud and say that it was not like that at all, it was that a woman must love herself enough ... She believed this but could not say it. What kept her quiet was that she remained puzzled by one aspect of her belief, the question she could not answer was how a woman got to do that, how she got to love her own knees, kiss her own elbows, how she got to feel that she was all the breeze there is and all the mornings there are and all the loving there could be. And then seek something more which perhaps only another can provide, and love a man simply because she could.

(Vera 1998, 80)

Before Phephelaphi answers her question about how a woman can love her elbow, we encounter two other women in Butterfly Burning, whose prioritisation of male affection and care as self-defining elements lead to their collapse when their men fail to deliver on this desire. In the first case, we learn about a woman who 'swallowed a sewing needle before going to bed, all two inches of it and followed it with water' because a man she cared for 'had not smiled back when she did, not touched her wrist on the pulsing wanting spot she asked him to, not come back home one night, and the many nights that followed' (Vera 1998, 90). Elsewhere in the neighbourhood, we meet a woman who sits at her doorstep perpetually knitting, beside a burning candle, whatever the time of the day. This woman's senses abandoned her when:

her husband sold her to another man for the value of a bicycle wheel but she had refused to leave and instead, stood on that asbestos roof with no clothes at all to cover her own body and announced loud and clear that she preferred two bicycle wheels to one, and if anyone had two bicycle wheels to give her husband, she would leave not only the rooftop but the house and the foolishness of her husband.

(Vera 1998, 91)

In presenting these two women's collapse under the weight of spited attraction, Vera counters the notion of 'a well-loved woman' as imagined by the man in the green suit; by underlining the forms of vulnerability and affective violence that attend the prioritisation of another's love. Although we see these women through Zandile's eyes and not Phephelaphi's, we nonetheless notice the cautionary note they sound. These glimpses of insights illustrate Ranka Primorac's reading of the novel as a portrait of fragmentary time 'measured by moments of insight and failed attempts at self-realization' by women she christens iron butterflies who 'combine strength and vulnerability' (2002, 106, 102).

Phephelaphi's thoughts as she listens to the man in the green suit sketch a compelling portrait of her gradual awakening to self-love as central to her idea of self-realisation and freedom. Yet, in greater ways than even she realises, the seeds of these ideas are planted in Phephelaphi's mind 
earlier, from watching her adoptive mother, Gertrude. In a childhood game, Gertrude, 'lifted her arm loosely like a rope and brought her elbow round to her ear and listened to it [as though] there was a message there' (Vera 1998, 76). Because the young Phephelaphi could never move her arm all around, she listened to the message in Gertrude's arms: 'She heard the hollow fluttering of wings' (76). Even as an adult, Phephelaphi is unable to move her arm like that, 'it was the sort of lightness that belonged solely to Gertrude [alongside] the sparkling reckless warmth that flowed from Gertrude's long endless arms' (76-77). Phephelaphi's inability to listen to the message in her elbow like her mother may be an invitation for her to chart a different course for her life, from both Gertrude and Zandile.

Although Phephelaphi does not judge either woman's work, she aspires to a different trajectory in life; a different set of relationships to men. When the policeman who shoots Gertrude hands back her favourite dress that 'pronounced the ooze and flow of all her energy' (76), Phephelaphi burns the dress - which, like the man's suit, is green - because she could not bear 'wearing another woman's wound' (77). In rejecting the dress, Phephelaphi rejects her mother's death, choosing her own, which is equally spectacular: she gains admission to the nursing college, but soon discovers she is pregnant, and the college does not admit pregnant or married applicants. Phephelaphi aborts her baby in a long and excruciating process. She shares her secret with Deliwe, who tells Fumbatha. She soon falls pregnant again. Fumbatha vindictively has an affair with Deliwe, who spitefully comes to tell Phephelaphi about the affair in person. Shattered by this double betrayal and the impossibility of pursuing her nursing dream now, Phephelaphi douses her body in kerosene and sets herself and her unborn baby alight; timing her suicide to coincide with Fumbatha's return from work. It is only in death that she listens to the message in her own arm: 'in flight like a bird, laden with the magnificent grace of her wings ... brimming with a lonely ecstasy gathered from all the corners of her mind' (Vera 1998, 35).

Primorac remarks on two ironies in the novel: firstly, that Fumbatha's tender love constrains her, while the oppressive Rhodesian regime holds the promise of fulfillment, illusory as it may be. The second irony is that where much African writing tends to chart the path of women's mental growth, for Vera's women who possess clear, mature minds, 'it is their bodies that they do not fully possess, and therein lies their tragedies' (Primorac 2002, 106-107). In the end, Phephelaphi's body conspires with the two patriarchal forces - a suffocating lover and a colonial regime intolerant of Black reproductive bodies - to stifle her dreams of self-realisation.

One reading of Phephelaphi's self-immolation would be to confirm her birth mother Zandile's earlier warning to her, when Phephelaphi rejects Zandile's gift of yet another dress:

You are not a man, Phephelaphi. ... Do you not know that a woman only has a moment in which to live her whole life? In it she must choose what belongs to her and what does not. No one can verify her claim except time. Makokoba is unkind to women like you who pretend to be butterflies that can land on any blossom they choose.

(Vera 1998, 129)

Read this way, her death would appear to be a spectacular act of surrender to time's refusal to verify her claim to freedom by, instead, exacting an impossible price for learning to love herself, and listening to the message in her elbows at last. In Violet Lunga's reading, Phephelaphi's death can be read as both the city's 'unreadiness for ambitious women like her' and an indictment of her failure to 'negotiate between freedom and circumscription' (2002, 193-194). Vera's decision to write the scene in a lyrical register risks veering into the terrain of what Alexander Weheliye terms the historical 'commonsensical twining of physical agony and enjoyment through the conduit of the Black female body' $(2008,325)$. However, the cumulative narrative 
empathy accrued across the novel towards the characters, most of all, Phephelaphi, nudges us to read the lyrical portrayal of her death as an authorial act of generosity, mobilising poetic language to honour the courage of her defiant surrender, which turns it into a transcendent surrender, an eloquent rejection of both colonial contempt for Black women's reproductive bodies and patriarchal circumscription of their desires.

In placing emphasis on the affective and imaginative power of desire as one of the currencies of freedom for her characters, Vera's writing invites us to embrace conceptual uncertainty; and accept the limitations of some of our available conceptual frameworks in making sense of women's affective worlds. Here then, Seigworth and Gregg's hopeful reminder about affect's possibilities bear remembering: 'affect's impinging/extruded belonging to worlds, bodies, and their in-betweens - affect in its immanence - signals the very promise of affect theory too: casting illumination upon the "not yet" of a body's doing, casting a line along the hopeful (though also fearful) cusp of an emergent futurity, casting its lot with the infinitely connectable, impersonal, and contagious belongings to this world' (2010,4).

In her last novel, The Stone Virgins, Vera returns to the theme of romantic love and women's articulations of romantic desire, sensuality and the erotic as sites of freedom. Through romance and popular photography, women stage freer versions of themselves that articulate their dreams of freedom which transcend the rigid colonial and patriarchal protocols that govern colonial Bulawayo. Confronted with buildings they may not enter and pavements they are forbidden to walk on, lovers meet at the corners of buildings - ekoneni - and visit photography studios where, 'another self flickers right past you while you stand still, and time stands still, and the self that you have prepared all week and now set free falls into the palm of your hand as easy as morning' (Vera 2002, 14). These women embrace 'the backdrop of sailing ships', seeing 'that sailing ship and that expanse of sea where her own body would fit and float and she would be as far from herself as she ever could be, as well travelled as the camera confirms' (15). Samuelson describes the city's promise of the freedom to fashion to the self and the simultaneous exclusion (2007, 24).

These grammars of the city lay the foundation for Thenjiwe's love story later in the novel, in the little village of Kezi, outside Bulawayo. While the primary narrative in the novel revolves around the build up to, and aftermath of, the Matabeleland massacre that spanned six brutal years, Vera offers Thenjiwe's passionate love affair with Cephas, a museum curator from Bulawayo, as one of the counterpoints to the weight of history. If as Driver and Samuelson argue through the title's nod to precolonial practices of young women accompanying kings into the afterlife, as memorialised in rock paintings - Vera gestures at Zimbabwean women and men's sacrifices, 'where lives and livelihoods were given up in the interests of a liberation, national harmony and prosperity that did not in fact materialize' (Driver and Samuelson 2002, 102-103), then the passionate romance between Thenjiwe and Cephas is a sliver of alternative bonds based on reciprocity and shared passion.

Vera's narration of the two-month affair forms an interesting recalibration of the encounter between the man and woman in 'Independence Day'. When they meet at the local store, Thandabantu - which also serves as the last stop for the Kezi-Bulawayo bus on which the man had randomly hopped to explore the region, and return to the city the same day - the encounter is alternately narrated from Thenjiwe's perspective, then Cephas'. As she walks to the store, Thenjiwe notices a man watching her; and together, they begin a wordless courtship dance, having recognised the desire in each other's eyes. When Cephas quietly whistles, Thenjiwe 'forgives the desire sparkling in her own fine limbs as she hears each whistle penetrate the air and move in her direction' (Vera 2002, 34). Thenjiwe takes Cephas home, a short footpath walk away, because 'he gives her all her hips, embraces her foot, collects her shadow and 
places it right back in her body as though it were a missing part of herself $[\ldots]$ he frees the entire weight of her body' (38). In sharp contrast to the unnamed woman in 'Independence Day', this affair is reciprocal; Cephas treats Thenjiwe with deep passion and care; he imagines a future with her, recognises that she is not ready for that yet. And so, before he leaves, he bathes her in milk and lyrically pays homage to their love and passion.

Vera's narration of the passion between Thenjiwe and Cephas lays emphasis on the mutuality of their desire; and Thenjiwe's embrace of desire and sexual pleasure that is not defined by the institutions or protocols of hetero-patriarchal courtship or the pressures of revolutionary motherhood in service to the nation project. This brings to mind Nkiru Nzegwu's insistence that not only did African societies historically have expectations of sexual pleasure and fulfillment for both men and women, 'sensuality was neither pornographic nor the basis for women's subjugation and domination as was the case in Europe' (2011, 22). Nzegwu outlines the processes by which associations of the erotic with men was consistent with the patriarchal orders of pre-modern and modern European worlds' emphasis on controlling women's bodies and deeming the creative life force male (22). Subsequently, the 'European/Western conception of eroticism underwrites [understandings] of sexuality from a phallocentric position that emphasizes and legitimises the privileging of men's needs, desires and fantasies' (24). Against this background, Lorde and Vera's reclamation of the erotic as both pleasurable and freedom-articulating for women is remarkably transgressive, given these re-encodings of any desire and embrace of female sexual pleasure as demeaning, and in effect, unfreeing.

Through conceptions of love and desire as sites of freedom, Vera presents us with women whose pursuit of freedom is articulated through ideas of self-love and the erotic, in ways that insist on the transgression of the limits imposed by present marginality, albeit often with tragic results.

Herbert Marcuse argues for art's capacity to be both grounded in the social realities it comments on, while simultaneously using estrangement to mediate the 'emergence of a new consciousness and a new perception' $(1978,41)$; even as artistic visions of liberation are 'fractured by reality' (183). For him, art's vision of a better world 'remains true even in defeat' (47). In Vera's 'Independence Day', Butterfly Burning and The Stone Virgins, the respective women's desires for freedom appear to be thwarted. On her way home the next morning, the woman in 'Independence Day' 'saw miniature flags caught along the hedge: the old flag and the new' (1994, 29), underlining the postponement of women's freedoms, suspended somewhere between the colonial and postindependent time. Yet, she retains the green space in her mind, as a hopeful site of retreat, which Vera subsequently invites us into, in Phephelaphi's meditations on finding herself. While it is hard to ignore the horror of Phephelaphi's body wrapped in flames at the end of the novel - a scene based on an actual story of a woman who set herself alight, for reasons unknown to Vera - what remains is the novel's articulation of a different vision of freedom; one defined by Phephelaphi's concern with finding herself and embracing her dreams, over and above a loving relationship with Fumbatha. Read this way, Vera's fiction adds an important imaginative canvas to canonical African literary conceptions of desire and freedom in women's lives. And while these women may not attain these freedoms in their lifetimes, their articulations of nostalgia for different futures other than those offered by the socio-structural realities they find themselves in remains an important intervention in debates on women's freedoms.

\section{Note}

1 See The Guardian Books for the debate on Junot Diaz: www.theguardian.com/books/junot-diaz. Accessed 16 July 2018. See also www.newyorker.com/culture/cultural-comment/the-swedish-academ 
y-sex-scandal-and-the-illusions-of-the-nobel-prize-in-literature for the debate on the Nobel Prize Committee member's partner, French photographer Jean-Claude Arnault and his alleged history of sexual harassment. Accessed 16 July 2018.

\section{Works cited}

Abrahams, Peter. 1956. A Wreath for Udomo. London: Faber and Faber.

Achebe, Chinua. 1988. Anthills of the Savannah. London: Pan Books.

Adebayo, Ayobami. 2013. Stay with Me. Edinburgh: Canongate Books.

Adichie, Chimamanda Ngozi. 2013. Americanah. London: Fourth Estate.

Ahmed, Sara. 2014. The Cultural Politics of Emotion. 2nd edition. Edinburgh: Edinburgh University Press.

Andrade, Susan. 2011. The Nation Writ Small: African Fictions and Feminisms, 1958-1988. Durham, NC: Duke University Press.

Arnfred, Signe, ed. 2004. Re-thinking African Sexualities. Uppsala: Nordic Africa Institute.

Attree, Lizzy. 2002. 'Language, Kwela Music and Modernity in Butterfly Burning'. In Sign and Taboo: Perspectives on the Poetic Fiction of Yvonne Vera, edited by Robert Muponde and Mandi Taruvinga, 63-82. Harare: Weaver Press.

Boehmer, Elleke. 2003. 'Tropes of Yearning and Dissent: The Troping of Desire in Yvonne Vera and Tsitsi Dangarembga'. Journal of Commonwealth Literature 38(1): 135-148.

Coetzeee, J. M. 1999. Disgrace. London: Secker \& Warburg.

Cousins, Helen and Pauline Dodgson-Katiyo, eds. 2012. Emerging Perspectives on Yvonne Vera. Trenton, NJ: Africa World Press.

Davis, Angela. 1988. Blues Legacies and Black Feminism. New York: Vintage Books.

Day, Martyn and Jill Patterson. 2003. 'The Mass Rape of Kenyan Women by British Soldiers'. Law, Social Justice \& Global Development Journal 2. http://elj.warwick.ac.uk/global/issue/2003-2/day.html. Accessed 16 July 2017.

Driver, Dorothy and Meg Samuelson. 2002. 'History's Intimate Invasions: Yvonne Vera's The Stone Virgins'. English Studies in Africa 50(2): 101-120.

Emecheta, Buchi. 1979. The Joys of Motherhood. London: Allison \& Busby.

Fanon, Frantz. 1967. Black Skin White Masks. New York: Grove Press.

Fanon, Frantz. 2001 [1961]. The Wretched of the Earth. Penguin classics, translated by Constance Farrington. London: Penguin.

Funaroff, Sol. 2002. 'The Bellbuoy'. In Exiles from a Future Time: The Forging of the Mid-Century Literary Left, edited by Alan M. Wald. Chapel Hill: University of North Carolina Press.

Gikandi, Simon. 2000. 'Africa and the Idea of the Aesthetic: From Eurocentricism to Pan-Africanism'. English Studies in Africa 43(2): 19-46.

Hassim, Shireen. 2004. 'Nationalism, Feminism and Autonomy: The ANC in Exile and the Question of Women'. Journal of Southern African Studies 30(3): 433-455.

hooks, bell. 1990. Yearning: Race, Gender and Cultural Politics. Boston, MA: Southend Press.

hooks, bell. 1996. 'Feminism as a Persistent Critique of History: What's Love Got to Do with It?' In The Fact of Blackness: Frantz Fanon and Visual Representation, edited by Alan Read, 76-85. Seattle: Bay Press.

Kelley, Robin G. 2002. Freedom Dreams: The Black Radical Imagination. Boston, MA: Beacon Press.

Lewis, Desiree. 2011. 'Representing African Sexualities'. In African Sexualities: A Reader, edited by Sylvia Tamale, 119-216. Cape Town: Pambazuka Press.

Lorde, Audre. 1984. Sister Outsider: Essays and Speeches by Audre Lorde. New York: The Crossing Press.

Lunga, Violet Bridget. 2002. 'Between the Pause and the Waiting: The Struggle Against Time in Yvonne Vera's Butterfly Burning'. In Sign and Taboo: Perspectives on the Poetic Fiction of Yvonne Vera, edited by Robert Muponde and Mandi Taruvinga, 191-202. Harare: Weaver Press.

Macharia, Keguro. 2012. 'How Does a Girl Grow into a Woman? Girlhood in Ngugi wa Thiong'o's The River Between'. Research in African Literatures 43(2): 1-17.

Macharia, Keguro. 2015. 'Love'. Critical Ethnic Studies 1(1): 68-75.

Marcuse, Herbert. 1978. The Aesthetic Dimension: Toward a Critique of Marxist Aesthetics. Boston, MA: Beacon Press.

McCullough, Kate. 1996. 'Slavery, Sexuality and Genre: Pauline Hopkins and the Representation of Female Desire'. In The Unruly Voice: Rediscovering Pauline Elizabeth Hopkins, edited by John Cullen Gruesser, 21-49. Urbana, IL: University of Illinois Press. 
Muponde, Robert and Mandi Taruvinga, eds. 2002. Sign and Taboo: Perspectives on the Poetic Fiction of Yvonne Vera. Harare: Weaver Press.

Ngũgĩ wa Thiong'o. 1965. The River Between. London: Heinemann.

Ngũgĩ wa Thiong'o. 1968. A Grain of Wheat. London: Heinemann.

Njau, Rebeka. 1978. Ripples in the Pool. London: Heinemann.

Nzegwu, Nkiru. 2011. 'Osunality (Or African Eroticism)'. In African Sexualities: A Reader, edited by Sylvia Tamale, 253-270. Cape Town: Pambazuka Press.

Owuor, Yvonne. 2015. Dust. London: Granta Books.

Primorac, Ranka. 2002. 'Iron Butterflies: Notes on Yvonne Vera's Butterfly Burning'. In Sign and Taboo: Perspectives on the Poetic Fiction of Yvonne Vera, edited by Robert Muponde and Mandi Taruvinga, 101-108. Harare: Weaver Press.

Ramphele, Mamphela. 1996. 'Political Widowhood in South Africa: The Embodiment of Ambiguity'. Daedalus 125(2): 99-117.

Ranger, Terence. 2002. 'History has its Ceiling: The Pressures of the Past in The Stone Virgins'. In Sign and Taboo: Perspectives on the Poetic Fiction of Yvonne Vera, edited by Robert Muponde and Mandi Taruvinga, 203-216. Harare: Weaver Press.

Samuelson, Meg. 2007. Remembering the Nation, Dismembering Women? Stories of the South African Transition. Pietermaritzburg: UKZN Press.

Seigworth, Gregory and Melissa Gregg, eds. 2010. The Affect Theory Reader. Durham, NC: Duke University Press.

Selasi, Taiye. 2013. Ghana Must Go. New York: Penguin Press.

Sembène, Ousmane. 1976. Xala, translated by Clive Wake. London: Heinemann.

Shoneyin, Lola. 2010. The Secret Lives of Baba Segi's Wives. London: Serpent's Tail.

Stratton, Florence. 1994. Contemporary African Literature and the Politics of Gender. London: Routledge.

Taoua, Phyllis. 2012. 'Of Prisons and Freedom: Liberation in the Work of Assia Djebar'. World Literature Today 86(6): 12-18.

Weheliye, Alexander G. 2008. 'After Man'. American Literary History 20(1/2): 321-335.

Wynter, Sylvia. 2003. 'Unsettling the Coloniality of Being/Power/Truth/Freedom: Towards the Human, After Man, Its Overrepresentation - An Argument'. CR - The New Centennial Review 3(3): 257-337.

Vera, Yvonne. 1994. 'Independence Day'. In Why Don't You Carve Other Animals? Harare: Baobab.

Vera, Yvonne. 1998. Butterfly Burning. New York: Farrar, Straus and Giroux.

Vera, Yvonne. 2002. The Stone Virgins. New York: Farrar, Straus and Giroux. 


\title{
The forms of shame and African literature
}

\author{
Naminata Diabate
}

Okonkwo, the male protagonist of Chinua Achebe's Things Fall Apart (1959), took his own life for various reasons, including certain legal trouble and possible incarceration in the colonial prison for killing a court messenger, and perhaps because of shame. Although the third person narrator provides no access to the protagonist's feelings leading up to his death, it is clear that shame followed Okonkwo his entire life. Not only did his father's disgraceful life and shameful death haunt him until his final moments, but the encroaching effects of missionary intervention and of the colonial administration combined with other life challenges, such as the inadvertent killing of a clansman, erode Okonkwo's self-confidence. I start with this reference to Achebe's Things Fall Apart in order to make a point. Colonization as a source of shame for the colonized is a recurring theme in African literature, as Cilas Kemedjio reminds us in his analysis of shame and modernity in African literary fiction (1999). Shame is inextricable from the advent of modernity, albeit suspended, argues Kemedjio, because it creates in the native an acute awareness of the germinal defeat of being colonized by foreign powers, and of being subsequently abused and cheated by postcolonial leaders. ${ }^{1}$

Unlike Okonkwo, Fama, the protagonist of Ahmadou Kourouma's The Suns of Independence (1968), seems immune to the most important affect in the Malinke world. In a generalized Malinke context, 'death is preferable to shame,' an idea enshrined in one of its most cited proverbs. In response to Fama's oblivion, a marginal male character chides him for his failure to express shame in socially sanctioned ways: 'Tu ne connais pas la honte et la honte est avant tout, ajouta-t-il en reniflant' (Kourouma 1968, 16) "'You know no shame, and shame is what counts above all," he added with a snort' (Kourouma 1981, 8). The marginal nature of the character, combined with his young age, indicates that most social constraints in the world of the novel have been challenged - so much so that a young man is sufficiently empowered to address an old jeliw (griot), Fama, in a disrespectful way. Indeed, the after effects of westernization - cultural diversification, erosion of tradition, urbanization - afford a certain kind of agency to a postcolonial subject, such as Fama. Given his function as a jeliw, an oral genealogist, a mediator and an entertainer in Mande society, he would otherwise be held to certain societal expectations of decorum.

In his 1967 A Grain of Wheat, published a year before The Suns of Independence and six years after Things Fall Apart, Ngũgĩ wa Thiong'o restages an account of both individual and collective shame in the newly independent context. Throughout the novel, the reader encounters Mugo's honorable acts: he defended a pregnant woman who was being beaten to death and he went on 
a hunger strike in the British concentration camp. That veneer of heroism, however, darkens with Mugo's spectacular public confession that it was he who betrayed his comrade Kikiya during Kenya's anticolonial revolution in order to collect a reward. Mugo's shame stems from a psychical inadequacy because his betrayal is unknown to the collective, but his awareness of his failure to live up to the normative code of loyalty pushes him to exteriorize his shame. The unforgettable public confession of his shameful betrayal ultimately fails to free the community that executes him. Mugo's death thus constitutes an event of shame, which calcifies the already entrenched shame of colonization. Rather than reinforce the meaning of liberation, the dominant mood at the end of the novel, argues Bewes, "is not celebration, nor even "understanding," as Killam has it, but shame' (2010, 118). The world of the novel is thus steeped in shame and spares no one except the betrayed Kihika. The reading of shame as a dark cloud hanging over the novel (Bewes 2010) is insightful in light of the limited number of times (six) that the term 'shame' appears in the novel.

In the dynamic of shame, it may be ludicrous to attempt suppression of shame through death since the system that created the circumstances for the onset of shame remains unchanged. Speaking of Ngũgĩ's novel, Timothy Bewes demonstrates the impossibility of extracting shame for a true liberation story in the postcolonial context. In The Event of Postcolonial Shame, Bewes foregrounds the inherent deficiency of the postcolonial novel in fulfilling certain ethical expectations. Given that shame is a constitutive element of writing in the postcolonial context, the purging of shame from the experience of the colonized becomes an impossible task:

Shame is a quality of writing, it cannot exist outside writing or, more accurately, outside the relations of incommensurability that writing emblematizes; nor can shame be adequately encoded or conveyed within a literary apparatus. There is no shame without form; moreover, in a world of 'absolute sinfulness' there is no form without shame. Form materializes shame by its inadequacy.

(2010, 46)

Hence the impossibility of writing the postcolonial free of shame.

Is the aspiration to purge postcolonial shame through writing the sole option available? Can the postcolonial novel aspire to accomplish more than just the purging of shame? It is the latter question that this chapter engages through several novels, but most notably Ngũgîs 2006 Wizard of the Crow, which was published four decades after A Grain of Wheat. I argue that through the dictator novel, ${ }^{2}$ with its undoubtedly grotesque content and form, Ngũgĩ provides a more expansive understanding of shame in the postcolony, and how it reflects the everchanging nature of oppressive power and resistance to it. The ways in which shame is meted out by female shaming institutions and that temporarily inconvenience (but ultimately fail to unseat) the brutal dictator suggests Ngũgî's abandonment of the complex hero characters that we encountered in his previous novels. Ultimately, I seek to uncover the shifting grammar of shame in Ngũgĩ's writings and relatedly his espousal of a more moderate view of how positive socio-political change is to unfold. In the process, I engage with other scholarly accounts of shame in African literary studies and discuss Sony Labou Tansi's The Shameful State to focus on the actors, the shamed and the shamers, the actions that precipitate the shame as well as its expected outcomes. The insights from this exploration enable a deeper understanding of the changes in depictions of the triggers and outcomes of shame from the 1950s, the decade of the earlier Europhone African literary fiction, to the most recent ones.

In the light of an ever expanding list of cultural products that engage with shame directly or indirectly, several critical questions regarding the causes that precipitate shame, its outcomes, 
and its agents and victims ought to inform studies of shame in African literature. What actions, attitudes and events are represented as the preferred outcome to depictions of shame? In the works studied, is the emphasis on the actions which might precipitate shame, or on the shame rightfully or unjustly experienced by the protagonists of a narrative? To what extent should we see an emphasis on shame as the dominant affect, as a sign of the loss of confidence in rationality, or trauma, or plenitude as the more probable trigger for social reform? What entities/subjects (collective or individual) feel shame in the text? What do they feel shame about? What metaphors are used to depict the affect of shame? How should we interpret the distinction between justifiable and unjustifiable shame with respect to particular agendas?

\section{Shame as form}

Both a story of oppression and resistance to oppression, Wizard of the Crow is a novel that has many affective dimensions, not just shame, but also anger, joy, disappointment and fear. Specifically, the narrative includes the terms 'shame' seventeen, 'shameful' nine, 'shamed' two, and 'shameless' three times. What constitutes shame remains undefined, albeit important in the novel. In the diseased and fictional postcolonial nation-state, Aburiria, autocratically governed by one man, known only as the Ruler, the sprawling tale of tricksters and magic, heroic escapes and outrageous somatic diseases exposes both the plots of the Ruler's deluded and sycophantic ministers to keep the despotic rule intact, and those of their opponents, members of the underground resistance movement of which the titular character is a part. At the heart of the novel is the Ruler petitioning the Global Bank for funds to build the absurd and doomed Marching to Heaven, a latter-day Tower of Babel that will be, in the Ruler's vision, the world's first 'superwonder' and will allow him to communicate with God. Once a petty bureaucrat, the mighty Ruler comes to power with the help of the USA to depose the British-backed dictator. But the machinations of the despotic ruler fail to secure the loan from the Western lenders because the resistance models of the people increasingly challenge his oppressive mechanisms. Frustrated, the Ruler goes on a diplomatic mission to New York with the goal of convincing the lenders, who recommend he return home to attend to the increasingly bold resistance movement by Nyawira and the people. Consistently successful at embarrassing the despotic ruler, Grace Nyawira is Kamiti's girlfriend and the leader of the democratic underground Movement for the Voice of the People. A graduate with a BA in economics and an MBA earned in India (paid after arduous financial sacrifices by his parents), Kamiti wa Karimiri returns home to a series of unsuccessful job interviews and bouts of hunger that lead him to forage in mountains of garbage. After three years in this predicament and during an unsuccessful and humiliating job interview at Tajirika's Eldares Modern Construction and Real Estate Company Kamiti meets Nyawira, Tajirika's secretary, who becomes his love interest and political ally.

One grotesque story, rumor and machination after another, the Ruler is finally deposed by Tajirika, the new Minister of Defense, who plots with Wonderful Tumbo and three bearded spirits. Not surprisingly, the overthrow of the Ruler fails to bring Aburiria the long-awaited freedom from autocracy, mismanagement and corruption as Tajirika declares baby D (democracy) dead, and the country an empire. He even names himself Emperor Titus Flavius White Head. True to his ideological position of opposing dictatorship, Ngũgi ends the multigenerational novel with Nyawira and Kamiti promising to continue fighting for freedom.

My exploration of shame takes into account both the shamers and the shamed. In the novel, 'shame' and associated terms - humiliation, which appears more than 40 times, embarrassment used 26 times, disgrace and dishonor - are used to designate the actions and behaviors of actors from across the social and political landscape. Unlike more recently published novels by 
diasporic African women's writers in which shame is often gendered female, ${ }^{3}$ in Wizard of the Crow, shame is not gendered, nor is it age specific. No one, independently of their social and political positioning, is immune to the feeling of inadequacy. Men as well as women, rulers as well as subordinates, young as well as old characters are all subject to shame, although they express it differently. However, it is important to note that in this novel, women are the ones with the authority, the power and the agency to shame both animate and inanimate others. Such authority and agency of womanhood to produce shame in others reflects the widespread accounts of masculinity, and the expectation that men have a deeper sense of shame. That gendered framing of shame de facto subordinates women to men and the slave to the noble (Broqua and Doquet 2013). Kemedjio uncovers a similar gendering of shame in Sembene Ousmane's Guelwaar (1996) and in Mande-Alpha Diarra's Sahel: Sanglante sécheresse (1981). In both novels, women and children enjoy a certain moral virginity in being shielded from the notions of being defeated and of falling short of expectations. The moral virginity reflects these figures' exclusion from communal decision-making, suggests Kemedjio (1999). This exclusion is also an index of the paternalistic attitude of the narrators toward women who are framed as too immature to experience the sense of being caught exposed or of feeling inadequate.

In his exploration of shame for social reform, Ngũgĩ positions women and their socially sanctioned shaming institution to wield this kind of power. Though consistent with historical accounts of women's forms of conflict management, Ngũgĩ's decision is unconventional in our globalized understanding of femininity as the repository of shame. Some scholars observe for example that menstruation putatively throws the girl into the realm of potential shame as 'she bears within her body the seeds of sexual shame in such a way that this feeling about herself detaches from any act she may or may not commit, for shameful acts can merely confirm this dreadful self-knowledge' (Johnson and Moran 2013, 2). That menstruation carries stigma in most contexts is undeniable, although Johnson and Moran's establishment of a direct correlation between femininity and shame does not necessarily pan out in the African contexts under consideration here. To avoid setting up the generalized African context as antithetical to the dominant West, I recognize that most postcolonial contexts have adopted Judeo-Christian precepts of decorum that underpin political secularism. From the published literature, however, women are either framed as incapable of feeling shame or endowed with the capacity to produce shame in others. It is unclear if, and how, these accounts explain why recently in South Africa, Malawi, Kenya and Zimbabwe women have been publicly stripped and humiliated in the streets and online spaces for their supposedly shameless sartorial and sexual choices (Ligaga 2014, 2016). These shaming assaults are undoubtedly disciplinary techniques deployed to inscribe heteropatriarchal ideals that attempt to normalize female corporeality and sexual practices. ${ }^{4}$ The technique is however mired in ambivalence because it assumes these women's shamelessness at the same that it seeks to shame them.

In Aburiria, the ability to feel shame is expected from all, even inanimate objects such as buildings, and corpses. And the failure to fulfill that expectation is grounds for public reprimand as several characters are unequivocally accused of having 'no shame' (Ngũgĩ 2007, 23, 40, 746) for failure to judge or for stealing ideas and clothing. In relation to corpses being accused of having no shame, toward the end of Book One, 'Queuing Daemons,' Kamiti, who possesses the ability to enter or discard his body, is searched by three garbage collectors. After discovering his 'lifeless' body in the pile of garbage, and searching him for money and valuables to find nothing but rags:

one of them started cursing the corpse as if it were alive. You stupid liar. I am sure these rags are your real clothes and the suit you have on is stolen property. Have you no shame, 
stealing other people's clothes? And you did not even have the good sense to steal a suit less worn out; at least we could have taken that.

(40 emphasis added)

That the three garbage collectors expect to acquire material goods from the 'corpse' but would not report the death to the police for fear of being embroiled in court proceedings or of being suspected of murder speaks to the prevailing and utter despair in the postcolony. This episode also allows the narrator to account for the pervasiveness of deaths in the novel, some of which are due to hunger, illness or suicide. More importantly, that a corpse could be held to the same standards as a living entity indicates the extent to which shame is considered as constitutive of a social being worthy of respect.

A crucial moment of active shame-inducing in the novel is the collective female shame dance performed on a number of occasions. The women of the Underground Movement are said to have 'brought shame' on the Ruler and the nation which he now claims to embody $(219,225$, 301, 347). Not only they are said to shame him (235) but they also shame 'the site of Marching to Heaven' (236). But in an ironic twist, the Ruler considers others as shameless when, in his phantasmagorical and delusional aspirations, one can trace a lack of shame - the encompassing sense of humility, discretion, respect for elders, harm avoidance, discernment and adequate public comportment and posture. ${ }^{5}$ It is in fact in reaction to his corrupt, degenerate and oppressive rule that the female members of the resistant movement decided to teach him a lesson by shaming him. Before shaming the Ruler, they deploy several other innovative strategies that are predicated on the female gender, the precariat and figures of animality: they assume beggarly appearances, the women of the People's Court create a parallel justice order wherein they kidnap, judge and sentence wife batterers, and they cause panic during political gatherings with plastic snakes.

Given that in the world of the novel, as in most postcolonial nation-states, the presence of women dancers in traditional garb carries significant political clout against local opponents and with international donor agencies interested in gender and tradition questions, Kaniuru, Deputy Chairman of Marching to Heaven, recruits women dancers to convince the 'missionaries' of the Global Bank of the people's support for the loan for the tower. His rationale is: 'How was he going to impress Sikiokuu [the Minister of State] and the media without women dancers?' (306). However, the dancers come with a plan to shame the Ruler, punishing him for incurring more debt to finance the unwanted project. The subversive intervention of the women crystallizes the reverse instrumentalization of gender and tradition in postcolonial nation-states.

In the middle of their procession and dance, which the narrator describes as solemn and dignified, the women stop according to their plan. In place of the third person narrator, the narrative suddenly switches to Nyawira's direct report of the dance in which she is a participant:

All of us suddenly faced the people, our backs turned to the platform. All together we lifted our skirts and exposed our butts to those on the platform, and squatted as if about to shit en masse in the arena. Those of us in the crowd started swearing: MARCHING TO HEAVEN IS A PILE OF SHIT! MARCHING TO HEAVEN IS A MOUNTAIN OF SHIT! And the crowd took this up. There were two or three women who forgot that this was only a simulation of what our female ancestors used to do as a last resort when they had reached a point where they could no longer take shit from a despot; they urinated and farted loudly. Maybe need or fear overcame them, or both.

(Ngũgĩ 2007, 250) 
During the drama of shaming, the police await the order to shoot the women, an order that is not granted because of the presence of foreign news reporters and their cameras. Here, the women employ the colonial tools of witness (capture) to their benefit despite the conventional tools for oppression. Following the dance, the details of which differ from one account to another, the platform that holds the Ruler and his guests begins to sink in what some observers consider to be a muddy pool made of a mixture of shit and urine.

The feeling of being shamed, of being defied, a sign of the loss of confidence in rationality rather than trauma, constitutes a trigger for more oppressive violence from the government. Note that all other contestation strategies fail to elicit a notable response from the supposedly untouchable Ruler. But the women's shame dance (a communal force to challenge the effects of colonialism and autocracy) sends him into hiding for 'seven days, seven hours, seven minutes, and seven seconds' (253). A correlation exists between the work of the female shaming institution, the Ruler's reactions to being shamed and narrative form.

The organizers of the dance are elated because the Ruler who has proved thus far untouchable was 'driven away by Women Power' (253). However, contrary to their deepest expectations, their shaming gesture only causes the Ruler a temporary inconvenience. More counterproductive to the women's gesture is that the autocrat, while in hiding, organizes his vengeance:

Vengeance is mine, sayeth the Lord, and was he not the Lord of all Aburirian women? Yet no matter how hard he considered the matter, he remained unsure as to what to do or where or with whom to start the vengeance like that which he had shown Rachael. ${ }^{6}$ Unable to act, his torturous thoughts always returned to the treacherous drama at Eldares in which the women shamed the nation before the eyes of foreign dignitaries and, worse still, in front of the Global Bank missionaries. For days on end, after the drama at Eldares, the Ruler kept to himself, trapped in secrecy.

(235, my emphasis)

The women's punitive gesture is referred to as 'shameful acts' $(242,244)$, 'shameful deeds' (336, 505), 'shameful betrayal' (378), 'acts of shame' (336), 'a shameful scandal' (218) and 'the drama of shame' (744). One of the most notable reactions of the Ruler is to construct the women in an ambiguous fashion in that they are both shameful and shameless: 'dancers of shame' (251), 'shameful dancers' (423), 'shameless women' (263) and 'shameless primitive dancers' (376). The link between primitiveness and shamelessness that he establishes is not surprising given the recurrent trope of racist judgments passed on the natives by the colonizers (Fanon 2008 [1952], Achebe 1970, Kemedjio 1999).

The Ruler's acts of withdrawal and hiding are consistent with conventional descriptions of shame reactions. Paradoxically, the content of the reaction is inconsistent with the writing style which becomes hyperbolic and recursive: 'seven days, seven hours, seven minutes, and seven seconds.' Perhaps, the need to construct women as endlessly powerful in order to uphold an indigenous mode of being, thereby complicating commonplace images of women as victimized by their traditions, accounts for the limited attention to the backlash against collective female defiant self-exposure. However, and while rage is a possible response to shame, the extant literature on defiant shaming in African societies does not suggest that rage and, relatedly, vengeance are expected reactions.

Increasingly, though, novels that circulate internationally are restaging a backlash against women's collective use of their nakedness to shame male targets, foreign or indigenous. In addition to Wizard of the Crow, T. Obinkaram Echewa's 1992 I Saw the Sky Catch Fire, a 
fictionalization of the 1929 Igbo Women's War, during which thousands of women opposed colonial incursion and exploitation, uncovers the possible counterproductive effects of shaming. In it, the narrator shows three instances where the targets of women's shaming seek vengeance in either committing suicide-homicide or killing women. For instance, following the historic act of self-exhibition, more than one hundred women are shot dead by the forces of the colonial administration. In Naked Agency, an exploration of defiant genital flashing in Africa, I argue for the potent necessity of including reactions to women's defiant self-exposure in the conceptualization of their agency (Diabate 2019). Defiant disrobing is a performance that targets audiences whose reactions constitute an essential element to a more comprehensive account of their tactics. These reactions, often immediate, often deferred, but always continuously unfolding, represent the naked and open aspect of women's agency.

Known as genital shaming/shame in anthropological texts, female defiant self-exposure and expulsion of intestinal gas, accompanied by incantations of curses, is a culturally sanctioned and gendered mode of conflict management in African societies where mature female bodies are revered, and where social cohesion carries weight. These 'shaming parties' (Edgerton and Conant 1964), 'women's mobbing' (Spencer 1988), and 'punitive delegation' (Talle 2007) often make men listen or comply when other mechanisms of resistance or retribution have failed. The potency of the practice can best be understood within the context of a society that has constructed its values around communitarianism, a social organizing principle predicated upon the belief that the formation of the self is dependent upon the cues of others. Thus, shame - the severing or the threatening of social bonds, the fear of having one's social status threatened with the resultant ostracism and rejection - is worse than literal death. Consequently, it constitutes a motivating force that causes one to abide by prevailing shared moral codes and socially sanctioned behaviors. This indicates that an individual is bound to the community, so much so that the construction and deconstruction of her identity is overwhelmingly accomplished in tandem with the moral approval and disapproval of other community members. That the preference for choosing death over shame is expressed as a proverb speaks to its axiomatic qualities.

The publicness, the cultural potency and the extreme socio-political conditions required to mobilize genital shaming explain the interest it has received from scholars of many disciplines, including anthropology, political science and history. ${ }^{7}$ That shame works explains the proliferation of the gesture and practice in more than 20 African countries.

Because of the effects of westernization in Aburiria, and the zealotry of the Ruler, this practice is only mildly effective: unlike in historical accounts of genital shaming where it was successful in unseating rulers (Ritzenthaler 1960; Prince 1961; Ardener 1973; Conrad 1999), it only temporarily inconveniences the autocrat. The small impact on the Ruler is also suggestive of the dwindling power of the female shaming act in the postcolonial African context. For instance, in 2015, in response to a series of protest-demonstrations during which women exposed their genitalia and buttocks to protect their lands, Uganda's Minister of Lands, claimed: 'Nudity is not the answer; there are other better ways of resolving women's land issues other than undressing [...] What works is legal papers' (Ocungi 2015). The Minister's statement is not specific to Uganda, as several instances from South Africa, Côte d'Ivoire, Cameroon and elsewhere demonstrate. The shaming gesture, a legitimate form of conflict resolution and claimsmaking, clashes with political secularism and its promise of freedom and democracy enshrined in the language of constitutions.

Nonetheless, the fact that the Ruler is not completely immune to the shame dance deserves recognition. The ruler's partial response to the shame dance is a way of suggesting that he retains some elements of personhood despite his authoritarianism and repressive political practices. Indeed, those immune to this punitive practice are considered dangerous elements to 
communal commerce. They are those who have no obligations to the normative codes, or those who entertain weak bonds with the community. Further, those with no social position to protect, and those suffering from mental illness and thus in the process of discarding their social identity as husband, nephew or father will not react according to certain expectations (conventional shame reactions) in the face of women's punitive act.

In this novel, the shame dance elicits multiple and conflicting interpretations and reactions from at least four categories of actors. These actors include the Ruler and his sycophants, foreign dignitaries, the women dancers and other dissidents, and the people. The foreign bankers, for instance, laugh, mistaking the flashing of buttocks for a 'humorous native dance.' Eventually, though, and in light of the Ruler's somber reaction, they understand it to be a 'solemn native dance' (Ngũgĩ 2007, 250), an expression of 'black humor from an ancient Aburĩian ritual' (252). Most people in the crowd are confused by the gesture while the official version by the Ruler and his cabinet explains the women's dance as 'a sacred Aburirian dance performed only before most honored guests' (242). The unofficial account presents it as a shaming gesture that the Ruler himself recognizes as suggested above.

The novel accounts for conflicting interpretations of the shame dance by using multiple narrators and by reporting rumors. Although Nyawira's recounting is matter-of-fact, the dominant narrator, in establishing the atmosphere preceding the shaming gesture, suggests a sense of awe, silence and deference on the part of the gathered crowd. The multiple narrators, which Robert Colson in his analysis of narrative time reads as signs of resistance (2011), give access to the interiority of the multiple actors, from the elite to the people. Further, the choice of Nyawira as the narrator for this shaming scene provides a paced and detailed description that ensures that the choreographed nature of self-exposure is not lost on the reader/listener. This technique of switching narrators helps to highlight the powerful nature of this form of resistance and punishment against the condensed nature of, and sensationalism inherent in, most news reports on defiant nakedness.

As a possible result of its multiplying tales, theories and narrators, the form of this novel is also boundless and expansive. For instance, it opens with five theories purporting to explain the strange illness of the Ruler. In addition to these proliferating rumors, one might also note the democratic distribution of forms and holders of supernatural powers, which finds expression in the titles of the six books 'Power Daemons,' 'Queueing Daemons,' 'Female Daemons,' 'Male Daemons,' 'Rebel Daemons' and 'Bearded Daemons.' In this fantastical tale, characterized by organized chaos, all major social categories are endowed with paranormal powers, which they can deploy in the fight for ultimate political power. This distribution speaks to the intrinsic fallibility of power and the unavoidable and unlimited repetition of violence that undergirds its possession. The boundlessness and possibly the delirium of the novel are correlated with its projected absurd scope: 'to sum up Africa of the 20th century in the context of 2,000 years of world history' as Ngũgĩ shares as his wish with Jeff Turrentine writing for The New York Times (2006). That one novel seeks to fulfill a goal of this sort may amount to delusion. Perhaps, that delusion arises from a desire to communicate the interminable contradiction of the postcolony where shamers become both shameful and shameless. Not surprisingly, an egregious form of governmentality in the postcolony resides in the ability to create a reality that is contrary to positive data.

Undoubtedly the grotesque is consistently at play in this narrative with the use of hyperbole both in content and form. For instance, unsuccessful and bitter over his failure to secure the loan to build Marching to Heaven, the Ruler loses his ability to speak and becomes ill with Self-Induced Expansion. His stomach continuously expands, and rumors have it that he is pregnant. Western medicine fails to cure him, but a fake wizard succeeds. The acts of the 
Ruler's three sycophants are as preposterous as those of their strongman. For instance, each undergoes body augmentation to more effectively serve their master: Machokali, the Minister of Foreign Affairs, has plastic surgery on his eyes, having them 'enlarged to the size of electric bulbs' (Ngũgĩ 2007, 13) to better spot the Ruler's opponents, and Sikiokuu, the Minister of State, enlarges his ears to enhance his abilities to hear even the most private conversations of citizens, in order, of course, to protect the Ruler. These embodiments of the grotesque speak to the prevailing immoderation of political power in the postcolonial nation-state.

The corresponding narrative form is not that of shame (restraint, withdrawal or paralysis), but rather one that is an embodiment of rage, shame-response, with boundary breaking, exaggeration and non-normative refusals. Unlike the dominant narrative perspective and the linear chronological framing - conventional novelistic features - in A Grain of Wheat that fail to free the community of shame, Ngũgĩ may have turned to the grotesque and its unsettling narrative structure to inscribe its new vision of social change and the working out of these through nonheroic characters.

\section{African literature and its shames}

Shame has received limited attention in literary studies despite the high number of times the term 'shame' appears in African fiction. A quick keyword search on shame in Heinemann's African Writers Series (1962-2003) of about 250 texts yields the following results: novels, 170 entries; poetry, 57 entries; and drama, 15 entries. In other words, a total of 242 entries with more than 1010 hits - almost 99 percent include the word shame, among them canonical as well as newer texts. ${ }^{8}$

The notion of shame is recurrent in fiction because of its palimpsestic nature in African societies (Constable 1999; Tansi 1981). Three major factors explain such recurrence: the first is the importance of shame in African societies, especially in societies of honor and shame and structured around a communitarian ethos and social interaction. The second factor relates to the afterlives of historical traumas, such as colonialism and apartheid, which brought with them not only an original defeat as Kemedjio calls it, but also the narrow coercive Judeo-Christian account of shame that Frantz Fanon identifies. And finally, the impact of neoliberalism, the dominant ideology of global capitalism, which is a shame-producing machine (Lasch 1991; Giddens 1991).

Acknowledging the psychic deformations and injuries of colonialism in the rest of SubSaharan Africa had previously preoccupied prominent thinkers, including Frantz Fanon, Chinua Achebe and Aimé Césaire. ' In Black Skin White Masks, a rebuttal of Octave Mannoni's 1947 explanation of the behaviors of Africans within the colonial frame as the dependency complex, Frantz Fanon diagnoses African responses to colonialism as the effects of cultural domination and economic exploitation, rather than as derived from a shared mental structure inherent to blackness. Shame caused by the rupturing history of African dispossession and disenfranchisement is not just an identifiable event, but rather the consequence of an existential condition. Almost two decades after Fanon, in 1968 speaking of the Biafran War, Chinua Achebe evoked the shame of colonialism, saying:

Biafra stands for true independence in Africa, for an end to the 400 years of shame and humiliation which we have suffered in our association with Europe [...] I believe our cause is right and just. And this is what literature should be about today - right and just causes. 
Although the produced condition, involving a 'noose of shame and disaster' as Aimé Césaire called it in 1956, may have been eroded under nominal political independence, the condition of the postcolonial is not necessarily free of neuroses.

Most literary analyses of shame have provided an array of conceptualizations of shame and of their corresponding literary registers. ${ }^{10}$ In the entire corpus of modern African literature, the Congolese Sony Labou Tansi's second novel The Shameful State constitutes the most powerful conceptualization of shame. Organized in nine sequences, the narrative, which uses the words shame 22 times and shameful 46 times, tells of the 40-year-long arbitrary power of Colonel Martillimi Lopez, the nation's president, whose eccentric series of grotesque and vicious actions led to the falling apart of his fictive central African country. Part of the second generation of writers who were already disillusioned with the failures of decolonization and whose works were even more militant than those of the first generation, ${ }^{11}$ Tansi's writing style stands out as the most unconventionally troubling. To provide a profound understanding of the writer's obsessive engagement with shame, the most authoritative study to date by Jean Michel Devésa combines an intellectual biography of the author with a close reading of his literary output. For instance, he quotes from a 1979 interview that the writer gave: 'My style simply comes from the great shame that I feel for chewing my words' ('Mon écriture vient tout simplement de la grande honte que j'ai de mâcher les mots') (1996a, 103) (my translation). In addition to the shame produced by an oppressive political system, Tansi's birth conditions, the child of an extra marital relationship, produced another layer of shame, which the writer embraced by renaming himself 'soni,' which means 'shame,' 'respect' and 'modesty' in his native language. In a later essay, 'Le Kongo mental de Sony Labou Tansi,' Devésa quotes Tansi as defining the 'shameful state' as:

la condition honteuse: l'ensauvagement de l'humain, l'incapacité de rester vivant. L'homme en dépaysement sous sa propre peau. C'est la faute à Voltaire? Je veux dire c'est la faute à Descartes. L'homme etait un beau tout. Aujourd'hui c'est un infirme qui face au monde n'a qu'un oeil: la raison.

$(1996 b, 6)$

the shameful condition: the ensavagement of the human, the inability to remain alive. Man with a sense of displacement in his own skin. Is it Voltaire's fault? I want to say that it is Descartes's. Man was a beautiful complete being. Today he is a disabled person who has only one eye to face the world: reason.

(Riesz and Allen 2000, 113-114)

For Tansi, argues Devésa, shame is a condition with a known etiology, as it is produced by (1) modernity and its after effect, colonialism, and (2) an oppressive, degenerate and corrupt post-independence state. As such, shame can be excised through writing and speaking out. The Shameful State is such an attempt, although the autocrat is immune to shame. In Tansi's novel, one of the Ruler's absurd acts consists of swallowing a coin and searching for it in his feces following the advice of a diviner who would then use the coin to predict the length of the president's rule: 'He continues searching for it in his historic turds for three years. Ecstatically' (Tansi 2015, 72), the smell of which pervades every inch of the country. With the exception of the president, the whole country is suffused with shame. The end of the novel, where the country is still embroiled in shame, raises the question as to how shame can be extracted if one of its patently crystallized symbols (the president) is replaced by an equally shameless one. I suggest that The Shameful State is not the novel to engage with when searching in fiction for the 
extraction of shame. In fact, the novel induces shame in the reader because of the president's grotesque actions. His preoccupation with his own waste is shameful, although he is impervious to the consequences of his own actions, leading the reader to feel shame in the president's stead. Perhaps it is this sense of shame combined with discomfort that prevented several students in my 2018 seminar 'Body Politics in African Literature and Cinema' from finishing the novel. This unwillingness to fully engage with an assigned text also produces a certain level of discomfort in the instructor who failed to gauge the power of the novel in producing shame.

Flora Veit-Wild (2005) uncovers a corresponding literary register of the grotesque in her comparative analysis of Tansi's The Shameful State and Dambudzo Marechera's Black Sunlight. Drawing on Achille Mbembe's reflection on the grotesque as an index of power in the postcolony, Veit-Wild sees the protuberant, deforming, hyperbolic and parodic qualities of the grotesque as embodied narrative strategies of shame. My comments about the presence of multiple narrators in Ngũgĩ's Wizard of the Crow recall Veit-Wild's observations about the deployment of multiple narrators to recount one grotesque situation after another, usually involving bloodshed, dismemberment, rape, torture and acts of terror that curdle the blood. ${ }^{12}$

If modernity-produced shame is materialized in fiction by wildness and senselessness, it can also take other forms, specifically ellipsis, and the inability to represent, as for example in Zoë Wicomb's analysis of the shame of being colored in the South African context. ${ }^{13}$ For Wicomb shame has a recognizable origin, and it can thus be cured because at 'the intersection of image and text there is a space where people can resist received racial descriptions, where they make their own meanings, oh and yeah, new discursive spaces in which modalities of blackness can wipe out shame' $(1998,106)$. Wicomb's essay is fundamentally an exploration of gendered, racialized and paralyzing postcolonial shame, which stems from certain historical traumas, such as the display and the naming of black female bodies, the Atlantic slave trade, the institutionalization of colonial racism and miscegenation. The essay turns to such writers as Mtutuzeli Matshoba, Don Mattera and Nadine Gordimer as accounting for these kinds of shame in the structure of their work. In her close reading of narrative voice in Gordimer's novel My Son's Story, the putative story of the father, a colored antiapartheid activist, Wicomb underscores how the story is not narrated through the father's voice but rather by both the son and a third person narrator. And that fact correlates with the inability to make public the father's sins of concupiscence and interracial sex, the publicness of which would undermine his work as a political activist. 'In the space between writing and making public lies an unacknowledged shame in its originary interracial sex' (Wicomb 1998, 104). Shame is materialized here following the conventional account of shame in Silvan Tomkins's biopsychological approach as withdrawal or near paralysis, specifically lowered head and eyes (1987, 139).

\section{Conclusion}

From ellipses to the grotesque, shame has taken many forms in African literature. These narrative strategies indicate the changes in depictions of shame since the emergence of Europhone literature to the current moment. If narratives that re-imagine the colonial period and its immediate era consider shame as worse than death, as in the cases of Mugo ${ }^{14}$ and Okonkwo, ${ }^{15}$ the post-independent and postcolonial periods chart a new cartography of shame. Novels of these eras represent characters for whom shame is a temporary inconvenience; Colonel Lopez Martillimi, the Ruler and Fama epitomize that trend. The shifting grammar of shame demonstrates the effects of westernization and the kind of agency that it affords postcolonial subjects, notably dictators, who are utterly and shamelessly impervious to shame, the most important affect in many societies. 


\section{Naminata Diabate}

The agency of these subjects should be considered in tandem with that of women who have historically, in some African contexts, been endowed with the authority and the power to shame male targets. Both Wizard of the Crow and I Saw the Sky Catch Fire demonstrate that agency is always co-constitutional, as the agency of the women stops where that of their targets begins. Following in Tansi's footsteps, Ngũgĩ has turned to depicting shameless leaders who barely acknowledge that they should be ashamed. The dictators in these novels are seemingly incapable of affect, with the exception of hunger. They have appetites to satisfy, but can never reach a state of satiety and fullness. The appearance of shame as major affect in this work suggests that in his most recent novels, Ngũgĩ is less confident about pathways to social and political change. The fact that the protagonists of this novel are anti-heroes rather than the admirable and sometimes heroic protagonists of his earlier work appears to further buttress this point.

The changes in portrayals of shame demonstrate one of the after effects of colonization, which crucially undermines the expansive indigenous conceptualizations of shame in favor of the narrow formulations described in certain affect studies circles as Judeo-Christian humiliation. Rather than consider shame as a dehumanizing affect and one that is reduced to feeling, a more generous account can include its humanizing capacities. Genital shaming, the utility of public shaming in creating social repair and cohesion, is one such means. Note that in this context, shaming is used as a means, not as an end, unlike John Braithwaite's invention of the misnomer 'reintegrative shaming,' which he recently turned away from, enduring much critique from within the restorative justice movement. ${ }^{16}$

This analysis of shame in recent works of African literature provides an opportunity to put pressure on affect studies' main focus on trauma at the expense of other affective realms. As scholarship in other fields has suggested, trauma is a less generative category for analyzing specific African communities than is shame. ${ }^{17}$ To dwell on trauma is to forego the possibilities of understanding how certain notions of shame may still operate in these societies. ${ }^{18}$

\section{Notes}

1 In 'La Modernité africaine et l'écriture de la honte: le spectre du déshonneur dans les impasses postcoloniales' Kemedjio outlines how shame, as a collective mistake, is a constitutive element of African literature. He closely reads Remember Ruben by Mongo Beti, Tu t'appelleras Tanga by Calixthe Beyala, Sembene Ousmane's Guelwaar and Mande-Alpha Diarra's Sahel: Sanglante secheresse to unpack the tripartite manifestation of shame in the colonial and postcolonial worlds. These include: the painful awareness of the native of being colonized, the filth of the African quarters and the emaciated and hungry postcolonial body.

2 The dictator novel is a literary genre that originated in Latin America. Although it dates back to the nineteenth century, the genre flourished in the 1960s and 70s to challenge the power of an authoritarian figure. The dictator novel often deploys formal elements such as fragmentation, stream of consciousness, interior monologues, multiple narrative points of view, frequent lack of causality, neologisms and unconventional narrative strategies, which resonate with the grotesque. For more, see Spencer (2012), Veit-Wild (2005) and Agosin and Pierce (1990).

3 These novels include Nathacha Appanah's Le Dernier frère (2007), Bessora, Petroleum (2004), Calixthe Beyala, Les Honneurs perdus (1996), Fatou Diome's Le Ventre de l'Atlantique (2003), Leonora Miano's Contours du jour qui vient (2006), and Marie NDiaye's Trois femmes puissantes (2009). For more on this critical trend, see Lindberg (2016).

4 To these assaults on their dignity and freedom, women have fought back to reclaim a space of agency. For more on their resistant protests, see Cuddihy (2014).

5 This expansive conceptualization of shame has appeared in multiple colonial and postcolonial African contexts, notably the Malinke, the Hausa, and Yoruba. For more see, Vuarin (2000), Kirk-Greene (1974), Babatunde (2000) and Lawuyi (2012).

6 The Ruler's legal wife. 
7 Ritzenthaler (1960), Prince (1961), Van Allen (1972), Ardener (1973), Buckley and Gottlieb (1988), Conrad (1999), Bastian (2002), Awasom (2003), Grillo (2013), Hodgson (2017).

8 These include: Chinua Achebe's Things Fall Apart (1958), Ahmadou Kourouma's The Suns of Independence (1968), Mongo Beti's Remember Ruben (1974), Kofi Awoonor's This Earth, My Brother (1980), Sony Tabou Tansi's The Shameful State (1981), Calixthe Beyala Tu t'appelleras Tanga (1988), Mariama Ba's So Longer a Letter (1989), Sembene Ousmane's Guelwaar (1996), Ama Ata Aidoo's Changes (2004), J. M. Coetzee's Disgrace (1999), Thando Mgqolozana's A Man Who Is Not a Man (2009) and Kopano Matlwa's Period Pain (2016).

9 In Notebook of a Return to the Native Land, Aimé Césaire cries out, 'this attitude, this behavior, this shackled life caught in the noose of shame and disaster rebels, hates itself, struggles, howls, and, my God, others ask: "What can you do about it?" "Start something!" "Start what?" "The only thing in the world that's worth the effort of starting: The end of the world, by God!"” (1956, 56).

10 These include Bewes', Lindberg's and Kemedjio's above-mentioned studies, Flora Veit-Wild's 2005 'The Grotesque Body of the Postcolony,' Zoe Wicomb's 1998 'Shame and Identity: The Case of the Coloured in South Africa,' János Riesz and Amy L. Allen's 'From L'etat sauvage to L'etat honteux' (2000), Jean Michel Devésa's Sony Labou Tansi: Ecrivain de la honte des rives magiques du Congo (1996), and Karen Lindo's 'Mapping Territories of Affective Communities in the Indian Ocean' (2010).

11 Leopold Sedar Senghor, Bernard Dadié, Mongo Beti and Ousmane Sembene.

12 Veit-Wild recalls previous comments on Sony Labou Tansi's troubling style, specifically the one made by French literary critic, Daniel-Henry Pageaux, who calls The Shameful State and similar novels 'The grotesque africain' $(2005,228)$. Although Veit-Wild does not mention the renowned French literary critic Jacques Chevrier, it is worth noting his less generous comment on the novel.

13 In South Africa, reflections on shame from an identitarian perspective have skyrocketed, from the Wicomb's work on colored people to that of Samantha Vice on white shame (2010). Vice considers shame as a viable stance by whites in Africa to own up to their part in the apartheid and colonial past.

14 Mugo, discussed above, is the central character of Ngũgî's $A$ Grain of Wheat whose death patently constitutes an event of shame in the post-independence era.

15 As discussed earlier, Okonkwo is one of the most discussed protagonists in African fiction. He took his life because of shame.

16 In his seminal Crime, Shame and Reintegration (1989) and in numerous subsequent publications, Braithwaite gives an account of his reintegrative shaming theory. He draws on multiple policing and educational practices in Asia to posit the following: tolerance of crime worsens things, outcasting shaming of crimes makes things even worse, reintegrative shaming instead, prevents crime. The laudable practice consists in disapproving crime while respecting the offender. The disapproval is terminated by rituals of forgiveness.

17 Skepticism about trauma studies has been raised in literary studies, postcolonial studies, as well as in political science. For more, see Roger Luckhurst's The Trauma Question (2008) and Antonio Traverso and Mick Broderick (2010) 'Interrogating Trauma: Towards a Critical Trauma Studies.'

18 I thank Michal Raizen, Somy Kim and the editors for their comments on a previous draft of this chapter. I also thank Karim Sagna, Olufemi Taiwo, David Conrad, Cherif Keita and Karim Traore for references on shame among the Malinke, and Marzia Milazzo and Bruce Janz for references on shame in South Africa.

\section{References}

Achebe, Chinua. 1970. 'The Duty and Involvement of the African Writer.' In The Africa Reader: Independent Africa, edited by Wilfred Cartey and Martin Kilson, 168-169. New York: Random House.

Adinkrah, Mensah. 2012. 'Better Dead than Dishonored: Masculinity and Male Suicidal Behavior in Contemporary Ghana.' Social Science \& Medicine 74(4): 474-481.

Agosin, Marjorie and Barbara E. Pierce. 1990. 'Inhabitants of Decayed Palaces: The Dictator in the Latin American Novel.' Human Rights Quarterly 12(2): 328-335.

Ardener, Shirley. 1973. 'Sexual Insult and Female Militancy.' Man 8(3) (September): 422-440.

Awasom, Susanna Yene. 2003. 'Through the Prism of Octogenarian Political Activism in Cameroon: A Critical Survey of the Adoption of Traditional Female Political Institutions to the Exigencies of Modern Politics in Cameroon.' In Indigenous Structures and Governance in Africa, edited by Olufemi Vaughan, 402-415. Lagos: Sefer Press. 


\section{Naminata Diabate}

Babatunde, E. D. 2000. 'Bini and Yoruba Notions of the Human Personality.' In Substance of African Philosophy, edited by C. S. Momoh, 274-310. Auchi: African Philosophy Projects' Publication.

Bailleul, Pere Charles. 2005. Sagesse Bambara: proverbes et sentences. Bamaka: Editions Donniya.

Bastian, Misty. 2002. "Vultures of the Marketplace": Southeastern Nigerian Women and Discourses of the Ogu Umunwaanyi (Women's War) of 1929.' In Women in African Colonial Histories, edited by Jean Allman, Susan Geiger and Nakanyiki Musisi, 260-281. Bloomington: Indiana University Press.

Bewes, Timothy. 2010. The Event of Postcolonial Shame. Princeton, NJ: Princeton University Press.

Braithwaite, John. 1989. Crime, Shame and Reintegration. Cambridge: Cambridge University Press.

Broqua, Christophe and Anne Doquet. 2013. 'Les normes dominantes de la masculinité contre la domination masculine? Batailles conjugales au Mali.' Cahiers d'études africaines 209-210: 293-321.

Buckley, Thomas and Alma Gottlieb. 1988. Blood Magic: The Anthropology of Menstruation. Berkeley: University of California Press.

Césaire, Aimé. 1956. Cahier d'un retour au pays natal. Paris: Présence Africaine.

Clark-Bekederemo, John Pepper. 1961. Song of a Goat. Ibadan, Nigeria: Mbari.

Colson, Robert L. 2011. 'Arresting Time, Resisting Arrest: Narrative Time and the African Dictator in Ngũgĩ wa Thiong'o's Wizard of the Crow.' Research in African Literature 42(1) (March): 133-153.

Conrad, David C. 1999. 'Mooning Armies and Mothering Heroes: Female Power in the Manden Epic Tradition.' In In Search of Sunjata: The Mande Oral Epic as History, Literature and Performance, edited by Ralph A. Austen, 189-230. Bloomington: Indiana University Press. Constable, Liz. 1999. 'Introduction - States of Shame.' L'Esprit créateur 39(4): 3-12.

Cuddihy, Martin. 2014. 'Nairobi Women Protest Public Shaming of Women for their Dress.' $A B C$. Tuesday November 18. www.abc.net.au/radio/programs/am/public-shaming-of-women-on-the-r ise-in-sub-saharan/5898650.

Davids, C. A. 2014. The Blacks of Cape Town. Cape Town: Modjaji Books.

Devésa, Jean Michel. 1996a. Sony Labou Tansi: écrivain de la honte et des rives magiques du Kongo. Paris: L'Harmattan.

Devésa, Jean Michel. 1996b. 'Le Kongo mental de Sony Labou Tansi.' In Colloque Sony Labou Tansi et Sylvain Ntari Bemba, edited by Alain Kounzilat and Ange-Séverin Malanda, 5-19. Corbeil-Essonnes: Editions Ices.

Diabate, Naminata. 2019. Naked Agency: Genital Cursing and Biopolitics in Africa. Durham, NC: Duke University Press. Forthcoming.

Echewa, Obinkaram T. 1992. I Saw the Sky Catch Fire. New York: Plume.

Edgerton, Robert B. and Francis P. Conant. 1964. 'Kilipat: The "Shaming Party" Among the Pokot of East Africa.' Southwestern Journal of Anthropology 20(4): 204-218.

Fanon, Frantz. 2008 [1952]. Black Skin White Masks. New York: Grove Press.

Giddens, Anthony. 1991. Modernity and Self-identity: Self and Society in the Late Modern Age. Stanford, CT: Stanford University Press.

Grillo, Laura S. 2013. 'Catachresis in Côte d'Ivoire: Female Genital Power in Religious Ritual and Political Resistance.' Religion and Gender 3(2): 188-206.

Hodgson, Dorothy L. 2017. Gender, Justice, and the Problem of Culture: From Customary Law to Human Rights in Tanzania. Bloomington: Indiana University Press.

Kemedjio, Cilas. 1999. 'La modernité africaine et l'écriture de la honte: le spectre du déshonneur dans les impasses postcoloniales.' L'Esprit créateur 39(4): 128-138.

Kirk-Greene, Anthony H. M. 1974. Mutumin Kirki: The Concept of the Good Man in Hausa. Bloomington: African Studies Program, Indiana University.

Kourouma, Ahmadou. 1968. Les soleils des indépendances. Montréal: Les Presses de l’Université de Montréal.

Kourouma, Ahmadou. 1981 [1968]. The Suns of Independence. Translated by Adrian Adams. London: Heinemann.

Johnson, Erica L. and Patricia Moran, eds. 2013. The Female Face of Shame. Bloomington: Indiana University Press.

Lasch, Christopher. 1991. The Culture of Narcissism: American Life in an Age of Diminishing Expectations. New York: W.W. Norton \& Company.

Lawuyi, Olatunde Bayo. 2012. Ijapa and Igbin: A Discursive Meditation on Politics, Public Culture and Moral Imagings in Nigeria. Ibadan: University Press.

Ligaga, Dina. 2014. 'Mapping Emerging Constructions of Good Time Girls in Kenyan Popular Media.' Journal of African Cultural Studies 26(3): 249-261. 
Ligaga, Dina. 2016. 'Presence, Agency and Popularity: Kenyan "Socialites," Femininities and Digital Media.' East African Literary and Cultural Studies 2(3): 111-123.

Lindberg, Ylva. 2016. 'La littérature francophone de l'Afrique subsaharienne en Suède. Les femmes font place à la honte.' Paralleles 28(1): 64-82.

Lindo, Karen. 2007. 'Shame and the Porosity of Self.' UCLA Center for the Study of Women CSW Update Newsletter, 21-23.

Lindo, Karen. 2011. 'Mapping Territories of Affective Communities in the Indian Ocean.' International Journal of Francophone Studies 13(3-4): 471-488.

Luckhurst, Roger. 2008. The Trauma Question. Abingdon: Routledge.

Ngũgĩ wa Thiong'o. 1967. A Grain of Wheat. London: Heinemann.

Ngũgĩ wa Thiong'o. 2007. Wizard of the Crow. New York: Anchor Books.

Ocungi, Julius. 2015. 'Nude Protests: The Acholi Signal of Distress.' Daily Monitor. April 30. www.moni tor.co.ug/artsculture/Reviews/Nude-protests-the-Acholi-signal-of-distress/-/691232/2701176/-/14nq 49t/-/index.html.

Olivier de Sardan, Jean Pierre. 1982. Concepts et conceptions songhay-zarma. Paris: Nubia.

Olivier de Sardan, Jean Pierre. 1983. Les sociétés songhay-zarma. Paris: Karthala.

Prince, Raymond H. 1961. 'The Yoruba Image of the Witch.' Journal of Mental Science 107(449): 795-805.

Riesz, János and Amy L. Allen. 2000. 'From L'etat sauvage to L'etat honteux.' Research in African Literatures 31(3): 100-128.

Ritzenthaler, Robert E. 1960. 'Anlu: A Women's Uprising in the British Cameroons.' African Studies 19(3): 151-156.

Scheff, Thomas J. and Suzanne M. Retzinger. 1991. Emotions and Violence: Shame and Rage in Destructive Conflicts. Lexington, KT: Lexington Books.

Spencer, Paul. 1988. The Maasai of Matapato: A Study of Rituals of Rebellion. Manchester: Manchester University Press.

Spencer, Robert. 2012. 'Ngũgĩ wa Thiong'o and the African Dictator Novel.' The Journal of Commonwealth Literature 47(2): 145-158.

Talle, Aud. 2007. “'Serious Games”: Licences and Prohibitions in Maasai Sexual Life.' Africa 77(3): 351-370.

Tansi, Sony Labou. 1981. L'etat honteux. Paris: Editions du Seuil.

Tansi, Sony Labou. 2015. The Shameful State. Translated by Dominic Thomas. Indianapolis: Indiana University Press.

Tomkins, Silvan S. 1987. 'Shame.' In The Many Faces of Shame, edited by Donald L. Nathanson, $133-161$. New York: Guilford Press.

Traverso, Antonio and Mick Broderick. 2010. 'Interrogating Trauma: Towards a Critical Trauma Studies.' Continuum 24(1): 3-15.

Turrentine, Jeff. 2006. 'The Strongman's Weakness.' The New York Times, September 10.

Van Allen, Judith. 1972. "Sitting on a Man": Colonialism and the Lost Political Institutions of Igbo Women.' Canadian Journal of African Studies / Revue Canadienne des Études Africaines 6(2): 165-181.

Veit-Wild, Flora. 2005. 'The Grotesque Body of the Postcolony: Sony Labou Tansi and Dambudzo Marechera.' Revue de littérature comparée 2(314): 227-239.

Vice, Samantha. 2010. 'How Do I Live in this Strange Place?' Journal of Social Philosophy 41(3): 323-342.

Vuarin, Robert. 1993. 'Quelles solidarités sociales peut-on mobiliser pour faire face au coût de la maladie?' In Se soigner an Mali, edited by Joseph Brunet-Jailly, 299-316. Paris: Karthala- ORSTOM (IRD).

Vuarin, Robert. 2000. Un système africain de protection sociale au temps de la mondialisation ou 'Venez m'aider à tuer mon lion ...'Paris: L'Harmattan.

Wicomb, Zoë. 1998. 'Shame and Identity: The Case of the Coloured in South Africa.' In Writing South Africa, edited by David Attridge and Rosemary Jolly, 91-107. New York: Cambridge University Press. 


\section{Scattered testimony Locating the Rwandan genocide in transnational witnessing}

Martina Kopf

\section{Introduction}

This chapter takes a look at how stories about the 1994 genocide in Rwanda have been filtering into the works of Kenyan writers since the turn of the century. ${ }^{1}$ It tackles a body of writing that has gone largely unnoticed in academic work on genocide literature so far, namely fictional responses by African authors from countries with either direct borders to Rwanda, or from those that are home to a larger Rwandan diaspora. The stories these authors tell are not, or only in minor parts, set in Rwanda. Instead, they engage - often unexpectedly for the reader - with the legacy of the genocide through their representations of exile and displacement. The notion of witnessing is crucial to the analysis laid out in this chapter.

In Rwanda Genocide Stories (2015), Nicki Hitchcott states that all those writing about genocide can be understood as witnesses insofar as each text becomes a kind of testimony, albeit a fictional one. In order to comprehend and to make meaning of this kind of testimony, she further suggests, we need to understand and acknowledge how positionality works both inside and outside the text. Following Mahmood Mamdani's analysis of the political history of Rwanda, she defines witnesses, survivors, victims and perpetrators as the four central subject positions through which the aftermath of the genocide has been negotiated. Hitchcott $(2015,16)$ reads the literatures of the genocide through these subject positions, adding, as a fifth, the position of 'tourists', to define those testimonies and literary engagements that arose from outsiders travelling to and visiting post-conflict Rwanda. All these categories, as Hitchcott points at, are loaded with political tensions and ambiguity. Fictional writing offers a way to open up and explore the complexity and ambiguity of these positions. Taking up her suggestion, this chapter explores the particular positions opened up through processes of what we are going to describe as 'displaced witnessing' in narratives that contextualise the aftermath of the genocide in transnational perspectives.

The works discussed are the three short stories 'Discovering Home' $(2003)^{2}$ by Binyavanga Wainaina, 'Weight of Whispers' (2003) by Yvonne Owuor and 'The Gorilla's Apprentice' (2010) by Billy Kahora. All three authors consider the aftermath of the genocide as Kenyans, and citizens of a country that has been involved as a host country and a significant political 
player in the political crises and conflicts of the wider East African region. In all three texts, the aftermath of the genocide is decentred and displaced in one fashion or another. In Wainaina's 'Discovering Home', the account of a family reunion in the Bufumbira region at the Ugandan/ Rwandan border in the last chapter underwrites the story of a returnee's re-discovery of his home country, Kenya, literally from its margins. Announced as a celebration of the grandparents' diamond wedding anniversary, the reunion gradually reveals itself as a celebration of genocide survival. Owuor's 'Weight of Whispers' is set in Nairobi in the period from April to July 1994, exactly at the time when Tutsi citizens and oppositional Hutu were systematically killed in Rwanda. Nevertheless, her story avoids giving any direct representation of the historical events. Instead, it spins a fictional story around a Rwandan royal, former diplomat and banker and his clan of women, who fall from the heights of a blatantly arrogant elite to the grounds of ordinary refugees struggling for survival in Nairobi. The drama and weight of the genocide is not conveyed by bearing witness to acts of atrocity that happened in Rwanda, but by the fact that even the exceptional wealth and sophistication of this exiled Tutsi family does not prevent them from a rapid and total decline. Finally, Billy Kahora's story, 'The Gorilla's Apprentice', set against the backdrop of the outbreak of post-election violence in Nairobi at the end of 2007, challenges the reader by choosing a gorilla in an animal orphanage as a traumatised survivor and witness of the genocide. What could be understood as the animal's testimony, is delivered in an animal language intelligible only to an escaped perpetrator, hiding under false identity in Nairobi. Testimony to the genocide, as we suggest in the title, becomes scattered and displaced in these stories by complicating the significance of the genocide and its reception in the wider region of East Africa.

\section{Reading the genocide through acts of displaced witnessing}

The notion of displaced witnesses or displaced witnessing in literary studies has been used to address the legacy of conflicts, of mass violence and persecution under violent regimes. Examples include scholarship on works by writers in exile, as for instance in Edurne Portela's (2011) study on the works of Argentine women writers, or through transgenerational and transnational processes of violent memories in diasporas, as in Phyllis Lassner's (2008) Anglo-Jewish Women Writing the Holocaust. We can think of much of the genocide literature by Rwandan authors in terms of displaced memories, highlighting the fact that dimensions of exile and displacement do not only appear as major subjects of narration, as we see in Gilbert Gatore's novel The Past Ahead (2012). Indeed, exile and displacement have often been a precondition for the actual production of many testimonial accounts of genocide. To wit, several Rwandan writers witnessed the genocide from the distance of exile and diaspora. Examples include Benjamine Sehene (2005), Scholastique Mukasonga (2010) and Jean-Marie Rurangwa (2007). Acts of displaced witnessing are to be found, not only in diasporic writing, but also in literary representations that engage with the aftermath of conflict - individual and collective - through displaced characters. Such an understanding would apply to the novels Champs de bataille et d'amour (1999) by Véronique Tadjo and Secrets No More (1999) by Goretti Kyomuhendo, two early works by African writers that approached the genocide through representations of Rwandan refugees. The first is set in an unnamed African country with references to South Africa, the latter in Uganda. Although completely different in style, in both texts the trauma of the genocide enters the narration through the figure of a refugee girl. Through its protagonist Marina, a survivor who escaped to Uganda, Secrets No More invites empathetic identification by giving a detailed account of sexualised genocidal violence and its psychological after-effects. In Champs de bataille et d'amour (1999), a nameless young woman narrates her experience to the 
main character, Aimée. Her testimony is not directly represented, but is conveyed through its unsettling effects on the listener. In Aimée's mind, the physical encounter with a survivor mingles with images of atrocities in media reports. Through the episode, Tadjo inscribes the genocide as a haunting presence which crosses national and physical boundaries and threatens the social and poetic fabric of the text.

As in Tadjo's novel, in the short stories under discussion in this chapter, fragments of the history of the genocide turn up and wander through the texts like fugitive moments of a distant, nonetheless intruding trauma. These fugitive moments, however, do not 'represent' trauma in the sense that they intend to rebuild or reproduce the effects of traumatisation, nor do they build a bridge to empathise with those who bear violent memories. Rather, these fugitive moments describe a process at work in the stories. None of the stories shows an obvious interest in opening empathetic approaches to factual victims of the genocide through fictional representation. They do not serve a victim-identified memory culture. One of the most striking commonalities is that the factual genocide in all three texts forms what Steve Partington (2006) in his analysis of Owuor's 'Weight of Whispers' termed a 'determinate absence'. The narratives touch memories of genocidal violence, but they do not develop them. This 'determinate absence', as Partington argues, elicits a politically and ethically responsible reader, willing to go beyond the text to make sense of the historical event.

The genocide in these stories is witnessed by African others who do not testify to the event, but to its repercussions in their vicinity. In this regard the stories differ significantly from another body of transnational writing, the works that emerged from the project Rwanda Writing in Duty of Memory. Pan-African in its conception and intention, the project initiated by the cultural initiative Fest'Africa in France assembled African writers of diverse national backgrounds - among them the Senegalese writer Boris Boubacar Diop, Véronique Tadjo from South Africa/Côte d'Ivoire, Jean-Marie Rurangwa from Rwanda and Tierno Monénembo from Guinea - in 1998 to create what can be regarded as a literary archive of the genocide (Small 2007; Porra 2011; Kopf 2012). Most of the book-length studies about the genocide in African literature focused on the works that emerged from this project (Coquio 2004; Stockhammer 2005; Dauge-Roth 2010; Soumaré 2013; Semujanga 2016). Creating a memory of the genocide and contributing to the reconciliation process in Rwanda was a major concern in these works. They enacted processes of secondary witnessing, in and through literary language, maintaining a self-reflexive dialogue between aesthetic choices and ethical commitment for the sake of creating a memory for the world. In critical debates on the literatures of the Shoah, ${ }^{3}$ which form a point of intersection in the scholarship on Rwandan genocide literatures, the concept of secondary witnessing has been used to describe an engagement with the Shoah 'not as something enclosed in the past but as a contemporary issue requiring an intensity of representation close to eyewitness report' (Hartman 1998, 38). Diverse in style and scope, the Fest'Africa texts shared common grounds by being, as Audrey Small $(2007,98)$ phrased it, 'in a way less about the genocide itself than about humanity's attempt to comprehend genocide: they are less an attempt to comprehend genocide than an attempt to explore and comprehend humanity's attempts to comprehend'.

What do we make of genocide narratives in African writing that refuse to testify for the other? This is exactly what happens in Wainaina's, Owuor's and Kahora's narrations. Even though each of the three stories deals with representations of Rwandans, who either survived, had to flee from or were involved in the killings in 1994, none of them gives an account of what exactly happened in Rwanda. They do not revisit acts of atrocity and crimes perpetrated, nor do they invite empathetic identification with victims or survivors. Owuor, Wainaina and Kahora do not serve a reader seeking to understand the genocide or to comprehend humanity's 
attempt to understand, as Small described the scope of the Fest'Africa texts. Rather, we are invited to follow the narrator in 'Discovering Home', who announces his first encounter with those members of his family who had survived the genocide: 'it saves me from trying to understand' (Wainaina 2003, 47). Once it is made clear that we are not here to 'understand' the genocide, these stories open up new perspectives. Beyond engaging with trauma, they address what Owuor terms 'loaded silences' in her story, when the narration shifts the plot from Kigali to Nairobi in April 1994 and we read a commentary by the first person narrator with the words:

Now, my world has tilted into a realm where other loaded silences lurk.

(Owuor 2003, 2)

\section{Addressing violent histories in transnational belonging: Binyavanga Wainaina's (2003) 'Discovering Home'}

In 2002, Binyavanga Wainaina first published the short story 'Discovering Home', a first-person narrative relating loosely connected episodes of the author's first return to Kenya after years spent as a student at the Transkei University in South Africa. The critical stations in this selfreflexive re-discovery are Nairobi, the author's home town Nakuru, the Mwingi district and Maasailand, with the last section leading to Wainaina's mother's ancestral home in Kisoro District, Uganda, for a reunion of the Bufumbira branch of the family. The occasion for the meeting is the 'diamond' wedding anniversary of the author's maternal grandparents, Kinyarwanda-speaking Bafumbira ${ }^{4}$ with origins in today's Rwanda and the Democratic Republic of Congo (Wainaina 2011, 159-160). It is the first reunion of the author's mother with her sisters and brothers after decades of separation. Among the siblings is one sister who survived the genocide and war in Rwanda, hidden in a basement for months with her two sons. Later, Wainaina integrated these episodes into his memoir One Day I Will Write About This Place (2011). In this chapter, I use Wainaina's memoir as a directory, or a more fully elaborated map, indicating ways to a deeper understanding of the mere sketch laid out in 'Discovering Home'. Just like sketches for a larger painting, the story works both as a fragment and as a work complete on its own.

In 'Discovering Home', the mother's Bafumbira origins and her first language Kinyarwanda remain peripheral to the narration until the author moves her cultural origins to the centre in the last episode, giving the whole story an unexpected turn. In his memoir, by contrast, Wainaina makes his mother's transnational identity central to the narration right from the first chapter. The account of the family reunion works as a hinge right in the middle of the memoir. It marks a turning point in the author's life as much as in its narration, from which he ultimately emerges as a writer. This turning point is depicted as the transition from a consumerist, escapist relationship with literature to the active appropriation of writing as a means to investigate the social, historical and spiritual patterns of his country, his continent and its people. This brings to the fore their silenced or unvalued significance and creates and shares a powerfully human vision of the present. This turning point corresponds with another key passage, where the author imagines his deceased mother as a teenage girl, standing on the balcony of her father's home, watching crowds of refugees fleeing the imminent political upheaval in the newly independent Congo in 1960.

This invocation of a teenage daughter of a border region, overlooking the confluence of hopes and tragedies in the wake of national independences in the East African region, keeps vigil over her son's narration like a watchful spirit, forming a tie between past and present 


\section{Martina Kopf}

stories of migration, refuge and displacement. Through this image, Wainaina transforms his mother's ancestral home into a station. This station is solid yet permeable to transregional movement and mobility through its location along the road, which itself transverses the wider region of East Africa:

From where Mum sits, this road leads deep into Congo, to Kigali, Rwanda, and the same road will take the refugees who are able to go to Kampala, then Nairobi, then Mombasa and to South Africa, Rhodesia, and Belgium.

(Wainaina 2011, 177)

In Wainaina's story of Kenya, the neighbouring Other is always present, embodied through his mother. She is central to the memoir. Instead of forming a unit with his father's ethnic affiliation as a Gikuyu, ${ }^{5}$ she represents a disruption, an opening. It is through the mother, through her speaking a different and unknown language, that the themes of migration and of the interconnectedness of countries and nations within a larger East African region enter the narrative. In large parts, the narrative seems to pursue the sole aim of giving meaning to this presence of the Other, of creating a story for this transnational belonging, unacknowledged and unintegrated in Gikuyu nationalism and Kenyan nationalism alike. Wainaina does not tell us much about his paternal lineage. The father plays an important role in the memoir, yet it is the story of the maternal line that forms the backbone of the narrative. Through this move, Wainaina succeeds in telling his story of Kenya as informed by, and related to the story of Uganda, and - through the mother's plural origin - as informed by, and related to the story of Rwanda. Furthermore, the metaphor of the girl overlooking the confluence of borders is reminiscent of the arbitrary, colonial creation of these borders and the continued presence of cultural and historical belongings that cut across these borders. Displacement, mobility and transnational belonging are recurrent issues throughout the memoir. Foreignness is repeatedly brought up, from the account of xenophobic attacks against the mother's enterprise in the Nakuru neighbourhood, the experiences of the young Kenyan student living in South Africa to the story of the family reunion in Kisoro. Just as the recounted instances of xenophobia and exclusion are countered by reactions of solidarity and friendship across multiple origins, the narration turns these moments into the germs for an honest and accountable Pan-African consciousness that transcends ethnic strife.

Reading 'Discovering Home' for the first time, one would not expect the narration to touch on the aftermath of the genocide. This event enters the narration from the margins, when in the last section, the first person narrator, together with his family, travels to Uganda for the first time in his life to meet his maternal grandparents. It is then that this story of a homecoming to Kenya unexpectedly departs from the Kenyan border and we have instead an account about Bufumbira identity, introduced by the words:

We are now on the outskirts of the theatre where the Hutus and the Tutsis have been performing for the world's media. My mother has always described herself as a Mufumbira, one who speaks Kinyarwanda. She has always said that too much is made of the differences between Tutsi and Hutu; and that they are really more alike than not. She insists that she is Bufumbira [sic], speaks Kinyarwanda. Forget the rest, she says.

(Wainaina 2003, 47)

Both the story and the memoir take this sentence seriously: 'Forget the rest', a phrase marking either insignificance or incommensurability in colloquial conversation. What saves the narrator 
from trying to understand, however, is knowing that his mother remembers. Her memory undergirds the son and narrator's deliberate oblivion and enables him to move into a different direction:

I am glad she hasn't [forgotten], because it saves me from trying to understand. I am not here about genocide and hate. Enough people have been here for that - try typing 'Tutsi' on any search engine.

I am here to be with family.

(Wainaina 2003, 47, italics my own)

With these words, Wainaina refrains from interpreting the genocide, and from explaining the multilayered political and social history of ethnic relations in Rwanda. He also avoids commenting on their intersection with class power and struggle, the transformation of these categories and their manipulation through racist politics and ideology under colonial rule, as well as their role in postcolonial processes of nation-building (see Mamdani 2001; Newbury 1998; Melvern 2004), caricatured in the extremely flat descriptions of 'Tutsi' and 'Hutu' which dominate media representations.

Wainaina inscribes this history as a determinate absence, which informs the story, but is not represented. Instead, he focuses on the reunion of a dispersed East African family. He depicts this reunion as a process of becoming, rather than being, family. The cousins of his generation meet as strangers, familiar only through mediated contacts and representations of each other, who have to get to know each other from scratch. 'At night, we split into our various age groups and start to bond with each other,' (Wainaina 2003, 49) the author writes. Among them are the three cousins and their mother, Aunt Rosaria, survivors of 'the war in Rwanda' (Wainaina 2003, 49), as he briefly mentions. Their testimony is not represented, nor does the story indicate that it is recounted within the family. At the level of language, it remains a loaded silence. This silence is not resolved by the way the narration gives voice to the cousins. Wainaina presents them as embodying the joy of being alive and entertaining the family with jokes. In fact, allusions to the trauma of genocidal violence reside within their joke, in which they imitate 'a vain Tutsi woman' kneeling before the priest and praying that her children may be tall and have a straight nose (Wainaina 2003, 50). What the story leaves aside is how the genocide had underwritten these and similar jokes with a completely different meaning, when women had been singled out, gang-raped and killed by militias because of the shape of their nose $^{6}$ (Mujawayo and Belhaddad 2004). The narration does not elaborate on these and other loaded silences. Instead, Wainaina focuses on the process of becoming family. In fact, there are at least two concepts of 'family' operating in this episode. One describes a fixed entity, a signifier, which gives reason to the event. The other concept describes its outcome in terms of a dynamic category. The latter concept acquires meaning and is confirmed through a gathering involving numerous individual and collective acts, emotions, memories, conversations and encounters: 'In two days, we feel a family. In French, Swahili, English, Kikuyu, Kinyarwanda, Kiganda, and Ndebele, we sing one song, a multitude of passports in our luggage' (Wainaina 2003, 51).

The story describes how an imagined community, one that existed for the younger generation as a mere virtual reality, rooted in the past lives of the parents' generation, is transmitted to and received in the present. The transcultural and transnational collective that emerges from the encounter is, in Wainaina's portrayal, the effect of a whole set of coping mechanisms which oppose the violent histories it has witnessed across three generations. 


\section{The meanings of silence: Yvonne Owuor's (2003) 'Weight of Whispers'}

If we maintained above the need to abandon expectations of comprehending the genocide through the stories at hand, this statement does not fully account for Owuor's short story 'Weight of Whispers'. With 'Weight of Whispers', Yvonne Owuor constructs a tale of genocide around the fictitious clan of the Kuseremanes, a highly privileged Rwandan royal family, that escapes to Nairobi briefly after the aeroplane carrying the presidents of Rwanda and Burundi has been shot down on 6 April 1994. For this family, Kenya signifies nothing more than an unwelcome, yet unavoidable transit station on their route to Europe, where the patriarch Boniface Kuseremane, together with his mother Agnethe, his fiancée Lune and his sister Bibi, intends to relocate with the help of a network of influential friends. However, the patriarch's network does not react as expected. His friends provide neither support nor shelter. As a result, Kuseremane, the protagonist, goes through a radical metamorphosis from prince, banker and diplomat to a stranded and lawless refugee. Worn down between hostile immigration offices, corrupt police forces and UNHCR officials, fellow compatriots who perceive Kuseremane as génocidaire (the term for those actively involved in the genocide), and a host country speaking foreign tongues, his cocoon of luxury and influential connections rapidly disintegrates.

Owuor's short story addresses a blind spot in the literary and scholarly archive relating to the aftermath of the Rwandan genocide. A significant number of scholars have turned their attention to Rwandan post-conflict society and politics. Much scarcer are ethnographies of the postgenocide diaspora, interpreting the legacy of the genocide from the viewpoint of the exiles it produced. $^{7}$ One of the rare exceptions is the work of the Zimbabwean sociologist Rose Jaji, based on field research among Rwandan refugees self-settled in Nairobi between the years 2006 and 2013. Of the 20 women and men she interviewed, some identified as Tutsi, some as Hutu and some as both. Her study gives important insights into the construction of Rwandans in Kenya. The prevailing public opinion of Rwandans in exile, who refused repatriation under the government of Paul Kagame, has depicted them as Hutu fugitives and génocidaires, as is captured in a typical reaction Jaji encountered among Kenyans: 'You are here to research on refugees. Which refugees are you talking about? The Hutu criminals who ran away after killing people?!' (Jaji 2017, 53). She contrasts these constructions of collective guilt with the multi-layered experiences and narratives of the refugees:

They queried the idea of a single, homogeneous experience of victimhood by starting their stories mostly with 'They say ...' or 'You hear people saying ...' and contrasting this to their own experiences and self-definition as victims who are excluded from sympathy because of association with a 'guilty' ethnic identity. This double-edged sword situation provides the backdrop against which the refugees contest the génocidaires label, even though in muffled tones, historicize ethnic relations in Rwanda, rebrand ethnicity and theorize about belonging, governance, democracy, politics and marginalization.

(Jaji 2017, 60)

Owuor's story resonates with the refugees' discourse. It confronts the 'weight of whispers', the 'you hear people saying' and challenges the reader to rethink simplifying constructions of ethnic relations in Rwanda as the alleged root cause of the genocide. Most significantly, her short story shifts attention from ethnicity to class and relations of power as determining factors. At the same time, it reproduces the power and the effect of rumour. While reading 'Weight of Whispers', the reader feels compelled to ask: 'What is true?' The narration thus constantly refers to the 
unsaid. The unsaid in 'Weight of Whispers', however, is not only the unspeakable and unfathomable effect of trauma. The story opens out layers of silence with very different meanings.

The narration of the protagonist's escape from Rwanda is foregrounded with an analepsis, which seems to offer a kind of epistemological key to the 'silence-scape' (Owuor 2003, 25) into which the world of the protagonist eventually disintegrates. In this brief paragraph the first person narrator recalls encounters with silences surrounding the Holocaust and Europe's fascist past. The paragraph describes a paradox between a perceived over-representation and overengagement with the history of national socialism in public media on the one hand, and the lingering silences met in personal encounters and conversations on the other. Through these encounters with different kinds and layers of silence, Owuor seems to map out a path for the reader showing how to make sense of the narration's confrontation with the 'loaded silences' surrounding and inhibiting the aftermath of the Rwandan genocide and the diaspora it produced. This guiding map, however, is in itself cryptic and hard to make sense of. The paragraph starts with words that capture the gaze of a foreigner directed at the European memorial culture of World War II and the Holocaust:

In the seasons of my European sojourn ... I wondered about the unsaid; hesitant signals and interminable reminders of 'What They Did'. Like a mnemonic device, the swastika would grace pages and, or screens, at least once a week, unto perpetuity. I wondered.

Repeated expressions of 'I wondered', 'I wondered about the unsaid', 'I pondered over what lay beneath the unstated' (Owuor 2003, 2) run through the whole paragraph, giving expression to the protagonist's unsuccessful quest for meaning, but also reproducing the effect in the reader. Essentially, Owuor inscribes her narration between two levels of restrained or redirected language: one is the level of silence; the other is the level of rumour. Both have different meanings, and both are connected to different realities. The unsettling and disintegrating experiences of displacement, of becoming vulnerable, are represented at the level of silence, while the story of the genocide is represented at the level of rumour throughout the narration. In this respect, the narrative comes very close to historical reality, since in the period between April and June 1994, the news seeping out of Rwanda was fragmentary, inadequate and additionally distorted by international reporting that decontextualised the conflict in neo-colonial diction as a 'tribal war'. What seeps into the story in the form of rumours, however, are not just fugitive moments of trauma. Questions of political responsibility, involvement and complicity too are relocated to the level of rumour. Owuor's narration thus not only portrays a reality that decisively shapes life under conditions of flight and displacement; it also performs the effective dependence on inadequate or unreliable chains of information and scattered pieces of testimony for the reader, who is equally forced to make sense out of allusions, half-truths and fragments.

As Partington has suggested, characterisation and its relation to historical reference in 'Weight of Whispers' pose problems rather than resolving them. In the story, Kuseremane is involved in the massacres from which he is fleeing. His name is on the list of génocidaires, while his actual guilt is left unconfirmed. Depicting him simultaneously as responsible for and victimised by the genocide, the story comes uncannily close to revisionist discourses, which put the blame on the Tutsi upper class for having created the conditions that fostered the outbreak of violence in 1994, thus taking a leap over the transformations of political power in postcolonial Rwanda (see Mamdani 2001, 134f). Partington underlines how improbable it would have been in 1994 for Kuseremane to be a senior diplomat, since at that time there was one single Tutsi ambassador in the entire diplomatic service in Rwanda (Nasong'o in Partington 2006, 114). Furthermore, the 


\section{Martina Kopf}

possibility that a Tutsi might have been involved in the genocide in the way Owuor's story suggests 'is a nonsense bordering on the obscene' (Partington 2006, 114). Therefore, an unquestioning reading of Kuseremane as a 'Tutsi prince' - a classification the story does not make - misses the point.

Who then is Kuseremane? It is this simple question, which, as Partington shows, leads into an interpretative dilemma that needs to be acknowledged and addressed rather than glossed over. Historicity in the story is complicated through the inscription of a master-servant relationship between Kuseremane and Roger, the clan's domestic servant (see Seel 2004). We can, therefore, add a second question: who is Roger? In the story, he takes to the streets a few days after the aeroplane carrying the presidents of Rwanda and Burundi has been shot down, and returns a few days later. He is caked in blood and carries with him the smell of the massacres, which the royals mistake for the smell of gorgonzola cheese unwrapped for dinner. Throughout the narrative, Roger repeatedly surfaces in the shape of rumours shared among the diaspora, as a relentless force in the genocidal murders. As with Kuseremane, his construction as génocidaire leaves behind questions that are never answered. At first sight, he comes across as representative of the Interahamwe militias, yet the symbolism inherent in his relationship with his master cannot easily be pinned down to a single and concrete historical referent. As Kruger $(2011,122)$ observes, the iconography of the dreadlocked, ragged man, who returns from a daylong disappearance, is reminiscent of a Mau Mau fighter, which further complicates the reading of the story. How could such an iconic invocation fit with Roger's message: 'tout a été nettoyé' 'everything has been cleansed' - the code used for genocidal murder?

In her study on Rwandan refugees in Nairobi, Jaji $(2017,49)$ describes how any attempt at addressing subjective truths is circumscribed and prevented by polarising constructions of collective guilt and victimhood, which undergird official memory politics in Rwanda and beyond:

[S]cholarly debates on Rwanda and, by extension, Rwandan refugees are fraught with the same polarization that characterizes the country's politics in that an observer who presents views beyond the official position seems unable to escape the trap of being seen as denying and condoning rather than acknowledging and condemning.

While Wainaina circumvents this trap by deliberately avoiding any interpretation of Rwandan politics before, during and after the genocide, Owuor seems to play with the trap, which - as her story makes clear - is a deadly serious game. She also shows a way to master the trap: by fully employing the possibilities of fiction. The royal clan, which settles in the Nairobi Hilton Hotel and sniffs at the poor performance of the hotel jewellery shop, only to leave a few weeks later secretly as thieves, with the bill unpaid and the hotel's towels in the baggage, is doubly displaced: once in time and once in space. Dislocation and displacement thus figure not only as subjects of Owuor's narration; they are central components of the narrative strategy that makes this story work. It is from the dual displacement that the story derives its ambiguity and nuance. Owuor uses a complex technique of intertextuality and blending. She combines fragments of a wider history of African independences, which reach both beyond the immediate history of the genocide and beyond Rwanda's national borders. As subjects, the Kuseremanes embody a racialised Tutsi superiority, forged through the racist discourse of European imperialism in the nineteenth century (Kruger 2011, 119). They do not, however, represent Tutsi as an ethnic group. What they do represent is a political and social class in its rituals of power. Through their dislocation in time, Owuor complicates simplified constructions of perpetrators and victims. She deconstructs ethnicity as a dominating category in the interpretation of the genocide by radically introducing class privilege and neocolonial relations of power as a major factor of the 
political destabilisation and the human catastrophe of which the genocide was a peak, but not the sole expression in the region of East Africa. The narration thus opposes a depoliticised reading of trauma. Instead, it demands that the trauma of genocide is to be understood as a problem of political power, or, as Kruger $(2011,129)$ points out:

the narrative's ultimate interest lies in the deconstruction of political identities enabling such exclusionary and violent practices. Between the Tutsi aristocrat and his sovereign drive to mastery and the vulnerable refugee complicit in his own dehumanization, indeed, ' $[\mathrm{t}]$ here must be another way to live'.

\section{Drama on a silent screen: Billy Kahora's (2010) 'The Gorilla's Apprentice'}

With 'Weight of Whispers', Kahora's story shares the locale of the Nairobi Animal Orphanage, a shelter and rehabilitation centre for wild animals in the Nairobi National Park. A popular leisure and tourist location, the orphanage in both narrations contains the promise of a safe, recreational space for humans and animals alike, a world apart and protected from the turmoil of man-made disaster. In 'Weight of Whispers', it is during a stroll through the Orphanage on the invitation of a befriended, influential Rwandan family that the Kuseremanes briefly recover a sense of unburdened presence. A sideshow in Owuor's narration, Kahora moves the Orphanage with its illusory promises centre stage, making of it a highly symbolic site of encounter. The Rwandan past enters the Kenyan present in the shape of a gorilla and a fugitive perpetrator living under a false identity in Nairobi. The story is set against the backdrop of the outbreak of post-election violence in the last days of December 2007, when the results of the presidential elections were announced and Mwai Kibaki was sworn-in as president. Jimmy Gikonyo, a regular visitor to the Orphanage, is about to have his eighteenth birthday, which will mean he forfeits a reduced entrance fee. He prefers the surroundings of the Orphanage to real life, and he particularly enjoys his regular visits to the caged gorilla, Sebastian, whom Jimmy considers a friend. 'Real life' means sharing a small flat with his alcoholic mother, a former teenage mother, who makes her income from fleeting relationships with men, after Jimmy's father, probably a well-situated white residing near State House, had left his mother and the seven-year-old boy.

It is at the Orphanage that Jimmy observes another visitor approaching the gorilla's cage and conversing with the animal in what appears to be the gorilla's language. On the side of the cage is a sign, identifying the gorilla as the: 'Oldest Gorilla in the World. Captured and Saved from the Near Extinction of His species After the Genocide in Rwanda. Sebastian, 56. Genus: Gorilla.' The gorilla whisperer turns out to be a fugitive génocidaire, now calling himself Professor Charles Semambo, renowned expert on mountain gorillas. The boy, unaware of Semambo's secret and eager to learn how to converse with his friend, approaches the Professor after one of his public lectures. Together, they return to the Orphanage the same night that violence erupts on a large scale in the slum area Kibera. They drive through rampaging gangs, whose portrayal is reminiscent of the road blockades set up by Interahamwe militias in Kigali in 1994. They find Sebastian in a kind of paralysed shock caused by the outburst of violence in close proximity to the Orphanage. Semambo, in what seems to be an act of offering help, enters the cage with a syringe and puts an end to the gorilla's life. The story ends with a ghostly scene, during which the gorilla, in a last outburst of fury, takes Semambo to his death:

Sebastian whirled his arms like windmills. Semambo stood without moving, then Sebastian wrapped his arms around him, roaring enough to drown out the rest of the world. Jimmy 
had scrambled away to the edge of the cage and Semambo's face turned apoplectic, red, crisscrossed with blood vessels. His glasses fell off, and his light eyes turned darker as the two figures became one.

(Kahora 2010, n.p.)

As with 'Weight of Whispers', we can ask the question: who is Sebastian? 'Jimmy had read all the books there were on gorillas, and he knew about their sense of community, their empathy - their embracing of death' (Kahora 2010, n.p.). The animal embodies a humanity destroyed in a human-made disaster. Sebastian is the only one who reacts emotionally to the collective anxiety, desperation, murderous aggression and fear inhabiting the neutral expression 'post-election violence'. Through him, Kahora creates a figure for trauma and re-traumatisation. He gives this figure an animal, and not a human appearance. The past returns in the ethnicisation of political conflict, in the fuelling of ethnic hatred and in the violence targeted at ethnic communities. Semambo, the fugitive perpetrator, is the one who recognises the signs and interprets them: 'While some fuss about whether to eat chicken or beef tonight, many won't see tomorrow morning. We are in the abyss and the abyss is in us' (Kahora 2010, n.p.). His calm assessment of the situation is undermined by the emotional suffering of the gorilla. Similar to Owuor's story, the factual mass violence happens outside the narrative. In Kahora's story, this is not the genocide against the Tutsi, but the post-election violence at the beginning of 2008. It forms the background, appears in silent media images on the TV screen with the sound switched off in the flat Jimmy shares with his mother, and in the screams and the reflections of fire invading the Orphanage.

'Nothing alive can take the past he has come from and then have to repeat it in old age' (Kahora 2010, n.p.). With these words, Kahora has the emotional subject, the main conveyor of affect in this narrative, killed. The ending is deliberately left ambiguous. Metaphorically, the story suggests that those who survived the genocide in Rwanda had been killed a second time in the ethnicised violence in Kenya 2007 and 2008. Emotionally, the trauma of the postelection violence is not bearable, any more than the genocide in Rwanda was. The animal's testimony remains undelivered; it is not rendered intelligible to the boy who forms a bridge between the two histories.

\section{Displacing empathetic witnessing}

As we saw in the beginning of this chapter, Wainaina's, Owuor's and Kahora's stories do not or very limitedly represent the genocide in the form of individual trauma. Reading them as forms of empathetic witnessing, as Edgar Nabutanyi (2014) suggests for the representation of the Tutsi refugee girl Marina in Goretti Kyomuhendo's novel (1999) Secrets No More, does not work with the texts under discussion here. Nor do the narratives work as witnesses to what happened in Rwanda in 1994, and this is deliberate. The uninformed reader will not get a picture which would help her to make sense of the concrete historical events. With Partington, we termed the way the stories refer to the genocide as 'determinate absence'. The narratives thus challenge the reader to engage differently with the presence of violent histories. Acts of witnessing in these stories become displaced in more than one sense. Not only do they take issue with the social and political realities of exile and displacement; the act of witnessing itself becomes displaced in the sense that positions that have already been developed in literatures on the genocide get shifted and transposed. The determinate absence of representation gives way to a shift in focus to important questions which relate to the aftermath of the genocide in the wider region of East Africa. Even though the genocide narratives in these stories do not open an 
empathetic approach, affect plays a significant role in the narrative processes in which the aftermath of the genocide is decentred and displaced.

The genocide narrative which Wainaina in 'Discovering Home' builds around the determinate absence of representation contains trauma without exposing it. This is an effect of careful narrative choices. As demonstrated above, the author does not exploit the individual stories of the family members who survived the genocide. The climax of the narration does not consist in their survival or triumph over genocide, but in the unexpected arrival of an eldest sister from the USA. With her arrival, the dispersed family is complete. This ending paragraph speaks as much through what remains unsaid as through what it says:

Nothing is said, the service motors on. Everybody stands up to sing. Somebody whispers to my Aunt Rosaria. She turns and gasps soundlessly. Others turn. We all sit down. Aunt Rosaria and Aunt Christine start to cry. Aunt Rosaria's mouth opens and closes in disbelief. My mother joins them, and soon everybody is crying. The priest motors on, fluently. Unaware.

(Wainaina 2003, 52)

The power of the moment speaks to the reader, aware of the abundance of meaning that it contains but does not represent. Wainaina makes of this moment a celebration of wholeness which is conveyed on the level of affect. The wholeness re-created through this moment of an inclusive, knowing silence gives trauma a space to be without the need of being mediated.

In the Kuseremanes, Owuor created characters with whom the reader does not sympathise at first. If nevertheless a sense of empathy arises, it is with an aim to bringing into focus the forms of concrete and structural violence that reside in the global and national politics of migration. Owuor's narrative remains intentionally vague about the historical events in Rwanda, but it is explicit about the global regime of borders. 'Weight of Whispers' presents a multi-layered examination of how dependencies are created through the national and international politics of migration, entry regulations and the governance of mobility within structures of global inequality. With respect to the genocide, the construction of the protagonists as members of an elite shifts the perspective from ethnicity to class relations. Their class status, as well as the social and political realities of flight and expulsion, function as narrative choices, used to highlight the precariousness and vulnerability inherent in the legal construction of the 'refugee'.

Kahora's short story interweaves the trauma of the post-election violence in Kenya with the trauma of the genocide in Rwanda. Through his narration, both instances of political violence are fused into one and dissolve into each other. Awareness of the parallels between Kenya and Rwanda were rife in the Kenyan media and in civil society as Jaji $(2017,53)$ points out:

Apprehension about the danger inherent in the concept of genocide was clearly expressed in references to Kenya as 'another Rwanda' by international media and Kenyans on Internet forums. ... Rwanda became the immediate graphic image invoked in pleas to stop the violence.

While using the reference to the genocide as a lens through which to view the Kenyan situation, Kahora at the same time signals an important shift. He redirects the central antagonism of the story away from the hegemonic narrative of ethnic conflict. The relationship between Semambo and Sebastian - the perpetrator and the victim/survivor - represents a conflict between a subjectivity that embodies empathy and a sense of community, in opposition to a subjectivity associated with a negation of these values. This conflict is not one between different 
ethnic groups, any more than it is necessarily one between separate individuals. It exists within one and the same person, within one and the same collective, in the way Semambo and Sebastian become one at the end of the story.

\section{Conclusion}

Witness accounts of the genocide are not critical in any one of these three narratives. Each story includes characters who may have witnessed the genocide, and whose factual position as a witness to past events and experience of actual trauma provides a basis for dealing with other questions. Wainaina's narration probes the bonds created through transnational and transcultural belonging as a resource to overcome the divisions created by colonial, national and ethnic circumscriptions of identity and space. Owuor highlights the precariousness of class positions in Africa and addresses states of lawlessness and dependency created through a global (mis-)governance of forced migration and conflict-driven movements. Kahora's narration diverts attention from the genocide to the reiteration of mass violence in Kenya in 2007 and 2008 and the unresolved trauma of politically fuelled inter-ethnic hatred in other national contexts. The determinate absence of immediate testimony to the genocide makes way for loaded silences that inhibit its aftermath in wider social and political landscapes. The processes at work in these stories have been described in this chapter as acts of displaced witnessing. 'Displaced', here, does not necessarily refer to giving testimony through representations of displaced persons and refugees, as is the case in the novels by Véronique Tadjo and Goretti Kyomuhendo mentioned above. Both 'Weight of Whispers' and 'The Gorilla's Apprentice' have displaced Rwandans as central characters. As witnesses to genocide, however, they are shown to be unreliable, as is the case of the Kuseremanes in 'Weight of Whispers', who had been fenced off through their privileged position, and Charles Semambo, the escaped perpetrator living under a false identity in Nairobi. They are not encouraged to tell their stories, as we see in 'Discovering Home', or testimony is represented in a language that is unintelligible to the reader, as is the case with Sebastian, the gorilla in Kahora's short story. The word, 'displaced', here refers to the narrative act itself, in the sense that the authors pivot from an engagement with the past in one location, to an engagement with the present in multiple sites. The notion of displaced witnessing does not serve to oppose, but to enhance forms of empathetic witnessing in and through literatures of the genocide. Empathy with those who suffered is not enough. There must be other ways to confront the presence of traumatic and traumatising histories. In fact, moving away from empathetic identification - which, in fact, remains an impossible act - does not constrain, but in fact broadens the recognition of the realities and subjectivities of those who have survived human atrocities. Through their subject positions as authors and through their texts, Wainaina, Owuor and Kahora connect the genocide with the political and social history of their countries and beyond. Their texts raise questions about the reception of the genocide in the wider region of East Africa, physically in terms of the diasporas it produced and symbolically in terms of how its significance is to be integrated into a larger narrative of Pan-African belonging.

\section{Notes}

1 The focus in this chapter is on Anglophone short stories. A more comprehensive analysis should include Mũkoma wa Ngũgĩ's crime novel Nairobi Heat (2010), Meja Mwangi’s novel The Big Chiefs (2008) and the Swahili short story 'Mkimbizi' [Swahili for 'refugee'] by John H. Habwe (2004).

2 The short story had first been published online in 2002. I am referring here to the first print edition, self-published 2003 by Binyavanga Wainaina.

3 'Shoah' is the Hebrew term for the genocide of the Jews under the German national-socialist regime. 
4 The Bafumbira (sg. Mufumbira), also identifying as Banyarwanda, are a national group of today's Uganda, living in Bufumbira, today Kisoro district in Southwestern Uganda. They are not nationals of today's Rwanda, but belong to the larger Kinyarwanda-speaking population of the Great Lakes region. Justice Patrick Tabaro gives an account of the rich cultural and political heritage of this border or rather turned-into border region from an indigenous perspective in 'Uganda: Tracing Incorporation of Bufumbira into Uganda British Protectorate' (2016).

5 In 'Discovering Home' Wainaina uses the spelling 'Kikuyu' throughout the text, in One Day I Will Write About This Place the spelling 'Gikuyu'.

6 See on this, for instance, the testimonial account of the Rwandan sociologist, activist and psychotherapist Esther Mujawayo (Mujawayo and Belhaddad 2004).

7 There are of course ethnographies of diasporas produced through earlier violent upheavals in Rwanda and Burundi, such as Liisa Malkki's (1995) Purity and Exile: Violence, Memory, and National Cosmology among Hutu Refugees in Tanzania.

\section{Acknowledgement}

This work was supported by the Austrian Science Fund (FWF) V 554 Richter Programme. I wish to thank Miša Krenceyova, whose careful reading and comments helped this work through its early stages; Inge Grau for our discussion of the texts; Sonja Wohlatz who gave the title to this chapter; Moradewun Adejunmobi and Carli Coetzee for their invaluable comments and suggestions that went into the framework of this chapter.

\section{References}

Coquio, Catherine. 2004. Rwanda. Le Réel et les Récits. Paris: Éd. Belin.

Dauge-Roth, Alexandre. 2010. Writing and Filming the Genocide of the Tutsis in Rwanda: Dismembering and Remembering Traumatic History. Lanham, MD: Lexington Books.

Diop, Boubacar Boris. 2006. Murambi, the Book of Bones. Bloomington: Indiana University Press.

Gatore, Gilbert. 2012. The Past Ahead. Translated by Marjolijn De Jager. Bloomington: Indiana University Press.

Habwe, John H. 2004. 'Mkimbizi'. In Mwongozo wa Mayai Waziri wa Maradhi, edited by Timothy M. Arege, K.W. Wamitila and Deogratias Mwakyembe, 83-84. Nairobi: Focus Publishers.

Hartman, Geoffrey. 1998. 'Shoah and Intellectual Witness'. Partisan Review 1: 37-48.

Hitchcott, Nicki. 2015. Rwanda Genocide Stories: Fiction after 1994. Liverpool: Liverpool University Press.

Jaji, Rose. 2017. 'Under the Shadow of Genocide: Rwandans, Ethnicity and Refugee Status'. Ethnicities 17 (1): 47-65.

Kahora, Billy. 2010. 'The Gorilla's Apprentice'. Granta 111 (February). https://granta.com/the-gorillas-app rentice/.

Kayimahe, Vénuste. 2014. La Chanson de l'Aube. Toulouse: Éd. Izuba.

Kopf, Martina. 2012. 'The Ethics of Fiction: African Writers on the Genocide in Rwanda'. Journal of Literary Theory 6(1): 65-82.

Kruger, Marie. 2009. 'History, Nation, Ghetto: Kenyan Women's Literature and the Ethics of Responsibility'. Postcolonial Text 5(3), 1-17.

Kruger, Marie. 2011. Women's Literature in Kenya and Uganda: The Trouble with Modernity. New York: Palgrave Macmillan.

Kyomuhendo, Goretti. 1999. Secrets No More. Kampala: FEMRITE Publications.

Lassner, Phyllis. 2008. Anglo-Jewish Women Writing the Holocaust: Displaced Witnesses. Basingstoke: Palgrave Macmillan.

Malkki, Liisa Helena. 1995. Purity and Exile: Violence, Memory, and National Cosmology among Hutu Refugees in Tanzania. Chicago, IL: University of Chicago Press.

Mamdani, Mahmood. 2001. When Victims Become Killers: Colonialism, Nativism, and the Genocide in Rwanda. Princeton, NJ: Princeton University Press.

Melvern, Linda. 2004. Conspiracy to Murder: The Rwandan Genocide. London:Verso.

Mujawayo, Esther and Souâd Belhaddad. 2004. Sur Vivantes: Rwanda, dix ans après le génocide. La Tourd'Aigues: Éditions de l'Aube. 


\section{Martina Kopf}

Mukasonga, Scholastique. 2010. L'Iguifou: Nouvelles Rwandaises. Paris: Gallimard.

Mũkoma wa Ngũgĩ. 2010. Nairobi Heat. New York: Melville House.

Mwangi, Meja. 2008. The Big Chiefs. Nairobi: East African Educational Publishers.

Nabutanyi, Edgar Fred. 2014. 'Affect in Representations of Children's Experiences of Mass Violence: Uwem Akpan's Say You're One of Them and Goretti Kyomuhendo's Secrets No More'. Matatu 45: 101-117.

Newbury, David. 1998. 'Understanding Genocide'. African Studies Review 41(1): 73-97.

Owuor, Yvonne Adhiambo. 2003. 'Weight of Whispers'. Kwani? 1: 8-37.

Partington, Stephen Derwent. 2006. 'Making Us Make some Sense of Genocide: Beyond the Cancelled Character of Kuseremane in Yvonne Adhiambo Owuor's "Weight of Whispers". Tydskrif Vir Letterkunde 43(1): 110-121.

Porra, Véronique. 2011. 'Y'a-t-il une spécificité africaine dans la representation romanesque de la violence génocidaire?' In Violences postcoloniales. Représentations littéraires et perceptions médiatiques, edited by Isaac Bazié and Hans-Jürgen Lüsebrink, 145-163. Berlin: LIT Verlag.

Portela, M. Edurne. 2011. Displaced Memories: The Poetics of Trauma in Argentine Women's Writing. Lewisburg, PA: Bucknell University Press.

Rurangwa, Jean-Marie Vianney. 2007. Au Sortir de l'Enfer. Paris: Harmattan.

Seel, Amanda M. 2004. 'Displacement and Diaspora: New Locations in African Writing'. Wasafiri 19(41): $21-24$.

Sehene, Benjamin. 2005. Le Feu sous la Soutane: Un Prêtre au Coeur du Génocide Rwandais. Paris: Esprit frappeur.

Semujanga, Josias. 2016. Narrating Itsembabwoko: When Literature Becomes Testimony of Genocide. New York: Peter Lang.

Small, Audrey. 2007. 'The Duty of Memory: A Solidarity of Voices after the Rwandan Genocide'. Paragraph 30(1): 85-100.

Soumaré, Zakaria. 2013. Le Génocide Rwandais dans la Littérature Africaine Francophone. Critiques Littéraires. Paris: L'Harmattan.

Stockhammer, Robert. 2005. Ruanda: Über einen anderen Genozid schreiben. Frankfurt am Main: Suhrkamp.

Tabaro, Justice Patrick. 2016. 'Uganda: Tracing Incorporation of Bufumbira into Uganda British Protectorate'. The Observer, 11 January. http://observer.ug/viewpoint/42008-tracing-incorporation-of-bu fumbira-into-uganda-british-protectorate.

Tadjo, Véronique. 1999. Champs de Bataille et d'Amour: Roman. Abidjan; Paris: Nouvelles éditions ivoiriennes; Présence africaine.

Tadjo, Véronique. 2002. The Shadow of Imana: Travels in the Heart of Rwanda. African Writers Series. Oxford: Heinemann.

Wainaina, Binyavanga. 2003. Discovering Home. Binyavanga Wainaina.

Wainaina, Binyavanga. 2011. One Day I Will Write About This Place: A Memoir. London: Granta. 


\section{Contestations through same-sex desire in Jennifer Nansubuga Makumbi's Kintu}

Edgar F. Nabutanyi

\section{Introduction}

Twenty-five years after the publication of Moses Isegawa's Abyssinian Chronicles - a novel that deploys a child narrator to expose the Ugandan postcolonial legacy of violence and dictatorship - in 1989, it can be argued that a successor to the category national Ugandan novel was published: Jennifer Nansubuga Makumbi's Kintu. While there are many points of divergence between Isegawa's and Makumbi's novels, the thread that connects them is the authors' expressed ambition to craft a Ugandan national tale. ${ }^{1}$ Abyssinian Chronicles explores how Uganda's postcolonial heritage of political violence is mobilised to affirm the idea of a Ugandan patriarchal and heterosexual postcolonial nation. Kintu interrogates these heteronormative foundational myths in which the depicted nation is anchored, creating what Bwesigye Bwa Mwesigire has called an expansive and 'contemporaneous postnation' (2018a: 113). By the author's own confession, Kintu:

flowed out of a desire to give Ugandans a taste of their own long and complicated history, to do for Ugandans something like what Chinua Achebe's novels did for Nigerians in the 1960s: to make them look at a hill for example, and know that Gandas ${ }^{2}$ have been climbing it for centuries. The goal was to remind Ugandans that Uganda's history did not begin in 1962 .

(Underwood 2017; Bady 2017)

Makumbi's reference to Achebe in the interview quoted above, and her intertextual mirroring of Things Fall Apart in Kintu, underlines the fact that she sees herself in the Achebean role of the 'novelist as a teacher' or what Wale Adebanwi calls a 'writer-social thinker'. As a 'novelist-teacher' (Achebe 1964) or 'writer-social thinker' (Adebanwi 2014), Makumbi distils profound insights about the Ugandan nation, as many analysts of the texts have already demonstrated. 
Envisioning herself as a novelist-teacher allows Makumbi to privilege and respond to typically Ugandan debates on such subjects as religion, the supernatural, myth, identity, love, justice and sexuality. The novel's treatment of history is elastic, as the plot expands over time and then contracts again; yet the novel does more than educate Ugandans about their past, present and future. The author's ambitious intention is to comment on significant Ugandan historical events stretching over a period of three hundred years, while discussing a variety of themes ranging from religion, AIDS, political violence, war and economic collapse to mob justice. This reminds us of Wale Adebanwi's observation that 'African creative writers [are] not merely intellectuals whose work mirror or can be used to mirror social thought, but [are] social thinkers themselves who engage with the nature of existence and questions of knowledge on the continent' $(2014,406)$. Adebanwi's vision of the role of an African writer as a social thinker is that of a public intellectual who uses his or her fiction to unearth complex versions of the continent's reality and that upon this exposition, then proceeds to theorise Africa's existential questions of the moment. Makumbi's desire to impart to Ugandans what one reviewer has called 'their own often-overlooked history' (Sarasien 2018), exemplifies Adebanwi's presentation of the African writer as a social thinker. In the statement quoted above, Makumbi admits that her novel imagines and gives voice to a Ugandan past of which many Ugandans are unaware, specifically given the fact that inconvenient Ugandan realities are often silenced and erased by the dominant forces in society. This is perhaps why, in many respects, Kintu can be read as a text that makes visible subjects that are rendered peripheral in a hetero-patriarchal society.

There are stories, Makumbi argues, that 'the archive won't tell, places where the historical record suddenly goes silent' (Bady 2017). If we were to read the preceding passage as suggesting that certain facets of Ugandan history are silenced or erased from the public record, then we can appreciate this novel's exploration of such silences. Conversely, it could be argued that fiction allows Makumbi to speculate on and engage with topical subjects at the time of writing and publication of her novel. We see this, for example, in Makumbi's declaration that she wanted 'to talk about homosexuality because Uganda is perceived as the most homophobic country in the world. There is the idea that homosexuality came with colonialism, that before that, Africans never engaged with homosexuality' (Underwood 2017). This declared intention places Makumbi within a Ugandan writing tradition on same-sex sexuality comprising intellectuals such as Sylvia Tamale and Stella Nyanzi, as well as fiction writers such as Monica Arac de Nyeko, Anthea Paleo and Beatrice Lamwaka who use their work either to advocate the rights to freedom of sexual orientation, or to challenge homophobia in the Ugandan public sphere. The works of these authors are often read as advocacy seeking to counter a conservative and Christian outlook that disingenuously frames homosexuality as a threat to the Ugandan patriarchal and heterosexual polity (Epprecht 2008). ${ }^{3}$

Challenging an essentialising and conservative rhetoric in Ugandan public discourses, these thought leaders consistently problematise depictions of same-sex sexuality in the country. Sylvia Tamale's contributions to Ugandan debates about sexuality occupy a distinct space because she approaches the discussion from a justice/equality/human rights perspective, and not from a religious-moral or cultural angle, as is often the case in debates on this subject in Ugandan public discourses. In her various writings including African Sexualities: A Reader (2011), 'A Human Rights Impact Assessment of the Ugandan Anti-Homosexuality Bill 2009' (2009), 'Homosexuality: Perspectives from Uganda' (2007a) and 'Out of the Closet: Unveiling Sexuality Discourses in Uganda' (2007b) Tamale interrogates the homophobic inflection of public debate about sexuality in Uganda. Tamale's objective in her publications is to challenge the premise on which Ugandan hostility towards same-sex sexuality is anchored, in order to argue for the protection of the rights of subjects who engage in same-sex intimacy. 
It is perhaps in African Sexualities: A Reader that Tamale's fiercest and most eloquent criticism of Ugandan opposition to same-sex sexuality is articulated. In the volume, she acknowledges that the continent is currently replete with vibrant movements, some seeking to reinforce sexual hegemonic powers and others challenging, subverting, resisting imposed modes of identity, morality and behavioural patterns' (Tamale 2011,2). As part of the movement of resistance and subversion, Tamale seeks to 'deconstruct, debunk, expose, contextualize and problematize concepts associated with African sexualities in order to avoid essentialism, stereotyping and othering' of this group (Tamale 2011, 1). It could be argued that Tamale's intention is to reclaim the humanity of sexual minorities that is often erased in African mainstream discourses. Her work 'unclothes, quizzes and gives voice to issues that society has clothed in taboos, inhibition and silence' (Tamale 2011, 5). The activism undertaken by other writer activists and public intellectuals like Nakisanze Segawa (2016) Beatrice Lamwaka (2012), Monica Arac de Nyeko (2007) and Anthea Paelo (2013) complement Tamale's commitment to exposing socially tabooed and silenced sexuality. These Ugandan writers deploy their fiction as interventions in a paradoxical national sexuality debate that is characterised by what Rahul Rao calls Ugandan homosexuality denialism (Rao 2015). Rao cites the case of Mwanga and the Ugandan martyrs to question why public discourses in Uganda argue that a spectrum of sexuality does not exist when the country annually celebrates the martyrdom of court attendants allegedly killed by Kabaka Mwanga for resisting his bisexual advances. The paradox that underlies Ugandan sexuality debates is that while homosexual denialism abounds in public discourses, there is a growing fictional archive that features same-sex desiring characters. Fiction, then, has become one of the many platforms through which Ugandan writers address the problematic of sexuality in specifically Ugandan debates.

The Ugandan Anti-Homosexuality Act of 2014 crystallised divergent positions in the disagreements over sexuality in Uganda. Supporters of the 2014 legislation argued that homosexuality represented a threat against the Ugandan heterosexual family and culture. The justification proffered in defence of the legislation prompted public intellectuals like Makumbi to question the misrepresentations of Uganda's history and culture for political expedience. She remarked in the previously cited interview: 'it wasn't homosexuality that Europe brought, it was homophobia' (Underwood 2017). However, and unlike her contemporaries Monica Arac de Nyeko (2007) and Beatrice Lamwaka (2012), who campaigned in their creative writing for the acceptance of lesbianism as a normative Ugandan sexual practice, Makumbi in Kintu presents fluid sexuality as a quintessentially Ugandan practice with deep roots and history in the society. And in order to make the argument that contemporary homosexuality cannot be attributed to the corrupting influence of colonialism, Makumbi deliberately skips over the 60 years of British colonialism in Uganda in her fictional representation of Ugandan history. In other words, Makumbi does more than recreate Ugandan history in this novel. One could say, in addition, that Makumbi uses fiction to rewrite and reimagine Ugandan sexual practices.

Makumbi's reliance on fiction to portray a Ugandan past where sexual orientations were not only fluid, but where such fluidity was also tolerated, aligns with recent scholarship on homosexuality in African society and fiction. Marc Epprecht's Heterosexual Africa?: The History of an Idea from the Age of Exploration to the Age of AIDS (2008) offers one of the most compelling surveys of the construction of heterosexuality on the African continent in relation to same-sex intimacy. The colonial and anthropological archive, says Epprecht, presented Africa as 'unwaveringly heterosexual' $(2008,35)$. In this view, the dominant forms of African sexuality were anchored in an 'overdetermined value of heterosexual marriage and reproduction. Individual sexual desire was largely subsumed to the broad interest of the extended family and lineage' (Epprecht 2008, 36). From this perspective it is no wonder, argues Epprecht, that 
homosexuality began to be framed as a sign of contamination by foreign entities, or as the negative consequence of modernity, urbanisation and industrialisation.

This point of view often ignored or silenced any evidence of African homosexuality, in order to privilege a uniform African heterosexuality. The paradox of African homosexuality - in spite of the evidence of its existence, it is denied in public discourses - is the point that Rahul Rao (2015), Kevin Ward (2013) and Neville Hoad (2007) variously make when they contend that homosexuality is indigenous and homophobia is an importation into Africa. Rao foregrounds the paradox that seeps through Ugandan debates about sexuality when he asks 'how public commemoration of [Ugandan martyrs: the young men who were allegedly executed by Kabaka Mwanga because they rejected his homosexual advances] can co-exist with the claims that same-sex intimacy is alien to Uganda' (Rao 2015, 1). Rao's point about ironies in Ugandan public discourses on homosexuality is replicated across the work of many commentators on this topic. Scholars such as Kevin Ward (2013) Neville Hoad (2007), Stella Nyanzi (2013, Nyanzi and Karamagi 2015) and Sylvia Tamale (2007a, 2009, 2011) examine how religion intersects with the state and simplified notions of tradition to erase and silence the subjectivity of persons who engage in diverse sexualities in the Ugandan context.

While African anthropological and Christian archives produce a rhetoric that purges homosexuality from the public record on African sexuality, Epprecht argues that fiction and film have done much to uncover and engage with questions relating to same-sex intimacy in Africa. In chapter five of his ground-breaking work, where he explores how fiction and film have responded to the question of African homosexuality, he identifies three recurrent tropes in most African narratives that feature characters represented as engaging in same-sex intimacy either willingly or under compulsion. The first trope is what he labels the didactic representation of samesex sexuality. In such instances, and according to Epprecht, homosexuality functions as a sign of corruption or contagion that is associated with modernity and urbanisation. African subjects in such narratives seek to avoid a form of corruption that is embodied in homosexual practices and connected to modernity. Brenna Munro echoes Epprecht's observations about the link between same-sex intimacy and unsettling social experiences in her 2016 article where she identifies war as a new motif in Nigerian writings that reference male-male sexual assault. Munro argues that novels published in the twenty-first century such as Beasts of No Nation and Song of Night use the male-male sexual assault of child soldiers as a metaphor for war-time trauma or military rites of passage that have a catastrophic impact on the psyche of the child. In the texts that Munro examines, these forms of sexual assault are depicted as tools of war. This is because neither the perpetrators nor the victims identify themselves as homosexual, thus pointing to the difficulty of portraying same-sex intimacy in normative settings. The didactic motif that both Epprecht's and Munro's analysis highlight in a number of novels frames homosexuality as a contagion that traumatises characters who are subjected to same-sex intimacy against their will.

Epprecht's second trope is one that is commonplace in postcolonial novels and can be found in Wole Soyinka's The Interpreters and Ayi Kwei Armah's Two Thousand Seasons. In these novels, Epprecht argues, same-sex desire is used as a metaphor signifying the presence of foreign and imperial agents. In these novels, the characters associated with same-sex intimacy are often foreigners while their sexual preferences serve to signal the depravity of their home countries or the corrupting impact of their imperial designs on African society. If characters associated with homosexuality are African in these texts, the implication is that they have been corrupted through their interaction with foreigners. The respective authors' emphasis on the foreignness of same-sex sexuality - for example the leading character in Soyinka's The Interpreters is oblivious of the fact that some Nigerian Northern traditional leaders are reputed to be bisexual - feeds into the widely held belief that homosexuality is un-African. 
The third motif in Epprecht's reading of homosexuality in African fiction focuses on the depiction of gay characters in novels written after 2000. He argues that novels such as Mark Behr's The Smell of Apples and K. Sello Duiker's The Quiet Violence of Dreams are African 'coming out' narratives because the centring of the gay theme in these novels coincides with their authors coming out as gay men. He argues that the coming out of the novels' gay authors cohere with their gay characters to confirm that homosexual characters exist not only in African literature, but also in real life. Therefore, the works underline the agency of both fictional characters and real homosexuals symbolised by the coming out authors of these books. The representation of an affirmative homosexuality in recent African texts is a thread that is taken up by Lindsey Green-Simms when she points out that despite the intense antagonism in Nigerian public discourses about same-sex intimacy, a tradition of same-sex desire writing has recently emerged. This tradition includes writers like Chimamanda Ngozi Adichie who treats same-sex attraction as part of African normal life experience in her short story 'Jumping Monkey Hill' in the collection The Thing Around Your Neck. I argue in this chapter that Makumbi's portrayal of fluid sexuality in precolonial Uganda society falls into this group of new African fictional works. In other words, we encounter characters who experience same-sex intimacy, not as trauma or contagion, but as an essential and fully accepted element of their subjectivity. The preceding survey of critical analyses of homosexuality in African fiction indicates that there is a rich and growing tradition of depicting same-sex intimacy in African literature and using fiction to highlight the suppressed reality of same-sex intimacy on the continent. Makumbi's Kintu is a further addition to this growing tradition.

In Kintu, Makumbi constructs for her readers a Ugandan society that was tolerant of sexuality, difference and diversity. Through this depiction, Makumbi affirms the subjectivity of a minority whose very presence and agency are under threat from the enactment of new laws criminalising same-sex intimacy in contemporary Uganda. Here, it is worth pointing out that given their stature in Ugandan literature, Kintu, like Moses Isegawa's Abyssinian Chronicles and Okot p'Bitek's Song of Lawino come close to being viewed as examples of Ugandan national texts. Song of Lawino is particularly important as a foundational text of Ugandan, and some might argue African, literature because of its resonance with a wide and diverse audience, on account of its deployment of Acholi insult poetry motifs, a seemingly naive persona, beautiful imagery and simple language to distil important themes such as divisive politics, disengagement with African values and the cultural hybridity that haunted the first generation of African writing. Abyssinian Chronicles and Kintu build on Song of Lawino's ideological impulse of artistic confrontation with issues of gender, social, racial, political and identity crises of African societies as they transitioned into modernity. However, the nation is typically imagined as a space to legitimise a patriarchal and heteronormative order. Accordingly, these three Ugandan national texts, despite featuring strong female characters like Lawino in Song of Lawino, Padlock in Abyssinian Chronicles and Fiasi Kanani Kintu or General Kusi Kintu in Kintu, present nations dominated by men who deploy their patriarchal privilege to fashion a heterosexual and patriarchal polity. For example, while p'Bitek insinuates that Ocol's abandonment of the masculinist-patriarchal old ways because of education amounts to the death of the nation, Isegawa foregrounds the hetero-patriarchal nation as a construction of men who build and destroy it in equal measures. This focus on powerful males is also evident in Kintu where the plot hinges on a curse that is triggered by the power struggle between two male characters, Kintu and Ntwire, and the efforts to combat that curse by other men in the clan - albeit with the assistance of strong female figures. However, and if in Makumbi's Kintu, the Ganda nation is patriarchal, it is as equally accommodating of other sexualities as it is of heterosexuality. It would seem then that the six books and prologue of this new national novel are, to borrow Adebanwi's (2014, 413) 
phrase designed to subvert the aegis of nationalist narratives, and to unearth one of many suppressed Ugandan stories.

This multi-layered narrative with a complex plot was first published by the Kenyan publisher Kwani? in 2014. The novel documents the story of a single family - the family of Kintu Kidda, an eighteenth century Governor of the Bugandan county of Buddu ${ }^{4}-$ as the family struggles in the eighteenth and twenty-first centuries to reverse a curse placed on them by a migrant Tutsi herdsman called Ntwire in the 1700s. What makes Kintu a distinctive national tale is its skillful oscillation between the eighteenth and twenty-first centuries as it traces the trials and tribulations - depicted as madness - that afflict the progeny of Kintu Kidda. Divided into six sections, the narrative begins in 1750 when Kintu Kidda sets off for the capital to pledge allegiance to the new leader of the Buganda Kingdom - King Kyabagu. Conflict in the novel erupts following the accidental killing of Kalema by Kintu Kidda (Kalema is Kintu Kidda's adopted son and Ntwire's biological son) during one of Kintu Kidda's journeys to the capital. On learning about the death of his son, Ntwire places a curse on Kintu Kidda and his descendants afflicting them with madness. Ntwire's curse not only destroys Kintu's family and his reign as Governor of Buddu, but also extends to members of the four family branches that trace their kinship through him, and who are afflicted by diverse mental health disorders. For example, Kintu's descendants in the twenty-first century - Suubi Nnakato, Kanani Kintu and Isaac Newton Kintu as well as Misirayimu (Miisi Kintu) all show evidence of mental health disorders or engage in socially prohibited activity such as incest. Although the family matriarchs like Bweeza and Suubi Nnakato's unnamed grandmother (Makumbi 2014, 98-101) use stories of the curse as a thread that links the eighteenth century narrative to that of the twenty-first century, it is the agency of the men of the family (Miisi Kintu, Isaac Newton Kintu and Kanani Kintu) after the death of Miisi Kintu's son in the slums of Kampala that drives the novel to its resolution. Mourning the loss of his son, Miisi mobilises a return by the surviving members of the family to their cradleland Kiyiika - to perform supplications intended to break the curse by appeasing the spirit of Kalema and his father Ntwire.

Makumbi's stitching together of the different stories of Kintu's descendants as they seek to break from the burden of their family curse and a troubled history exemplifies a quest to recover a lost paradise. The details of the Kintu clan's search for a new Eden and for respite from the maledictions of the past speaks to contemporary Ugandan reality and concerns. In other ways and as Aaron Bady boldly asserts, this is a novel 'written for Ugandans. This book is for Ugandans because it's saturated with Ugandan words and places and names' (Bady 2017). Amanda Sarasien echoes Bady's observation in stating that 'it is not hyperbole to call Kintu the great Ugandan novel. It is simply and obviously a plain fact' (Sarasien 2018). Despite being viewed as a great Ugandan novel, Kintu has not yet attracted a great deal of critical attention outside Uganda. At the time of writing, there were only two articles - by Ken Lipenga (2016) and Madhu Krishnan (2017) - that analyse the text, but mainly to advance arguments that do not focus on the Ugandan character of the novel. For example, while Lipenga explores the theme of fatherhood in Kintu, Krishnan refers to the novel in order to illustrate her point regarding literary periodisation in the Anglophone African novel.

This chapter seeks to add to the growing scholarship on this great Ugandan novel by examining how Makumbi attempts to construct a tale that reminds Ugandans that same-sex desire did not elicit homophobic treatment in their past as it does today. This reading significantly extends the arguments of a few Ugandan commentators who read the curse of the Kintu progeny and the family's search for reprieve as an allegory of Uganda as a cursed society seeking ways of liberating itself. The motif of Uganda as a cursed society is evident in the analysis of Kintu by Ugandans like Joel Ntwatwa, Bwesigye Bwa Mwesigire and Nyana Kakoma. ${ }^{5}$ 
Ntwatwa, for example, notes that 'it is a tale of its characters alongside that of Buganda and Uganda. This is one book where finally someone talks about pre-British and pre-independence Uganda and what it meant for locals' (Ntwatwa 2015). In speaking of a tale of 'characters alongside that of Buganda and Uganda', Ntwatwa conflates the story of the characters with that of the Ugandan nation itself. But he also highlights how Makumbi dispenses with an anxiety about colonialism that was more commonplace among earlier generations of African writers. I agree with Ntwatwa that by skipping the 60 years of colonialism in Uganda, Makumbi alludes to Things Fall Apart in seeking to affirm the existence of a complex culture in Buganda and Uganda before the onset of colonialism, a culture that could perform caesarean operations and at the same time accommodate sexual differences, one might add. Ntwatwa's reading of Kintu also underlines the postcolonial troubles of the country. He argues that Makumbi uses the curse on the Kintu lineage to highlight Uganda's postcolonial troubles such as violent regime change, wars, lawlessness and HIV (Ntwatwa 2015). It is true that the Kintu familial trials and tribulations mirror the national challenges. For example, the collapse of social services and the privatisation of education at Makerere University in the 1980s/1990s forces Miisi - a Cambridge trained philosopher - to prematurely retire to rural Luwero where the civil war disrupts the life of his family.

Bwesigye Bwa Mwesigire and Nyana Kakoma highlight the affirmation of African culture in their reading of Kintu. Bwa Mwesigire argues that 'Makumbi takes us back to the 1750s, a depiction of life before the white man. These scenes are not as we have seen them elsewhere nasty, brutish and short - but respectful and respectable' (Bwa Mwesigire 2015). Similarly, Kakoma praises Makumbi's ability to illuminate pre-colonial Africa since 'very little of precolonial Africa is written about and it was such a delight to re-imagine with Makumbi how life was then' (Kakoma 2014). Both Bwa Mwesigire's and Kakoma's observations above echo Chinua Achebe's argument in 'The Role of the Writer in a New Nation' that writers should use their fiction to show 'African peoples [that they] did not hear about culture for the first time from Europeans, that their societies were not mindless but frequently had a philosophy of great depth and value and beauty' (Achebe 1964, 157). The Buganda/Uganda that Makumbi depicts in Kintu is a society that is sophisticated and highly organised and in direct contrast to the image of Africa conveyed in European colonial fiction.

Another thread that runs through the three critics' analysis of Makumbi's novel is their attention to the depiction of sexuality in the novel. For example, Joel Ntwatwa says that what attracted him to Kintu is how life 'might have been in the 1700s in Buganda. Family life, sexuality, kingdom and the other interesting aspects you will find' (Ntwatwa 2015). Similarly, Bwa Mwesigire argues that Makumbi addresses many topics: 'from homosexuality in pre-colonial Buganda to the Christian fanaticism of the East African revival days, through to HIV/AIDS, traditional spirituality, psychology, child sacrifice, mental health troubles, palace intrigues' (Bwa Mwesigire 2015). The theme of sexuality is also the focus of Nyana Kakoma who writes that she loved reading 'about Baale being prepared for marriage with counselling from different men on how to treat his new wife' (Kakoma 2014). The three critics' observations above underline the fact that sexuality is an important theme in the novel. While Kakoma focuses on heterosexual conduct and pre-marital sex education in the novel, Ntwatwa and Bwa Mwesigire also highlight the text's discussion of the topical theme of homosexuality. However, their reading of the references to sexuality stops at an acknowledgement that the novel discusses homosexuality.

I build on and extend their work by arguing that Kintu does more than acknowledge the existence of same-sex sexuality in precolonial Uganda. I show that by locating bisexuality in a broader context of complicated and fluid Ugandan sexualities, Makumbi usefully reconfigures Ugandan sexuality debates. The novel's nonchalant and almost casual depictions of homosexuality at Kabaka Kyabagu's court normalises same-sex desire in the Ganda nation's history. 
This is especially pertinent given the fact that same-sex desire is attributed to the nation's conquering/founding figure - Ssentalo. If in a patriarchal society, heterosexuality tends to be framed as the national sexuality of preference, then, the impact of Makumbi's inclusion of bisexuality at the foundational moment of the nation and attribution of same-sex desire to the hero or nation builder cannot be underestimated. This novel alerts Ugandans to the possibility of an alternative history that does not require suppressing same-sex desire. In this case, Makumbi follows the stance of the writer-social thinker that allows her to 'think with and beyond the possible' (Adebanwi 2014, 416). This is perhaps why bisexuality is set in the part of the text set in the eighteenth century rather than in the twenty-first century. For example, in the section of the novel set in twenty-first century Uganda, although Makumbi variously hints at competing and often diverse sexual preferences of some characters in the text, none of them is involved in bisexuality or other forms of same-sex desire. Three narratives in the novel are relevant here, namely that of the incest of Kanani Kintu's son Job and his daughter Ruth that leads to the birth of Paulo Kalemanzira (Makumbi 2014, 214), that of the rape of Suubi Nnakintu by Toofa and her adopted father Kiyaga $(128,150)$ and the case of teacher Putu Kintu's rape of his student Nnamata that leads to the birth of Isaac Newton Kintu (258). These instances of non-consensual or socially unacceptable sexual activity all occur in the twenty-first century rather than in the 1700 s.

Similarly, the part of the novel set in the 1750s chronicles various cases of contested sexualities. These include the question of a child bride as discussed by Kintu's party and specifically the party's derision of Gitta's marital troubles on account of his failure to tame his child bride Zaya. Equally important is Kintu's story of an asexual groom who throws up on the bride on the night of his wedding to the consternation of the community. The tales of complicated sexuality in both parts of the novel alert us to the existence of other sexual orientations and practices alongside a privileged heterosexuality. In the depicted society, heterosexuality is privileged, but primarily for utilitarian purposes. However, as Kintu vividly reminisces, '[s]ociety heaped such expectation on manhood that in a bid to live up to them some men snapped' (Makumbi 2014, 24). Although heteronormativity puts pressure on men in society to perform in certain ways, it does not preclude the agency of those men and women who engage in same-sex intimacy. Speaking about the functions of sexuality in Ganda society, Kintu declares at one point in the narrative: 'I will tell you three things I learned that day, Baale, [...] Our culture does not joke with sex' (78). Kintu's declaration that sex is a serious matter is borne out by the depictions of contested sexuality in both the precolonial and contemporary settings of the novel. While heterosexuality is the national sexual orientation, the tale of Ssentalo allows Makumbi to use fiction to suggest that perhaps the various sexual differences are or were acceptable in the depicted society.

Although prostitution, incest, underage sexual abuse, child brides, defilement and asexuality offer additional perspectives on Makumbi's writing on sexuality in Kintu, in this chapter I focus on her vision of how sexuality in Ganda history and culture of the eighteenth century differs significantly from contemporary discourses of Ugandan sexualities. It is important to note that, rather than place the bisexual character in the present day as a way of responding to current homophobia, Makumbi sets the scenes of same-sex desire in the eighteenth century. This perhaps helps her to create a productive distance from the polarised on-going debates. In spite of her intention in crafting a bisexual character at the founding moment of the Ugandan heterosexual nation, the novel's explicit acknowledgement of the coexistence of heterosexuality with other types of sexual orientation in a precolonial society (and elsewhere) is an important point of departure in a society where non-heterosexual practices, and discussions about them, excite polarised discourses. 
This is particularly significant in the case of Ssentalo, who confides in Kintu that he sleeps with women as a patriotic duty - to father sons and daughters for the kingdom - but prefers sex with men. Unlike the simple polarities prevalent in contemporary Ugandan debates on sexuality, Makumbi's novel draws attention to the problematic issues associated with sexual labels (Makumbi 2014, 46-48). Makumbi's willingness to look beyond handy labels calls to mind Stella Nyanzi's contention that it is impossible to categorise 'any social unit within Uganda as homogenously homophobic or universally opposed to same-sex practices' (Nyanzi and Karamagi 2015, 24). While there might be a vocal homophobic lobby in the country, anecdotal evidence, Nyanzi's observation and Makumbi's fictional exploration of the topic testify to the complex nature of same-sex sexuality in any society. Makumbi's dispensing with the sexual labels that are central to current Ugandan sexuality debates reminds us of Adebanwi's postulation that 'the writer in Africa has had much data for social reflection as she/her has been confronted with, [contra Kundera] the unbearable heaviness of things' (2014, 414). I would argue that hostility directed against same-sex intimacies is an example of the 'unbearable heaviness' that Adebanwi has in mind, and which Makumbi uses fiction to address. In aligning depiction of a repressed sexuality with an otherwise favourable account of the nation's history and culture, Makumbi creates an opportunity for bringing new insights into debates on this issue.

Makumbi achieves this goal by contrasting obligation and desire in the practice of both heterosexuality and same-sex sexuality. Here, we recall Kintu's conversation with Ssentalo on a previous visit to the capital. Teasing Kintu about his sexual performance, and wondering whether Kintu is bisexual, Ssentalo confides to Kintu thus:

I have wives and I enjoy them. To the kingdom, I've given a lot of children. Do you see what women do when they harvest cassava? [...] As humans, we don't only replace ourselves, we multiply. Where there was one man, ten boys should grow [...] sheer labour! What agony.

(Makumbi 2014, 46)

The dialogue between Kintu and Ssentalo about sexuality, and in this case, heterosexuality confirms two points. First, heterosexuality is sex in service of the nation, namely to produce children critical for the growth of the nation. Second, heterosexuality is a task and a form of necessary labour. This is a point made by both a bisexual man and a heterosexual one. The laborious and functional type of heterosexuality that Kintu and Ssentalo confess to engaging in for societal good recalls Lydia Boyd's observation about the functions of sexuality for the Baganda. She notes that for the Baganda, 'sexuality and reproduction are still embedded in experience of kinship' (Boyd 2013, 705). The essence of Boyd's observation is confirmed by both Ssentalo (regarding why he has sex with women) and Kintu (why he endures sex with his other wives when the only woman he desires is Nnakato). The two men admit that heterosexuality plays a utilitarian and political function for the good of the kingdom. What is striking about this exchange is not so much the discussion of functional heterosexuality by the two men. It is the candour with which they contrast sexual duty to the nation with what Ssentalo does for recreation and in the area of sexual desire that stands out.

It is also important to note that Ssentalo's sexuality defies neat categorisation in a typical same-sex desire theoretical framework. This is because he has sex with both men and women, even if he prefers men to women. Makumbi uses this depiction to complicate and nuance same-sex sexuality and to delink a sexual practice from the totalising register that serves to ostracise certain sexual categories. Here, we recall Makumbi's comment in an interview with Aaron Bady when she states that she wanted to 'place today's cultural politics - of citizenship, 
sexuality, and spirituality - into the deep and long endurance of centuries' (Bady 2017). Makumbi's intention as articulated in Kintu is in the register of advocacy. She seeks to deploy fiction to interrogate the ostracising homophobia that seeps through Ugandan public discourses of identity. This contestation is accentuated by Makumbi's depiction of Ssentalo's bisexuality as not only normal, but also acceptable in eighteenth century Ugandan society. This is supported by Ssentalo's confession about his sexual preferences. He states that when he wants a 'woman, I go for a proper woman: soft, smooth and round. When I want a man, I want hairy, sweat, musk granite' (Makumbi 2014, 46). After outlining his sexual preferences, he warns Kintu:

don't ever try men out of curiosity [...] it is like a river: a one-way flow for many people, no return. Once you have heard the hoarse groan of a man, felt the moist hairy skin and drunk the scent of male sweat you will not want to hold a woman again.

Ssentalo's matter of fact and unapologetic tone in this quotation does not just normalise samesex intimacy, but aligns same-sex intimacy with desire while linking heterosexuality with labour. Makumbi skilfully introduces this perspective through her careful handling of the scene and in particular through her depiction of Ssentalo's boastful tone.

Ssentalo's self-assurance in his sexuality supports fictional affirmation of the existence of bisexuality in precolonial Uganda. This is reflected in his statement that his body was meant to 'be enjoyed' (47). Ssentalo's unapologetic stance reveals the extent to which Makumbi's vision of sexuality in Ugandan culture and history differs from the socio-anthropological versions of this society painted by scholars such as Lydia Boyd, who argue that much of the 'antihomosexual rhetoric is Uganda is animated by a conflict between two frameworks for ethical personhood: one related to the Ganda value of "ekitibwa," or respect/honour, and the other based in discourse of rights autonomy and freedom' (2013, 701). If one were to interpret Boyd's understanding of Ganda notions of respectability as privileging heterosexuality, and dishonour as potentially discrediting same-sex sexuality, then Makumbi's Kintu appears to question this certainty. The Uganda that Makumbi depicts is not governed by these anxieties. Instead of being an image of dishonour, Ssentalo is respected as a general who has served eight kings and conquered a wide territory for the nation. Even when Ssentalo is killed by Kabaka Kyabagu, it is clear that his crime is unrelated to his sexual orientation. This novel's chronicling of a history and culture that accommodates sexual difference is further emphasised by Kintu's reflections on Ssentalo's execution.

In front of them, Ssentalo the Ssabatabazi's freshly severed head glared at them like a ghoulish trophy. [...] Then, there was that issue of Ssentalo's revelling in his indiscriminate sexual tendencies. But as long as the kingdom's frontiers kept shifting outwards, his sexual avidity had not bothered earlier kings. Besides, he was always away looking for war.

(Makumbi 2014, 45)

Kintu's speculation about Ssentalo's execution provides interesting clues about the ways in which the fact of same-sex intimacy is envisioned in this history of the nation. Granted, it might be argued that Ssentalo's military prowess gave him the licence to indulge his sexual preferences. More significantly and in the larger scheme of the Buganda monarchy's agenda, as portrayed here, the sexual preferences of a resourceful and fearless general could be ignored in exchange for the expansion of the kingdom. In this narrative, the general's execution stems from a geopolitical calculation by the new king trying to cement his authority after a power 
grab. The general's sexuality plays no role in these geopolitical calculations. Kintu's words confirm the thinking of the Buganda kings about the general's private life: 'But as long as the kingdom's frontiers kept shifting outwards, his sexual avidity had not bothered earlier kings.' His usefulness in expanding Buganda's glory and territory is what complicates his execution rather than his sexual practices. Although it is valid to argue that as a conquering hero, Ssentalo would have enjoyed privileges that other mortals would not have - 'revelling in his indiscriminate sexual tendencies' being one of them - there is no indication in the novel that these 'indiscriminate sexual tendencies' could lead to social exclusion in this society. A failure at sexual performance might have been frowned at, or have generated derision as the cases of Gitta and the unnamed groom who threw up on his bride eloquently demonstrates. In this presentation, heterosexuality might be the national norm, but it is a norm that does not preclude other sexual orientations. In his sexual inclinations, Ssentalo's differs from other Ganda notables like Kintu. However, and in Makumbi's fictional representation, Ssentalo's fluid sexuality does not arouse fear or revulsion from his peers.

\section{Conclusion}

I have argued that Makumbi as a writer-social thinker uses fiction to interrogate the contemporary understanding of same-sex sexuality in Ugandan society. Her fictionalised portrayal of the acceptance of bisexuality in precolonial Uganda in Kintu stands in contrast to the homophobia that pervades current sexuality debates in contemporary Uganda. In this respect, her writing Kintu generally, and her insertion of a case of bisexuality in a precolonial Ugandan setting particularly, is an activist gesture. Makumbi's intervention in Ugandan sexuality debates through the medium of fiction, queries the dominance of what Michael Warner calls regimes that 'govern the sex of others - and not just harmful or coercive sex, like rape, but most personal dimensions of pleasure, identity and practice' $(1999,1)$.

Makumbi's fictionalised claim that a founding general of the kingdom (Ssentalo) could be bisexual subverts the popular Ugandan homophobic rhetoric on three counts. First, the depiction normalises this sexuality as just what it is: a sexual practice. In the novel, its practitioner is a well-known and respected member of society. In fact, the fictional bisexual character is portrayed as a man of substance, whose sexuality is an acceptable eccentricity that has no bearing on his worth and contribution to society in the fictional world of the novel. Second, the political/military stature of the fictional character, who significantly contributes to the expansion and development of the kingdom of Buganda, discredits the idea that a non-heterosexual sexual practice poses a threat to society. In fact, it could be said that Makumbi portrays the general as a builder of society. Third, the fluidity of the characters' sexual identities develops an important fictionalised critique of the totalising categorisation of sexual orientation in contemporary society.

In Kintu Makumbi attempts to humanise and normalise a range of sexual orientations by transporting us back into the past so that we might imagine a society devoid of discrimination on account of sexual orientation. Makumbi's novel seeks to humanise men who have sex with men such as Ssentalo, but surprisingly the part of her narrative set in the twenty-first century does not explicitly discuss same-sex sexuality. While there are scenes of complicated sexuality such as incest, underage sex, prostitution and HIV/AIDS stigma in the parts of the story set in the twenty-first century, there is no mention of homosexuality in this section of the novel or in relation to the surviving progeny of Kintu. The sections of the story set in the eighteenth century give Ugandan readers a glimpse into a society and culture that they can be proud of, but one where sexual difference does not give rise to homophobia. What is more, the curse that devastates Kintu's family does not relate to sexuality, but to an accidental killing. That is the 
crime for which Kintu's descendants pay, and which is replayed from one generation to the next. Makumbi's decision to locate a bisexual character in a re-creation of the Ganda past, but without making that character's sexuality the centrepiece of the narrative, functions to deliberately subvert the claims of the Anti-Homosexuality lobby in the country that this type of sexuality is un-Ugandan and a danger to society. In Kintu, Makumbi offers a different kind of Ugandan national tale and a different kind of Ugandan novel. The nation as depicted is still patriarchal, and heterosexuality is still the norm, but this novel also provides a vision of possibly less polarised Ugandan sexuality discourses.

\section{Notes}

1 While both novels focus their discussion of how post-independence challenges such as political violence, war, AIDS and the impact of structural adjustment policies have impacted on individual Ugandan families, their authors differ in the setting and controlling metaphors they choose for their respective novels. While Makumbi starts her novel in eighteenth century Buganda, Isegawa locates his action in post-independence Uganda, specifically the 1966 Buganda crisis. Furthermore, while Isegawa deploys the adjective abyss in the novel's title Abyssinian Chronicles to signal the depth into which the Ugandan body politic had descended, Makumbi signposts her discussion with a mysterious title echoing the founding father of the Ganda nation - Kintu - in order to link the past to the present.

2 The term Ganda is the name of a group of people who inhabit an area in central Uganda known as Buganda. Given its central position and early contact with British colonialists in the late nineteenth century, it is the kingdom of Buganda on which the modern Ugandan nation is founded. In fact, the novel Kintu is more about this group of people (tribe) than it is about modern Uganda.

3 The sexuality debates in Uganda in the last decade have been characterised by an attempt to erase and/ or silence same-sex desire. This perhaps explains the insertion of a clause criminalising same-sex marriages in the amended 1995 Ugandan constitution in 2005 and the expunging of sexuality as a claim to minority status from the 2007 Equal Opportunities Commission Act. The sexuality crisis facing the Ugandan polity that necessitated the laws above is perhaps eloquently captured in the justification for Honourable David Bahati's 2009 Anti-Homosexuality Bill. The claim that the law would protect the Ugandan nation against the emerging threat of homosexuality to the heterosexual family and traditional Ugandan culture frames gayness as an existential threat.

4 Buddu is one of the counties of the ancient kingdom of Buganda and one of the regions of modern Uganda composed of five districts. It is located due south of Kampala city bordering Lake Victoria in the East and Tanzania in the South. It is considered one of the key and most influential counties of the Buganda Kingdom and/or regions of Uganda.

5 Joel Ntwatwa, Bwesigye Bwa Mwesigire and Nyana Kakoma are leading Ugandan literary activists who have written about Ugandan new writing in various platforms. While the late Ntwatwa was a graphic artist and blogger who had a passion for Ugandan writing, Bwa Mwesigire is perhaps best known for his founding and curation of Writivism - a literary organisation that offers a platform to upcoming writers to showcase their work. Kakoma's So Many Stories is a literary organisation that publishes new Ugandan writing (she published and markets Phillipa Namutebi Kabali's Flame and Song) and teaches creative writing in the country.

\section{Acknowledgement}

The research published in this chapter was funded under the Sida-Makerere V project 377 postdoc funding.

\section{Works Cited}

Achebe, Chinua. 1964. 'The Role of the Writer in a New Nation'. Nigeria Magazine 81: 157-160.

Achebe, Chinua. 1974. 'The Novelist as Teacher'. In Morning Yet on Creation Day: Essays, 55-56. New York: Anchor. 
Achebe, Chinua. 1988. Hopes and Impediments: Selected Essays 1965-1987. London: Heinemann.

Adebanwi, Wale. 2014. 'The Writer as a Social Thinker'. Journal of Contemporary African Studies 32(4): 405-420.

Adichie, Chimamanda. 2009. The Thing Around Your Neck. New York: Random House.

Arac de Nyeko, Monica. 2007. 'Jambula Tree'. In African Love Stories: An Anthology, edited by Ama Ata Aidoo, 164-177. Cape Town: Lynne Rienner Publishers.

Armah, Ayi Kwei. 1979. Two Thousand Seasons. London: Heinemann.

Bady, Aaron. 2017. 'In Kintu, A Look at What It Means to Be Ugandan Now'. Literary Hub, May 15. www.lithub.com/in-kintu-a-look-at-what-it-means-to-be-ugandan-now/.

Behr, Mark. 1995. The Smell of Apples. London: Abacus.

Boyd, Lydia 2013. 'The Problem with Freedom: Homosexuality and Human Rights in Uganda'. Anthropological Quarterly 86(3): 697-724.

Bwa Mwesigire, Bwesigye. 2015. 'Breaking the Rules Beautifully'. Chimurenga Chronic, March 19. https:// chimurengachronic.co.za/breaking-the-rules-beautifully/.

Bwa Mwesigire, Bwesigye. 2018a. 'Beyond the Afropolitan Postnation: The Contemporaneity of Jennifer Makumbi's Kintu'. Research in African Literature 49(1): 103-116.

Bwa Mwesigire, Bwesigye. 2018b. 'English's Tendency to Obliterate Other Languages Does Not Apply Here: Review of Jennifer Nansubuga Makumbi’s Kintu'. The Johannesburg Review of Books. https://joha nnesburgreviewofbooks.com/2018/04/04/englishs-tendency-to-obliterate-other-languages-does-not-a pply-here-bwesigye-bwa-mwesigire-reviews-jennifer-nansubuga-makumbis-kintu/.

Duiker, K. Sello. 2001. The Quiet Violence of Dreams. Cape Town: Kwela.

Epprecht, Marc. 2008. Heterosexual Africa?: The History of an Idea from the Age of Exploration to the Age of AIDS. Athens: Ohio University Press.

Green-Simms, Lindsey. 2016. 'The Emergent Queer: Homosexuality and Nigerian Fiction in the 21st Century'. Research in African Literatures 47(2): 139-161.

Government of Uganda. 2005. Constitution of the Republic of Uganda. Kampala: Government of Uganda.

Government of Uganda. 2007. Equal Opportunities Commission Act. Kampala: Government of Uganda.

Government of Uganda. 2007. Penal Code (Amendment) Act. Kampala: Government of Uganda.

Government of Uganda. 2014. Anti-Homosexuality Act. Kampala: Government of Uganda.

Hoad, Neville. 2007. African Intimacies: Race, Homosexuality, and Globalisation. Minneapolis: University of Minnesota Press.

Isegawa, Moses. 2001. Abyssinian Chronicles. New York: Vintage.

Kakoma, Nyana. 2014. 'Jennifer Nansubuga Makumbi's Kintu Made Me Want to Tell Our Stories'. Africa in Words, November 12, www.africainwords.com.

Krishnan, Madhu. 2017. 'Periodizing the Anglophone Novel: Location(s) in a Transnational Literary Marketplace'. In Literature in the Global Contemporary, edited by Sarah Brouillere, Emilio Sauri and Mathias Nilges, 135-155. London: Palgrave Macmillan.

Lamwaka, Beatrice. 2012. 'Pillar of Love'. In African Violet and Other Stories, compiled by Lizzy Attree, 183-191. Sunnyside: Jacana Media.

Lipenga, Ken. 2016. 'The (Un)making of a Man: Fathers and Sons in the African Novel'. Paper given at the 17th Triennial Conference of the Association for Commonwealth Literature and Language Studies (ACLALS), July.

Makumbi, Jennifer Nansubuga. 2014. Kintu. Nairobi: Kwani Trust.

Munro, Brenna. 2016. 'Locating "Queer" in Contemporary Writing of Love and War in Nigeria'. Research in African Literatures 47(2): 121-138.

Ncube, Gibson. 2014. 'Sexual/Textual Politics: Rethinking Gender and Sexuality in Gay Moroccan Literature'. Journal of Contemporary African Studies 32(4): 479-490.

Ntwatwa, Joel. 2015. 'Kintu by Jennifer Nansubuga Makumbi'. Goodreads. November 15. www.goodrea ds.com.

Nussbaum, Martha. 1995. Poetic Justice: The Literary Imagination and Public Life. Boston, MA: Beacon Press. Nyanzi, Stella. 2013. 'Dismantling Reified African Culture through Localised Homosexualities in Uganda Culture, Health and Sexuality'. An International Journal for Research, Intervention and Care 15(8): 952-967.

Nyanzi, Stella. 2014. 'Queering Queer Africa: Reclaiming Afrikan'. In Queer Perspectives on Sexual and Gender Identities, edited by Zethu Matabeni, 61-66. Athlone: Modjaji Books.

Nyanzi, Stella and Andrew Karamagi. 2015. 'The Social-Political Dynamic of the Anti-Homosexuality Legislation in Uganda'. Agenda: Empowering Women for Gender Equity 29(1): 24-38.

Paelo, Anthea. 2013. 'Picture Frames'. In Picture Frames and Other Stories, 1-4. Kampala: Boda Book.

P’Bitek, Okot. 1966. Song of Lawino. Nairobi: East African Educational Publishers. 
Rao, Rahul. 2015. 'Re-membering Mwanga: Same-sex Intimacy, Memory and Belonging in Postcolonial Uganda'. Journal of Eastern African Studies 9(1): 1-19.

Sarasien, Amanda. 2018. 'A Review of Kintu by Jennifer Nansubuga Makumbi'. The Literary Review. January 16. www.theliteraryreview.org/category/book-review.

Segawa, Nakisanze. 2016. The Triangle. Kampala: Mattville Publishing House.

Soyinka, Wole. 1972. The Interpreters. London: Fontana/Collins.

Tamale, Sylvia. 2007a. Homosexuality: Perspectives from Uganda. Kampala: Sexual Minorities Uganda.

Tamale, Sylvia. 2007b. 'Out of the Closet: Unveiling Sexuality Discourses in Uganda'. In Africa After Gender?, edited by Catherine M. Cole, Takyiwa Manuh and Stephen F. Miescher, 17-29. Bloomington: Indiana University Press.

Tamale, Sylvia. 2009. 'A Human Rights Impact Assessment of the Ugandan Anti-Homosexuality Bill 2009'. The Equal Rights Review 4: 49-57.

Tamale, Sylvia. 2011. 'Introduction'. In African Sexualities: A Reader, edited by Sylvia Tamale. Cape Town: Pambuzuka.

Underwood, Alexia. 2017. 'Interview with Jennifer Nansubuga Makumbi'. Los Angeles Review of Books. August 3. http://lareviewofbooks.org/article/so-many-ways-of-knowing-aninterview-with-jennifer-na nsubuga-makumbi-author-of-kintu/\#.

Ward, Kevin. 2013. 'The Role of the Anglican and Catholic Churches in Uganda in Public Discourses on Homosexuality and Ethics'. Journal of Eastern African Studies 9(1): 127-144.

Warner, Michael. 1999. The Trouble with Normal: Sex, Politics and the Ethics of Queer Life. Cambridge, MA: Harvard University Press. 
Part VII

Literary Networks 


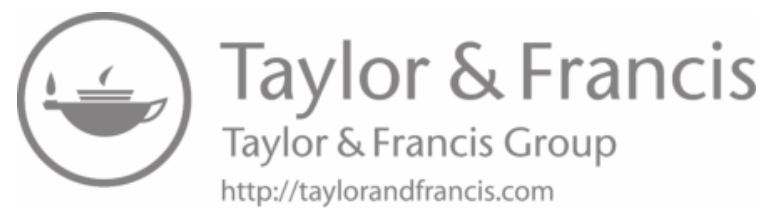




\title{
The Story Club
}

\section{African literary networks offline}

\author{
Stephanie Bosch Santana
}

Increasingly, the future of African literature on African-initiated literary networks seems to be located in digital space. Jalada magazine has reinvigorated African language publishing through hyperlinks, translating a single short story by Ngũgĩ wa Thiong'o into more than sixty languages. A blog, Mike Maphoto's Diary of a Zulu Girl, is one of the most-read works of fiction in post-apartheid South Africa. The internet has also provided an important outlet for African literary criticism, from Africa is a Country's viral essays to the hundreds of comments that appear on one of Diary of a Zulu Girl's installments. ${ }^{1}$

Despite this, there is an equally significant resurgence of offline literary groups in southern Africa. Book clubs sprung up across South Africa to discuss Maphoto's diary, and in Malawi, award-winning writer Shadreck Chikoti has succeeded in creating and self-funding another such face-to-face forum for literature. The Story Club was launched in Lilongwe in December 2013 and has since added branches and held events in other major Malawian cities. The club's eclectic format varies somewhat per session and has included talks by writers, filmmakers and academics, poetry readings, film screenings and live musical performances. Many sessions have also featured the reading and discussion of a guest writer's story, and it is in this respect that the Story Club recalls the famed Malawi Writers Group, formed at Chancellor College in 1969 by Jack Mapanje, Lupenga Mphande and James Ng'ombe amongst others. Significantly, the club is a 'space' aimed not just at writers but also readers, journalists, critics, teachers and editors: anyone who is 'passionate' about literature (personal interview, July 5, 2016).

This chapter considers the role of such literary clubs in the digital age, focusing in particular on how the Story Club-as-network connects to traditional publishing infrastructures, literary workshops and prizes, and online networks such as blogs and Facebook in both English and African languages. Chikoti, who is one of Malawi's best-known contemporary writers, is also the Executive Director of Pan African Publishers, which publishes 'African literature for the African market' in English and Chichewa (personal interview, April 19, 2014). In 2014, the Story Club hosted a writing workshop called 'Imagine Africa 500,' which led to the publication of a collection of Afrofuturist short stories by Pan African. The Story Club then held a book launch, which in Malawi functions as a kind of live auction, where the entire cost of publishing a book can be raised in a single evening, often with the help of government ministers who are 
in attendance. Through all of these interconnected activities, the Story Club is deeply involved in the making and selling of literary value in Malawi.

Recently, Achille Mbembe suggested that 'Africa was digital before the digital,' pointing in particular to the continent's 'flexibility and this capacity for constant innovation' (2015, 2-3). While the Story Club is certainly innovative, Mbembe's formulation privileges the digital over the material, as does much scholarship on contemporary networks. ${ }^{2}$ Drawing on Stephanie Newell's concept of 'paracolonial networks,' I argue that rather than prefigure or anticipate digitality, the Story Club and literary networks like it are better thought of as 'paravirtual': digital-age networks that are mediated in significant ways but that operate 'alongside and beyond' the virtual sphere (2011a, 350). ${ }^{3}$ In what follows, I show how the Story Club makes strategic use of digital connections, often in order to foster face-to-face interactions offline. Like the paracolonial, paravirtual literary networks can help us to move beyond a center/periphery framework to see forms of literary value that are enabled by global digital connectivity but ultimately exceed virtual space.

\section{African literary clubs and networks}

World systems approaches to the literary field have emphasized a singular, if uneven, global marketplace in which texts circulate and gain visibility and value. ${ }^{4}$ Pascale Casanova, for example, argues for the existence of 'a literary universe relatively independent of the everyday world and its political divisions' that is characterized by 'incessant struggle and competition over the very nature of literature itself' $(2004$, xii, 12). The centers of Casanova's 'world republic of letters' are located in European and American metropolises like Paris, London and New York, where writers from the peripheries seek recognition and literary capital via a host of intermediaries, including publishers, prizes, well-known authors, critics, translators and editors. In The Economy of Prestige, James English considers the significance of these intermediaries, and of prizes, in particular, in conferring cultural value. Like Casanova, English observes the diminishing importance of the nation in the global cultural market, where 'the artist celebrated at the subnational level of indigenous community, can now be fed directly into a global market for indigenous cultural production' (2005, 272). Graham Huggan (2001) argues that this global market for the exotic and marginal has fundamentally shaped postcolonial writing.

While the above studies give little agency to writers, Sarah Brouillette and Akin Adesokan recast postcolonial authors as active negotiators of the global literary space and its institutions. Brouillette suggests that by reading postcolonial authors' identities and careers as 'key paratexts for reception and reproduction,' we can see beyond what Huggan has identified as a 'strategic exoticism,' to writers' more nuanced textual engagements with their own positionality (2007, 3). Adesokan, for his part, considers the role of the artist-intellectual as a 'mediator in certain kinds of commercial deals,' who can 'assert artistic control' to critique the very value and meaning-creating institutions that underwrite his or her work $(2011,4,27)$. He understands global literary space to operate simultaneously as system and network, which he compares to the West African marketplace: it is a meeting place where the regulations of global and local institutions intersect with the 'human network' of 'potential collaborators' (10).

Only very recently have studies focused on Africa-based literary institutions and networks. Doreen Strauhs considers the role of African literary NGOs, which she calls 'LINGOs,' as 'noteworthy sites of literary innovation and public opinion making in the field of African literary production' $(2013,5)$. These 'homegrown' organizations, from the Nigerian Mbari club and Kenyan Chemchemi Creative Center that were established in the 1960s, to contemporary organizations like the Ugandan women's writers group, FEMRITE, and Kwani Trust in Kenya, 
are rooted in national spaces but operate as key nodes in pan-African and global literary networks (29). Much of the current debate on Africa-based literary institutions like these has centered on how dependent and determined their networks and cultural capital are on Western funding and institutions, from the Ford Foundation and the Caine Prize to literary agencies like Andrew Wylie's, which represents many of today's internationally recognized African writers. Drawing on Strauhs as well as conversations and forthcoming material from specialists in the field, Sarah Brouillette's 2017 essay, 'On the African Literary Hustle,' deduces that Western donor funding has helped to create a select 'coterie' of African writers in 'key cities' like Nairobi and Lagos. In an argument that recalls Casanova's, Brouillette finds that:

while there is a small readership in these urban centers, it isn't that important that there be local readers. These writers have bypassed the problem of the absent African reader. There is donor funding to support the activity of writing, to award prizes to authors, and to facilitate access to US and other foreign markets.

In contrast, Kate Wallis (on whose data Brouillette's essay largely depends) gives examples from Kwani Trust and Nigeria's Farafina to demonstrate convincingly that:

writing from Africa that is published by UK and US 'powerhouses' is often brought to attention and consecrated with cultural value by structures of literary production based on the continent. Equally writers who achieve critical acclaim internationally are often part of and deeply entrenched within a larger continent-based community of writers.

(Wallis 2018, 180)

The Story Club, like the organizations Wallis describes, demonstrates the centrality of Africabased institutions to the production of literary value on the continent, even as it participates in broader circuits. Like Kwani Trust and FEMRITE, the Story Club hosts writing workshops and public readings for aspiring and established authors, aims to bolster national writing and reading cultures outside of academic institutions, and operates as (or in close connection with) local publishers. Indeed, in a 2016 interview, Chikoti told me he had something like Kwani Trust in mind when he started the Story Club, and like Kwani's founder Binyavanga Wainaina, Chikoti used prize money that he had won to start the club. Chikoti said that after he won the Peer Gynt Award, Malawi's most lucrative prize, people began to ask him what he would do to help other aspiring artists. His solution was to create a space akin to Kwani Trust where people of 'different backgrounds' could 'meet and celebrate art.' However, the Story Club differs somewhat from Kwani and organizations like it in its complete lack of funding from international or domestic institutions. ${ }^{5}$ Since Chikoti has continued to self-fund the Story Club entirely, he is free to operate it without any external influence. Nevertheless, Chikoti has expressed a desire to find funding partners in order to help sustain the club's incredible growth, from 10-15 participants at early meetings to hundreds at later events.

In its informal structure and reliance on individuals for effort and funds, the Story Club resembles the literary and social clubs popular throughout West Africa in the 1920s and 30s. Stephanie Newell argues that these groups served as significant literary, social and political networks for a newly literate class and help us to see 'paracolonial' cultural flows, which occurred 'alongside and beyond the British presence in the region, as a consequence of the British presence but not as its direct product' (2011a, 350). In the Gold Coast, the founders of these clubs were 'youngmen,' who were 'neither chiefs nor members of the established coastal elites,' and who considered themselves to be part of the 'intelligentsia' (Newell 2000, 53, 55). Chikoti, who is 
only 39 and who is not involved in the government, might certainly be considered to occupy a similar position in Malawian society today. Like the Story Club, the early clubs in the Gold Coast had both literary and social aims and engaged in a variety of activities, from the discussion of particular texts to lectures and debates. The membership of these clubs included local authors, readers and 'readers turned writers,' who 'responded to the books they read by producing their own texts and inviting readers to debate the issues raised' (Newell 2006, 232). In taking English 'raw material' (literature, language, styles) and appropriating it for local ends, Newell finds that these clubs 'created meanings which were not anchored to meanings generated in the metropolis' (Newell 2011a, 350). One such club, the New Tafo Literary and Social Club described its mission in the Gold Coast Observer in 1942 as follows: 'to foster an intelligent interest in the community in all literary and social pursuits, and to educate public minds on all the current affairs by means of public debates, lectures, talks and so forth' (quoted in Newell 2000, 55). This particular club even boasted a circulating library and had ambitions of building 'a Club House, tennis courts, a lending library and to acquire a wireless radio receiving set and a Cinema Pathe [sic] Projector, to keep its members and the general public in touch with current world affairs' (quoted in Newell 2000, 55). The Story Club, similarly, is aimed not just at writers (although it draws many) but at a broader community of enthusiasts for literature and the arts, and it, too, endeavors to keep members 'in touch' with international literary trends by making use of new technologies. And yet, also like the New Tafo Literary and Social Club, its establishment of an actual physical location, the Story Club Café in Lilongwe in August 2017, anchors it firmly in the Malawian milieu.

In the Malawian context, there are several precursors to the Story Club: the Malawi Writers Group, started by students at the University of Malawi's Chancellor College in Blantyre in 1969, and the Lingadzi Writers Club, which operated in Lilongwe in the 1980s and 90s. At the Story Club's launch, Chikoti said, 'these are not in operation right now. So this [the Story Club] is basically revamping that kind of the spirit. And I think the difference is that those ones only involved writers' (Malawi Broadcasting Corporation 2014). These clubs also operated in a much different political environment than today's Story Club. After independence in 1964, Malawi's first prime minister and then president, Hastings Kamuzu Banda, immediately began consolidating his power through repressive legislation, including the 1968 Censorship and Control Entertainments Act which made it 'a criminal offense, punishable by imprisonment, to possess, import, print, publish, distribute, display, exhibit or reproduce any publication which the Board had declared "undesirable" (Mphande 1996, 81). Banda's approach to literary and cultural production is best exemplified by the college he built in Kasungu. Known as the 'Eton of Africa,' it taught students English, Latin, Greek and French and excluded all African literature and history from the curriculum (86). In this environment of severe political and cultural repression, Lupenga Mphande, one of the founders of the Malawi Writers Group, describes the group's objectives as both cultural and political in scope: 'to embark on the multi-dimensional task of redefining the national culture, creating a more liberatory environment, and constructing democratic structures within an oppressive system' (1996, 88). While Chikoti suggests that the group was primarily for writers, it seems that this designation was taken loosely. Mphande writes, 'Membership was completely voluntary, and many of the students who joined were not even "writers" in the traditional meaning of that word' (89). The organization was democratic in structure, with the chairman rotating at each meeting, one of the many ways through which it sought to 'create culture through practice' (89). Overall, the group was purposefully 'informal, defiant, and rebellious,' which is partly why the University of Malawi's English Department eventually incorporated it and sought to control its agenda and leadership $(90,99)$. While the Story Club operates in a comparatively much less repressive political and social 
environment, post-Banda Malawi has also suffered its share of censorship, as is evident from the arrests of journalists in 2011 and very recent efforts to punish 'offensive communication' on social media (Freedom House 2017).

Despite increasing censorship of social media in many African contexts, literary organizations have made use of various digital networks to expand their reach. A digital presence has been important to Kwani Trust, for example, and new writers' collectives like Jalada are mostly digitally based (although it has also staged live events). In contrast, the Story Club lacks a website, and activity on its Facebook page is minimal. This certainly has something to do with Malawi's very low internet penetration rate and small percentage of Facebook users. However, this alone does not explain the Story Club's primary operation as an offline rather than virtual network, particularly since Malawians, many of whom are part of the club, are very active and engaged with Chikoti's personal Facebook page. Rather, it seems that there is something to be gained from face-to-face literary networks that cannot be attained online. In the case of the Story Club, participants benefit from local exposure for their work and sometimes in-depth discussion of it, which is often lacking in the digital space. They have also gained face-time with well-known authors including Tsitsi Dangarembga and Zukiswa Wanner. Importantly, these in-person engagements are facilitated by digital technologies like Facebook and WhatsApp, which Chikoti says are the primary means through which he keeps in touch with other African writers (Facebook message, January 29, 2018). As I explore below, the club operates through a complex network of friendships and professional associations, with a broad Malawian base that interacts with individuals and organizations in Africa, Europe and the United States based on Chikoti's own affiliations.

\section{Shadreck Chikoti: the face of the Story Club's networks}

Shadreck Chikoti's reputation as one of the most successful contemporary Malawian writers gave him the platform to launch the Story Club in December 2013. Chikoti has been on the Malawian literary map since he published his first book while still in secondary school at the age of 19, at the time the youngest Malawian to have done so. A few years later, in 2001, Chikoti's story 'The Trap' won first prize in the Malawi Writers Union's Peer Gynt Literary Award. Named after the Norwegian playwright, the Peer Gynt is sponsored by the Norwegian embassy and administered by the Malawi Writers Union (MAWU), the nation's body of professional writers. That same year, Chikoti spoke at the Zimbabwe International Book Fair, which featured his book Free Africa Flee! Over the next several years, Chikoti's short stories continued to win MAWU prizes and were included in several MAWU anthologies. In September 2013, Chikoti won the Peer Gynt award for his first full-length novel, Azotus the Kingdom, which is set in an unnamed African country 500 years in the future. Chikoti (2014) says that he considers the award, which came with a prize of 500,000 Malawian Kwatcha (more than 600 USD), as one of the highest literary honors he has received.

As a result of his literary successes in Malawi and southern Africa, Chikoti was able to enter into broader international literary circuits. In 2008, Chikoti attended the first Writers' and Literary Translators' International Congress (WALTIC) in Stockholm, where he met Danish writer Trine Andersen. This proved to be a particularly fruitful connection: in 2008, Chikoti and Andersen founded Pan African Publishers, and in 2009 Chikoti was a writer in residence in Denmark, where he began writing Azotus the Kingdom. In 2011, the Caine Prize selected Chikoti and fellow Malawian writer Lawrence Kadzitche to attend the Caine Prize workshop in Cameroon. Chikoti's first international publication, 'Child of a Hyena,' was in the Caine Prize 2011 collection, To See the Mountain and Other Stories. Overall, Chikoti's literary trajectory supports 
Wallis's argument that many African writers gain literary capital in local and pan-African networks prior to being recognized elsewhere.

Chikoti has further immersed himself in local literary networks through his work with Pan African Publishers, which he founded, in part, as a result of his frustration with international publishers and competitions like Caine. When I interviewed Chikoti in Lilongwe in $2012,{ }^{6}$ he emphasized that African writers are too often forced to cater to 'what international publishers and competitions want,' usually culturally specific stories and/or 'protest literature.' Within Malawi, book sales are low, printing is expensive, and publishers are often unwilling to take risks on fiction. Therefore, 'the aim of Pan African Publishers is to encourage writers from across Africa to write with the freedom of theme' and without limitations as to genre. At the time of our interview, Pan African had published eight books for the Malawian secondary school market in order to 'generate income' as well as Chikoti's speculative historical novel Mwana wa Kaтuzu, or The Son of Kamuzu (2010). Chikoti writes in both English and Chichewa and takes a pragmatic approach to choosing the language in which to write and publish. For example, Chikoti wrote Mwana wa Kamuzu in Chichewa because he 'wanted to reach a wider audience and [he] was aiming at the rural areas.' Since most Malawians do not have access to bookshops, Chikoti traveled to rural regions and sold the book directly to street vendors and in tea rooms. For Chikoti, a 'wider audience' is a variable concept: within Malawi, a much larger rural audience can be reached in Chichewa, whereas English is necessary to communicate beyond Malawi's borders.

The Story Club emerged from Chikoti's diverse experiences as both a writer and publisher. 'There are so many factors affecting the writing industry in Malawi,' Chikoti said in our 2014 interview, emphasizing in particular the lack of professional editors, outlets for writers to publish their work, fora for creative exchange, and a book-buying public. The Story Club is Chikoti's attempt to address this hydra-headed problem. 'If we want to improve the writing standards and the reading standards in Malawi, we need many players,' Chikoti argues. To this end, the Story Club is enmeshed in a number of literary networks, from local writers' groups to continental and international organizations. Locally, the Story Club intersects with several writing groups, such as the Poetry Association of Malawi and the Mzuni Writers Forum at Mzuzu University. Poets from these organizations, and others, are often invited to perform at club gatherings. There is also some connection between the Story Club and the Malawi Writers Union (MAWU), the largest and most influential writing organization in the country. Chikoti was the vice president of MAWU for a number of years, and the current president, Sambalikagwa Mvona, spoke at the Story Club's official launch in December 2013. Although MAWU remains powerful as the country's largest body of writers, there is evidence that some members may be growing tired of Mvona's leadership and of the organization's publishing practices. The Story Club is of a decidedly different nature than MAWU, which collects dues from members and has a clear leadership structure. In contrast, in a Malawi Broadcasting Corporation news feature on the Story Club's launch, Chikoti emphasized, 'We are not an organization ... just a space for enthusiasts.' This statement may have been designed to show that the Story Club is not in active competition with pre-existing groups such as MAWU as well as to draw a distinction between them. Unlike MAWU, Chikoti acts as the 'coordinator' and 'founder' of the Story Club, rather than its president. However, Chikoti's centrality to the club also differs from the more obviously democratic - although male-dominated - Malawi Writers Group of the 1970s, with its rotating chairmen.

The founding of the Story Club coincided with a sharp rise in Chikoti's international profile, and it is through Chikoti's connections that the Story Club has been inserted into a number of significant pan-African networks like the African Writers Trust (AWT) and Africa39. In March 
2013 (building on his connections to both FEMRITE and the Prince Claus foundation, a sponsor of AWT), Chikoti was invited to attend the first Uganda International Writers Conference, a project of the AWT. Founded in 2009, the AWT is an NGO registered in Uganda, with offices in both Kampala and London. In December 2013, the Story Club posted the link to an article Chikoti wrote about his experience at the conference, where he first met influential Malawian writer Jack Mapanje, who had been living in the UK in exile. In his essay, Chikoti focuses on the network of connections he forged while there, writing:

But as it turned out, the conference was not only about me meeting Uncle Jack; the picture became even bigger than I had imagined. The conference became a confluence where African writers of notable levels living in Africa and in diaspora converged to form one lasting network that will yield results for a life time [sic].

While in Uganda, Chikoti met Billy Kahora of Kwani, Ugandan writer Doreen Baingana, Nii Parkes and Goretti Kyomuhendo, the director of AWT and then judge of the Commonwealth prize. He also reconnected with fellow Caine workshop attendee Beatrice Lamwaka, and the coordinator of FEMRITE, Hilda Twongyeirwe, whom he first met at the Ethiopian African writer's conference. These encounters did indeed prove useful and lasting: in November 2014, the Story Club held an 'Imagine Africa 500' short story workshop facilitated by Kahora and Lamwaka along with Ugandan Jackee Batanda and Trine Anderson. Pan African published the resulting collection, the first volume of speculative fiction to be published in Malawi, which included several of the workshop participants in addition to writers from Nigeria, South Africa, Uganda and Botswana.

Also in 2014, Chikoti was named by Africa39 as one of the 39 most promising African writers under 40. Africa39, in particular, underscores the entwinement - and power dynamics - of pan-African and global literary networks. Binyavanga Wainaina of Kwani Trust, who has publicly identified himself as a pan-Africanist and emphasized the importance of grounding African literary networks on the continent, curated the prize long-list. According to the Hay Festival's Africa39 website, both the prize and the resultant Africa39 anthology 'will bring to worldwide attention the best work from Africa and its diaspora.' The simultaneous announcement of the prize at the Hay Festival in Port Harcourt, Nigeria and at the London Book Fair is symbolic of Africa39's efforts to bridge the divide between sites of literary power. In our 2014 interview, Chikoti told me, 'the biggest thing about Africa39 is the publicity,' emphasizing that the prize brings attention to both himself as a writer and to Malawi as a nation. Indeed, shortly after the award was announced, Chikoti was featured on CNN's African Voices. While individual African writers have clearly benefited from awards like Africa39, we should also be mindful of the way that such prizes can reinforce existing literary hierarchies. For example, the winning writers were brought to Europe to help publicize the Bloomsbury-published anthology.

In contrast to Africa39, the Story Club espouses a kind of local pan-Africanism. ${ }^{7}$ In 2014, Chikoti explained his version of pan-Africanism as being rooted in forms of local social activism, like the Story Club.

For me, to be a pan-Africanist is to be someone who wants to contribute to the discourse of the future of Africa, you know, current affairs, social activities. Which is also why I involve myself so much in social activities. It is different, I think, my idea of pan-Africanism, from the idea that was there in the 60s, which was kind of a protest movement against the West. It has lost that tone in many who would call themselves pan-Africanists. The problems that Africa is facing are not necessarily from external forces. Many of them are also 
from within. It's to look at all of those things, internal, external, and see how can you contribute to that.

(personal interview, April 19, 2014).

Much like 'local cosmopolitanism,' this local pan-Africanism is both inward and outward looking and makes use of pan-African networks with the ultimate aim of benefiting Malawian writers (Newell 2011b; Primorac 2012). Chikoti has called upon his Africa-wide connections to bring a host of well-known writers to Malawi, including fellow Africa39 recipient Zukiswa Wanner. Despite Chikoti's assertion about the changing nature of pan-Africanism, the Malawi Writers Group espoused a similar kind of local pan-Africanism in the 1970s. Mphande recounts the pan-Africanist stance of the group and its deliberate incorporation of other African members, which it used to counter the Chewa-nationalist and British-inflected Malawian culture that Banda's regime was actively constructing. Similarly, in our 2016 interview, Chikoti emphasized that following Malawi's many years of isolation under Banda's rule, 'having artists come from different places, puts us in a network ... they will help us to open up.'

As is evident from the above, Chikoti stands firmly at the center of the Story Club's many networks. In this way, the club resembles Kwani Trust and FEMRITE, which Strauhs describes as 'highly dynamic social networks' whose international connections are often forged and maintained through personal relationships (Strauhs 2013, 30). As Strauhs finds, it is the personal nature of these transnational relationships that has allowed organizations such as Kwani Trust to benefit from networks like the Caine Prize and to simultaneously critique and claim independence from them, as Wainaina has done very publically (75). Like Adesokan's artist-as-mediator, these organizations have found a way to both utilize and critique powerful structures. Chikoti, too, has openly critiqued organizations like Caine while personally benefiting from its international platform. And while the Story Club lacks official 'Literary Partners' (which is how Kwani Trust describes organizations like the Caine Prize and Commonwealth Writers on its website), it too sees a benefit in being part of their informal, virtual networks, as is evident from the Story Club's Facebook page. On Facebook, Chikoti's own social network interplays with the club's: the man and the club are two sides of the same coin, and which one we see is often a strategic calculation.

The club's Facebook page boasts 1,266 followers, more than the Malawi Writers Union (917 members). As a point of comparison, SocialBakers records the highest-ranking media page in Malawi as Malawi24, with 418,262 fans. Overall, internet access remains low in Malawi. Internet World Stats recorded only $9.6 \%$ of the population online as of June 2017; the Facebook penetration rate is even lower at $3.9 \%$ or 720,000 people. The club's Facebook page primarily promotes the club's upcoming events and posts pictures of past ones, although when the page first began it was administered by both Chikoti and Pius Nyondo (the coordinator of the Mzuzu branch of the Story Club) and more regularly posted news about African writers (particularly Chimamanda Ngozi Adichie), literary awards and writing competitions. There are also several posts that celebrate Chikoti's achievements. On June 11, 2014, the Story Club shared a Facebook post by the South African NGO, Short Story Day Africa, which listed Chikoti as their Writer of the Week. The Story Club's post explained the significance of this news in terms of Short Story Day Africa's connection to the Caine Prize, which had selected two of its 2014 shortlisted stories from Short Story Day Africa's collection, Feast, Famine and Potluck: 'Two of this year's Caine Prize shortlisted authors are from Short Story Day Africa. Proud of you Shadreck, founder of the Story Club.' In moments like this, we can see the ways that Chikoti, the club's face, recedes (even as he is featured) so that the club can claim a connection to Caine that Chikoti himself might personally be more critical of. 
The Story Club's Facebook page also makes visible many of the networks described above. On August 23, 2014, the club posted a call for participants in its 'Imagine Africa 500' workshop and 'tagged,' or linked, to many of the people and organizations in its network so that they might further disseminate it. Those tagged included, in order: 'Commonwealth Writers, Uganda Women Writers' Association (FEMRITE), African Writers Trust - AWT, Youthful Malawian Writers, Babishai Niwe Poetry Foundation, Caine Prize for African Writing, Malawi Short Stories and Poems, Mzuni Writers' and several individuals including Trine Andersen and myself. Through practices like tagging, we can see who the Story Club envisions as its network of collaborators, and it is not insignificant that the first several groups listed are European, then African, then Malawian.

Nevertheless, the Story Club's Facebook profile picture, a computer-generated image of a bookshelf, reverses this hierarchy. The image, which advertises the club - 'Passionate about literature? Join us at the Story Club' followed by Chikoti's email address and cell phone number - depicts a two-tiered bookshelf with an eclectic group of titles. Notably, the top shelf is comprised of works by Malawian authors such as Stanley Kenani's short story collection and the Caine Prize volume in which Chikoti and Kadzitche appear, in addition to books written by international writers (many of them volunteers in the development sector) that are set in Malawi. One such title, which garnered a lot of attention locally, is The Boy who Harnessed the Wind: the non-fictional account of a Malawian teenager who built a windmill in his village, coauthored by William Kamkwamba and Bryan Mealer. The fact that these texts occupy the Story Club's first shelf shows its emphasis on Malawi and seeming openness to including nonMalawian writers in its national canon. The Story Club's second shelf features Dan Brown and John Grisham next to Dickens, Austen and Chimamanda Ngozi Adichie's Half of a Yellow Sun. This mix of popular fiction and English classics with Africa's most internationally recognized contemporary writer, Adichie, resembles the eclectic reading habits of many African readers past and present. ${ }^{8}$

In sum, the Story Club's networks cannot be adequately described as national (this would be a more fitting description of MAWU), nor are they only local, in that so many of the connections from which it draws literary capital are located elsewhere on the African continent and in Europe and America. It is strategically, if not ideologically, pan-African and is facilitated by virtual networks, but is not reducible to them. In fact, the club's Facebook page has less activity today than when it first began. As the minimal engagement with its Facebook page demonstrates, the club's most significant work takes place in person at its live events. Nevertheless, it still sees value in maintaining a digital presence. Finally, while the Story Club revolves in many ways around Chikoti and has benefited from his international profile, it is not entirely dependent on it. The most lasting contribution to come out of the club, the Imagine Africa 500 anthology, makes no mention of Chikoti's international profile either in its prefatory material or on the Kindle site where it is now being sold. In other words, while Chikoti, as the face of the club, is the center of its many networks, its work also exceeds him.

\section{Face-to-face meetings and live crowdfunding}

The Story Club's fourth 'congregation' was held at Fantasia Korean Restaurant and Bar in Lilongwe's Old Town on April 20, 2014. It was Easter Sunday, but still there was a crowd of about 30, including journalists, teachers, students and several vendors from the craft market down the street, whom I had met earlier in the week and invited. The windowless room at the back of the restaurant was filled with rows of heavy wooden tables and chairs; the dimmed lights created a nightlife ambiance, despite it being the middle of a Sunday afternoon. 
The event started at least an hour behind schedule, as Chikoti dedicated himself to the slow assembly of an impressive amount of technical equipment, including a microphone and sound system that he himself had rented. The space was not particularly large - not large enough to really require the use of a microphone - and it seemed that the sound equipment was, in part, a means of increasing the entertainment value of the event, which included live songs and poetry in addition to literary and critical discussion. However, it also presaged the way in which the entire event was mediated - literally and figuratively - by various technologies. The MC, Pius Nyondo, guided the proceedings from notes on his laptop, and Lily Banda sang several songs, including her hit 'Shampoo Your Locks,' over pre-recorded music. Most significantly, the audience listened to a pre-recorded track of Chikoti reading the story of guest author, Muthi Nhlema, who sat in the audience. A story of nearly 6,400 words, 'The Journey of Restoration,' took some time to play. During the discussion of Nhlema's story that followed, I noticed some of the participants using their smartphones to scroll through the text online (others perhaps using their phones, as many of us do, for other purposes). Overall, these technologies - while technically unnecessary - had the effect of making the club's activities seem both more professional and more 'connected,' much in the same way that the New Tafo Literary and Social Club sought to buy a wireless radio set and a Pathé projector in order to keep its members up to date with global affairs.

The discussion of the story began with the reflections of three pre-designated readers, including Nyondo, Lawrence Kadzitche and Immulanie Makande, chairperson of the Poetry Association of Malawi, Central Region chapter. The critiques of Nhlema's story were perceptive and surprisingly detailed. Kadzitche, who writes primarily in Chichewa but sometimes in English as well, suggested the story read as though it was written by someone for whom English is a second language. Makande, in his critique, drew attention to small details of language and setting. 'You don't need to say "sweltering hot,"' he suggested, 'just one of these adjectives will do.' He also noted minor inconsistencies in the narrative: although the story is set during the 2001 drought, when '[i]t hadn't rained in ages,' one of the characters looks out the minibus window and admires the green trees along the roadside. Makande repeated much of the story in his critique, a technique that reviewers of stories in Malawi's newspapers have used since the 1970s. As Karin Barber has observed in other instances of what she calls 'entextualization,' '[c]reative capacities are engaged not only when people compose, improvise or write new texts, but also when they read, listen, repeat or remember them' (2008, 210). I suggest that these retellings can constitute not only creative, but critical engagement. Recounting the scene where the story's protagonist, a teacher, masturbates in the latrine while imagining his female students, Makande said the scene concerned him because 'life imitates art' and 'what we write influences people.' In some contrast to the other reviewers, Chikoti praised the story as 'one of the best short stories by a Malawian' and pointed to its skillful use of symbolism. The rain at the end, he argued, serves as a symbol of restoration and hope, a new chapter for both the characters and the country.

The above shows the Story Club to be a space for the sustained discussion of literary language and craft as well as larger issues such as the social and ethical role of literature. The role of the artist in society was also a topic of discussion at the 'Imagine Africa 500' workshop. Further, Chikoti (2014) says he sees the club as a way of advancing feminism through art. The club has featured a significant number of female writers, directors and academics at club meetings. The need for men to be allies and feminists is also something Chikoti frequently speaks out about. However, sustained discussion of social issues has not thus far translated into the club's digital realm. In January 2018, the Story Club made a formal statement on Facebook condemning Mwiza Chavura's controversial song 'Rape.' Chikoti wrote on both the club's page and his personal Facebook page: 
We at the Story Club know that artists have the right to speak and produce art without limitations. But we also understand that, as artists we have the responsibility to protect the rights of others and to ensure that our art does not lead to the violation of the law ... We at the Story Club promote women's rights, and celebrate womanhood in all its varied aspects.

While the statement garnered 78 likes and numerous supportive comments on Chikoti's personal page, the post on the club's page got little engagement (only three likes). Fittingly, the kinds of posts that get the most attention on the club's Facebook page are pictures of its live events.

While there are more and more blogs for Malawian writing online, including the Nthanda Review and Makewana's Daughters, few readers take advantage of this space to post comments, substantive or otherwise. Popular Facebook pages like Chichewa Stories and Juniah Ngwira's Diary of a Single Mum have, in contrast, drawn many more comments on each post. Often these comments signify engagement and that one is reading, rather than providing feedback. Most of the hundreds of commenters on Chichewa Stories, which is written entirely in Chichewa, simply reply 'Next' or perhaps 'Ili bho' (it's fine/good). The comments on Ngwira's diary (which has not been updated since 2016), were generally more substantive, with readers comparing the story to their own personal experiences of heartbreak, loss and single motherhood and sometimes even engaging with issues of form and language. These Malawian digital reading communities both confirm and challenge some of what we know about how literary networks operate online and off in other contexts.

DeNel Rehberg Sedo's 2003 comparative study of virtual and face-to-face book clubs based on online surveys with 252 readers, most of whom were from Canada and the USA, finds that readers join virtual book clubs to discuss particular books and to connect with people like themselves, whereas face-to-face clubs tend to attract members who join equally for 'intellectual stimulation' as for 'fun' (80). Although Sedo discusses more formal online discussion groups, there are similarities to today's social media landscape in southern Africa, where readers 'follow' specific stories and writers on Facebook and other platforms. However, unlike the clubs that Sedo studied, where a much larger percentage of face-to-face book clubs (74\%) 'use personal experiences to interpret the books' than virtual clubs (51\%), Malawian readers of Facebook diaries like Ngwira's relate to it in an intensely personal way. Further, while Sedo suggests that 'virtual meetings allow the reader to transcend physical, geographical, and time boundaries, enriching her interpretation of the book,' Facebook pages like Ngwira's and blogs like Mike Maphoto's Diary of a Zulu Girl are often more likely to appeal to local readers, who sometimes live in the very city where the story is set (Bosch Santana 2018). In South Africa, which has a much better digital infrastructure than Malawi, this has led to the creation of offline networks that derive directly from virtual ones. In addition to the book clubs that formed around Maphoto's Diary of a Zulu Girl blog, fans of Thulani Lupondwana's Facebook story Diary of a Cheating Husband organized events with the author across South Africa in November and December of 2017. Nevertheless, these offline occasions differ from the Story Club in that the virtual space remains the central realm of engagement. Further, these blog and Facebook groups draw mostly readers rather than writers, although many of the diary writers themselves were once avid readers of other blogs (as Lupondwana was of Maphoto's). As more of a writerly network, the Story Club depends on the face-to-face interactions and more substantive discussions that the offline space affords.

As a paravirtual network, the Story Club has been extremely successful in localizing and materializing its global/pan-African resources and connections in the Malawian literary space. As 
Wallis argues in regard to Kwani Trust and Farafina, making 'material' denotes 'both the processes through which writing is created, takes form and is published, and the processes through which writing is validated and consecrated with literary value' $(2018,182)$. The Story Club has done this by providing Malawian writers with hands-on training from other professional writers, such as Billy Kahora and Jackee Batanda, and face-to-face discussions with world-renowned African writers like Tsitsi Dangarembga. Through its publishing arm, Pan African, it has also mobilized monetary and literary capital - funding from the Prince Claus fund and editorial expertise from Billy Kahora - to materialize books like Imagine Africa 500 for the Malawian and international market. However, the Story Club has been equally successful in utilizing local resources, from the talents of writers to funding mechanisms, such as the book launch. In Malawi, the book launch is not merely an event to unveil the book to the public and sell a few copies - as we often see in USA and UK contexts. Rather, book launches are an essential part of both advertising and funding publishing projects. They are a form of live crowdfunding that somewhat resemble local lending practices like chiperegani or chilimba, savings associations where friends and neighbors pool their resources (Chipeta and Mkandawire 1992).

On July 1, 2016 Chikoti and I attended the book launch for Loving Your Career by first-time author Kasuzi Mbaluko. The event, held at the Riverside Hotel in Lilongwe, was a formal affair, with mauve tablecloths covering the horseshoe-shaped arrangement of tables and bottled water, glasses and mints carefully placed at each participant's seat. The two-and-a-half-hour meeting included an opening prayer, several songs, comments on the book by Janet Liabunya, a speech by the author, and a speech by the guest of honor Madalitso Kazombo, the Member of Parliament in Mbaluko's home district of Kasungu East. The most important feature of the event, however, was the live auctioning of the book, during which the MC took pledges from audience members, many of whom bought copies of the book for much more than an individual copy would normally sell for. Mbaluko said he raised a total MK70,000, which was just enough to pay for the launch itself. Afterwards, Chikoti told me that at the launch of Imagine Africa 500, they were able easily to raise more than the cost of producing the book in a single evening.

Overall, Chikoti understands the book to be a networked object. Discussing the impetus for the club with me in 2014, Chikoti argued, 'The book can't just come out by the writer himself.' Leveraging material and virtual networks to turn ideas into books is one of its core activities according to the club's Facebook page. The 'many players' that contribute to this might occasionally include international donors like the Prince Claus Fund, which contributed to the publication of the anthology, but equally important were the crowd of people in Blantyre, who together raised enough money to publish the book by each contributing a few thousand kwacha for their copies and, most importantly, lent legitimacy to the publication through their physical (and later virtualized) presence. As Moradewun Adejunmobi reminds us, 'No matter the structural inequalities at play, we should be careful about inferring the powerlessness of the subjugated and the muteness at the margins' $(2017,140)$.

Paravirtual networks like the Story Club - networks that are made possible by a shrinking digital world, but that operate in ways that exceed the digital's affordances - are likely to become more and more common. In addition to Malawi's many poetry clubs and initiatives like the African Women Writers Trust (Kalinga 2015), new face-to-face forums for fiction continue to take shape. In November 2017, writers Ekari Mbvundula and Wonawaka Gondwe started Storytelling Sessions in Blantyre to introduce local readers to local writers. Mbvundula says that while Malawians use the internet for many things, reading literature isn't yet one of them. These face-to-face clubs challenge the notion that literary value is primarily created in literary centers in the global North and that the relationship between local readers and writers has been obviated. While the Story Club's physical network engages with virtual networks 
across the globe and is deliberately mediated - from its sound equipment to its Facebook page its most important work happens offline, in a physical space, rather than a digital one. Mbvundula provides the following maxim for writers operating in such an environment: 'presence is everything.'

\section{Notes}

1 Parts of this chapter originally appeared on Africa in Words.

2 See for example Castells (1996) and Varnelis (2008).

3 Other recent scholarship also explores the entanglement of online and offline territories (Christensen et al. 2011) and the simultaneous virtuality and materiality of digital infrastructures (Hu 2015).

4 See Moretti (2003).

5 Kalinga (2015) makes this point about Malawian literary clubs more broadly.

6 I first met Chikoti in 2007 on a visit to the orphan care center that he runs with his wife, Yamikani. We later reconnected in 2012, when I interviewed him and Kadziche about their writing and their participation in the 2011 Caine Prize workshop in Cameroon. I also interviewed Chikoti in 2014 and 2016, attending Story Club sessions in both of these years. On each visit, Chikoti asked me to be one of their speakers, and I presented some of my own academic work to the club. In 2016, I invited Chikoti to the University of Michigan, where he gave a public reading and visited two of my courses.

7 This term resonates with Tsitsi Jaji's (2014) study of cultural, 'small "p"” pan-Africanism in relation to African diasporic music.

8 Nuttall (1994) observes the eclectic reading histories of black South African women, from British classics to popular genre writers like James Hadley Chase. Similarly, Stephanie Newell argues that 'while scholars might divide novels into "literary" and "popular" genres, West African readers seem unwilling to discriminate between high and low forms' $(2000,157)$.

\section{Bibliography}

Adejunmobi, Moradewun. 2017. 'Native Books and the "English Book".' PMLA 132(1): 135-141.

Adesokan, Akin. 2011. Postcolonial Artists and Global Aesthetics. Bloomington: Indiana University Press.

Barber, Karin. 2008. The Anthropology of Texts, Persons, and Publics. Cambridge: Cambridge University Press.

Bosch Santana, Stephanie. 2014. 'The Story Club: Malawi's Newest Literary Initiative Goes Off-line.' Africa in Words. July 17. https://africainwords.com/2014/07/17/the-story-club-malawis-newest-litera ry-initiative-goes-off-line/.

Bosch Santana, Stephanie. 2018. 'From Nation to Network: Blog and Facebook Fiction from Southern Africa.' Research in African Literatures 49(1): 187-208.

Brouillette, Sarah. 2007. Postcolonial Writers in the Global Literary Marketplace. London: Palgrave Macmillan.

Brouillette, Sarah. 2017. 'On the African Literary Hustle.' Blind Field: A Journal of Cultural Inquiry, August 14. https://blindfieldjournal.com/2017/08/14/on-the-african-literary-hustle/.

Casanova, Pascale. 2004. The World Republic of Letters. Cambridge, MA: Harvard University Press.

Castells, Manuel. 1996. The Rise of the Network Society. Oxford: Blackwell Publishers.

Chikoti, Shadreck. 2013. 'How the Uganda International Writers Conference Changed My Life.' African Writers Trust, June 7. http://africanwriterstrust.org/how-the-uganda-international-writers-conference-cha nged-my-life/.

Chikoti, Shadreck. 2014. CNN African Voices. July 25.

Chipeta, C. and M. Mkandawire. 1992. 'The Informal Financial Sector in Malawi.' African Review of Money Finance and Banking 2: 121-157.

Christensen, Miyase, André Jansson and Christian Christensen. 2011. 'Introduction: Globalization, Mediated Practice and Social Space.' In Online Territories: Globalization, Mediated Practice and Social Space, edited by Miyase Christensen, André Jansson and Christian Christensen. New York: Peter Lang.

English, James. 2005. The Economy of Prestige: Prizes, Awards, and the Circulation of Cultural Value. Cambridge, MA: Harvard University Press.

Freedom House. 2017. 'Freedom on the Net 2017.' https://freedomhouse.org/report/freedom-net/2017/ Malawi. 


\section{Stephanie Bosch Santana}

Hu, Tung-Hui. 2015. A Prehistory of the Cloud. Cambridge, MA: The MIT Press.

Huggan, Graham. 2001. The Postcolonial Exotic: Marketing the Margins. London: Routledge.

Jaji, Tsitsi. 2014. Africa in Stereo: Modernism, Music, and Pan-African Solidarity. Oxford: Oxford University Press.

Kahora, Billy, ed. 2015. Imagine Africa 500. Lilongwe, Malawi: Pan African Publishers.

Kalinga, Chisomo. 2015. 'The Clubs Shaping Malawi's Literary Future.' OkayAfrica. November 6. www. okayafrica.com/the-writing-clubs-shaping-malawis-literary-future/.

Malawi Broadcasting Corporation. 2014. 'Launch of the Story Club Malawi.' YouTube video, 2:53. Posted by Shadreck Chikoti, January 10. https://m.youtube.com/watch?v=tvaOgdJsFgE.

Mbembe, Achille in conversation with Bregtje van der Haak. 2015. 'How I See It: The Internet is Afropolitan.' Chimurenga Chronic, Mar: 2-3.

Mphande, Lupenga. 1996. 'Dr. Hastings Kamuzu Banda and the Malawi Writers Group: The (Un)Making of a Cultural Tradition.' Research in African Literatures 27(1): 80-101.

Moretti, Franco. 2003. 'More Conjectures.' New Left Review 20: 73-81.

Newell, Stephanie. 2000. Ghanaian Popular Fiction. Oxford: James Currey.

Newell, Stephanie. 2011a. "Paracolonial” Networks: Some Speculations on Local Readerships in Colonial West Africa.' Interventions: International Journal of Postcolonial Studies 3(3): 336-354.

Newell, Stephanie. 2011b. 'Local Cosmopolitans in Colonial West Africa.' Journal of Commonwealth Literature 46(1): 103-117.

Newell, Stephanie. 2006. 'Entering the Territory of Elites: Literary Activity in Colonial Ghana.' In Africa's Hidden Histories: Everyday Literacy and Making the Self, edited by Karin Barber, 211-235. Bloomington: Indiana University Press.

Nuttall, Sarah. 1994. 'Reading in the Lives and Writing of Black South African Women.' Journal of Southern African Studies 20(1): 85-98.

Primorac, Ranka. 2012. 'Legends of Modern Zambia.' Research in African Literatures 43(4): 50-70.

Sedo, DeNel Rehberg. 2003. 'Readers in Reading Groups: An Online Survey of Face-to-Face and Virtual Book Clubs.' Convergence 9(1): 66-90.

Strauhs, Doreen. 2013. African Literary NGOs: Power, Politics, and Participation. London: Palgrave Macmillan.

Varnelis, Kazys, ed. 2008. Networked Publics. Cambridge, MA: The MIT Press.

Wallis, Kate. 2018. 'Exchanges in Nairobi and Lagos: Mapping Literary Networks and World Literary Space.' Research in African Literatures 49(1): 163-186. 


\title{
Language and prizes
}

\section{Exploring literary and cultural boundaries}

\author{
Doseline Kiguru
}

This chapter examines the value of creative writing in African languages within the African literary prize industry. In particular, it reviews deliberate efforts by award industries to expand cultural and literary boundaries through selected languages, and the effect that this has had on the East African literary scene. Focusing on awards for Kiswahili literature, the chapter seeks to bring two sets of discussion into dialogue with one another: the debates about award culture and African dependency on the one hand, and the debates about the languages of African literature, on the other hand. This discussion of awards for Kiswahili literature addresses some of the concerns expressed by scholars on African language writing like Clarissa Vierke (2016) who in a recent article highlighted the failure of critics to engage with African language writing. The chapter will also reflect on the shifting positions of African languages within national culture industries and the global literary economy.

To start, I want to note that there is no shortage of national and international awards specifically targeting literary writing in and from East Africa, or directed at literary writing from the entire continent. The relevant and most important awards for the East African region include the following: the Jomo Kenyatta Prize for Literature, the Wahome Mutahi Literary Award, the Burt Award for African literature, the Writivism short story prize, Kwani? manuscript project, Jalada Prize for Literature, the Macmillan Prizes, the National Book Development Council of Kenya Literary Award, the National Book Trust of Uganda Literary Awards, the Noma Award for Publishing in Africa (1980-2009), the Tanzania Best Book Prize, the Uganda Publishers and Booksellers Association Award, and the Uganda Writers Prize, among others. Most of these are explicitly or implicitly prizes for published works written in English. However, a number of recently created awards for the East African region cater specifically to literary writing in Kiswahili. These include the Mabati-Cornell Kiswahili Prize for African Literature and the Tuzo ya Fasihi ya Ubunifu Kiswahili Literary Award. It is also worth pointing out here that since 2016, the Commonwealth Short Story prize has revised its language requirements to include submissions written in languages other than English. The additional languages made eligible for consideration in this prize competition are Bengali, Portuguese and Kiswahili. Clearly, one cannot account for the selection of these three languages without referencing the political and historical realities of a prize funded and managed in the UK and only open to writers from the former British colonies. 
Starting from the 1960s, critics of African literature such as Ngũgĩ wa Thiong'o in 'The Language of African Literature' (1981) and Obi Wali in 'The Dead End of African Literature' (1997 [1993]) have been debating the question of African writing in European languages and the question of audience for African literature. This chapter returns to that debate, but from the perspective of the cultural value and prestige conferred on chosen works of literature when literary awards and prizes are awarded. One of the major factors for consideration is the strict language requirements for many awards and the framing of the African writer through the lenses of European languages. This trend that several prestigious awards facilitate has the potential to perpetuate hierarchies of literature according to the language of presentation.

\section{African literature and the awards industry}

Since the late twentieth century, in the African literary field, international literary awards such as the Booker Prize, the Caine Prize for African Writing and the Commonwealth Prize have played an important role in shaping the field of African literature. There are other fully or partly Africa-based prizes whose influence on contemporary African writing has also been significant. The prominent Africa-based prizes include the Etisalat Prize for Literature, the University of Johannesburg Prize for South African Writing, the Wole Soyinka Prize for Literature in Africa, the Kwani? Manuscript Prize and the Sunday Times Fiction Prize, to name but a few. These awards have been instrumental in creating links to the local as well as the global literary marketplace. The prestige accrued from major literary awards has also had a significant impact on how contemporary African literature is produced, disseminated and consumed.

The impact of the awards can be understood in several ways. For some observers, the role of literary prizes as agents of canonisation is problematic, while for others the danger of being coopted by powerful institutions is a cause for concern. For instance, major awards like the Nobel Prize or the Booker Prize have continued to generate controversy over their role as canonisation agents, especially when it comes to African literature. Sandra Ponzanesi, in The Postcolonial Cultural Industry (2014), echoes the opinion of those critics who have condemned the Nobel Prize in Literature as a Eurocentric prize "which has been slow to recognise the talents and literary worth of authors from former European colonies, and writing in the language of their former masters' (74). French writer and philosopher, Jean-Paul Sartre refused the 1964 Nobel Prize in Literature, arguing that writers should not allow themselves to be turned into an institution. He proposed that writers should be wary of who is validating and canonising them. Following his refusal to accept the Nobel Prize, and in an interview with Simone de Beauvoir published in Adieux: A Farewell to Sartre (1985), Sartre stated that:

These honours are given by men to other men, and the men who give the honour, whether it's the Légion d'honneur or the Nobel Prize, are not qualified to give it. I can't see who has the right to give Kant or Descartes or Goethe a prize which means now you belong in a classification. We have turned literature into a graduated reality and in that literature you occupy such and such a rank. I reject the possibility of doing that, and therefore I reject all honours.

(Quoted in Carter 2012, 35-36)

David Carter, in How to Win the Nobel Prize in Literature (2012), emphasises that for Jean-Paul Sartre, 'standardization and placement in hierarchical structures (by awarding prizes which recognized achievements of specific values) meant the loss of individual freedom' (33).

In his own resistance against these hierarchical structures decades after Sartre's refusal to accept the Nobel Prize, Amitav Ghosh declined the Commonwealth Best Book Award for The 
Glass Palace (2000). He argued that his nominated novel was only considered for the award 'partly because it was written in English and partly because I happen to belong to a region that was once conquered and ruled by imperial Britain', noting that '[o]f the many reasons why a book's merits may be recognized, these seem to be the least persuasive. ${ }^{1}$ It is important to note here that the Commonwealth Book Prize (1987-2013) as well as the Commonwealth Short Story Prize, until 2015, were open only to writers writing in the English language, and who also belonged to any of the Commonwealth nations. Ghosh's decision to pull his work out of the competition recalls Sartre's argument about canonisation agents and the power to confer prestige on a literary work.

We have seen similar efforts to assert individuality among winners of awards specifically aimed at African authors. When she was awarded the 2015 Caine Prize, the Zambian author, Namwali Serpell echoed Sartre, and seemed to call for the erasure of literary hierarchies that are instituted by the prize competitions, arguing that 'writing really isn't a competition' and that 'when it comes to how we feel about writing as writers together, talking about words, talking about literature, talking about life, I don't think we really enjoy being pitted against each other. ${ }^{2}$ While Sartre refused to accept the Nobel Prize, Serpell accepted the Caine Prize but decided to distribute the $\mathcal{E} 10,000$ cash prize equally among the five shortlisted writers that year. Through this action the Zambian-born writer who was first shortlisted for the Caine Prize in 2010 argued against ranking of writers in the literary market.

The Caine and the Commonwealth prizes, especially, have gained considerable popularity on the continent not only for the prize money they award, $\mathcal{f}_{10,000}$ and $\mathcal{f}, 000$ for the winners respectively, but also because the short story genre is the most favourable to upcoming writers especially in the absence of strong mainstream publishing structures. Through these prize bodies, the short story becomes a stepping stone to longer narratives, usually novels, that come after the win, and aided by the prize which facilitates access to literary agents and to publishers. Some of the well-known examples of this progression include Binyavanga Wainaina who was one of the first winners and who later published the memoir, One Day I Will Write About This Place (2011), and NoViolet Bulawayo who won the Caine Prize in 2011 for 'Hitting Budapest', a short story that was later extended to become the Booker shortlisted novel We Need New Names (2013). Other examples include Helon Habila's 2001 Caine winning story, 'Love Poems', which he later expanded into the novel Waiting for an Angel (2002), and which won the Commonwealth Writers' Prize for the African Region in 2003. It is important to also mention Zimbabwean writer, Brian Chikwava who won the Caine Prize in 2004 for 'Seventh Street Alchemy' and later wrote the novel, Harare North (2009). A final illustration comes from South African Mary Watson, who won the 2006 Caine for her short story 'Jungfrau', and later published The Cutting Room (2013), among other examples where the short story has been 'invariably treated as a mere appendage to the novel' (Balogun 1991, 4).

The Caine Prize has attracted a great deal of commentary from academic and non-academic critics of African literature, who worry about the role of this award as an untrustworthy gatekeeping agency. For example, one of the earliest academic papers on the role of the Caine Prize in Africa's literary and cultural industry, by Dobrota Pucherová, condemned the prize for perpetuating a stereotypical image of Africa as a place of pain and suffering. Pucherová argued that:

many Caine finalists seem to reproduce such stereotypes, in complicity with the spectacularization of African poverty and pain in western media, such as images of hungry, snotnosed children covered with dust, amputated limbs, the killing of dogs for food, piles of dead human bodies, death as a result of miscarriage or AIDS.

$(2011,20)$ 
She concluded that by focusing on such images of the continent 'the Caine Prize markets certain authors as authentic representatives of something called "Africa", providing authentic access to the "African experience"” (14).

In her analysis, Samantha Pinto notes that African writers have learned to view the Caine Prize as a double-edged gift "pursued in the face of minimal continental support for African writing' (2013, 141). Writing in 'The Caine Prize and the Impossibility of "New" African Writing', she adds that the Caine Prize lies at the 'uncomfortable crossroads of the temporal "modalities" of colonial aesthetics and anthropology' and its own critical reception should be viewed 'as proof of old injustices' (142). Doreen Strauhs's comprehensive work on literary organisations on the continent in African Literary NGOs discusses the contribution of the Caine and Commonwealth literary prizes to the growth of writing organisations such as FEMRITE in Uganda and Kwani? in Kenya. Strauhs calls the beneficiaries of such award bodies, literary NGOS or LINGOS. She also worries that this kind of external investment can have 'a negative impact on the literary output of a LINGO, for it influences, if not limits, the range of its literary output decisively' (2013, 87).

Writing in response to some of this criticism, and in defence of the award, Lizzy Attree, the former administrator of the Caine Prize, applauded the prize for its contribution 'to encourag[ing] the growing recognition of the worth of African writing in English' (2013, 36). South African writer, Zoë Wicomb (2015 Caine Prize Chair of Judges), offers a contrary view and questions the legitimacy of literary prizes in a country and continent characterised by social, economic and political inequalities. In 'Culture Beyond Colour? A South African Dilemma', Wicomb observes that the function of a literary prize in a society faced with different levels of inequality, especially in the education sector, is not only inappropriate or inadequate as a means of encouraging writing, but it actively perpetuates inequity by rewarding those who have been privileged' (1993, 28). These divergent reactions highlight the often contested function of literary prizes. As Gillian Roberts (2011) notes in the context of the Canadian literary award industry, prizes do not merely reflect and celebrate literature, 'they are entities unto themselves, carrying as many cultural implications as the works they celebrate, and forming a cultural frame in which the works are consumed and read' (51).

Alongside the different reactions from African literature scholars that the Caine Prize has elicited, there is a wider discussion unfolding about the relationship between literary prizes in general and the institutionalisation of literature in the African setting. The examination of the value attributed to literary works in African languages in this chapter is directly related to the kinds of question raised in this broader discussion about prizes and literature in an African context. In one article (Kiguru 2016a), for example, I have written about the ways in which African creative writers' programmes interact with specific prize award institutions to advance canonisation of particular literary works. Elsewhere (2016b) I take up the role of literary awards in canonising selected works of African literature, but in this case from the perspective of aesthetic qualities or literary taste criteria used by the award bodies. Ruth Bush and Claire Ducournau (2015) review the legacy of a literary prize for African literature in French in developing standards of literary value for Francophone African literature, as well as for France's own understanding of its relationship to postcolonial culture. Pushing back against the tendency to focus on the ability of prize institutions located in the global North to privilege certain types of African writing, Shirin Edwin (2016) points out how several of the short stories selected for the Caine Prize recently, actually aim to highlight strategies for evading control by powerful aid agencies engaged in humanitarian work on behalf of Africans. 


\section{Language and literary awards}

Pierre Bourdieu (1993) and James English (2005) both note that the process of submission for awards, selection, shortlisting and eventual process of awarding literature is determined mainly by power relations between the systems of cultural production and consumption. Those who nominate stories or literary works for particular awards are likely to be individuals who have been able to read the literary works that have previously won the same award. It comes as no surprise then that although the Caine has always been open to translated short stories, former Caine Prize Administrator Lizzy Attree $(2013,37)$ admits that the organisation receives very few stories in translation. The sole exception to this trend is the 2017 winning entry, 'The Story of the Girl Whose Birds Flew Away' by Sudanese writer Bushra al-Fadil, a translation from Arabic. Attree acknowledges that most of the stories submitted to the Caine competition are originally published in English.

The pattern of power relations that apply to the awards to be discussed in this chapter will be similar - up to a point, but there will also be differences. As noted above, the chapter is based on analysis of three major award bodies: the Commonwealth Short Story Prize, the MabatiCornell Kiswahili Prize for African Literature and the Tuzo ya Ubunifu Kiswahili Literary Award. One of the major reasons for choosing these three is their international reach in terms of the eligibility criteria as well as in terms of funding and institutional support, and with the latter two, the fact that they have been conceived as prizes devoted entirely to Kiswahili language writing. By focusing on the language policies of these three prize organisations this chapter raises a number of questions. Does this focus on writing in African languages by international award bodies decentre the power of institutions based in the global North for elevating particular types of African writing? Do these prizes change the balance of power and prestige between African literatures in European languages and African literatures written in African languages? In order to respond to these questions and to assess the impact of the new awards on the field of literary production in East Africa, a brief history of the awards will be required.

The Commonwealth Short Story Prize was originally a competition for radio stories and was named the Commonwealth Short Story Competition until 2011, with the revision making it an annual award for unpublished stories managed and funded by the Commonwealth Foundation. The original focus on radio stories that were broadcast through the BBC played an important role in promoting the literary careers of various African writers and this dissemination structure relied on orality under the reality of weak literary publishing platforms on the continent at that time. Some contemporary African writers - for instance, Chimamanda Ngozi Adichie, Sefi Atta, Chika Unigwe, Jackee Budesta Batanda, Lauri Kubuitsile, Ellen Banda-Aaku, Molara Wood and Taddeo Bwambale Nyodo - were launched onto the African literary scene through this competition. The Commonwealth Short Story Prize awards writers from the Commonwealth regions of Asia, Canada, Africa, Europe, the Pacific and the Caribbean. As in the other regions, an African regional winner is selected each year, together with some commended entries. Of significance to this chapter is the 2016 submission guidelines revision that saw the Commonwealth Short Story Prize open up to receiving submissions of stories written in other languages apart from English. As noted earlier, the prize is now open to stories in Bengali, Portuguese and Kiswahili where both the original writer and the translator are awarded. Although data is unavailable about the submitted stories, what is evident is that there has not been a story either written in Kiswahili, or translated from Kiswahili, that has been shortlisted or won this prize. However, there have been single stories translated from Bengali that were shortlisted in 2016 and in 2018. Despite the lack of Kiswahili stories in this competition, the Commonwealth Writers Prize is involved in a literary translation project aiming to come up 
with an anthology of stories in English translated from Kiswahili. This project, which started in 2017, builds on an earlier successful one on Bangla-English translation. It involves workshops focusing on literary translation skills, a mentorship project, and an editing phase aiming at coming up with an anthology in partnership with Soma (Tanzania), and English PEN. ${ }^{3}$

The Mabati-Cornell Kiswahili Prize for African Literature, established in 2014, is fashioned around language as a major influence in African cultural production. The prize seeks to reward 'excellent writing in African languages and encourage [s ...] translation from, between and into African languages'. ${ }^{4}$ Its funding is both local and international as it is supported by the business entity Mabati Rolling Mills Limited of Kenya, but also by Cornell University in the United States. The prize was co-founded by Mukoma wa Ngũgĩ and the then Caine Prize Administrator Lizzy Attree, and among its board members and trustees is renowned African writer, Ngũgĩ wa Thiong'o. This prize has gained from the symbolic capital of the Caine Prize as well as from that of Ngũgĩ wa Thiong'o, who has tirelessly campaigned for African literature written in African languages, a struggle that has been echoed in the work of his son, Mukoma wa Ngũgĩ, who sits on the prize's board and was one of the founding members. The winner walks away with $\$ 15,000$ for the best unpublished manuscript across the categories of fiction, poetry, memoir and graphic novels. Each year, the winning entries from the Mabati-Cornell prize are published in Kiswahili by the East African Educational Publishers. In addition, the best poetry book each year is meant to be published in English translation by the Africa Poetry Book Fund.

A new prize was also launched in Kenya in 2015, named Tuzo ya Fasihi ya Ubunifu Kiswahili Literary Award. It pursues the same goals as the Mabati-Cornell prize. The Ubunifu Prize seeks to award novels written in Kiswahili with a cash prize worth Ksh1,000,000 $(\$ 10,000)$ for unpublished manuscripts. The prize is co-funded by the French Embassy in Kenya and a local publisher - Spotlight Publishers, in partnership with the Nation Media Group. This award body also aims to promote Kiswahili language. Part of the award package includes the publication of the winning works in Kiswahili by Spotlight Publishers. The partnership with the French Embassy in Kenya also ensures that winning works are translated into French and published. However, since the launch of the award in 2015, only the first winning work has so far been published. Nyota Njema Mawinguni by Amos Nandasaba was published in 2016. The second winning work by Gulamu Mwaviro is yet to be published. In 2017, the prize was not awarded for what the organisers cite as lack of funds. In addition to these publication gaps, the French translations of these winning works are also yet to see the light of day.

These twenty-first century awards for writing in African languages are of particular interest in this chapter because they appear to refute the most important criticism levied against international awards, which is that they undermine the independence of African literary writing and cultural institutions. If writing in African languages is considered an important measure of African cultural independence, then support for African language writing might be seen as a contribution towards the independence of African literary writing and cultural institutions.

While the recent establishment of such prizes as the Mabati-Cornell or Tuzo ya Ubunifu has received a great deal of acclaim, especially by media in East Africa, ${ }^{5}$ it is important to acknowledge that the giving of international awards for (creative) writing in African languages has a long history. Indeed, the very first awards for African writing were for writing in African languages. For instance, and as far back as the early twentieth century, Diedrich Westermann, founding editor of the journal Africa, reported on the work of the International Institute of African Languages and Cultures (IALC) and the fact that it had 'established an annual competition for African vernacular literature in December 1928 to act as a stimulus for authors writing in indigenous African languages' (see Adejunmobi 2004, 6-7). As further noted by Adejunmobi $(2004,7)$, 'the canon of early African vernacular literature was largely formed from authors who 
first received recognition... through these competitions.' The award was named the Prize Competition for Books in African Languages and was an annual award based in and funded from the UK, managed by the IALC in London. It was suspended after 1939 because of the start of WWII but resurfaced again after the war as a prize competition for essays in African languages. However, there is little evidence indicating that it lasted for more than one year after the war.

Following the suspension of the Prize Competition for Books in African Languages, the Noma award for publishing in Africa, which ran from 1979 to 2009, represented another foreign initiative intended to boost publishing in Africa, and indirectly writing in African languages. This award was founded by the late Shoichi Noma, formerly President of Kodansha Ltd, a Japanese publishing house. The award aimed to promote African publishing by awarding US $\$ 10,000$ annually to an African writer or scholar whose work was published by an autonomous African publisher on the continent in any of the languages spoken in Africa, including English and Afrikaans. The prize was awarded for an outstanding new book in any of the categories of 'academic and scholarly books, children's books, and literature and creative writing' (Kimani 2009, 112). Although most of the Noma award winning works were written in English or French, texts in African languages won the award at least twice. This award too was discontinued after the Noma family ended its sponsorship for the prize in 2009.

As mentioned earlier in this chapter, several other locally based awards for African literature are currently administered on the continent. However, only submissions in English are eligible for many of these awards, including the following: the Etisalat Prize for Literature, Wole Soyinka Prize for Literature in Africa, Kwani? Manuscript Prize, Sunday Times Fiction Prize, among others. For Kiswahili literature in particular, other regional or country-based award bodies do exist. These awards, such as the Jomo Kenyatta Prize for Literature $(\$ 1500)$, the Wahome Mutahi Prize $(\$ 500)$, the Jalada Prize $(\$ 330)$, among others, include categories for Kiswahili literature. Within Kenya, local awards like the Jomo Kenyatta Prize and the Wahome Mutahi Prize attract a high number of entries each year and considerable media attention despite the fact that they do not offer as high a compensation as do the continent wide and international awards.

Given this background, the creation of new awards for Kiswhaili language writing represents more of an expansion of support for literature in Kiswahili than a pioneering initiative. Nonetheless, the new awards differ from earlier awards for Kiswahili literature in important ways. First, the Mabati-Cornell, Tuzo ya Ubunifu and Commonwealth Short Story Prize share one thing in common - they are all awards for unpublished manuscripts and this has proved significant for encouraging subsequent publication of award winning manuscripts. In this regard, the awards can be described as having a developmental impulse. Second, they all pay great attention to and acknowledge the question of literary translations. Third, two of these awards the Mabati-Cornell and Tuzo ya Ubunifu - involve collaboration between local and international institutions and figures. How significant are these areas of difference?

Starting with the language of writing, there is no doubt that the creation of additional awards for literature in Kiswahili fits in with growing attention to the status of lingua francas in discussions about African language writing. Kiswahili is a regional lingua franca with speakers spread widely within East and Central Africa. It has been a language of commerce, education, religion - bridging language boundaries between different ethnic groups and languages in the region. This is a language with greater visibility within the global cultural market and a greater global reach than other African languages such as, for example, Gikũyũ. As a result, Kiswahili also enjoys more prestige than other languages that do not function as a lingua franca. In fact, the website for the Mabati-Cornell Prize states clearly that 'Kiswahili is an established world 
language and should be considered as such. ${ }^{6}$ The emphasis on Kiswahili's position as a 'world language' is not exactly the same thing as advocating writing in mother tongues that may not be 'world languages'. For this reason, Ngũgĩ wa Thiong'o's presence on the board for the MabatiCornell prize, as a writer and critic known for his support of writing in Africa languages and especially in the mother tongue, is noteworthy.

In addition to his commitment to writing in mother tongues, Ngũgĩ has given increasing attention to the status of the lingua franca in some of his more recent essays. For example, writing in 'The Politics of Translation' (2017), a paper that was initially presented as the 2016 Neville Alexander Memorial Lecture at the Harvard Centre for African Studies, Ngũgĩ acknowledged the role of the lingua franca in what he calls 'the network of languages' (2017, 127). But he also made a distinction between languages like Kiswahili that he sees as a lingua franca, and those languages that he called the languages of power $(2017,127)$. He writes: 'A language of power assumes that for it to be, other languages must cease to be. It desires to replace or silence all the other languages' $(2017,127)$. Presumably, these languages of power are the languages of the former coloniser. As will be evident below, other critics of African literature do not necessarily agree with Ngũgĩ's understanding of the lingua franca. However, it is clear that involvement with this award has allowed him to foreground an additional perspective in his call for writing in African languages.

All three awards include an expression of support for translation of the winning entries into additional languages. The 'News' page of the Mabati-Cornell Prize states that the prize 'has the express goal ... of encouraging translation between and into African languages'. ${ }^{7}$ An English translation of the award-winning book of poetry is also supposed to be published by the Africa Poetry Book Fund. The Tuzo ya Fasihi ya Ubunifu prize comes with a provision for translation of the winning entry into French. Since these awards are fairly new, it may be some time before any translations of the winning books are actually published. There are signs that Mohammed Ghassani's N'na Kwetu, ${ }^{8}$ winner of the 2015 Mabati-Cornell prize, is in the process of being translated into English, but there is no evidence of current translation projects for any of the other winners of these awards. This too is significant.

The fact that the only translation of these award-winning works currently in preparation is from Kiswahili to English would seem to reinforce existing hierarchies of language. Furthermore, this is important because the English language, and other European languages such as French, as is the case with the Tuzo ya Fasihi ya Ubunifu award, tend to be seen as giving greater access to the international audience while by comparison, literature produced in local languages is often viewed as restricted to a more localised audience. Writing for example about African literature in 2017, Sarah Brouillette in an online piece, 'On The African Literary Hustle', acknowledges that there is 'an important African literary community thriving across key cities'. However, she claims:

there is a small readership in these urban centers [... but] it isn't that important that there be local readers. These writers have bypassed the problem of the absent African reader. There is donor funding to support the activity of writing, to award prizes to authors, and to facilitate access to US and other foreign markets.

On the one hand, this postulation assumes that literature in English is mainly for export and therefore excludes a local audience. On the other hand, and while Kiswahili has a wide reach on the continent and even beyond, literatures in Kiswahili continue to circulate in very different literary circles and markets when compared with literatures translated into or written in languages like English or French. Indeed, as Moradewun Adejunmobi (2004, 66) notes: 
It is certainly true on the one hand that the canon of 'African literature' has since the 1970s been considerably expanded to make room for texts composed in indigenous languages. But on the other hand, indigenous language texts that are not translated into the founding languages of this entity, and that do not become the object of critical discourse in these languages rarely gain entrance into this field of interactions. They may exist, and even be popular with certain audiences, but they will not feature in the anthologies, journals, curricula and discussions that purport to represent 'African literature' unless they are translated into the languages that predominate in the circuits of communication which together constitute and literally produce the category of 'African literature'.

Each of these awards, and in particular the Mabati-Cornell, benefit from the prestige of being associated with prominent figures in the world of African literature. Just like other major award bodies - such as the Caine Prize - where board members or patrons, judges and others are carefully selected in order to lend specific value to the award (say for instance having the African Nobel Laureates in Literature - Wole Soyinka, J. M. Coetzee, Nadine Gordimer - as 'patrons' of the prize), the Mabati-Cornell also gains from the symbolic capital of the Caine (Attree) as well as from that of Ngũgĩ wa Thiong'o who has tirelessly campaigned for African literature in African languages. Apart from Attree, Ngũgĩ and Mukoma wa Ngũgĩ, the others on the board include: Abdilatif Abdalla, Happiness Bulugu, Walter Bgoya, Henry Chakava, Chege Githiora, Carole Boyce Davies and Rajeev Shah, many of whom are well known figures connected to Kiswahili language literature and to publishing in East Africa. Also, the initial announcement for this prize was made during the Aké Arts and Book Festival, held in Nigeria. ${ }^{10}$ The presence of individuals connected with Kiswahili literature, or who are publishing in East Africa, contributes to enhancing literary networks - networks that are further realised with the publishing agreements between the prize and local publishers such as Spotlight Publishers and East African Educational Publishers.

However, the prestige and value that comes with Ngũgĩ wa Thiong'o as one of the board members also inadvertently draws attention to contradictions surrounding the politics of the award organisation, its board members, and the winners of the award. Although Ngũgi argues that, 'a lingua franca assumes the existence of co-equal languages' (2017, 127), the MabatiCornell award website itself seems to imply a ranking of languages. Although the site says that all languages are equal, it also acknowledges that some languages, like Kiswahili are 'world languages' which would seem to imply that not all languages are 'world languages'. Biodun Jeyifo in his response to Ngũgĩ in the same issue of the Journal of African Cultural Studies where Ngũgĩ's article appears, maintains that English 'is a national lingua franca that serves as a "link language" for and between all the indigenous languages of the nation' $(2017,137)$. As one of his most important areas of disagreement with Ngũgĩ, Jeyifo then states that 'the assumption first, of parity or equality between all indigenous African languages ... is a gross and unhelpful simplification of the structure of power and dominance among the languages in use in Africa at the present time' (2017, 143). In other words, all languages, including other African languages, do not occupy the same position in any African nation. John Mugane, another contributor to the same edition of the journal, introduces further complications to Ngũgís notion of equality between all languages by calling for attention to the different forms of a given language that may be in use. Mugane asks what differences exist between local forms of English and French, and those languages corresponding to what he calls 'the press release languages of Africa's intellectual products' (2017, 155). While Ngũgĩ and Jeyifo debate whether English is an African language or not, Mugane proposes a different way of looking at languages, involving a study of 
'the vertical/horizontal typology [which] is a mapping of power relations that cut across standard/non-standard distinctions of English' (2017, 151).

If the presence of major figures from the world of African literature brings prestige and contradiction, so also does the support of other entities for these awards. Much of the prestige associated with the Tuzo ya Fasihi ya Ubunifu award seems to come from the fact that it is sponsored by the French Embassy in Kenya, in addition to offering a more substantial prize than other national awards. And even though the Mabati-Cornell Prize website credits 'African philanthropy' for sponsoring the prize, the name of Cornell University features in the prize, next to that of the local sponsors, Mabati Rolling Mills in Kenya. These award bodies represent new forms of partnership between local and transnational actors. But they still depend to some extent on either financial or symbolic power from outside Africa. James English indicates in The Economy of Prestige (2005), that 'the investment of foreign symbolic capital in emergent symbolic markets has been seen [...] as a means of sustaining less overtly and directly the old patterns of imperial control over symbolic economies and hence over cultural practice itself (298). Sarah Brouillette echoes this interpretation when she argues that the 'field of contemporary Anglophone African literature relies instead on private donors, mainly but not exclusively American, supporting a transnational coterie of editors, writers, prize judges, event organizers, and workshop instructors' and adds that the 'literary works that arise from this milieu of course tend to be targeted at British and American markets' (2017). These comments do not seem directly relevant for literary works in African languages, especially if those works are not yet being translated into English and cannot be easily targeted at British and American markets. This would suggest that the language of initial publication might make a difference for reading publics in specific regions of Africa.

While Brouillette's comments apply specifically to 'Anglophone African literature', this does not mean that African authors writing in English are themselves unaware of the way symbolic capital from outside Africa affects the reception of their work. Madhu Krishnan suggests that 'writers in a global literary marketplace both challenge and are constrained by the conventions mediating the reception of postcolonial literatures' (2014, 3). Shirin Edwin, quoted earlier provides evidence for Krishnan's position.

For example and in his debut novel, Waiting for an Angel (2002), Helon Habila explains the significance of an international prize to a writer faced with political and economic constraints. In the novel a young journalist, Lomba, and his newspaper editor talk about publishing and literary awards in Nigeria at a time when the country is facing different sanctions and suspension from the Commonwealth of Nations. ${ }^{11}$ The ambitious Lomba is trying to publish a novel but his editor is discouraging him:

You won't find a publisher in this country because it'd be economically unwise for any publisher to waste his scarce paper to publish a novel which nobody would buy, because the people are too poor, too illiterate, and too busy trying to stay out of the way of the police and the army to read. And of course you know why paper is scarce and expensive because of the economic sanctions placed on our country. But forget all that. Say you found an indulgent publisher to publish your book, someone who believes in this great book as much as you do; and because you are sure your book is good, you'd want to enter it for a competition - what is the most obvious competition for someone from a Commonwealth country? Of course, the Commonwealth Literary Prize. But you can't do that [...] Because Nigeria was thrown out of the Commonwealth of Nations early this morning. 
This excerpt from Habila's novel, which won the Commonwealth Writers Prize for the 2003 Best First Book, Africa Region, paints a picture of the self-aware writer who is all too familiar with the challenges of publication, and the constraints surrounding international awards for African literature. In Lomba's case, the Commonwealth Prize is his most obvious option, but he has to get his book published first before he can enter it for the prize. It is important to note that this novel in which Habila writes about the difficulties faced by African writers in the search for authentication and canonisation was initially self-published. After a chapter from the book, a short story titled 'Love Poems', won the Caine Prize in 2001, the book was later acquired and published by an international publisher - Penguin Press. Whether concerns of this kind will begin to appear in literature in African languages when such works are submitted for internationally supported prizes remains to be seen. Further reflecting on the relationship between the audience for African literature, and the mechanisms of publishing and canonisation, Krishnan also states that the question of an audience for African literature 'cannot and does not exist within a simple binary of us and them, West and rest' because the relationship between the text, the author and the audience 'is one which defies reduction to a single form of directionality' $(2014,37-8)$. The postulation of the reading public as a homogenous group, she says, 'fails to grasp the complexity of cultural transmission and circulation' (37).

Different forms of patronage continue to play a major role for African literature at all levels from the completion of a manuscript to the winning of an award. For publishing for example, Cecilia Kimani remarks that the 'roles of government, donors and multinationals on the continent are three important areas of concern' $(2009,104)$. Patronage in the case of these awards is both local and foreign. The support offered by the Mabati-Cornell Prize seems to have facilitated publication by the East African Educational Publishers of the novel, Penzi la Damu by the 2015 winner, Anna Samwel, and the novel, Kolonia Santita by the 2016 winner, Enock Maregesi. The support offered by the French Embassy in Kenya and Spotlight Publishers enabled publication of the novel Nyota Njema Mawinguni by Amos Nandasaba Kundu, winner of the 2015 Tuzo ya Fasihi ya Ubunifu award. However, plans for the translation of several of these award winning literary texts appear stalled despite the patronage provided by the award bodies. The difficulty with accomplishing all the stated goals for these awards confirms the observations of Sarah Brouillette and David Finkelstein when they state that ' $[t]$ he manner in which these texts reach audiences involves complex negotiations of political, commercial, and cultural boundaries and sensibilities' (2013,3). Sometimes, it would seem, the negotiations do not yield the expected results. Ironically, and though delays in translating these award winning books are probably not intentional, the delays may have the effect of ensuring that these works circulate mainly in Kiswahili speaking regions of Africa instead of circulating mainly outside Africa.

\section{Conclusion}

Do the awards for writing in Kiswahili decentre the power of international award bodies based in the global North? As has been mentioned in this chapter, a lot of the prestige that comes with the Mabati-Cornell Prize, and the Tuzo ya Fasihi ya Ubunifu Award stem from their association with institutions or figures located in or with connections outside Africa like the French Embassy, Cornell University and the former director of the Caine Prize. The most prominent African writers and critics on the board are also resident outside Africa, have benefitted from being published by both local and international publishing houses, and have had their own works translated into English or initially written in English. However, it is also important to acknowledge the contributions of local institutions and literary or academic personalities, whether as co-funders such as the case with the Mabati Rolling Mills, as publishers, 
or as board members and judges. It is also interesting to note that the local supporting institutions like the East African Educational Publishers and Spotlight Publishers have been fulfilling their own pledges to publish the winning works, while the plans for translation that appear to depend on external resources, and which would enable these texts to circulate more broadly are moving much more slowly. What this chapter shows is that internationally connected award bodies remain powerful, even for literature that circulates mainly regionally and nationally and in a regional lingua franca. But these awards cannot be described as 'Eurocentric', to borrow the words of Ponzanesi $(2014,74)$. Most of the attention that these awards have attracted has been highly localised, on the African continent and especially in East Africa. Despite the relative power of the foreign figures and institutions supporting the awards, the Mabati-Cornell and the Tuzo ya Fasihi ya Ubunifu in particular are perceived as African, perhaps because in addition to the language factor, the award ceremonies take place in Africa and involve mainly local dignitaries. In short, and to quote Pascale Casanova:

$[\mathrm{P}]$ atterns of literary domination cannot be reduced to a political balance of power, as is sometimes done by academic critics who treat perceived differences in rank between national literatures as a simple function of economic domination analyzed in terms of a binary opposition between center and periphery [...] a more sophisticated model would take into account a peculiar ambiguity of the relation of literary domination and dependence, namely that writers in dominated spaces may be able to convert their dependence into an instrument of emancipation and legitimacy.

(2004, 116-117)

Less than ten years after the awards were founded, it is not yet clear whether these twenty-first century awards will alter the balance of prestige between African literatures in European languages and African literatures in African languages. Although the awards are for literature in Kiswahili, the winning texts may end up circulating more in English or French when, and if, they are translated into European languages. Though translation into other African languages does not yet appear to be on the horizon, the works selected for the awards do have greater visibility locally (and especially in East Africa) than they do internationally. Despite all this, this chapter acknowledges the important role that these prizes play in the development and promotion of contemporary African literature. They help not only to create a literary market for these works but also to claim a space for African literature in African languages on the global literary scene. They contribute to affirming the significance of knowledge produced and presented in African languages. However, as the chapter demonstrates, the award sector is just one of the many structures of cultural production that exists and it is important to also analyse these prizes and their publication guidelines within the wider context of literary production in the region and even beyond, in order to understand how different structures influence each other.

\section{Notes}

1 See: www.outlookindia.com/article/the-conscientious-objector/211102. Also quoted in Allison (2001), and in Brouillette (2007, 71).

2 This was in an interview with Radio France International soon after winning the Caine Prize. The full interview is available here: www.english.rfi.fr/africa/20150707-caine-prize-winner-namwali-serpell-wr iters-writer.

3 For more information on this, see: www.commonwealthwriters.org/swahili-translation/.

4 See: http://kiswahiliprize.cornell.edu/news/. 
5 See for example: www.thecitizen.co.tz/magazine/success/Finally-Recognition-for-Kiswahili-writers__/ -/1843788/2611710/-/io68flz/_/index.html; www.swahilihub.com/habari/MAKALA/mshindi-tuzo-ya -Kiswahili-kupokea-Sh1m/1310220-2788190-p1gd1r/index.html; www.spotlightpublishers.co.ke/index. php/tuzo-ya-fasihi-ya-ubunifu.

6 See: http://kiswahiliprize.cornell.edu/about-the-prize/.

7 See: http://kiswahiliprize.cornell.edu/about-the-prize/.

8 See: https://pahc.princeton.edu/postdoc/african-humanities-fellows/.

9 This piece is available here: https://blindfieldjournal.com/2017/08/14/on-the-african-literary-hustle/.

10 This festival was founded in 2013 by the Nigerian writer, Lola Shoneyin, and takes place in the city of Abeokuta, where the writer Wole Soyinka spent his childhood years.

11 Nigeria was suspended from the Commonwealth of Nations between 11 November 1995 and 29 May 1999, following the execution of writer and political activist Ken Saro-Wiwa. He was executed, together with eight other leaders of the Movement for the Survival of the Ogoni People (MOSOP), by the military government of Sani Abacha for their campaign against environmental degradation in the Niger Delta region. They were hanged on the eve of the 1995 Commonwealth Heads of Government Meeting. See McLuckie and McPhail (2000).

\section{Works cited}

Adejunmobi, Moradewun. 2004. Vernacular Palaver: Imaginations of the Local and Non-native Languages in West Africa. Clevedon, UK: Multilingual Matters.

Allison, Rebecca. 2001. 'Novelist Quits “Imperial” Contest'. The Guardian, 22 March.

Attree, Lizzy. 2013. 'The Caine Prize and Contemporary African Writing'. Research in African Literatures 44(2): 35-47.

Balogun, F. Odun. 1991. Tradition and Modernity in the African Short Story: An Introduction to a Literature in Search of Critics. New York: Greenwood Press.

Bourdieu, Pierre. 1993. The Field of Cultural Production: Essays on Art and Literature. Cambridge: Polity Press.

Brouillette, Sarah. 2007. Postcolonial Writers in the Global Literary Market. Basingstoke: Palgrave Macmillan.

Brouillette, Sarah. 2017. 'On the African Literary Hustle'. Blind Field: A Journal of Cultural Inquiry: n.p. Accessed January 4, 2018. https://blindfieldjournal.com/2017/08/14/on-the-african-literary-hustle/.

Brouillette, Sarah and David Finkelstein. 2013. 'Postcolonial Print Cultures'. The Journal of Commonwealth Literature 1(48): 3-7.

Bush, Ruth and Claire Ducournau. 2015. 'Francophone African Literary Prizes and the "Empire of the French Language"'. In The Book in Africa: Critical Debates, edited by Caroline Davis and David Johnson, 201-222. London: Palgrave Macmillan.

Carter, David. 2012. How to Win the Nobel Prize in Literature. London: Hesperus Press.

Casanova, Pascale. 2004 [1999]. The World Republic of Letters. Edited by M. B. Debevoise. London: Harvard University Press.

Cornell University. 2014. 'Mabati-Cornell Kiswahili Prize for African Literature'. www.cornell.edu. November 21. http://kiswahiliprize.cornell.edu/.

Edwin, Shirin. 2016. '(Un)solving Global Challenges: African Short Stories, Literary Awards, and the Question of Audience'. Journal of African Cultural Studies 28(3): 359-371.

English, James F. 2005. The Economy of Prestige: Prizes, Awards and the Circulation of Cultural Values. Cambridge, MA: Harvard University Press.

Habila, Helon. 2002. Waiting for an Angel. New York: Norton.

Jeyifo, Biodun. 2017. 'English is an African language - Ka Dupe!' Journal of African Cultural Studies 30(2): 133-147.

Kiguru, Doseline. 2016a. 'Literary Prizes, Writers' Organisations and Canon Formation in Africa'. African Studies 75(2): 202-214.

Kiguru, Doseline. 2016b. 'Prizing African Literature: Creating a Literary Taste'. Social Dynamics 42(1): 161-174.

Kimani, Cecilia. 2009. 'Publishing in Africa'. In Media and Indentity in Africa, edited by Kimani Njogu and John Middleton, 103-113. Bloomington: Indiana University Press.

Krishnan, Madhu. 2014. Contemporary African Literature in English: Global Locations, Postcolonial Identifications. Basingstoke: Palgrave Macmillan.

McLuckie, Craig W. and Aubrey McPhail. 2000. Ken Saro-Wiwa: Writer and Political Activist. London: Lynne Rienner. 


\section{Doseline Kiguru}

Mugane, John. 2017. 'The Great English Heist in African Studies'. Journal of African Cultural Studies 30(2): 148-162.

Ngũgĩ wa Thiong'o. 1981. 'The Language of African Literature'. In Decolonising the Mind: The Politics of Language in African Literature, by Ngũgĩ wa Thiong'o, 4-33. London: James Currey.

Ngũgĩ wa Thiong'o. 1987. Decolonising the Mind: The Politics of Language in African Literature. Portsmouth: Heinemann.

Ngũgĩ wa Thiong'o. 2017. 'The Politics of Translation: Notes towards an African Language Policy'. Journal of African Cultural Studies 30(2): 124-132.

Pinto, Samantha. 2013. 'The Caine Prize and the Impossibility of "New" African Writing'. Journal of Commonwealth and Postcolonial Studies 1(1): 140-149.

Ponzanesi, Sandra. 2014. The Postcolonial Cultural Industry: Icons, Markets, Mythologies. London: Palgrave Macmillan.

Pucherová, Dobrota. 2011. 'A Continent Learns to Tell Its Story at Last: Notes on the Caine Prize'. Journal of Postcolonial Writing 48(1): 13-25.

Roberts, Gillian. 2011. Prizing Literature: The Celebration and Circulation of National Culture. Toronto: Toronto University Press.

Serpell, Namwali, interview by Laura Angela Bagnetto. 2015. 'Caine Prize Winner Namwali Serpell: A Writer's Writer'. Radio France International: English, (July 7). Accessed July 23, 2018. www.english.rfi. fr/africa/20150707-caine-prize-winner-namwali-serpell-writers-writer.

Strauhs, Doreen. 2013. African Literary NGOs: Power, Politics and Participation. London: Palgrave Macmillan.

Vierke, Clarissa. 2016. 'From across the Ocean: Considering Travelling'. Journal of African Cultural Studies 28(2): 225-240.

Wali, Obiajunwa. 1997. Reprint of 1963 article 'The Dead End of African Literature'. Transition 75/76: $330-335$

Wicomb, Zoë. 1993. 'Culture Beyond Colour? A South African Dilemma'. Transition 60:27-32. 


\section{Publishers' networks and the making of African literature}

\section{Locating communities of readers and writers}

Kate Wallis

In May 1964, UK book trade weekly The Bookseller reported on Heinemann's successful launch of Chinua Achebe's third novel Arrow of God in Lagos. This 'publishers' reception' held on 4 April 1964 at the Bristol Hotel was heralded as 'the most successful occasion of its kind yet to be held in Nigeria', attended by 300 guests who included 'the heads of various government departments, the editors of the principal newspapers, the leaders of Nigerian broadcasting, and prominent figures in industry, education, the law, medicine and the Churches' (The Bookseller 1964). Later that same year in Nairobi, Heinemann launched Ngũgĩ wa Thiong'o's first novel Weep Not, Child at an event organised by South African writer Es'kia Mphahlele in collaboration with the ESA bookshop (Bejjit 2015, 229). It is possible to trace a number of significant intersections between these two launch events held in 1964 on opposite sides of the African continent, as well as the literary and publishing relationships out of which they emerge. The most immediately visible of these is both events being financed by London-based publisher William Heinemann with the intention of drawing attention and readers to their publishing of African writers, part of a strategy spearheaded by Alan Hill across the 1960s to capitalise on the expanding education and trade markets that had opened up in newly independent Africa while investing in local publishing and authors (Hill 1988, 122-123). Launched in 1962 the African Writers Series [AWS] formed a core part of this strategy, with Arrow of God and Weep Not, Child making the sixteenth and eighth titles in this series respectively.

However, Heinemann's African Writers Series was not responsible for creating the link between Achebe and Ngũgĩ, rather it was Achebe who had connected Ngũgĩ and the AWS. Achebe met Ngũgĩ in Kampala in 1961 and offered encouragement on his first short story published in Penpoint (Ngũgĩ 2013, 760). A year later in June 1962, in what has become an iconic moment in the history of Anglophone African literature (Hill 1988, 126; EzenwaOhaeto 1997, 91; Griffiths 2000, 84; Currey 2008, 3; Ngũgĩ 2013, 760; Bejjit 2015, 225), Achebe and Ngũgĩ met again in Kampala at the 'Conference of African Writers of English Expression' held at Makerere University College. Ngũgĩ has described how Things Fall Apart was the most discussed novel at the conference 'as a model of literary restraint and excellence' 
and that 'what most attracted' him to this event was the opportunity to share with Achebe the draft manuscript for his own novel Weep Not, Child (Ngũgĩ 2013, 760). As Ngũgĩ's and Alan Hill's accounts of this encounter both recall, Achebe was impressed by the manuscript and not only shared useful editorial suggestions but brought it to the attention of his publisher HEB who made an immediate offer to publish (Ngũgĩ 2013, 760-761; Hill 1988, 126). This sequence of events not only, according to Ngũgĩ, had a 'profound impact on my life and career' (Ngũgĩ 2013, 760), it also prompted HEB to realise the value of Achebe as a 'magnet for young writers' and later that year he was appointed as AWS Series Editor (Currey 2008, 3).

The continent-based literary and publishing relationships that are made visible by the 1964 launch events for Arrow of God and Weep Not, Child both enabled and emerge out of this encounter at Makerere between Achebe and Ngũgĩ. By mapping these relationships, my intention is to bring into view literary and publishing networks that weren't convened by AWS but through which the series was able to access new writers and accumulate cultural value. So for example, Es'kia Mphahlele, who was responsible for organising the Nairobi launch event for Weep Not, Child, played a critical role in conceptualising and bringing together the African Writers conference at Makerere. The conference was co-organised by Ibadan-based Mbari Artists' and Writers' Club and Makerere's Department of Extra-Mural Studies with funding from the Congress for Cultural Freedom (CCF); Mphahlele, who lived in Nigeria between 1957 and 1961, was Mbari's first president and by 1962 was working in Paris as Director of African Programmes for CCF (Mphahlele 1995, 30). As a result of conversations and connections forged at the Makerere conference, Mphahlele subsequently asked CCF to release him so that he could set up a 'sister' organisation to Mbari in Kenya (Mphahlele 1995, 38). By 1964 then Mphahlele was in Nairobi establishing the creative centre Chemchemi (also funded by $\mathrm{CCF}$ ) and so able to facilitate the launch of Ngũgĩ's first novel.

If one key node or point of intersection grounding the literary and publishing relationships out which these two launch events emerge is the 1962 conference at Makerere, then another is the institutional structures surrounding this, and in particular conference organisers Mbari Artists' and Writers' Club. Established in 1961 as a creative centre for exhibitions, performances and literary discussions by a group of writers and artists including Achebe, Ulli Beier, Wole Soyinka, J. P. Clark and Christopher Okigbo, Mbari also immediately set up its own publishing house with Okigbo as editor (Nwakanma 2010, 178). Again with funding from CCF, by 1966 Mbari had published 17 titles (Currey 2008, xxx), often being the first to publish writers who would go on to become an established part of the African literary canon. As Nathan SuhrSytsma has highlighted, 'publication by Mbari made previously unknown writers desirable to commercial publishers in London' (Suhr-Sytsma 2017, 68) with several titles being reprinted in the AWS (Currey 2008, xxx) including Alex La Guma's $A$ Walk in the Night. ${ }^{1}$ Notably, when in 1964 HEB needed to recruit a new manager and publisher for Nigeria, they appointed active Mbari member Aig Higo - who was then taught the first things he needed to know about the publishing business by Okigbo (Nwakanma 2010, 186).

Opening this chapter by exploring some of the interactions that surround the launch of Achebe's Arrow of God in Lagos and Ngũgĩ's Weep Not, Child in Nairobi, draws attention to the ways in which 'publishers' networks' can act as a useful frame for reading African literary production. These interactions make visible the role of key individuals and their relationships in the construction of literary institutions, and in particular relationships between writers (Achebe and Ngũgĩ) and between editors (Higo and Okigbo) which are focused on craft and generative of new writing and publishing. In addition, they highlight the overlaps between the roles of writer and editor, for example between Mbari as a club - invested in building a community of writers and artists - and Mbari as a publishing house. What this particular example enables me to 
foreground is that publishers don't necessarily convene the networks that their publishing depends on for finding new writers, investing those writers with cultural value and reaching audiences. Instead, they just need to understand how to access and build their publishing out of existing networks and markets. So here we see Heinemann's AWS able to access through Mbari a community of writers with its existing structures of prestige and publishing, and build out of this what Achebe would go on to herald as 'the largest and best library of African literature' (Achebe 2009, 97). These dynamics and their effect on the production and circulation of African literature will ground the arguments developed through the rest of this chapter. In the section that follows, I will provide an overview of previously published work that has shaped an understanding of and approaches to the role of publishers and networks in African cultural production. Building on this and focusing in on the launch events for Chimamanda Ngozi Adichie's Purple Hibiscus in Nigeria in 2004 and Binyavanga Wainaina's One Day I Will Write About This Place in Kenya in 2012, I go on to examine the complex and shifting relationships at stake in the publishing of Anglophone African literature over the last two decades from both outside the continent by publishers in New York and London, and inside the continent by publishers in Lagos and Nairobi.

\section{Publishers' networks and African literary production}

Patrick Jagoda has explored the ways in which from the 1990s onwards the language and science of networks as 'the principal architecture and most resonant metaphor of the globalizing world' has come to frame and influence our perception and methodological approach to a diverse range of forms and disciplines (Jagoda 2016, 3). It is therefore perhaps surprising that relatively little work on African cultural production has emerged that explicitly uses 'networks' as a concept or frame. In my own work it was Nairobi-based publisher Kwani Trust's deliberate positioning of themselves as a 'literary network' that prompted me to develop a methodology through which this could be conceptualised and characterised, and realise the potential of this for examining the structures of contemporary Anglophone African literary production more broadly (Wallis 2018). However, the concept of 'literary networks' is beginning to gain increasing currency in the field, as a recent 'Call for Papers' for a special issue of Postcolonial Text on 'Literary Networks and Digital Media in Contemporary African Literatures' edited by Aurélie Journo attests (Africa in Words 2018), as well as Madhu Krishnan and Chris Ouma's AHRC Research Network 'Small Magazines, Literary Networks and Self-Fashioning in Africa and its Diasporas' (Small Magazines 2018).

One area of study where the concept of 'networks' in relation to African literary production has been more visible is in work that maps a longer history of African print cultures and in particular the role of newspapers (Newell 2002; Peterson, Hunter and Newell 2016). However, even where relationships between writers, publishers, critics and readers haven't been framed as 'networks', there remains a significant body of work that has documented and theorised these relationships and that future studies of publishers' networks can draw on. As my account of the launch events for books by Achebe and Ngũgĩ shows, the exchanges out of which publishers' networks are constructed can often be traced through autobiographies and memoirs of writers and editors (see: Hill 1988; Soyinka 1994; Mphahlele 1995; Chakava 1996; Achebe 2009; Ngũgĩ 2017). James Currey's Africa Writes Back (2008) provides a particularly valuable insight into the relationships with writers, editors and critics out of which the AWS was constructed, drawing both on memories of his own interactions as publisher of the series between 1967 and 1984 and the archive of series correspondence held at University of Reading. Currey's account foregrounds the significant roles played by complexities of friendship, finance and the work of 
publishing houses and literary journals on the continent (from East African Publishing House to The New African) in these relationships.

Biographies also offer a potentially rich resource for studying publishers' networks. Obi Nwakanma's Christopher Okigbo 1930-67: Thirsting for Sunlight for example, places particular emphasis on Okigbo's work in publishing. Nwakanma records that Okigbo developed good relationships with a number of international publishers while working as librarian for the recently established University of Nigeria, Nsukka (Nwakanma 2010, 174). His move to Ibadan in 1962 - which also enabled him to take up an active role in Mbari - came out of this and was as a result of his appointment as West African Manager for Cambridge University Press (CUP). Nwakanma describes how Okigbo's work as CUP's representative was 'largely a public relations role', building connections and cultural value through 'the life and personality of the poet' (Nwakanma 2010, 214). He was aided in this by the house and retinue of personal staff the job provided for him in Ibadan, with his home and work place, Cambridge House, becoming 'the hub of Ibadan café culture' where business, socialising and informal creative writing workshops all took place (Nwakanma 2010, 187-196). Nwakanma's biography also documents the immediate connection Okigbo established with the founder of Transition Rajat Neogy at the Makerere Conference, with Okigbo taking on the role of West African Editor for the magazine by the end of the event (Nwakanma 2010, 183).

A significant body of scholarly work has developed around the AWS, which draws on these autobiographies and biographies, as well as shorter first-hand accounts by editors (Clarke 2003; Maja-Pearce 1992) and archival material. Particular emphasis has been placed on AWS's relationship to colonial forms of patronage and to educational networks, as well as the ways in which editorial decisions were shaped by relationships with both Western and local audiences (Griffiths 2000, 79; Huggan 2001, 80; Barnett 2006, 76; Low 2011, 71, 86). However, the detailed archival work of Nourdin Bejjit perhaps offers the most compelling insight into the 'complex web of economic, political and literary conditions' out of which the AWS was constructed. Challenging arguments made by Huggan and Griffiths, Bejjit tracks the political, personal, commercial and literary factors that shaped both Ngũgĩ's and Achebe's relationships with HEB and foregrounds the ways in which over time both writers became increasingly committed to 'moving the centre' of African cultural production to the African continent (Bejjit 2015, 2009).

As I've highlighted, publishers often do not convene the networks that their publishing depends on but work in dialogue with or extend their reach through existing structures, relationships and literary spaces. Recent scholarly work has importantly drawn attention to the relationship between publishers' networks and structures of education, the space of the city, and literary magazines. Jinny Prais, while rejecting the conception of network in favour of the 'West African public sphere', shows the intersections between the paracolonial network of African newspapers described by Stephanie Newell (2002, 3), and an educated African elite associated with the West African Students Union in London, in building communities of readers and writers in London, Accra and beyond (Prais 2008, 148). Terri Ochiagha and Olabode Ibironke have both challenged a narrative of Nigeria's literary renaissance that begins with the literary networks forged at University College, Ibadan (Ochiagha 2015, 3; Ibironke 2015a, b). Instead Ochiagha has highlighted the friendships established between Achebe, Okigbo, Elechi Amadi, Chukwuemeka Ike and Chike Momah at Government College, Umuahia, documenting formative experiences and literary exchanges at secondary school that sparked their careers as creative writers and directly fed into later interactions at university and through Mbari in Ibadan (Ochiagha 2015, 7, 9). Alternatively Ibironke has brought into view the ways in which the city space of Ibadan itself and its 'social character' manifested in both 'physical surroundings and humanity’ produced Wole Soyinka and Mbari (Ibironke 2015a, 548, 2015b, 556). 
Kachifo and Kwani Trust, the publishers responsible for organising the launch events that form the focus of the second half of this chapter, both began by publishing literary magazines Farafina and Kwani? respectively. This choice of case studies reflects the role played by literary magazines in building literary communities and networks on the African continent from the 1950s onwards, visible both in the periodicals brought together by the Chimurenga Library ${ }^{2}$ and Peter Benson's editorial history of Black Orpheus and Transition (Benson 1986). Macharia Mwangi's work has drawn particular attention to the complex intersections between the publishing industry and literary magazines through his study of Busara, Mũtiiri and Kwani? (Mwangi 2015). For Mwangi these literary magazines are 'publishing outposts', outside the established structures of the mainstream Kenyan publishing industry and therefore able to encourage experimentation and nurture creativity. He documents Busara starting life from University College Nairobi and shows how the writers publishing short stories and poetry in the magazine very often had significant roles in other publishers and publishing initiatives - from Jonathan Kariara as editor of Oxford University Press to David Rubadiri as editor of Poems from East Africa published by the AWS in 1971 (Mwangi 2015, 75).

A number of recent studies have worked with and against framings by Bourdieu of the 'field of cultural production' and, building on this, by Casanova of 'world literary space', as producing cultural value and ultimately African literature (van der Vlies 2007; Helgesson 2008; Strauhs 2013; Davis 2013; Bush 2016; Suhr-Sytsma 2017; Ibironke 2018). This body of work opens up a range of significant new models for thinking about the medium and geographies through which publishers' networks operate. Stefan Helgesson's study of southern African literature between 1945 and 1975 demonstrates the role of print in enabling literary cultures associated with the journals Itinerario and Drum to become significant beyond national boundaries (Helgesson 2008). While the work of Caroline Davis importantly traces the financial exchanges that are fundamental to the construction of publishers' networks (Davis 2013). Like Davis, Ruth Bush has challenged received models of 'world literary space' (Casanova 2004, xii) in her study of African literary production from Paris between 1945 and 1967 (Bush 2016). Through archival work Bush explores ways in which literary representations were mediated by publishers, translators, booksellers and reviewers, and convincingly shows individuals and communities resisting dominant structures of literary value and negating singular ideas of a Parisian literary geography (Bush 2016, 20). Most recently, Nathan Suhr-Sytsma has read both Ibadan and Belfast as nodes in a 'wider set of transnational networks' which in the era of decolonisation altered the contours of the 'anglophone literary world' (Suhr-Sytsma 2017, 11). By putting the poetry and publication histories of Okigbo and Mbari into dialogue with those of Seamus Heaney and Derek Walcott, Suhr-Sytsma shows the ways in which these poets are connected through the 'structural dilemmas' and cultural institutions they negotiate (Suhr-Sytsma 2017, 19).

Placing particular emphasis on the role of the Internet (Adenekan 2012) and on relationships between continent-based writers' organisations and international prizes (Kiguru 2016), the work of Shola Adenekan and Doseline Kiguru has been significant in analysing the structures through which communities of writers have been formed, nurtured and canonised on the continent in the twenty-first century. Building on this work, here I explore the extent to which in a world of the present, marked by 'electronic media and mass migration' as forces that impel 'the work of the imagination' (Appadurai 1996, 4), there has been a shift in the institutions and relationships through which African writing is fostered, published and consecrated with cultural value. Arguing that new models are needed that draw attention to the role played by pan-African exchanges and local publishers in the global movement and circulation of African literature, my 2018 article for Research in African Literatures advocated a theory of literary networks (Wallis 
2018). Proposing a relational model that puts Appadurai's concept of '-scapes' into dialogue with Bourdieu's 'network of relations of exchange', I argued in particular for the potency of reading located literary events as 'multilayered expressive fragment(s)' (Quayson 2014, 21) through which to explore the relationships and flows out of which writers and texts are created. This chapter further develops and refines this critical model, shifting the emphasis from 'literary' networks to 'publishers' networks.

\section{Launching Chimamanda Ngozi Adichie's Purple Hibiscus in Nigeria}

In July of 2004 the literary magazine Farafina, published by Kachifo, organised a series of readings in Nigeria for Chimamanda Ngozi Adichie's debut novel Purple Hibiscus. Farafina magazine had launched online the previous year and, as founder Muhtar Bakare observed, by 'being online we met a lot of people' (Bakare 2006). One of these people was Chimamanda Ngozi Adichie who was living in the USA at the time, and whose short story 'Fide' was published in the third online edition of Farafina in 2003. ${ }^{3}$ This reading tour for Purple Hibiscus was organised by Farafina in order to promote and celebrate Adichie as a contributor to the newly launched magazine, as well as more specifically to bring her novel, which had been published at the end of 2003 in the USA and early in 2004 in the UK, to the attention of a wider public in Nigeria (Feludu 2014). The tour included three public events - one in Abuja hosted by the British Council, one in Ibadan hosted by the Educare Trust Exhibition Centre and one in Lagos at the Nigerian Institute of International Affairs (NIIA) aimed primarily at university students (ThisDay 2014). In addition, there was an invitation-only 'premier' event for sponsors and members of Nigeria's literati at the Yellow Chilli restaurant on Victoria Island in Lagos, featuring Adichie in conversation with Jeremy Weate, staged readings from the novel, and performances from Nigerian musical icon Fatai Rolling Dollar and the, then relatively unknown, young female singer Asa (Feludu 2014; Bakare-Yusuf 2013).

Moving across the five dimensions of global cultural flows that Appadurai argues act as 'building blocks' of 'imagined worlds' - ethnoscapes, mediascapes, technoscapes, financescapes and ideoscapes (Appadurai 1996, 33) - I argue that Farafina's launch events for Purple Hibiscus act as a significant moment of instantiation for the publishers' networks this chapter is concerned to map. So what were the ideas behind this reading tour? Significantly at the time these events were organised Bakare was very much focused on establishing Farafina as an online magazine and had no intention of moving into book publishing (Bakare 2014). This series of events to promote Adichie's first novel, which as yet had no Nigerian publisher, was therefore not driven by the financial imperative of selling copies of the book. Instead it had two ideological objectives (Bakare 2014; Feludu 2014). Firstly, the desire to 'burst the bubble' and reach a larger public in Nigeria with news of this novel rather than just the existing literary community (Feludu 2014). Reflecting this, care was given to make the events themselves as engaging and entertaining as possible with actors performing sections of the novel, and musicians also included as part of the programme (Feludu 2014; Weate 2016). Secondly, Farafina wanted to frame the events in a way that validated a larger and more sustainable literary community or network. As a press release and associated media interviews make evident, Farafina emphasised that the reading tour aimed to inspire and build a literary community and new writing by giving 'validity to other young Nigerian writers' (Ufine 2004) and showing 'other promising writers that the craft of writing can also be rewarding' (ThisDay 2014). Equally evident is the care that was taken to reach out to existing individuals and institutions with the power to consecrate the novel with cultural value in Nigeria, engaging with universities, arts organisations from ANA (Association of Nigerian Authors) to CORA (Committee for Relevant Arts), leading writers 
such as Niyi Osundare and Femi Osofisan, and partnering with the British Council and the Educare Trust Exhibition Centre (ThisDay 2014; Ufine 2004).

Muhtar Bakare had hired Yemisi Aribisala and Ebun Feludu (then Ebun Olatoye) as Farafina magazine's first Editor and Editorial Assistant. Although putting together this series of events was part of a larger collaborative effort, it was Feludu, a recent graduate, serving her year as a member of Nigeria's National Youth Service Corps, who was the driving force behind it (Bakare 2014; Aribisala 2015). As a recently established publishing company, set up with Muhtar Bakare's personal capital, Kachifo did not have the resources available to fund this author tour. Feludu therefore put together a proposal and Kachifo began to seek sponsorship for these events. Feludu - who Bibi Bakare-Yusuf has described as a 'powerhouse' who was 'singular in focus' in relation to the launch of Adichie's first novel (Bakare-Yusuf 2014) - was driven by passion ('I was totally totally in love with her writing') and also able to draw on her own 'tidy network' to make the events possible (Feludu 2014). A personal friend of Feludu's, building contractor Kunle Ogunkoya, was so persuaded by her passion for the book that he committed the seed money that enabled the project to get off the ground (Feludu 2014). Alongside in-kind sponsorship from partners such as the British Council, Educare Trust and Moorhouse, Chris Okeke (introduced to Farafina via a mutual friend of Muhtar Bakare's, Bayo Adeniji), founding partner of a leading Lagos law practice, also gave a substantial amount of money without which the events would not have been possible (Feludu 2014). ${ }^{4}$ Feludu was similarly able to draw on personal contacts of both herself and Bakare to secure high profile media coverage for the event, commissioning a review from Dr Olaokun Soyinka (Nobel Laureate Wole Soyinka's son), persuading friend Jahman Anikulapo (Arts Editor of The Guardian of Nigeria) to help champion the book in his own newspaper and among the wider arts journalism community, and securing television interviews for Adichie with popular broadcasters Adesuwa Onyenokwe and Funmi Iyanda (Feludu 2014; Anikulapo 2018).

By mapping the exchanges out of which this first reading tour for Purple Hibiscus in Nigeria was constructed, I want to draw attention to Farafina's role in shaping Adichie's significance within Nigerian cultural production. The ways in which these events were conceived and brought together, and the drawing in of Lagos's cultural elite to fund and support them, has shaped not only Adichie's own literary output but her role within a larger literary community. Several of the writers and publishers I interviewed for this study identified this event as marking the beginning of a period of more incentives and opportunities for writers in Nigeria, and a growing sense of community (Ogunlesi 2013; Imasuen 2014; Ndibe 2014; Aribisala 2015; Anikulapo 2018). In particular Farafina editor Yemisi Aribisala commented that 'it was amazing what that launch represented', explaining how it 'brought what wasn't yet a literary community together and gave them a sense of belonging and gave them hope' (Aribisala 2015). This sentiment is echoed in a blog post by Ayodele Olofintuade who describes how as a result of Farafina pushing Purple Hibiscus 'like cocaine', and the interlinked founding of the NLNG (Nigeria Liquefied Natural Gas) Prize for Literature, a new vibrancy developed in Nigerian literature and 'we all became "writers"' (Olofintuade 2013; Bakare-Yusuf 2013). In her article 'The Rebirth of Nigerian Publishing,, Bakare-Yusuf emphasises 'the energetic and fluid way Yemisi and Ebun worked together to put Farafina and Adichie on the map' and the impact of this on opening up a new era of Nigerian publishing and writing (Bakare-Yusuf 2013). She recalls the buzz of recognising that 'Nigeria had new talent', as she and Jeremy Weate were drawn in to support 'behind the scenes'. Bakare-Yusuf evocatively describes the evening event at Yellow Chilli and in particular the pervasive sense in the audience that this heralded a 'new cultural moment' (Bakare-Yusuf 2013). Showing publishers' networks as generative not only of new writers and writing but also new literary institutions, Bakare-Yusuf and Weate both credit 
Farafina's launch events for Purple Hibiscus as one of the 'sparks' that led them to set up Cassava Republic Press (Bakare-Yusuf 2013, 2014; Weate 2016).

The exchanges that emerged from and enabled this reading tour also led to Kachifo deciding to publish an edition of Purple Hibiscus for the Nigerian market, and the launch of the Farafina Books imprint (Wallis 2016). This marked the beginning of a decade-long publishing relationship between Adichie and Farafina who released Nigerian editions of all her fiction between 2004 and 2013. Adichie and Bakare also collaborated to set up Farafina Trust, through which from 2009 Adichie ran the annual Farafina Trust Creative Writing Workshop. So, Kachifo's literary publishing and Adichie's relationship with Nigerian readers grew in dialogue with and out of each other, with Adichie publicly celebrating Bakare in both her acclaimed TED Talk 'The Danger of a Single Story' and in an article for the UK Guardian 'My Hero: Muhtar Bakare' (Adichie 2009a, 2009b). Adichie's Guardian piece emphasises the personal connection so many publishing relationships are based on; she writes that on meeting Bakare she knew almost immediately that he was the right person to publish Purple Hibiscus, '[n]ot only because he was humanist, widely read, pan-African, thoughtful and had an instinctive understanding of the nuances of Nigerian society but also because there was a fundamental lack of falseness about him' (Adichie 2009b).

In the UK, while Adichie's Purple Hibiscus was very successful, it was the publication of Half of a Yellow Sun that 'burst the bubble' and brought Adichie to mainstream attention, with the novel winning the Orange Prize for Fiction and featured as part of the UK's influential Richard $\mathcal{E} J u d y$ Book Club. However, in Nigeria, I would argue Farafina did succeed in their aim of bursting the bubble with the launch events for Purple Hibiscus, reaching beyond an existing literary community to a wider middle-class public. Organiser Feludu commented that as a result of the PR and media campaign it felt almost like audiences were 'going from an Usher concert' not a literary event (Feludu 2014). This sentiment is echoed by Jahman Anikulapo, arts journalist and now director of the Lagos Book \& Art Festival, who similarly recalls the reading tour being 'packaged with as much gusto and panache as a showbiz event' and this being the first time a literary book had launched with so much 'paparazzi sort of packaging'. Anikulapo positions this as the beginning of the CNA (Chimamanda Ngozi Adichie) brand, 'before the global literary circuit jumped on the wagon', even though Purple Hibiscus had first been published outside Nigeria (Anikulapo 2018). In contrast, while the launch of Purple Hibiscus is referenced as a literary moment in Nigeria, very few people I interviewed remember any specific events or incidents marking the publication of Adichie's second novel Half of a Yellow Sun in Nigeria (Bakare 2014; Dosekun 2014). Bakare explained to me that the launch of Purple Hibiscus was so successful in establishing the profile of Adichie as a new literary name (with her second novel so highly anticipated there was even speculation that she might be a 'one book wonder'), that Farafina felt confident they were publishing Half of a Yellow Sun into an established market and didn't need to push it in the same way (Bakare 2014).

\section{Launching Binyavanga Wainaina's One Day I Will Write About This Place in Kenya}

On 1 June 2012, Kwani Trust launched the East African edition of Binyavanga Wainaina's One Day I Will Write About This Place in the grounds of the Nairobi Railway Museum. This event, held on Madaraka Day ${ }^{5}$ in an old railway building complete with a disused Uganda Railways carriage and train track running through it, took the form of a party with a DJ set from Just a Band. Wainaina was in conversation with Ellah Wakatama Allfrey, and this was followed by a performance from Eric Wainaina ${ }^{6}$ and a book signing. Focusing on exchanges or movements of 
people, images, technology, money and ideas visible in this literary event, I again want to argue for this as a moment of instantiation for the publishers' networks this chapter seeks to map. Like Farafina's reading tour for Purple Hibiscus, it is an event that can be read as generative of new audiences, writers and publishing. However, it is also significant as an event that is reflective of the networks that had enabled Kwani Trust's publishing over the previous decade.

So what were the ideas out of which this event emerged? In One Day I Will Write About This Place, Wainaina writes about the railway as 'the origin and spine of what we now call Kenya' (Wainaina 2012, 59). Wainaina was keen for the launch to capture an idea and language of nostalgia (Wainaina 2014) and, as Kwani Trust's Managing Editor Billy Kahora explained, the railway symbolised a 'prop from history' with the potential to 'bring us back to what Kenya is, to what Kenya represents, that now has been discarded' (Kahora 2018). Kwani Trust originally explored the idea of a literary safari by train from Nairobi to Wainaina's home town of Nakuru to launch the book, before settling on the Nairobi Railway Museum when this turned out to be more feasible in terms of costs and practicalities (Wainaina 2014; Wachuka 2018; Kahora 2018). Kwani Trust had a total budget of just over $\$ 5000$ to bring together the event, the majority of which had come from their annual marketing budget covered by a grant from the Ford Foundation. The Ford Foundation money was then supplemented by $\$ 600$ from Wainaina's workplace Bard College, which was used to hire Sandra Chege to coordinate marketing and publicity, and $\$ 800$ from Kwani Trust's sales which paid for the DJ set by Just a Band's Blinky Bill (Kwani Trust 2012c).

Another objective grounding the curation of the event was that it should celebrate Wainaina as the founding editor of Kwani?. Talking about how the event was conceptualised, Kahora reflected on One Day I Will Write About This Place as a 'symbol' of what Kwani Trust had been able to achieve over its first decade, and the importance of this event as an act of 'recognition of Binyavanga as a writer and editor, and all the things he had set out to do when he and others founded Kwani?' (Kahora 2018). This was also reflected in Kahora's brief introductory remarks on the night, where he told two anecdotes about the experience of working with Wainaina, the first describing staying up through the night to finish work on Kwani? 03 and the second reflecting on the rigorous editing process for his own book The True Story of David Munyakei. The programming choices for the event were consistently informed by this sense of wanting the night to celebrate Wainaina's achievements not only as a writer but as Kwani? editor. As well as speaking to ideas of nostalgia in Wainaina's writing, the Nairobi Railway Museum had also been used as the backdrop to a video commissioned as part of Kwani? 03 (2005) for Ukoo Flani Mau Mau's 'Mashairi'. This choice of venue was then also evocative of Wainaina's collaboration with hip hop collective Ukoo Flani Mau Mau in the early years of Kwani?, with lyrics by several members presented as Sheng poetry in Kwani? 03 and Kwani Trust supporting the group to set up their own studio to record their second album 'Dandora Burning'. Similarly, musician Eric Wainaina performed 'Joka' at the launch event - a track from his 2006 album Twende Twende!. 'Joka' had started life as a fictional song in the pages of Kwani? 02 in Parselelo Kantai's 'Comrade Lemma \& the Black Jerusalem Boy Band' before being brought to life in music at the instigation of Binyavanga Wainaina (Rosenberg 2007, 121).

Finally, driving this event was the sense that it should draw a wider audience beyond the literary community, positioning itself as a 'book party' rather than a 'book launch'. Based on a launch concept by Wainaina, Kwani Trust's Executive Director Angela Wachuka worked with Wanjiru Koinange using lights and tents to transform the unusual space of the Nairobi Railway Museum into a public arts space. Posters for the event highlighted the DJ set from cutting-edge Nairobi musicians Just a Band. As with Farafina's events for Purple Hibiscus, by playing with the possibilities of spectacle and tapping into links with musicians, the event was framed through 
popular as well as literary culture. However, Wainaina's book as a physical object, packaged with newly commissioned artwork from Catherine Anyango and Wainaina's own handwriting for the title, was very much foregrounded and was the ticket everyone had to buy for 500 Kenyan Shillings in order to get entry to the party.

Founded in 2003 in the aftermath of Wainaina winning the Caine Prize, from the outset Kwani Trust has been concerned with 'establishing and maintaining global literary networks' (Kwani Trust 2016) through continual dialogue with a pan-African and international space of writing, publishing and prizing. Reflecting this, publicity for this launch event emphasised that the book had been 'first released to great critical acclaim and commercial success in the USA and the UK in 2011', and celebrated its selection as an 'Oprah Book Club: Book of the Week' and one of New York Times' '100 Most Notable Books of 2011' (Kwani Trust 2012b). In 2008, Wainaina took up the position of Director of the Chinua Achebe Center for African Writers and Artists at Bard College in the USA, and part of the excitement in Nairobi around this event was that it represented a 'homecoming' both for Wainaina and for this memoir which had received international acclaim (Kahora 2018; Mburu 2018; Wachuka 2018). Kwani Trust's transnational networks were also in evidence in the choice of Ellah Wakatama Allfrey as host for the event. At the time Allfrey was Deputy Editor of the literary magazine Granta whose books division had published Wainaina's memoir in the UK and where seven years earlier (before Allfrey took up this role in 2009) he had published his seminal essay 'How to Write About Africa' (Wainaina 2005). As a member of the Council of the Caine Prize, Allfrey's presence was also a reminder of the links to this leading UK literary prize for African writing in Kwani Trust's institutional history. ${ }^{7}$ Her prominent role in the event also reflected a longstanding friendship and working relationship with Kwani Trust - in 2008 while Senior Editor at Jonathan Cape she held 'manuscript doctor' sessions as part of 2008 Kwani? Litfest and in 2013 would take on the role of series editor for the Kwani? Manuscript Project. Recalling the image of Wainaina and Allfrey in conversation at the event on 'an orange couch at the main stage, with Binyavanga drinking a Tusker throughout the dialogue', writer Isaac Otidi Amuke observed that 'Nairobi felt properly placed on the global literary map that night'. In interview he went on to describe that for him the event opened up 'possibilities', showing that 'writing and literature were something bigger, something tangible, something with tentacles that could connect to other parts of the world, something larger than the page and the text' (Amuke 2018).

During her conversation with Wainaina, Allfrey drew attention to the fact that as he read from the memoir the audience had laughed 'at things I didn't necessarily get' and that 'even though it is the same book in all those markets, your audiences are different audiences' (Kwani Trust 2012a). While Kwani Trust might be concerned with maintaining 'global literary networks', the audience present at this event brought into view the local networks out of which Kwani Trust's publishing has been and continues to be constructed. Angela Wachuka highlighted that this was one of the first events which brought together the 'founding members of Kwani?' with 'newer writers that were emerging' (Wachuka 2018). So, present in the crowd of nearly 400 people were writers and creatives who were part of conversations and publications that defined Kwani Trust's early years such as Patricia Amira, Muthoni Garland, Judy Kibinge and Ann McCreath. However, there were also younger writers who over the next few years would come to both work with Kwani Trust and shape the contemporary Kenyan literary landscape more broadly. Present was Kiprop Kimutai who in 2013 would be awarded third place in the Kwani? Manuscript Project, and Margaret Muthee who would become an editorial intern at Kwani Trust and part of the 2015 Writivism Mentoring Programme. In an interview with Geosi Reads, Muthee has talked publicly about Wainaina's book launch as a catalyst for her 
wanting to work at Kwani Trust and pursue her dreams of becoming a writer, and her application for the internship itself also makes reference to this (Geosi Reads 2015; Muthee 2018). In addition Moses Kilolo, now Managing Editor of pan-African writers' collective Jalada, was there, as well as 2016 Caine Prize winner Okwiri Oduor, who wrote powerfully about the event for the Port Harcourt Book Festival blog (Oduor 2012).

Oduor describes how as Eric Wainaina played 'Joka', as if in self-fulfilling prophecy of the song's title, 'long, winding queues snaked their way to the book-signing table' (Oduor 2012). I would argue that this event also succeeded in its aim of 'bursting the bubble' and reaching beyond Kwani Trust's established literary community to a wider middle-class and student public. In interviews both the organisers and audience-members repeatedly emphasised this event as not only attracting a broader arts and media community not usually seen at 'literary' events but the audience having the feel of that of a 'music festival' or 'concert' (Amuke 2018; Kahora 2018; Kimutai 2018; Mburu 2018; Muthee 2018; Wachuka 2018). Wachuka in particular described how this event shifted Kwani Trust's relationship with public space, and that following this staging book launches in unusual venues - from a car garage to the KICC ${ }^{10}$ Helipad - became a Kwani? hallmark (Wachuka 2018). The event also planted the idea of the Nairobi Railway Museum as a public arts space in the mind of others, and it went on to become a leading Nairobi venue with UP Magazine regularly staging live music events there (Wachuka 2018). For Wachuka and Koinange this event sparked an ongoing collaboration on curating events that rethink the relationship between books and public spaces, out of which in 2017 they founded the social impact firm Book Bunk (Wachuka 2018).

\section{Disjunctures and intersections}

This ‘book party' undoubtedly enabled One Day I Will Write About This Place to reach beyond Kwani Trust's established literary networks and, with the book taking on the role of ticket, placed copies in the hands of an audience of potentially new readers and book buyers. However, in interview Kahora marked a note of caution in relation to this (Kahora 2018). He explains that while Wainaina very much wanted the event to reach a larger space 'outside the literary and the text', his own question would be - how many of the audience bought the book to actually read it? He argues that there are ways in which the free literary events that Kwani Trust regularly stages in their garden, where the audience, whether they be students, older writers, publishers, librarians or work in the media, all have an existing relationship with books and texts, have more impact (Kahora 2018). This draws attention to the disjunctures as well as the intersections between the networks that publishers need to convene or access in order to publish new writing. As literary publishers, Farafina and Kwani Trust need to find new writers, and for both institutions convening writing communities by hosting creative writing workshops has formed a major part of this work. Over the last 15 years Kwani Trust has regularly run writing workshops, partnering with organisations from Granta to SLS to Somali Heritage Week, very often linking these to generating content for a particular edition of the journal. Equally Adichie ran the Farafina Trust Creative Writing Workshop annually with a group of 20 to 30 participants between 2009 and 2016, building a group of over 150 writers who started to identify as 'alumni' (Anya 2014) and were celebrated by Farafina as such (Farafina Books 2014). I have previously argued for Kwani Trust and Farafina as forming the foundations of an overlapping pan-African literary network with the power not only to nurture and bring literary value to individual writers, but to inspire and validate new literary institutions (Wallis 2018). The links between these two organisations and the relational pan-African exchanges out of which their publishing is consecrated with cultural value are particularly visible in the space of 
the Farafina Trust Creative Writing Workshop. Having forged a close friendship after meeting on the Zoetrope website in 2001 (Adichie 2013), each year the workshop was taught by Adichie with Binyavanga Wainaina. Out of this relationship, Kenyan writers including Kiprop Kimutai and Isaac Otidi Amuke attended the Farafina Trust workshop and Nigerian writers including Eghosa Imasuen and A. Igoni Barrett were published in Kwani?. Adichie and Wainaina's friendship has found form not only in these exchanges that 'support local literary production' (Kiguru 2016, 212) but also in physical editions of texts, with Kwani Trust launching a Kenyan edition of Purple Hibiscus in Nairobi in 2006 and Farafina launching a Nigerian edition of One Day I Will Write About This Place in Lagos in 2013.

However, in addition to convening a community of writers and consecrating their work with cultural value, literary publishers also need to be able to draw on a network of professionals who can edit, produce and market their books, as well as then be able to reach an audience of book buyers who might enable their publishing to become commercially sustainable. My critical model of literary networks makes visible the ways in which these networks are built across and through exchanges across multiple 'scapes', with new writing constituted out of movements of people, digital exchanges, and flows of ideas and media. However, publishing is also grounded in financial relationship and contractual obligations. While publishing relationships do often develop out of personal connections and friendships like that of Adichie and Bakare or Adichie and Wainaina, ultimately the practical elements of payment and the agreement that a publisher will make the writer's work available to readers also have a significant role to play. So, even publishing relationships formed out of closely intertwined personal relationships can break down when a shared understanding of what is possible or reasonable in terms of money or distribution also breaks down. For example in August of 2017 Binyavanga Wainaina announced publicly on Facebook that he was withdrawing Kwani Trust's rights to distribute any of his books, a decision he would come to regret and reverse the following month. Perhaps more significantly, in February 2018, a new Lagos-based publishing company Narrative Landscape Press announced they had acquired the Nigerian rights to publish Adichie's writing (Sabi News 2018). While this ended a decade-long publishing relationship between Farafina and Adichie, a relationship on which to a large extent the Farafina brand had been built, it is notable that Narrative Landscape Press was founded by two former Farafina editors who both consider Bakare a mentor (Imasuen 2018).

\section{Conclusion}

In a contemporary moment of comparatively low-cost travel and digital communication, exchanges between writers and publishers based inside and outside the African continent have become logistically easier. However, significant parallels can still be drawn between Mbari and Kwani Trust as donor-funded publishers that convene local writing communities and open up opportunities for writers by cultivating 'global literary networks'. As this chapter has shown, key to the functioning of both these publishers' networks are individuals such as Es'kia Mphahlele and Binyavanga Wainaina who act as brokers of both cultural and economic capital, as well as friendships across East and West Africa, like those of Okigbo and Neogy or Wainaina and Adichie, that go on to shape literary output on both sides of the continent. Yet, what technology and increasing mobility have enabled is a stronger and more sustainable network of pan-African connections between institutions rather than individuals. As Cape Town literary magazine Chimurenga's founder Ntone Edjabe has observed, through this network Africa-based literary publishers have been able to 'mainstream our own aesthetics and reduce our dependency on the global publishing system' (Edjabe 2012). While Kwani Trust might be donor 
funded, since 2003 an increasing number of publishers have been established on the continent that acknowledge a debt to Kwani Trust or Farafina, and are set up as businesses funded through personal capital - from Storymoja to Narrative Landscape Press, from Cassava Republic Press to Sooo Many Stories. As a result it has become increasingly common for African writers (as pioneered in later years by Achebe and Ngũgĩ) to retain Africa publishing rights to their books, instead of signing these over to UK- or US-based publishers, and through this build long-term relationships with publishers based on the continent. As Bakare-Yusuf has repeatedly stressed in interview, one of her key drivers with Cassava Republic Press was that Africans should not just be creating their own narratives and stories, but 'owning the means of production' (Bakare-Yusuf 2017). She has also emphasised the significance of African publishers shaping the visual identity of African literature, creating branding and cover designs that genuinely reflect 'the complex, gorgeous realities of the continent' (Bakare-Yusuf 2017). This significance and the implications of owning and constructing the means of production is similarly emphasised by Narrative Landscape Press in the 'About' section of their website, which begins:

Narrative Landscape Press Limited (NLP) believes that owning the means of production is essential to a vibrant publishing industry. The firm believes that the 'means of production' here does not just mean physical books but also means editorial expertise, book design expertise and developing a cadre of excellent writers.

(Narrative Landscape Press 2018)

This chapter has been concerned with bringing into view the ways in which African literary production can be read through the frame of publishers' networks and in particular with arguing for book launches as offering moments of instantiation in relation to these networks. I have shown how Adichie's significance within Nigerian cultural production, both in terms of her own literary output and as a figure who is part of a larger literary community, has been directly shaped by the way in which Farafina conceived and brought together the launch of Purple Hibiscus. Equally, I have examined the ways in which the launch of Wainaina's One Day I Will Write About This Place was deliberately planned not only to mark and celebrate the publication of this memoir but also Wainaina's relationship to Kwani Trust as an institution. Both events make visible the Nairobi- and Lagos-based publics and communities of writers out of which Kwani Trust and Farafina have been constituted, and the ways in which these are generative of new writing and publishing. A critical model of publishers' networks, as opposed to literary networks, enables me to better allow for the practical and professional relationships at stake in owning the means of book production. For commercial publishing to be sustainable and to thrive on the continent, new audiences and markets do need to be opened up which reach beyond a community of writers and literary professionals. With this in mind, initiatives by individuals such as Feludu in drawing in Lagos's cultural elite to both fund and support a reading tour for Purple Hibiscus, and by institutions such as Kwani Trust to re-conceptualise relationships between books and public space, need to be both studied and celebrated.

\section{Notes}

1 This was published by Mbari in 1962 and became AWS's thirty-fifth title in 1967.

2 http://chimurengalibrary.co.za/periodicals.

3 A later version of the story would be published in 2007 by the New York Times as 'Real Food'.

4 At the time both Ogunkoya and Okeke asked to remain anonymous in their sponsorship (Feludu 2014).

5 A national holiday celebrated every 1 June to mark the day in 1963 Kenya attained internal self-rule and the end of British colonial rule. 
6 Acclaimed Kenyan musician, not a relative of Binyavanga Wainaina.

7 Yvonne Adhiambo Owuor won the prize in 2003 for a story published in Kwani? 01. Parselelo Kantai was shortlisted for the prize in 2004 for a story published in Kwani? 02. Managing Editor of Kwani Trust Billy Kahora was shortlisted for the prize in 2012 and 2014.

8 Creative non-fiction writer Isaac Otidi Amuke would be published in Kwani? 07 in 2012, in Kwani? 08 in 2016 and would later work as Wainaina's personal assistant.

9 Joka means 'large snake' in Kiswahili.

10 The Kenyatta International Convention Centre known as KICC is a 28-storey building located Nairobi's CBD.

\section{References}

Achebe, Chinua. 2009. The Education of a British-Protected Child. New York: Alfred A. Knopf.

Adenekan, Shola. 2012. 'African Literature in the Digital Age: Class and Sexual Politics in New Writing From Nigeria and Kenya'. PhD dissertation, University of Birmingham.

Adichie, Chimamanda Ngozi. 2009a. 'The Danger of a Single Story'. 7 October. Accessed 19 August 2011. www.ted.com/talks/chimamanda_adichie_the_danger_of_a_single_story.html.

Adichie, Chimamanda Ngozi. 2009b. 'My hero: Muhtar Bakare'. The Guardian, 19 September, 5.

Adichie, Chimamanda Ngozi. 2013. 'Plenary Lecture'. Kwani? at 10, University of Nairobi, 29 November.

Africa in Words. 2018. 'CfP: Special Issue: Postcolonial Text (Abstract Deadline: 16th March)'. Accessed 16 July. https://africainwords.com/2018/03/09/cfp-special-issue-postcolonial-text-abstract-deadline-16th-march/.

Amuke, Isaac Otidi. 2018. Interview by Kate Wallis. Email, 27 April.

Anikulapo, Jahman. 2018. Interview by Kate Wallis. Email, 28 April.

Anya, Ike. 2014. Interview by Kate Haines. London, 27 November.

Appadurai, Arjun. 1996. Modernity at Large: Cultural Dimensions of Globalization. Minneapolis: University of Minnesota Press.

Aribisala, Yemisi. 2015. Interview by Kate Haines. Email, 5 March.

Association of Nigerian Authors. 2015. 'History'. Accessed 24 June. http://ana-nigeria.com/?q=history.

Bakare-Yusuf, Bibi. 2013. 'The Rebirth of Publishing in Nigeria'. Cassava Republic Blog, 16 July. www.ca ssavarepublic.biz/blogs/main/8319848-the-rebirth-of-publishing-in-nigeria.

Bakare, Muhtar. 2006. 'Publishing Literature in Nigeria - Challenges and Opportunities'. African Studies Association of the UK, University of London.

Bakare, Muhtar. 2014. Interview by Kate Haines. Lagos, 21 February.

Bakare-Yusuf, Bibi. 2014. Interview by Kate Haines. Abuja, 19 February.

Bakare-Yusuf, Bibi. 2017. 'Publisher Cassava Republic is Changing the Way We Read about Nigeria'. Interview by Kai Ryssdal. www.marketplace.org/2017/05/08/business/publisher-cassava-republic-cha nging-way-we-read-about-Nigeria.

Barnett, Clive. 2006. 'Disseminating Africa: Burdens of Representation and the African Writers Series'. New Formations 57 (Winter): 74-94.

Bejjit, Nourdin. 2009. 'The Publishing of African Literature: Chinua Achebe, Ngũgĩ wa Thiong'o and the Heinemann African Writers Series 1962-1988'. PhD dissertation, Department of English, Open University.

Bejjit, Nourdin. 2015. 'Heinemann's African Writers Series and the Rise of James Ngũgĩ'. In The Book in Africa: Critical Debates, edited by Caroline Davis and David Johnson, 223-244. Basingstoke: Palgrave Macmillan.

Benson, Peter. 1986. Black Orpheus, Transition and Modern Cultural Awakening in Africa. Berkeley: University of California Press.

Bush, Ruth. 2016. Publishing Africa in French: Literary Institutions and Decolonization 1945-1967. Liverpool: Liverpool University Press.

Casanova, Pascale. 2004. The World Republic of Letters. Translated by M. B. DeBevoise. Cambridge, MA: Harvard University Press.

Chakava, Henry. 1996. Publishing in Africa: One Man's Perspective. Oxford: Bellagio Publishing Network.

Clarke, Becky. 2003. 'The African Writers Series - Celebrating Forty Years of Publishing Distinction'. Research in African Literatures 34(2): 163-174.

Currey, James. 2008. Africa Writes Back: The African Writers Series and The Launch of African Literature. Oxford: James Currey. 
Davis, Caroline. 2013. Creating Postcolonial Literature: African Writers and British Publishers. Basingstoke: Palgrave Macmillan.

Dosekun, Simi. 2014. Interview by Kate Haines. London, 14 February.

Edjabe, Ntone. 2012. Interview by Dzekashu MacViban. 'On Chimurenga, Fela and Politics'. Bakwa. Yaoundé. 2012. Accessed 3 March 2016. https://bakwamagazine.com/2012/08/18/conversation-nto ne-edjabe-by-breaking-the-divide-between-the-public-and-the-private-he-fela-expanded-our-vocabula ry-of-resistance-the-musician-was-no-longer-simply-an-entertainer/,

Ezenwa-Ohaeto. 1997. Chinua Achebe: A Biography. Bloomington: Indiana University Press.

Farafina Books. 2014. 'Farafina Trust Creative Writing Workshop Alum Onyinye Ihezukwu (Class of 2009) Wins Heinfield Prize'. 19 May. Accessed 14 January 2015. https://farafinabooks.wordpress.com/ 2014/05/19/farafina-trust-creative-writing-workshop-alum-onyinye-ihezukwu-class-of-2009-wins-hei nfield-prize/.

Feludu, Ebun. 2014. Interview by Kate Haines. Skype, 10 November.

Geosi Reads. 2015. 'Interview with Kenyan Writer, Margaret Muthee'. May. https://geosireads.wordpress. com/2015/05/17/interview-with-kenyan-writer-margaret-muthee/.

Griffiths, Gareth. 2000. African Literatures in English: East and West. London: Longman.

Helgesson, Stefan. 2008. Transnationalism in Southern African Literature: Modernists, Realists, and the Inequality of Print Culture. Abingdon: Routledge.

Hill, Alan. 1988. In Pursuit of Publishing. London: John Murray.

Huggan, Graham. 2001. The Postcolonial Exotic: Marketing the Margins. London: Routledge.

Ibironke, Olabode. 2015a. 'The Fourth Stage: Wole Soyinka and the Social Character of Ibadan'. History Compass 13(11): 541-549.

Ibironke, Olabode. 2015b. 'The Ibadan Origins of Modern African Literature: African Writers Series, Mbari Club and the Social Character of Ibadan'. History Compass 13(11): 550-559.

Ibironke, Olabode. 2018. Remapping African Literature. New York: Palgrave Macmillan.

Imasuen, Eghosa. 2014. Interview by Kate Haines. Lagos, 25 February.

Imasuen, Eghosa. 2018. Interview by Kate Wallis. Email, 27 April.

Jagoda, Patrick. 2016. Network Aesthetics. Chicago, IL: The University of Chicago Press.

Kahora, Billy. 2018. Interview by Kate Wallis. Bristol, 26 April.

Kiguru, Doseline. 2016. 'Literary Prizes, Writers' Organisations and Canon Formation in Africa'. African Studies 75(2): 202-214.

Kimutai, Kiprop. 2018. Interview by Kate Wallis. Email, 26 April.

Kwani Trust. 2012a. 'Kwani? Book Launch: Binyavanga Wainaina \& Ellah Allfrey' You Tube, 29 August 2012. Accessed 14 July 2018. www.youtube.com/watch? $\mathrm{v}=\mathrm{ALKrgHOwur0 \& t}=2 \mathrm{~s}$.

Kwani Trust. 2012b. 'One Day I Will Write About This Place - Book Launch'. Facebook. Accessed 1 April. www.facebook.com/events/355550344509836/.

Kwani Trust. 2012c. ONE DAY I WILL WRITE ABOUT THIS PLACE LAUNCH BUDGET SUMMARY.

Kwani Trust. 2016. 'About Us'. Accessed 2 June. http://kwani.org/aboutus/kwani.htm.

Low, Gail. 2011. Publishing the Postcolonial: Anglophone West African and Caribbean Writing. Abingdon: Routledge.

Maja-Pearce, Adewale. 1992. 'In Pursuit of Excellence: Thirty Years of the Heinemann African Writers' Series'. Research in African Literatures 23(4): 125-132.

Mburu, Mike. 2018. Interview by Kate Wallis. Email, 27 April.

Mphahlele, Es'kia. 1995. Afrika, My Music. Johannesburg: Ravan Press.

Muthee, Margaret. 2018. Interview by Kate Wallis. Email, 26 April.

Mwangi, Macharia. 2015. 'Publishing Outposts on the Kenyan Literary Landscape: A Critique of Busara, Mũtiiri and Kwani?'. PhD dissertation, University of Nairobi.

Narrative Landscape Press. 2018. 'About'. Accessed 15 April. http://narrativelandscape.com/about/.

Ndibe, Okey. 2014. Interview by Kate Haines. Brighton, 4 November.

Newell, Stephanie. 2002. Literary Culture in Colonial Ghana: 'How to Play the Game of Life'. Manchester: Manchester University Press.

Ngũgĩ wa Thiong'o. 2013. 'My Encounters with Chinua Achebe'. Journal of Asian and African Studies 48(6): 760-762.

Ngũgĩ wa Thiong'o. 2017. Birth of a Dream Weaver: A Writer's Awakening. London: Vintage.

Nwakanma, Obi. 2010. Christopher Okigbo 1930-67: Thirsting for Sunlight. Woodbridge: James Currey. 


\section{Kate Wallis}

Ochiagha, Terri. 2015. Achebe and Friends at Umuahia: The Making of a Literary Elite. Woodbridge: James Currey.

Oduor, Claudette. 2012. 'Binyavanga Wainaina's Memoir Launches in Nairobi'. The Voice. http://p hbookfestival.blogspot.co.uk/2012/06/binyavanga-wainaina-memoir-launches-in.html.

Ogunlesi, Tolu. 2013. Interview by Kate Haines. Lagos, 9 May.

Olofintuade, Ayodele. 2013. 'The Torch Died a While Ago'. Nigerian Talk, 7 April. Accessed 14 October 2015. http://nigerianstalk.org/2013/04/07/the-torch-died-a-while-ago/.

Peterson, Derek R., Emma Hunter and Stephanie Newell. 2016. African Print Cultures: Newspapers and Their Publics in the Twentieth Century. Ann Arbor: University of Michigan Press.

Prais, Jinny. 2008. 'Imperial Travelers: The Formation of West African Urban Culture, Identity, and Citizenship in London and Accra, 1925-1935'. PhD dissertation, University of Michigan.

Quayson, Ato. 2014. Oxford Street, Accra: City Life and the Itineraries of Transnationalism. Durham, NC: Duke University Press.

Rosenberg, Aaron. 2007. 'The Literature of Song: Kantai and Wainaina's “Joka” as Syncretic Multi- Text'. Journal of the African Literature Association 1(2): 108-128.

Sabi News. 2018. 'Narrative Landscape Press Acquires Rights to Chimamanda Ngozi Adichie's Books'. Accessed 15 July 2018. www.sabinews.com/narrative-landscape-press-acquires-rights-chimamanda -ngozi-adichies-books/.

Small Magazines, Literary Networks and Self-Fashioning in Africa and its Diasporas. 2018. 'Home'. Accessed 16 July 2018. www.smallmagazinesafrica.org/.

Soyinka, Wole. 1994. Ibadan. London: Methuen.

Strauhs, Doreen. 2013. African Literary NGOs : Power, Politics, and Participation. New York: Palgrave Macmillan.

Suhr-Sytsma, Nathan. 2017. Poetry, Print, and the Making of Postcolonial Literature. Cambridge: Cambridge University Press.

The Bookseller. 1964. Bookseller: The Organ of the Book Trade, Issues 3041-3053, 1783. London Booksellers Association of Great Britain and Ireland, Publishers' Association.

ThisDay. 2014. 'Nigeria: Now Touring "Purple Hibiscus"”. ThisDay, 2 July. Accessed 14 October 2015. http://allafrica.com/stories/200407020592.html.

Ufine, Ayodele. 2004. 'Nigeria: For Purple Hibiscus, the Reading Now Begins'. ThisDay, 13 July. Accessed 15 October 2015. http://allafrica.com/stories/200407130355.html.

van der Vlies, Andrew. 2007. South African Textual Cultures: White, Black, Read All Over. Manchester: Manchester University Press.

Wachuka, Angela. 2018. Interview by Kate Wallis. Skype, 25 April.

Wainaina, Binyavanga. 2005. 'How to Write about Africa'. Granta 92.

Wainaina, Binyavanga. 2012. One Day I Will Write About This Place. Nairobi: Kwani Trust.

Wainaina, Binyavanga. 2014. Interview by Kate Haines. London, 7 March.

Wallis, Kate. 2016. 'How Books Matter: Kwani Trust, Farafina, Cassava Republic Press and the Medium of Print'. Wasafiri 31(4): 39-46.

Wallis, Kate. 2018. 'Exchanges in Nairobi and Lagos: Mapping Literary Networks and World Literary Space'. Research in African Literatures 49(1): 163-186.

Weate, Jeremy. 2016. Interview by Kate Haines. Skype, 27 February. 


\section{Literary networks in the Horn of Africa}

\section{Oromo and Amharic intellectual histories}

Sara Marzagora and Ayele Kebede

\section{Scholarship on Ethiopian and African literature}

In his 1971 study on Four African Literatures, Albert Gérard states that 'no imaginative literature seems to have been produced in any of the non-Amharic vernaculars of Ethiopia' so that 'the phrase Amharic literature can legitimately be used nowadays as a synonym for Ethiopian literature' $(1971,272)$. This remark reflects a broader bias in Ethiopian literary scholarship. Ethiopia has over 80 languages, some of them spoken by millions of people, but scholars throughout the twentieth century have largely privileged the study of Geez and Amharic traditions. ${ }^{1}$ These two languages were considered 'the virtually exclusive carriers of Ethiopian civilization, literature and intellectual prestige', in the now infamous words of Edward Ullendorff (1960: 116). Other language-traditions, one may deduce from Ullendorff's statement, were not as prestigious, aesthetically accomplished or even 'civilised'. The scholarly dismissal of non-Amharic literatures had strong political reverberations. For the majority of the twentieth century, successive Ethiopian rulers attempted to impose Amharic as the only national language. By belittling the literary heritage of non-Amharic traditions, scholars like Gérard lent support and legitimacy to the Ethiopian state's linguistic centralism. Some of the prime targets of the state's policy of Amharisation were Oromo-speaking people, whose literature, as a result, was systematically marginalised. Literary scholarship has been, from this point of view, firmly on the side of the state.

Only recently has Oromo literature received a degree of scholarly attention, but its development remains for the most part understudied, as are other smaller Ethiopian language-traditions. Current literary scholarship in Ethiopia is characterised by monolingual approaches that tend to present different language-traditions as internally homogeneous blocs in antagonistic relations with each other. This linguistic nationalism reflects the rigidification of ethnic identities following the post-1991 restructuring of the state along ethno-federalist lines. As a result, comparative approaches bringing together two or more languages are almost non-existent. And yet, Ethiopian literary history saw not only antagonism, but also intellectual exchanges, parallel developments, thematic synergies and shared political concerns between different traditions. 
Only multilingual methodologies can fully capture such complex patterns of linkages and disjunctions.

In conducting a comparative study of literatures in two indigenous African languages, we are consciously departing from current ways of studying African-language literatures. When studies of literatures in African languages adopt a comparative lens, it is almost always to discuss an intersection between Afrophone and Europhone writing. Even works entirely dedicated to African-language literatures tend to present the various traditions as existing side by side, oblivious of one another. ${ }^{2}$ Sara Marzagora (2015) analysed the reasons and implications for this methodological split, advocating a criticism able to valorise the 'connectivities' and 'disconnectivities' between different language-traditions. This chapter builds on her call by examining the linkages and disjunctions between Oromo- and Amharic-language networks. To narrow the scope of the analysis, we will look at written literature only, although we are keenly aware of the rich expressive role played by Amharic and Oromo oratures. We are not aiming at giving a comprehensive historical picture of the two literary traditions, but rather to offer a typology of how their interaction can be studied.

\section{Studying literary networks: theory and methodology}

A methodology focused on networks allows us to move beyond the nation as a unit of analysis. While national (and nationalist) literary histories have rigidly assumed that state borders coincide with literary borders, an approach based on networks, in Vilashini Cooppan's words, 'allows us to highlight the principle of circulation, sedimentation, and linkage; distinct objects such as languages, cultures, identities, and aesthetic forms that move rhizomatically' (2012, 616). Cooppan argues that literature:

lends itself to the network model, whether the intersecting lines that link individual national works to one another in patterns of what used to be called literary influence or the recent world-scale models of circulation and interaction that go beyond the author-text system to reflect on various currencies of flow, including the material histories of publication, translation, adaptation.

(2012, 196)

In this chapter, we will employ a loose definition of literary networks based on three factors. Firstly, we will look at the physical circulation of literary texts, and, as a corollary, of genres and themes: where are the texts read? How far do they circulate? This also includes translations: from what languages do Ethiopian intellectuals translate? What are their literary influences and the literary traditions they contribute to? The second factor in defining a literary network is the location of cultural infrastructures such as publishing houses, bookstores, theatres and schools, or in other words, the physical apparatus of cultural production. The third defining feature of a network is the intellectuals themselves, their location, their travels and their interpersonal relations. While the chapter identifies general trends, our analysis will remain open-ended. Ethiopian intellectual history is still under-researched, comprehensive studies are missing, and the little information in our possession does not allow us to draw clear-cut conclusions.

The evidence in our possession shows that Amharic and Oromo literary networks were characterised throughout the twentieth century by a relationship of structural inequality, with Amharic in a dominant position and Oromo marginalised either de iure or de facto. Amharic and Oromo traditions were at the opposite ends of the system of power relations on which literary production in Ethiopia was structured and continues to be structured. The history of the two 
networks illustrates, more broadly, the geography of Ethiopian centres and peripheries of literary production, and the ways in which they are connected to broader regional hegemonies. Amharic print culture was located in Addis Ababa, while Oromo literature, which for the most part had to develop outside state infrastructures, had a much more transregional character. Transnational networks proved vital, at different stages, for the survival and activities of various opposition movements. Censorship and the repression of dissent are two contextual factors that force us to be cautious in our analysis, since they could easily produce the impression, reading available literary sources, that no opposition existed.

Our model to study the development and mutual orientation of the two networks will take the state as a point of departure (the first dimension of our analysis). Official language policy had a determinant effect on literary histories, and our first task will be to trace the history of language policies adopted by successive Ethiopian regimes throughout the century. We will then ask how the two literary networks behaved towards the state (the second dimension): did they antagonise the state? Did they support state policies? Was repression all-encompassing or were there possibilities of resistance? After having explored the key political mediation of state institutions, we will be in a position to explore how the networks behaved towards each other (the third dimension). Did they act independently of each other, ignoring each other? Was there a relationship of conflict or competition between them? Did Oromo texts, for example, antagonise Amharic-language production? Did Amharic novels, poems and plays perpetuate a pejorative view of the Oromo? Were there moments of cooperation, collaboration, solidarity between Oromo and Amhara writers? Or does censorship make it hard to assess the relationship between the two?

Before starting our analysis, we would like to underline that the Amharic and the Oromo literary networks do not define two separate and distinct ethnic communities. Language does not correspond to ethnicity. In several areas, communities mixed and intermarried. Multilingualism was widespread, and a lived reality for a significant number of writers. Several Oromo adopted Amhara names, and thus attempting to attach ethnic labels to twentieth-century authors would not only be impossible, but also ahistorical. Networks do not exist in the abstract, but are made by individual agents, whose language choices can be influenced by their class, educational, gender, geographical or religious backgrounds, or can even be completely idiosyncratic. Talking about macro relations of structural inequality between the Amharic and the Oromo language, in other words, should not erase individual agency and its consequences. A mother-tongue Oromo speaker could have a variety of reasons for choosing to write in Amharic, and we should not assume that the decision is necessarily due to cultural alienation or political submissiveness. Similarly, labelling Amharic as the language of power and Oromo as the language of resistance would mean missing a rich and nuanced body of evidence. Amharic, too, has been subject to state control and censorship, and has been used by many intellectuals to articulate opposition and resistance. An Oromo author writing against the state, on the other hand, could at the same time uphold other systems of power relations, for example gender hierarchies. Any abstract typology of interfaces between networks risks rigidifying and essentialising relationships that were porous, variable and often ambivalent. Positive interpersonal relations between writers of Oromo origin and writers of Amhara origin certainly existed even while Amharic literature represented the Oromo pejoratively and derogatively. The two networks were not self-contained and mutually exclusionary, but fluctuating, overlapping and multi-layered.

The relationship between Amharic literature and Oromo literature offers an example of power relations between two African languages. In other African countries, the colonial imposition of European languages caused the marginalisation of local languages, which were for the 
most part relegated to secondary functions. In Ethiopia we have a case of an indigenous language, spoken only by part of the population, being imposed as the sole state language and marginalising other indigenous languages in the process. ${ }^{3}$ Such top-down policies of language homogenisation should be understood in the context of the political transition from empire to state. The transition to statehood was violently forced from the outside in the case of European colonies, and internally enacted in the case of Ethiopia. For the Ethiopian elites, a unifying official language was deemed necessary to the process of modernisation, and modernisation, in turn, was seen as necessary to maintain Ethiopian independence against encroaching European colonialism. Only a culturally united population and a strong, centralised state would be able to assert Ethiopia's importance on the world stage. Language was tasked with ethnogenesis, that is with creating the Ethiopian nation.

Ethiopia was far from being the only state to proceed in this direction. Benedict Anderson describes nationalism as being underscored by the belief 'that each true nation was marked off by its own peculiar language and literary culture, which together expressed that people's historical genius' (1983, 40). Alyssa Ayres argues that the 'phenomenon of new nation-states legitimizing polity through creating new national languages, sometimes quite abruptly' was 'globally widespread' $(2009,10)$. Political elites believed it necessary 'to collapse regions of intense multilinguality into a new national zone of monolingualism' (Ayres 2009, 152). Not only in the history of political practice, but also in the history of nationalism studies, nationbuilding was thought to be indissolubly linked to a move towards monolingualism. For Etienne Balibar, for example, a single national language is required in order to produce the 'fictive ethnic identity' animating the nation $(1991,96)$. The Ethiopian elites, like several other political elites across the world, operated on the assumption that national progress and development would be achieved through cultural assimilationism.

\section{Ethiopia: historical background}

Ethiopian emperors ruled for centuries over a highland territory that was for the large part Orthodox Christian, but with sizeable Muslim and Jewish minorities. In this area, from the beginning of the Solomonic dynasty ${ }^{4}$ in 1270 until the late nineteenth century, education revolved around centres of religious learning. For Orthodox Christians, these were churches and monasteries, where a sophisticated system of education in Geez was offered to children and young adults. Since the introduction of Christianity in the fourth century, Geez literature had actively participated in the literary networks of Eastern Christianity. Churches and monasteries were the hubs of a thriving manuscript culture. Besides churches and monasteries, another prominent centre of knowledge production was the imperial court. Emperors sponsored cultural activities and attracted scholars to their court. Each emperor appointed an official chronicler to record the history of his reign. Some emperors were accomplished scholars in their own right. Collections of manuscripts were preserved in monasteries and imperial libraries, the most notable of which was Tewodros II's library at Magdala.

Amharic (in the central and southern part of the highland plateau) and Tigrinya (in the north of the highland plateau) gradually supplanted Geez as spoken languages outside the Church. Geez, Amharic and Tigrinya are all classified as Semitic languages and use the same Ethiopic script. The earliest examples of Amharic literature are praise poems to the emperors Amda Seyon and Yeshaq composed in the fourteenth and early fifteenth century. By this time, the diglossia between Geez as the high language of written culture, mostly the preserve of ecclesiastics, and Amharic/Tigrinya as 'secular' spoken languages had consolidated. Amharic progressively acquired authority as the language spoken inside the imperial court (lassanä nagus, 
'royal language') and as a lingua franca of the Ethiopian highlands. Under Tewodros II (r. 1855-1868) the imperial chronicles and other state documents started being produced in Amharic, making Amharic the de facto official language of the court.

At the end of the nineteenth century, emperor Menelik II embarked upon a series of military offensives that led to the conquest of large swathes of territories to the east, west and south of the historical highland core of the age-old Ethiopian empire. The old Ethiopian empire had always been internally multicultural, multilingual and multiethnic, but the range and scale of ethnic diversity encompassed by the new state was unprecedented, and required Ethiopian leaders to both rethink ideas of nationhood and develop additional policies for the new provinces. The ruling elites in Addis Ababa saw nation-building through 'a centralist vision of national integration and a corresponding anxiety about the centrifugal tendencies latent in a heterogeneous state like Ethiopia' (Bahru 2008, 86-87). Cultural diversity was perceived as a threat, and unity was thought to be achievable only through sameness and homogeneity. Non-Christians in the southern lowlands had to be Christianised and had to learn Amharic. The argument in favour of policies of cultural assimilationism was twofold. Firstly, the ruling class in Addis Ababa was acutely aware of the dangers of European colonialism. Linguistic and religious homogenisation were seen as necessary steps to forge the social cohesion that would protect Ethiopia against European expansionist ambitions. Secondly, the Amharic-speaking Ethiopian elites were also moved by the belief in the superiority of their heritage over the cultures of newly annexed peoples. Assimilation was, therefore, a way to uplift and enlighten the 'less-developed' cultures of the southern lowlands.

By the beginning of the twentieth century Amharic was firmly established as the official language of culture and politics, with Geez increasingly relegated to religious matters. The government's investment in education, deemed central to the modernisation process, led to the formation of a new Amharic-speaking elite (Bahru 2002). The government established new printing presses and new Amharic newspapers (Meseret 2013). Supported by these cultural investments, Amharic literature rapidly took off, and the 1920s and 1930s saw the publication of a number of novels, religious volumes and history texts. Cut off from state-sponsored innovations, Oromo literature initially developed away from Addis Ababa through networks independent of the Ethiopian government.

\section{Amharic and Oromo literary networks in the late nineteenth and twentieth century}

\section{From empire to state at the turn of the century}

The bulk of Oromo-inhabited areas were annexed to the Ethiopian empire in the last three decades of the nineteenth century, but the transition to statehood took longer to implement. Even after the new borders were officially demarcated at the turn of the century, state institutions maintained low levels of penetration in the south. According to the three dimensions we use to analyse literary networks, this was a period when there was no official state policy on language and education (the first dimension). There was a disjuncture between Oromo literary networks and the state (the second dimension), but with occasional episodes of repression. And there was for the most part a disjuncture between Amharic-language and Oromo-language networks (the third dimension), even if pejorative descriptions of the Oromos were already present in Amharic literature.

The political context was still decentralised, and the early stages of Oromo literature took shape across two networks that at the time were still relatively independent of the state. The 
first of these networks is that of European missionaries, whose arrival in the Horn in the nineteenth century opened up new literary opportunities for local intellectuals. This development was particularly significant for Oromo scholars. For them, missionary networks offered an avenue to formalise the study of the Oromo language and to preserve some of the Oromo oral heritage. The second of these networks was that of the slave trade. The commerce of slaves had been for centuries an essential part of the economy of north-eastern Africa, but intensified in the nineteenth century. Several Oromos were forcefully uprooted from their homes and taken to other Ethiopian regions or further afield in the slave trading hubs of Egypt and the Arabian peninsula. In this forced diaspora, the lives of some Oromos intersected with those of European travellers. Acquired and freed by these European agents, many Oromos ended up in France and Germany. Some European Orientalists arranged for Oromo slaves to be purchased and taken to Europe to work as language and culture assistants.

This is how Ruufoo, a 16-year-old boy from Guummaa, arrived in Germany in 1866. Enslaved in his youth, he was purchased on the Ethio-Sudanese border by a missionary station on behalf of John Ludwig Krapf. Krapf, a Protestant missionary, had briefly preached in Ethiopia before returning to his country, and was looking for a language assistant to complete his Oromo translation of the Bible. The scholarly relations between Ruufoo and Krapf were characterised by a profoundly unequal power dynamic. Ruufoo was immediately put to work on the translation of the New Testament, which Krapf finally published in the 1870s. While earlier missionary work among the Oromo had employed Roman characters, Menelik II strongly advocated the use of Ethiopic script for the Christianisation of the Oromos, and Krapf reluctantly accepted that he had to employ Ethiopic script. Despite receiving little recognition at the time, Ruufoo is now remembered as 'a pioneer of the early Oromo literature. His translation of the Holy Bible is one of the earliest written examples of the Oromo language and hence an important part of the language's history' (Smidt 2015, 68).

Another former slave, Onesimos Nasib, would rise to become the most prominent Oromo intellectual of the nineteenth and early twentieth century. Born in the 1850s in Illubabor, he was sold into slavery when he was four. At 16, he was purchased and freed by a Swiss traveller, who handed him over to the Swedish Missionary Station in Massawa. Onesimos started an illustrious career as translator and teacher for the ever-growing numbers of Oromo boys and girls freed from slavery and taken to the Swedish mission. In thirteen years (1885-1898), Onesimos completed at least seven major translations of religious texts, including gospel songs, the translation of one of John Bunyan's works, the catechism, a collection of Bible stories, and a hymnbook. The Oromo language team that was trained at the Swedish mission formed 'a miniature Oromo academy in exile' (Mekuria 1995, 41). A woman named Aster Ganno would become Onesimos's main collaborator on two major projects. The first was a new translation of the Bible into Oromo. Instead of editing Krapf's translation, Onesimos produced a new translation starting from Amharic and Swedish copies, while keeping Krapf's version as reference. Aster provided much of the material for the translation, which was published in 1899. The second project was the publication of a pioneering Oromo cultural reader (1894), for which Aster wrote down from memory a collection of five hundred Oromo songs, proverbs, riddles, fables and stories. The resulting publication is one of the most significant texts ever published in Oromo folklore studies.

After 35 years in exile and a few failed expeditions to Oromo-inhabited lands, Onesimos was finally granted permission to go back to his birthplace in Wollega. His fame preceded him. He was welcomed with great honours, and the locals were excited to study with him. The school he set up, where he finally got to use all the Oromo-language materials he had compiled over the previous years, grew rapidly from 20 to 80 pupils. In those 35 years, however, the political 
situation in the land of his birth had changed. Wollega had been brought under the authority of Menelik II, and the Orthodox priests sent to Wollega to educate and Christianise the Oromos did not take kindly to competition.

The hostility that the Orthodox clergy in Wollega developed for Onesimos has more than one explanation. Onesimos was Protestant, much admired locally, he was highly educated, and had come home after several decades spent working with Europeans. Even more significantly, he preached in Oromo, a language the Orthodox clergy did not understand. Threatened by his popularity, the Orthodox priests filed an accusation of blasphemy, and in 1905 Onesimos was summoned to Addis Ababa to stand trial in front of the bishop of the Orthodox Church. The bishop excommunicated Onesimos and condemned him to imprisonment and the loss of all his property. Menelik, however, did not confirm the verdict, and allowed Onesimos to go back to Wollega, but barred him from preaching and teaching. The 1905 trial of Onesimos can be taken as a symbolic date that marks the divergent trajectories of Oromo and Amharic literatures. While the state gradually increased its institutional support for Amharic, Oromo was more and more marginalised and its development forcefully stunted.

\section{Haile Selassie's reign}

After the Italian occupation (1936-1941), the government's language policy became even more firmly monolingual. As state power was centralised and grew more authoritarian, the relationship between Amharic and Oromo became strongly conflictual. New regulations in 1942 prohibited the public and institutional use of languages other than Amharic (Mekuria 1994, 99). A new law in 1944 made it compulsory for missionaries to learn Amharic and to use it as the only language of instruction in mission schools, effectively turning missionaries into agents of Amharisation in the south of the country. The 1955 constitution formally declared Amharic to be Ethiopia's national language. In the 1950s and 1960s, a series of successive curriculum reforms made Amharic the single medium of instruction in all government schools up to the sixth grade. From grade seven onwards, instruction was in English, which in the post-liberation period replaced French as the most spoken foreign language. Foreign languages therefore had a higher status than indigenous languages other than Amharic. Oromo pupils were severely underrepresented in the school system, and school enrolment and literacy rates remained extremely low in Oromo-inhabited regions. Teachers were mostly native Amharic speakers, and the language barrier meant there was a high dropout rate for Oromo students. State policies in the 1960s aimed at further reinforcing the role of Amharic as official state language, including literary prizes and a language academy for the promotion of Amharic literature. When it comes to the first dimension of our analysis, then, we are in a situation of de iure monolingualism. Amharic print culture in this period appears overall supportive of the state, while Oromo networks mobilised in the periphery against Haile Selassie's monolingual language policy (the second dimension). The two literatures diverged in this period, and a deep tension existed between them (the third dimension): Amharic literature flourished, while the development of Oromo literature was blocked.

The nationhood envisioned by the ruling elite was not an egalitarian synthesis of all Ethiopian cultural traditions, but a forceful imposition of one culture onto others. This hierarchical nationhood was based on a clear power relation between cultures that, by nature and birthright, were 'Ethiopian', and cultures that, by nature and birthright, were 'un-Ethiopian'. It is important, though, not to map language policy over ethnic discrimination. It is ahistorical and simplistic to characterise Haile Selassie's regime as one of 'Amhara' domination over the 'Oromo' 5 Such a statement assumes an essentialised and rigid conception of ethnic identities that did not 
exist in Ethiopia at the time. Crummey points out that power relations in Haile Selassie's Ethiopia are better understood on a regional, rather than ethnic, basis $(2003,128)$.

The relationship between cultural identification, language and social status was fluid and multi-layered. There was, for example, a good degree of conflict not only between the state and Oromo literary networks, but also between the state and Amharic literary networks. Amharic was the official language and was supported by state institutions, but this did not mean that all Amharic writers were powerful. The authoritarian nature of the state meant that Amharic writers were not fully free to express themselves. The almost complete absence of cultural infrastructures outside government control, coupled with the institutionalisation of preand post-publication censorship, meant that Amharic writers, too, were subject to a number of restrictions. For most of the 1940s and 1950s, though, Amharic writers tended to support the government and its assimilationist policies towards the Oromo.

Oromo intellectuals employed two main strategies to assert their heritage on the national scene. Firstly, they attempted to reform the system from within. There were some writers of Oromo origin, or who were Oromo-speaking, in the Amharic literary scene. They had to write in Amharic and their Amharic-language works were similar, in both theme and content, to those of their colleagues of non-Oromo origin. Those who attempted to revise the unicentrality of state nationalism were quickly marginalised. Yilma Deressa and Emmanuel Abraham were part of a group of Amharic-speaking Oromos who, as happens frequently in Ethiopian history, had risen to high ministerial positions through assimilation. Yilma Deressa was accused of giving too much importance to the role of the Oromo in his 1967 study of sixteenth-century Ethiopia (YäItyopya Tarik BäAsra Saddastäñ̃a Kaflä Zämän, 'Ethiopian history of the sixteenth century'). In reaction to the book, many high-profile politicians called for Yilma to be removed from his position as Minister of Finance (Paulos 2014, 47). Emmanuel Abraham was removed from his post as Minister of Education in 1947 because his educational policies were perceived to favour the Oromo and promote the use of the Oromo language (Zitelmann 2001, 170-171).

The second strategy for the Oromo was open resistance from outside the system. The Eastern network of Islamic knowledge production was promptly mobilised against Haile Selassie's government. The first Oromo written texts had been produced within this network, ${ }^{6}$ when teachers in Islamic schools needed material in local languages to reach out to non-Arabicspeaking audiences (Gori 2015). Despite Haile Selassie's policies of centralisation, the network had managed to maintain a degree of independence from the Ethiopian state apparatus. It is from this network that one of the key opponents of Haile Selassie's monolingual policy, Sheikh Bakri Sapalo, emerged. A larger-than-life intellectual figure, Sheikh Bakri was born in 1895 near Harar and received advanced Islamic education. From his base in Eastern Ethiopia, he soon started denouncing the economic, political and cultural marginalisation of the Oromo. Against the government's attempts to dismiss Oromo cultural achievements, he strove to promote the Oromo language and cultural heritage. He translated algebra and geometry textbooks into Oromo, composed Oromo poems, and wrote three works on the history of the Oromo. Sheikh Bakri's work 'led to the appearance of a new Oromo literature that reflected the people's dayto-day realities'. The Oromo 'literary renaissance' that he inaugurated laid the ideological foundations for the Oromo struggle for self-determination (Mohammed 2009, 102).

The literary networks that Sheikh Bakri created and in which he participated were truly transnational in scope. Fascinated by the Egyptian president Gamal Abdel Nasser, he listened to Radio Cairo, read Egyptian newspapers, and wrote in solidarity with anti-colonial struggles in Algeria and Vietnam. Some of Sheikh Bakri's students took refuge in Somalia and started an Oromo-language radio station in Mogadishu from where they broadcast readings of his poems. Preaching and teaching in Oromo was prohibited at the time, but what triggered the state's 
punitive intervention was not so much the content of his anti-government rhetoric, but a new script he created for the Oromo language in the mid-1950s. The script started spreading clandestinely through informal networks, and Ethiopian authorities found it in the possession of Oromo nationalist fighters in Bale. Accused of threatening Ethiopia's unity, in 1965 Sheikh Bakri was condemned to ten years of house arrest, and his script was banned. But while the trial of Onesimos 60 years before had set off decades of Oromo cultural suppression, in the 1960s Oromo nationalists were ready to fight back.

\section{The Ethiopian student movement and 1974 revolution}

In the history of the Ethiopian student movement, the so-called 'national question' was raised quite late, in 1969. After this date, the marginalisation of groups like the Oromo became a major topic of discussion among members of Ethiopian student organisations. In this period, while state monolingualism was still in place (the first dimension) the Oromo and the Amharic networks converged in their opposition to Haile Selassie's regime (the second and third dimensions). Earlier, the antagonism towards the regime's monocultural and monolingual policies was mostly voiced through peripheral networks. In the late 1960s and early 1970s, the opposition moved to the centre of the state in Addis Ababa.

The student movement, to which many students of Oromo origin belonged, was truly international in scope. North American, European and Ethiopian-based university groups collaborated closely with one another and actively sympathised with black civil right movements, anti-apartheid struggles and transnational Marxist debates. The student movement did not produce much creative literature, even though their journals sometimes included political poems. The promotion of Oromo language and literature, though, did not disappear from the political agenda of major Marxist activists such as Haile Fida Kuma, who from his base in Paris put together an Oromo grammar (1973) and published a novel (Bara Birraan Barihe, 'When Autumn Comes'), using his adapted 35-letter Latin alphabet. Dafa Jammo's Oromo novel Huursaa (1973) (named after the Huursaa river in Wollaga) was a didactic allegory that condemned gender inequality and the large dowries given for brides during marriage.

The 1974 revolution that toppled Haile Selassie's regime promised a new era of literary freedom. In the early phases of the revolution, the strict Amharic-only policy of imperial Ethiopia was loosened. The post-revolution ruling committee, called Derg, eased restrictions on vernacular publications, as long as the Ethiopic script was used. In the 1976 programme of the National Democratic Revolution, each nationality was given regional autonomy to choose their own working languages. A new Oromo newspaper called Barriisaa ('Dawn') was started in 1975 and published several revolutionary poems. An Oromo Cultural Association was established in the same year, and in 1977 organised a big Oromo cultural show to raise funds for Barriisaa. The show was held in the National Theatre of Addis Ababa, one of the cultural bastions of the previous regime. Now, for two days, it hosted singing, dancing and the performance of praise poems by dozens of Oromo cultural troupes coming from the far corners of the Ethiopian state.

\section{The Derg}

The hope of change to be brought by the 1974 revolution would soon be disappointed. The 1987 constitution stated that 'the people's democratic republic of Ethiopia shall ensure the equality, development and respectability of the languages of nationalities', but also added that the 'working language of the state shall be Amharic'. In 1979 the National Amharic Language Academy was renamed, more inclusively, Academy of Ethiopian Languages, but remained 
mostly dedicated to standardising Amharic translations of scientific and technological terms. Amharic and English remained the sole media of school instruction. The adult literacy programme launched by the Derg in 1979 was designed to be implemented in 15 different national languages, marking a critical departure from the Amharic-English language hegemony in education. Oromo would have to be taught using the Ethiopic script, now elevated to the status of a supra-ethnic national symbol. The success of the programme was nevertheless patchy. Few languages had an orthography and there were no studies, textbooks, grammars or dictionaries to support teaching in non-Amharic languages. Knowledge of Amharic continued to be necessary for any jobs in the public sector, and Amharisation continued unabated via the literacy campaign, educational programmes, state-controlled peasants' associations, forced population movement and government-owned mass media. Although on paper some of the most rigid monolingual measures had been lifted, de facto state institutions, educational institutions and cultural institutions remained for the most part monolingual (the first dimension). A certain pluralism was introduced at the level of government policies and the law, but neither Amharic nor Oromo writers benefited from it because, in parallel, political and cultural repression became significantly harsher. Punishment for any form of dissent ranged from prison and torture to execution, and censorship was pervasive. Both Amharic and Oromo were employed by writers to oppose the regime (the second dimension) but the politics of the two blocs took them in separate directions and concretised in different regional and/or ethnic nationalisms (the third dimension).

Perhaps the most notorious instance of the Derg's cultural crackdown was that of Baalu Girma, a towering figure of Amharic literature. Himself of Oromo origin, he had only learnt Amharic at the age of ten, and in a celebrated Amharic-language novel, KäAdmas Bašagar, he touched on the theme of how Oromos are pushed to adopt Amharic names. After the revolution, he worked for the Ministry of Information, but his political stature did not protect him from the ire of the Derg when, in 1983, he published Oromay, a novel ridiculing some of the Derg's top officials. Oromay was abruptly removed from bookstores and banned from the market, and Baalu disappeared from his house, never to be seen again. It was not a climate in which literature could thrive. Though some of the older Amharic authors remained active under the Derg, not one of the younger Amharic writers built a solid reputation for aesthetic craft and innovation. The government dictated that novels and plays be written according to the parameters of social realism, and plots generally reiterated government propaganda on the positive achievements of the revolution.

As it had been under Haile Selassie, writing in Oromo and other expressions of Oromo cultural identity were accused of bolstering 'tribalism'. The Derg considered the popularity of the 1977 Oromo cultural show to be unacceptable, and quickly banned all cultural groups and arrested some of the artists who had performed. No Oromo novels were printed during these years. Gaddisa Birru's first Oromo novel was written in 1984 but could not evade regime censorship. Barriisaa, the Oromo language newspaper, was nationalised, and it was decided that it would be sold on par with the Amharic weekly YäZarayatu Ityopya ('Today's Ethiopia'). From the nationalisation onwards, it mostly published Oromo translations of the government's Amharic propaganda. The number of copies sold decreased steadily from around 20,000 to barely 2,000. Even then, many in Addis Ababa questioned whether it should circulate at all. Sheikh Bakri Sapalo had energetically supported the revolution, but in 1978 the government branded him 'a narrow nationalist reactionary leader', forcing him to flee to Somalia to escape execution. He died in exile at the age of 85 .

These geographies of exile shaped the increasingly important networks for Oromo language and literature. Resistance moved to the peripheries, where armed liberation movements took it 
upon themselves to valorise regional cultural identities. These liberation movements often relied on transnational networks of resistance, just as had been the case for Sheikh Bakri. Geographically removed from the Derg's imposition of the Ethiopic script, the different Oromo diaspora associations in Europe, the Middle East and the USA communicated using the Latin script. Under the leadership of the Oromo Liberation Front (OLF), who led the Oromo struggle against the Derg, Oromo became the language of instruction in refugee camps in Sudan, Kenya, Somalia and Djibouti. The OLF and its humanitarian wing, the Oromo Relief Association, published Oromo textbooks and literacy materials, starting a literary and cultural revival that would gain further momentum when the OLF and other armed groups, after years fighting at the peripheries of the Ethiopian state, finally managed to seize power at its centre.

\section{The EPRDF}

The Derg was toppled in 1991 by a coalition of armed resistance movements in alliance with the OLF. Once in power, the coalition (Ethiopian People's Revolutionary Democratic Front, EPRDF) approved a new constitution that turned Ethiopia into a federation of ethnically defined regions. The new constitution declared that 'all Ethiopian languages shall enjoy equal state recognition' and every region was given the right to teach children in local languages. Both Amharic and Oromo networks responded positively to the new de iure multilingualism (the first and second dimensions). In November 1991, the Latin script was officially chosen for the Oromo language in a meeting attended by Oromo intellectuals and representatives. The choice 'had a huge implication for the future of Oromo literature' (Mohammed 2002, 225) and was praised as a stepping-stone towards 'the psychological liberation of the Oromo people' (Kiflu 1993, 20). Between September 1991 and June 1992, textbooks for elementary curriculum were prepared and school-teachers were given intensive training to start teaching in Oromo. The first classes in Oromo were started in 1993.

Oromo literary production finally boomed. Within two years (1991-1993), around ten novels and six books of poetry were published, and five plays were performed. By 2013, the Oromo literary corpus comprised around two hundred novels, two hundred poetry books and fifty anthologies of short stories (Teferi 2015, 89). Lexicographies, grammars and documentation of oral literature also advanced steadily. This Oromo literary renaissance was strongly energised by Oromo nationalism. The new Oromo production denounced the historical marginalisation of the Oromo, valorised Oromo customs and traditions, and attempted to define, often in essentialist ways, the contours of Oromo identity. After decades of repression, Oromo literature defined itself in opposition to Amharic literature, using modes typical of postcolonial literatures to 'write back' to the former oppressors. Naming practices were for Oromo authors an important theme to show the alienating effects of cultural assimilationism. In the plots of these novels, Oromo characters are forced to change their Oromo name into an Amharic one. ${ }^{7}$ For the characters, rediscovering old Oromo names and becoming aware of the history of their erasure are first steps towards self-emancipation. In these passages, Oromo authors bring to light a lost multilingualism, although more than celebrating plurality, their main polemical thrust is to define Oromo culture as cohesive and internally homogeneous. The legally enshrined multilingualism, therefore, did not mark the end of hostilities between the Oromo and the Amharic literary networks (third dimension). Oromo writers were finally free to publicly antagonise the Amharic-language heritage, and the tone of the new Oromo publications remained deeply adversarial.

The divisions between the two literatures, however, is not so rigid. While recent Amharic writers such as Adam Reta nostalgically uphold the old imperial nationalism, Fiqre Marqos 
Desta has chosen to write about the people whose voice was never heard in the Amharic literary tradition. His ethnographic novels in Amharic talk about the Hamar, Kio, Ebore and other 'minor' ethnic groups in the south-western parts of Ethiopia. He also incorporates linguistic elements from the community about whom he is writing, meaning that his writing style takes account of linguistic diversity. Tesfaye Gebreab has been praised as the writer who created the first Oromo protagonist in the history of Amharic literature. ${ }^{8}$ Born from an Eritrean family in Bishoftu (a town now in Oromia, south of Addis Ababa), Tesfaye defines himself as an Oromo by experience and attachment, and his Amharic novels condemn the historical subjugation of the Oromo. He has been accused by the EPRDF and its supporters of being an agent of the Eritrean government, and of having been paid to destabilise Ethiopia. Tesfaye mixes in several Oromo words in his Amharic, and his novels include some Oromo oral poems in both Latin and Ethiopic script.

The two literary traditions also share some thematic synergies. Both Amharic and Oromo writers show deep concern for the exploitation of peasants in the countryside. A recurrent character in Oromo novels is the ruthless Amhara landlord, who exploits the labour of Oromo farmers. An example of this trope is Ras ${ }^{9}$ Getaw in Yoomi Laataa? ('When Will It Be?'), a 2011 historical novel by veteran journalist Isayas Hordofa. Ras Getaw defends Menelik's conquests and the cultural superiority of Amharic. The theme of the elitist, conservative and callous landlord had been a staple of Amharic literary production throughout the twentieth century. Members of the landowning class are represented in Amharic literature as arrogant and selfentitled; they enjoy their hereditary privileges, live a wealthy life of indolence and indulgence, and ruthlessly exploit their tenants through taxes and tributes. Fitawrari Mäššsa in Haddis Alemayehu's Fakar askä Mäkabar, Wäyzaro Asäggaš in Daniachew Worku’s Adäfras, and Fitawrari Woldu in Daniachew's other novel The Thirteenth Sun offer good examples of this trope. Yet, while Amharic writers tackle this problem from the point of view of class, Oromo writers foreground ethnicity and gender as other fundamental sources of discrimination. From this angle, Oromo literature does not merely antagonise Amharic literature, but also expands and complicates the significant geographies that Amharic writers have in mind. The same is true for gender. Both Amharic and Oromo literatures ask questions about the changing nature of gender roles. Amharic writers hardly ever look at ethnicity as a further source of discrimination for some women, while in the Oromo context, the oppression of women has three dimensions: gender, class and ethnicity.

\section{The twenty-first century}

Despite the multilingual promises of the new constitution, repression against Oromo cultural expression has re-intensified after the national elections in 2005 (the first dimension). Oromo writers are often accused of undermining the unity of the state. Many have been arrested and jailed or have had to escape abroad. Oromo authors, together with some prominent Amharic writers, have been deeply critical of the government (the second dimension). The literary scene in Ethiopia is still strongly skewed in favour of Amharic, and increasingly so over the last few years. Amharic writers have at their disposal a large infrastructural network of Amharic-language television, radio, cinemas and publishers, while publication and dissemination venues are far fewer for Oromo writers. This severely affects literary production, since radio and television have been energising factors for both Oromo and Amharic traditions. Novels and short stories are narrated on the radio, and several radio programmes read proverbs, idiomatic expressions and uncommon words, thus contributing to preserving the oral heritage, but also giving writers 
materials and inspiration. Films and television shows give writers the chance to fine-tune their style and try their hand at screenwriting.

University syllabi on Ethiopian literature cover Oromo, Amharic, Geez and English writings, but Geez and Amharic continue to dominate class time. The Ethiopian Writers Association sometimes publishes works in languages other than Amharic, but the slow pace of this multilingual opening has driven dissatisfied Oromo scholars to establish a separate Oromo Writers Association (OWA). Oromo women writers are markedly underrepresented in the Ethiopian Women Writers Association. The government's crackdown on freedom of expression has severely affected the OWA. Censorship is pervasive, and suspicious printed material often destroyed. This has meant, for Amharic and Oromo literatures, that diaspora groups in the USA, and to a lesser extent in Europe, are now pivotal agents of literary production and circulation. Each of the two traditions can count on a transnational network of television channels, news portals, conferences and events through which to promote and stimulate literary pursuits. Social media such as Facebook have been used as a springboard by young writers in search of an audience. The disconnect between the Amharic and the Oromo tradition is particularly evident when it comes to translations. There are very few translations from Oromo into Amharic and vice versa. Amharic and Oromo writers tend to translate from foreign languages into their own. In the diaspora, the Amharic and Oromo literary scenes are even more polarised, with very little communication between the two (the third dimension). A thriving future for the two literary traditions is very much contingent on an authentic democratisation of the Ethiopian cultural and political space.

\section{Notes}

1 And, to a minor extent, also Tigrinya.

2 Gérard's books on African-language literatures, for example, discuss individual languages in separate chapters, rather than in terms of actual interaction (see, for example, Gérard 1981).

3 From this point of view, Amharic in Ethiopia could be compared to Swahili in Tanzania.

4 A ruling dynasty that claimed to descend from the son of King Solomon and the Queen of Sheba.

5 Asafa Jalata has been the most prolific scholar to promote such characterisation, but the argument is common in Oromo nationalist scholarship. For a critical assessment of this position, see Triulzi (2002).

6 Not all Oromo were Muslim, though. Many were Christians or practised traditional religions.

7 See Teferi (2015) for examples.

8 Hunde Dhugassa (2012). Hunde further elaborates that 'Even though many [Amharic] authors have tried to insert Oromo characters in their works, none has had the courage to put them at the helm of their efforts'.

9 A high-level aristocratic and military title.

\section{References}

[Ethiopian authors are listed by first name followed by their father's name].

Anderson, Benedict. 1983. Imagined Communities: Reflections on the Origin and Spread of Nationalism. London: Verso.

Ayres, Alyssa. 2009. Speaking Like a State: Language and Nationalism in Pakistan. Cambridge: Cambridge University Press.

Bahru Zewde. 2002. Pioneers of Change in Ethiopia: The Reformist Intellectuals of the Early Twentieth Century. Oxford: James Currey.

Bahru Zewde. 2008. Society, State and History: Selected Essays. Addis Ababa: Addis Ababa University Press.

Balibar, Etienne. 1991. 'The Nation-Form: History and Ideology'. In Race, Nation, Class: Ambiguous Identities, edited by Etienne Balibar and Immanuel Wallerstein, 86-106. London: Verso. 
Cooppan, Vilashini. 2012. 'World Literature Between History and Theory'. In The Routledge Companion to World Literature, edited by Theo Haen, David Damrosch and Djelal Kadir, 194-203. New York: Routledge.

Cooppan, Vilashini. 2013. 'Net Work: Area Studies, Comparison, and Connectivity'. PMLA 128(3): 615-621.

Crummey, Donald. 2003. 'The Horn of Africa: Between History and Politics'. Northeast African Studies 10 (3): $117-138$.

Gérard, Albert. 1971. Four African Literatures: Xhosa, Sotho, Zulu, Amharic. Berkeley: University of California Press.

Gérard, Albert. 1981. African Language Literatures: An Introduction to the Literary History of Sub-Saharan Africa. London: Longman.

Gori, Alessandro. 2015. 'Languages and Literatures of the Muslims of the Horn of Africa: Some First General Reflections'. In L'Africa, l'Oriente mediterraneo e l'Europa, edited by Paolo Nicelli, 119-123. Rome: Bulzoni.

Hunde Dhugassa. 2012. 'Tesfaye Gebreab: The Man who Created the First Oromo Main Character in the History of the Vast Amharic Literature'. Finfinne Tribune, 7 Augusthttp://gadaa.com/oduu/15158/ 2012/08/07/tesfaye-gebreab-the-man-who-created-the-first-oromo-main-character-in-the-history-ofthe-vast-amharic-literature/ [retrieved 11/07/2018].

Kiflu Tadesse. 1993. The Generation: The History of the Ethiopian People's Revolutionary Party, Part 1: From the Early Beginnings to 1975. Silver Spring, MD: Independent Publishers.

Marzagora, Sara. 2015. 'African-language Literatures and the "Transnational Turn" in Euro-American Humanities'. Journal of African Cultural Studies 27(1): 40-55.

Mekuria Bulcha. 1994. 'The Language Policies of Ethiopian Regimes and the History of Written Afaan Oromoo: 1844-1994'. Journal of Oromo Studies 1(2): 91-115.

Mekuria Bulcha. 1995. 'Onesimos Nasib's Pioneering Contributions to Oromo Writing'. Nordic Journal of African Studies 4(1): 36-59.

Meseret Chekol Reta. 2013. The Quest for Press Freedom: One Hundred Years of History of the Media in Ethiopia. Lanham, MD: University Press of America.

Mohammed Hassen. 2002. 'Review of "Demystifying Political Thought, Power and Economic Development” by Tecoia Hagos'. Journal of Oromo Studies 9(12): 213-234.

Mohammed Hassen. 2009. 'Islam as Ideology of Resistance among the Oromo of Ethiopia'. American Journal of Islamic Social Sciences 26(3): 86-109.

Paulos Milkias. 2014. 'Yəlma Däressa'. In Encyclopaedia Aethiopica, Y-Z, edited by Alessandro Bausi, 46-48. Wiesbaden: Harrassowitz Verlag.

Smidt, Wolbert. 2015. 'A Remarkable Chapter of German Research History: The Protestant Mission and the Oromo in the Nineteenth Century'. Ityopis 1: 60-77.

Teferi Nigussie Tafa. 2015. "The Representation of "Ethiopianness" and "Oromoness" in Two OromoLanguage Novels: Yoomi Laataa by Isayas Hordofaa and Kuusaa Gadoo by Gaaddisaa Birru'. Journal of African Cultural Studies 27(1): 84-97.

Triulzi, Alessandro. 2002. 'Battling with the Past: New Frameworks for Ethiopian Historiography'. In Remapping Ethiopia: Socialism and After, edited by Wendy James et al., 276-288. Athens, OH: James Currey.

Ullendorff, Edward. 1960. The Ethiopians: An Introduction to Country and People. Oxford: Oxford University Press.

Zitelmann, Thomas. 2001. 'Anthropology and Empire in Post-Italian Ethiopia: Makonnen Desta and the Imagination of an Ethiopian "We-race". Paideuma 47: 161-179. 


\section{Index}

A Bit of Difference 4, 47, 54-7, 94, 105 see also Atta, Sefi

A Daughter of Isis 170, 173, 175, 178, 183-4 see also Saadawi, Nawal el

A Question of Power 215, 225, 287 see also Head, Bessie

Abani, Chris 282, 284 see also GraceLand

Abrahams, Peter 324, 327 Mine Boy 10

Aboke girls, disappearance of 69

Aboulela, Leila 13, 75, 78-81, 84, 87, 262, 273-4

Coloured Lights 79, 273

see also Lyrics Alley

Minaret 79, 273

'The Boy from the Kebab Shop' 262, 273-4

The Translator 79, 273

academics as characters in novels

Lloyd in The Book of Memory 36

Professor in Oil on Water 204-5, 207, 209, 211

Richard and Olanna in Half of a Yellow Sun 63, 65-6, 69-70, 280

Achebe, Chinua 5, 22, 70, 77, 79, 110-12, 117, 135, 141, 216, 231, 250, 292-3, 317, 324, 339, 344, 347, 369, 375, 413-6, 422, 425 see also African Writers Series (ASW) A Man of the People 22, 112, 122, 293 Anthills of the Savannah 324

Arrow of God 79, 293, 413-14

Hopes and Impediments 5

see also village novel

'The Novelist as Teacher' 152, 380

Things Fall Apart 106, 111-12, 276, 292-3, 339, 369, 375, 413

adaptation 92-3, 95-101

Adéèko, Adélékè 13

addressing others

addressee of a story 64

Novak, Amy 65-6

relational structures of 63
Adebanwi, Wale 369-70, 373, 376-7 see also writer as social-thinker

Adebayo, Ayobami 36, 39-41, 43-5, 302, 325

Stay with Me 36, 39, 41, 43-5, 302, 325

Adesokan, Akin 12, 211, 386, 392

Africa as site of perennial political and humanitarian emergency 12, 211

new African writing and outside readership 14, 211

Adeyemi, Tomi 7-8

Adichie, Chimamanda Ngozi 4, 11, 13, 76-7, 94, $162,216,231,272,274,373,392,403,423-5$

'African authenticity' 71

Americanah 11, 97, 105, 325

'A Private Experience' 262, 271-4

'Danger of a Single story', Ted Talk 61, 231

Half of a Yellow Sun 4, 11, 61, 64-6, 69, 242, 280-3, 302, 393, 420

Purple Hibiscus 110, 115-17, 282, 415, 418-20

The Thing Around Your Neck 373

adultery 36, 40, 292

affect 2, 10-2, 322-82

affect theory 326, 331, 335

Black affect 331

see also desire

see also emotions

see also shame

see also trauma

African-Asian encounters 5, 22, 28, 92-109, 276-8

African languages 13, 110, 385, 399-412, 429-442

Acholi 67-8, 373

Amharic 429-442

Chichewa 385, 390, 394-5

Geez 429, 432-3, 441

Gikuyu (also spelled Gikũyũ, Kikuyu) 30, 85, 87, 112, 249, 251, 255-6, 358, 405

Igbo $10,62,65,111-12,115-17,154,158$,

162-3, 237, 239, 290-304, 345

IsiXhosa 31, 115, 158, 161-2

IsiZulu 115, 220 
Kinyarwanda 30, 86, 118, 357-9, 367

Kiswahili 13, 30, 32, 85, 142, 145, 359, 366, 399, 403-10

Oromo 429-42

SePedi 115

SeTswana 115, 227

African language literatures

absence of critical discourse on 407

African language publishing 385

see also Amharic literary networks

challenge to existing power relations 216, 403,

408, 410, 431

see also Facebook

see also literary prizes

see also Oromo literary networks

translation 403-6, 409-10, 430, 434, 438, 441

African print cultures

histories 415

role of newspapers 433, 436, 141-2, 413, 415-16

African Writers Series (AWS) 347, 413, 415, 292

see also Chinua Achebe

colonial forms of patronage 416

educational networks 3, 416, 438

see also Heinemann Books

African writers

in global literary networks $30,60,62,66,76$, 111, 211, 386, 391, 196, 408, 420, 422, 424 international constraints for authors 498 participants in Cold War discourses 21-34, 49, 77, 99

Africanism 114

Afro-Asian solidarity 95, 99, 103-4

Afro-Asian Writers Association 22, 28 see also Cold war

Afroeuropean 47 see also Afropean

Afrofuturism 385

Afropean literature 77 see also Afroeuropean

Afrophone 430 see also African language literatures

Afropolitanism 4-5, 56, 75-91 Afropolitanism and decolonization 75-91 Afropolitan as much maligned figure 76 agency 125, 128-9, 160-1, 163, 165, 171, 179, 204, 220, 234, 245, 250-1, 254, 282, 284, 287, 295, 339, 342, 349-50 see also nonhuman agency sexual agency 324, 345, 373-4, 376

Agyei-Agyiri, Alex 75, 78, 81-7 see also Unexpected Joy at Dawn

Ahmed, Sara 10, 331

see also affect see also emotion

Ake Arts and Book Festival 407 albinism 36, 39, 44 and the whiteness of murungu 36 as source of pity, fear 36 as ethical challenge 44, 139

Aidoo, Ama Ata 77-8

Akpome, Aghogho 128

alcohol 9, 149, 305-19, 363

Akyeampong, Emmanuel 308-10

bar scenes 31, 308-12, 315

consumption 305-6, 308-10, 313-16

Couchoro, Félix 305

drinking scenes 9, 305-19

liquorpoetic 9

liquorpolitical 9

Tutuola, Amos 305, 317

Ali, Ayaan Hirsi 170-2, 179-85

see also autobiography

see also Infidel

see also Nomad

A Personal Journey through the Clash of Civilisations

All for Catherine 92, 94-5 see also Osofisan, Femi

allegories

of the nation 29, 79, 329, 374, 437

of women's lives and struggles 329

Amadi, Elechi 293-6, 301

Estrangement 293

The Concubine 293-6

Amadiume, Ifi 290-1, 302

Male Daughters, Female Sons 290-1, 302

Ambiguous Adventure 262, 266

see also Kane, Cheikh Hamidou

American journalists 65

Amharic literature 429-442

Amharic literary network 429-442

see also African language

see also African language literatures

literary networks 3, 12-13, 385-6, 389-95, 407, 415-18, 422-5, 429, 430-42

see also network

see also Oromo literary networks

Amony, Evelyn 61, 66-70

Baines, Erin 61, 67-9

see also I am Evelyn Amony

An Ordinary Man 110, 117-18, 120, 122

see also Rusesabagina, Paul

Andrade, Susan 171, 329

nation, representation of 171,329

see also women authors

animals

animal figures $8,231-43$

animality $8,231-43,343$

animal narrator $232,234-6$

animal studies 8, 203, 231, 234, 242

animal subjectivities 203

anthropomorphic commentary on human 
world 233, 235, 237, 254

centrality in African literature 232-3

Khoi animal poetry 233, 241

see also Memoirs of a Porcupine

Moolla, F. Fiona 203, 208-9, 212

relationship with humans 233-4, 239

species hierarchy $8,232-5,237-8,241$

Woodward, Wendy 14, 203, 234-5

in Zimbabwe poetry 204

anthropocentrism 8, 204, 218, 220, 231-44

and colonialism 232-3

and postcolonial studies 232

and whiteness 233

anthropocentric 204

anthropomorphism 233

anti-colonial struggle 104, 111, 118-19, 122, 178, 251, 256, 326-9, 436

women's role in 251

anti-nativism 125

appetite 11, 80, 276-90, 327, 331, 350

see also food

appropriation $61,63,86,94-5,171,216-17$, 262, 357

Arendt, Hannah 37-9, 41

see also speech

Armah, Ayi Kwei 77, 81, 112, 187-8, 278, 324, 372

see also homosexuality

Osiris Rising 187-8

The Beautyful Ones are Not Yet Born 81, 112

Two Thousand Seasons 372

arrested decolonization 328

see also Gikandi, Simon

Asian-African encounters 5, 22, 28, 92-109, 276-8

Chinese 5, 92-110, 315

Asong, Linus 25

detective fiction 25

Atta, Sefi 47-9, 54-58

A Bit of Difference 47-9

Everything Good Will Come 141

Attree, Lizzy 111, 123, 402-4, 407

audience

complicity in Africa's ills 211

local and global 30, 98, 406, 426

see also readers

autobiography 7, 61-2, 117, 124, 127, 129, 141, 151, 170-185, 232, 234-6, 250, 276, 293, 415-16

see also Ali Ayaan Hirsi

see also Amony, Evelyn

as cross-cultural project 63

Eggers, Dave 61-3

fictional autobiography $61-3$

filial voice $170-185$

see also literary non-fiction see also memoir

relationality $170-5,183$

Saadawi, Nawal el 170-80, 183-4

Smith, Sidonie and Julia Watson 170, 183

award culture 399

award ceremonies for African literature 13, 28,

387, 389-392, 399-412

see also literary prizes

AWS 413-17

see also African Writers Series

Bâ, Mariama 78, 262

Scarlet Song 292

So Long a Letter 183, 262, 267, 292, 298, 329

Baalu Girma 438

see also Amharic literature

KäAdmas Bašaga 438

Balogun, Odun 23, 27, 265-6, 401

see also Marxist aesthetics

see also Ngũgĩ wa Thiong'o

Bandung conference 22, 95, 99, 106

see also Cold war

see also Non-aligned movement

Bangla-English translation 404

Barra Birraan Barihe 437 see also Oromo literature

Barrett, Igoni 6, 197, 424 Blackass 6, 197

Behr, Mark 11, 373

The Smell of Apples 11, 373

Beti, Mongo 112, 305, 307, 317, 350-1

see also Boto, Eza

Beukes, Lauren 7, 8, 166, 179 Zoo City 166, 179

Beyala, Calixthe 285, 350, 351

How to Cook your Husband the African Way 285

Biafra 62, 64-5, 113, 347

see also Adichie, Chimamanda Ngozi

famine 280-1

war 62, 64-6

war literature 113

bildungsroman 33, 35, 60, 173, 236

biopolitics 234

biopower 238

Black Atlantic 22

blackface 61 see also Murphy, Laura

Black nationalism 244, 326

see also land see also nationalism

Black Orpheus 22, 417 see also Cold War see also Kalliney, Peter see also magazines 
blogs 92, 141, 385, 395

see also digital

see also on-line publishing

Sooo Many Stories 425

blues 324

music 324

women 324

body

see also albinism

augmentation 347

Black body 238-9

see also desire

disability $5,12,80$

disease 5, 12, 36, 83, 313, 341

female body as site of freedom and desire 12, $323,328,334$

female body reconfiguring of nationalist

cartographies 323

gender and value 39-40, 298, 329, 333, 371

see also infertility

memory 42-3

see also pain

see also pleasure

self-love 323, 328-30, 332-3, 336

see also soccer

suffering $10,29,35,60,62,65-6,69-70$, 83-4, 102, 128, 195, 212, 217, 225-6. 248, 254, 267, 274, 281, 285, 287, 346, 364, 401 vulnerability $8,36,39,42-3,45,49,51$, 60-70, 163, 210, 215-17, 219, 221-2, 224, 228-9, 232, 238-41, 253, 314, 330, 333, 361, 363, 365

Bofane, In Koli Jean 94

Congo Inc

Bismarck's Testament 94

book manuscripts $65,97,174,292,400,404-5$, $409,414,422,432$

book clubs 12, 70, 420, 422, 385, 395

social function 12

The Story Club in Malawi 385-98

book launches 12-13, 385, 396

book launch culture 13, 425

book party 421,423

Farafina 387, 396, 417-24

launch of Arrow of God 413-15

launch of One Day I will Write About this Place 420-3

launch of Weep Not, Child 413-5

see also Purple Hibiscus

live auctioning of books 396

borders $13,32,50,52,54,78,83,85,187-8$, 194, 263

as fluid spaces of exchange 263

Boto, Eza 305, 317

Ville Cruelle (Cruel City) 305, 317

Boyce Davies, Carole 76, 296, 407

see also motherhood
Brouillette, Sarah 13, 211, 386-7, 406, 408-9

Bugul, Ken 11, 270, 317

Le baobab fou 11

The Abandonned Baobab 270-1, 262, 274

Bulawayo National Gallery 323

see also Vera, Yvonne

Bulawayo, NoViolet 94, 162, 213, 401 We Need New Names 94, 162, 213, 401

Bushra al-Fadil 403

Arabic language winner of Caine prize

403

see also Caine Prize

Butterfly Burning 323-37

see also Vera, Yvonne

Caine Prize for African literature 13, 32, 84, 387, 389-93, 397, 400-4, 407, 409, 422-3

see also Bushra al-Fadil

gatekeeping agency 401

perpetuating stereotypes of Africa 401

Serpell, Namwali 401

capitalism 23, 29, 32, 48-50, 52-3, 97, 99, 166, $315,325,347$

cartography 48, 54, 255, 323, 349

Cassava Republic Press 420, 425 see also publishing

center and periphery 1, 50, 76-7, 87, 93, 255, 316, 386, 410

Chemichemi Creative Center 386, 414

Chichewa literature 385, 390, 394-5

chick lit 325

Chikoti, Shadreck 385-97

Azotus the Kingdom 389

'Child of a Hyena' 389

Free Africa Flee! 389

Mwana wa Kamuzu 390

'The Trap' 389

Chikwava, Brian 47, 401

Harare North 47, 401

child soldiers 213, 372

see also memoirs

childlessness 36, 39-40, 162, 298-300

see also infertility

social and cultural repercussions 39

social responses to 300

Chimurenga 198, 417, 424, 427

Chinua Achebe Center for African Writers and Artists, Bard College 421-2

Christianity 32, 63, 114-15, 117, 131, 139, 141, 142-3, 145-6, 148-51, 158, 248, 266, 270-1, 294, 299, 326, 329, 342, 347, 350, 370, 372, 375

Catholic 115-17, 248, 268

Christian devotional texts 140

Christian-Muslim contact and relations 173,

121-2, 265-6, 271-5

Orthodox Christian (Ethiopia) 432-3, 
$434-5$

Pentecostal self-help 142, 145, 149, 316

circulation, of texts 13, 61-2, 94, 111, 409, 415, $417,430,441$

see also networks

class

African middle class 47, 84, 144-5, 173, 326, $420,423,431$

class struggle $23-4,26-31,50,81,93-4,310$, $311,315,317,359-66$

in study of African literature 12, 48, 50-1, 54-8, 76, 93-7, 271-4, 280, 284-5,

Coconut 110, 113, 116, 121-2

see also Matlwa, Kopano

Coetzee, J M 4, 156, 216, 233, 245, 328,

407

Disgrace 4, 328, 233

see also landscape

Life \& Times of Michael K 216

The Lives of Animals 233

Cold War 21-34, 49, 77, 99, 261, 265, 3

see also Afro-Asian Writers Association

and African Literature 21-34, 77

alternative lens to Postcolonial studies 32

Black Orpheus 22, 417

decolonization 21-3, 32

Hammond, Andrew 21

Non-aligned movement 22, 31, 99

Popescu, Monica 77

Soviet Union 21-2, 27-8, 31

see also sponsorship of African literature

Cole, Teju 6, 61, 77, 94, 140

Every Day is for the Thief 105, 140

'The White Savior Industrial Complex' 61

colonialism

and dehumanization 83

colonialists 97, 119, 222

colonial gaze 253

colonial landscape as metaphor 245

see also homosexuality

native and settler 247

settler colonialism 247

comfort zones 60

companion species 238

see also animals

confessional 281, 140

Congress for Cultural Freedom 22, 414 see also sponsorship

Conrad, Joseph 111

Heart of Darkness, contrasted with Oil on Water 211-12

cookbooks 265, 278, 287

cosmopolitan 50, 76, 79, 80-1, 87, 88, 111, 115,

151, 189

as ethics $47,56-7$

as homelessness $56-7$ labor 57

local cosmopolitanism 392

critics and criticism

critics' failure to engage with African literature 399-407

see also feminist criticism

Crossbones 204, 207-9, 212

see also Farah, Nuruddin

Couchoro, Félix 305

see also alcohol

L'Esclave 305

Cousins, Helen 50, 77, 234

Couto, Mia 234, 235

Confession of the Lioness 235

Cruel City 305-9, 312-17

see also Beti, Mongo

see also Boto, Eza

Dadié, Bernard 47, 351

Un nègre à Paris 47

Dafa Jammo 437

Huursaa 437

see also Oromo literature

Dangarembga, Tsitsi 216, 238, 276, 282-8, 324, 389, 396

Nervous Conditions 216, 238, 276, 282-8, 324

The Book of Not 216, 283

Daniachew Worku 440

Adäfras 440

see also Amharic literature

The Thirteenth Sun 440

Darko, Amma 4 Beyond the Horizon 4

daughterhood 37, 42, 44-5, 68, 170-84

biological and non-biological 171

see also filial voice

Davis, Angela 324

decolonial shift 78

see also Mignolo, Walter

death

necropolitics 232

suicide $51,112,180,192,300,334$,

343-5

decolonizing ethos 21

Decolonising the Mind 23, 29, 233

see also Ngũgĩ wa Thiong'o

dehumanization 9-10, 83, 126, 226, 231-2, 240, 331, 350, 363

Deng, Valentino Achak 61-4 see also Eggers, Dave

What is the What? 61-6, 69, 242

desire

hooks, bell 325, 328

Kelley, Robin G 325-6

Lewis, Desiree 184, 328-9

Macharia, Keguro 325 
male desire 324

Nzegwu, Nkiru 328, 336

see also pleasure

same sex desire 11, 369-382

sexual desire 324-5, 329, 371, 377

women's desire 10, 11, 324-5, 328-9, 336

detective fiction 25-6, 29

see also genre

see also Asong, Linus

detention 83-4, 250, 256

dialogism 176

diasporic fiction $7,47-59,76,78,83,86,158$, 179, 180, 263, 286, 292, 342, 355

diasporic longing 83,285

see also travel digital space

and African literature 415

digital-age networking 385-97, 415, 424

see also networks

see also on-line publishing

see also offline 385-6

Diome, Fatou 47-9, 51-5, 57, 350

Le Ventre de'l Atlantique 47, 51-2, 350

Diop, Boubacar Boris 356

dirt

as metaphor $82,219,222$

Harrow, Kenneth 8

see also nature

Newell, Stephanie 8

proximity to $218,240,250-1$

reminder of corporeal vulnerability 215

soil reclaimed as community 215

displaced witnessing 355-65

Dodgson-Katiyo, Pauline 77, 324

dogs $232,234,238,240-1,401$

see also animals

colonial policing and governmentality 232

Dongala, Emmanuel 48, 187

'Jazz and Palm Wine' 187

Photo de groupe an bord du fleuve 48

Donkor, Michael 4

Housegirl 4

donor-funded publishers $387,396,406,408-9$, 424

see also funding

see also Kwani Trust

literary NGOs, and external investment 386, 402

local and transnational donors 396, 408-9

see also Mbari

see also sponsorship

see also Strauhs, Doreen

dreamer-women 325

see also desire

Drum 142, 145, 150, 417

see also magazines

dystopia 7, 54, 76, 188, 190-2, 314
East African literary cultures 5, 23, 84, 105, 278, 399-12, 413-28, 429-42

ecocriticism, African 203-4, 217, 218

Caminero-Santangelo, Byron 94, 98, 203, 212,

217, 218, 220

Egya, Sule 213

Iheka, Cajetan 8, 14, 35, 216-17

Nixon, Rob 203, 205, 210, 215, 217, 219

Okuyade, Ogaga 76, 205

see also zoocriticism

ecological politics 204

see also Habila, Helon

see also Farah, Nurrudin

oil and oil exploration 97, 203-14, 217

ecology

dirty ecology $215-30$

ecosystem (as hostile) 205-7,210, 212, 224-5, 246

gender 217

linguistic 141, 206

Edwin, Shirin 10, 78, 277, 402, 408

see also food

see also Islam

Efuru 39, 291-304

see also Nwapa, Flora

Eggers, Dave 61-4, 69-70, 242

see also Deng, Valentino Achak

see also What is the What?

Egyptian literature 75, 78-9, 173, 176-9, 186, 273,75

women writers $75,78-9,173,176-9,186$, 273, 75

Emecheta, Buchi 11, 47, 77, 122, 183, 187, 198, 232, 237-9, 291, 298, 302, 325

Second Class Citizen 47, 232, 237-9

TheJoys of Motherhood 11, 291, 302, 325

The Rape of Shavi 187

Emezi, Akwaeke 8

Freshwater 8

emotion

see also affect

see also Ahmed, Sara

empire 35, 45-6, 79, 93, 101-4, 155, 164, 167, 196, 287, 293-6, 307-8, 316, 341, 432-3

see also imperialism

English

as link language 407

in digital space 385

rejection of 27

writing in $30,60,67,112,142,211,390,394$, 399-410, 441

entextualization 394

Barber, Karin 394

environment

as significant other 204

see also ecocriticism

see also ecology 
environmental infertility 224

environmental issues and humans 203

environmental writing 203, 217

ethical obligation to nature 215

nature and power 203

nonhuman world 203-4, 212-13, 216, 218, 220, 229

piracy as strategy for protecting environment 208-9, 211-12

Somalis as protectors of endangered ecosystems 208-9, 210, 212

epistolary novel and global mobility 52

erotic 187, 323-6, 328-9, 330-2, 335-6

see also desire

hooks, bell 325, 328

Kelley, Robin G 325-6

Lorde, Audre 326, 330, 331

Macharia, Keguro 325

Nzegwu, Nkiru 328, 336

Estrangement 293

see also Amadi, Elechi

ethics

Arendt, Hannah 37-9, 41

ethical agency 35, 282

ethical and political 36-7, 42, 57, 62, 66

ethical concerns in literature $35,37,233$, 340

ethical failings of postcolonial novels 340

ethical obligation to nature 215-16, 219

Eze, Chielozona 162

in everyday life 36-45

Ethiopian literary scholarship

Amharic literature 429-42

bias towards Amharic 429, 430-42

Geez literature 429, 430, 432, 433, 441

monolingual approaches 432, 435, 436, 437,

438

Oromo literature 429-42

Tigrinya literature 432

ethnicity 5, 6, 14, 48, 75, 110-23

ethnic identity 110

ethnicization 364

inter-ethnic relations 142

every day practices

as space for ethical action 35-46

as space for self making 38

see also food

literature as intervention that addresses

everyday practice 36

see also Ndebele, Njabulo

spectacular action 38-9, 41-3

see also topology

exchanges

see also Cold War

lateral 22

see also networks

south-south 77 exile $30,76,130,133,172-3,179-80,182,219$, 255, 279, 286, 328-31, 354-5, 360, 364, 391, 434, 438

Eze, Chielozona 162

Facebook 385, 389, 392-7, 424, 441 and African languages 385

Fagunwa, D.O. 187

Fanon, Frantz 22-3, 42, 245, 326, 328, 330-1, 344, 347

Black Skin, White Masks 330, 347

The Wretched of the Earth 330

Farah, Nuruddin 78, 204-15, 265

Crossbones 204, 207-15

Links 208

piracy 208-12

farming 8-9, 96, 215-17, 220-5, 251, 297

gardening 8-9, 215-28

gendered 215-17

feminist literary criticism

African feminism 162, 263-4

African feminist literary criticism 263, 329

Banyiwa-Horne, Naana 293

Motherism 296

Nnaemeka, Obioma 292, 296, 298

see also Stratton, Florence

see also Womanism

FEMRITE 386-7, 391-3, 402

filial voice $170-85$

Fine Lines from the Box 239

first person narration 53, 66, 357-8, 361

folklore 112, 134, 157, 233, 246-7, 279, 434

folktales 189, 279, 295

food 9, 43, 101-2, 175, 209, 217, 221, 226-7,

251, 276-89, 327, 401, 425

appetite $11,80,276-89,331,350$

comfort 280-1, 283

eating and everyday life 9, 150, 276, 278

excess 12, 102

famine and food security 62, 276, 279-81, 392

Highfield, Jonathan Bishop 9, 220, 279,

282-3, 287

see also intimacy

pleasure 9, 279-80, 283

as political index 276-8, 284

Shirin, Edwin 277

scholarship on food in African literature 276, 279

football 47, 51-2, 273

see also soccer

Forna, Aminatta 216, 280-2, 284

Ancestor Stones 216

The Memory of Love 280-2, 284

foundation myths 369

heteronormative 324, 369, 373

see also Kintu

foundational fictions 290-304 
freedom 10, 310, 323-38, 341, 345, 370, 378

and joy 325

and obligation 300

and pleasure 327

Black freedom 10, 325

dreams of $324,326-8,330,335$

independence 328-9

nationalism 10, 327-8

personal freedom, as linked to the erotic for women 329, 330, 335-6, 400

sexual freedom 324

see also Taoua, Phyllis

see also unfreedom

funding

NGOs 35, 45, 234, 386, 391, 392, 402

NGOs and corruption 56

see also sponsorship

Gaddisa Birru 438

Galassi, Jayne 216

Cactus Letters 216

Gappah, Petina 36, 41-6

The Book of Memory 36, 41-6

Garuba, Harry 7, 79, 80, 88, 93, 98, 106, 111, $122,155,157,159,241$

gardening 8-9, 215-30

African women 215-19, 225

cultivation 215-30

see also dirt

literary gardening 215-17, 220

minor forms of

farming 215, 217, 225

see also nature

gastropoetics 276, 279, 281-3, 285, 287

see also food

liquorpoetic 9

Roy, Parama 9, 276

gastropolitics $277-9,281,283,285-7$

see also food

liquorpolitical 9

Geez literature 429, 432-3, 441

see also African language

see also Ethiopian literary scholarship

gender 11, 110, 116, 141-53, 156, 160-4,

173

gender of children 40

gendered identity $51,75,93,101,171,173$,

175

gendering 50, 298, 330, 342

norms 145-6, 150, 175-6, 216-17, 221, 291, 311,431

power and authority 160-2, 278

relationships 141-4

roles 149, 161, 223, 291-2, 296, 311

sexuality 11,146

spirituality/religion 101, 116, 431

with age/class/culture/ethnicity/nation/race
48, 50-1, 75, 93, 110, 116, 160, 237, 239,

$286,307,317,349,373,440$

genocide 117-20, 172, 213, 232, 354-68

Coquio, Catherine 356

Dauge-Roth, Alexandre 356

Gatore, Gilbert 355

Hitchcott, Nicki 354

in fiction by Kenyan writers 354-69

in relation to exile and displacement 354-5,

364

Mamdani, Mahmood 110-1, 119-20, 354,

359, 361

Rwanda Writing in Duty of Memory 356

Semujanga, Josias 356

Soumaré, Zakaria 356

genre

AIDS memoir 60, 371

child soldier

narrative $60,68,172,213,372$

critiquing genre 26, 37, 206, 211, 229

epistolary 52

see also green novel

horror 154, 162, 165, 167

hybrid genre 171

Jaji, Tsitsi and Lily Saint 6

memoir $6,7,21,23,29-32,60,64,75,84-7$, $110,117-18,120,124-37,219,232,234-7$,

$250,256,357-8,401,404,415,422,425$

new genres adapted to local cultural heritage 29

postcolonial bildungsroman 60

reworked 24

science fiction $7,186-7$

speculative fiction 186-8, 390-1

testimonio 60

thriller and detective 25, 47, 53, 54, 57, 198, 317

Gérard, Albert 13, 429, 441

Four African Literatures

Xhosa, Sotho, Zulu, Amharic 13, 429

Gikandi, Simon 14, 23-4, 26-7, 33, 50, 104, $155,208,326,328$

cosmopolitanism 50

Slavery and the Culture of Taste 155

Gikuyu 30, 85, 87, 112, 249, 251, 255-6, 358, 367,405

see also animal stories, Ngũgĩ

oral narratives 27,131

Global South 15, 197

cultural production $21,29,75,82$

China's inclusion 93-7, 105

globalization 291

and increased mobility $47-60$

and transnationalism $48-50$

as deterritorialization 49

movement of capital and information 52, 245

Gold Coast literary and social clubs 387-8 
Gordimer, Nadine 22, 78, 156, 198, 349, 407

gorilla 354-5, 363-6

see also animals

as non-human witness 355

gossip 268-270, 299, 301

gothic 6, 7, 154-69

see also horror

white authors 156

Granta 422-3

green novel 206

see also genre

Gurnah, Abdulrazak 47, 265

By the Sea 47

Habila, Helon 6, 204-14, 401, 408-9

Oil on Water 204-14

Waiting for an Angel 6, 401, 408

Haddis Alemayehu 440 see also Amharic literature

Fakar askä Mäkabar 440

Haile Fida Kuma 437

Bara Birraan Barihe 437

see also Oromo literature

Half of a Yellow Sun 4, 11, 14, 61, 64, 69, 242, 280-2, 287, 302, 393, 420

see also Adichie, Chimamanda Ngozi

haunting 154, 158, 159, 161, 276, 356

see also genocide

see also horror

see also witnessing

Head, Bessie 187, 215-16, 219-20, 228, 279, 287

A Question of Power 215, 225-8

When Rain Clouds Gather 215, 226-8

Heinemann Books 12, 292, 347, 413, 415

see also African Writers Series

hero 28, 124-37, 176, 178, 181, 201, 217-221, $227,246-8,273,287,293,340-1,347,350$, $376,379,420$

heroic mythos 126

political hero $124-37$

heterosexuality $371-3$, 376-80

see also homosexuality

heteropatriarchy 325

see also Kintu

history 78, 82, 118-21, 125, 127-8, 130, 236, 261, 265-6, 279, 306, 323, 346-7, 354, 362 African literary history 12, 22, 233, 413-28, 429-42

Afro-Asian history 97, 99-100, 103

colonialism and history 23, 66, 94, 104, 161, 189, 194, 234, 240

family history $85-7,170-85$

Kenyan 24, 28, 224-54

literature and history 126, 157, 250

memoir and history 124-36, 170-85

movement of history 28-9, 79, 270 see also nationalism

oral history 127, 176-7, 233

peoples' history in Half of a Yellow Sun 66

Ugandan 369-82

violence in 240, 246, 247

women in 130-1, 170-8, 217-18, 248-57, 323

Holy Hill 154, 158, 160-2, 167

see also Sithebe, Angelina

home

'Discovering home' 84-7, 354-5, 357-69

and immigration 35-6

domestic space 39, 96, 113-16, 160, 178-80, 223-7, 238, 332

homeland 68, 87, 111, 119, 195, 219-222,

208, 286

homelessness 57, 101, 131, 133, 205,

208, 284

notions of home 54, 56-7, 77, 101, 166, 180, 191-4, 217, 220-8, 245-60, 252-5, 281-6, 294-300, 327

homosexuality 142, 370-82

Behr, Mark 11, 373

see also colonialism

Duiker, Sello K. 373

Kintu 11, 369-82

see also Makumbi, Jennifer Nansubuga

The Interpreters 135, 372

Two Thousand Seasons 372

hooks, bell 325-6, 328-9

see also erotic

horror 154, 162, 165, 167

see also genre

see also haunting

'How to Write about Africa' 30, 84-5, 422

see also Wainaina, Binyavanga

Huggan, Graham 203, 211, 386, 416

postcolonial exotic 211

human rights $35,43,60-71$

audiences 60-71

see also humanitarianism

see also memoir

personal storytelling 60

Schaffer, Kay and Sidonie Smith, Human Rights

and Narrated Lives 60-1, 63, 69-70

Slaughter, Joseph Human Rights Inc 35

truth-telling 62

writing and reception of literature 60-71

human

ethical recognition 36

ethnochauvinist definitions of 326

human nonhuman encounter and gardening 221

human-animal 232-5, 237

personhood 43, 62, 147-8, 181, 284, 345, 378

proximity between humans and nonhumans

204, 207-8, 210, 241 
humanitarianism

as sympathetic self-projection 61,66 complexities of self-representation 4 humanitarian discourses 56, 60-71

humanitarian group 60

see also imagination

post-humanitarianism 63

religious humanitarianism 61

suffering 35, 60, 62, 65-6, 69

Huursaa 437

hybridity 76-7, 79-80, 85, 88, 94, 155, 171, 173, $179,216,228,309,310-2,318,373$

I am Evelyn Amony 61, 66-71 see also Amony, Evelyn

Ibadan, The Penkelemes Years 129-30, 132-5, 373 see also Soyinka, Wole

Idemili, water goddess 291 see also religion

identity

African identity/Africanness 75, 113, 125, 128

Blackness, Black identity 113-5, 121, 160, 232, 239, 347, 349

ethnic identity 111, 118, 360, 432

Gonja 120-1

Hutu 118-20, 122, 232, 355, 258-60, 367 indigenous cultural identity 110, 113-7, 121, 155, 157-61, 176, 204, 217, 220, 247-8, 250, 325-6, 328, 344, 372, 386

Pedi identity 113-15, 122

political identity $110,124,134$

postmodern conceptions of identity 110, 116, 125,129

Tswana 115, 215, 219-28

Tutsi 118-22, 172, 232, 355, 358-67, 374

whiteness 41, 113-17, 194, 233, 241, 286

Idu 291-4, 296-7, 300

see also Nwapa, Flora

Iheka, Cajetan 8, 35, 216-17

imagination

African 154-70

colonial 231-2, 234, 239, 250

connection to unfreedom 326-7

humanitarian 60-72

imperial discourse 94

radical $10,326,330$

utopian 188

immigration 48, 82-3, 360

see also migration

see also mobility

independence 7-8, 27-9, 32, 75, 79-83, 93, 103, 111-13, 118-19, 121, 128, 132, 142, 159, $164,176,233,244,248,250-2,254-6,278$, 281, 284, 323, 327-36, 339, 347, 348, 351, $357,362,375,380,388,436$

see also matunda ya Uhuru
In Arcadia 7, 188-98

see also Okri, Ben

infertility 10-11, 39, 224, 297, 300

barrenness 298

see also childlessness

Efuru 39, 291-303

Half of a Yellow Sun 302

Idu 291-4, 296-304

Stay with Me 36, 39-45

The Secret Lives of Baba Segi's Wives 39, 302, 325

Infidel 170, 179-85

see also Ali, Ayaan Hirsi

intertextuality 362, 94, 98, 104, 127

Irele, Abiola 14, 112, 154, 156

Isayas Hordofa 440

Amharic literature 440

Yoomi Laataa? 440

Isegawa, Moses 369, 373, 380

Abyssinian Chronicles 396, 373

Islam 10, 78-9, 141-3, 173, 179-82, 196, 208, 210, 261-75, 436

and limitations of 9/11 as lens 261

as social rituals and community 262

Baderoon, Gabeba 10, 234, 240, 265, 273

Christian-Muslim contact 261-2, 265, 271

see also Edwin, Shirin

Harrow, Kenneth 10, 263-5, 273-4

in everyday life 10, 261, 273-5

Islam, in African fiction 12-13, 141, 261, 263,

265,267

Islamophobia 261, 263

Mirmotahari, Emad 10, 265

topology of diverse constituents 261-75

island narratives 93

Jalada 385, 389-390, 405, 225 see also magazines

Jeyifo, Biodun 126, 131, 134, 135, 407

English as an African language 407

Jones, Rebecca 5, 7, 93, 261, 265 see also travel writing

Julien, Eileen 211, 213 extroverted novel 211, 213

Kahiu, Wanuri 190 Pumzi 190

Kahora, Billy 94, 105, 354-6, 363-9 The True Story of David Munyakei 421 'The Gorilla's Apprentice' 354-6, 363-9

Kampala 86, 358, 374, 380, 391, 413 Conference of African Writers of English Expression 1962413

Kane, Cheikh Hamidou 262, 266, 317 Ambiguous Adventure 262, 266

Kelley, Robin G 325, 326, 328 see also desire 
Kenyan history 24-9, 244-57

colonial versions of 24

Mau Mau resistance 24-9, 244-5, 250-1, 254-6, 324, 362, 421

Kenyan independence 251

Kenyan women authors

see also Likimani, Muthoni

see also Ogola, Margaret

see also Ogot, Grace

see also Owuor, Yvonne

Khoi poetry 233, 241

Kiguru, Doseline 14, 402, 417, 424

kimay 32, 85-7

see also Wainaina, Binyavanga

see also Cold war

ideological cacophony 32

Kintu 11, 369-82

see also Makumbi, Jennifer Nansubuga

Kiswahili 13, 30, 32, 85, 399, 403-28

literature 399, 405, 407

regional lingua franca $405-7,410$

Koran 267, 270-1, 306

see also Qu'ran

Kourouma, Ahmadou 78, 339, 351

The Suns of Independence 339, 351

Krishnan, Madhu 10, 77, 374, 408, 415

Kwani Trust 386-7, 389, 391-2, 396, 415, 417, 420-5

Kwani? 374, 391, 399, 400, 402, 405, 424, 426

see also magazines

see also publishing

kwela music 332

Kyomuhendo, Goretti 355, 364, 366, 391

Secrets no More 355, 364, 366

La Guma, Alex 22, 414

see also Cold war see also travel

labor 4, 11, 35, 38, 47-52, 194, 198, 211, 218, 226, 245, 251, 279, 309, 329, 440

and cosmopolitan ethics 47, 56-7

Black labor 50, 160, 245

laborer 48, 94, 333

legitimate and illegitimate 53

migrant labor 49-50, 333

mobility 47-52, 54

reserve work force 51

Standing, Guy 48

unremunerated 47

Laing, Kojo 186, 187, 197

Major Gentl and the Achimota Wars 187

Woman of the Aeroplanes 186

land

agricultural resource 245

ancestral connections to land 246-7, 250, 257-8 and landscape $8,244-6$

as terrain 233-6, 249, 251, 253-5

see also Black nationalism

contested 244, 248

farming 8-9, 96, 215-30

see also mythology

ownership 207, 245, 247, 249-58

tactile and tangible $8,244,250$

landscape 8, 215-230, 244-257

as praxis 215,244

communal heirloom 249

embodied 244, 251

history, connection to 246

identity 244

sentient 246

Le Ventre de l'Atlantique 47, 51-2, 350

see also Diome, Fatou

Lewis, Desiree 184, 328-9

see also desire

life writing 6-7, 14, 23, 32, 62-3, 124-34, 170

collaborative life writing 63

see also Twidle, Hedley

women's life writing 170

Likimani, Muthoni 244, 250-1, 255

Passbook Number F.47927: Women and Mau

Mau in Kenya 244, 250-1

Lindfors, Bernth 23, 24, 122

Lipenga, Ken 12, 80, 374

liquor 9, 305-19

see also alcohol

literary non-fiction 124, 127, 134

see also autobiography

see also memoir

see also Twidle, Hedley

literary prizes 14, 30, 399-412, 413-428, 435

see also awards

see also Caine Prize

cultural value 386-7, 400, 414-18, 423-4

depicted in novels 408-9

expectations for authors 32, 402

history of in Africa 402, 435

loss of autonomy for authors 442

Mabati-Cornell Kiswahili Prize 399, 403-11

NLNG Prize for literature 419

Peer Gynt Award 387, 389

power relations 403, 408, 430

Tuzo ya Fasihi Ubunifu Kiswahili Prize 399, 403-10

see also Waiting for an Angel

literary value $23,386,-7,396,402,417,423$

Loba, Ake 47

Kocoumbo, l'etudiant noir 47

located literary events 418

Lorde, Audre 326, 330-2, 336

love $3,5,37,139,140,142-53,161,174-5,178$, 192-4, 205, 222-3, 226-8, 238, 252, 
280-9, 293-304, 323-38, 341, 370, 401, 409 see also desire

in contexts of unfreedom 326

see also romance

self-love 323-8, 329, 330, 332-3

technologies of policing love 326

Luo heroes 248

mythology 248

Lyrics Alley 75, 79, 81, 87

see also Aboulela, Leila

Maathai, Wangari 216

Mabanckou, Alain 4, 47, 48-9, 52-5, 57, 232, 234-41, 317, 318

Broken Glass 236

Memoirs of a Porcupine 232, 234-41

Tais-toi et meurs 4, 47, 52

Macharia, Keguro 325-6, 417

see also desire

Madondo, Bongani 94, 97

'Jozi 2020' 94, 97

Mahama, John Dramani 110, 117, 120-2

My First Coup d'Etat 110, 117, 120-1

magazines 114, 140, 142, 147, 150, 198, 212, 280, 385, 415-19, 422-4

see also Black Orpheus

Busara 417

Chimurenga 198, 417, 424

see also Drum

Farafina 387, 417-25

Itinerario 417

see also Jalada

see also Kwani?

Mũtiiri 417

Penpoint 413

see also Transition

Makumbi, Jennifer Nansubuga 11, 369-82

see also heterosexuality

see also homosexuality

see also Kintu

Malawi Writers Group 385, 388-90, 392

Mamdani, Mahmood 110, 111, 119, 120, 122 , 354, 359, 361

Mami Wata 158, 164, 291

see also Mammywater

Mammywater 291, 294-5

see also Mami Wata

Maphoto, Mike 385, 395

Diary of a Zulu Girl 385, 395

mapping

cartography 48, 54, 255

marriage 10, 36-40, 139, 141-52, 174, 176, 179-80, 211, 224

and procreation 36-40, 291-302

and Romantic love 293-5, 298, 302

as duty 291

see also Efuru see also Kintu

marriage plot 10, 290-304

see also self-help literature

see also So Long a Letter

trans-historical significance 290, 295

utilitarian marriage 295, 299

wife, first wife and second wife 40, 79, 117, 293, 298-9, 300

Marxist aesthetics 23, 33 see also Balogun, Odun see also Ngũgĩ wa Thiong'o

Matlwa, Kopano 11, 113-23, 351

Coconut 110, 113-23

matunda ya Uhuru 248

see also independence

Mau Mau 24-9, 244-5, 250-1, 254-6, 324, 362, 421

fighters and guerrillas 27, 29

resistance $24-5,26,28$

Mbari 386, 414-17, 424-5

as club 414-17, 424-5

see also donor-funded publishers

see also publishing

Mbembe, Achille 82, 87, 125, 126, 128, 232, 276, 278, 349, 386

'African Modes of Self-Writing' 125, 128

see also self-fashioning

Mbue, Imbolo 47

Behold the Dreamers 47

Mda, Zakes 11, 234, 318

see also The Whale Caller

see also Ways of Dying

mediated performance 149

melancholia

diasporic 83

postcolonial 83,318

memoir

African politicians 117, 124, 170-85

AIDS memoir 60, 371

see also autobiography

child soldier narrative $60,68,172,213,372$

see also humanitarianism

see also Ibadan: The Penkelemes Years

literary memoir 7, 75, 84, 87

see also literary non-fiction

My First Coup d'Etat 110, 117, 120, 122

personal storytelling 26, 29, 60-9, 113, 254, 267

post-colonial memoir 32

refugee memoir 60, 62, 86, 172, 179, 182

Soyinka, Wole 6, 124-36

see also You Must Set Forth at Dawn

Memoirs of a Porcupine 232, 234-41

see also Mabanckou, Alain

memory 63, 83, 128, 170, 175, 189, 228, 247, $276,356,362$

displaced memory 335, 355 
re-memory $172,177,183$

Rwanda - Writing in Duty of Memory 356

see also The Book of Memory

see also The Memory of Love

Menkiti, Ifeanyi 43

Middel, Cristina 188

Afronauts 188

Mignolo, Walter D. 78, 87, 105

see also decolonial shift

migration

African migration narrative 47,63 ,

76-7, 78, 80, 83, 87

African migration patterns 78,87

see also Afropolitan

asylum seekers 47,179

Black bodies 155, 194, 238

human trafficking 51, 53

intra-continental migration $75,81,83,84$,

86-7

migrant subjectivity $75,77,79,85$

migrant/immigrant 47, 49-54, 76, 78-81, 83-6, 144, 160, 180, 247, 333, 374

see also mobility

nationality 56,76

pluriversal migration $78,83,87,88$

soccer/football 47, 51-2, 273

transportation 49

minority literatures 62, 279

mobility

see also Afroeuropean

see also agency

commuting 49, 54-6

see also labor

migrant mobility 49

modernity 7, 9, 79-82, 88, 101, 102, 111, 156-6, 157-8, 188, 190, 205, 215-16, 222, 224, 241, 255, 264, 265, 271, 274, 292, 294, 307-8, $310,312,318,325,326,339,348-9$, $372-3$

culture of 326

Gikandi, Simon 326

modernization 80, 102, 222, 224, 296, 432, 433

tradition 79-80, 306-9, 311

Monenémbo, Tierno 356

monolingual approaches 429

see also Ethiopian literary scholarship

monolingualism 432,

435-8

Moolla, F. Fiona 203, 209, 212

motherhood/mothering 11, 68, 128, 161, 164, 182-3, 291, 293, 296, 298-9, 302, 325, 336, 395

see also Boyce Davis, Carole

compulsory motherhood 325

in scholarship 296

Lewis, Desiree 184, 328-9
Nnaemeka, Obioma 163-4, 296, 302

see also Oyěwùmí, Oyèrónkẹ

Motherism 296

Acholonu, Catherine 296

Mphahlele, Es'kia 78, 234

'Mrs Plum' 234

Mukasonga, Scholastique 355

multilingual 430, 440-1

multilingualism 431, 432-3, 439

Muponde, Robert 323-4

Mujila, Fiston Mwanza 305, 309, 312-13, 315, 316, 318

see also Tram 83

Musila, Grace A. 84, 241

see also Redykyulass Generation

Mũtiiri 417

Mwangi, Evan 5, 84, 93-4

My First Coup d'Etat 110, 117, 120, 122

see also Dramani, John Mahama

myth and mythology

about land 247-9

Chewa 112

see also foundational myth

Gikuyu 112

Igbo 158

Luo 248

see also Ogun

Shona 203

tortoise as trickster in Yoruba mythology 233

Xhosa 158

Yoruba 6, 126, 134-5, 158, 189, 233

Nairobi Railway Museum 420-1, 423

nation

see also Andrade, Susan

see also heterosexuality

male desire and nation project 11, 324

national allegory 29

national and nationalist literary histories 430

national novel, Ugandan 369, 380

nationalism $32,48,81,87,99,125,171,244-5$, 358, 392, 432, 436-8, 439

Black nationalism 244, 326

Chewa nationalist 392

cultural nationalism 76, 80, 87, 118, 329, 331

indigeneity 128

land rights 244-5

linguistic nationalism 429-42

nationalist history of Zimbabwe 323

nationalist literary history $128,323-4,369-82$,

430

nation-building 22, 75, 278, 296, 359, 433

postnation, postnational $77,87,128,316,369$

nature

aesthetics of proximity 204, 207, 210

gardening as way of living in relation to 215

primacy of in African cultural systems 203 
nativism 125

Ndebele, Njabulo 4, 9, 37-8, 41-6, 232, 239-41, 359

see also everyday

Fine Lines from the Box: Further Thoughts about

Our Country 239

'The Year of the Dog' 232, 239

'The Rediscovery of the Ordinary' 37

Negritude 135

Nehanda 323

see also religion

spirit medium

see also Vera, Yvonne

neoliberalism 3, 23, 30, 48-9, 51-4, 57, 63, 39, $145,164,166,264,269,347$

networks

African Writers Trust 390, 393

as concept or frame $12,77,208,386,415$,

431

books as networked objects 396

digital-age networking 12, 386, 389, 395

see also exchanges

Jagoda, Patrick 415

language-based network 429-42

Levine, Carol 208

literary network 2, 3, 12, 386-7, 390-1, 395, 407, 415, 422-3, 424, 430-41

paracolonial networks 386-7, 392, 415-16

paravirtual networks 386, 392, 395, 396

publishers' networks 12, 414-28

transnational network 12, 417, 422, 431, 439,

441

see also travel

writers' networks $62,389,391-2$

Newell, Stephanie 7-8, 139-46, 148-9, 151,

386-8, 392, 397, 415-16

dirt 8,228

paracolonial networks 386-7, 392, 415-16

self-help texts 7, 139, 141-6, 148-9, 151

Nganang, Patrice 11, 235, 318

Temps de chien (Dog Days) 11, 235, 318

Ngũgĩ, Mukoma wa 33, 366, 404, 407

Ngũgĩ wa Thiong'o 3, 11, 21-34, 112, 135 , 187-8, 216, 233, 250, 278, 324-5, 328, 339, 385, 400, 404, 406, 407, 413

A Grain of Wheat 28, 324, 328, 339-40, 347, 351

African languages 385, 400, 404-7

animal stories 233

anticolonial resistance 23, 29

autobiography 135

Cold War travel 3, 21-34

critical responses 21, 23, 23, 325-8

Decolonising the Mind 23, 29, 233

literature as agent of

transformation 24, 28, 31, 33

Marxist Aesthetics 23, 26, 27, 29, 30-3
Matigari 188

Penpoint 413

Petals of Blood 23-5, 28-9, 31, 245

reflection on function of literature 24 ,

30, 32

The River Between 325

translation 385, 404-5, 406

Weep Not, Child 112, 413

Wizard of the Crow 12, 188, 340-2, 344, 349-50

Niger Delta 204-5, 207-8, 210, 212, 411

Njau, Rebeka 325

Ripples in the Pool 325

Nkosi, Lewis 22, 78

travel 22, 78

Nnaemeka, Obioma 292, 296, 298

feminist literary criticism 292, 296, 298

see also motherhood

Nomad: A Personal Journey through the Clash of Civilisations 170, 179-83

see also Ali, Ayaan Hirsi

Non-aligned movement 22, 31, 99

see also Bandung Conference

nonhuman 8, 203-7, 210-3, 216-19, 220-29

see also human

nonhuman agency 203, 221, 246

nostalgia 128-9, 175, 253, 278, 312

for different futures 331, 336

novel

Anglo-American 292, 294-5, 297-8

dictator novel 11-12, 340, 350

see also epistolary novel

Francophone African 9, 12, 77, 183, 278, 292,

305-19, 402

historical novel in Africa 24, 27, 29, 30, 32,

75, 390, 440

Igbo-Anglophone 292, 294, 302

see also nation

national novel 373

nationalist novel $110,118,125,323-4$,

327-30, 374, 392, 430

'The Novelist as Teacher' 141

village novel 292-5, 301

Nwakanma, Obi 414, 416 see also Okigbo, Christopher

Nwapa, Flora 39, 290-4

Efuru 39, 290-4

Idu 291-4, 296-304

mother of African literature 292

Nyanzi, Stella 370, 372, 377

see also sexuality

Nyeko, Monica Arac de 370-1

Nzegwu, Nkiru 328, 336

see also erotic

Ochiagha, Terri 416

Oduor, Okwiri Claudette 423 
Ogola, Margaret 244, 248-50, 255 see also The River and the Source

Ogot, Grace 244, 246-57 see also The Promised Land

Ogun 6, 125-6, 131-5 see also mythologies

Oil on Water 204-14 see also Habila, Helon

Ojaide, Tanure 76

Okadabooks 143

Okigbo, Christopher 414, 416-17, 424 as West African Manager for Cambridge University Press 416-17 see also Nwakanma, Obi see also publishing Suhr-Sytsma, Nathan 13, 14, 414, 417

Okparanta, Chinelo 11 Under the Udala Trees 11

Okri, Ben 7, 165-9, 186-200, 279, 287 Astonishing the Gods 188-9, 191-6 see also fabulism In Arcadia 7, 188-98 Starbook 7, 188-98 The Age of Magic 188-99 The Famished Road 165-9

Okorafor, Nnedi 7, 8, 162, 186, 197 The Book of Phoenix 8

Okuyade, Ogaga 76, 205

Olaniyan, Tejumola 2

One Day I Will Write About this Place 7, 21-9, 75, 87, 357, 367, 401-15, 420-5

see also Wainaina, Binyavanga

Onesimus Nasib 434

Onitsha market literature 142-3, 294

online publishing 13, 92, 143, 149, 342, 389, 392, 294-5, 397, 418

Adenekan, Shola 50, 417 see also blogs digital 60, 385-6, 389, 393-7, 415, 424

Facebook 385, 389, 392-7, 424, 441 WhatsApp 389

Onoh, Nuzo 154, 156, 158-9, 162-6 see also The Sleepless

Unhallowed Graves 154, 162-6

Onyebuchi, Tochi 11

Beasts Made of Night 11

oral forms 27, 31, 127, 156, 176-83, 189, 231, 279, 287, 403, 434, 439-40

African oral narratives $67,112,153,171-2$, 233, 311-12

African oratures 134, 233, 263, 292, 430 oral traditions $112,156,170-2,176-83,209$, 249-50, 277, 279, 312, 339

orality in literature $134,156,171-2,292,403$, 312 ordinary $4,9,35-46,128,142,151,215-16$, 218-19, 224-8, 276, 323, 355

see also everyday

Oromo literature 429-42 see also African languages see also African language literatures see also Amharic literary networks literary networks 13, 429-42 Oromo literary network 13, 429-42

Osinubi, Taiwo 11, 22

Osofisan, Femi 5, 92-109 All for Catherine 92-109

Ousmane Sembène 4, 22, 48, 78, 242, 327, 329, 342, 350, 351 see also Sembène, Ousmane

Owuor, Yvonne 77, 88, 244-57, 325, 354-7, 360-6, 426 Dust 77, 244-57, 325

'Weight of Whispers' 88, 354-7, 360-6

Oyěwùmí, Oyèrónkẹ 160, 296 see also motherhood

Oyeyemi, Helen 7, 154, 158-68

The Icarus Girl 154, 158, 160-2

Oyono, Ferdinand 4, 317 Une Vie de boy 4

pain $10,35,38,42,45,81,84,102,162,167$, 267, 283-4, 323, 401

body $12,35,45$

Norridge, Zoe 10, 35

palm wine $187,191,305-15$ see also alcohol

paracolonial networks 386-7, 392, 415-16 see also network see also Newell, Stephanie

parody 76, 238, 349

Passbook Number F.47927: Women and Mau Mau in Kenya 244, 250-1 see also Likimani, Muthoni

patronage 99, 119, 309, 407, 409, 416 see also sponsorship see also funding

pavements, colonial urban spaces 327,335

p'Bitek, Okot 373 Song of Lawino 373

personhood 43, 62, 247-8, 181, 284, 345, 378 Menkiti, Ifeanyi 43 see also human

Petals of Blood 23-5, 28-9, 31, 245 see also Ngũgĩ wa Thiong'o

Plaatje, Sol 78, 112, 115 Mhudi 112, 115

Playing in the Light 216

pleasure $10,38,142,223,239,276,279,280-3$, 315-16, 323-9, 336, 379

see also desire see also food 
politics

actor/activist 29, 52, 69, 124-5, 129-32, 134-5, 173, 175, 215, 245, 349, 371, 379, 391,437

see also agency

necropolitics 232

polis $36,39,41,43,45$

political role/work of literature 23-33, 36-46,

48, 57, 60, 62, 66

political unconscious 104, 287

political widowhood 324

social movements/solidarity 35, 48, 95, 99

Popescu, Monica 22, 33, 77

see also Cold war

popular forms as subversion of ideology 26

Portuguese/Wolof encounter 306

postcolonial studies

see also African writers, neglect of 170, 217

blind spots 21-4

ethical failings of postcolonial novels 30 , 217

postcolonial exotic 211, 387

postcolonial literary scholarship, shift away

from 12, 35, 93-105

post-humanitarianism 61,63

see also humanitarianism

postnation 77, 316, 369

see also nation

precarity $48-58,207,234,241-2,283,365$,

366

of the ocean as site of capitalist exploitation 210

prizes 14, 30, 399-412, 413-428, 435

see also literary prizes

prosperity text 143

prostitution 164, 213, 312, 376, 379

proverbs 231-2, 301, 339, 345, 434, 440

public intellectual 106, 129, 370-1

publishing

Bakare-Yusuf, Bibi 418, 419, 420, 424-5

see also Cassava Republic

East African Educational Publishers 404, 407, 409, 410

see also Heinemann Books

Kachifo 417, 418-20

Kwani Trust 386-7, 389, 391-2, 396, 415,

417, 420-6

see also Mbari

Narrative Landscape Press 424, 425

see also on-line publishing

Pan African Publishers 390

publishers' networks 12

self-publishing 143, 366, 409

Sooo Many Stories 425

Spotlight Publishers 404, 407, 409, 410

Storymoja 425

Tana Press 292
Purple Hibiscus 110, 115-17, 282, 415, 418-20

see also Adichie, Chimamanda Ngozi

Quayson, Ato 2, 7, 9, 12, 126, 156, 158-9, 165-7, 418

Qur'an, 267, 270-1, 306

see also Koran

Qur'anic school 266-8, 270-1

quest motif 207

race $5-6,8,48,56,82,83-4,93,97,110$, 113-14, 118, 160, 207, 237-9, 242, 265, 270, 274, 284-6, 330

inter-racial relations 98, 113-14, 225,

349

otherness 5, 44, 50, 75, 92-104, 247

race consciousness 114

racialized hierarchy 50, 51, 160, 233, 362

racism 22, 41, 56, 103, 160, 226, 237-8,

270-1, 284-5, 296, 317, 328, 331, 344, 349, 359,362

rape $162,172,187,240,324-5,349,359,376$, 379,394

readership 12, 112, 142-3, 146, 150, 186, 211, 387, 406

see also Adesokan, Akin

see also audience

differently located readers 3, 14, 61, 386, 393,

402, 409

implicated readers $62-4$

literary groups and reading groups 12, 150

postcolonial exotic 211

self-reflexivity as ethical reading practice 25 , 70, 77, 84, 295-356

realism 22-24, 26-30, 41, 101, 157-69, 294-5, 301, 316, 438

animist realism 7, 157-9, 241

fabulism 86, 190, 154-6

magical realism 7, 24, 157-69, 189-90

Redykyulass Generation 84

see also Musila, Grace A.

refugees $60,62,64,76,85,86,72,179,182,220$, $225,273-4,355,357-8,360,362-7,439$

Jaji, Rose 360

relationality, 62, 170-5, 183, 234, 264

Glissant, Edouard 264

in women's autobiographies 170-5, 185

instances of connection 264

religion $10,42,101,117,119,139,163,174$, $179,261-3,265,267,269,271,273-4,280$, 306, 370, 372, 405, 441

see also Christianity

diviner 42, 146, 348, 370, 372, 405, 441

egungun 189, 191

Idemili 291

Isis $170,173,175,178-9,183,184$

see also Islam 
Nefertiti 173, 178, 179

New Age 189, 195

Ogbuide 291, 294

see also Mammywater

see also Mami Wata

secular 7, 61, 69, 79, 117, 157, 265, 326, 342, 345,432

spirits 42, 116, 129, 154, 158, 163, 189-90,

192-4, 269, 271, 194, 341

spirit medium 323

spirituality 116-17, 157, 196, 217, 250, 272-4,

291, 375, 378

Uhamiri 291

remediation 134

respectability

anxiety about 324,378

rhetoric of disillusionment 112

Richards, Jo-Anne 11

The Innocence of Roast Chicken 11

romance 295-6, 302, 329, 335

see also marriage

Rurangwa, Jean-Marie 355-6

Rusesabagina, Paul 110, 117-19, 120, 122

An Ordinary Man 110, 117-18, 120, 122

Russia 27-31, 33, 186

Black Russians 31

see also Cold war

One Day I will write about This Place 7, 21-9,

75, 87, 357, 367, 401-15, 420-5

Petals of Blood 23-5, 28-31, 245, 255

Soviet Union 21-2, 28

Rwanda 86, 110, 117-20, 172, 232, 354-68

see also genocide

Saadawi, Nawal el 170-85

see also A Daughter of Isis

see also autobiography

God Dies by the Nile 174

see also Walking through Fire

sacrifice zone 205

same sex sexuality 11, 369-382

see also Armah, Ayi Kwei

see also desire

see also Soyinka, Wole

Uganda $345,355,369-82$

Samuelsson, Marcus 279, 287

see also food

Samuelson, Meg 78, 324, 327, 335

Sapeurs

la Sape 54

science fiction 7, 186-7

African sf 7, 186-7

see also genre

see also speculative fiction

Second Class Citizen 47, 232, 237-9

see also Emecheta, Buchi
Sehene, Benjamine 355

Selasi, Taiye 76-7, 325

'Bye-bye Barbar' 76

Ghana Must Go 325

self-fashioning 7, 13, 124, 131, 415

'African Modes of Self-Writing' 125, 128

western technologies of 30

see also Mbembe, Achille

notions of an uncontaminated self $30-1$

readerly self 146

self-historicism 130

self-help literature 7, 139, 141-6, 148-9, 151

7 Steps to Meeting the One 144

How to be a Single Woman in your 30s in Lagos 139, 143-5, 147-9, 150-1

How to Enjoy your First Year of Marriage 144

Loving and Living as an Introvert Woman 144

Newell, Stephanie 7, 139, 141-6, 148-9,

151

The Nigerian Bachelor's Guide 143

pentecostal self-help texts 142, 145, 149,

316

Secrets of Sexually Irresistible Women 139

self-help texts 7, 139, 141-6, 148-9, 151

Sembène, Ousmane 4, 22, 48, 78, 242, 327, 329, 342,350

Guelwaar 342, 350

Le Docker noir 48

Les Bouts de bois de Dien 4, 242

training in USSR 22

Xala 329

Senghor, Leopold Sédar 331, 351

Serpell, Namwali 401

see also Caine Prize

sexuality

Arnfred, Signe 329

see also desire

see also homosexuality

Nyanzi, Stella 370, 372, 377

queer $11,155,232,325$

same-sex sexuality $11,369-382$

sexual violence and silence 145, 323, 329

Tamale, Sylvia 370-2

shame 10-2, 160, 175, 226, 270, 286,

339-53

Bewes, Timothy 11, 340, 351

genital shaming 345,350

Kemedjio, Cilas 339

postcolonial shame $11,340,349$

shebeen 9, 332-3

see also alcohol

Sheng, poetry 421

Shoneyin, Lola 39, 162, 302, 325

The Secret Lives of Baba Segi's Wives 39, 302, 325

short stories 32, 87, 94, 127, 144, 262, 271, 273, $287,323,354-66,373,385,392-7$ 
and their appeal for upcoming writers 391, 401 and prizes 84, 389, 392, 399, 401-5, 409

silence $24,81,104,116,159-60,173,176,181$, 182-3, 282, 323, 324, 346, 357, 359, 360-6, 370-2, 380, 406

see also speech

Sithebe, Angelina N. 154, 158-62

Holy Hill 154, 158, 160-2, 167

slavery $4,46,49,79,125,155,173,177-8$, 181, 192, 194-5, 265, 306-7, 326, 329, 349, 434

enslavement 326

Murphy, Laura 4, 46, 49

Gikandi, Simon Slavery and the Culture of Taste 155

slave trade $49,195,306,349,434$

slave trade and pursuit of capital 49 ,

306-88

labor mobilities linked to 49

slow violence 210, 215

and ecological devastation 210

see also ecocriticism

Nixon, Rob 203, 205, 210, 215, 217, 219

soccer 51

as route to the West 51

Black bodies as raw material 51

see also football

see also mobility

social subjectivity 110

sociality 9, 14, 262-3, 278-81, 283, 285-7, 297-8

bar scenes 31

drinking scenes 9, 305-19

see also everyday

intimacy 2, 10, 222, 226-8, 238, 276, 278,

279-80, 294, 310, 328

small talk 300, 301

sociability $310,312,315$

see also topology

socialist Realism 6, 27, 29

Soetan, Lape 139-53

see also self-help literature

How to be a Single Woman in your 30s in Lagos 139, 143-5, 147-9, 150-1

soil 8, 14, 215-28, 244, 250-4, 283

as material object 250

see also dirt

solidarity 22, 48, 51, 54, 57, 82, 95, 99, 103-4, 106-7, 163-4, 224, 248, 263, 358, 431, 436

Chouliaraki, Lilie 61, 63

Soyinka, Wole 6, 77, 112, 124-36, 317, 372, 400, 405, 407, 411, 414-15, 419

A Dance of the Forests 135

Ake, The Years of Childhood 127, 130, 135

Death and the King's Horseman 112

see also homosexuality
Ibadan: The Penkelemes Years: A Memoir

1946-65 130

Isara: A Voyage around Essay 130, 134, 135

political agent 129

self-construction 129

self-historicization 130

The Interpreters 135, 372

The Man Died 130, 135

The Road 132, 135

The Road Map of a Nation 133

The Strong Breed 135

You Must Set Forth a Dawn 129, 130-5

spectacle 38-9, 41-2, 46

see also Ndebele, Njabulo

see also everyday

spectacular events 4, 9, 38, 41, 44-5, 218, 261, 334, 340, 401

speculative fiction 186, 188, 391

see also genre

speech 37-43

see also Arendt, Hannah

speaking animal 232

see also voice

sponsorship

Afro-Asian networks 22, 28

CIA 22

see also Cold war

Congress for Cultural Freedom 22, 414

donor-funded publishers 387, 391, 418, 424

Soviet and Chinese 22

Starbook 7, 188-98

see also Okri, Ben

Stay with Me 36, 39, 41, 43-5, 302, 325

see also Adebayo, Ayobami

stereotype 5, 8, 56, 61, 79, 100, 104-5, 271-3, 311, 317, 401

see also Caine Prize

Stratton, Florence 293, 301, 329

see also women

Strauhs, Doreen 13, 386, 387, 392, 402, 417

see also donor-funded publishers

see also sponsorship

subjectivity 38-9, 45, 50, 61, 125, 129, 146-9, 170-1, 180, 220, 222, 284, 292-3, 365, 372-3

African 111-12, 125

see also animals

see also migration

social subjectivity 110

sublime 217-29

female sublime 219, 223, 228

nature 217-29

suffering 10, 29, 35, 60, 62, 65-6, 69, 70, 83-4, 102, 128, 195, 212, 217, 225-6, 240, 248, $252,254,267,274,281,285,287,346,364$, 401

Suhr-Systma, Nathan 113, 14, 414, 417

see also Okigbo, Christopher 
superhero (African) 134

supernatural 7, 154-69, 187, 269, 270, 293, 295, 346

Cooper, Brenda 7, 156-7, 160

see also Garuba, Harry

Mafe, Diana 7, 160-1, 163, 167

Stobie, Cheryl 7, 160, 167

Tadjo, Veronique 355-6, 366

Champs de bataille et d'amour 355-6

Tais-toi et meurs 4, 47, 52

see also Mabanckou, Alain

Tamale, Sylvia 370-2

African Sexualities: A Reader 370-1

see also homosexuality

Tansi, Sony Labou 11, 187, 340, 347-51

The Shameful State 340, 348-51

Taoua, Phyllis 10, 326

African Freedom: How Africa Responded to Independence 10

see also freedom

Taruvinga, Mandi 323-4, 328

temporality 125-6

of Blackness 239

post-apocalypse 192

The Abandoned Baobab 11, 270-1, 262, 274 see also Bugul, Ken

The Book of Memory 36, 41-6 see also Gappah, Petina

The Concubine 293-6 see also Amadi, Elechi

The Icarus Girl 154, 158, 160-2 see also Oyeyemi, Helen

The Memory of Love 280-2, 284

see also Forna, Aminatta

The Promised Land 244-9 see also Ogot, Grace

The River and the Source 249-56 see also Ogola, Margaret

The Sleepless 154, 158, 163-4 see also Onoh, Nuzo

The Stone Virgins 287, 323-38 see also Vera, Yvonne

The Whale Caller 234 see also Mda, Zakes

The Story Club, Malawi 385-98

see also book clubs

Thiam, Pierre 279, 287 see also food

Things Fall Apart 412, 106, 111, 112, 117, 276, 292-3, 339, 351, 369, 375 see also Achebe, Chinua

third generation literature 76-6, 111, 162

topology 261-75 see also everyday

Tram 83 305, 309, 312-13, 315, 316, 318 see also Mujila, Fiston Mwanza
Transition (magazine) 22, 416-17

see also Cold war

see also magazines

translation 12-13, 67-8, 80, 98-9, 106, 218, 287, 291, 318, 403-6, 409-10, 430, 434, 438, 441

see also Bangla-English translation

delays in translating African language texts

404

inter-cultural re-translation 80

as intervention 67

transnational belonging 357-8

see also network

transnationalism 9, 75, 78

within African continent 75,78

trauma 10-1, 62-3, 66-7, 69-70, 81, 83, 175, 180, 228, 253, 281-2, 284, 327, 341, 344,

$347,349,350,351,355-9,361,363-6,372-3$

see also affect

Ndĩgĩri, Gĩchingiri 11

travel 4-5, 6, 8, 22, 28, 49, 52-6, 65, 79, 92-3, $95,100-4,127,133,135,143-4,165,191$, 204-5, 208, 227, 249, 251, 265, 274, 291, $307,311,335,354,358,390,424,430$, 434

and Cold War 21-34, 49, 77, 99

cosmopolitan travel 56

see also Dadié, Bernard

decolonization 77, 99

intra-African travel 79-85, 358

La Guma, Alex 22, 414

see also Ngũgĩ wa Thiong'o

Nkosi, Lewis 22, 78

see also Sembène, Ousmane

through telephone or television 51-2

to Soviet Union 21-2, 28

travel writing 5, 47, 92-104, 151

Truth Commission 67, 140

TRC and confessional modes 67, 140

Tutuola, Amos 305

The Palmwine Drinkard 305

see also alcohol

Twidle, Hedley 127

see also life writing

Ude, A O 143

see also self-help literature

The Nigerian Bachelor's Guide 143

Uhuru 24, 248, 256

and revolutionary spirit 24

unconscious 158, 166, 175, 226

animist 157

political 104, 287

slavery, connections to 155

tropes 144

Unexpected Joy at Dawn 75, 81, 87

see also Agyei-Agyiri, Alex 
unfreedom 326-7, 331

colonial subjection 326-7

de-humanization 194, 326

see also freedom

Unhallowed Graves 154, 162, 164

Onoh, Nuzo 58-9, 154, 162-6

Unigwe, Chika 4, 302, 403

On Black Sisters' Street 4

university

Chancellor College, Malawi 388

Makerere University College 77, 375, 413-14, 416

University College Nairobi 417

University of Ibadan 416

University of Nigeria, Nsukka 416

University of Transkei 86, 357

Utopia 6, 7, 186-200

Ashcroft, Bill 7, 105, 186-9, 192, 195-6

eutopia 7

Orlando, Valerie 7

Vassanji, M. G. 265, 279, 287

Veit-Wild, Flora 349, 350-1

Vera, Yvonne 11, 279, 287, 323-38

see also Bulawayo National Gallery

Butterfly Burning 323-37

The Stone Virgins 287, 323-38

Under the Tongue 323

Without a Name

virginity $36,39,181,305$

voice and agency 65

see also speech

vulnerability $8,36,39,45,49,51,60-70,163$, 210, 219, 221-2, 224, 228-9, 238-41, 253,

$314,330,333,361,363,365$

bodies 42-3, 60-70, 215-17, 232, 238

see also body

nonhumans/nature 217, 221, 240

Waberi, Abdourahman 3, 7, 76, 87

In the United States of Africa 76, 87

Wainaina, Binyavanga 3, 6, 7, 13, 21-34, 60, 75, 78, 84-7, 354-9, 362-6, 387, 391-2, 401, $415,420-5$

'How to Write about Africa' 30, 84-5, 422

One Day I will write about this Place 7, 21-9, 75, 87, 357, 367, 401-15, 420-5

'Discovering Home' 84-7, 354-5, 357-69

Wakatama Allfrey, Ellah 420, 422

Wallis, Kate 387, 390, 396

war 50, 62-71, 76, 113, 130, 132-3, 176-83, 203-10, 237-8, 246-52, 281, 284, 323, 327, $347,357-61,370,372,375$ see also Biafra

war fiction

Coundouriotis, Eleni 66

warriors 131

Ways of Dying 11, 279-80

see also Mda, Zakes

What is the What? 60-3, 65-6, 69 see also Deng, Valentino Achak

When Rain Clouds Gather 215, 219-30 see also Head, Bessie

Wicomb, Zoë 12, 216, 349, 402 David's Story 12

witnessing bearing witness, across divides 62 , 355

displaced witnessing 354-66 see also genocide Nabutanyi, Edgar 184, 364

Wizard of the Crow 12, 188, 340-2, 344, 349, 350

see also Ngũgĩ wa Thiong'o

womanism

Kolawole, Mary Modupe 179

women

victims of history $217,237,324$

world literature

see also Brouillette, Sarah

Casanova, Pascale 386-7, 410, 417

Yoon, Duncan 22

world systems theory 386

writer as social thinker 369-70, 376, 379

see also Adebanwi, Wale

writing and reading as relational acts 69

writing workshop

Farafina Trust Creative Writing Workshop

420-4

Writivism Mentoring Programme

422

Writivism 399

Wynter, Sylvia 326

Yan, Geling 92, 93, 95, 100-4

Notes on Africa 92, 95, 100

Yoomi Laataa 440

You Must Set Forth at Dawn 129, 130-5

see also Soyinka, Wole

Yu, Cao 95, 98, 99, 106

Thunderstorm 92, 95, 98-9, 106

Zimbabwean nationalist history 323

see also nationalism

zoocriticism 203

see also ecocriticism 